
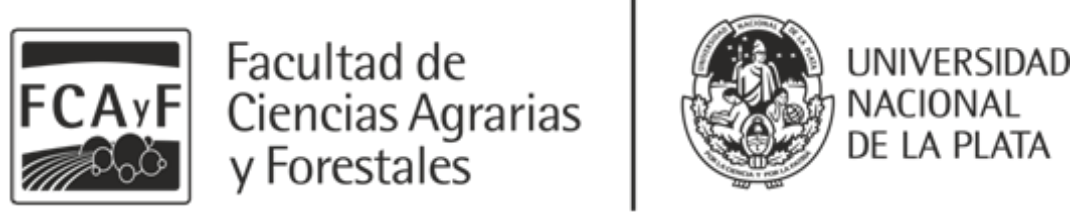

\title{
Flujos de nutrientes en la agricultura y la alimentación para un ecosistema alimentario sostenible en la provincia de Buenos Aires
}

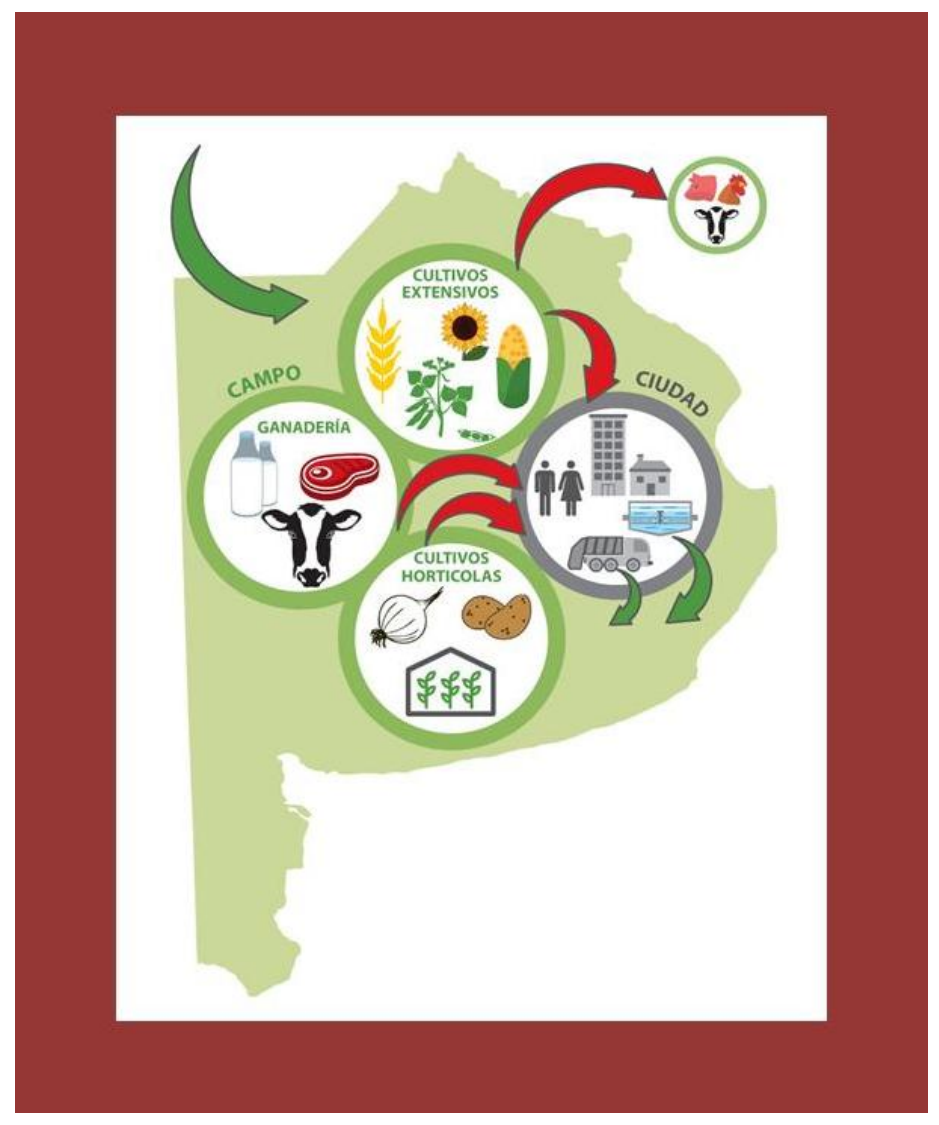

\section{Esteban A. Abbona}

Director: Ing. Agr. Santiago J. Sarandón

Codirectora: Dra. Mabel Vázquez 
"La cultura ecológica no se puede reducir a una serie de respuestas urgentes y parciales a los problemas que van apareciendo en torno a la degradación del ambiente, al agotamiento de las reservas naturales y a la contaminación. Debería ser una mirada distinta, un pensamiento, una política, un programa educativo, un estilo de vida y una espiritualidad que conformen una resistencia ante el avance del paradigma tecnocrático. De otro modo, aun las mejores iniciativas ecologistas pueden terminar encerradas en la misma lógica globalizada. Buscar sólo un remedio técnico a cada problema ambiental que surja es aislar cosas que en la realidad están entrelazadas y esconder los verdaderos y más profundos problemas del sistema mundial."

LAUDATO SI' (Francisco, 2015) 
Abbona, Esteban Andrés

Flujos de nutrientes en la agricultura y la alimentación para un ecosistema alimentario sostenible en la provincia de Buenos Aires / Esteban Andrés Abbona. - 1a ed. - La Plata: Universidad Nacional de La Plata. Facultad de Ciencias Agrarias y Forestales, 2017.

Libro digital, PDF

Archivo Digital: descarga y online

ISBN 978-950-34-1515-3

1. Ecosistema . 2. Agricultura. I. Título.

CDD 577

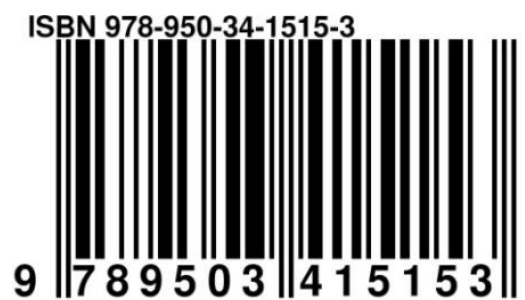




\section{AGRADECIMIENTOS}

En los años que llevo dedicado a la tesis muchas son las personas que me han apoyado, desde lo académico, institucional, personal, anímico. La fuerza que me ofrecieron permitió que arribara a buen puerto y así concluir este largo, fascinante, pero también cansador viaje.

$\checkmark$ A mi esposa Andrea, por la paciencia, comprensión y cariño brindado a lo largo de estos años.

$\checkmark$ A mis hijos Santiago, Francisco y Victoria por entender y compartir el esfuerzo familiar que implicó la realización de la tesis.

$\checkmark$ A mis padres por todo el apoyo a la distancia y por haberme educado en el esfuerzo y la perseverancia.

$\checkmark$ A mi abuela Ana Lucía por su cariño, amor y paciencia trasmitidos a lo largo de mi vida.

$\checkmark$ A mi director Santiago, por su constante apoyo, dirección, paciencia y calidad humana, que respetó mis tiempos de avance e ideas en el desarrollo de esta tesis.

$\checkmark$ A mi codirectora Mabel por el acompañamiento y apoyo académico brindado.

$\checkmark$ A María José lermanó por su extraordinario y firme apoyo durante el proceso de desarrollo de la tesis, que me permitió avanzar, aclarar ideas y convencerme que se podía.

$\checkmark$ A Miriam Presutti, Mariana Licursi y Paula Perez Roig, por la valiosa colaboración en la realización de los diferentes mapas, el diseño de las portadas y la revisión del abstract respectivamente.

$\checkmark$ A mis compañeras de Agroecología, Claudia, Mariana, Agustina, Margarita, Fernanda, Susana, María Luz, por contribuir con un ambiente cálido de trabajo.

$\checkmark$ A los compañeros y compañeras de la Facultad, que me acompañaron durante este viaje.

$\checkmark$ A los evaluadores Fernando García, Water Pengue y Guillermo Studdert por los valiosos aportes realizados a la presente tesis. 
Un agradecimiento especial al Consejo Nacional de Investigaciones Científicas y Técnicas (CONICET) porque la mayor parte del desarrollo de la presente tesis se realizó durante las becas de investigación que me fueran otorgaras por esta institución (Becas de posgrado tipo I y II). 


\section{ÍNDICE}

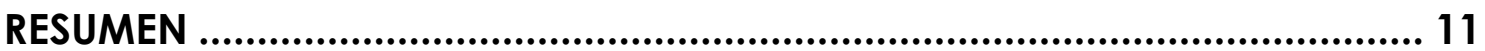

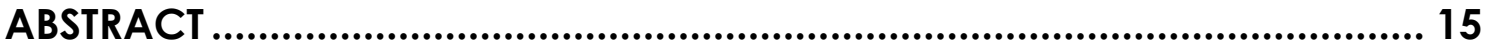

INTRODUCCIÓN GENERAL .......................................................................... 19

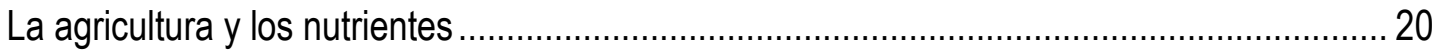

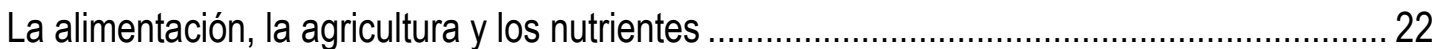

Sosteniendo los flujos de nutrientes ................................................................................ 23

El caso de la provincia de Buenos Aires, Argentina ........................................................... 25

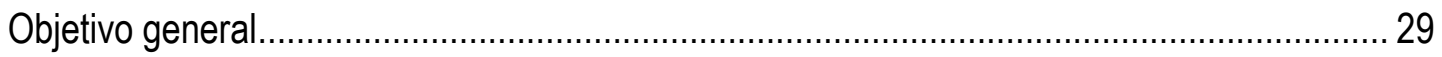

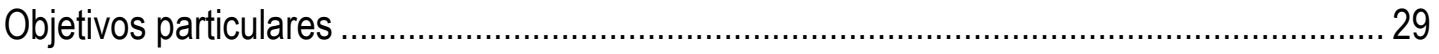

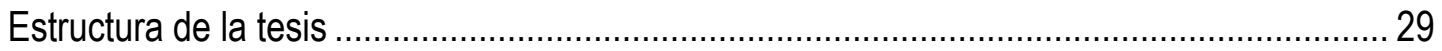

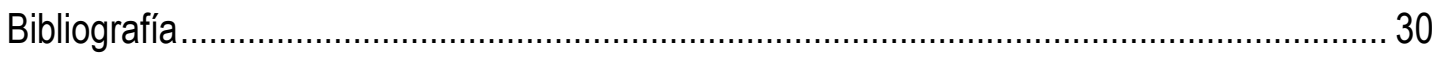

Capítulo I. Cambios en los flujos de nutrientes a escala regional y global y su vinculación con demografía, comercio internacional y desarrollo ................... 35

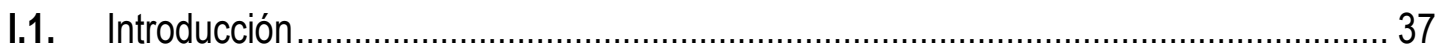

I.2. Cambio de los flujos de nutrientes a escala global: de la autosuficiencia al despilfarro 37

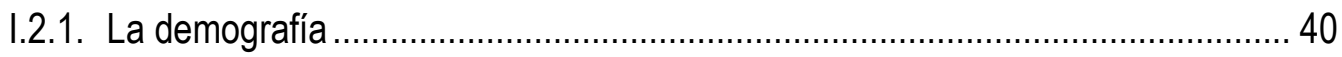

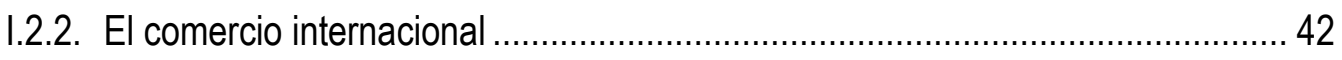

I.2.3. El desarrollo ............................................................................................... 45

I.2.3.1. El concepto de desarrollo: desde su origen hasta el informe Brundtland

1.2.3.2. Antecedentes al "desarrollo sostenible" ............................................. 47

I.2.3.3. Los objetivos de Desarrollo del Milenio y de Desarrollo Sostenible .... 49

1.2.3.4. Necesidad de un nuevo marco de evaluación del desarrollo .............. 50

I.2.3.5. Los nutrientes y el desarrollo sostenible ........................................... 52

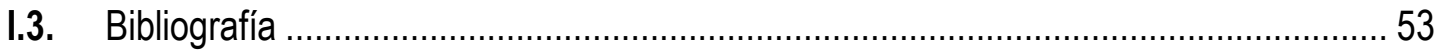

Capítulo II. Aspectos metodológicos................................................... 57

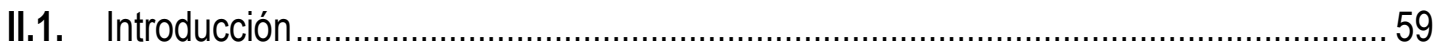

II.2. Actividades agropecuarias de la provincia de Buenos Aires ....................................... 59

II.2.1. Características edafoclimáticas de la provincia............................................. 59

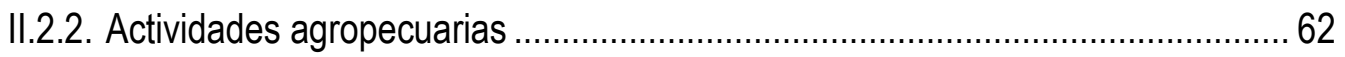

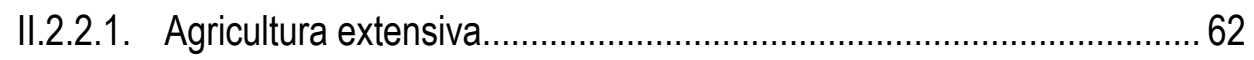




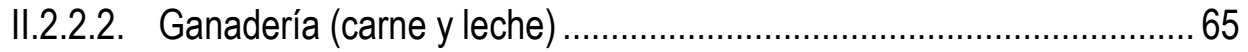

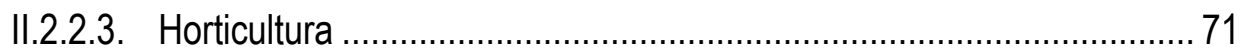

II.3. Cuantificación de los nutrientes: balances y eficiencias ............................................. 73

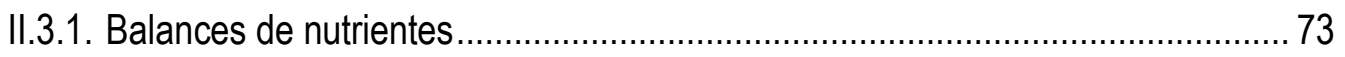

II.3.1.1. Pasos para realizar un balance de nutrientes .................................... 74

II.3.1.2. Eficiencias en el uso de nutrientes ............................................... 79

II.4. Criterios metodológicos asumidos en la tesis......................................................... 82

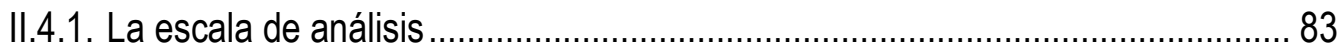

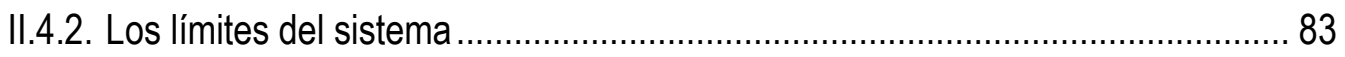

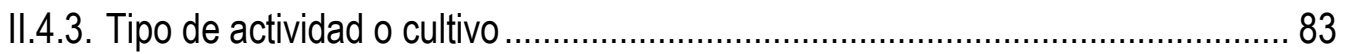

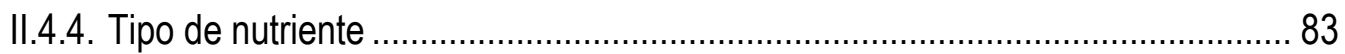

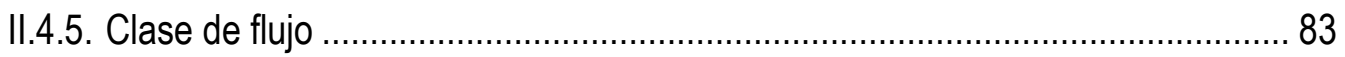

II.4.6. Generación de mapas temáticos.............................................................. 84

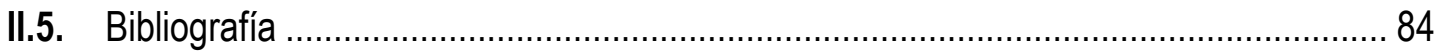

Capítulo III. Nutrientes en las actividades agropecuarias de la provincia ...... 89

III.1. Subcapítulo 1: Los cultivos extensivos y la conservación de los nutrientes del suelo 93

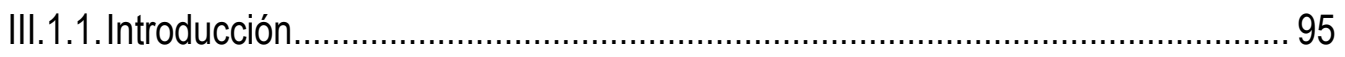

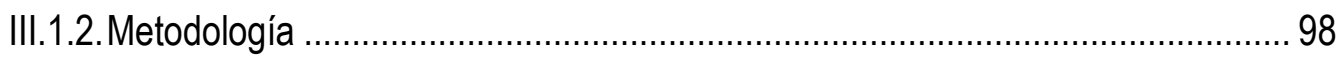

III.1.2.1. Cultivos empleados .................................................................... 98

III.1.2.2. Balance de nutrientes ................................................................ 98

III.1.2.3. Reposición de nutrientes ............................................................. 100

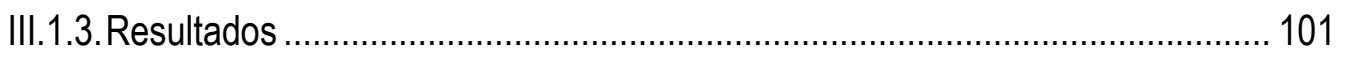

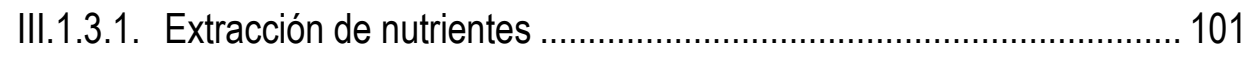

III.1.3.2. Balance de nutrientes ................................................................... 107

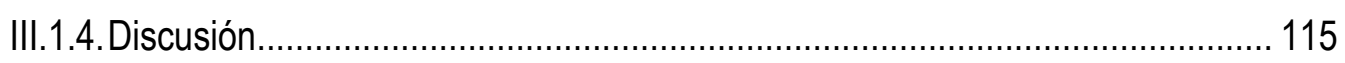

III.1.4.1. Extracción de nutrientes .......................................................... 115

III.1.4.2. Balance de nutrientes .................................................................. 116

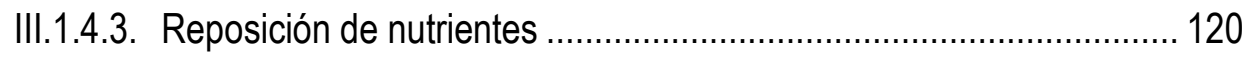

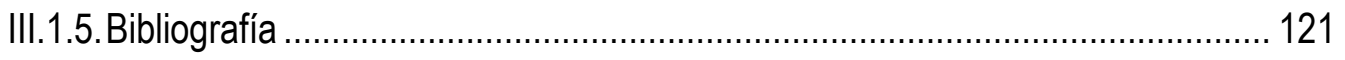

III.2. Subcapítulo 2: La horticultura y la conservación de los nutrientes del suelo ............. 125

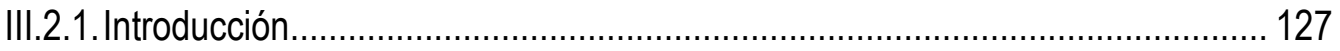

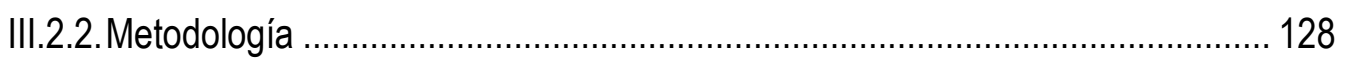

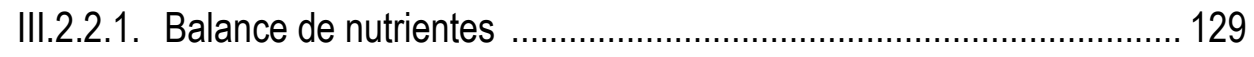

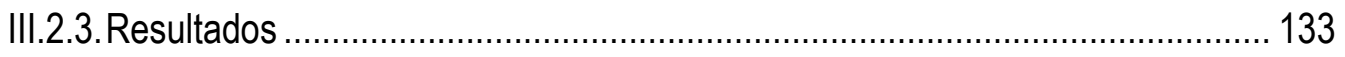

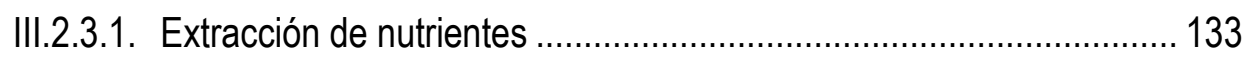

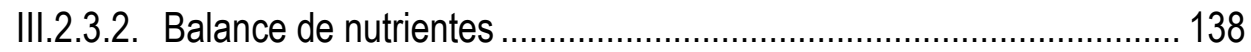

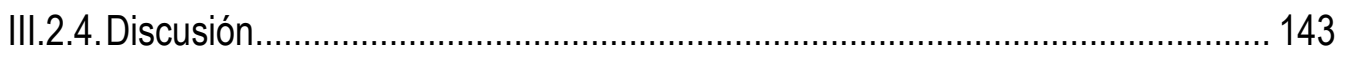

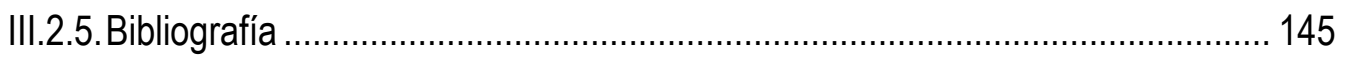

III.3. Subcapítulo 3: La producción de carne y leche bovinas y la conservación de los nutrientes del suelo 


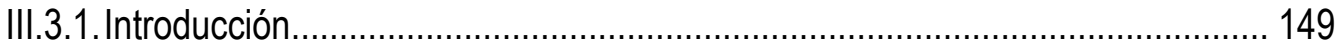

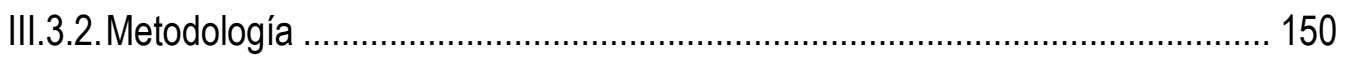

III.3.2.1. Estimación de la superficie de cría, recría, invernada y tambo ......... 150

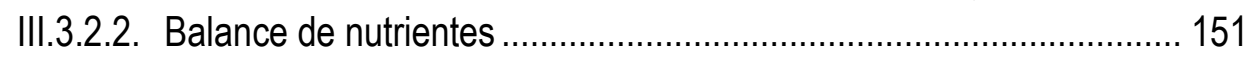

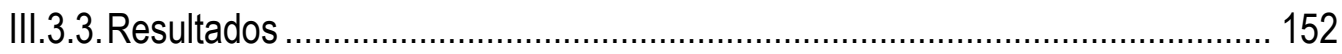

III.3.3.1. Extracción de nutrientes ........................................................... 152

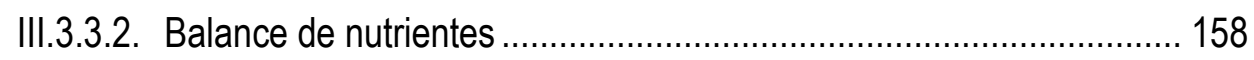

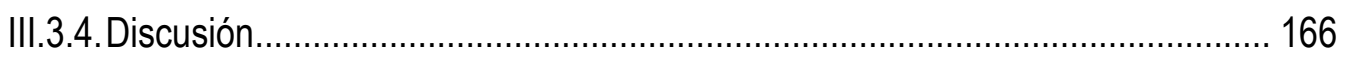

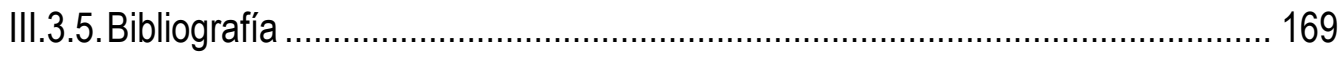

III.4. Subcapítulo 4: Horticultura, cultivos extensivos y producción de carne y leche bovinas en la provincia de Buenos Aires y la conservación de los nutrientes del suelo .......... 173

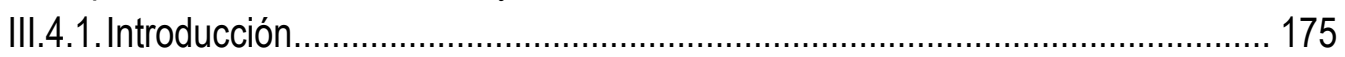

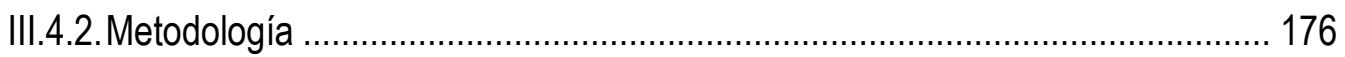

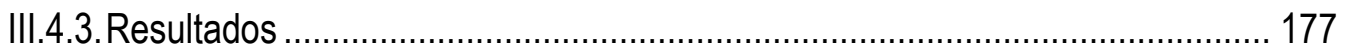

III.4.3.1. Extracción de nutrientes ............................................................... 177

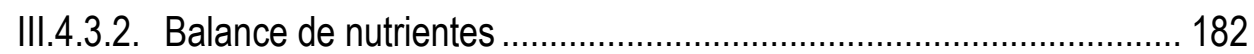

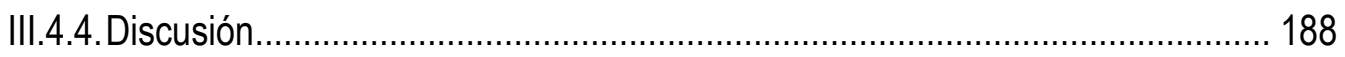

III.4.4.1. Extracción de nutrientes ........................................................... 188

III.4.4.2. Balance de nutrientes .............................................................. 190

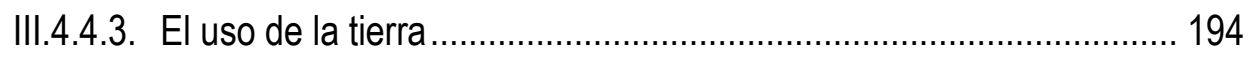

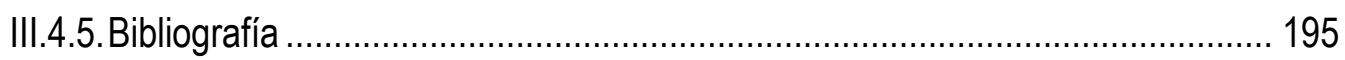

Capítulo IV. Exportación de granos y harinas para alimentación animal versus carne producida con los mismos: un análisis para la conservación de los nutrientes del suelo ........................................................................ 199

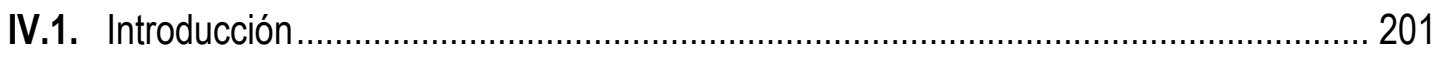

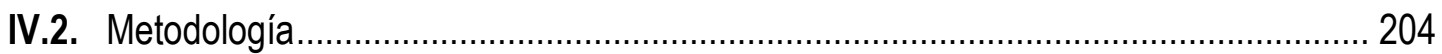

IV.2.1. Balance de nutrientes ............................................................................ 204

IV.2.1.1. Balance en la exportación de granos y harina para la alimentación

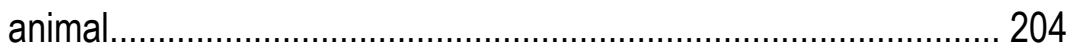

IV.2.1.2. Balance en la exportación de diferentes tipos de carne ................. 207

IV.2.1.3. Balance en la superficie total de cultivos extensivos..................... 208

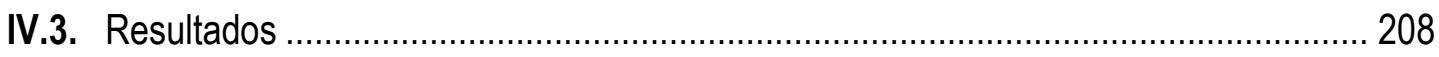

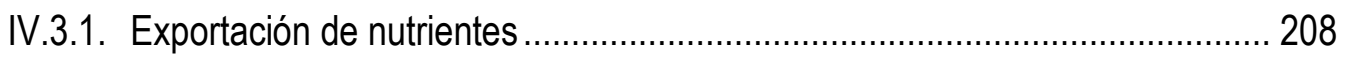

IV.3.1.1. En la exportación de grano y harina con destino a la alimentación

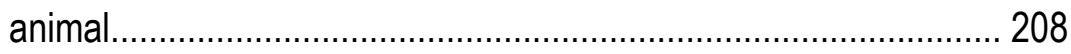

IV.3.1.2. En la exportación de carne obtenida de grano y harina para alimentación animal..................................................................... 210

IV.3.2. Balance de nutrientes .......................................................................... 212

IV.3.2.1. Balance en la exportación de granos y harinas o carne................. 212 
IV.3.2.2. Balance en la superficie total de cultivos extensivos 214

IV.4. Discusión 215

IV.4.1. El reemplazo de exportaciones y los nutrientes del suelo 215

IV.4.2. Cambio de exportaciones: nuevos desafíos 218

IV.4.3. Producción de carne y demanda de granos: su impacto en la implantación de cultivos. 218

IV.4.4. Alimentos para el ser humano o para la producción de carnes. 219

IV.5. Bibliografía 221

Capítulo V. Ciudad-campo: construyendo un ecosistema alimentario en la provincia de Buenos Aires 225

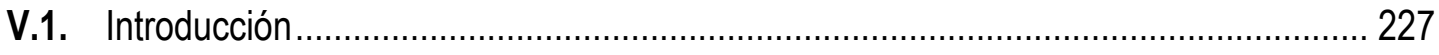

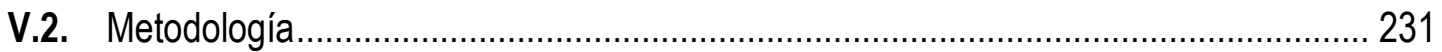

V.2.1. Demanda de alimentos y nutrientes para la población ................................... 232

V.2.2. Situación actual y potencial de reutilización de los desperdicios en residuos sólidos urbanos

V.2.3. Situación actual y potencial de reutilización de nutrientes de la alimentación en

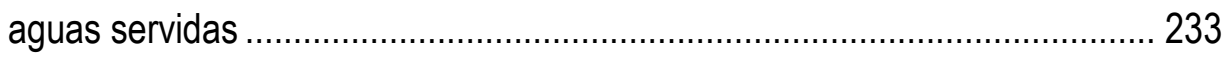

V.2.4. Extracción de nutrientes de las actividades agropecuarias ........................... 233

V.2.5. Generación de mapas temáticos ................................................................ 234

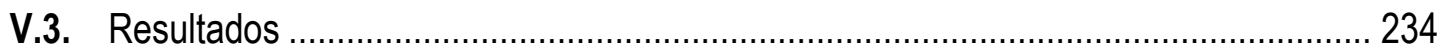

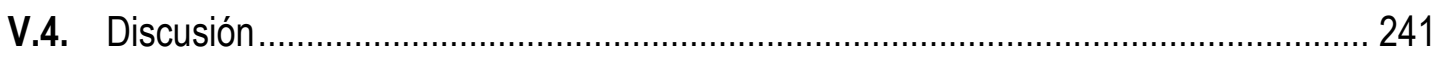

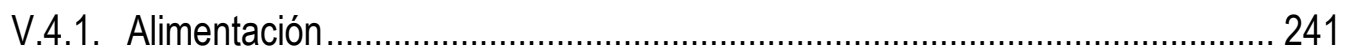

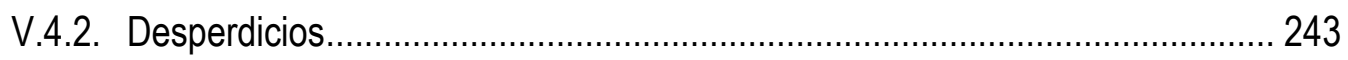

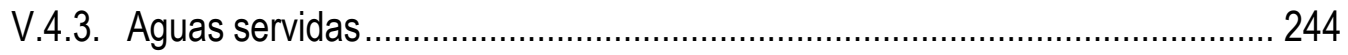

V.4.4. Ecosistema alimentario ....................................................................... 246

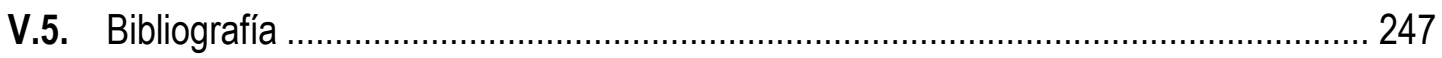

Discusión general............................................................................. 251

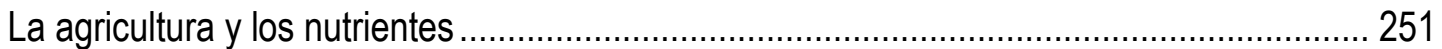

Las exportaciones y la conservación de los nutrientes del suelo....................................... 255

El ecosistema alimentario de la provincia de Buenos Aires ................................................. 257

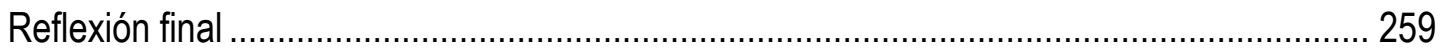

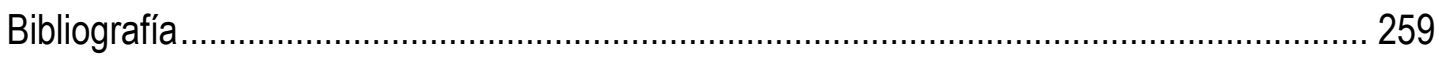




\section{RESUMEN}

La agricultura y la alimentación son actividades estrechamente vinculadas de las cuales dependen todas las sociedades. Actualmente, parte de la reposición de nutrientes en los sistemas agrícolas se realiza a través de fertilizantes minerales que se obtienen, en gran parte, de yacimientos finitos. Luego, parte de estos nutrientes constituyen los alimentos que tienen por destino, mayoritariamente, los centros urbanos, finalizando, una vez aprovechados por los seres humanos, en rellenos sanitarios, ríos o mares. Esto genera un flujo unidireccional de los nutrientes desde fuentes de alta concentración a fuentes de baja concentración, lo que permite inferir que las futuras generaciones no contarán con fuentes de alta concentración para reponer los elementos extraídos de los sistemas agrícolas. Aunque la existencia o reservorio total de nutrientes a nivel de planeta no cambiará, sí lo hará su concentración y distribución. Las generaciones futuras requerirán concentrar los nutrientes, lo que implicará un incremento en los costos económicos y energéticos.

Para poder proyectar una sostenibilidad de la agricultura y la alimentación es necesario superar la visión lineal que prevalece en el abordaje de las mismas y convertirla en cíclica, es decir, pasar de una noción de "sistema alimentario" a una de "ecosistema alimentario". Aún es incipiente el interés por vincular los flujos de nutrientes entre agricultura y alimentación y tratar de cerrarlos para buscar una mayor autosuficiencia. La generación de un ciclo de nutrientes entre la ciudad y el campo podría lograrse utilizando los residuos sólidos urbanos y aguas servidas. Adicionalmente, es necesario tener en cuenta que muchos de los nutrientes relacionados con la agricultura son exportados, siendo muchos de ellos destinados a la alimentación animal, lo que afecta la autosuficiencia en el ecosistema alimentario.

El objetivo general de la tesis es conocer los flujos de nutrientes en el ecosistema alimentario de la provincia de Buenos Aires y su relación con la sostenibilidad, asumiendo que actualmente presenta un flujo unidireccional de nutrientes desde los sistemas agrícolas a los cuerpos de agua.

Para el análisis de los flujos de nutrientes en el ecosistema alimentario de la provincia se tomó como referencia el período 2005-2006. Se consideró la conservación de los nutrientes del suelo a partir del cálculo del balance de nutrientes (N, P, K, Ca y S) en horticultura, cultivos extensivos y producción de carne y leche bovina. Se analizó la conservación de los nutrientes del suelo presentando un escenario de cambio de las 
exportaciones de granos y harinas con destino a la alimentación animal por diferentes tipos de carnes (vacuna, de cerdo o de pollo) producidas a partir de estos alimentos. Finalmente se evaluó la reposición potencial de nutrientes de la ciudad al campo a partir de su reciclaje en la alimentación de la población, considerando los residuos sólidos urbanos y aguas servidas, en relación a las extracciones del conjunto de actividades agropecuarias analizadas.

La extracción de nutrientes en la provincia de Buenos Aires por las diferentes actividades agropecuarias fue mayor que la reposición entre fertilización y fijación biológica, lo que señala la disminución de su reservorio en el suelo, con el consiguiente riesgo para la sostenibilidad. La horticultura es la actividad que mejor conserva los nutrientes del suelo (a excepción del K), siendo las producciones más intensivas, que se realizan cerca de los centros urbanos, las que generan mayores excedentes de nutrientes. Estos excedentes deben ser tenidos en cuenta por el riesgo de contaminación que pueden generar por lixiviado en los acuíferos, principalmente, de nitratos. En cambio, las producciones hortícolas semiextensivas (papa (Solanum tuberosum L.)) generan las mayores pérdidas de K, Ca, e incluso de N. También se encontró que la ganadería (producción de carne y leche bovina) genera, en toda su extensión, un vaciamiento de los suelos en K, Ca y S y, además, de P en las zonas de pastizal natural. La fijación biológica de $\mathrm{N}$ es una vía natural de ingreso que permite reponer, adecuadamente, este nutriente en la totalidad de los suelos ganaderos de la provincia. La producción de leche, siendo aún más extractiva que la de carne, genera mayores excedentes en $\mathrm{N}$ y $\mathrm{P}$ por la fertilización y fijación biológica $(\mathrm{N})$, pero mayores pérdidas por unidad de superficie en el resto de los nutrientes ( $K$, Ca y S). Los cultivos extensivos producen un vaciamiento de todos los nutrientes en los suelos ( $N, P, K, C a$ y S). A excepción de $P$ en trigo (Triticum aestivum L.) y cebada cervecera (Hordeum vulgare L. var. distichum), en el resto de los cultivos, se registraron pérdidas en todos los nutrientes, siendo la soja (Glycine max (L.) Merr.) el principal responsable de la pérdida de nutrientes.

Los nutrientes contenidos en la exportación de granos y harinas con destino a la alimentación animal constituyen el $66 \%$ de los nutrientes del conjunto de cultivos extensivos. La producción agrícola de estas exportaciones genera balances negativos en todos los nutrientes. La sustitución de las exportaciones de granos con destino a la alimentación animal por la de carne obtenida con los mismos (vacuna, de cerdo o de pollo), implicaría una disminución de las salidas de nutrientes de entre 84 y $92 \%$, dependiendo el tipo de carne. Esto implicaría alcanzar, en la superficie que produce los granos con destino a la alimentación animal, balances positivos de N, P y S para cualquiera de las producciones de carne, y de Ca con las producciones de carnes de 
cerdo y de pollo. Esto implica aportar al mantenimiento de la fertilidad química del suelo en el $46 \%$ de la superficie destinada a cultivos extensivos.

El consumo anual de alimento fue de $583 \mathrm{~kg}$ por persona. Los nutrientes contenidos en estos alimentos representan el $11 \%$ del total de nutrientes extraídos por las principales actividades agropecuarias de la provincia. De los nutrientes en los alimentos, un $93 \%$ fue ingerido, mientras que el $7 \%$ restante fue derivado a residuos sólidos urbanos. Esto implica una posibilidad de reposición de sólo el $10 \%$ de los nutrientes que se extraen en las actividades agropecuarias a partir de las aguas servidas y del $1 \%$ por residuos sólidos urbanos.

El funcionamiento actual del ecosistema alimentario de la provincia de Buenos Aires presenta un riesgo para la sostenibilidad porque los suelos que producen alimentos están disminuyendo la dotación de nutrientes, y la reposición potencial de los mismos a partir del cerramiento de los flujos entre la ciudad y el campo, es baja. Considerando el predominio de fuentes minerales finitas para la reposición, una posibilidad a corto plazo es cambiar el tipo de producto exportado, mientras que, en el largo plazo, será necesario repensar el ecosistema alimentario global para incrementar la vinculación de los nutrientes entre la ciudad y el campo, y entre países productores y demandantes de alimentos. 


\section{ABSTRACT}

\section{NUTRIENT FLOWS IN AGRICULTURE AND FOOD FOR A SUSTAINABLE FOOD ECOSYSTEM IN THE PROVINCE OF BUENOS AIRES}

Agriculture and food are closely linked activities on which all societies depend. Currently, part of nutrients replenishment in agricultural systems is done through mineral fertilizers that are obtained, mainly, from finite mineral deposits. Then, these nutrients convert to foods that are destinated mostly to urban centers, ending, once used by humans, in landfills, rivers or seas. This generates a unidirectional flow of nutrients from high concentration to low concentration sources, which allows inferring that future generations would not have enough high-concentration sources to replenish the extracted elements from agricultural systems. Although the existence or total reserve of nutrients in the world would not change, it would their concentration and distribution. Future generations will require concentrating the nutrients, which would imply an increase in economic and energy costs.

To be able to project agriculture and food sustainability, it is necessary to overcome the linear vision that prevails and turn it into a cyclic one, that is, to switch from a "food system" notion to a "food ecosystem" one. There is still an incipient interest in linking nutrient flows between agriculture and food, and looking to close them to seek greater self-sufficiency. The generation of a nutrient cycle between the city and the farmland could be achieved using municipal solid waste and sewage. However, it is also necessary to take into account that many of the nutrients from agriculture are exported, and a large portion of them is destined to feed animals, which affects selfsufficiency in the food ecosystem.

The main objective of this thesis is to know about nutrient fluxes in food ecosystem of the province of Buenos Aires and its relation with sustainability, assuming that nowadays it presents a unidirectional flow of nutrients from the agricultural systems to the bodies of water.

For the analysis of nutrient fluxes in the food ecosystem in the province, the period 2005-2006 was taken as reference. Soil nutrient conservation was considered from nutrient balance (N, P, K, Ca and S) in horticulture, extensive agriculture and production of beef meat and milk. Soil nutrient conservation was analyzed in a scenario of change in the exports of grains and flour destined for animal feed by different types of meat (bovine, swine or chicken) produced from these foods. Finally, the potential 
replacement of nutrients from city to farmland was evaluated, starting from recycling food nutrients, considering urban solid waste and wastewater, in relation to the extractions of all the agricultural activities analyzed.

The extraction of nutrients in the province of Buenos Aires by the different agricultural activities was greater than the replacement from fertilization and biological fixation, which indicates decreases in soil nutrient reservoirs, with risk to sustainability. Horticulture is the activity that best preserves soil nutrients (with the exception of K), with the most intensive production that generates greater nutrient surpluses being carried out near urban centers. This surplus must be taken into account because of the risk of contamination that can generate in the aquifers by leaching, mainly of nitrates. On the other hand, the semi extensive horticultural productions (potato (Solanum tuberosum L.)) generate the highest losses of $\mathrm{K}, \mathrm{Ca}$, and even of $\mathrm{N}$. It was also found that livestock production (bovine meat and milk) generates, in all its extension, a decrease in soil $\mathrm{K}$, $\mathrm{Ca}$ and $\mathrm{S}$ and, in addition, of $\mathrm{P}$ in the areas of natural pasture. Biological fixation of $\mathrm{N}$ is a natural input that allows to adequately replenish this nutrient in all soils with livestock. Milk production, which is even more extractive than meat production, generates higher $\mathrm{N}$ and $\mathrm{P}$ surpluses, due to fertilization and biological fixation $(\mathrm{N})$, but higher losses per unit area of the other nutrients ( $\mathrm{K}, \mathrm{Ca}$ and $\mathrm{S}$ ). Extensive crops decrease all nutrients in soils (N, P, K, Ca and S). Wheat (Triticum aestivum L.) and malting barley (Hordeum vulgare L. var. distichum) had P surpluses, but the other crops led losses in all nutrients, with soybean (Glycine max (L.) Merr.) showing the highest nutrient losses.

Nutrients contained in the export of grains and flour destined to animal feed constitutes $66 \%$ of nutrients removed in extensive crops. Agricultural production of these exports generates negative balances in all nutrients. The replacement of exports from grains destined to animal feed with the meat obtained from them (bovine, swine or chicken) would imply a reduction of nutrient outputs between 84 and $92 \%$, depending on the type of meat. This would result, in the areas that produce grains destined to animal feed, on positive balances of $\mathrm{N}, \mathrm{P}$ and $\mathrm{S}$ with any meat productions and $\mathrm{Ca}$ with swine and chicken. This change on exportations would contribute to the maintenance of chemical soil fertility in $46 \%$ of the area destined to extensive crops.

Annual food consumption was $583 \mathrm{~kg}$ per person. Nutrients contained in these foods represent $11 \%$ of total nutrients extracted by the main agricultural activities of the province. From the nutrients in food, $93 \%$ was ingested, while the remaining $7 \%$ was derived to urban solid waste. This implies a possibility of replenishing only $10 \%$ of the nutrients extracted in agricultural activities from sewage and $1 \%$ from solid urban waste.

The current situation of the Buenos Aires province food ecosystem presents a sustainability risk because soils that produce food are showing a decrease in nutrient 
stocks, and the potential replacement of nutrients from the city to the farmland is low. Considering that current nutrient replenishment depends on finite mineral sources in a short-term possibility is to change the type of exported product, while in the long term, it will be necessary to rethink the global food ecosystem to increase the linkage of nutrients between city and farmland and between producing and demanding food countries. 


\section{INTRODUCCIÓN GENERAL}

La agricultura y la alimentación son actividades estrechamente vinculadas de las que dependen todas las sociedades. La agricultura genera la mayoría de los alimentos que, de manera directa o con procesamiento de por medio, serán adquiridos por la población. A partir de los mismos, las personas obtienen la energía y los nutrientes necesarios para poder realizar las actividades cotidianas. La sostenibilidad de este vínculo entre agricultura y alimentación, es necesaria para el ser humano, y la misma podrá alcanzarse si los recursos naturales de los cuales depende pueden mantenerse en cantidad y calidad (Abbona et al., 2007).

Existe preocupación por lograr una producción, distribución y acceso a los alimentos suficientes para la población mundial actual y futura (FAO, 2001; Godfray et al., 2010; Ingram et al., 2012). A causa de ello, se han propuesto distintos enfoques que intentan abordar el tema integralmente, a los fines de conocer y analizar las distintas etapas que median entre la producción y el consumo de alimentos (Ingram et al., 2012; Garnett, 2014; Soussana, 2014).

En general, la manera con que se abordan la agricultura y la alimentación, responde a una mirada lineal, que coloca a la agricultura en el inicio del proceso y a la alimentación en el final del mismo. Se busca eficientizar los procesos de producción, procurando que se pierda y desperdicie la menor cantidad de alimentos (Sutton et al., 2013; Gustavsson et al., 2012), a la vez que disminuya el impacto ambiental que generan (Eickhout et al., 2006). Esta mayor eficiencia es necesaria para no derrochar recursos naturales y económicos, pero no garantiza la sostenibilidad en el tiempo. Para poder proyectar una sostenibilidad de estas actividades es necesario superar la visión lineal y convertirla en cíclica, pasar de una noción de "sistema alimentario" a una de "ecosistema alimentario". El enfoque de sistema alimentario permitió vincular la agricultura y la alimentación tanto desde la producción como en su distribución y acceso, incluyendo las consecuencias ambientales que se generaban a lo largo del mismo (Ingram et al., 2012; Garnett, 2014; Soussana, 2014). Asumir una concepción de ecosistema alimentario permitiría vincular mejor estas actividades y contribuiría a lograr una mayor autosuficiencia en todo este proceso.

Un factor que vincula la agricultura y la alimentación y que se relaciona con la sostenibilidad de dicho vínculo, es el flujo de nutrientes (Fernández-Mena et al., 2016). Los nutrientes se encuentran en el suelo, son absorbidos por las plantas y luego son 
extraídos en los productos cosechados (Magdoff et al., 1997; Drinkwater \& Snapp, 2007; Bouwman et al., 2009). Éstos continúan en la alimentación humana, donde una parte es desperdiciada (Gustavsson et al., 2012) y otra parte es ingerida por las personas. A partir de allí son excretados y su flujo continúa hacia los cuerpos de agua o los rellenos sanitarios (Odum, 1998; Nebel \& Wright, 1999). No existe suficiente preocupación en la necesidad de cerrar estos flujos para que la agricultura cuente nuevamente con los nutrientes que fueron extraídos con la cosecha de los cultivos. Este es el mayor desafío de los próximos años si se busca garantizar la sostenibilidad de ecosistema alimentario. La visualización y comprensión de los flujos de nutrientes que atraviesen ambas actividades puede incorporar otro punto de análisis a la temática que permita brindar nuevos elementos a quienes toman las decisiones políticas (Grote et al., 2005). Para ampliar el tema de los nutrientes en el ecosistema alimentario se profundizará el abordaje que los mismos han tenido, tanto en la agricultura como en la alimentación.

\section{LA AGRICULTURA Y LOS NUTRIENTES}

La producción de cultivos, pasturas y pastizales ocupa el $38 \%$ de las tierras y más del 70\% del uso del agua a nivel mundial (Cassman et al., 2003; Pengue, 2015). Se calcula que en procesos económicos se utiliza el 35\% de la producción primaria neta de materiales bióticos del planeta (Pengue, 2015). En los últimos 50 años, el área cultivada a nivel mundial creció un 12\% y la irrigada se duplicó (Drechsel et al., 2015), demostrando que el suelo ha sido y será el sustento de la agricultura y la producción de alimentos.

La comprensión de la importancia del suelo en la producción de alimentos ha estado presente en diferentes civilizaciones. Durante el imperio Romano se daba mucha importancia al reciclado del guano de los animales y se conocía el beneficio de especies leguminosas (Sutton et al., 2013). Después de la primera revolución industrial y ante el crecimiento de la población, comenzó a tener más consenso, incluso científico, el rol de los nutrientes en el crecimiento de los cultivos y la necesidad de encontrar nuevas fuentes de abastecimiento (Sutton et al., 2013). En este desarrollo conceptual, Liebig puede ser considerado el padre de la concepción moderna de los nutrientes. El guano de Perú y el nitrato proveniente de las minas de Chile fueron fuentes muy empleadas para abonar los campos. Hacia fines del siglo XVIII, el guano de Perú comenzó a exportarse y aplicarse en Europa hasta su colapso a fines de de 1870 (Clark \& Foster, 2009). Paralelamente, con el advenimiento del carbón como fuente de energía comenzó la producción de un compuesto nitrogenado (sulfato de amonio) como fertilizante químico a gran escala. Se estima que hacia 1900 en el 
ingreso global de nitrógeno $(\mathrm{N})$, el guano contribuía con 6 Mt año-1, la fijación biológica con $4 \mathrm{Mt}^{\mathrm{anno}} \mathrm{o}^{-1}$, mientras que los fertilizantes manufacturados 0,2 $\mathrm{Mt}$ año-1 (Sutton et al., 2013). Una segunda gran etapa en la utilización de nutrientes a escala global estuvo impulsada por la revolución verde, que contaba con la expansión previa de la industria de $\mathrm{N}$ a partir del proceso de Haber-Bosch descubierto en 1909 y empleado a escala industrial a partir de 1913 (Bouwman et al., 2013). Entre los años 1950 y 2000, el uso de fertilizante nitrogenado mineral se incrementó de 4 a 83 Mt año-1,

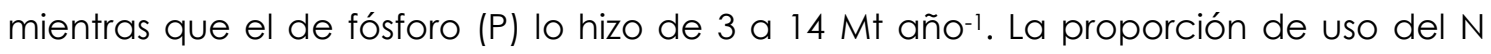
proveniente entre fijación biológica y fertilizantes minerales bajó de 14:1 en 1900 a 6:1 en 1950 y a 0,5:1 en 2000 (Bouwman et al., 2013). En los países desarrollados, el incremento en el uso anual de P fue gradual a mediados de 1950, se incrementó rápidamente entre 1950 y 1970, antes de estabilizarse e incluso disminuir hacia fines del siglo XX (Syers et al., 2008). La producción de superfosfato simple (SFS) comenzó en el Reino Unido en 1943 (Syers et al., 2008).

El uso de fertilizantes estuvo muy relacionado a la concepción prevaleciente sobre el rol de los nutrientes en la agricultura. Inicialmente, los mismos sólo se tenían en cuenta cuando su disponibilidad en el suelo limitaba la producción. En este contexto, se desarrollaron modelos de respuesta al agregado de fertilizantes, los cuales permitieron diagnosticar las condiciones de suficiencia-deficiencia en relación al rendimiento del cultivo para mejorar la rentabilidad económica. Estos modelos responden a una visión de corto plazo, su análisis se limita a la parcela o lote y sólo buscan el rédito económico, no considerando la conservación del reservorio de nutrientes. El manejo continuo de nutrientes basado en este enfoque durante mucho tiempo, ha conducido a la degradación del suelo en distintas partes del mundo, inclusive de la Argentina (Viglizzo et al., 2001; García, 2006; Cruzate \& Casas, 2012). En respuesta a esto, surge el balance de nutrientes como una herramienta que propende a la conservación del reservorio de nutrientes. Ésta metodología, amplía el horizonte temporal y la escala espacial de valoración de la conservación del recurso suelo y posibilita, de alguna manera, calcular costos ocultos (Flores \& Sarandón, 2003). El balance de nutrientes ha sido empleado tanto a nivel de sistema agrícola (finca) (Brouwer, 1998; de Jager et al., 1998; Harris, 1998; Van den Bosch et al., 1998; Bekunda \& Manzi, 2003; Oenema et al., 2003; FAO, 2003, 2004; van Beek et al., 2003; Viglizzo et al., 2006), como a escala regional (Smaling \& Fresco, 1993; Viglizzo et al., 2001, 2004; Flores \& Sarandón, 2003; Veneciano \& Frigerio, 2003; Sacco et al., 2003; FAO, 2003, 2004), nacional (Stoorvogel et al., 1993; Koning et al., 1997; Sheldrick et al., 2002, 2003; Cruzate \& Casas, 2003, 2012; Faerge \& Magid, 2004) o supranacional (Stoorvogel et al., 1993; FAO, 2003, 2004; Henao \& Baanante, 1999, 2006; Tan et al., 2005). 
Si bien este enfoque brinda información inherente a la sostenibilidad, resulta aún insuficiente cuando se quiere considerar la posibilidad de mantener en el tiempo el suministro de nutrientes al agroecosistema. Un balance equilibrado sólo indica que el "caudal" de ingreso de nutrientes a un sistema es suficiente para contrarrestar las salidas del mismo. Es decir, que dicho sistema mantendrá constante el reservorio de nutrientes. Sin embargo, el balance de nutrientes no brinda información acerca de si el flujo de entrada puede ser mantenido en el tiempo, lo cual es un aspecto esencial para el desarrollo de una agricultura sostenible.

\section{LA ALIMENTACIÓN, LA AGRICULTURA Y LOS NUTRIENTES}

El análisis de flujos de nutrientes entre distintos componentes de un socioagroecosistema con el objetivo de visualizar el recorrido de los mismos y la eficiencia de su uso, es entonces un enfoque superador en la búsqueda de la sostenibilidad. Este análisis, permite ampliar la escala incorporando, en algunos casos, zonas no agrarias como las ciudades y relacionarlo con la alimentación. Este tipo de análisis se ha aplicado a nivel de agroecosistema (Haas et al., 2002; Gustafson et al., 2003; Saporito \& Lanyon 2004; Öborn et al., 2003), a nivel de ciudad o provincia (Faerge et al., 2001; Barles, 2007; Forkes, 2007), a nivel de país (Antikainen et al., 2005; Mishima, 2002) y global (Morée et al., 2013; Metson \& Bennett, 2015). Estos estudios han sido implementados principalmente en Europa y Estados Unidos y, más recientemente, en Asia. El objetivo de los mismos es identificar las etapas donde se generan los excesos de nutrientes que causan contaminación ambiental, tanto del aire como del agua (Öborn et al., 2003). Si bien se conoce el destino final de los nutrientes luego del consumo de los alimentos por la población, pocas veces se vincula a estos flujos con la posibilidad de restitución de los nutrientes a las zonas agrícolas-ganaderas (Toze, 2006; Forkes, 2007; Westhoek et al., 2014). En la agricultura se busca la eficiencia en la reposición de nutrientes provenientes de fuentes minerales (Syers et al., 2011), mientras que en la alimentación se busca atenuar el impacto ambiental de los nutrientes relacionados a la misma (Eickhout et al., 2006; Van Drecht et al., 2009). No obstante, aún es incipiente el interés por vincular los flujos de nutrientes entre agricultura y alimentación e intentar generar ciclos para buscar una mayor autosuficiencia.

La utilización de residuos sólidos urbanos y aguas servidas, son algunas de las maneras que contribuirían a generar ciclos de nutrientes entre la ciudad y el campo (Odum, 1998; Nebel \& Wright, 1999; Syers et al., 2011). El cambio demográfico hacia una mayor urbanización que registra la población mundial determina una mayor concentración de nutrientes a partir de la alimentación, así como un mayor recorrido de los alimentos desde el lugar de producción al de consumo. El manejo de los 
desechos orgánicos en las ciudades ha tenido como mayor preocupación la salud de la población, por lo que los esfuerzos se han centrado en retirar estos desechos de las ciudades (Barles, 2007). Esto ha sido vehiculizado a través de los residuos sólidos urbanos o de las aguas servidas mediante una red cloacal (Forkes, 2007). Cada vez más, se buscan nuevos tratamientos para mejorar la performance ecológica referida a la contaminación que generan los desechos, pero es escasa la motivación para intentar cerrar los ciclos de nutrientes entre la ciudad y el campo. En parte, esto se debe a cuestiones económicas, pero también al desinterés y al real desconocimiento acerca de la necesidad de constuir un ecosistema alimentario. Para avanzar hacia un ecosistema alimentario es necesario conocer las demandas de nutrientes de las ciudades para la alimentación, y la potencialidad de reposición en la agricultura luego de su consumo.

Otro aspecto que relaciona a los nutrientes con la alimentación es el consumo de alimentos que provienen de otros países o la generación de alimentos que serán exportados (Grote et al., 2005). Por ejemplo, Europa es un importador de alimentos, principalmente de granos y harinas para la alimentación animal (Nesme et al., 2016). Aquí la preocupación de los científicos radica en los destinos de los nutrientes generados luego del consumo de los alimentos (Grote et al., 2005). Argentina, por el contrario, es un exportador de alimentos, lo que genera una salida de nutrientes que impacta sobre el reservorio de nutrientes del suelo (Pengue, 2015). En estudios realizados en Europa acerca de los flujos de nutrientes en el sistema alimentario, como en el trabajo de Antikainen et al. (2005), no se analiza el origen de los nutrientes que se utilizan para la fertilización en la agricultura o la posibilidad de mantener en el tiempo estos flujos. En parte, esto se debe a las características socioeconómicas de sus países. Argentina, en este contexto, es considerablemente distinta, por lo que el estudio de los flujos de nutrientes debería centrarse en aspectos diferentes de los utilizados en Europa.

\section{SOSTENIENDO LOS FLUJOS DE NUTRIENTES}

El ser humano ha estado alterando los ciclos biogeoquímicos del mundo por algunos milenios (Sutton et al., 2013) y con mayor fuerza en los últimos 200 años, principalmente desde 1950 (Lavelle et al., 2005). Rockström et al. (2009) y Bouwman et al. (2013) señalan que los sistemas de producción de cultivos y ganado son la mayor causa de alteración de los ciclos de $\mathrm{N}$ y $\mathrm{P}$ realizado por el ser humano. Los ciclos biogeoquímicos están íntimamente ligados a la producción de alimentos. El $\mathrm{CO}_{2}$ ha sido estudiado con más énfasis en las últimas décadas, impulsado por la preocupación sobre el cambio climático. Sin embargo, la alteración de los ciclos del $\mathrm{N}$ y del $\mathrm{P}$ a 
escala global, son un desafío emergente que ha recibido poca atención (Lavelle et al., 2005; Bouwman et al., 2009, 2013; Rockström et al., 2009; Sutton et al., 2013; Lassaletta et al., 2016).

La intensificación de la producción agrícola en las últimas décadas ha incrementado la producción global de alimentos pero, a su vez, ha generado un elevado costo ambiental (Tilman et al., 2002; Oenema et al., 2003; Vitousek et al., 2009). Efectos ambientales de la intensificación de la agricultura se manifiestan en la eutrofización de los cuerpos de agua (Syers et al., 2008), disminución de la biodiversidad de áreas naturales y contaminación atmosférica (Oenema et al., 2003; Bouwman et al., 2013), entre otros. Por eso, si bien hasta ahora la producción de alimentos ha cubierto la demanda (valores en promedio), la duda que surge es si el aumento de la demanda de alimentos podrá ser alcanzado protegiendo los recursos naturales para las futuras generaciones (Cassman et al., 2003). Dentro de este desafío se encuentran los nutrientes. El interés por comprender mejor el vínculo de los nutrientes, la agricultura y los ciclos en general (Lavelle et al., 2005), ha tenido mayor desarrollo en N y P (Syers et al., 2008; Cordell et al., 2009; Cordell \& White, 2013; Bodirsky et al., 2014; Lassaletta et al., 2016) que en otros nutrientes.

Con relación al $\mathrm{P}$ este es indispensable para producir alimento (Stauffer \& Sulewski, 2003), no puede ser sustituido en el crecimiento de las plantas y no puede ser manufacturado (Syers et al., 2008; Cordelll \& White, 2013). La principal fuente de P es la roca fosfórica, la cual es un recurso finito (Syers et al., 2008; Cordell et al., 2009), que está geográficamente concentrado y contiene metales pesados como cadmio y elementos radioactivos (Cordell \& White, 2013). Se espera que las reservas de roca fosfórica de alta calidad sean más escasas en el futuro, por lo que su obtención demandará más energía y, por lo tanto, se esperaría un incremento en el valor del fertilizante. Marruecos tiene el $70 \%$ de las reservas de P del planeta (Cordell \& White, 2013) estimadas en 5 Gt (Syers et al., 2011). De la producción total de P (mineral) a nivel mundial, el $80 \%$ tiene como destino la agricultura, un $5 \%$ alimentos animales, y un $15 \%$ usos industriales ( $12 \%$ detergentes y $3 \%$ tratamientos de metales) (Heffer et al. (2006) en Syers et al., 2008). No obstante, sólo un quinto del P proveniente de la minería con destino a la producción de alimentos forma parte del alimento consumido por la población global cada año (Cordell \& White, 2013). Si bien, aún se encuentra en debate cuáles son las reservas de $\mathrm{P}$ y hasta cuándo alcanzarán, los científicos acuerdan que es necesario incrementar el reciclado y ser más eficiente en el uso del $P$ en la cadena de alimentos (Cordell \& White, 2013; Torri et al., 2017).

La reposición de nutrientes a los sistemas agrícolas se realiza, en general, a través de fertilizantes minerales (Hossain \& Singh, 2000) que, en la mayoría de los casos 
(a excepción del $\mathrm{N}$ que se obtiene de la atmósfera), se extraen de las acumulaciones en las rocas $u$ otros depósitos minerales. Luego, parte de estos nutrientes constituye los alimentos que tienen por destino, mayoritariamente, los centros urbanos, finalizando, una vez aprovechados por los seres humanos y, a través de la cadena de deposición de residuos, en los ríos o mares. Esto genera un flujo unidireccional de los nutrientes desde fuentes de alta concentración a fuentes de baja concentración, lo que permite inferir que las futuras generaciones no contarán con fuentes de alta concentración para reponer los elementos extraídos. A lo largo de la historia, el ser humano pasó de favorecer un ciclo de nutrientes prácticamente cerrado (pre-agricultura e inicio de la agricultura) a uno prácticamente abierto (apogeo de las ciudades) (Magdoff et al., 1997). En el futuro, con una población mundial estimada de 8.000 millones en 2020 y 9.400 millones en 2050 (Lal, 2000) se requerirá una mayor producción de alimentos y, por lo tanto, de demanda de nutrientes. Aunque la existencia o reservorio total de nutrientes a nivel de planeta no cambiará (Dibb, 2004), sí lo hará su concentración y distribución. Para proveer de nutrientes a la agricultura y, de esta manera, generar los alimentos necesarios, las generaciones futuras requerirán concentrarlos, lo que implicará un incremento en los costos económicos y energéticos. En este sentido, Magdoff et al. (1997) y Odum (1998) señalan la necesidad de reutilizar los residuos orgánicos generados en las ciudades para cerrar los ciclos de los nutrientes, lo que contribuiría a lograr una mayor autosuficiencia del ecosistema alimentario. Un paso necesario en este sentido es conocer los nutrientes contenidos en los alimentos que llegan a las ciudades y el potencial reaprovechamiento de los mismos en las zonas agrícolas.

\section{EL CASO DE LA PROVINCIA DE BUENOS AIRES, ARGENTINA}

La Argentina y la provincia de Buenos Aires carecen de estudios que aborden integralmente los nutrientes en la agricultura y la alimentación, aunque sí existen trabajos que los abordan separadamente.

Los estudios que incorporan el balance de nutrientes se han centrado, principalmente, en los cultivos extensivos de mayor relevancia económica (trigo (Triticum aestivum L.), maíz (Zea mays L.), soja (Glycine max (L.) Merr.), girasol (Helianthus annuus L.) (Cruzate \& Casas, 2003, 2012; Darwich, 2003; Flores \& Sarandón, 2003; Veneciano \& Frigerio, 2003; Forján, 2004; Berardo, 2004; Oliverio et al., 2004; García \& González Sanjuán, 2010; Manchado, 2010; Zazo et al., 2011) o en algunos nutrientes (García, 2005, 2006, 2011; Díaz-Zorita \& Barraco, 2002; Vázquez, 2002). En estos trabajos se estimó un balance de nutrientes negativo tanto para P como para $\mathrm{N}$, señalando una pérdida de fertilidad de los suelos. La magnitud del déficit informada 
varía según la escala de análisis y la zona considerada. Dichos estudios no consideran el flujo de nutrientes fuera de los sistemas agrícolas, ni analizan el origen y la disponibilidad de las fuentes de nutrientes y la factibilidad de mantenerlas en el tiempo.

A pesar de que las actividades hortícolas, de producción de carne y leche bovina también generan importantes flujos de nutrientes y forman parte de la alimentación de la población, en general, no han sido debidamente consideradas respecto a la conservación de los nutrientes del suelo. Herrero et al. (2006) analizaron el balance de nutrientes en 17 tambos de la provincia de Buenos Aires y señalan un excedente en el balance de $\mathrm{N}$ y $\mathrm{P}$, pero se desconoce el impaco del manejo de los nutrientes de esta actividad a nivel regional. Por su parte, Cabrini \& Calcaterra (2009) y Manchado (2010) analizaron balances de nutrientes en algunas zonas o partidos de la provincia de Buenos Aires, incluyendo los principales cultivos extensivos y la ganadería. Viglizzo et al. $(2001,2002,2003,2004,2006)$ analizaron el balance de nutrientes (N y P) de producción de granos y carne, en distintas eco-regiones de la Región Pampeana (definidas por condiciones edafoclimáticas homogéneas), así como el riesgo de contaminación de los mismos. Todos estos trabajos también informaron un balance de nutrientes negativo generalizado. En algunas zonas, producto de la rotación con pasturas con base de leguminosas, se estimaron balances de $\mathrm{N}$ levemente positivos, a la vez que llegaron a la conclusión de que el riesgo de contaminación era bajo en estos casos. En todas las situaciones, el P aparece como el nutriente más problemático para el largo plazo. Estos estudios realizaron balances, principalmente, hasta fines de la década del 90 del siglo XX. Son escasos los estudios que incluyan balances en la producción de carne a nivel regional desde comienzos del siglo XXI. Paralelamente, estos trabajos utilizan información de fertilización general y no desagregada por región. Es necesario conocer de manera integral qué sucede con los nutrientes en la producción de carne y leche de la provincia de Buenos Aires, siendo que estas dos actividades ocupan el $54 \%$ de la superficie de la provincia (MA, 2015; MAA, 2007).

La horticultura, a pesar de ser una actividad intensiva y con alto uso de insumos incluyendo fertilizantes minerales y abonos orgánicos (Fernández Lozano, 2012), tampoco ha sido muy analizada en lo relativo a la conservación de los nutrientes del suelo o analizando el posible impacto sobre los recursos como el agua y el aire (Abbona et al., 2011). La cercanía de estas producciones a los centros urbanos determina la necesidad de monitorear el impacto que puede generar en el ambiente y, a través de éste, en la salud de la población.

En Argentina y en la provincia de Buenos Aires, desde comienzos del siglo XXI se produjeron cambios en el uso de la tierra definidos, principalmente, por la expansión 
de la zona agrícola sobre la ganadera (Satorre, 2005; Viglizzo et al., 2010). Estos cambios en el uso de la tierra seguramente han determinado variaciones en los flujos de nutrientes a nivel regional. Un análisis de los mismos en las principales actividades agropecuarias de la provincia a comienzos del siglo XXI puede contribuir a un mejor diagnóstico de la situación presente y anticipar cambios ante variaciones en el uso del suelo. Esto es clave como herramienta para la generación de mejores políticas públicas. Un análisis de la sostenibilidad a nivel regional requiere incorporar estas actividades productivas de alimentos en el análisis global de los flujos de nutrientes ya que, al formar parte de la dieta diaria, son indispensables para la alimentación humana.

La provincia de Buenos Aires es la principal productora agrícola del país (SAGPyA, 2006; MAA, 2007), concentra el 38\% de la población nacional (MAA, 2007), de la cual menos del $4 \%$ vive en áreas rurales (MEBA, 2014). Esto sugeriría que la mayor parte de los nutrientes presentan un flujo unidireccional del campo a la ciudad y de ésta a los ríos y mares, lo que implica, a mediano plazo, un pasaje hacia una fuente de baja concentración de nutrientes (cuerpos de agua). La recolección de residuos sólidos urbanos es una práctica extendida en la provincia y existen estudios que analizan la composición de la misma (Rossi et al., 2002; González, 2010; FIUBA-CEAMSE, 2011; Schejtman \& Cellucci, 2014). Aunque en algunos partidos de la provincia se realiza un aprovechamiento de la fracción orgánica de los residuos sólidos urbanos, se desconoce la relevancia de los mismos en relación al flujo total de nutrientes provenientes del campo. Debido a ello, sería importante analizar cuál sería la potencialidad en la reutilización de nutrientes si todos los partidos realizasen un reaprovechamiento de los residuos sólidos urbanos. Además, los nutrientes contenidos en las aguas servidas y su potencial reaprovechamiento en la agricultura tampoco han sido tenidos en cuenta a nivel provincial. Poder estimar estos flujos permitiría conocer la posibilidad de autosuficiencia del ecosistema alimentario de la provincia de Buenos Aires. Aunque, debido a las elevadas extracciones de las actividades agropecuarias, se esperaría a que este ciclado de nutrientes no sea suficiente para la reposición de la totalidad de nutrientes extraidos.

Por otro lado, parte de la producción agrícola de la provincia se exporta a otros países (SAGPyA, 2006; MAA, 2007), principalmente granos y harina para alimentación animal (Andreani, 2008), lo que genera una importante salida de nutrientes fuera de los límites de la provincia, incluso del país (Krauss, 2000; Pengue, 2007). Si los balances de nutrientes en la producción de estos granos son negativos, esto podría implicar, a largo plazo, un riesgo para la sostenibilidad de la agricultura. En este sentido, sería útil para el desarrollo de políticas agrícolas en materia de nutrientes, 
analizar distintos escenarios futuros posibles, tales como: qué sucedería con los flujos de nutrientes si, en lugar de exportar granos para alimentar el ganado en Europa o Asia, sólo se exportara carne obtenida de esos granos o si cambiara el patrón de uso de la tierra, reemplazando superficie agrícola por mixta (agrícola y ganadera). Tener información sobre el impacto de los usos de la tierra en los flujos de nutrientes permitiría anticipar cambios ante variaciones en los mismos.

Debido a la relevancia de la agricultura y la alimentación para la provincia de Buenos Aires, es necesario generar un conocimiento que contribuya a establecer criterios para lograr un ecosistema alimentario y generar estrategias que garanticen a las generaciones presentes y futuras disponer de manera adecuada de nutrientes para la alimentación.

Se asume, por lo tanto, que en la provincia de Buenos Aires los nutrientes relacionados a la agricultura y la alimentación presentan un flujo unidireccional desde los agroecosistemas hacia los cuerpos de agua.

En este marco se plantean las siguientes hipótesis:

I. El balance de nutrientes por unidad de superficie para una misma actividad agrícolo-ganadera presenta valores absolutos similares entre los diferentes partidos de la provincia de Buenos Aires.

II. El sistema de producción de leche es más extractivo por unidad de superficie en N, P, potasio (K), calcio (Ca), azufre (S) que la producción de carne, pero, debido a la reposición en el sistema de producción de leche, los nutrientes presentan balances por unidad de superficie, más equilibrados que en los de producción de carne.

III. Las actividades ganaderas de producción de carne y leche presentan una mejor conservación de los nutrientes del suelo por unidad de superficie que las actividades agrícolas (cultivos extensivos y horticultura)

IV. La exportación de carne en reemplazo de la de granos destinados a la alimentación de ganado, favorecería una mayor conservación de los nutrientes del suelo en la provincia

V. El potencial reaprovechamiento de los residuos domiciliarios y aguas servidas a nivel provincial resultaría insuficiente para reponer los nutrientes extraídos en la actividad agropecuaria 


\section{OBJETIVO GENERAL}

Conocer los flujos de nutrientes en el ecosistema alimentario de la provincia de Buenos Aires y su relación con la sostenibilidad.

\section{OBJETIVOS PARTICULARES}

I. Conocer, a partir de un balance simplificado de nutrientes (N, P, K, Ca, S), el impacto de los sistemas de cultivos extensivos, la horticultura y la producción de carne y leche bovinas, en la conservación de los nutrientes del suelo de la provincia de Buenos Aires.

II. Comparar el balance simplificado de nutrientes (N, P, K, Ca, S) entre las diferentes actividades agrícolo-ganaderas de la provincia de Buenos Aires.

III. Cuantificar y comparar los balances de nutrientes a nivel de la provincia, a partir del cambio en la exportación, reemplazando los granos destinados a la alimentación animal por diferentes tipos de carnes producidas con los mismos.

IV. Cuantificar el aporte potencial de los nutrientes contenidos en los residuos domiciliarios y aguas servidas en el reciclado de nutrientes de la provincia.

\section{ESTRUCTURA DE LA TESIS}

Para cumplir con los objetivos, la tesis ha sido dividida en cinco capítulos y una discusión general. En el capítulo I se intenta brindar un marco histórico y global a partir del análisis de los cambios en los flujos de nutrientes asociados a las variaciones demográficas, el comercio internacional y el concepto de desarrollo. Luego en el capítulo II se abordan aspectos metodológicos, se describen las características edafoclimáticas y la estructura agropecuaria de la provincia de Buenos Aires, se realiza una breve revisión de los conceptos de balance y eficiencia de nutrientes y se detallan algunos criterios metodológicos asumidos en la tesis. En el capítulo III se analizan los balances de nutrientes en las actividades agropecuarias de la provincia. Para esto, el capítulo se divide en cuatro subcapítulos. Los tres primeros analizan los balances de nutrientes en cada actividad: a) cultivos extensivos, b) horticultura y c) producción de carne y leche bovinas, para finalizar en un cuarto subcapítulo que integra las tres producciones. En el capítulo IV se realiza un análisis de los nutrientes en los productos exportados con destino a la alimentación animal y lo que sucedería en la conservación de los nutrientes del suelo de la provincia si, en vez de exportar granos y harinas para alimentar ganado, se exportaran diferentes tipos de carnes (vacuna, de cerdo o de pollo) obtenidas con esos alimentos para el ganado. El capítulo $\vee$ analiza 
la potencialidad de reutilización de los nutrientes que llegan en la alimentación de la población en la construcción de un ecosistema alimentario. Por último, la discusión final integra el conjunto de capítulos abordados en la presente tesis.

\section{BIBLIOGRAFÍA}

Abbona, E.A., S.J. Sarandón, M.E. Marasas \& M. Astier. 2007. Ecological sustainability evaluation of traditional management in different vineyard systems in Berisso, Argentina. Agriculture, Ecosystems \& Environment 119:335-345.

Abbona, E.A., S.J. Sarandón \& M. Vázquez. 2011. Balance de nutrientes como indicador del manejo sustentable del suelo y el agua en la producción hortícola a campo de la provincia de Buenos Aires, Argentina. VII Congresso Brasileiro de Agroecología. Cadernos de Agroecologia 6(2) 11707: 5pp.

Andreani, P. 2008. Mercado del complejo soja y análisis de la competitividad de los países exportadores. Programa de Inserción Agrícola. Entidad Coordinadora Sociedad Rural Argentina. $169 \mathrm{pp}$.

Antikainen, R., R. Lemola, J.I. Nousiainen, L. Sokka, M. Esala, P. Huhtanen \& S. Rekolainen. 2005. Stocks and flows of nitrogen and phosphorus in the Finish food production and consumption system. Agriculture, Ecosystems \& Environment 107:287-305.

Barles, S. 2007. Feeding the city: Food comsumption and flow of nitrogen, Paris, 1801-1914. Science of the Total Environment 375:48-58.

Bekunda, M. \& G. Manzi. 2003. Use of partial nutrient budget as an indicator of nutrient depletion in the highlands of southwestern Uganda. Nutrient Cycling in Agroecosystems 67:187-195.

Berardo, A. 2004. Manejo de la fertilización en una agricultura sustentable. Informaciones Agronómicas 23:23-25.

Bodirsky, B.L., A. Popp, H. Lotze-Campen, J.P. Dietrich, S. Rolinski, I. Weindl, C. Schmitz, C. Müller, M. Bonsch, F. Humpenöder, A. Biewald \& M. Stevanovic. 2014. Reactive nitrogen requirements to feed the world in 2050 and potential to mitigate nitrogen pollution. Nature Communications 5:3858.

Bouwman, A.F., A.H.W. Beusen \& G. Billen. 2009. Human alteration of the global nitrogen and phosphorus soil balances for the period 1970-2050. Global Biogeochemical Cycles 23 GB0A04: 116.

Bouwman, L., K.K. Goldewijk, K.W. Van Der Hoek, A.H.W. Beusen, D.P. Van Vuuren, J. Willems, M.C. Rufino \& E. Stehfest. 2013. Exploring global changes in nitrogen and phosphorus cycles in agriculture induced by livestock production over the 1900-2050 period. Proceedings of the National Academy of Sciences of the United States of America 110(52): 20882-20887.

Brouwer, F. 1998. Nitrogen balances at farm level as a tool to monitor effects of agrienvironmental policy. Nutrient Cycling in Agroecosystems 52:303-308.

Cabrini, S.M. \& C.P. Calcaterra. 2009. Sistemas de producción en el partido de Pergamino. Valoración económica del impacto sobre la capacidad productiva de los suelos. INTA. Estudios socioeconómicos de la sustentabilidad de los sistemas de producción y recursos naturales $N^{\circ} 12$. $36 \mathrm{pp}$.

Cassman, K.G., A. Dobermann, D.T. Walters \& H. Yang. 2003. Meeting cereal demand while protecting natural resources and improving environmental quality. Annual Review of Environment \& Resources 28:315-358.

Clark, B. \& J.B. Foster. 2009. Imperialismo ecológico y la fractura metabólica global. Intercambio desigual y el comercio de guano/nitratos. Theomai 26: 23pp.

Cordell, D. \& S. White. 2013. Sustainable phosphorus measures: strategies and technologies for achieving phosphorus security. Agronomy 3(1):86-116.

Cordell, D., J-O. Drangert \& S. White. 2009. The story of phosphorus: Global food security and food for thought. Global Environmental Change 19: 292-305.

Cruzate, G. \& R.R. Casas. 2003. Balance de nutrientes. Revista Fertilizar (Número especial "Sostenibilidad"): 7-13.

Cruzate, G. \& R.R. Casas. 2012. Extracción y balance de nutrientes en los suelos agrícolas de la Argentina. Informaciones Agronómicas de Hispanoamérica 6:7-14.

Darwich, N. 2003. El balance físico económico en las rotaciones agrícolas. Proyecto Fertilizar. INTA. Disponible en: http://www.fertilizando.com/articulos/El\%20Balance\%20Fisico\%20Economico\%20en\%20las\%20Rot aciones.asp. Último acceso: abril 2017. 
de Jager, A., I. Kariuku, F.M. Matiri, M. Odendo \& J.M. Wanyama. 1998. Monitoring nutrient flows and economic performance in African farming systems (NUTMON) IV. Linking nutrient balances and economic performance in three districts in Kenya. Agriculture, Ecosystems \& Environment 71:81-92.

Díaz-Zorita, M. \& M. Barraco. 2002. ¿Cómo es el balance de fósforo en los sistemas pastoriles de producción de carne en la región pampeana? Informaciones Agronómicas 13:8-1 1 .

Dibb, D. 2004. ¿̇Nos quedaremos sin fósforo? Informaciones Agronómicas 22:1-3.

Drechsel, P., P. Heffer, H. Magen, R. Mikkelsen, H. Singh \& D. Wichelns. 2015. Managing water and nutrients to ensure global food security, while sustaining ecosystem services. En: Managing Water and Fertilizer for Sustainable Agricultural Intensification. Drechsel. P., P. Heffer, H. Magen, R. Mikkelsen, H. Singh \& D. Wichelns (Editores). International Fertilizer Industry Association (IFA), International Water Management Institute (IWMI), International Plant Nutrition Institute (IPNI), and International Potash Institute (IPI). Paris. Capítulo 1:1-7.

Drinkwater, L.E. \& S.S. Snapp. 2007. Nutrients in agroecosystems: rethinking the management paradigm. Advances in Agronomy 92:163-186.

Eickhout, B., A.F. Bouwman \& H. van Zeijts. 2006. The role of nitrogen in world food production and environmental sustainability. Agriculture, Ecosystems \& Environment 116:4-14.

FAO (Organización de las Naciones Unidas para la Alimentación y la Agricultura). 2001. Cuestiones éticas en los sectores de la alimentación y la agricultura. Estudio FAO: Cuestiones de ética. 39pp. Disponible en: ftp://ftp.fao.org/docrep/fao/003/x9601s/x9601s00.pdf. Último acceso: septiembre 2016.

FAO (Organización de las Naciones Unidas para la Alimentación y la Agricultura). 2003. Assessment of soil nutrient balance. Approaches and methodologies. Rome. Fertilizer \& Plant Nutrition Bulletin 14. 88pp.

FAO (Organización de las Naciones Unidas para la Alimentación y la Agricultura). 2004. Scaling soil nutrient balances. Enabling mesolevel applications for African realities. Rome. Fertilizer \& Plant Nutrition Bulletin 15. 150pp.

Farge, J. \& J. Magid. 2004. Evaluating NUTMON nutrient balancing in Sub-Saharan Africa. Nutrient Cycling in Agroecosystems 69:101-109.

Farge, J., J. Magid \& F.W.T. Penning de Vries. 2001. Urban nutrient balance for Bangkok. Ecological Modelling 139:63-74.

Fernández Lozano, J. 2012. La producción de hortalizas en Argentina. Caracterización del sector y zonas de producción. Secretaría de comercio Interior. Corporación del Mercado Central de Buenos Aires. 29pp.

Fernandez-Mena, H., T. Nesme \& S. Pellerin. 2016. Towards an agro-industrial ecology: A review of nutrient flow modelling and assessment tools in agro-food systems at the local scale. Science of the Total Environment 543:467-479.

FIUBA-CEAMSE (Facultad de Ingeniería de la Universidad de Buenos Aires. Coordinación Ecológica Metropolitana). 2011. Estudio de la calidad de los residuos sólidos urbanos del área metropolitana de Buenos Aires. Tercer Informe de avance. 106pp.

Flores, C.C. \& S.J. Sarandón. 2003. ¿Racionalidad económica versus sustentabilidad ecológica? El ejemplo del costo oculto de la pérdida de fertilidad del suelo, durante el proceso de Agriculturización en la Región Pampeana Argentina. Revista de la Facultad de Agronomía 105 (1) (2002,2003): 53-67.

Forján, H.J. 2004. Balance de nutrientes en secuencias agrícolas de la región sur bonaerense. Informaciones Agronómicas 21:8-11.

Forkes, J. 2007. Nitrogen balance for the urban food metabolism of Toronto, Canada. Resources, Conservation \& Recycling. 52:74-94.

García, F.O. 2005. Balance de nutrientes y necesidades de fertilización del cultivo de trigo. 1ra Jornada de Trigo de la Región Centro. 7pp.

García, F.O. 2006. La nutrición de los cultivos y la nutrición de los suelos. Informaciones Agronómicas 29:13-16.

García, F.O. 2011. Balances de carbono y de nutrientes: buscando el equilibrio en la agricultura del Cono Sur. II Simposio Nacional de Agricultura. Uruguay. 135-147.

García, F.O. \& M.F. González Sanjuán. 2010. Balances de nutrientes en Argentina ¿Cómo estamos? ¿Cómo mejoramos? Informaciones Agronómicas 48:1-5.

Garnett, T. 2014. Three perspectives on sustainable food security: efficiency, demand restraint, food system transformation. What role for life cycle assessment? Journal of Cleaner Production 73: 10-18.

Godfray, H.C.J., J.R. Beddington, I.R. Crute, L. Haddad, D. Lawrence, J.F. Muir, J. Pretty, S. Robinson, S.M. Thomas \& C. Toulmin. 2010. Food Security: The Challenge of Feeding 9 Billion People. Review. Science 327:812-818. 
González, G.L. 2010. Residuos sólidos urbanos en Argentina. Tratamiento y disposición final. Situación actual y alternativas futuras. Área de Pensamiento Estratégico. Cámara Argentina de la Construcción. 63pp.

Grote, U., E. Craswell \& P. Vlek. 2005. Nutrient flows in international trade: Ecology and policy issues. Environmental Science \& Policy 8:439-451.

Gustafson, G.M., E. Salomon, S. Jonsson \& S. Steineck. 2003. Fluxes of K, P and $\mathrm{Zn}$ in a conventional and an organic dairy farming system through feed animals manure, and urine- a case study at Ojebyn, Sweeden. European Journal of Agronomy 20:89-99.

Gustavsson, J., C. Cederberg, U. Sonesson, R. van Otterdijk \& A. Meybeck. 2012. Pérdidas y desperdicio de alimentos en el mundo. Alcance, causas y prevención. FAO. Roma. 33pp.

Haas, G., B. Caspari \& U. Kopke. 2002. Nutrient cycling in organic farms: stall balance of a suckler cow herb and beef bulls. Nutrient Cycling in Agroecosystems 64:225-230.

Harris, F.M.A. 1998. Farm-level assessment of nutrient balance in northen Nigeria. Agriculture, Ecosystems \& Environment 71:201-214.

Henao, J. \& C. Baanante. 1999. Estimating rates of nutrient depletion in soils of agricultural lands of Africa. Muscle Schoals, USA. International Fertilizer Development Center (IFDC). 80pp.

Henao, J. \& C. Baanante. 2006. Agricultural production and soil nutrient mining in Africa. Implications for resource conservation and policy development. Summary. Muscle Schoals, USA. International center for soil fertility and agricultural development (IFDC). 95pp. Disponible en: https://ifdcorg.files.wordpress.com/2015/01/t-72-agricultural_production_and_soil_nutrient.pdf. Último acceso: septiembre 2016.

Herrero, M.A., S.B. Gil, M.C. Flores, G.M. Sardi \& A.A. Orlando. 2006. Balance de nitrógeno y fósforo a escala predial, en sistemas lecheros pastoriles en Argentina. Investigación Veterinaria 8:9-21.

Hossain, M. \& V.P. Singh. 2000. Fertilizer use in agriculture: implications for sustaining food security and the environment. Nutrient Cycling in Agroecosystems 57:155-169.

Ingram, J., P. Aggarwal, P. Ericksen, P. Gregory, L. Horn-Phathanothai, A. Misselhorn \& K. Wiebe. 2012. Food security for a planet under pressure. Rio+20 Policy Brief 2. 8pp. Disponible en: http://www.icsu.org/rio20/policy-briefs/BiodiversityLowRes.pdf. Último acceso: abril 2017.

Koning, G.H.J., P.J. van de Kop \& L.O. Fresco. 1997. Estimates of sub-national nutrient balances as sustainability indicators for agro-ecosystems in Ecuador. Agriculture, Ecosystems \& Environment 65:127-139.

Krauss, A. 2000. Nutrient cycling and transfers in the global dimension. En: Nutrient management in China. Part 1. Nutrient management and nutrient cycling in agro-ecosystems. Hardter R., J-C. Xie, J.M. Zhou \& Q-Z. Fan (Editores). International Potash Institute. Capítulo 1:13-24.

Lal, R. 2000. Soil management in the developing countries. Soil Science 165:57-72.

Lassaletta, L., G. Billen, J. Garnier, L. Bouwman, E. Velazquez, N.D. Mueller \& J.S Gerber. 2016. Nitrogen use in the global food system: past trends and future trajectories of agronomic performance, pollution, trade, and dietary demand. Environmental Research Letters 11(9) 095007.

Lavelle, P., R. Dugdale, R. Scholes, A.A. Berhe, E. Carpenter, L. Codispoti, A-M. Izac, J. Lemoalle, F. Luizao, M. Scholes, P. Tre'guer \& B. Ward. 2005. Nutrient Cycling. En: Ecosystems and Human Wellbeing: Current State and Trends, Volume 1. R. Hassan, R. Scholes \& N. Ash (Editores). Editorial Island Press. Estados Unidos. Capítulo 12:331-353.

MA (Ministerio de Agroindustria). 2015. Caracterización de la producción bovina. Buenos AiresCorrientes- Chaco- Formosa- La Pampa- Misiones. INTA, SENASA. Serie I. 194pp.

MAA (Ministerio de Asuntos Agrarios). 2007. Nuestra provincia nuestro campo. El sector agropecuario de la provincia de Buenos Aires. 147pp.

Magdoff, F., L. Lanyon \& B. Liebhardt. 1997. Nutrient cycling, transformations and flows: implications for a more sustainable agriculture. Advances in Agronomy 60:1-73.

Manchado, J.C. 2010. La sustentabilidad en la agricultura pampeana: Valoración económica del balance de nutrientes para las principales actividades agropecuarias extensivas en la Región Centro Sur de la Provincia de Buenos Aires. Revista Argentina de Economía Agraria XII(2):51-68.

MEBA (Ministerio de Economía de la provincia de Buenos Aires). 2014. Distribución de la población de la provincia de Buenos Aires. Período 1947 - 2010. Serie Estudios Demográficos 19. $29 \mathrm{pp}$.

Metson, G.S. \& E.M. Bennett. 2015. Phosphorus cycling in Montreal's food and urban agriculture systems. PLOS ONE 10(3): e0120726.

Mishima, S. 2002. The recent trend of agricultural nitrogen flow in Japan and improvment plans. Nutrient Cycling in Agroecosystems 63:151-163. 
Morée, A.L., A.H.W. Beusen, A.F. Bouwman \& W.J. Willems. 2013. Exploring global nitrogen and phosphorus flows in urban wastes during the twentieth century. Global Biogeochemical Cycles 27:836-846.

Nebel, B.J. \& R.T. Wright. 1999. Ciencias Ambientales. Ecología y desarrollo sostenible. Sexta edición. Editorial Prentice Hall. México. 720pp.

Nesme, T., S. Roques, G.S. Metson \& E.M. Bennett. 2016. The surprisingly small but increasing role of international agricultural trade on the European Union's dependence on mineral phosphorus fertiliser. Environmental Research Letters 11 (2) 025003.

Öborn, I., A.C. Edwards, E. Witter, O. Oenema, K. Ivarsson, P.J.A. Withers, S.I .Nilsson \& A. Richert Stinzing. 2003. Element balances as a tool for sustainable nutrient management: a critical appraisal of their merits and limitations within an agronomic and environmental context. European Journal of Agronomy 20:211-225.

Odum, E.P. 1998. Ecología: El vínculo entre las ciencias naturales y las ciencias sociales. Editorial Continental S.A. XX Reimpresión. Mexico. 295pp.

Oenema, O., H. Kros \& W. de Vries. 2003. Approaches and uncertainties in nutrient budgets: implications for nutrient management and environmental policies. European Journal of Agronomy 20:3-16.

Oliverio, G., F. Segovia \& G.M. López. 2004. Fertilizantes para una agricultura de 100 millones de toneladas. Fundación Producir Conservando. Disponible en: http://producirconservando.org.ar//intercambio/docs/fertil_100_tn.pdf. Último acceso: septiembre 2016.

Pengue, W. 2007. Modelo agroexportador, monoproducción y deuda ecológica. ¿̇acia el agotamiento del granero del mundo? Revista Aportes para el Debate 59-81.

Pengue, W. 2015. Recursos naturales, servicios ambientales y desarrollo en América Latina. Revista Redbioética/UNESCO. Año 61 (1 1):64:69.

Rockström, J., W. Steffen, K. Noone, A. Persson, F.S. Chapin, E. Lambin, T.M. Lenton, M. Scheffer, C. Folke, H. Schellnhuber, B. Nykvist, C.A. De Wit, T. Hughes, S. van der Leeuw, H. Rodhe, S. Sorlin, P.K. Snyder, R. Costanza, U. Svedin, M. Falkenmark, L. Karlberg, R.W. Corell, V.J. Fabry, J. Hansen, B. Walker, D. Liverman, K. Richardson, P. Crutzen \& J. Foley. 2009. Planetary boundaries: exploring the safe operating space for humanity. Ecology and Society 14(2): 32.

Rossi, A., R. Sarafián, A. Cittadino \& D. Castiglione. 2002. Diagnóstico de la situación de los residuos sólidos en Argentina. AIDIS Argentina. 232pp.

Sacco, D., M. Bassanino \& C. Grignani. 2003. Developing a regional agronomic information system for estimating nutrient balances at a larger scale. European Journal of Agronomy 20:199210.

SAGPyA (Secretaría de Agricultura Ganadería Pesca y Alimentos). 2006. Buenos Aires: Economía de la producción primaria y agroindustrial. Disponible en: http://www.agroindustria.gob.ar/sitio/. Último acceso: septiembre 2016.

Saporito, L.S. \& L.E. Lanyon. 2004. Evaluating the spatial and temporal dynamics of farm and field phosphorus and potassium balances on a crop and livestock farm. Nutrient Cycling in Agroecosystems 69:85-94.

Satorre, E.H. 2005. Cambios tecnológicos en la agricultura argentina actual. Revista Ciencia Hoy 15(87):24-31. Disponible en: http://agriskmanagementforum.org/sites/agriskmanagementforum.org/files/Documents/Anexo\% 203-\%20Satorre\%20en\%20colores-1.pdf. Último acceso: septiembre 2016.

Schejtman, L. \& M. Cellucci. 2014. Gestión integral de residuos sólidos urbanos. Políticas municipales que promueven la sustentabilidad. Serie Buenas Prácticas Municipales 3. 33pp.

Sheldrick, W., J.K. Syers \& J. Lingrad. 2002. A conceptual model for conducting nutrient audits at national, regional, and global scales. Nutrient Cycling in Agroecosystems 62:61-72.

Sheldrick, W.F., J.K. Syers \& J. Lingrad. 2003. Soil nutrient audits for China to estimate nutrient balances and output/input relationships. Agriculture, Ecosystems \& Environment 94:341-354.

Smaling, E.M.A. \& L.O. Fresco. 1993. A decision-suppport model for monitoring nutrient balances under agricultural land use (NUTMON). Geoderma 60:235-256.

Soussana, J-F. 2014. Research priorities for sustainable agri-food systems and life cycle assessment. Journal of Cleaner Production 73:19-23.

Stauffer, M.D. \& G. Sulewski. 2003. Fosforo: Un nutriente esencial para la vida. Actas Simposio "El Fósforo en la Agricultura Argentina". Rosario, Santa Fe. INPOFOS. 4-7.

Stoorvogel, J.J., E.M.A. Smaling \& B.H. Janssen. 1993. Calculating soil nutrient balances in Africa at different scales. I. Supra-national scale. Fertilizer Research 35:227-235.

Sutton, M.A., A. Bleeker, C.M. Howard, M. Bekunda, B. Grizzetti, W. de Vries, H.J.M. van Grinsven, Y.P. Abrol, T.K. Adhya, G. Billen, E.A. Davidson, A. Datta, R. Diaz, J.W. Erisman, X.J. Liu, O. Oenema, C. Palm, N. Raghuram, S. Reis, R.W. Scholz, T. Sims, H. Westhoek \& F.S. Zhang. 2013. Our nutrient 
world: The challenge to produce more food and energy with less pollution. Global Overview of Nutrient Management. Centre for Ecology and Hydrology, Edinburgh on behalf of the Global Partnership on Nutrient Management and the International Nitrogen Initiative. 128pp.

Syers, J.K., A.E. Johnston \& D. Curtin. 2008. Efficiency of soil and fertilizer phosphorus use. Reconciling changing concepts of soil phosphorus behavior with agronomic information. FAO. Rome. Fertilizer \& Plant Nutrition Bulletin 18. 123pp.

Syers, K., M. Bekunda, D. Cordell, J. Corman, J. Johnston, A. Rosemarin, I. Salcedo \& T. Lougheed. 2011. Phosphorus and food production. En: UNEP, Year Book. UNEP, Nairobi. 34-45.

Tan, Z.X., R. Lal \& K.D. Wiebe. 2005. Global soil nutrient depletion and yield reduction. Journal of Sustainable Agriculture 26(1):123-146.

Tilman, D., K.G. Cassman, P.A. Matson, R. Naylor \& S. Polasky. 2002. Agricultural sustainability and intensive production practices. Nature 418: 671-677.

Torri, S.I., R.S. Corrêa \& G. Renella. 2017. Biosolid application to agricultural land- a contribution to global phosphorus recycle: A review. Pedosphere 27(1): 1-16.

Toze, S. 2006. Reuse of effluent water-benefits and risks. Agriculture \& Water Management 80 (13):147-159.

van Beek, C.L., L. Brouwer \& O. Oenema. 2003. The use of farmgate balances and soil surface balances as estimator for nitrogen leaching to surface water. Nutrient Cycling in Agroecosystems 67:233-244.

Van den Bosch, H., J.N. Gitari, V.N. Ogaro, S. Maobe \& J. Vlaming. 1998. Monitoring nutrient flows and economic performance in African farming systems (NUTMON). III. Monitoring nutrient flows and balances in three districts in Kenya. Agriculture, Ecosystems \& Environment 71:63-80.

Van Drecht, G., A.F. Bouwman, J. Harrison \& J. M. Knoo. 2009. Global nitrogen and phosphate in urban wastewater for the period 1970 to 2050. Global Biogeochemical Cycles 23:GB0A03, 19 pp.

Vázquez, M.E. 2002. Balance y fertilidad fosforada en suelos productivos de la región pampeana. Informaciones Agronómicas 16:3-7.

Veneciano, J.H. \& K.L. Frigerio. 2003. Exportación de nutrientes en sistemas extensivos de San Luis. Informaciones Agronómicas 17:17-21.

Viglizzo, E.F., F. Lértora, A.J. Pordomingo, J.N. Bernardos, Z.E. Roberto \& H. del Valle. 2001. Ecological lessons and applications from one century of low external-input farming in the pampas of Argentina. Agriculture, Ecosystems \& Environment 83:65-81.

Viglizzo, E.F., A.J. Pordomingo, M.G. Castro \& F.A. Lértora. 2002. La sustentabilidad ambiental del agro pampeano. INTA. Programa Nacional de Gestión Ambiental Agropecuaria. Ediciones INTA. $84 \mathrm{pp}$.

Viglizzo, E.F., A.J. Pordomingo, M.G. Castro \& F.A. Lértora.2003. Environmental assessment of agriculture at a regional scale in the pampas of Argentina. Environmental Monitoring \& Assessment 87:169-195.

Viglizzo, E.F., A.J. Pordomingo, M.G. Castro, F.A. Lértora \& J.N. Bernardos. 2004. Scale-dependent controls on ecological functions in agroecosystems of Argentina. Agriculture, Ecosystems \& Environment 101:39-51.

Viglizzo, E.F., F. Frank, J. Bernardos, D.E. Buschiazzo \& S. Cabo. 2006. A rapid method for assessing the environmental performance of commercial farms in the pampas of Argentina. Environmental Monitoring \& Assessment 117:109-134.

Viglizzo, E.F., L.V. Carreño, H. Pereyra, F. Ricard, J. Clatt \& D. Pincén. 2010. Dinámica de la frontera agropecuaria y cambio tecnológico. En: Expansión de la Frontera Agropecuaria en Argentina y su Impacto Ecológico-Ambiental. Viglizzo, E.F. \& E.G. Jobbágy (Editores). Ediciones INTA. Capítulo 1:9-16.

Vitousek, M., R. Naylor, T. Crews, M.B. David, L.E. Drinkwater, E. Holland, P.J. Johnes, J. Katzenberger, L.A. Martinelli, P.A. Matson, G. Nziguheba, D. Ojima, C.A. Palm, G.P. Robertson, P.A. Sanchez, A.R. Townsend \& F.S. Zhang. 2009. Nutrient Imbalances in Agricultural Development. Science 324:1519-1520.

Westhoek, H., J.P. Lesschen, T. Rood, S. Wagner, A. De Marco, D. Murphy-Bokern, A. Leip, H. van Grinsven, M.A. Sutton \& O. Oenema. 2014. Food choices, health and environment: Effects of cutting Europe's meat and dairy intake. Global Environmental Change 26:196-205.

Zazo, F., C. Flores \& S. Sarandón. 2011. El "costo oculto" del deterioro del suelo durante el proceso de "sojización" en el Partido de Arrecifes, Argentina. Revista Brasileira de Agroecologia 6(3):3-20. 


\section{CAPÍTULO I}

Cambios en los flujos de nutrientes a escala regional y global y su vinculación con demografía, comercio internacional y desarrollo

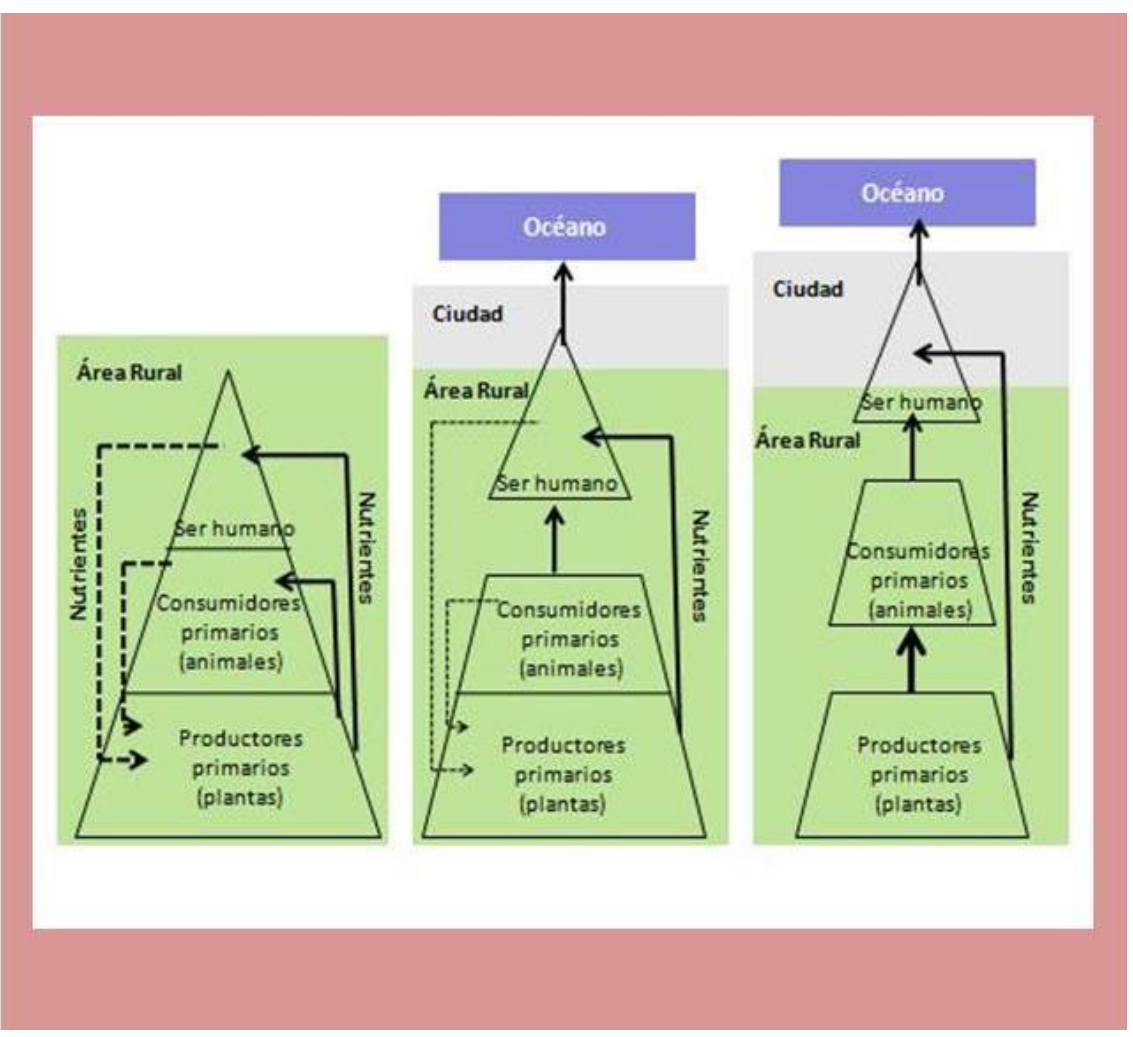




\section{I.1. INTRODUCCIÓN}

Un ecosistema alimentario debe ser parte de un desarrollo sostenible. Para ello, es necesario realizar un análisis multidimensional, que involucre aspectos económicos, ecológicos y socioculturales (Sarandón \& Flores, 2009, 2014). Este análisis multidimensional no debería acotarse sólo al presente sino incorporar la perspectiva histórica, lo que permitiría generar mejores herramientas que ayuden a definir políticas que tiendan a la sostenibilidad. Dentro de la complejidad del desarrollo sostenible, un aspecto a tener en cuenta es la disponibilidad y el flujo de nutrientes relacionados al ecosistema alimentario. La perspectiva histórica de esta temática podría ayudar a comprender mejor cómo han cambiado estos flujos a nivel regional y global, y analizar algunas causas de esos cambios. Esta mirada puede ser útil en la construcción de un cambio en la tendencia actual del modo de producción y consumo de alimentos, a la vez que permitiría abrir un camino acorde con la sostenibilidad.

En este capítulo se presenta una breve síntesis de los cambios en los flujos de nutrientes a escala global basados en el trabajo de Magdoff et al. (1997), para luego realizar un análisis de los mismos a partir de la vinculación con los conceptos de demografía, comercio internacional y desarrollo (Abbona \& Sarandón, 2013).

\subsection{CAMBIO DE lOS flujOS DE NUtRIENTES A escalA GLOBAL: DE LA AUTOSUFICIENCIA AL DESPILFARRO}

Desde una mirada ecológica, el cambio producido en los modelos de producción y consumo de alimentos sobre el ciclo de los nutrientes a escala global, puede representarse a través de una pirámide de tres escalones (Magdoff et al., 1997), que representa la relación entre productores (plantas verdes), consumidores primarios (ganado) y el ser humano (Figura 1.1).

Antes de que el ser humano practicara la agricultura, vivía en pequeñas comunidades de cazadores recolectores. Consumía los alimentos y, los desechos, retornaban al suelo dentro de la zona de donde eran extraídos. Por tanto, se podría considerar que existía un ciclo cerrado de nutrientes (Figura 1.1.a). Con la aparición de la agricultura, y a través de sus distintas etapas, se produjeron diferentes modificaciones en la dinámica de los nutrientes. En parte, esto estuvo asociado al surgimiento de las ciudades y el éxodo del ser humano (Abbona \& Sarandón, 2014).

En los inicios de la agricultura, hace unos 10.000 años, el ser humano vivía mayoritariamente en el campo o en pequeñas aldeas, donde producía y extraía los alimentos en cercanías al lugar de consumo. Los desechos retornaban al suelo dentro de la zona de producción. Los animales domésticos se alimentaban con el pastizal 
natural obtenido en esos suelos y sus desechos también retornaban a los mismos. Con la aparición de las ciudades y el inicio del éxodo de las personas a la ciudad, comienza la separación entre el lugar de consumo y el de producción. Los productos primarios y la carne eran transportados a las ciudades, y los nutrientes contenidos en estos productos ya no retornaban a los lugares de donde habían sido extraídos, interrumpiéndose el reciclaje de nutrientes (Figura 1.1.b).

Desde la mitad del siglo XX, con la agriculturización por un lado, y con la concentración de la población en las ciudades por otro, se acrecentó la ruptura entre producción y consumo (Magdoff et al., 1997). La producción animal, que hasta el momento se basaba principalmente en los pastizales naturales, comienza a utilizar reservas forrajeras traídas de lugares más distantes. El feed-lot (engorde a corral) empieza a ser un sistema de producción de carne que irrumpe con gran fuerza desde mediados del siglo XX. Se inicia de esta manera, la separación entre producción primaria (plantas forrajeras) y secundaria (ganado doméstico), con la consecuente ruptura del retorno de parte de los nutrientes consumidos por el ganado a través de forraje (Figura 1.1. c).

Al estar los alimentos destinados en su mayoría a los centros urbanos, el destino final de los nutrientes pasó a ser el río y, posteriormente, el océano. Este recorrido ha sido facilitado por el sistema de cloacas presentes en las ciudades, que permite trasladar los desechos hasta los cuerpos de agua retirados. Esto ha llevado a que el flujo de nutrientes pasara de ser prácticamente cerrado (Figura 1.1a.), a uno totalmente abierto (Figura 1.1c). Para la reposición de nutrientes en los sistemas agrícolas de hoy en día, se depende de fuentes minerales (rocas) o fertilizantes sintéticos (Syers et al., 2011). 


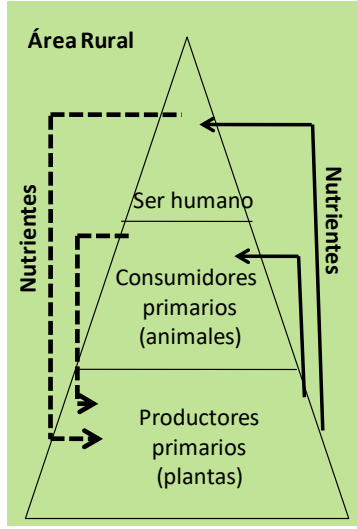

a)

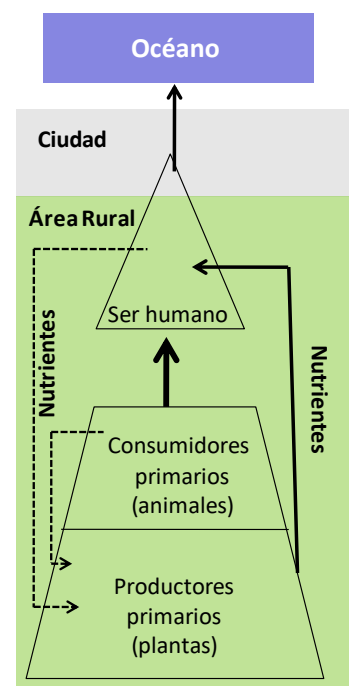

b)

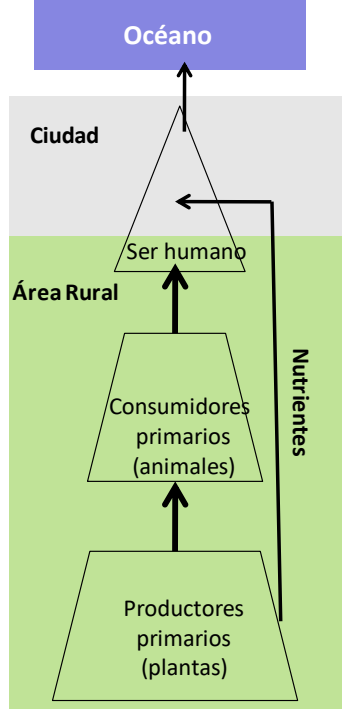

c)

Figura 1.1. El ciclo de los nutrientes en distintos momentos desde el inicio de la agricultura. a) Preagricultura e inicio de la agricultura (ciclo cerrado). b) Comienzo del auge de las ciudades (ciclo semi-cerrado). c) Agricultura Industrializada (ciclo abierto). Modificado de Magdoff et al. (1997).

Otras de las grandes modificaciones en los flujos de nutrientes a escala global han estado motorizadas por el comercio mundial. Por ejemplo, Argentina exporta miles de toneladas de granos a distintos países (principalmente de Europa y Asia) para alimentar el ganado, generando déficit de nutrientes Argentina (García \& González Sanjuán, 2010; Cruzate \& Casas, 2012) y excesos en los otros países (Grote et al., 2005).

De mantenerse este modelo de producción-consumo, en el largo plazo, las fuentes de nutrientes de alta concentración serán cada vez más escasas, y los sistemas no tendrán una adecuada posibilidad de reposición de los mismos, ya que la mayoría se encontrarán dispersos en los océanos.

Si al análisis anterior se incluyera el aumento de la población mundial proyectada en 9.000 millones para el año 2050 (Godfray et al., 2010), se observaría que, además de la apertura del ciclo de nutrientes, crecería enormemente la extracción de nutrientes debido a la producción de alimentos. Todo esto lleva a considerar que el análisis de los nutrientes, es indispensable para la sostenibilidad de la agricultura y de la alimentación mundial dentro de un ecosistema alimentario, en el marco de un desarrollo sostenible.

Para ayudar a comprender mejor los cambios en los flujos de nutrientes a escala global mencionados en esta síntesis, se incorporará la perspectiva histórica vinculada a: a) el cambio en la demografía, b) el devenir del comercio internacional, y c) el desarrollo. 


\section{I.2.1. La demografía}

Uno de los mayores cambios del flujo de nutrientes ha estado asociado a los cambios demográficos ocurridos desde el inicio de la agricultura, que comenzó con aldeas, pueblos y ciudades, hasta llegar hoy en día a las metrópolis de más de un millón de habitantes. La concentración de la población en pequeñas superficies (ciudades) determina que, para poder subsistir, los alimentos deben recorrer un trayecto desde el lugar de producción al de consumo.

En Europa, hasta la época medieval las aldeas eran predominantemente de base agrícola, la industria tenía un fuerte componente artesanal. Tres cuartas partes de la población activa se encontraba en el sector primario (Ferrer, 2013). Muy pocas ciudades superaban los 50 mil habitantes presentando una fuerte diseminación de la población. Otra característica era el estancamiento poblacional motivado por la alta mortandad que igualaba la alta natalidad existente. Esta diseminación de la población rural en el territorio generaba gran cantidad de pequeños poblados lo que determinaba que los flujos de nutrientes debido a la producción de alimentos fueran cortos y más cerrados. Hasta esta época se podría decir que predominaba el flujo de nutrientes de la Figura 1.1 a.

Hacia mediados del siglo XVIII, motivado por un inicio de mejora en las condiciones de salubridad y mayor producción de alimentos, se logró contrarrestar la mortalidad y Europa comienza a incrementar significativamente la población. Esto, sumado al inicio de la primera revolución industrial ocurrida en Inglaterra en el siglo XVIII, impulsa un éxodo del sector rural al urbano y las ciudades se transforman en el polo de atracción en busca de una mejor calidad de vida. Se inicia así el paso al flujo de nutrientes de la Figura 1.1b. Este cambio ocurrido en Inglaterra se traslada durante el siglo XIX al resto de Europa, Estados Unidos y Japón. Es la industrialización la que permite, en parte, absorber este flujo migratorio del campo. La concentración de la población en pocas ciudades y la desaparición de varias aldeas distribuidas en el territorio, implica una mayor separación entre los lugares de producción y de consumo de alimentos, con el consecuente alargamiento de los flujos de nutrientes. Las ciudades, al ser el destino de gran cantidad de alimentos para la población, comienzan a tener problemas de salubridad, entre otras cosas, por la acumulación de desechos urbanos (Barles, 2007).

En América Latina, se considera que la urbanización es el principal proceso de redistribución de la población en los últimos 100 años (Vignoli, 2002; Lattes, 2004). Para el año 1925 el porcentaje de población urbana en Latinoamérica era del 25\%, llegando en el año 2000 al 75,3\%, lo que muestra el importante y constante flujo migratorio. 
A su vez, en varios países de la región la mayor proporción de la población se sitúa en ciudades de más de 100 mil habitantes. En Argentina, en 1991, el 60\% de la población se encontraba asentada en ciudades de este tipo y la urbanización total era del $87,3 \%$ (Vignoli, 2002). Si bien en el período mencionado la región sufrió diferentes etapas de crecimiento económico, inclusive con gran desocupación en las ciudades, el flujo de personas desde el ámbito rural al urbano no cesó. El sector rural de Latinoamérica ha mostrado un estancamiento y un envejecimiento de la población, ya que gran parte del éxodo se debe a las personas jóvenes que emigran en busca de un mejor futuro. La migración del campo a la ciudad no ha tenido la misma intensidad en todos los países de Latinoamérica, pero sí la misma tendencia. Ortiz Davison et al. (2003) consideran que la industrialización de las naciones ha sido el motor de este cambio poblacional en la región. El cambio demográfico en Latinoamérica generó cambios en los flujos de nutrientes creando áreas de producción de alimentos (rurales) y áreas de consumo (ciudades). Los flujos de nutrientes crecieron en magnitud y distancia y los retornos desde las ciudades a las áreas rurales han sido inexistentes. El paso del flujo de nutrientes de la Figura 1.1b a 1.1c puede considerarse desde mediados del siglo XX, con la consolidación del proceso de urbanización y con la aparición de la Revolución Verde.

Otro de los aspectos demográficos que inciden en los flujos de nutrientes, es la migración internacional. Inicialmente ocurrieron grandes migraciones de África a América provocadas por el tráfico de esclavos, luego grandes flujos migratorios de Europa a América desde mediados de siglo XIX a mediados de siglo XX, como consecuencia de diferentes etapas de hambrunas y guerras (Ferrer, 2013). En América Latina, desde la década de 1980, se inició un flujo migratorio entre países de la región en busca de mejores condiciones de vida (CEPAL, 2000) y también un flujo hacia Europa. Las migraciones generan cambios en los flujos de nutrientes al incrementar la demanda de alimentos en determinados lugares y disminuirla en otros. Muchas veces las migraciones conllevan el traslado de cultivos propios de cada cultura o la posterior demanda de determinados alimentos desde los lugares de origen de la población.

Los cambios demográficos antes señalados han estado asociados e influenciados, entre otras cosas, por las dinámicas económicas generadas por el comercio internacional.

\section{I.2.2. El comercio internacional}

El origen del "comercio" es atribuido a diferentes momentos de la historia de la humanidad, aunque el más remoto puede referirse a cuando se instituyó la agricultura 
hace unos 10.000 años. Al principio se realizaba una agricultura de subsistencia, donde las cosechas obtenidas eran las justas para la población. Sin embargo, a medida que fueron incorporándose nuevos desarrollos en la actividad agrícola, las cosechas comenzaron a ser cada vez mayores y los excedentes facilitaron un intercambio local de otros bienes por alimentos. Los intercambios fueron creciendo así como las relaciones entre pobladores y entre diferentes poblaciones.

A lo largo de la Edad Media, el comercio creció y empezaron a surgir rutas comerciales transcontinentales que intentaban suplir la alta demanda europea de bienes y mercancías. Entre las rutas más famosas destaca la Ruta de la Seda, pero también había otras importantes como las rutas de importación de especias (Arosemena, 2012; Amin, 2008).

Para algunos autores la conquista de América representa el inicio del "comercio internacional" (Schwartz, 2001) e incluso de la globalización (Vilas, 1999; Ferrer, 2013). Para afirmar esto, se basan en que las magnitudes de intercambio comercial desde entonces fueron sustancialmente mayores. La introducción del cultivo de la caña de azúcar (Saccharum officinarum L.) en el Caribe y Brasil, basada en la mano de obra esclava, vinculó estas tierras con el mercado europeo. La incorporación posterior del cultivo de algodón (Gossypium hirsutum L.) con características similares de esclavitud, generó un proceso globalizador de gran magnitud en la época, trayendo a América más de 10 millones de africanos (Ferrer, 1997). La exportación de estos cultivos implicó la exportación de los nutrientes contenidos en los mismos. De esta manera, el comercio internacional contribuyó al traslado de nutrientes a gran escala entre diferentes partes del mundo, principalmente desde las "colonias" hacia los países centrales. Al no existir la reposición de nutrientes, se puede asumir que la agricultura constituía otra actividad "minera" de la época. Otro cambio iniciado desde entonces fue que en Europa comenzaron a utilizarse cultivos provenientes de América, que rápidamente formaron parte de la dieta como ser: maíz (Zea mays L.), tabaco (Nicotiana tabacum L.), cacao (Theobroma cacao L.), papa (Solanum tuberosum L.), tomate (Solanum lycopersicum L.), entre otros (Vilas, 1999).

Los avances tecnológicos promovidos por la revolución industrial de fines del siglo XVIII fueron aplicados a la agroindustria, como la del algodón, generando un impulso a las plantaciones de este cultivo principalmente en los Estados Unidos (Ferrer, 1997). El comercio entre los siglos XVI, XVII y mediados del XVIII estaba basado en el mercantilismo, el cual se caracterizó principalmente por un fuerte "proteccionismo" estatal en las economías nacionales, la acumulación de oro y plata como fuentes de poder, el concepto de economía nacional a través del incentivo a las exportaciones y 
restricciones a las importaciones en miras de mantener una balanza comercial favorable, y la constante búsqueda por parte de las potencias económicas de la época de expandir sus fronteras en ultramar a través de la conquista y el colonialismo (Arosemena, 2012).

El liberalismo, modelo económico basado en la premisa de que la completa libertad de los factores económicos produciría el mayor beneficio para cada individuo y la sociedad, comienza su difusión en el siglo XVIII con el aporte de Adam Smith, a través de su obra "La Riqueza de las Naciones"; de David Ricardo por la "Teoría de las Ventajas Comparativas"; y los aportes del resto de otros economistas clásicos con la "Teoría de las Ventajas Competitivas" (Arosemena, 2012). La consolidación de esta idea de comercio condicionó a los países no europeos a una posición de proveedores de materias primas y, los europeos y Estados Unidos (aunque también mantuvo la provisión agropecuaria), como proveedores de manufacturas, originando el desequilibrio y la dependencia que perdura hasta estos días. Esto implicó que diferentes áreas del planeta se posicionaran como proveedoras de alimentos, por lo tanto, de nutrientes, y otras como destinatarias de los mismos, con un inexistente retorno de los nutrientes.

En el último tercio del siglo XIX, la llamada segunda revolución industrial con el desarrollo de nuevos medios de transporte terrestre y naval, y las nuevas técnicas de conservación de alimentos, entre otros, estimularon masivos desplazamientos de población excedente de Europa hacia América y Oceanía. Hacia el interior de la Argentina el sistema de ferrocarriles permitió que la región pampeana se insertara al sistema global (Ferrer, 1997) promoviendo una comunicación ferroviaria tal que permitiera la llegada de las diferentes producciones agropecuarias a los puertos para la exportación. De esta manera, se facilitó la extracción de nutrientes de diferentes regiones del país hacia Europa.

Durante la segunda mitad del siglo XIX y principios del siglo XX, las principales economías de Europa habían terminado de pasar de un sistema mercantilista a un sistema de libre comercio.

En 1944, hacia el final de la Segunda Guerra Mundial y con el objetivo de lograr una recuperación de la economía mundial, surgen instituciones de carácter multilateral basadas en el acuerdo de Bretton Woods: el Banco Mundial, el Fondo Monetario Internacional y el Acuerdo General sobre Aranceles y Comercio (GATT). Este último, con la finalidad de impulsar rápidamente la liberalización y el crecimiento del comercio internacional.

En el marco del GATT se realizaron ocho rondas de negociaciones multilaterales. En todo este período, la cuestión de la agricultura estuvo excluida de sus 
tratados ya que generaba las mayores controversias entre los países desarrollados y subdesarrollados (Osorio, 1992). Para los primeros, principalmente los europeos y Japón, fue una prioridad lograr la autosuficiencia alimentaria luego de la guerra. Sin dudas, esta autosuficiencia sólo podría lograrse evitando el ingreso irrestricto de alimentos producidos en países que presentaran mejores ventajas comparativas. Esta situación derivó a que el tema de agricultura no fuera incluido en las negociaciones. Por otro lado, el comercio internacional se encaminaba hacia una mayor liberación en los rubros donde los países desarrollados eran fuertes y no corrían riesgo frente a los países en vía de desarrollo.

La Organización Mundial del Comercio (OMC) fue creada en 1995 y es la base jurídica e institucional del actual sistema multilateral de comercio. Es también la plataforma en la que se desarrollan las relaciones comerciales entre los distintos países mediante un ejercicio colectivo de debate, negociación y enjuiciamiento. A pesar de la creación de la OMC, el comercio internacional de las últimas dos décadas ha estado más atado a los tratados entre bloques comerciales (Mercosur, Unión Europea, Estados Unidos, Sudeste Asiático, etc.), que en una negociación multilateral. Entre los tratados entre bloques se desataca el del Mercosur con la Unión Europea iniciado en 1995 (Bouzas, 2004). A pesar de que este acuerdo se originó para contrarrestar el avance geopolítico de Estados Unidos en la región, se han realizado varias rondas de negociación sin llegar a un acuerdo definitivo. En tanto, Estados Unidos, dado el difícil camino para lograr establecer el Área de Libre Comercio de las Américas, ha promovido acuerdos bilaterales o minilaterales con varios países de la región (Bouzas, 2005), principalmente aquéllos que ofrecen menos resistencias a sus demandas y cuyas exigencias son menos conflictivas para la economía política interna de los Estados Unidos.

De acuerdo con la OMC, entre 1948 y 1997 el comercio mundial de mercancías se multiplicó 18 veces, a un promedio del $6 \%$ anual, mientras que el producto mundial lo hizo a un $4 \%$ anual. Por su parte, las exportaciones de manufacturas aumentaron 43 veces (Romero, 2002). A pesar del crecimiento del comercio internacional, el $80 \%$ de la producción mundial tiene como destino el mercado interno de los países (Ferrer, 1997). Para el año 2011, la exportación de productos agrícolas, representó un $11 \%$ de las exportaciones a nivel mundial (OMC, 2012).

Desde la segunda guerra mundial, el comercio internacional ha mostrado un incremento en los flujos de nutrientes por los volúmenes de productos agrícolas comercializados. En muchos casos, se ha producido un traslado de los nutrientes desde los países menos desarrollados, que dependen de sus exportaciones para poder 
crecer, hacia los países más desarrollados. En estos últimos, se han generado problemas ambientales derivados del exceso de nutrientes (Grote et al., 2005) mientras que, en algunos países exportadores como Argentina, el deterioro ambiental se debe a la pérdida de la fertilidad química del suelo, asociada a la pérdida de nutrientes (García \& González Sanjuán, 2010; Cruzate \& Casas, 2012).

El posicionamiento de los diferentes países en el comercio internacional ha estado muy vinculado al concepto de desarrollo por ellos asumido.

\section{I.2.3. El desarrollo}

La sostenibilidad surge como objetivo internacional cuando se la vincula al desarrollo. Es la unión entre los conceptos desarrollo y sostenibilidad lo que impulsa e introduce a esta última en el discurso internacional (Abbona, 2004). Para comprender el sentido que adquiere la sostenibilidad en el contexto del desarrollo, es necesario conocer el origen del desarrollo como estrategia internacional, así como los marcos teóricos de los distintos modelos que se implementaron hasta arribar al desarrollo sostenible. Los cambios producidos en la concepción del desarrollo o, mejor dicho, los matices que fue adquiriendo en el tiempo, permiten interpretar mejor el sentido que lvego adquiere la sostenibilidad en el discurso internacional. La aparición de conceptos en el plano internacional no es casual, por lo cual es necesario comprender los fundamentos que les dan sustento, como así también los contextos dentro de los cuales se originan.

\subsubsection{El concepto de desarrollo: desde su origen hasta el informe Brundtland}

El concepto "desarrollo", en su acepción más amplia, significa el despliegue de las potencialidades de una entidad, sea esta biológica o sociocultural. Se trata de alcanzar un estado superior o más pleno al preexistente, tanto cuantitativa como cualitativamente (Sevilla Guzmán, 2002).

En los últimos tres siglos se han explicitado diferentes conceptos históricamente equivalentes al de desarrollo económico, lo que permite observar cómo cada uno de ellos refleja en realidad, una corriente de pensamiento (Camellón Pérez, 2009). Como antecedente al concepto de desarrollo más empleado a partir de la segunda guerra mundial, cabe mencionar las ideas de riqueza empleada por los mercantilistas y fisiócratas durante los siglos XVIII y XIX (Camellón Pérez, 2009). Para los mercantilistas, la fuente de la riqueza era el comercio, mientras que para los fisiócratas lo era la producción agrícola. Posteriormente, a partir de los neoclásicos fueron incorporadas las nociones de evolución, concepto derivado de las teorías evolucionistas, de 
crecimiento y de progreso. Esta última, con el sentido de acentuar la importancia de las innovaciones técnicas en el proceso de crecimiento (Sunkel \& Paz, 1999).

El sentido que adquirió el desarrollo cuando apareció en la escena internacional en la década del cuarenta del siglo XX, fue como sinónimo de crecimiento, más específicamente, como crecimiento económico. Esto se debió a que el origen del mismo fue dentro del pensamiento liberal y aplicado a la economía. El proceso de industrialización surgido con mayor fuerza a fines del siglo XIX y principios del siglo XX, había generado una gran demanda de mano de obra en las ciudades que fue provista por el campo, provocando un éxodo de enorme magnitud. Esto llevó al detrimento del medio rural y, a su vez, contribuyó a que en las ciudades se generaran enormes bolsones de pobreza, por la migración rural que no logró introducirse en el sistema productivo industrial. Se arriba así, a la necesidad del desarrollo unida a la idea de crecimiento económico. Por otra parte, a fines de la década del cuarenta, se estaba consolidando un nuevo escenario internacional. Al término de la segunda guerra mundial, Estados Unidos tenía una clara superioridad económica sobre el resto del mundo y Europa se encontraba devastada por la guerra. En este contexto, Estados Unidos lanza una campaña política global, con la cual intenta hacer llegar su progreso industrial y su beneficio económico a los países subdesarrollados (Esteva, 1997). De esta manera, coloca a los países "subdesarrollados" en la cola del camino al desarrollo. En este sentido, desarrollo no se considera un proceso, sino un estado al cual se debe llegar. Este concepto de desarrollo adquiere una fuerte dimensión etnocentrista, al identificarse como la mayor plenitud o superioridad desplegada por la entidad sociocultural occidental y las formas de producción y consumo implementada por esta (Guzmán Casado et al., 2000). Para los países subdesarrollados, el desarrollo dependía de la ayuda brindada por los países ricos, con lo cual, se trataba de acciones paternalistas "de arriba abajo" que anulaba las posibilidades de participación real de la población (Villasante, 1998 citado por Sevilla Guzmán, 2002).

Durante la década del cincuenta prevaleció la obsesión por la industrialización y el crecimiento del Producto Nacional Bruto (PNB) (Esteva, 1997). A fines de esta década, comienza a percibirse "lo social" dentro del marco del desarrollo, aunque, en un principio, como algo desvinculado de lo económico. Simplemente, se veía al desarrollo social como una contraparte del desarrollo económico (Esteva, 1997). Un enfoque más unificado de desarrollo y planificación para integrar los componentes sociales y económicos se da en la década del setenta, a través del "desarrollo integrado". En esta época, en los países industrializados, los esquemas teóricos de la modernización, dieron un giro hacia lo que se llamó "estado de bienestar". Esto se 
tradujo en un cambio desde los objetivos e indicadores del desarrollo puramente económico, hacia metas que, además del crecimiento, atendían a los problemas sociales más preocupantes del momento (la pobreza, el empleo, la desigualdad social) (Guzmán Casado et al., 2000). Por otra parte, en la década del setenta, a partir de la crisis petrolera, los gobiernos comenzaron a comprender que la continuidad del crecimiento, no dependía de la formación de capital o mano de obra calificada, sino también de la disponibilidad a largo plazo de recursos naturales (Sachs, 1996). De a poco, se empiezan a tener en cuenta los aspectos ambientales relacionados al desarrollo. La década del ochenta fue llamada la década perdida para el desarrollo. A fines de ésta, a través del Informe Brundtland se define al Desarrollo Sostenible (WCED, 1987), siendo éste, el último estilo de desarrollo promulgado "oficialmente".

Se puede considerar que, desde 1945, el concepto de desarrollo ha sido abordado por dos grandes corrientes, la ortodoxa y la heterodoxa. Cada una con divisiones internas que basaron su análisis desde cuestiones macro a micro, perspectiva del desarrollo desde los países llamados centrales y escuelas desarrolladas desde los países periféricos. No obstante, todas fueron alcanzadas por el desarrollo sostenible. Posteriormente, cada una incorporó la cuestión ambiental desde sus propias perspectivas.

\section{I.2.3.2. Antecedentes al "desarrollo sostenible"}

El Informe Brundtland en 1987 fue el disparador que colocó a la "sostenibilidad" en la agenda internacional. Sin embargo, en diferentes círculos científicos ya se estaba advirtiendo sobre las consecuencias globales negativas que el modelo de desarrollo predominante estaba generando (Pierri, 2001). En 1972, se realiza en Estocolmo la conferencia sobre Desarrollo y Medio Ambiente Humano. En ésta, la noción de medio ambiente llega a la agenda internacional. A su vez, surge la cuestión "global" que lleva a que los países se den cuenta de que no son unidades autodefinidas, sino que son vulnerables a las consecuencias de las acciones tomadas por otros países (Sachs, 1996). Se establece la discusión sobre la responsabilidad en el origen de los problemas ambientales, según se lo vea desde los países pobres o ricos. En este sentido triunfa la postura de los países industrializados, al sembrar la semilla de que el subdesarrollo es el que origina las deficiencias medioambientales, es decir, la pobreza es la causa fundamental del deterioro de los recursos naturales (Guzmán Casado et al., 2000). En esta conferencia se impone la postura del ambientalismo moderado, siendo este el primer antecedente de la formulación del objetivo de Desarrollo Sostenible, que más tarde la ONU consolidará a través del Informe Brundtland (Pierri, 2001). En 1972 también se publica el libro "Los límites del crecimiento", elaborado por el Club de Roma, en el 
cual se cuestiona el crecimiento infinito, puesto que se basa en un mundo finito, en un espacio cerrado y con una capacidad de carga limitada (Sachs, 1996). En el año 1980 se realiza el Informe Global 2000 a pedido del presidente Carter de los Estados Unidos. En este informe se establece que el estilo de vida de las sociedades desarrolladas no es extensible a todo el mundo, debido a que supondría una amenaza para la supervivencia de la vida humana en el planeta (Guzmán Casado et al., 2000). A su vez, se comienza a percibir que la economía mundial está alcanzando sus límites de crecimiento. Según Goodland (1997) existen 4 señales importantes que apoyan esta hipótesis: a) el impacto de las actividades humanas en el calentamiento global, b) el deterioro de la capa de ozono, c) el aumento de la degradación de tierras, d) la pérdida de biodiversidad.

Hacia fines de los años ochenta, la preocupación sobre el agotamiento de los recursos y la contaminación ambiental llegó a las altas esferas de la política internacional, colocando a la sostenibilidad en el debate de la época (Sachs, 1996). A su vez, se había alcanzado una gran amplitud de críticas a las aproximaciones industriales del proceso de desarrollo agrícola (Ruttan, 1994). No obstante, con el Informe Brundtland, la noción de sostenibilidad se instala definitivamente en la agenda internacional. Esto se debió, en parte, a que permitió anunciar el matrimonio entre el gran apetito por el desarrollo y la preocupación por el medio ambiente (Sachs, 1996). También, entre otras cosas, al cambio ocurrido en los años 1970-80, respecto a la responsabilidad en el origen de los problemas ambientales. En una primera instancia, el problema ambiental se lo asociaba al impacto generado por el ser humano industrial. Luego con la deforestación y la desertización de tierras, los países pobres se convirtieron en agentes de destrucción. Esto permitió justificar la necesidad del crecimiento económico con el fin de disminuir la pobreza, facilitando la unión entre desarrollo y medio ambiente.

El Informe Brundtland define al desarrollo sostenible como "aquél que permite satisfacer las necesidades de la presente generación sin comprometer la capacidad de las futuras generaciones de satisfacer sus propias necesidades" (WCED, 1987). En la citada definición se rescatan aspectos relevantes: considera la capacidad de carga de las entidades ecológicas, así como la equidad intra e intergeneracional (Müller et al., 2000). Por su parte, Daly \& Gallo (1995) resaltan tres características: I) se amplía la extensión del horizonte temporal, II) se exige una valoración del medio ambiente más adecuada, III) se busca satisfacer las necesidades (presentes y futuras) surgiendo el problema de la equidad intra e inter generacional. 


\subsubsection{Los objetivos de Desarrollo del Milenio y de Desarrollo Sostenible}

En el año 2000, se realiza la Cumbre del Milenio, en el cual se fijaron los Objetivos de Desarrollo del Milenio (ODM) por un período de 15 años (Di Paola, 2015). Enmarcada en el desarrollo sostenible, esta cumbre planteaba 8 objetivos destinados principalmente, a los países en vías de desarrollo. Hacia el año 2014 comienza una evaluación de esta etapa y la transición hacia los Objetivos de Desarrollo Sostenible (ODS), los cuales guiarán el accionar internacional hasta el año 2030 (UN, 2015). Los ODS plantean un universo mayor que los ODM que estaban destinados a países en vía de desarrollo (Di Paola, 2015). Además, contienen 17 objetivos con 169 metas a alcanzar para el año 2030. En América Latina, la CEPAL (2017) plantea una agenda para cumplir con los ODS, donde reconoce que América Latina no es la región más pobre del mundo pero si la más desigual.

La FAO (2015) se suma los ODS, ya que uno de los principales objetivos es erradicar el hambre para el año 2030, y para ello se plantea 5 objetivos estratégicos. Reconoce que 8 de los 17 ODS se encuentran más vinculados a la agricultura (FAO, 2015): ODS 1 Poner fin a la pobreza: porque reconoce que el $80 \%$ de los pobres vive en área rurales y la agricultura es el mayor empleador del mundo. ODS 2 Hambre cero: por la necesidad de producir alimentos para toda la población, aunque reconoce que hoy en día se producen alimentos suficientes para alimentar el mundo. ODS 6 Agua: por la necesidad de aumentar la producción siendo más eficientes con el uso del agua, siendo que entre el 70 al 95\% (según cada país) de las extracciones de agua se usan para los cultivos y el ganado. ODS 7 Energía: señala que los sistemas alimentarios actualmente consumen el $30 \%$ de la energía del mundo por lo que deberían comenzar a desvincularse gradualmente de la dependencia de energía fósil. ODS 12 Consumo y producción sostenibles: por la necesidad de disminuir la pérdida y desperdicio de alimentos y para que las actividades agropecuarias reduzcan el impacto ambiental negativo. ODS 13 Combatir el cambio climático: porque la agricultura tiene un papel importante que desempeñar en la respuesta al cambio climático, considerando los riesgos que implica para la agricultura el aumento de la temperatura media del planeta. ODS 14 Océanos, mares y recursos marinos: por la importancia de la proteína animal de pescado en la alimentación y la importancia de la pesca para los pescadores artesanales de pequeña escala. ODS 15 Ecosistemas terrestres: porque los bosques contribuyen con la biodiversidad y son fuente de alimentos, medicinas y combustible para mil millones de personas.

En estos objetivos se observa que los esfuerzos deben ser desde de los gobiernos, pero también desde las sociedades, que a través de los patrones de 
consumo influyen en lo modos de producción e, indirectamente en la demandas de recursos del ambiente.

Uno de los aspectos que se observan con los ODS es que si bien, desde que se propuso el desarrollo sostenible, lo ambiental no se ha traducido en acciones concretas de los países para revertir su deterioro, éste sigue siendo parte de la agenda internacional y, con cada vez, mayor incidencia.

\subsubsection{Necesidad de un nuevo marco de evaluación del desarrollo}

Una de las deudas que ha tenido la búsqueda de un desarrollo sostenible, es la implementación de un marco de evaluación apropiado para ello. Al ser la sostenibilidad un concepto complejo, que comprende aspectos sociales, ecológicos y económicos, los marcos de evaluación hasta ahora implementados, muchas veces con predominio de un enfoque reduccionista, resultan inapropiados. Se requiere de marcos de evaluación acordes con este nuevo desafío. Para esto es necesario repensar y crear una nueva forma de abordaje y evaluación que contemple la complejidad intrínseca de la sostenibilidad (Abbona, 2004). Existen herramientas metodológicas que han servido en la evaluación tradicional de los modelos de desarrollo y que pueden ser utilizadas para este nuevo desafío. Sin embargo, lo esencial del cambio debe darse en el marco teórico que le da sustento.

Las evaluaciones de los diferentes modelos de desarrollo antes descritos, sólo se limitaban a la entidad sociocultural en desarrollo y a las metas por ella cumplidas (Figura 1.2a). Dentro del proceso de evaluación no se tenían en cuenta los impactos generados por el proceso de desarrollo sobre los recursos internos y externos.

En los años 1950-60, las variables económicas fueron las únicas utilizadas para determinar el grado de desarrollo alcanzado por una entidad sociocultural. En los años setenta, las metas sociales empezaron a ser incorporardas dentro de los proyectos de desarrollo, aunque no de manera integral. Lo social y lo económico aparecían como áreas independientes, sin vinculación, sin influencia mutua. En general, se supeditaba lo social a lo económico; se asumía que si había crecimiento económico también se generaba desarrollo social. Con los programas de desarrollo implementados no se logró producir una mejora integral de la sociedad. 


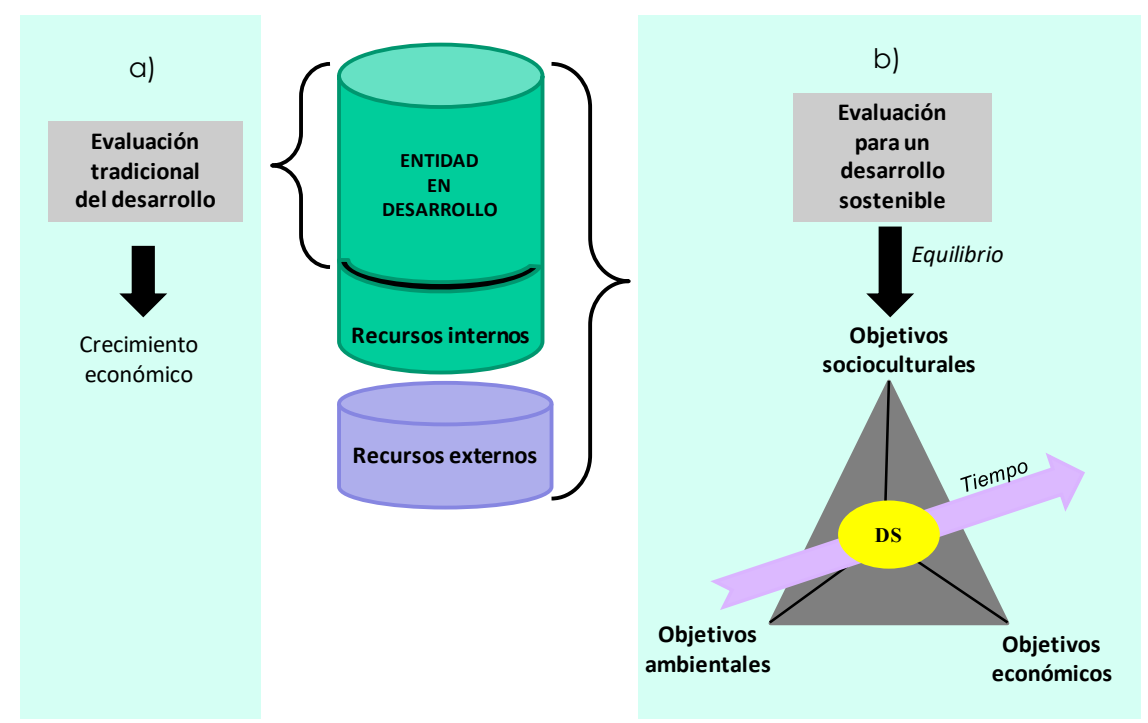

Figura 1.2. Evaluación tradicional del desarrollo (a) y propuesta de evaluación para un desarrollo sostenible (DS) (b). Modificado de Abbona (2004).

Dentro del nuevo marco de evaluación de la sostenibilidad propuesto se contempla tanto la entidad sociocultural en cuestión, como los recursos internos y externos a la misma (Figura 1.2b). De esta manera, los ámbitos de evaluación se amplían. Así se evita arribar a una conclusión que una entidad sociocultural se está desarrollando, cuando los recursos sobre los cuales depende son finitos o los está degradando. Todo proceso de desarrollo genera un impacto en el medio, el cual debe ser considerado y evaluado a fin de conocer si la magnitud del mismo es tal, que pone en riesgo la perdurabilidad de los recursos naturales.

En varias ocasiones el desarrollo alcanzado por una sociedad se debe a que utiliza recursos naturales que pertenecen a otra sociedad, por lo cual su desarrollo sólo puede explicarse por esta apropiación de recursos externos. Esta situación relega a muchas naciones a un estado permanente de subdesarrollo que sólo puede ser revertido si se analiza esta situación de explotación. Es por esto, que para un desarrollo sostenible se deben evaluar tanto los aspectos económicos, como los ecológicos y socioculturales. Estas dimensiones son consideradas básicas en la evaluación de la sostenibilidad, aunque también pueden incorporarse otras como la política y la ética (Caporal \& Costabeber, 2002).

Ampliar los ámbitos de evaluación (entidad sociocultural, recursos internos, recursos externos), las dimensiones a considerar (ecológica, económica y sociocultural) y la escala temporal de análisis, es un requisito fundamental para un nuevo marco de evaluación de la sostenibilidad (Figura 1.2b). Esta ampliación de la escala temporal debe incluir el análisis histórico de la entidad y del proceso de desarrollo e incorporar el futuro, en relación a la posibilidad de sostener el proceso de 
desarrollo. Para poder llevar a cabo este nuevo marco de evaluación de la sostenibilidad, será necesario el trabajo interdisciplinario. De evaluarse la sostenibilidad sólo desde un área específica, no se estaría abarcando su complejidad. Con ello, la evaluación se verá simplificada de tal manera que difícilmente pueda reflejar la realidad.

\subsubsection{Los nutrientes y el desarrollo sostenible}

En este capítulo se ha presentado el tema de los nutrientes como uno de los aspectos a tener en cuenta en un ecosistema alimentario para un desarrollo sostenible. A su vez, este aspecto se abordó desde una perspectiva acorde con la nueva propuesta de evaluación del desarrollo sostenible. El actual flujo de nutrientes entre producción agropecuaria y consumo, analizada desde una perspectiva ecológica, muestra la necesidad de un cambio para lograr un desarrollo sostenible.

En Argentina, las diferentes etapas de industrialización que intentaron generar un desarrollo interno, motorizaron el éxodo rural. Con ello se llegó hoy en día a una elevada tasa de urbanización de la población, alcanzando un $97 \%$ en la provincia de Buenos Aires (MEBA, 2014). Esto ha promovido que los flujos de nutrientes dentro del país y dentro de la provincia fluyeran de una región a otra con un escaso o nulo retorno. Esta dinámica de los flujos de nutrientes tendrá consecuencias negativas para la alimentación de las futuras generaciones.

Por otro lado, gran parte del desarrollo del país ha estado vinculado al sistema agropecuario exportador. El rótulo de "granero del mundo" ha estado vinculado a su rol en el contexto internacional de proveedor de materias primas de origen agropecuario (Reca, 2006; Colomé \& Gumierato, 2009). Este rol en el contexto internacional, así como la forma en que se realiza, debe ser replanteado para evitar la degradación de los suelos con el consiguiente riesgo para la sostenibilidad. A nivel internacional, la puja por el desarrollo ha condicionado a los países menos fuertes a la oferta de "commodities" agrícolas y, a los más fuertes, a la oferta de manufacturas.

Para lograr un desarrollo sostenible es necesario replantear la relación entre las diferentes entidades que buscan el desarrollo (países, regiones). Es necesario conocer cuál es la disponibilidad de recursos propios (internos) y cuál es el grado de dependencia de recursos externos. En esto hay que asumir que los recursos externos para una entidad son los recursos internos de otra. Por lo tanto, para que se genere un desarrollo sostenible en ambas entidades, se quiere un cambio cualitativo en la vinculación, que tienda a una verdadera cooperación. De lo contrario, se va a continuar con el sometimiento que realizan los países más fuertes, que cuentan con 
pocos recursos propios, hacia los países que presentan una alta disponibilidad de recursos naturales pero un bajo grado de autonomía.

Para avanzar hacia un ecosistema alimentario dentro de un desarrollo sostenible es necesario considerar el contexto histórico, analizar el presente y proyectar el futuro de la dinámica de los flujos de nutrientes, contemplando la complejidad intrínseca a la sostenibilidad.

\section{I.3. BIBLIOGRAFIA}

Abbona, E.A. 2004. Evaluación de la sustentabilidad ecológica de sistemas agrícolas y su aporte al Desarrollo Rural Sustentable: el caso de los viñateros de Berisso, Argentina. Tesis de Maestría. Universidad Internacional de Andalucía, España. 166pp.

Abbona, E.A. \& S.J. Sarandón. 2013. Cambios en los flujos de nutrientes a escala regional y global y su vinculación con los conceptos de Demografía, Comercio Internacional y Desarrollo. VIII Jornadas Interdisciplinarias de Estudios Agrarios y Agroindustriales. Buenos Aires. 20pp.

Abbona, E.A. \& S.J. Sarandón. 2014. Manejo de nutrientes en los agroecosistemas. En: Agroecología. Bases teóricas para el diseño y manejo de agroecosistemas sustentables. Sarandón, S.J. \& C.C. Flores (Editores). Editorial de la Universidad Nacional de La Plata (EDULP). Capítulo 8:211-234. Disponible en: http://sedici.unlp.edu.ar/handle/10915/37280. Último acceso: septiembre 2016.

Amin, S. 2008. Capitalismo, imperialismo, mundialización. IADE / Realidad Económica. Disponible en: http://www.iade.org.ar/noticias/capitalismo-imperialismo-mundializacion-samir-amin. Último acceso: septiembre 2016.

Arosemena, P. 2012. El origen del comercio exterior Revista Zona Franca. Disponble en: http://www.revistazonafranca.com/?p=216. Último acceso: septiembre 2016.

Barles, S. 2007. Feeding the city: Food comsumption and flow of nitrogen, Paris, 1801-1914. Science of the Total Environment 375:48-58.

Bouzas, R. 2004. Las negociaciones Unión Europea-Mercosur. Entre la lentitud y la indefinición. Nueva Sociedad 190:125-135.

Bouzas, R. 2005. El "nuevo regionalismo" y el área de libre comercio de las Américas: un enfoque menos indulgente. Revista de la CEPAL 85:7-18.

Camellón Pérez, A. 2009. Reflexiones sobre las principales elaboraciones teóricas con relación al desarrollo. En: Contribuciones a la Economía, marzo 2009. Dispónible en: http://www.eumed.net/ce/2009a/acp.htm. Último acceso: septiembre 2016.

Caporal, F.R. \& J.A. Costabeber. 2002. Análise multidimensional da sustentabilidade. Uma proposta metodológica a partir da Agroecologia. Agroecologia e Desenvolvimento Rural Sustentável 3:70-85.

CEPAL (Comisión Económica para América Latina y el Caribe). 2000. De la urbanización acelerada a la consolidación de los asentamientos humanos en América Latina y el Caribe: el espacio regional. Santiago de Chile. 99pp

CEPAL (Comisión Económica para América Latina y el Caribe). 2017. Agenda 2030 y los Objetivos de Desarrollo Sostenible. Una oportunidad para América Latina y el Caribe. Naciones Unidas. Chile. 63pp.

Colomé, R.A. \& L.H. Gumierato. 2009. Sobre los orígenes de la comercialización de granos en Argentina (c. 1870 - 1920). Revista de la Bolsa de Comercio de Rosario: 52-61.

Cruzate, G. \& R.R. Casas. 2012. Extracción y balance de nutrientes en los suelos agrícolas de la Argentina. Informaciones Agronómicas de Hispanoamérica 6:7-14.

Daly, H.E. \& D. Gallo. 1995. Significado, conceptualización y procedimientos operativos del desarrollo sostenible: posibilidades de aplicación a la agricultura. En: "Agricultura y desarrollo sostenible". Cadenas Marín Alfredo (Editor). Serie Estudios, Ministerio de Agricultura, Pesca y Alimentación, Secretaría General Técnica. 21-38.

Di Paola, M.E. 2015. Objetivos de Desarrollo Sostenible: ¿̇Oportunidad o desencanto? Fortalezas y desafíos en su proceso de construcción global. Informe ambiental anual FARN. 115-134.

Esteva, G. 1997. Desarrollo. En Diccionario del Desarrollo. Una guía del conocimiento como poder. Sachs, W. (Editor). 2da edición en castellano. Editado por CAl. 52-78.

FAO (Organización de las Naciones Unidas para la Alimentación y la Agricultura). 2015. La FAO y los 17 Objetivos de Desarrollo Sostenible. 8pp. 
Ferrer, A. 1997. Hechos y ficciones de la globalización. Conferencia dictada en la Academia Nacional de Ciencias Económicas el 16 de julio de 1997. 22pp. Disponible en: http://eco.mdp.edu.ar/cendocu/repositorio/00232.pdf. Último acceso: septiembre 2016.

Ferrer, A. 2013. Historia de la Globalización I. Orígenes del orden económico mundial. 2da edición. Fondo de cultura económica. Buenos Aires. 344pp.

García, F.O. \& M.F. González Sanjuán. 2010. Balances de nutrientes en Argentina ¿Cómo estamos? ¿ Cómo mejoramos? Informaciones Agronómicas 48:1-5.

Godfray, H.C.J., J.R. Beddington, I.R. Crute, L. Haddad, D. Lawrence, J.F. Muir, J. Pretty, S. Robinson, S.M. Thomas \& C. Toulmin. 2010. Food Security: The Challenge of Feeding 9 Billion People. Review. Science 327:812-818.

Goodland, R. 1997. La tesis de que el mundo está en sus límites. En: Medio ambiente y desarrollo sostenible. Más allá del Informe Brundtland. Goodland, R., H. Daly, S. El serafy \& B. von Droste (Editores). Editorial Trotta. Madrid. Capítulo 1:19-36.

Grote, U., E. Craswell \& P. Vlek. 2005. Nutrient flows in international trade: Ecology and policy issues. Environmental Science \& Policy 8:439-451.

Guzmán Casado, G., M. González de Molina \& E. Sevilla Guzmán. 2000. Introducción a la agroecología como desarrollo rural sostenible. Ediciones Mundi Prensa. España. 535 pp.

Lattes, A.E. 2004. La urbanización y otros modos de asentamiento de la población: desafíos para la reflexión conceptual y la producción de datos demográficos. Población y Sociedad 10/11:71108.

Magdoff, F., L. Lanyon \& B. Liebhardt. 1997. Nutrient cycling, transformations and flows: implications for a more sustainable agriculture. Advances in Agronomy 60:1-73.

MEBA (Ministerio de Economía de la provincia de Buenos Aires). 2014. Distribución de la población de la provincia de Buenos Aires. Período 1947 - 2010. Serie Estudios Demográficos 19. $29 \mathrm{pp}$.

Müller, F., R. Hoffmann-Kroll \& H. Wiggering. 2000. Indicating ecosystem integrity - theoretical concepts and enviromental requirements. Ecological Modeling 130:13-23.

OMC (Organización Mundial del Comercio). 2012. Estadísticas del comercio internacional 2012. Disponible en: http://www.wto.org/spanish/res_s/statis_s/world_region_export_11_s.pdf. Último acceso: septiembre 2016.

Ortiz Davison, J., E.O. Ortiz Mendoza \& M.J. Cuervo Morales. 2003. La transición demográfica y urbana en el marco de la globalización: implicaciones para la articulación económica del espacio urbano-regional. Análisis Económico 39(XVIII):229-254.

Osorio, M.X. 1992. La Ronda Uruguay y la agricultura: Crónica de un conflicto anunciado. Revista Colombia Internacional 17:14-19. Disponible en: http://colombiainternacional.uniandes.edu.co/view.php/129/index.php?id=129. Último acceso: septiembre 2016.

Pierri, N. 2001. El proceso histórico y teórico que conduce a la propuesta del desarrollo sustentable. En: ¿Sustentabilidad? Desacuerdos sobre el desarrollo sustentable. Pierri, N. \& G. Folarodi (Editores). Montevideo, Uruguay. Capítulo 2:27-80.

Reca, L.G. 2006. Aspectos del Desarrollo Agropecuario argentino 1875-2005. Academia Nacional de Agronomía y Veterinaria. Buenos Aires. Tomo 15:175-231. Disponible en: http://www.anav.org.ar/trabajos publicados/4/reca.pdf. Último acceso: agosto 2016.

Romero, A. 2002. Reflexiones sobre la globalización. Pensamiento económico Año 1 No.1 Primer semestre 2002. Disponible en http://revistapensamiento.galeon.com/ultimaedicion/romero.htm. último acceso: septiembre 2016.

Ruttan, V. 1994. Constraints on the design of sustainable systems of agricultural production. Ecological Economics 10:209-219.

Sachs, W. 1996. Medio Ambiente. En: Diccionario del Desarrollo. Una guía del conocimiento como poder. Sachs, W. (Editor). 2 edición en castellano. Editado por CAl. 115-131.

Sarandón, S.J. \& C.C. Flores. 2009. Evaluación de la sustentabilidad en Agroecosistemas: una propuesta metodológica. Universidad de Murcia, España. Revista Agroecología 4:19-28.

Sarandón, S.J. \& C.C. Flores. 2014. Análisis y evaluación de agroecosistemas: construcción y aplicación de indicadores. En: Agroecología: bases teóricas para el diseño y manejo de agroecosistemas sustentables. Sarandón, S.J. \& C.C. Flores (Editores). Editorial de la Universidad Nacional de La Plata. Capítulo 14:375-410. Disponible en: http://sedici.unlp.edu.ar/handle/10915/37280. Último acceso: septiembre 2016.

Schwartz, P. 2001. El comercio internacional en la historia del pensamiento económico. IUDEM Documento de Trabajo $3 . \quad 66 \mathrm{pp}$. Disponible http://pendientedemigracion.ucm.es/info/iudem/2001-3.pdf. Último acceso: septiembre 2016. 
Sevilla Guzmán, E. 2002. Agroecología y desarrollo rural sustentable: una propuesta desde Latinoamérica. En: "Agroecología. El camino hacia una agricultura sustentable". Sarandón, S.J. (Editor). Ediciones Científicas Americanas. Buenos Aires. Capítulo 3:57-81.

Sunkel, O. \& P. Paz. 1999. El subdesarrollo latinoamericano y la teoría del desarrollo. 25a edición. Siglo veintiuno editores. Textos del ILPES. 15-40.

Syers, K., M. Bekunda, D. Cordell, J. Corman, J. Johnston, A. Rosemarin, I. Salcedo \& T. Lougheed. 2011. Phosphorus and food production. En: UNEP, Year Book. UNEP, Nairobi. 34-45.

UN (Naciones Unidas). 2015. Transforming our world: the 2030 agenda for sustainable development. $41 \mathrm{pp}$.

Vignoli, J.R. 2002. Distribución territorial de la población de América Latina y el Caribe: tendencias, interpretaciones y desafíos para las políticas públicas. CEPAL ECLAC Serie Población y Desarrollo. $32-\quad 82 . \quad$ Disponle en: http://repositorio.cepal.org/bitstream/handle/11362/7170/S02121008 es.pdf;sequence=1. Último acceso: abril 2017.

Vilas, C.M. 1999. Seis ideas falsas sobre la globalización. Argumentos desde América Latina para refutar una ideología. En: Globalización: crítica a un paradigma. Saxe-Fernández, J. (Coordinador). México, UNAM-IIEC-DGAPA-Plaza y Janés. 69-101.

WCED (World Comission on Environment and Development). 1987. Our common future. Oxford Univ. Press, Oxford. 300pp. 


\section{CAPÍTULO II}

\section{Aspectos metodológicos}

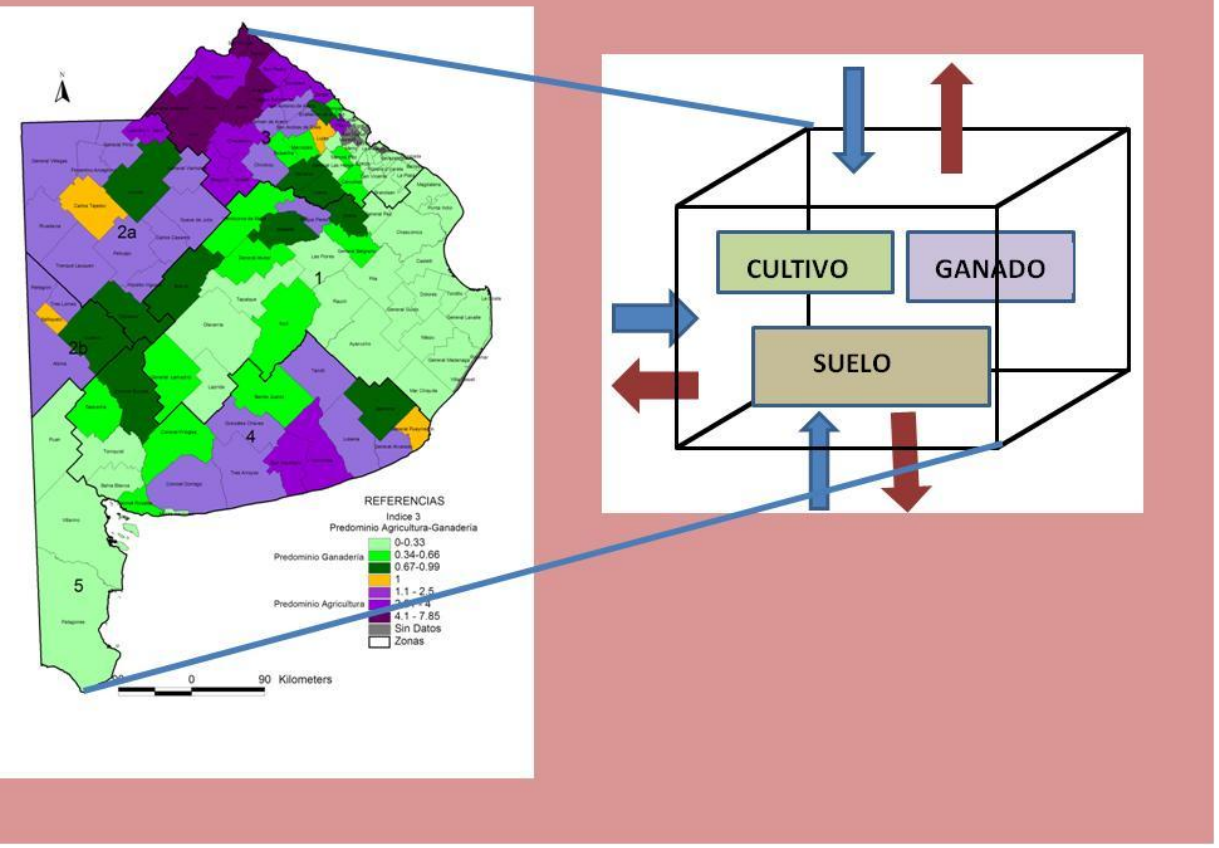




\section{II.1. INTRODUCCIÓN}

En este capítulo se abordan aspectos metodológicos generales de la tesis que permiten dar un marco a los capítulos que continúan. Primero se presentan las actividades agropecuarias de la provincia de Buenos Aires, iniciando en la descripción de las características edafoclimáticas, para continuar con la estructura agropecuaria. Luego, se realiza una breve revisión de metodologías de balance y la eficiencia de nutrientes. Finalmente, a partir de lo desarrollado se establecen los criterios metodológicos asumidos en la tesis.

\section{II.2. ACTIVIDADES AGROPECUARIAS DE LA PROVINCIA DE BUENOS AIRES}

\section{II.2.1. Características edafoclimáticas de la provincia}

La provincia de Buenos Aires se ubica en la Región Pampeana, posee una extensión de 307.751 km² (30,7 Mha), lo que representa el 11\% de la Argentina. Desde el año 2009 cuenta con 135 partidos con poderes políticos y administrativos propios. Debido a las características climáticas, edáficas y fisiográficas, en la provincia se pueden definir ocho subregiones (MAA, 2007) (Figura 2.1).

Las principales zonas por su desarrollo agropecuario (incluyendo horticultura) son (MAA, 2007):

\section{Subregión Pampa Arenosa:}

Tiene una superficie de $8 \mathrm{Mha}$, con clima templado sub-húmedo con época seca en invierno. La zona configura una llanura con pendiente regional suave de oeste a este. La escasa pendiente, sumada a una granulometría gruesa de los suelos, hace que el escurrimiento potencial sea prácticamente nulo. Dentro de esta subregión se pueden identificar tres sectores bien definidos: a) zona norte o de médanos longitudinales, b) zona sur o de dunas parabólicas, c) zona de las planicies extendidas. Los suelos predominantes de la subregión son Hapludoles y Haplustoles típicos y/o énticos hacia el oeste y Hapludoles tapto-árgicos o nátricos en las depresiones hacia el este. Debido al aumento en las precipitaciones en los últimos 25 años se ha observado un incremento de la agricultura en desmedro de la ganadería. 


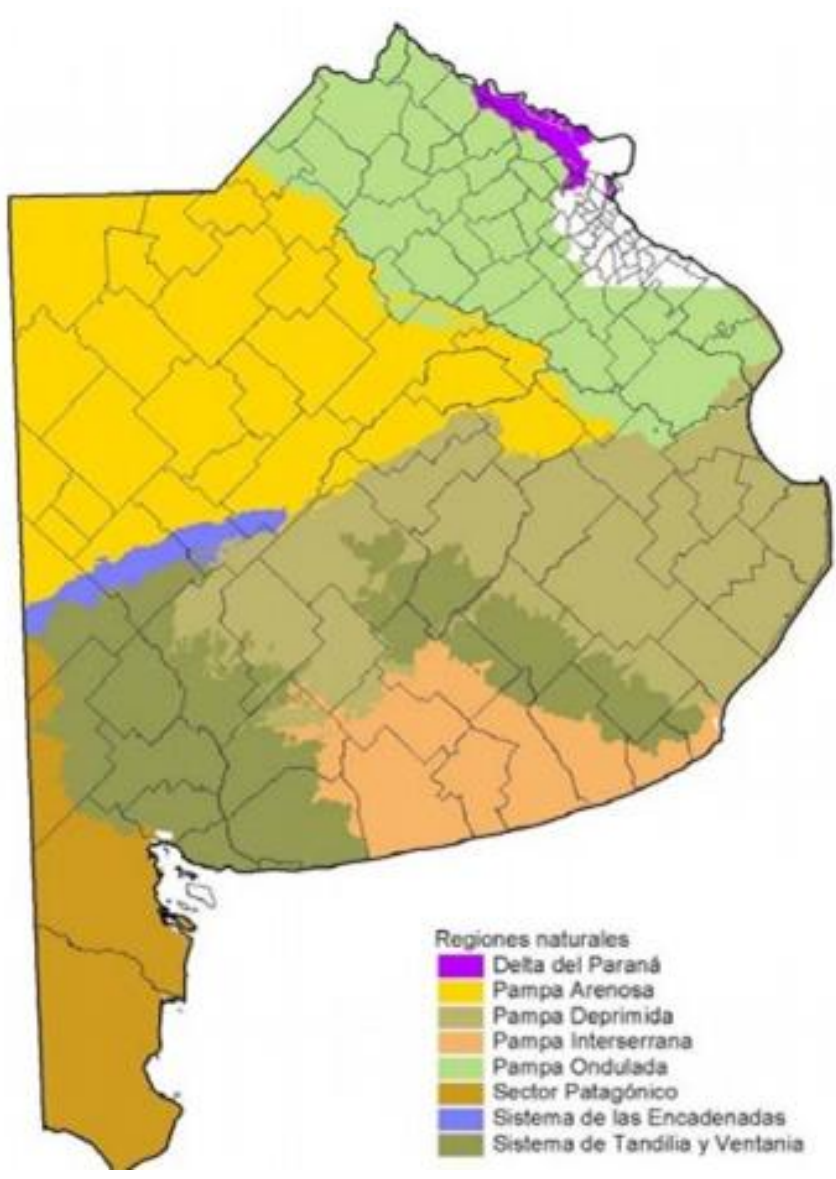

Figura 2.1. Regiones naturales de la provincia de Buenos Aires. Fuente: MAA (2007).

\section{Subregión Pampa Ondulada:}

Se ubica entre los ríos Paraná, de la Plata y Salado, abarcando una superficie de 4,7 Mha. El clima es subhúmedo-húmedo, con precipitaciones en el orden de 900 $\mathrm{mm}$, con mayor incidencia en los meses de verano y menor en invierno. El material originario es el loess pampeano lo que, sumado al clima y relieve, ha dado origen a los suelos característicos de la zona, clasificados como Argiudoles típicos. Los principales suelos zonales presentan un perfil A-B-C, horizonte $A+/-25 \mathrm{~cm}$, franco limoso. El horizonte $B_{2 \dagger}$ es argílico, potente, de muy baja permeabilidad. La profundidad efectiva del perfil es de $+/-180 \mathrm{~cm}$. Esta zona presenta los suelos más productivos del país, existiendo pocos casos comparables en el mundo.

\section{Subregión Pampa Deprimida:}

Es una llanura que abarca prácticamente toda la cuenca del Río Salado y la del arroyo Vallimanca. El conjunto abarca una 6,9 Mha. Presenta precipitaciones de $1.000 \mathrm{~mm}$ en el noreste y de $800 \mathrm{~mm}$ en el sudeste y parte occidental. Son frecuentes los excesos hídricos en invierno y deficiencias en verano. Desde el punto de vista geomorfológico tiene una pendiente de muy bajo gradiente regional y falta de un 
drenaje definido. Los suelos poseen un horizonte superficial somero y en profundidad se encuentran elevados contenidos de arcilla. En grandes sectores se suma una capa compacta de costra calcárea a escasa profundidad. Por estas condiciones que dificulta la infiltración hacia capas profundas de los suelos, se producen períodos de anegamiento que alternan con otros de sequía. Son suelos de baja fertilidad y aptitud potencial, por lo que se destinan mayormente a pastizales naturales para producción ganadera. En esta subregión se realiza principalmente la cría, por sectores de ciclo completo y, en menor parte, ganadería mixta con una agricultura limitada.

\section{Subregión Interserrana:}

Se ubica entre los sistemas serranos de Tandilia y Ventania, limitando al norte con la Pampa Deprimida y comprende un área de 2,5 Mha. Posee un régimen hídrico subhúmedo-seco, con precipitaciones superiores a los $700 \mathrm{~mm}$, con déficit hídrico potencial severo entre diciembre y febrero, superando los $80 \mathrm{~mm}$ mensuales. Geomorfológicamente es una llanura loéssica suavemente drenada hacia el océano Atlántico. Los suelos son Argiudoles típicos y Argiudoles petrocálcicos. Estos últimos presentan una plancha de tosca entre los $50-100 \mathrm{~cm}$ de profundidad. La actividad tradicional de la zona ha sido la mixta (agricultura y ganadería pastoril). El trigo (Triticum aestivum L.) ha sido el cultivo más representativo de la zona aunque en los últimos años irrumpió con fuerza la soja (Glycine max (L.) Merr.).

\section{Subregión Ventania y Tandilia:}

Los dos sistemas montañosos ocupan una superficie de 4,8 Mha. El sistema de Tandilia se encuentra más al este, se desarrolla con orientación NO-SE y presenta una cadena de sierras que no superan los 500 msnm. El régimen climático es subhúmedohúmedo, con $800 \mathrm{~mm}$ de precipitaciones, con un invierno más seco. El sistema de Ventania se encuentra más al oeste y las sierras presentan una altura de $1.200 \mathrm{msnm}$. El régimen hídrico es subhúmedo-seco, siendo el inverno la época más seca. En general, prevalecen suelos medianamente profundos y profundos aptos para el laboreo, clasificándose en Argiudoles y Argiustoles típicos. Los suelos son de un perfil A-B-C, con horizonte superficial profundo, textura franca, estructura migajosa y riqueza en materia orgánica (4-6\%). El horizonte $\mathrm{B}_{2 t}$, de escaso desarrollo se manifiesta a los $50 \mathrm{~cm}$ de profundidad; su textura es franco arcillosa.

\section{Subregión Sector Patagónico:}

Se ubica en el extremo sur de la provincia, con una superficie de 2,6 Mha. El régimen hídrico es subhúmedo-seco en la parte norte, transformándose en semiárido y árido hacia el sur, con precipitaciones entre 600 y 400 mm, respectivamente. Los suelos que se han desarrollado son producto de depósitos de arena en forma de delgada 
cobertura, dando perfiles someros. Las características de suelo y clima exigen que las actividades agropecuarias se realicen con técnicas conservacionistas.

\section{II.2.2. Actividades agropecuarias}

Se estima que la provincia de Buenos Aires destina a las actividades agropecuarias unas 24 Mha (MAA, 2007). La ganadería es la actividad que predomina, seguida de los cultivos extensivos y, con una muy pequeña incidencia en superficie, la horticultura (Figura 2.2 a, b). En la primera década del siglo XXI se ha observado un aumento de los cultivos extensivos a partir de superficie destinada a ganadería, aunque debido a la falta de datos oficiales actuales a partir de censos agropecuarios, no es posible conocer la dinámica de estos cambios en el territorio de la provincia.

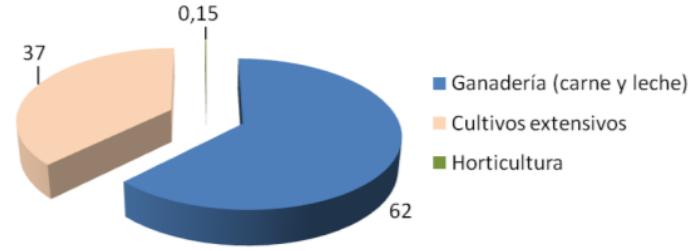

a)

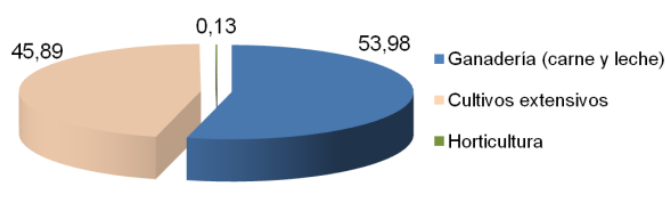

b)

Figura 2.2. Distribución porcentual de la superficie agropecuaria en la provincia de Buenos Aires: a) año 2006 y b) año 2010. Fuente: Elaboración propia a partir de datos del CNA (2002), CHFBA (2005) y SIIA (2016).

\section{II.2.2.1. Agricultura extensiva}

Los principales cultivos extensivos de la provincia de Buenos Aires son: soja; trigo, maíz (Zea mays L.), cebada cervecera (Hordeum vulgare L. var. distichum), girasol (Helianthus annus L.), sorgo (Sorghum bicolor (L.) Moench) y colza (Brassica napus L.).

En los últimos 25 años, el área sembrada de cada cultivo fue variando, siendo las principales tendencias el aumento de la soja y la cebada cervecera y disminución del trigo (Figura 2.3). 


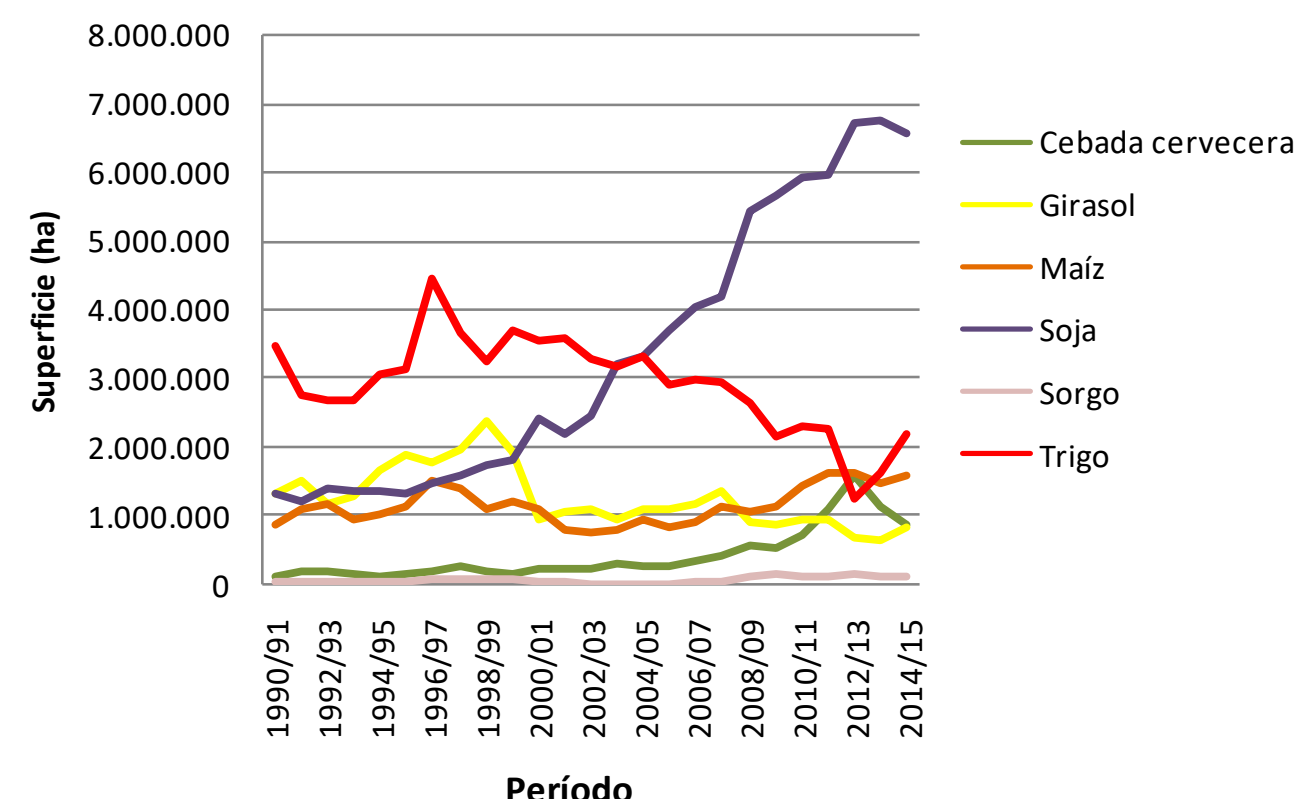

Figura 2.3. Superficie sembrada de los principales cultivos agrícolas en la provincia de Buenos Aires (período 1990 y 2015). Fuente: Elaboración propia a partir de SIIA (2016).

Por las condiciones edafoclimáticas, sumadas a una tradición de manejo de los distintos cultivos, la distribución de los mismos no es uniforme en todo el territorio provincial. Una clara descripción de la incidencia de las diferentes actividades agropecuarias en la provincia puede encontrarse en DPPBA (2015). En este informe, se empleó el CNA (2002) para describir el uso de la superficie ganadera y el SllA para la agricultura extensiva del año 2010.

Según DPPBA (2015), el cultivo extensivo principal en la mayoría de los partidos de la provincia es la soja y, en menor medida, trigo, maíz y cebada cervecera (Figura 2.4). En cuanto a los cultivos secundarios llevados a cabo en los distintos partidos, se encuentra una mayor variedad, con predominio de trigo y maíz y, en menor medida, soja, girasol, cebada cervecera y colza (Figura 2.5). 


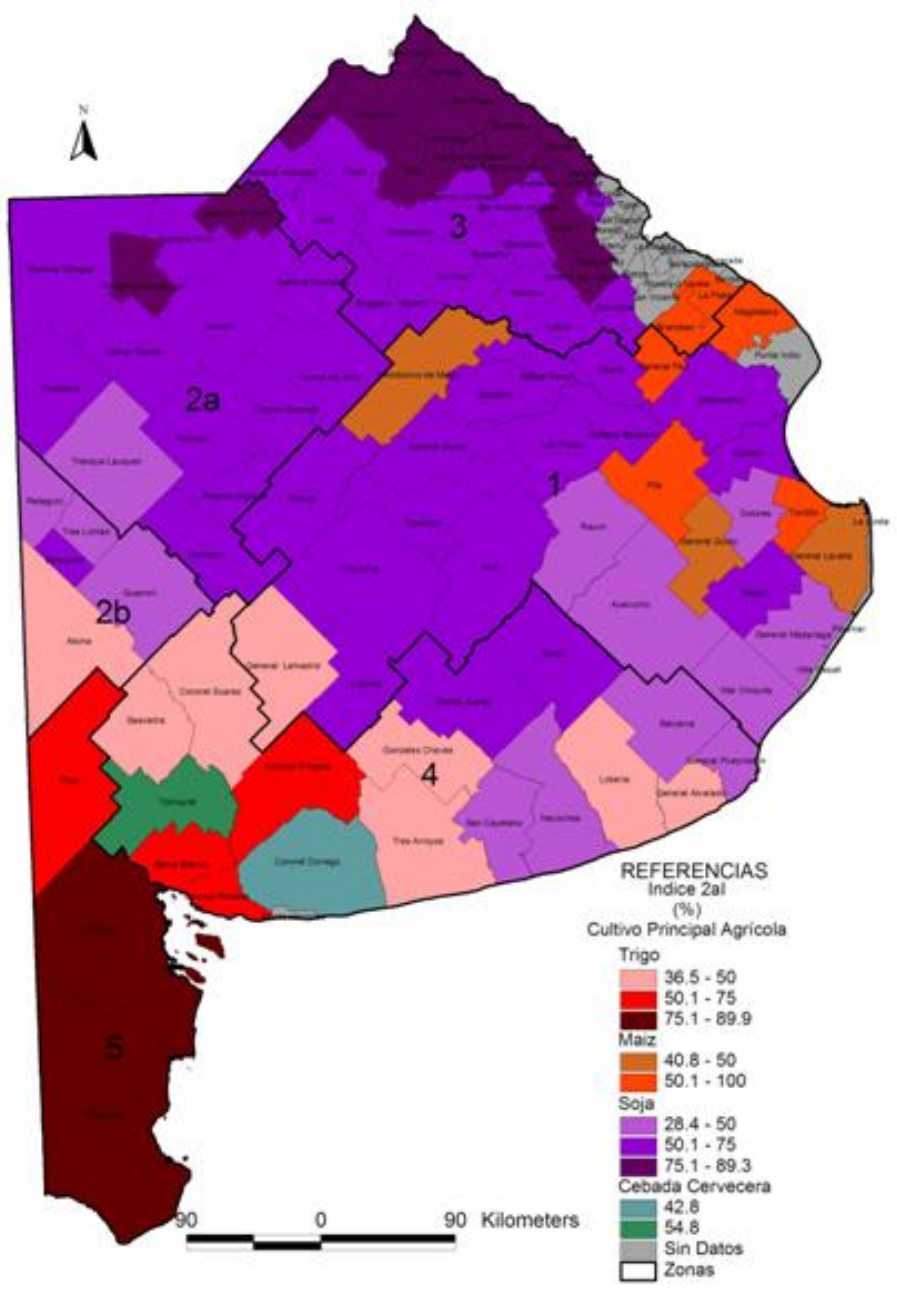

Figura 2.4. Cultivo agrícola extensivo principal en base al porcentaje de superficie ocupada por partido (año 2010). Fuente: DPPBA (2015). 


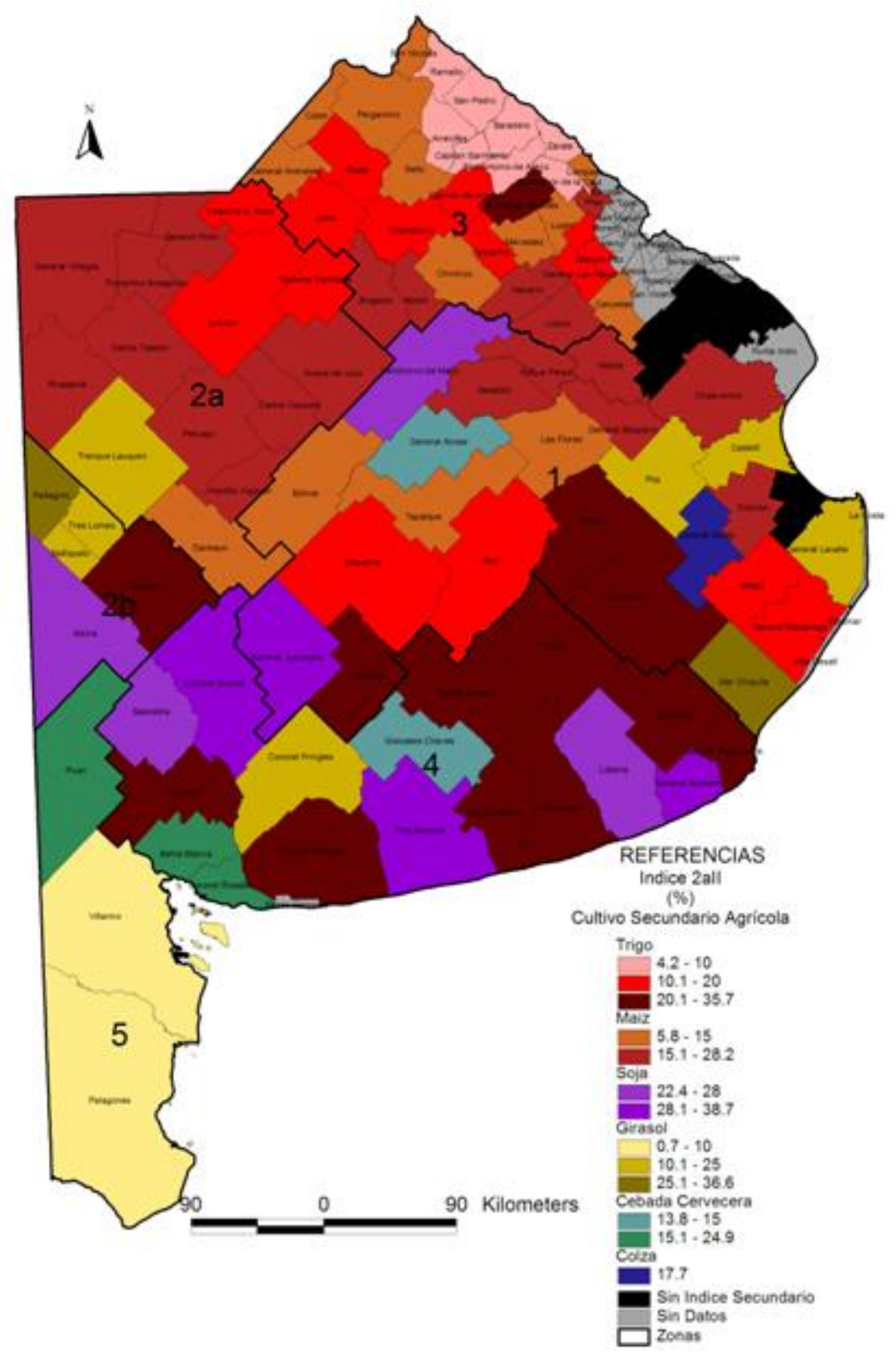

Figura 2.5. Cultivo agrícola extensivo secundario en base al porcentaje de superficie ocupada por partido (año 2010). Fuente: DPPBA (2015).

\section{II.2.2.2. Ganadería (carne y leche)}

El pastizal natural es el principal recurso forrajero de la provincia, seguido de las pasturas implantadas y forrajeras anuales (verdeos de invierno y verano) (Figura 2.6). La proporción estimada de estos recursos en el territorio provincial para el año 2002 (CNA, 2002) era del 70, 20 y 10\% para pastizal natural, pasturas perennes y forrajeras anuales, respectivamente. La zona de la Pampa Deprimida es la que presenta mayor superficie con pastizal natural, mientras que en el oeste y sudeste se incrementa la destinada a pasturas perennes. Las pasturas perennes son el recurso forrajero 
secundario en la mayor parte de los partidos de la provincia, teniendo los verdeos anuales una mayor incidencia en el oeste, sudoeste y centro este de la provincia (Figura 2.7).

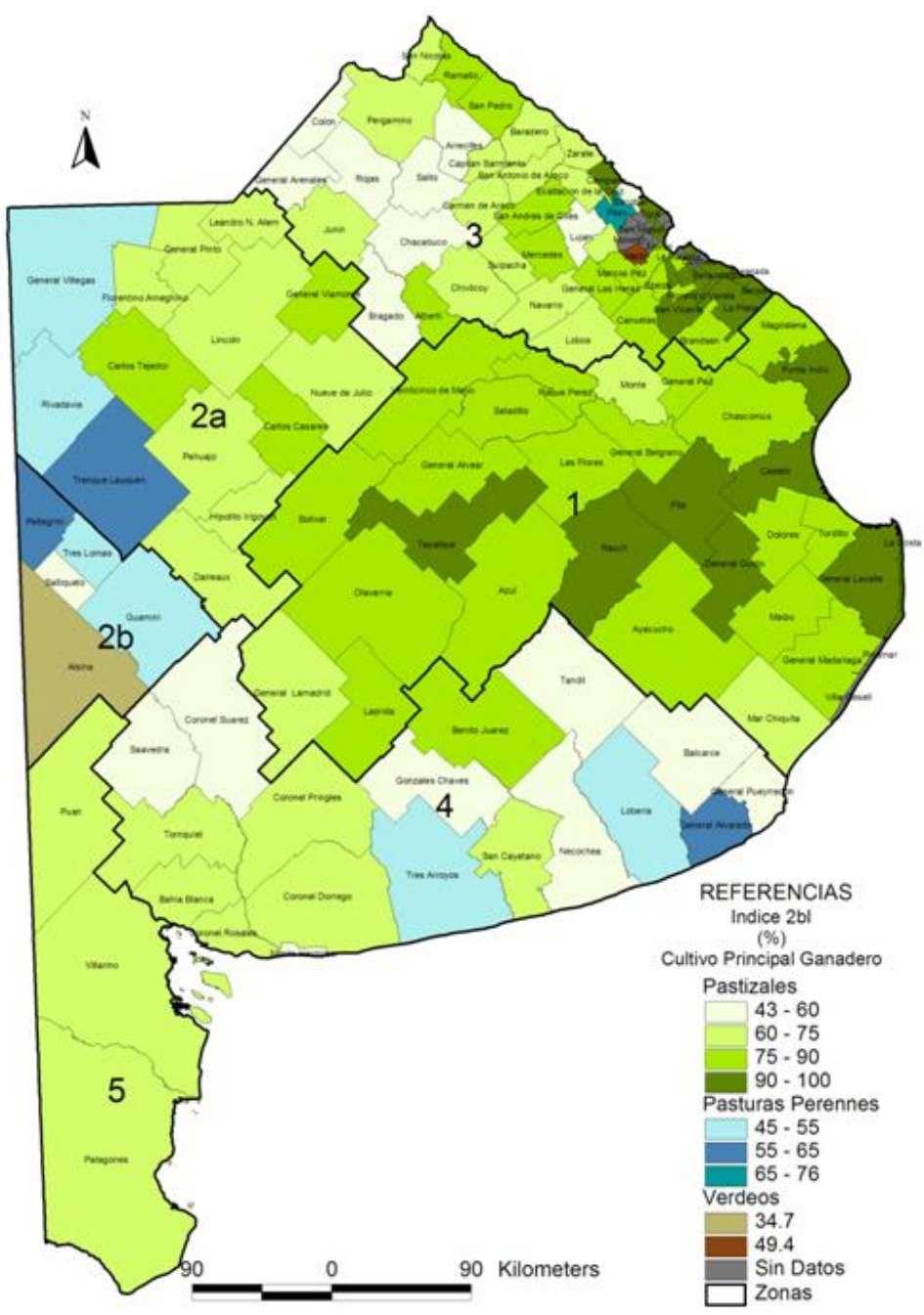

Figura 2.6. Recurso forrajero principal de cada partido de la provincia de Buenos Aires. Fuente: DPPBA (2015). 


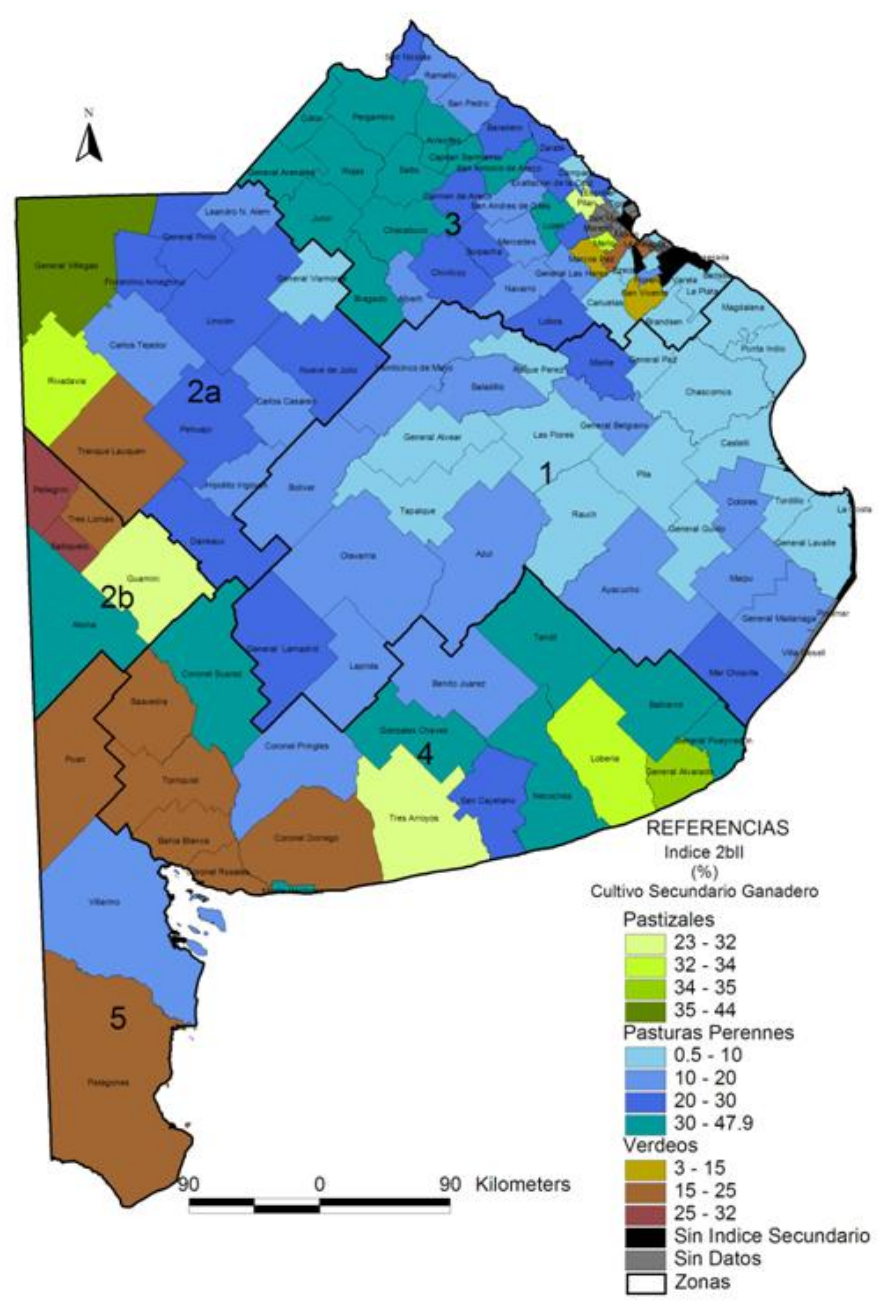

Figura 2.7. Recurso forrajero secundario de cada partido de la provincia de Buenos Aires. Fuente: DPPBA (2015).

La provincia presenta seis cuencas lecheras (Figura 2.8a) siendo la principal la del oeste, ya que concentra la mayor cantidad de tambos, superficie y producción destinada a la actividad (Figura 2.8b), seguida de Abasto Sur, Abasto Norte, Mar y Sierras, Sur y otras (MAA, 2007). 


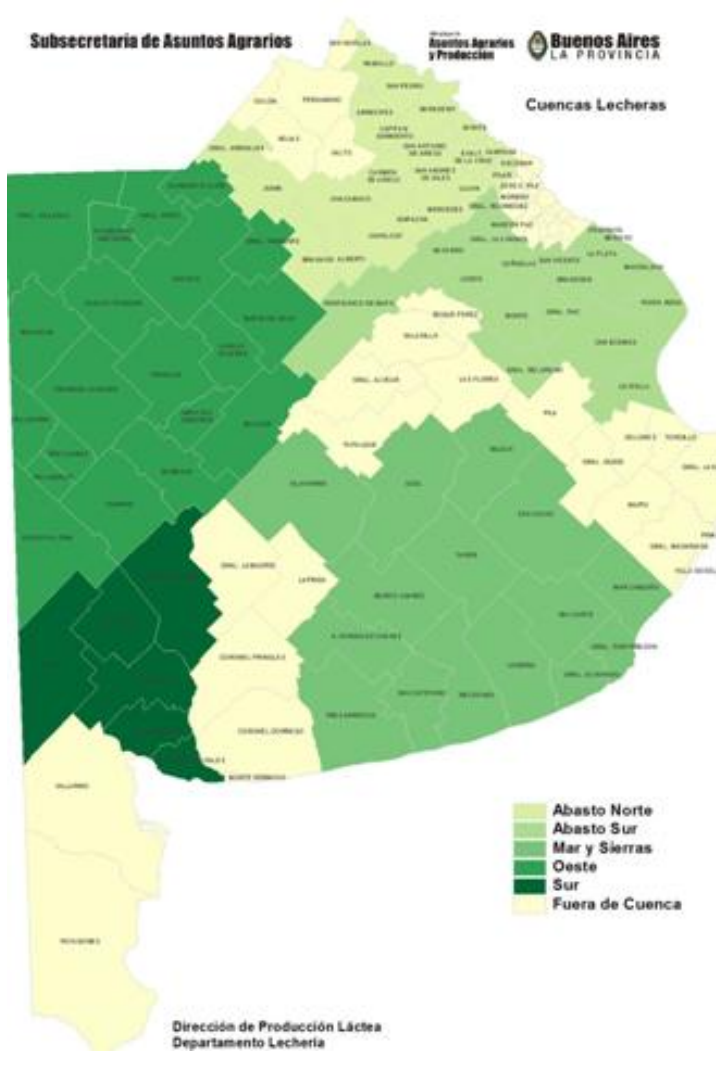

a) Cuencas lecheras

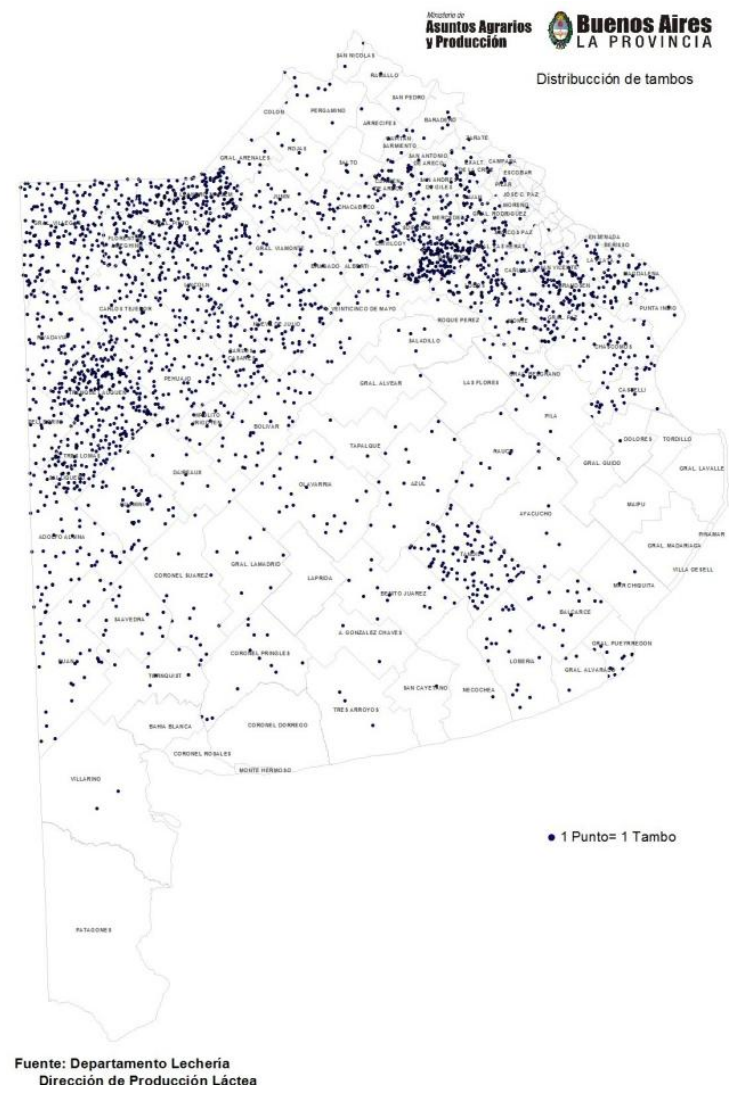

b) Distribución de tambos

Figura 2.8. Actividad lechera en la provincia de Buenos Aires: a) cuencas lecheras y b) distribución de tambos. Fuente: MAA (2007).

Considerando los cultivos extensivos y los recursos forrajeros en conjunto, se visualiza que la relación superficie agrícola/ganadera de cada partido, divide a la provincia en tres sectores (Figura 2.9): a) norte y noroeste con predominio agrícola, coincidiendo con las subregiones Pampa Arenosa y Pampa Ondulada (Figura 2.1), b) centro, del este al sudoeste con predominio ganadero, comprendiendo las subregiones Pampa Deprimida, Sistemas de Ventania y Tandilia y Sector patagónico (Figura 2.1) y c) sudeste agrícola perteneciente a la subregión Interserrana (Figura 2.1). 


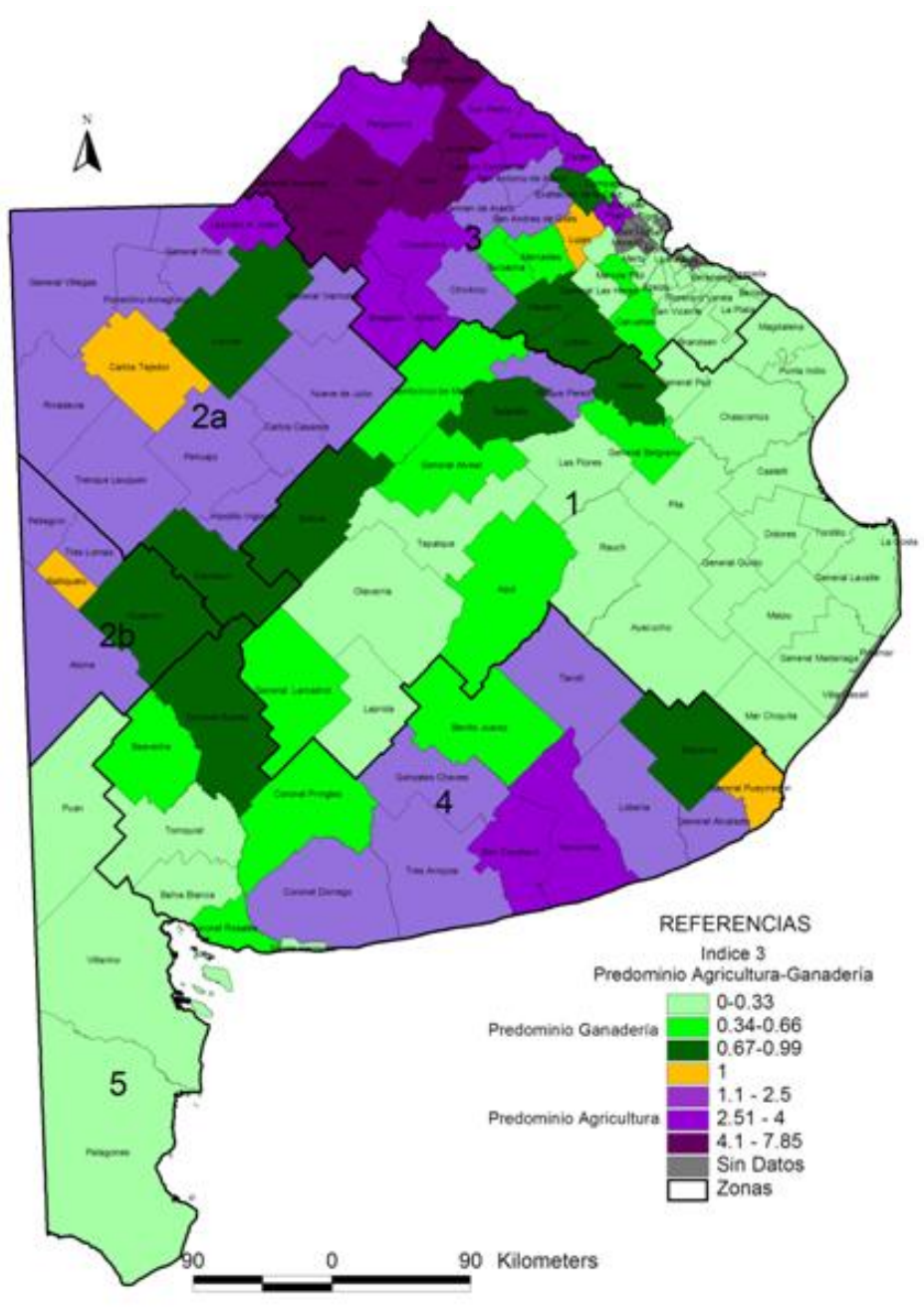

Figura 2.9. Predominio de actividad agrícola o ganadera por partido en la provincia de Buenos Aires. Fuente: DPPBA (2015).

En los partidos del norte, noroeste y sudeste presentan mayor incidencia de cultivos extensivos soja y trigo, mientras que en el resto de la provincia predominan los pastizales $y$, en menor medida, las pasturas perennes y verdeos (Figura 2.10). Los cultivos secundarios agropecuarios presentaron mayor diversidad, con predominio de soja, pasturas perennes y pastizales (Figura 2.11). 


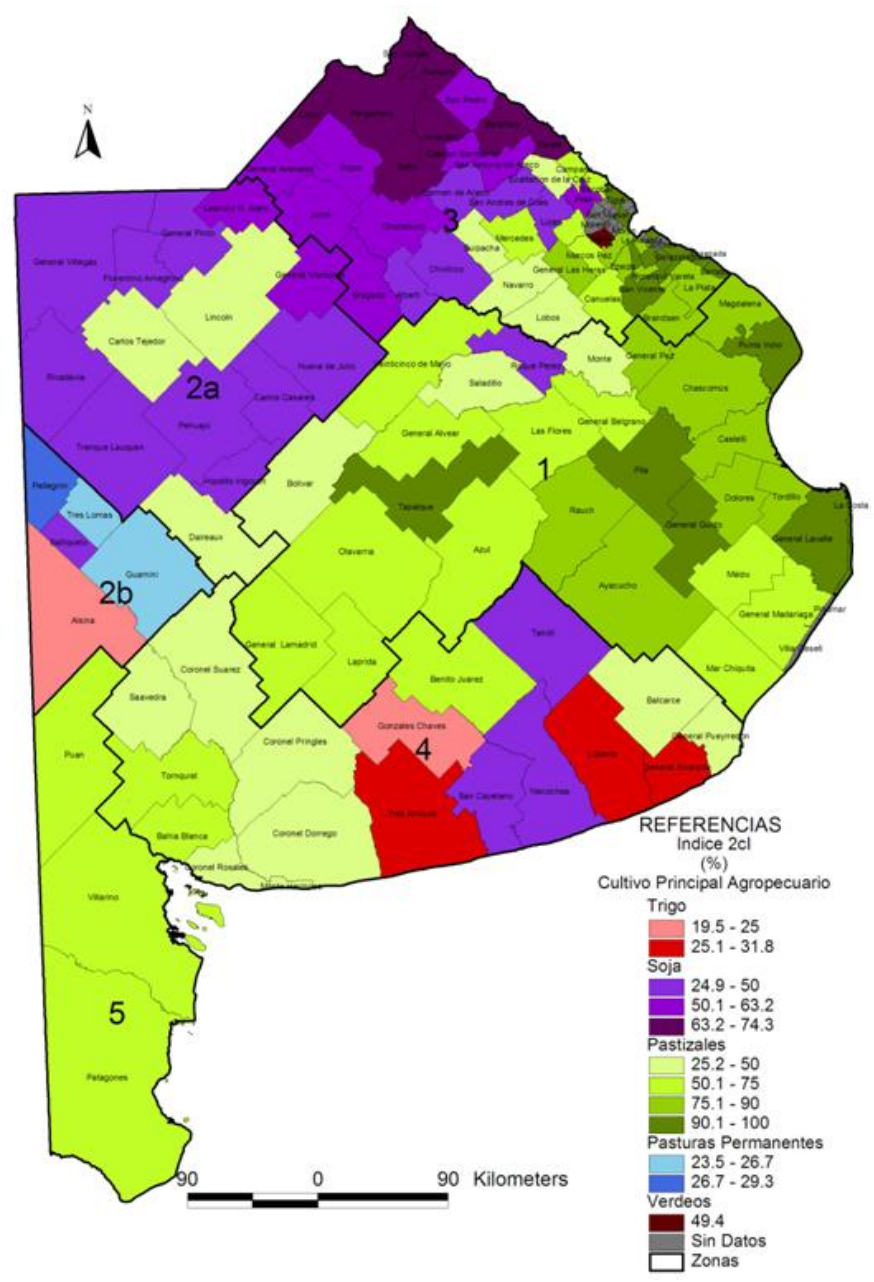

Figura 2.10. Principales cultivos agropecuarios por partido en la provincia de Buenos Aires. Fuente: DPPBA (2015). 


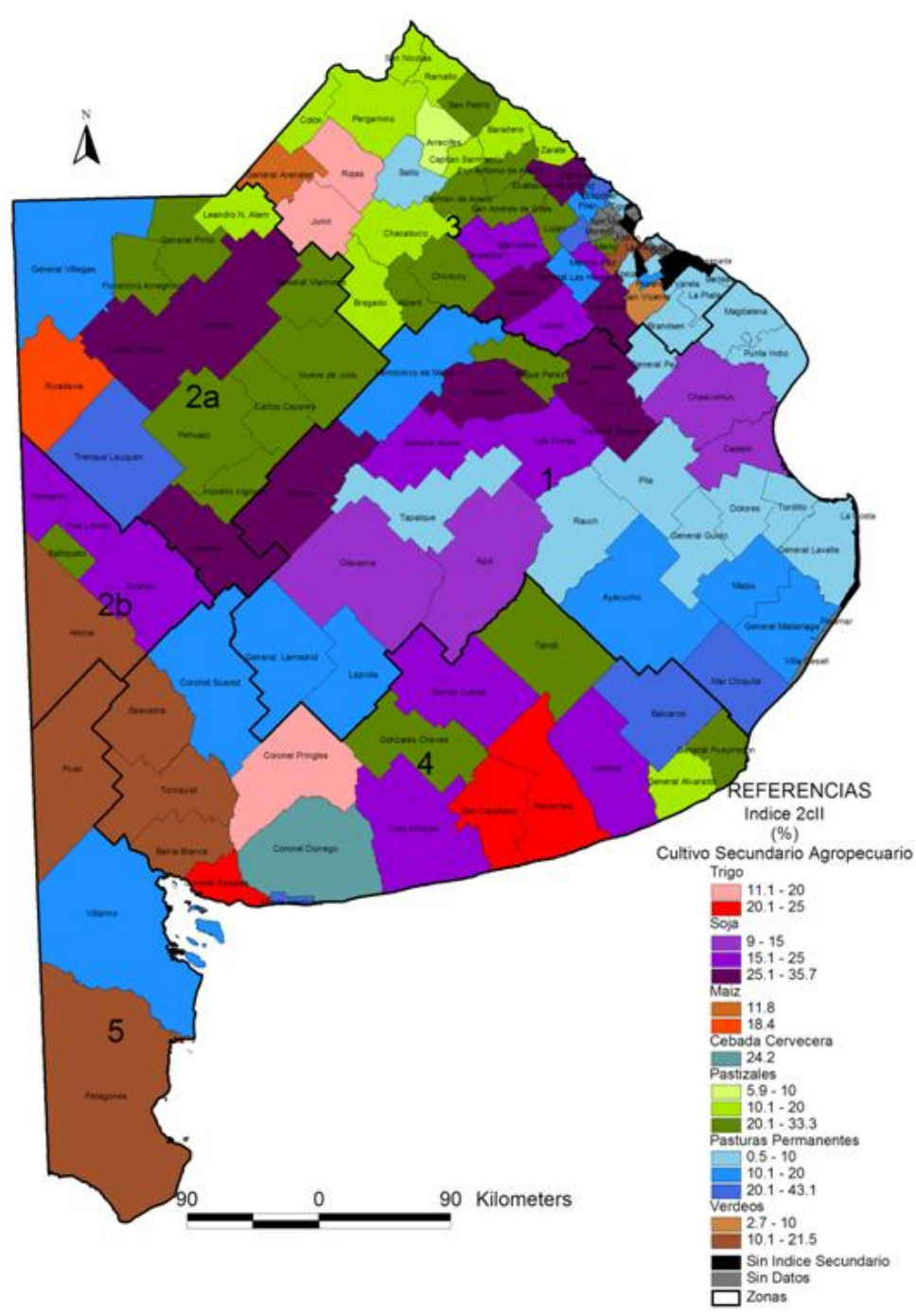

Figura 2.11. Cultivos agropecuarios secundarios por partido en la provincia de Buenos Aires. Fuente: DPPBA (2015).

\section{II.2.2.3. Horticultura}

La actividad se desarrolla en diversos ámbitos geográficos de la provincia (Tabla 2.1), comprendiendo una superficie total cercana a las 32.000 ha (CHFBA, 2005). Los tipos de producción hortícola se pueden clasificar como: cinturones verdes, zonas hortícolas especializadas y áreas de horticultura extensiva (MAA, 2007; Fernández Lozano, 2012).

Cinturones verdes: se desarrollan en los alrededores de las grandes ciudades, y se cultivan hortalizas para abastecer a la población urbana. La producción se lleva a cabo en las llamadas quintas o huertas de tipo familiar, que presentan en promedio 7 ha (varían de 1 a 40 ha). Tienen gran diversidad de cultivos (10 o más), la mayoría de ellos de carácter perecederos como los cultivos de hoja, inflorescencia y de fruto para 
consumo en fresco (MAA, 2007). En la planificación de los cultivos se tiene en cuenta el escalonamiento en la siembra y cosecha para realizar un abastecimiento continuo del mercado. Los tres cinturones verdes más importantes de la provincia, son el del gran Buenos Aires y los de Mar del Plata (partido Gral. Pueyrredón) y Bahía Blanca (ME \& INET, 2010). El primero se extiende en forma de anillo entre 30 y $100 \mathrm{~km}$ alrededor del área metropolitana (MAA, 2007). Posee la mayor superficie bajo cubierta del país estimada, para el año 2009, en más de 3.000 ha (Argerich \& Troilo, 2010; Stavisky, 2010; García, 2011 a).

Zonas hortícolas especializadas: la producción se realiza con pocos cultivos, con mano de obra asalariada, en zonas de menor valor de la tierra y en las que el clima es propicio para la producción de ciertas hortalizas que se comercializan a larga distancia para el consumo en fresco (tomate (Solanum lycopersicum L.), pimiento (Capsicum annuum L.), ajo (Allium sativum L.), cebolla (Allium cepa L.), melón (Cucumis melo L.). Se ubican en zonas más alejadas de los cinturones verdes.

Áreas de horticultura extensiva: se corresponden con cultivos más mecanizados, tanto en parte como en todas las etapas de producción. Tienen un manejo de rotaciones incluyendo especies no hortícolas, mayores superficies por cultivo y/o destino industrial de la producción: tomate, papa (Solanum tuberosum L.), arveja (Pisum sativum L.), lenteja (Lens culinaris L.), zanahoria (Daucus carota L.). Esta forma de horticultura se desarrolla en partidos como General Rodríguez y Balcarce. El sudeste de la provincia, con epicentro en Balcarce constituye el principal núcleo papero de la Argentina con el $60 \%$ de la producción y el $30 \%$ de la superficie nacional (MAA, 2007).

En la horticultura bonaerense, la producción se comercializa en los mercados concentradores, con la presencia física del producto. El destino principal de la producción es el mercado interno (92-93\%) (Fernández Lozano, 2012). La cantidad de mano de obra permanente ocupada es de 9.960 trabajadores dando un promedio cercano a las 4 personas por establecimiento (MAA, 2007). 
Tabla 2.1. Principales zonas hortícolas de la provincia de Buenos Aires.

\begin{tabular}{|c|c|c|}
\hline Zona & Partidos & Principales productos \\
\hline $\begin{array}{l}\text { Cinturón verde de las } \\
\text { ciudades de Buenos Aires y La } \\
\text { Plata }\end{array}$ & $\begin{array}{l}\text { Luján, San Fernando, Escobar, } \\
\text { Pilar, Marcos paz, Florencio } \\
\text { Varela, La Plata, Berazategui, } \\
\text { Esteban Echeverría, Coronel } \\
\text { Brandsen }\end{array}$ & $\begin{array}{l}\text { Hortalizas de hoja, tomate, } \\
\text { pimiento, lechuga, acelga, } \\
\text { apio, alcaucil, frutilla, } \\
\text { chaucha, perejil, choclo, } \\
\text { espárrago, lechuga, } \\
\text { mantecosa, zapallito, } \\
\text { berenjena }\end{array}$ \\
\hline $\begin{array}{l}\text { Noreste de la provincia de } \\
\text { Buenos Aires }\end{array}$ & $\begin{array}{l}\text { San Nicolás, Ramallo, San } \\
\text { Pedro, Baradero, } \\
\text { Chacabuco, Carmen de } \\
\text { Areco, Suipacha, Chivilcoy, } \\
\text { Navarro, Mercedes }\end{array}$ & $\begin{array}{l}\text { Batata, papa, zapallo, } \\
\text { zanahoria, choclo, espárrago. }\end{array}$ \\
\hline $\begin{array}{l}\text { Centro de la provincia de } \\
\text { Buenos Aires }\end{array}$ & $\begin{array}{l}\text { Ayacucho, Azul, Bolívar, } \\
\text { Daireaux, Gral. Alvear, Gral. } \\
\text { Belgrano, Gral. Lamadrid, H. } \\
\text { Irigoyen, Laprida, Las Flores, } \\
\text { Olavaria, Saladillo, Tandil, } \\
\text { Tapalqué y } 25 \text { de Mayo }\end{array}$ & $\begin{array}{l}\text { Hortalizas de hoja, como } \\
\text { lechuga, acelga, repollo, } \\
\text { espinaca y otras, zapallo y } \\
\text { zapallito, batata, frutilla, maíz } \\
\text { dulce, sandía. }\end{array}$ \\
\hline $\begin{array}{l}\text { Sudeste de la provincia de } \\
\text { Buenos Aires }\end{array}$ & $\begin{array}{l}\text { Balcarce, General } \\
\text { Madariaga, General } \\
\text { Pueyrredón, General } \\
\text { Alvarado, Lobería, Necochea, } \\
\text { Tandil. }\end{array}$ & $\begin{array}{l}\text { Papa, lechuga, tomate, } \\
\text { pimiento, cebolla de verdeo, } \\
\text { chaucha, zanahoria, endivia, } \\
\text { hongos. }\end{array}$ \\
\hline $\begin{array}{l}\text { Cinturón hortícola de la } \\
\text { ciudad de Bahía Blanca }\end{array}$ & Bahía Blanca y alrededores & Hortalizas de hoja, tallo y fruto. \\
\hline $\begin{array}{l}\text { Sudoeste de la provincia de } \\
\text { Buenos Aires }\end{array}$ & Villarino, Patagones & $\begin{array}{l}\text { Cebolla, ajo, pimiento, } \\
\text { zapallo, tomate. }\end{array}$ \\
\hline
\end{tabular}

Fuente: modificado de MAA (2007), Fernández Lozano (2012) y Argerich \& Troilo (2010).

\section{II.3. Cuantificación de los nutrientes: balances y eficiencias}

La cuantificación de los nutrientes en los sistemas agrícolas, así como en el sistema alimentario, se ha desarrollado a través del balance de nutrientes y la eficiencia de nutrientes. El primero asumido como diferencia entre entradas y salidas de nutrientes en un sistema determinado, mientras que la segunda implica diferentes relaciones. A continuación, se profundizan estas maneras de evaluar los nutrientes.

\section{II.3.1. Balances de nutrientes}

Cultivar la tierra continuamente sin una adecuada práctica que restituya los nutrientes puede poner en peligro la sostenibilidad de las actividades agropecuarias (FAO, 2003). Numerosos estudios muestran que el minado del suelo y la declinación de 
la fertilidad del mismo está ampliamente esparcido en el mundo (FAO, 2003; Tan et al., 2005). La cuantificación de los flujos de nutrientes ha sido una herramienta valiosa para los científicos para resumir y entender el ciclado de nutrientes en los agroecosistemas (Oenema et al., 2003). Los balances de nutrientes, definidos como la diferencia entre las entradas y las salidas de nutrientes en un sistema y en un tiempo determinado, pueden servir como indicadores de sostenibilidad de sistemas agrícolas (FAO, 2003; Abbona et al., 2007) o como indicadores del impacto de la agricultura en el ambiente (Gaj \& Bellaloui, 2012), asumiendo que son simplificaciones de procesos complejos y variables (Panten et al., 2009).

En los cálculos de nutrientes siempre estará presente la incertidumbre asociada a diferentes sesgos que Oenema et al. (2003) clasifican en: a) sesgo personal, b) sesgo de muestreo, c) sesgo de medición, d) sesgo de manipulación de los datos y e) sesgo debido a fraude. También mencionan que la incertidumbre se debe a errores de muestreo y de medición, cada uno de los cuales toma diferente magnitud e importancia según la escala de análisis.

La consideración de los balances de nutrientes ha estado focalizada en evaluar las pérdidas de nutrientes, principalmente en África, o los excesos y su riesgo de contaminación de los cuerpos de agua o la atmósfera en los países más desarrollados o de la OECD (Organización para la Cooperación y el Desarrollo Económico) (OECD \& EUROSTAT, 2007a, 2007b). En este sentido, China se ha convertido en uno de los países que ha incorporado con mayor énfasis el análisis de la dinámica de los nutrientes en los sistemas agrícolas, tanto por su preocupación por la producción de alimentos para su población, como por las consecuencias ambientales que está teniendo el modelo de agricultura empleado en los recursos hídricos (Sheldrick et al., 2003).

\section{II.3.1.1. Pasos para realizar un balance de nutrientes}

El balance de nutrientes de un sistema resume los flujos de nutrientes que entran y salen del mismo (Oenema et al., 2003; Panten et al., 2009; García \& González Sanjuán, 2010). Entonces, para realizar el balance de nutrientes de un determinado sistema se deben definir cinco aspectos:

- La escala de análisis.

- Los límites del sistema.

- Tipo de actividad o cultivo.

- Tipo de nutriente.

- Clase de flujo. 


\subsection{La escala de análisis:}

La FAO (2003) define tres grandes niveles para el análisis del balance de nutrientes: a) nivel macro (macrolevel): comprende el nivel de país, continente, b) nivel meso (mesolevel): nivel de provincia o región dentro del país, c) nivel micro (microlevel) nivel de finca o distrito (partido, departamento). La FAO (2003) considera que el nivel meso es apropiado para definir políticas de intervención. No obstante, la escala más apropiada depende del objetivo del estudio y del alcance del mismo. Esto dependerá, en parte, de los destinatarios del estudio, si son agricultores, asesores, decisores políticos del ámbito local, provincial o nacional. Estas escalas han sido empleadas en diferentes trabajos (Schlecht \& Hiernaux, 2004). Por ejemplo, a nivel nacional o supranacional Stoorvogel et al. (1993), Henao \& Baanante (1999), Koning et al. (1997), Sheldrick et al. $(2002,2003)$, Cruzate \& Casas $(2003,2012)$, Faerge \& Magid (2004), FAO $(2003,2004)$ y Tan et al. (2005). A escala meso se destacan trabajos de Smaling \& Fresco (1993), Viglizzo et al. (2001, 2004), Flores \& Sarandón (2003), Sacco et al. (2003) y FAO $(2003,2004)$ y a escala micro los de Brouwer (1998), de Jager et al. (1998), Bekunda \& Manzi (2003), FAO (2003,2004), van Beek et al. (2003) y Viglizzo et al. (2006).

\section{II.3.1.1.2. Definición de los límites del sistema:}

Los balances de nutrientes deben estar basados en una correcta definición de los límites del sistema. Esto permite no sobreestimar o subestimar flujos de nutrientes que puedan influenciar los cálculos. Un sistema adecuadamente identificado debe contar con tres límites, uno lateral (perimetral), otro inferior y otro superior. Esta delimitación tridimensional permitirá visualizar todos los flujos que entran y salen del sistema, y distinguirlos de aquellos flujos que son internos. Muchas veces, estos últimos no son claramente percibidos $y$, ante la falta de una adecuada delimitación superior 0 inferior del sistema, pueden generar confusión. En los diferentes trabajos que abordan los balances de nutrientes no se mencionan claramente estos límites y es por ello, que las diferentes metodologías utilizadas, terminan asumiendo distintos flujos en los cálculos de balances. Cuando se considera la misma escala y/o cultivo existe mayor coincidencia en cuanto a los límites laterales tenidos en cuenta, pero no respecto a los límites superior e inferior.

A partir de lo planteado por Oenema et al. (2003) se pueden asumir tres tipos de sistemas: a) sistema superficie del suelo, coloca ambos límites (superior e inferior) en la superficie del suelo (Figura 2.12a). b) sistema suelo productivo, considera la porción de suelo comprendida entre la superficie del mismo (límite superior) y la profundidad de exploración de las raíces (límite inferior) (Figura 2.12b) y c) agroecosistema, 
mantiene la profundidad de exploración de las raíces como límite inferior, pero coloca el superior en la altura del cultivo o animal considerados (Figura 2.12c).

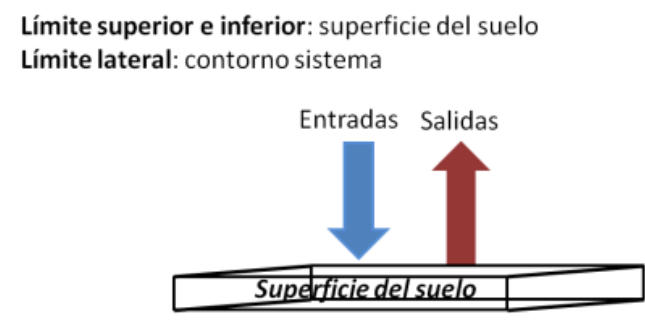

a)
Limite superior: superficie del suelo

Limite inferior: profundidad sistema radicular $(1 \mathrm{~m}$ Limite lateral: contorno sistema

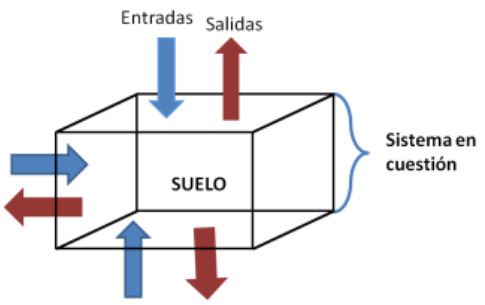

b)

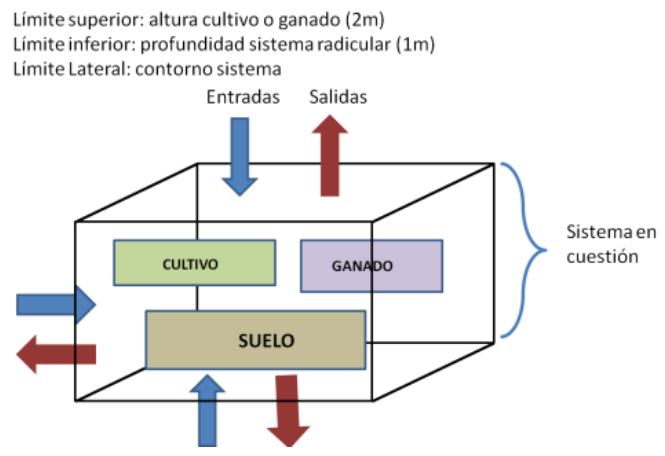

C)

Figura 2.12. Diferentes sistemas empleados en el cálculo de balance de nutrientes con sus respectivos límites: a) sistema superficie del suelo, b) sistema suelo productivo, c) agroecosistema. Adaptado de Oenema et al. (2003).

El modelo soil surface budget usado por la OECD (Oenema et al., 2003; OECD \& EUROSTAT, 2007a, 2007b; Panten et al., 2009); sería un exponente del primer caso que unifica el límite superior con el inferior (Figura 2.12a). En esta metodología se registran los ingresos de nutrientes a través de la superficie (fertilizantes, estiércol, deposiciones seca y húmeda) y que salen a través de los cultivos y/o forrajes. Los ingresos por fertilización y abono se ajustan por las pérdidas por volatilización (Oenema et al., 2003).

Un modelo que utiliza la capa de exploración de las raíces como límite inferior sería el soil system budget (Figura 2.12b). Este modelo registra todos los ingresos y egresos de nutrientes al suelo, incluyendo las pérdidas. Este modelo permite identificar varias vías de pérdida de nutrientes, por eso, es empleado en investigaciones que quieren identificar el camino de los excesos de nutrientes (Oenema et al., 2003).

Dos metodologías que utilizan el tercer ejemplo de los límites (Figura 2.12c) son el farm-gate research o caja negra y el NUTMON (Smaling \&Fresco, 1993). El farm-gate research es una metodología que registra todos los nutrientes que ingresan y salen a través de la "tranquera". Ninguna de las dos metodologías explicita claramente los 
límites superior e inferior, pero esto se puede inferir a partir de los flujos y los criterios que se tienen en cuenta en los cálculos.

Diversos trabajos comparan metodologías que emplean estos límites (Sheldrick et al., 2002, 2003; Oenema et al., 2003; FAO, 2003; Panten et al., 2009). Oenema et al. (2003) compararon los tres sistemas y encontraron que, aplicado a pequeños sistemas de producción especializados, el "farm-gate research" y el "soil surface budget" arriban a resultados similares, más allá de la consideración de flujos diferentes. Por ejemplo, cuando se analiza un sistema ganadero, el "soil surface budget" considera que los nutrientes absorbidos por el forraje producido en el sistema forman parte de las salidas y, los nutrientes del rastrojo que retornan al suelo, junto con las deyecciones de los animales, son entradas. En cambio, el "farm-gate research" asume, para el mismo análisis, que los flujos de nutrientes de la alimentación del ganado a partir de recursos forrajeros internos, así como los flujos de las deyecciones de los animales son un ciclado interno.

Cuando los límites no son especificados, resulta difícil estimar si se están considerando adecuadamente todos los flujos. Un ejemplo de esto podría ser el trabajo de Sheldrick et al. (2002) donde los límite superior e inferior no están especificados $y$, dentro de todas las salidas, considera a la inmovilización. Si se considera como límite inferior la profundidad de las raíces, la inmovilización debería ser un flujo interno y no una salida ya que, por un cambio de pH o posterior mineralización, los nutrientes inmovilizados podrían quedar nuevamente disponibles dentro de los límites del sistema. En cambio, si el límite superior e inferior fuera la superficie del suelo, la inmovilización podría ser considerada una salida, pero, en este caso, debería contemplarse a la mineralización o la solubilización como entradas y, en el trabajo, no están contempladas.

\subsection{1.3. Tipo de actividad o cultivo:}

Los balances pueden referirse a cultivos específicos como soja, maíz o pueden referirse a actividades como cultivos extensivos, producción de carne, leche, horticultura, fruticultura. El objetivo del estudio determinará lo más apropiado a considerar.

\section{II.3.1.1.4. Tipo de nutrientes:}

El nitrógeno $(\mathrm{N})$ es el nutriente más empleado en los cálculos de balance de nutrientes, principalmente en los países desarrollados, como indicador del riesgo ambiental ante la contaminación de acuíferos o la atmósfera (Brouwer, 1998). Luego le siguen en consideración el fósforo $(\mathrm{P})$ y el potasio $(\mathrm{K})$, siendo muy escasa la inclusión de otros nutrientes como calcio (Ca), magnesio (Mg) y azufre (S). 


\subsection{Clase de flujos:}

Stoorvogel \& Smaling (1990) han sintetizado las distintas entradas y salidas que se pueden considerar en un balance de nutrientes (Tabla 2.2) (FAO, 2003). Sin embargo, no siempre se cuenta con toda la información necesaria para calcular todas las salidas y entradas del sistema.

Tabla 2.2. Entradas y salidas consideradas en los balances de nutrientes. Fuente: Stoorvogel \& Smaling (1990).

\begin{tabular}{ll}
\hline Entradas (IN) & Salidas (OUT) \\
\hline IN1 Fertilización mineral & OUT1 Productos cosechados \\
\hline IN2 Fertilización orgánica & OUT2 Residuos de cultivo \\
\hline IN3 Deposición seca y húmeda & OUT3 Lixiviación \\
\hline IN4 Fijación de nitrógeno & OUT4 Pérdidas gaseosas \\
\hline IN5 Sedimentación & OUT5 Erosión de suelo \\
\hline
\end{tabular}

La fuente empleada en los datos de cada una de las entradas y salidas varía según la escala de análisis del balance. Puede ir desde medición directa cuando se realiza un cálculo a nivel de finca, hasta datos de base estadística cuando el nivel es mayor (partido, provincia, país, o mayor) (FAO, 2003; Schlecht \& Hiernaux, 2004).

Las salidas por lixiviación, pérdidas gaseosas y erosión se calculan a partir de diferentes ecuaciones de transferencia (Stoorvogel \& Smaling, 1990; Farge \& Magid, 2004). Las salidas por residuos de cultivos dependen del manejo que se realiza de los mismos, y varía entre cultivos y también entre regiones. Stauffer \& Beaton (1995, citado Sheldrick et al., 2002) estimaron que en China un 66\% del rastrojo del arroz es empleado como combustible, un $12 \%$ como forraje y sólo el $20 \%$ retorna al suelo. Estos autores señalan que gran parte de los nutrientes del forraje se pierden de los suelos arables.

Más allá de la escala y de los límites del sistema escogido, cada metodología también define los flujos a considerar. Por ejemplo, el método empleado por la OECD no evalúa pérdidas por lixiviado y volatilización, por lo que los balances con esta metodología tienden a mostrar excesos de nutrientes (Sheldrick et al., 2002). 


\section{II.3.1.2. Eficiencias en el uso de nutrientes}

Además del balance de nutrientes, considerado como la diferencia entre las entradas y salidas a un sistema en un tiempo determinado, existen otras relaciones que abordan la eficiencia en el uso de nutrientes (NUE, en inglés). Estas relaciones para determinar la eficiencia del uso de nutrientes en agricultura pueden agruparse a través de distintos métodos de cálculo o índices (Cassman et al., 2003; Stewart, 2007; Syers et al., 2008; Fixen et al., 2015).

\subsection{Método directo:}

Se usa donde se puede marcar el nutriente a través de radioisótopos como ${ }^{32} \mathrm{P}$ o isótopos ${ }^{15} \mathrm{~N}$ en el fertilizante, lo que permite medir cuánto nutriente del fertilizante es absorbido. Este índice es la proporción de nutriente agregado recuperado en el cultivo.

\subsection{Método por diferencia:}

Presenta dos caminos, uno usando el rendimiento y otro la absorción. Usando rendimiento, también conocido como "eficiencia agronómica" se calcula $\left(\mathrm{Y}_{N}-Y_{0}\right) / F_{N}$ donde $Y_{N}$ y $Y_{O}$ son, respectivamente, los rendimientos con y sin el nutriente a ser evaluado, y $\mathrm{F}_{\mathrm{N}}$ es la cantidad de nutriente aplicado en $\mathrm{kg} \mathrm{ha}^{-1}$. Usando los nutrientes absorbidos, también conocido como "recuperación aparente" o "eficiencia aparente" del nutriente aplicado. La fórmula es similar a la anterior pero en reemplazo de los rendimientos se usan los nutrientes absorbidos (con y sin fertilización) (UN-Uo)/FN).

\subsection{Eficiencia fisiológica:}

De un nutriente aplicado, la misma es calculada en términos de kilogramos de producto incrementado por kilogramos absorbidos incrementados $\left(Y_{N}-Y_{O}\right) /\left(U_{N}-U_{O}\right)$.

\subsection{Método de balance parcial:}

Refiere al cociente entre el total de nutriente absorbido y la cantidad aplicada $\left(U_{N} / F_{N}\right)$.

Estas eficiencias pueden considerarse a corto o largo plazo y resumirse en el rendimiento, en la recuperación o la remoción (Stewart, 2007). Syers et al. (2010) comparan el método por diferencia y el método de balance, y consideran que el primero es más apropiado para $\mathrm{N}$ mientras que el segundo lo es para $\mathrm{P}$, porque tiene en cuenta el efecto residual del mismo. Esto último también coincide con lo expuesto por Stewart (2007) y Johnston \& Syers (2009), quienes también incluyen al K. Fixen et al. (2015) mencionan que un balance parcial $\left(U_{N} / F_{N}\right)$ superior a 1 puede ser deseable en un suelo donde la disponibilidad de nutrientes sea alta. Sin embargo, esta 
recomendación asume una disminución en la dotación de nutrientes del suelo lo que implica que las futuras generaciones dispondrán de un recurso de menor calidad.

Estos índices y métodos pueden ser aplicados en diferentes escalas: parcela, finca, región, país, o mayores (Fixen et al., 2015). En general, son empleados para compatibilizar el incremento del rendimiento del cultivo con el agregado de fertilizante. Sin embargo, hay que tener en cuenta que muchas veces las recomendaciones derivadas de los mismos pueden atentar contra el mantenimiento de la dotación de nutrientes del suelo y, por lo tanto, poner en riesgo la sostenibilidad. Entendiendo la dotación de nutrientes como la totalidad de nutrientes en el suelo, lo que incluye tanto las fracciones de nutrientes disponibles, de mayor interés agronómico para el crecimiento de los cultivos, como las de menor o nula disponibilidad (Abbona \& Sarandón, 2014). Por ejemplo, Sheldrick et al. (2003) consideran que un balance de un nutriente se alcanza cuando, ante el incremento en el agregado del mismo, no se produce un aumento en sus salidas (no aumenta el rendimiento). Este criterio es cuestionable porque no tiene en cuenta que el suelo mantenga la cantidad de nutrientes original, lo cual debería ser el objetivo de los estudios de balances de nutrientes. Bajo este criterio, para alcanzar el máximo rendimiento de un cultivo en dos suelos con distinta dotación de nutrientes (alta y baja), será necesaria distinta cantidad de fertilizante. No obstante, si el rendimiento alcanzado es el mismo, también lo será la extracción de nutrientes. Por lo tanto, la reposición de nutrientes de ambos suelos será diferente. Esto se asemeja al concepto de "nutrición balanceada" que no hace referencia a equilibrar las entradas y las salidas de nutrientes del sistema sino a que se brinden a los cultivos todos los nutrientes necesarios para un desarrollo sin deficiencias, pero sin considerar si se mantiene la dotación en el suelo (Drechsel et al., 2015). Los métodos por diferencia, también suponen la utilidad de la fertilización en el incremento del rendimiento y no la reposición de los nutrientes que se extraen con la cosecha. Estos métodos son los más empleados para recomendar la fertilización, ya que el incremento de rendimiento esperado, transformándolo a dinero y comparado con el costo de la fertilización, determina la mejor dosis a emplear. No obstante, en los suelos con buena fertilidad natural, esto implica la pérdida paulatina de nutrientes por la menor reposición en relación a la extracción. Asumir este criterio permite que un agricultor destine menos dinero en fertilización para alcanzar el rendimiento buscado, pero será a costa de la degradación del suelo. Este es el criterio que prevalece en la decisión de fertilizar los cultivos extensivos en Argentina.

La consideración de la eficiencia en el uso de los nutrientes tiene un sentido diferente cuando se lo aborda desde los países más o menos desarrollados. Para los 
primeros, el debate acerca de mejorar la eficiencia está más relacionado a disminuir los grandes excedentes de nutrientes que genera la fertilización, que superan ampliamente las extracciones $y$, al no poder ser retenidos en los sistemas, terminan en los cuerpos de agua y atmósfera (Vitousek et al., 2009). Esto ha sido más tenido en cuenta para $\mathrm{N}$ y P. Por lo tanto, las recomendaciones intentan mostrar que una menor aplicación de fertilizante, que se asemeje a las extracciones puede permitir mantener los niveles de productividad y, a su vez, disminuir el impacto externo (Vitousek et al., 2009). En cambio, para los países menos desarrollados, las eficiencias se basan en agregar sólo los nutrientes necesarios para complementar la disponibilidad del suelo y permitir un incremento de los rendimientos que acompañe una maximización de las ganancias. En estos casos se dan dos situaciones, en suelos con baja fertilidad natural, las fertilizaciones alcanzan y a veces superan las extracciones de los cultivos, como ocurre en Brasil (Melgar, 2011). Pero en suelos con buena disponibilidad y dotación de nutrientes, implica agregar lo que al suelo le falta para alcanzar un rendimiento adecuado y, a su vez, permita maximizar la ganancia. Por lo tanto, la mineralización de la materia orgánica del suelo se transforma en la principal, pero insostenible fuente de $\mathrm{N}$ que reemplaza la remoción del cultivo (Bruulsema et al., 2004). Esto, como se mencionaba anteriormente, ocurre en gran parte de los suelos de la Región Pampeana argentina.

Otro aspecto a tener en cuenta, es que en general se considera la fertilización en el corto plazo, la cual lleva a buscar la eficiencia en la recuperación de nutrientes durante el primer año de aplicación (Bruulsema et al., 2004). Evaluaciones de las eficiencias de N, P y K para los principales cereales en parcelas de investigación, sugieren que sólo el 40 al $65 \%$ puede ser recuperado el primer año (Fixen et al., 2015). Según Tilman et al. (2002) solamente el 30-50\% del fertilizante nitrogenado aplicado y $45 \%$ del fertilizante fosforado son tomados por el cultivo. Sin embargo, no se analiza si los nutrientes son capturados por el sistema en distintos compartimientos y luego liberados para que sean tomados por el cultivo o, si la baja eficiencia, implica la salida de nutrientes del sistema por diferentes vías (erosión, lixiviación, volatilización) generando problemas ambientales. En los balances de $P$ se hace énfasis en la residualidad del mismo (Johnston \& Syers, 2009; Drechsel et al., 2015). A causa de ello, en algunos casos la recomendación de la fertilización se hace en función de la rotación de cultivos y no sólo en el cultivo en sí (García, 201 lb; Divito et al., 2010).

Para incrementar la eficiencia del uso de los nutrientes en los sistemas agrícolas y no sólo en la relación suelo-cultivo, se requiere mejorar la comprensión de la dinámica de los mismos en el suelo y de los caminos que siguen los nutrientes agregados, teniendo en cuenta la posible captura por el cultivo $u$ otras especies 
vegetales, incluso cultivos de cobertura. Conocer las posibles vías de retención, acumulación y liberación de los nutrientes de acuerdo a las diferentes características de los distintos tipos de suelos, permitirá mejorar la nutrición de los cultivos optimizando la conservación de los nutrientes en los agroecosistemas. La materia orgánica es clave en el ciclo de algunos nutrientes en el agroecosistema (Drinkwater \& Snapp, 2007). La misma cumple un rol fundamental en la retención y liberación de nutrientes a partir de la mineralización, en aquellos elementos cuya mayor reserva se aloja en ella, como es el caso del N (Stewart, 2007). A causa de ello, la acumulación de materia orgánica sería una buena manera de disminuir las pérdidas de este elemento causadas por otras vías (lixiviación, volatilización, desnitrificación) (Bruulsema et al., 2004). A los fines de dar la importancia que amerita la materia orgánica en estas consideraciones, es necesario pasar de la relación fertilizante-cultivo a fertilizante-agroecosistema. Debe buscarse equilibrar las entradas y salidas de nutrientes, a la vez que las salidas sean exclusivamente las deseables, es decir, la cosecha, minimizando aquéllas que causan problemas ambientales. Hay que tener en cuenta que el solo incremento de la materia orgánica no implica un incremento en la dotación de nutrientes del sistema, ya que esto dependerá de la diferencia entre las entradas y salidas de nutrientes. Para elementos como el N, cuya reserva es esta fracción, favorecer un balance positivo de materia orgánica evita pérdidas por otras vías que no sean la cosecha, aunque el incremento de la dotación de nutrientes estará sujeto al resultado del balance de los mismos.

En los últimos años suele hacerse alusión a las "mejores prácticas de manejo" en relación a la nutrición de los cultivos (Snyder \& Bruulsema, 2007; Stewart, 2007; IFA, 2009; García \& González Sanjuán, 2010). Algunos autores resumen este concepto en las siglas "4R", fuente correcta (right source), dosis correcta (right rate), en el tiempo (right time) y en el lugar correcto (right place). A la luz de lo discutido, sería más apropiado cambiar la R de "dosis correcta" por "dosis de reposición" (replacement rate) a los fines de lograr un manejo que conserve los nutrientes del suelo.

\section{II.4. Criterios metodológicos asumidos en la tesis}

Para estudiar los nutrientes en el ecosistema alimentario, se consideró que la metodología del balance de nutrientes, definido como la diferencia entre las entradas y salidas en un sistema y en un tiempo determinado (Flores \& Sarandón, 2003; García \& González Sanjuán, 2010), es la más apropiada para evaluar la conservación de los nutrientes del suelo en las actividades agropecuarias, requisito necesario para la sostenibilidad.

Se utilizaron los pasos descriptos en la sección II.3.1.1 de este capítulo: 


\section{II.4.1. La escala de análisis:}

Se tuvieron en cuenta las escala "meso", es decir a nivel de provincia, y "micro", a nivel de partido.

\section{II.4.2. Los límites del sistema:}

El sistema elegido fue el de agroecosistema. Los límites laterales, tanto para la escala "micro" como "meso", fueron los determinados por cada actividad definida en el punto II.4.3 (perímetro de cada una), el límite inferior por la profundidad de exploración de las raíces de los respectivos cultivos o recursos forrajeros $(2 \mathrm{~m}$ aproximadamente) y, el límite superior, por la altura del cultivo o ganado (3m aproximadamente). De esta manera, se asumió que los rastrojos de cultivos y recursos forrajeros, al igual que las deyecciones de los animales en la producción de carne y leche bovinas, conforman flujos internos.

\section{II.4.3. Tipo de actividad o cultivo:}

Se evaluaron tres actividades, cultivos extensivos, horticultura y producción de carne y leche bovinas.

\section{II.4.4. Tipo de nutriente:}

Los nutrientes considerados fueron N, P, K, Ca y S.

\section{II.4.5. Clase de flujo:}

Los flujos considerados fueron: en las entradas, la fertilización mineral y orgánica (esta última en horticultura) y la fijación biológica de N. En el caso de la ganadería, se incluyó como ingreso para la producción de leche, el alimento balanceado, que se asumió que provenía de la agricultura. Se tuvieron en cuenta las salidas de nutrientes a través de los productos extraídos (productos cosechados, carne, leche). Por la dificultad para realizar los cálculos a nivel regional y las limitaciones estadísticas, se omitieron otros flujos como deposición seca y húmeda, sedimentación, lixiviación, pérdidas gaseosas y erosión. 
En cuanto al aspecto temporal de la evaluación, los cálculos se realizaron sobre una base anual, tomando como período de referencia el comprendido por los años 2005-2006. Esta decisión se basó en el período al que corresponde la información estadística disponible para realizar el estudio. La misma fue tomada de tres fuentes:

- Censo Nacional Agropecuario (CNA, 2002), último censo con datos oficiales discriminados por partidos de todas las producciones agropecuarias. De ahí en adelante, se produjo un cambio en el uso de la tierra principalmente con el avance de la agricultura sobre la ganadería, que no puede ser cuantificado en ese nivel de desagregación.

- Base de datos de fertilización por partido de los cultivos extensivos y una parte de forrajes de la ex SAGPyA, del año 2006.

- Censo Hortiflorícola de la provincia de Buenos Aires (CHFBA, 2005), lo más actualizado en horticultura en la provincia.

Debido a que el período 2005-2006 se puede asumir como el más próximo del que se puede contar con información productiva de la provincia discriminada por partido (cultivos, recursos forrajeros, rendimientos, existencias ganaderas), se decidió asumirlo como escenario de referencia para la tesis, pero los cálculos siempre fueron referidos a una base anual. En los subcapítulos del capítulo III, correspondientes a las diferentes actividades se analizan, adicionalmente, tendencias generales ocurridas en el uso de la tierra y sus implicancias.

\section{II.4.6. Generación de mapas temáticos}

La representación de extracciones (por unidad de superficie y totales), balances de nutrientes (por unidad de superficie y totales), reposiciones, se realizaron mediante la utilización de sistemas de información geográfica (SIG). Con las superficies calculadas, se generaron puntos aleatorios en cada partido (un punto cada 10.000 ha) y a todos los puntos dentro de un mismo partido se les asignó el mismo valor de la variable a mapear. Los mapas, se generaron utilizando una interpolación inversamente proporcional a la distancia con los seis vecinos más cercanos, con el fin de obtener una superficie continua de valores. Dichas figuras se emplearon en el Capítulo III, subcapítulos I, II, III y IV.

\section{II.5. BIBLIOGRAFÍA}

Abbona, E.A. \& S.J. Sarandón. 2014. Manejo de nutrientes en los agroecosistemas. En: Agroecología. Bases teóricas para el diseño y manejo de agroecosistemas sustentables. 
Sarandón, S.J. \& C.C. Flores (Editores). Editorial de la Universidad Nacional de La Plata (EDULP). Capítulo 8:211-234.

Abbona, E.A., S.J. Sarandón, M.E. Marasas \& M. Astier. 2007. Ecological sustainability evaluation of traditional management in different vineyard systems in Berisso, Argentina. Agriculture, Ecosystems \& Environment 119:335-345.

Argerich, C. \& L. Troilo. (eds.). 2010. Manual de Buenas Prácticas Agrícolas en la cadena de tomate Buenos Aires: FAO, MAGyP, INTA. 258pp.

Bekunda, M. \& G. Manzi. 2003. Use of partial nutrient budget as an indicator of nutrient depletion in the highlands of southwestern Uganda. Nutrient Cycling in Agroecosystems 67:187-195.

Bruulsema, T.W., P.E. Fixen \& C.S. Snyder. 2004. Fertilizer nutrient recovery in sustainable cropping systems. Better crop 88(4):15-17.

Brouwer, F. 1998. Nitrogen balances at farm level as a tool to monitor effects of agrienvironmental policy. Nutrient Cycling in Agroecosystems 52:303-308.

Cassman, K.G., A. Dobermann, D.T. Walters \& H. Yang. 2003. Meeting cereal demand while protecting natural resources and improving environmental quality. Annual Review of Environment \& Resources 28:315-358.

CHFBA (Censo Hortiflorícola de la Provincia de Buenos Aires). 2005. Gobierno de la Provincia de Buenos Aires, Ministerio de Economía y Ministerio de Asuntos Agrarios. 115pp. Disponible en: http://www.maa.gba.gov.ar/agricultura ganaderia/archivos/resultadofinal.pdf. Último acceso: octubre 2016.

CNA (Censo Nacional Agropecuario). 2002. Instituto Nacional de Estadísticas y Censos de la República Argentina. Disponible en: http://www.indec.gob.ar/cna index.asp. Último acceso: octubre 2016.

Cruzate, G. \& R.R. Casas. 2003. Balance de nutrientes. Revista Fertilizar (Número especial "Sostenibilidad"): 7-13.

Cruzate, G. \& R.R. Casas. 2012. Extracción y balance de nutrientes en los suelos agrícolas de la Argentina. Informaciones Agronómicas de Hispanoamérica 6:7-14.

de Jager, A., I. Kariuku, F.M. Matiri, M. Odendo \& J.M. Wanyama. 1998. Monitoring nutrient flows and economic performance in African farming systems (NUTMON) IV. Linking nutrient balances and economic performance in three districts in Kenya. Agriculture, Ecosystems \& Environment 71:81-92.

DPPBA (Defensoría del pueblo de la provincia de Buenos Aires). 2015. Relevamiento de la utilización de agroquímicos en la provincia de Buenos Aires. Mapa de situación e incidencia sobre la salud. Defensor del pueblo de la provincia de Buenos Aires, Universidad Nacional de La Plata. 533pp.

Divito, G.A., H. Sainz Rozas \& H.E. Echeverría. 2010. Estrategias de fertilización fosforada en una rotación de cultivos en el sudeste bonaerense. Ciencia del suelo 28(1):47-55.

Drechsel, P., P. Heffer, H. Magen, R. Mikkelsen, H. Singh \& D. Wichelns. 2015. Managing water and nutrients to ensure global food security, while sustaining ecosystem services. En: Managing Water and Fertilizer for Sustainable Agricultural Intensification. Drechsel, P., P. Heffer, H. Magen, R. Mikkelsen, H. Singh \& D. Wichelns (Editores). International Fertilizer Industry Association (IFA), International Water Management Institute (IWMI), International Plant Nutrition Institute (IPNI), and International Potash Institute (IPI). Paris. Capítulo 1:1-7.

Drinkwater, L.E. \& S.S. Snapp. 2007. Nutrients in agroecosystems: rethinking the management paradigm. Advances in Agronomy 92:163-186.

FAO (Organización de las Naciones Unidas para la Alimentación y la Agricultura). 2003. Assessment of soil nutrient balance. Approaches and methodologies. Rome. Fertilizer \& Plant Nutrition Bulletin 14. 88pp.

FAO (Organización de las Naciones Unidas para la Alimentación y la Agricultura). 2004. Scaling soil nutrient balances. Enabling mesolevel applications for African realities. Rome. FAO Fertilizer and Plant Nutrition Bulletin 15. 150pp.

Fernández Lozano, J. 2012. La producción de hortalizas en Argentina. Caracterización del sector y zonas de producción. Secretaría de comercio Interior. Corporación del Mercado Central de Buenos Aires. 29pp.

Farge, J. \& J. Magid. 2004. Evaluating NUTMON nutrient balancing in Sub-Saharan Africa. Nutrient Cycling in Agroecosystems 69:101-109.

Fixen, P., F. Brentrup, T.W. Bruulsema, F. Garcia, R. Norton \& S. Zingore. 2015. Nutrient/fertilizer use efficiency: measurement, current situation and trends. En: Managing Water and Fertilizer for Sustainable Agricultural Intensification. Drechsel. P., P. Heffer, H. Magen, R. Mikkelsen, H. Singh \& D. Wichelns (Editores). International Fertilizer Industry Association (IFA), International Water Management Institute (IWMI), International Plant Nutrition Institute (IPNI), and International Potash Institute (IPI). Paris. Capítulo 2:8-38. 
Flores, C.C. \& S.J. Sarandón. 2003. ¿Racionalidad económica versus sustentabilidad ecológica? El ejemplo del costo oculto de la pérdida de fertilidad del suelo, durante el proceso de Agriculturización en la Región Pampeana Argentina. Revista de la Facultad de Agronomía 105 (1) (2002,2003): 53-67.

Gaj, R. \& N. Bellaloui. 2012. Evaluation of phosphorus and nitrogen balances as an indicator for the impact of agriculture on environment: A comparison of a case study from Poland and Mississippi US. Agricultural Sciences 3(2):317-329.

García, M. 2011 a. El cinturón hortícola platense: ahogándonos en un mar de plásticos. Un ensayo acerca de la tecnología, el ambiente y la política. Theomai 23:35-53.

García, F.O. 201 lb. Balances de carbono y de nutrientes: buscando el equilibrio en la agricultura del Cono Sur. II Simposio Nacional de Agricultura. Uruguay. 135-147.

García, F.O. \& M.F. González Sanjuán. 2010. Balances de nutrientes en Argentina ¿Cómo estamos? ¿Cómo mejoramos? Informaciones Agronómicas 48:1-5.

Henao, J. \& C. Baanante. 1999. Estimating rates of nutrient depletion in soils of agricultural lands of Africa. Muscle Scholas, USA. International Fertilizer Development Center (IFDC). 80pp.

IFA (International Fertilizer Industry Association). 2009. The global "4R" nutrient stewardship framework developing fertilizer best management practices for delivering economic, social and environmental benefits. Paris, France. 10pp

Johnston, A.E.J. \& K. Syers. 2009. A new approach to assessing phosphorus use efficiency in agriculture. Better Crops 93(3):14-16.

Koning, G.H.J., P.J. van de Kop \& L.O. Fresco. 1997. Estimates of sub-national nutrient balances as sustainability indicators for agro-ecosystems in Ecuador. Agriculture, Ecosystems \& Environment 65:127-139.

MAA (Ministerio de Asuntos Agrarios). 2007. Nuestra provincia nuestro campo. El sector agropecuario de la provincia de Buenos Aires. 147pp.

ME \& INET (Ministerio de Educación de la Nación. Instituto Nacional de Educación Tecnológica). 2010. La Horticultura en la Argentina. Informe Final. Disponible en: http://catalogo.inet.edu.ar/files/pdfs/info sectorial/horticultura-informe-sectorial.pdf. Último acceso: junio 2016.

Melgar, R. 2011. La reposición de nutrientes en EEUU, Brasil y Argentina: tres escenarios contrastantes. Fertilizar 19:5-11.

OECD \& EUROSTAT (Organización para la Cooperación y el Desarrollo Económicos. Oficina Europea de Estadística). 2007a. Gross nitrogen balances handbook. 24pp.

OECD \& EUROSTAT (Organización para la Cooperación y el Desarrollo Económicos. Oficina Europea de Estadística). 2007b. Gross phosphorus balances handbook. 18pp.

Oenema, O., H. Kros \& W. de Vries. 2003. Approaches and uncertainties in nutrient budgets: implications for nutrient management and environmental policies. European Journal of Agronomy 20:3-16.

Panten, K., J. Rogasik, F. Godlinsky, U. Funder, J-M. Greef \& E. Schung. 2009. Gross soil surface nutrient balances: The OECD Approach implemented under German conditions. Agriculture \& Forestry Research 1 59:19-28.

Sacco, D., M. Bassanino \& C. Grignani. 2003. Developing a regional agronomic information system for estimating nutrient balances at a larger scale. European Journal of Agronomy 20:199210.

Schlecht, E. \& P. Hiernaux. 2004. Beyond adding up inputs and outputs: process assessment and upscaling in modelling nutrient flows. Nutrient Cycling in Agroecosystems 70:303-319.

Sheldrick, W., J.K. Syers \& J. Lingrad. 2002. A conceptual model for conducting nutrient audits at national, regional, and global scales. Nutrient Cycling in Agroecosystems 62:61-72.

Sheldrick, W.F., J.K. Syers \& J. Lingrad. 2003. Soil nutrient audits for China to estimate nutrient balances and output/input relationships. Agriculture, Ecosystems \& Environment 94:341-354.

SIIA (Sistema Integrado de Informaciones Agropecuarias). 2016. Disponible en: http://www.siia.gov.ar/. Último acceso: septiembre 2016.

Smaling, E.M.A. \& L.O. Fresco. 1993. A decisión-suppport model for monitoring nutrient balances under agricultural land use (NUTMON). Geoderma 60:235-256.

Snyder, C.S. \& T.W. Bruulsema. 2007. Nutrient use efficiency and effectiveness in North America: indices of agronomic and environmental benefit. IPNI. Ref. \# 07076. 4pp.

Stavisky, A. 2010. Situación actual de la plasticultura en Argentina. XXXIII Congreso Argentino de Horticultura. ASAHO. Rosario.

Stewart, W.M. 2007. Consideraciones en el uso eficiente de nutrientes. Informaciones Agronómicas 67:1-6.

Stoorvogel, J.J. \& E.M.A. Smaling. 1990. Assessment of soil nutrient depletion in sub-Saharan Africa: 1983-2000. Report 28. Winand Staring Centre, Wageningen, The Netherlands. 585pp. 
Stoorvogel, J.J., E.M.A. Smaling \& B.H. Janssen. 1993. Calculating soil nutrient balances in Africa at different scales. I. Supra-national scale. Fertilizer Research 35:227-235.

Syers, J.K., A.E. Johnston \& D. Curtin. 2008. Efficiency of soil and fertilizer phosphorus use. Reconciling changing concepts of soil phosphorus behaviour with agronomic information. FAO. Rome. Fertilizer \& Plant Nutrition Bulletin 18. 123pp.

Syers, K., J. Johnston \& D. Curtin. 2010. A new perspective on the efficiency of phosphorus fertilizer use. $19^{\circ}$ World Congress of Soil Science. Soil Solutions for a Changing World. 3pp.

Tan, Z.X., R. Lal \& K.D. Wiebe. 2005. Global soil nutrient depletion and yield reduction. Journal of Sustainable Agriculture 26(1):123-146.

Tilman, D., K.G. Cassman, P.A. Matson, R. Naylor \& S. Polasky. 2002. Agricultural sustainability and intensive production practices. Nature 418:671-677.

van Beek, C.L., L. Brouwer \& O. Oenema. 2003. The use of farmgate balances and soil surface balances as estimator for nitrogen leaching to surface water. Nutrient Cycling in Agroecosystems 67:233-244.

Viglizzo, E.F., F. Lértora, A.J. Pordomingo, J.N. Bernardos, Z.E. Roberto \& H. del Valle. 2001. Ecological lessons and applications from one century of low external-input farming in the pampas of Argentina. Agriculture, Ecosystems \& Environment 83:65-81.

Viglizzo, E.F., A.J. Pordomingo, M.G. Castro, F.A. Lértora \& J.N. Bernardos. 2004. Scale-dependent controls on ecological functions in agroecosystems of Argentina. Agriculture, Ecosystems \& Environment 101:39-51.

Viglizzo, E.F., F. Frank, J. Bernardos, D.E. Buschiazzo \& S. Cabo. 2006. A rapid method for assessing the environmental performance of commercial farms in the pampas of Argentina. Environmental Monitoring \& Assessment 117:109-134.

Vitousek, M., R. Naylor, T. Crews, M.B. David, L.E. Drinkwater, E. Holland, P.J. Johnes, J. Katzenberger, L.A. Martinelli, P.A. Matson, G. Nziguheba, D. Ojima, C.A. Palm, G.P. Robertson, P.A. Sanchez, A.R. Townsend \& F.S. Zhang. 2009. Nutrient Imbalances in Agricultural Development. Science 324:1519-1520. 


\section{CAPÍTULO III}

Nutrientes en las actividades agropecuarias de la provincia

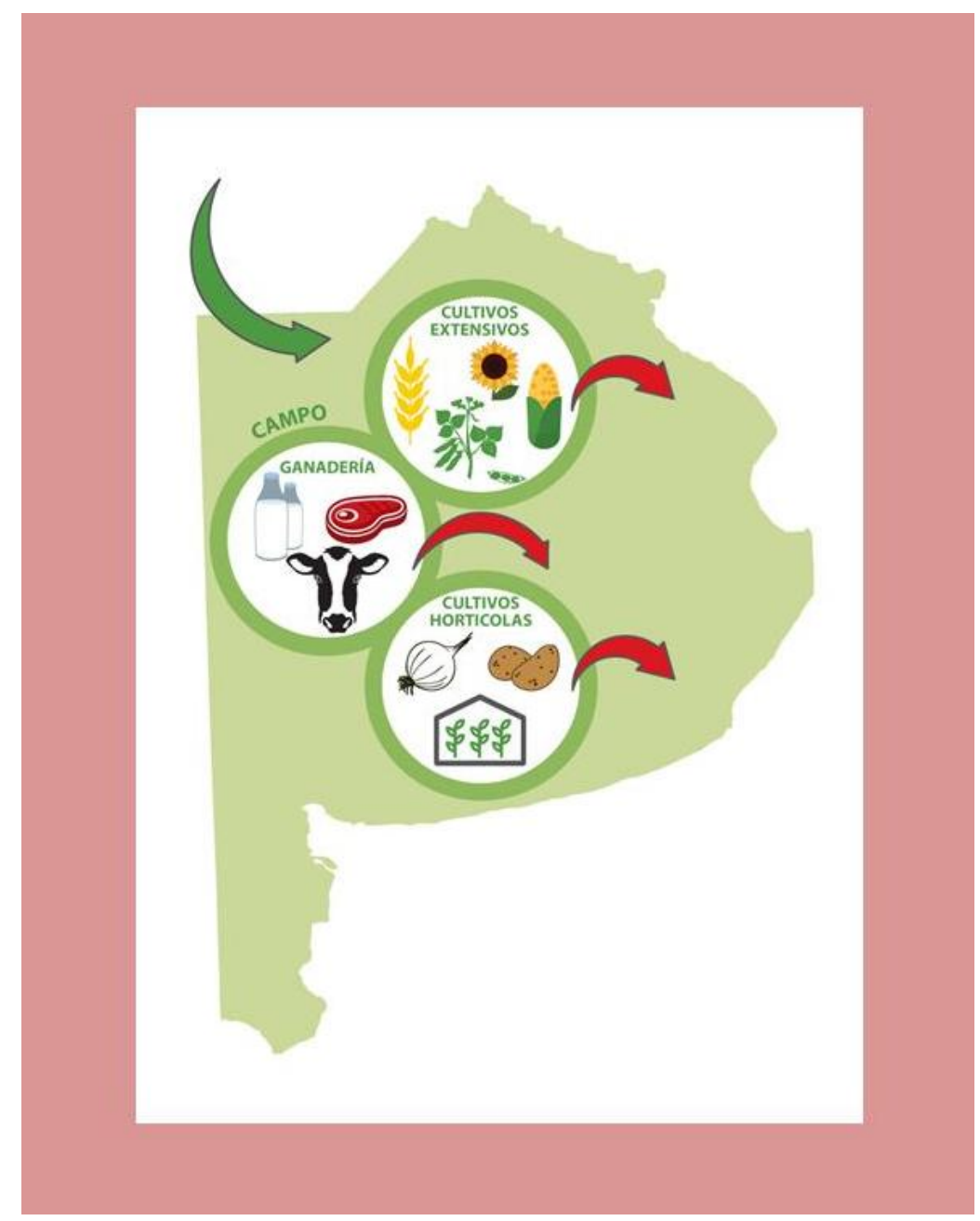


En el capítulo III se analizan los balances de nutrientes en las actividades agropecuarias de la provincia. Para esto, el capítulo se divide en cuatro subcapítulos. Los tres primeros, analizan los balances de nutrientes en cada actividad: I) cultivos extensivos, II) horticultura y III) producción de carne y leche bovinas, para finalizar en un cuarto subcapítulo que integra las tres producciones. 


\section{CAPÍTULO III}

\section{SUBCAPÍTULO 1}

Los cultivos extensivos y la conservación de los nutrientes del suelo

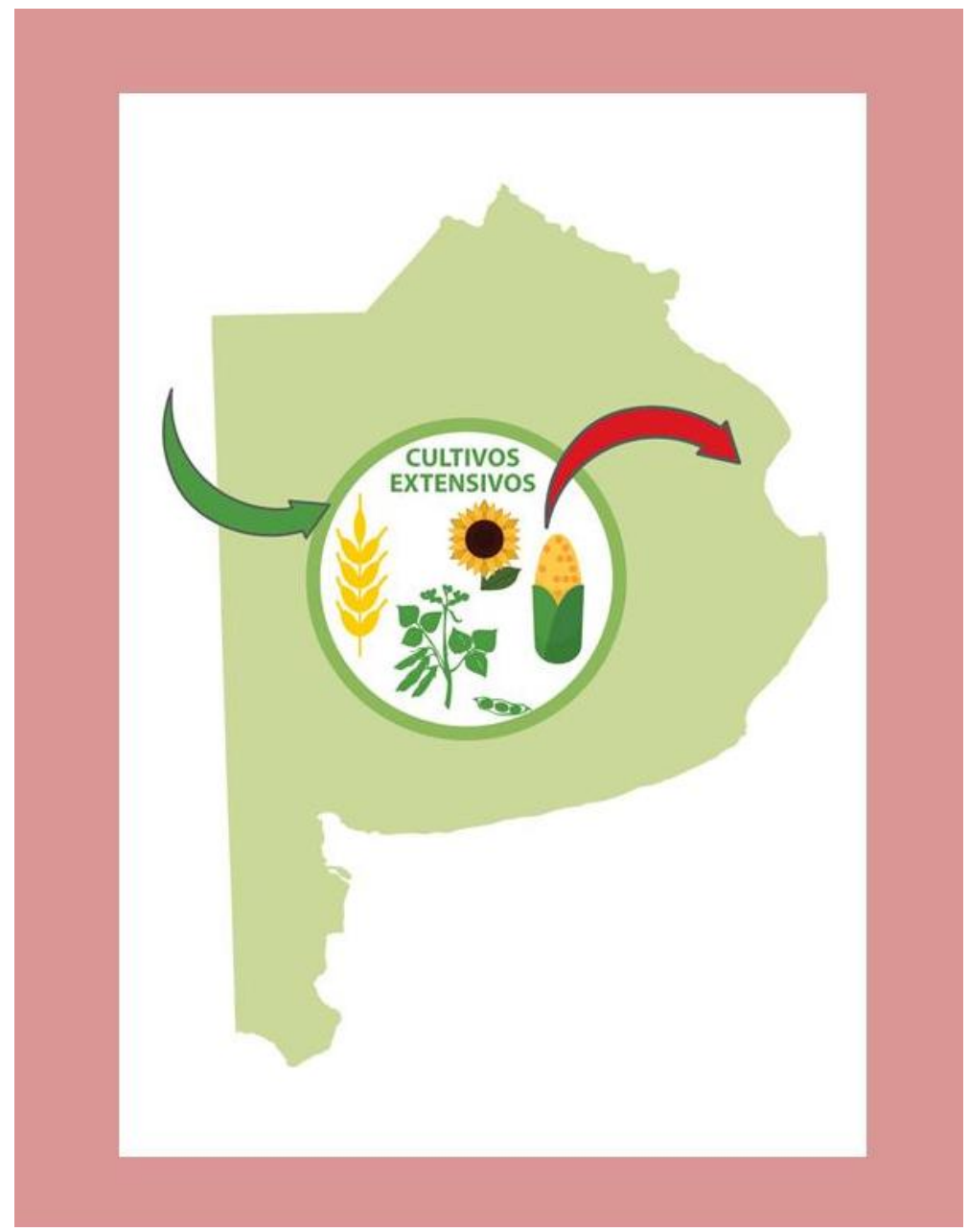




\section{III.1.1. Introducción}

La agricultura extensiva de la provincia de Buenos Aires ocupa el $34 \%$ del territorio y tiene como principales cultivos a los de soja (Glycine max (L.) Merr.), maíz (Zea mays L.), trigo (Triticum aestivum L.), cebada cervecera (Hordeum vulgare L. var. distichum), girasol (Helianthus annus L.) y, en menor medida, sorgo (Sorghum bicolor (L.) Moench). La producción agrícola de la provincia es relevante ya que aporta el 35\% de la producción de granos del país (MAA, 2007). En el norte y el oeste de la provincia predominan los cultivos de verano, mientras que en el sudoeste los de invierno (Figura 2.4). Hasta principios del siglo XXI, en el sudeste de la provincia predominaron los cultivos de invierno, situación que se fue revirtiendo por la irrupción de la soja.

Los suelos sobre los que se realiza la agricultura presentan una alta fertilidad (principalmente Molisoles), tanto por sus propiedades químicas y biológicas, como por sus características físicas: alto contenido original de materia orgánica, un $\mathrm{pH}$ levemente ácido, una textura superficial franca o franca arenosa y un material madre (loess) rico tanto en bases (calcio (Ca), magnesio (Mg) y, sobre todo, en potasio (K)), como en otros nutrientes (Berardo, 2004).

En Argentina, la actividad agrícola extensiva recibió la mayor atención en cuanto a la necesidad de conocer y evaluar la conservación de los nutrientes del suelo. En el país se estimaron diversos balances de nutrientes para la Región Pampeana (Viglizzo et al., 2001, 2002; Flores \& Sarandón, 2003; Cruzate \& Casas, 2003, 2012; García, 2006; García \& González Sanjuán, 2010), y para algunas de las provincias que la componen (Ghida Daza, 2013; Vicente \& Engler, 2008). Estos estudios encontraron que, desde los años 60 del siglo XX, las extracciones de nutrientes generadas en la agricultura por la cosecha, no han sido compensadas con las fertilizaciones. En Argentina, y principalmente en la Región Pampeana, la producción agrícola se ha realizado durante casi un siglo aprovechando la fertilidad natural de sus tierras (Berardo, 2004). Es decir, que la producción de los cultivos se ha estado subsidiando con la riqueza de los suelos (Stauffer \& Sulewski, 2003; Cruzate \& Casas, 2012).

La fertilización de los cultivos era inexistente antes de la década del 60 del siglo XX (Melgar \& Torres Duggan, 2005), y comenzó un lento proceso de intensificación durante la década del 70 con el período de agriculturización (Gudelj et al., 2006) (Tabla 3.1.1). Impulsada por una mayor presencia del INTA durante las décadas del 80 y 90, la fertilización se acrecienta y asume un papel más importante persiguiendo mayor productividad de los cultivos. Recién a comienzos del siglo XXI se introduce el concepto de reposición de nutrientes con el propósito de mantener o mejorar la fertilidad natural. A partir de entonces, la fertilización alcanza los mayores volúmenes 
de consumo, superando las 3 Mt (Cruzate \& Casas, 2012; González Sanjuán et al., 2013). Este aumento de la fertilización se debió, en parte, a que, producto de la intensificación de la agricultura de los años 80 y 90, comienzan a encontrarse respuestas al agregado de nutrientes como el azufre (S) que hasta entonces no eran deficitarios en los principales suelos agrícolas pampeanos (Melgar \& Torres Duggan, 2005).

Tabla 3.1.1. Consumo de fertilizantes en diferentes décadas del siglo XX y XXI por la agricultura de todo el país. Elaborado a partir de: Gudelj et al. (2006), Oliverio \& Segovia (2004) y González Sanjuán et al. (2013).

\begin{tabular}{rrr}
\hline Década & Año & Consumo fertilizante (t) \\
\hline Antes 1960 & $1948 / 49$ & 15.000 \\
Década 60 & $1960 / 61$ & 16.241 \\
Década 70 & $1970 / 71$ & 82.000 \\
Década 80 & $1980 / 81$ & 115.568 \\
Década 90 & $1990 / 91$ & 325.000 \\
Década 00 & $2000 / 01$ & 1.800 .000 \\
Década 10 & $2011 / 12$ & 3.721 .221 \\
\hline
\end{tabular}

Las primeras respuestas a la fertilización fueron encontradas para nitrógeno (N) en los años 70-80, más tarde para fósforo $(\mathrm{P})$ en los 80-90 y para $S$ en los 90 y comienzos del 2000 (Melgar \& Torres Duggan, 2005). En los últimos años, se han encontrado respuestas en otros nutrientes, entre ellos algunos micronutrientes como zinc (Zn), molibdeno (Mo), cobre (CU) y boro (B). Del consumo total de fertilizantes, el $90 \%$ tiene como destino los cultivos agrícolas extensivos (González Sanjuán et al., 2013).

A pesar del aumento de la fertilización, los estudios siguen mostrando la pérdida de nutrientes del suelo (García \& González Sanjuán, 2010). A causa de ello, Fontanetto \& Gambaudo (2010) y Darwich (2003) consideran que la actividad agrícola se ha desarrollado bajo un concepto de "extracción minera". Como consecuencia de esta disminución de la fertilidad de los suelos, Melgar (2011) señala que esto generará un impacto negativo en los rendimientos, que afectará la capacidad de devolver residuos (rastrojo) al suelo, afectando el contenido de carbono y, por lo tanto, de la materia orgánica. La materia orgánica tiene un rol relevante, tanto por su contenido de nutrientes (principalmente N, P y S potencialmente disponibles para las plantas), como por sus efectos sobre la disponibilidad de los micronutrientes boro (B), zinc (Zn), cobre ( $\mathrm{Cu}$ ), etc.), sobre las propiedades físicas y la actividad biológica del suelo (Berardo, 2004). La pérdida de nutrientes ha estado acompañada de la disminución de la materia orgánica (Cruzate \& Casas, 2012; Fontanetto \& Gambaudo, 2010) para proveer los nutrientes necesarios para los cultivos. La pérdida de un contenido de $1 \%$ de materia orgánica en un suelo representativo de la Región Pampeana implica la 
pérdida de $1.100-1.200 \mathrm{~kg} \mathrm{ha}^{-1}$ de $\mathrm{N}, 100-110 \mathrm{~kg} \mathrm{ha}^{-1}$ de $\mathrm{P}$ y $80-90 \mathrm{~kg} \mathrm{ha}^{-1}$ de S (Berardo, 2004; Darwich, 2003; Fontanetto \& Gambaudo, 2010).

Flores \& Sarandón (2003) atribuyen este deterioro de los suelos al criterio de fertilización basado en la dosis respuesta. Este criterio con énfasis en la retribución económica en el corto plazo, considera fertilizar los cultivos en función de la probable respuesta económica (por aumento del rendimiento) al agregado de fertilizantes y no para reponer los nutrientes con el fin de mantener la calidad del suelo. Por ejemplo, la evaluación de la fertilidad fosfatada de los suelos en Argentina se basa en el análisis en pre-siembra, que determina en muchos sitios mediante el método de $\mathrm{P}$ extractable de Bray \& Kurtz (1945) a una profundidad 0-20 cm. Esta metodología ha sido probada y recomendada para muchos cultivos. Las calibraciones sugieren niveles críticos por debajo de los cuales la probabilidad de respuesta es alta: rangos de 15-20, 9-14, 10-15 y $13-18 \mathrm{mg} \mathrm{kg}^{-1}$ de $\mathrm{P}$ son utilizados para trigo, soja, girasol y maíz, respectivamente (García, 2011). Es decir, si un suelo tiene alta disponibilidad recibirá baja o ninguna fertilización y terminará subsidiando la producción con la consecuente pérdida de nutrientes.

Para hacer visible esta pérdida de nutrientes es que se comenzó a asignar costo económico a esta degradación ambiental llamada "costo oculto" (Flores \& Sarandón, 2003; Manchado, 2010; Zazo et al., 2011; Cordone \& Trossero, 2012; Cruzate \& Casas, 2012; Cabrini et al., 2013; Manchado et al., 2013). Esta valoración económica de la pérdida de nutrientes se utiliza tanto para que el productor tome conciencia del problema, como para criticar al sistema actual de cuentas nacionales que definen la actividad productiva sin considerar los efectos indirectos de dicha actividad. De este modo, se intenta mostrar que los recursos naturales no son un bien gratuito (Cordone \& Trossero, 2012). Este costo oculto se visualiza como un porcentaje del margen bruto de los cultivos que debería contribuir con la conservación del capital natural.

Dentro de la provincia de Buenos Aires se han desarrollado trabajos que calculan el balance de nutrientes a nivel de partido, región y cultivos (Forján et al., 2002; Manchado, 2010; Forján et al., 2011; Manchado et al., 2013; Ferraris et al., 2015), los cuales encontraron tendencias similares que a nivel de la Región Pampeana. Ello marca la necesidad de generar un estudio sobre la reposición de nutrientes a nivel provincial que permita contar con mejor información para que los decisores políticos cuenten con mejores herramientas para la generación de políticas que favorezcan un desarrollo sostenible.

El objetivo del presente subcapítulo es conocer el balance de nutrientes de los cultivos extensivos de la provincia de Buenos Aires. Se plantea como hipótesis que el 
balance de nutrientes por unidad de superficie de los cultivos extensivos, presenta valores absolutos similares entre los partidos de la provincia de Buenos Aires.

\section{III.1.2. METODOLOGÍA}

\section{III.1.2.1. Cultivos empleados}

Se seleccionaron aquellos cultivos extensivos cuya superficie sembrada en la provincia superara las 10.000 ha para la campaña 2005-2006 (cultivos de invierno 2005 y verano 2006). Se empleó como fuente el Sistema Integrado de Informaciones Agropecuarias (SIIA, 2016). Los cultivos seleccionados fueron: soja, trigo, cebada cervecera, maíz, sorgo y girasol. La avena (Avena sativa L.) se consideró entre las especies relacionadas a la ganadería, ya que el principal destino es la alimentación del ganado.

Para el sorgo la superficie de cultivo agrícola y ganadero se calculó a partir de la proporción de sorgo agrícola y ganadero (granífero + forrajero) del CNA (2002). Esa proporción se utilizó para calcular la superficie de sorgo granífero sembrada, a partir de los datos del SIIA (2016) para la campaña 2005-2006.

\section{III.1.2.2. Balance de nutrientes}

Para cada partido de la provincia de Buenos Aires (134, Lezama se incluyó en Chascomús) se realizó un balance anual de nutrientes (N, P, K, Ca, S) de cada cultivo y total. En las entradas se consideraron la fertilización mineral y la fijación biológica por los cultivos leguminosos, mientras que en las salidas se tuvieron en cuenta los nutrientes extraídos por la cosecha. Se consideró que el rastrojo permaneció en los campos.

El balance anual por unidad de superficie $\left(b a l_{i j}^{k}\right)$ se calculó de la siguiente manera:

$$
b a l_{i j}^{k}=f_{i j}^{k}-e_{i j}^{k}
$$

donde $f_{i j}^{k}$ es la fertilización anual por unidad de superficie y $e_{i j}^{k}$ la extracción anual por unidad de superficie, del nutriente i (N, P, K, Ca, S), para el cultivo j (soja, maíz, sorgo, girasol, trigo, cebada cervecera) correspondiente al partido k. Para el cultivo de soja, además de la fertilización, se asumió una entrada de $\mathrm{N}$ por fijación biológica correspondiente al 50\% del valor de la extracción (Flores \& Sarandón, 2003; Austin et al., 2006; Cruzate \& Casas, 2010, 2012). 
El balance total anual por nutriente para cada partido $\left(B a l_{i_{T O T}}^{k}\right)$ se calculó mediante:

$$
B a l_{i_{T O T}}^{k}=\sum_{j} b a l_{i j}^{k} \cdot s_{j}^{k}
$$

donde $s_{j}^{k}$ es la superficie del cultivo $j$ en el partido $k$.

\section{III.1.2.2.1. Entradas de nutrientes}

Los datos de fertilización se calcularon para cada partido en función de los datos de la ex-Secretaría de Agricultura, Ganadería y Pesca de la Nación (ex-SAGPyA Com. Pers.) para los cultivos extensivos en la campaña 2005-2006. En el caso de que no hubiera información sobre la fertilización de algún cultivo para un partido se utilizó el promedio provincial calculado a partir de los datos de la ex-SAGPyA.

\section{II. 1.2.2.2. Salidas de nutrientes}

El rendimiento de los cultivos de cada partido se obtuvo a partir de la información del SIIA (2016) para los cultivos seleccionados y la campaña 2005-2006. En función del contenido de nutrientes de los granos (Tabla 3.1.2) se calcularon los nutrientes extraídos por unidad de superficie.

$$
e_{i j}^{k}=q_{i j} \cdot r_{j}^{k},
$$

donde $e_{i j}^{k}$ : extracción anual por unidad de superficie del nutriente $i$, del cultivo j, para el partido $k\left(\mathrm{~kg} \mathrm{ha}^{-1}\right), q_{i j}$ : contenido del nutriente $i$ en el cultivo $j\left(\mathrm{~kg} \mathrm{t}^{-1}\right)$ y $r_{j}^{k}$ : rendimiento del cultivo j, para el partido $k\left(t \mathrm{ha}^{-1}\right)$.

La extracción total anual de nutrientes en cada partido $\left(\operatorname{Ext}_{i_{T O T}}^{k}\right)$ se obtuvo de:

$$
E x t_{i_{\text {TOT }}}^{k}=\sum_{j} e_{i j}^{k} \cdot s_{j}^{k}
$$

donde $e_{i j}^{k}$ : extracción anual del nutriente i por unidad de superficie $\left(\dagger \mathrm{ha}^{-1}\right)$, del cultivo j correspondiente al partido $k, y s_{j}^{k}$ : superficie del cultivo $j$, en el partido $k$ (ha). 
Tabla 3.1.2. Contenido de nutrientes de los órganos cosechados en diferentes cultivos extensivos.

\begin{tabular}{|c|c|c|c|}
\hline Cultivo & Nutriente & $\begin{array}{c}\text { Contenido } \\
\left(\mathrm{kg} \mathrm{t}^{-1}\right)\end{array}$ & Fuentes ${ }^{* 1}$ \\
\hline \multicolumn{4}{|l|}{ Cereales } \\
\hline \multirow{5}{*}{$\begin{array}{l}\text { Cebada } \\
\text { Cervecera }\end{array}$} & $\mathrm{N}$ & 17,90 & \multirow{5}{*}{$\begin{array}{l}\text { Argenfoods (2010); Ciampitti \& } \\
\text { García (2007) }\end{array}$} \\
\hline & $\mathrm{P}$ & 2,00 & \\
\hline & K & 1,38 & \\
\hline & $\mathrm{Ca}$ & 0,15 & \\
\hline & $S$ & 2,00 & \\
\hline \multirow{5}{*}{ Maíz } & $\mathrm{N}$ & 14,90 & \multirow{5}{*}{$\begin{array}{l}\text { Flores \& Sarandón(2003); } \\
\text { Berardo (2004) }\end{array}$} \\
\hline & $P$ & 2,50 & \\
\hline & K & 5,00 & \\
\hline & $\mathrm{Ca}$ & 0,50 & \\
\hline & $S$ & 1,00 & \\
\hline \multirow{5}{*}{ Sorgo } & $\mathrm{N}$ & 19,00 & \multirow{5}{*}{$\begin{array}{l}\text { Veneciano \& Frigerio (2003); } \\
\text { Ciampitti \& García (2007) }\end{array}$} \\
\hline & $P$ & 4,00 & \\
\hline & $\mathrm{K}$ & 4,00 & \\
\hline & $\mathrm{Ca}$ & 0,15 & \\
\hline & $S$ & 2,00 & \\
\hline \multirow{5}{*}{ Trigo } & $\mathrm{N}$ & 21,00 & \multirow[t]{5}{*}{ Berardo (2004) } \\
\hline & $\mathrm{P}$ & 3,50 & \\
\hline & K & 5,00 & \\
\hline & $\mathrm{Ca}$ & 0,70 & \\
\hline & S & 1,20 & \\
\hline \multicolumn{4}{|l|}{ Oleaginosas } \\
\hline \multirow{5}{*}{ Soja } & $\mathrm{N}^{* 2}$ & 55,00 & \multirow{5}{*}{$\begin{array}{l}\text { Argenfoods (2010); Berardo } \\
\text { (2004); Flores \& Sarandón } \\
\text { (2003) }\end{array}$} \\
\hline & $P$ & 4,98 & \\
\hline & K & 20,00 & \\
\hline & $\mathrm{Ca}$ & 1,75 & \\
\hline & S & 3,00 & \\
\hline \multirow{5}{*}{ Girasol } & $\mathrm{N}$ & 25,00 & \multirow[t]{5}{*}{ Berardo (2004) } \\
\hline & $\mathrm{P}$ & 4,50 & \\
\hline & $K$ & 1,00 & \\
\hline & $\mathrm{Ca}$ & 2,50 & \\
\hline & $S$ & 2,00 & \\
\hline
\end{tabular}

\footnotetext{
${ }^{*}$ Algunas fuentes brindan información de contenido de nutrientes sobre sustancia seca y otras sobre fresca. En el primer caso se realizó la correspondiente conversión del rendimiento (fresco) a base seca.

*2 Corresponde a extracción total, se asumió que un 50\% lo aporta la fijación biológica y lo restante el suelo.
}

\section{III.1.2.3. Reposición de nutrientes}

Se calculó la reposición (\%) de cada nutriente para cada cultivo, partido y a nivel provincial, mediante la relación entre la fertilización y la extracción correspondiente, multiplicado por 100. 


\section{III.1.3. RESULTADOS}

\section{III.1.3.1. Extracción de nutrientes}

1II.1.3.1.1. Extracción por unidad de superficie y su distribución espacial

Se encontró que la mayor extracción anual por unidad de superficie fue de $\mathrm{N}$ $\left(102,6 \mathrm{~kg} \mathrm{ha}^{-1}\right)$ siendo 3,$3 ; 7,0 ; 15,2 ; 23,5$ veces superior a K, P, S y Ca, respectivamente (Figura 3.1.1).

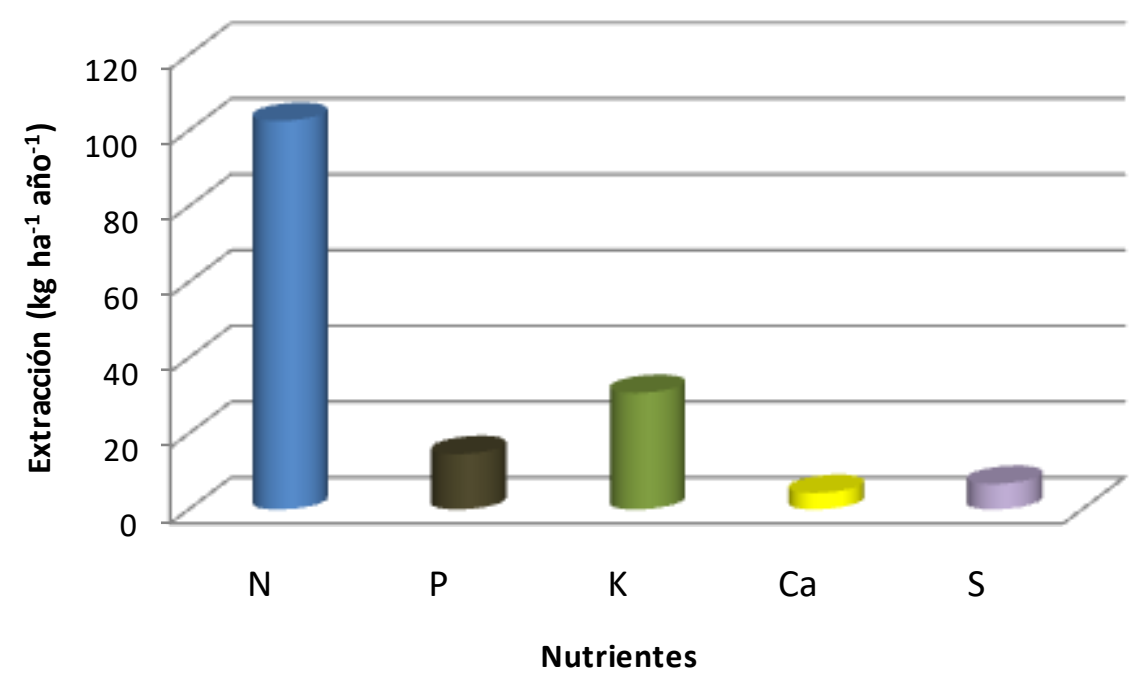

Figura 3.1.1. Extracción promedio (ponderado por la superficie), correspondiente a cultivos extensivos de la provincia de Buenos Aires (período 2005-2006).

Los cultivos que registraron mayor extracción de nutrientes por unidad de superficie fueron la soja seguido del maíz y el sorgo y, en menor medida, el trigo, la cebada cervecera y el girasol (Figura 3.1.2). La mayor extracción de N, K y Ca fue debida a la soja, mientras que la mayor extracción de $\mathrm{S}$ se debió al sorgo. En soja, el $\mathrm{N}$ correspondió a extracción total, es decir que incluyó el $\mathrm{N}$ extraído proveniente tanto de fijación biológica como del suelo. 


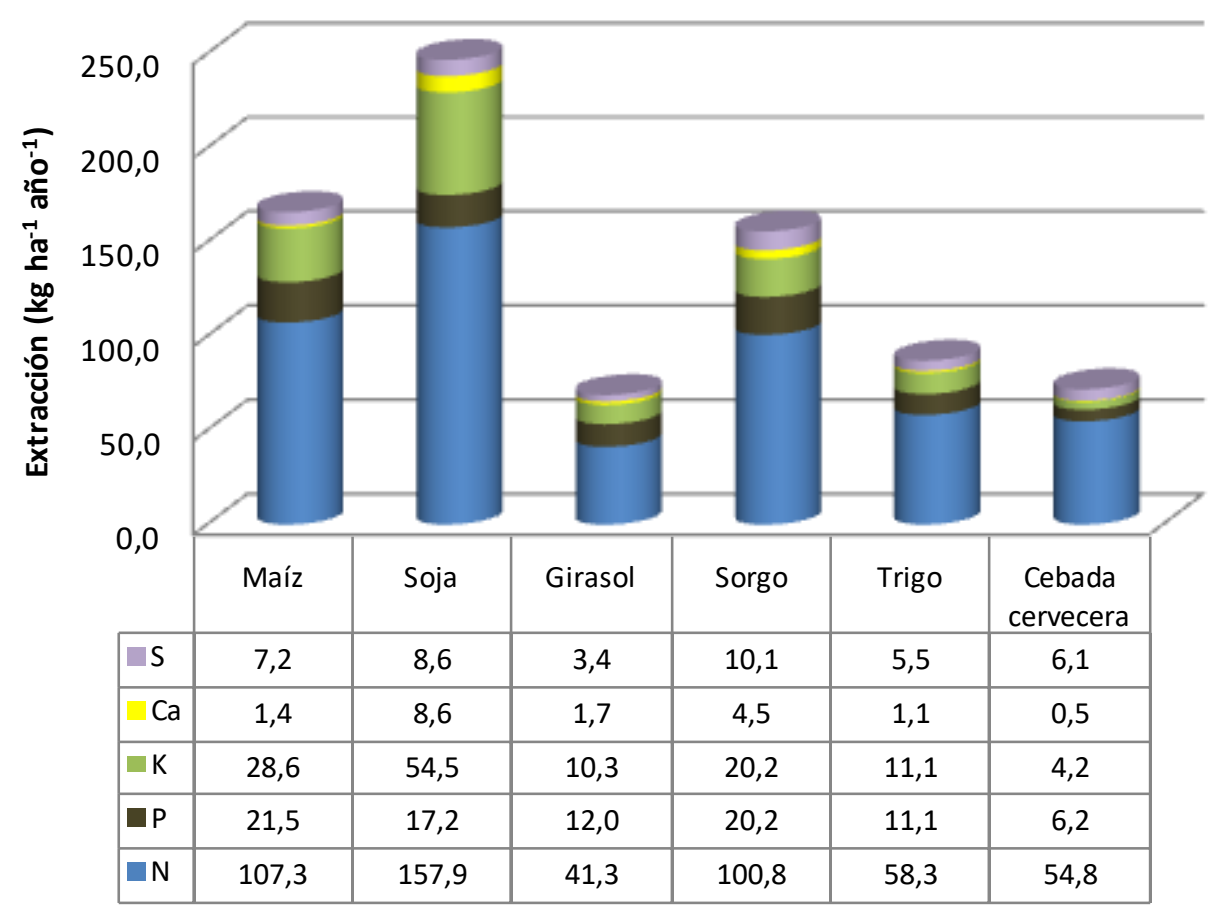

Cultivos

Figura 3.1.2. Extracción de nutrientes por unidad de superficie, por cultivos extensivos de la provincia de Buenos Aires (período 2005-2006).

La extracción de nutrientes por hectárea en los diferentes partidos de la provincia de Buenos Aires mostró un incremento desde el sudoeste hacia el sudeste y la Pampa Deprimida, luego hacia la región central para finalizar con los mayores valores en la norte y noroeste (Figura 3.1.3. a, b, c, d, e). En todos los nutrientes la tendencia en el incremento de la extracción fue similar. 


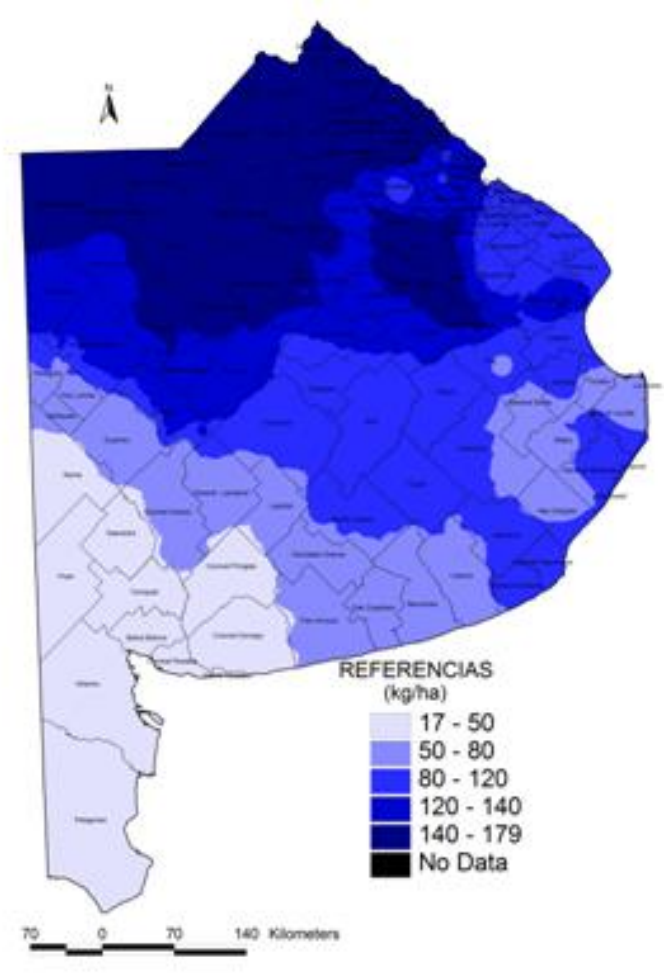

a)

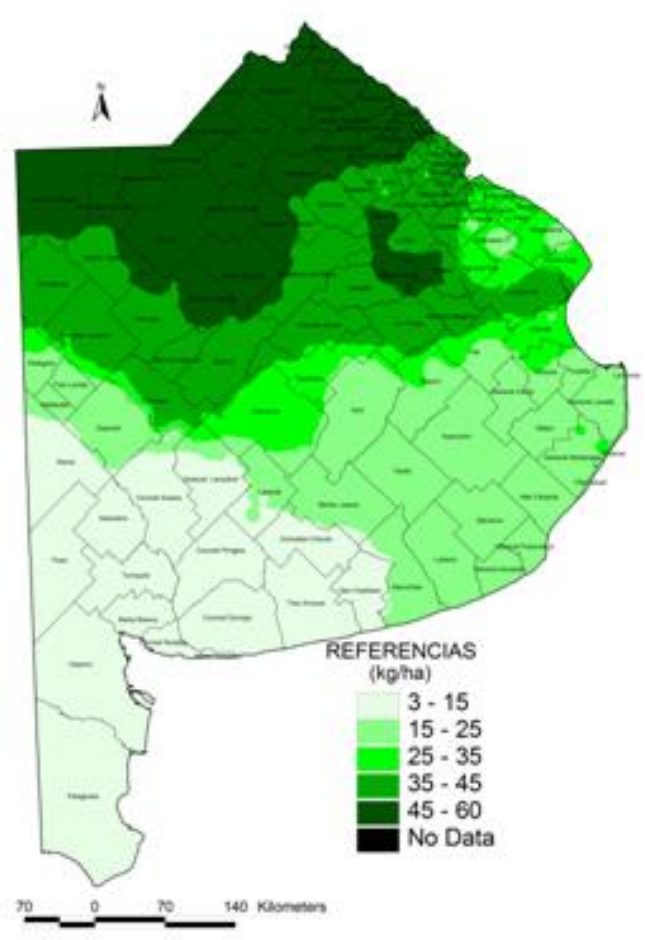

c)

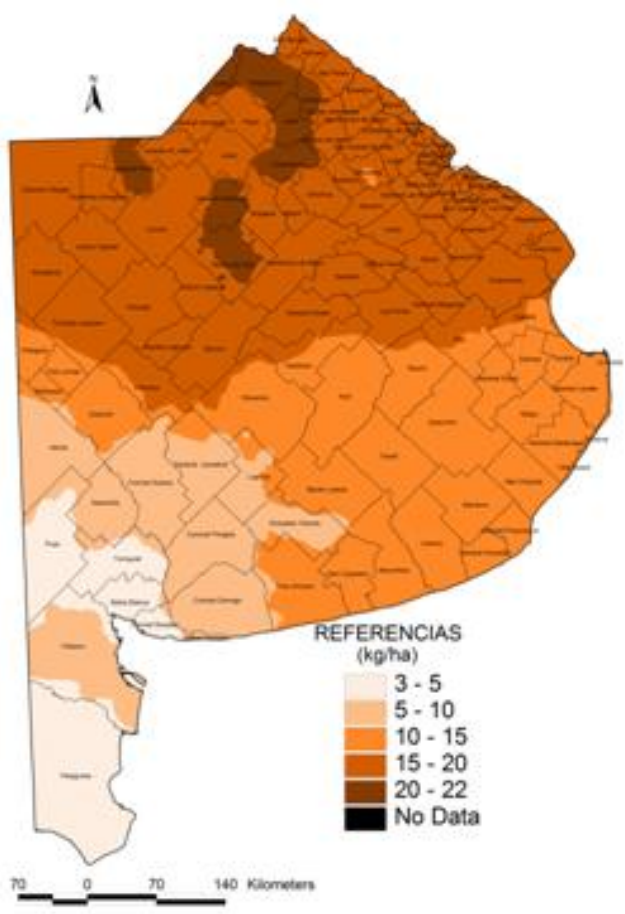

b)

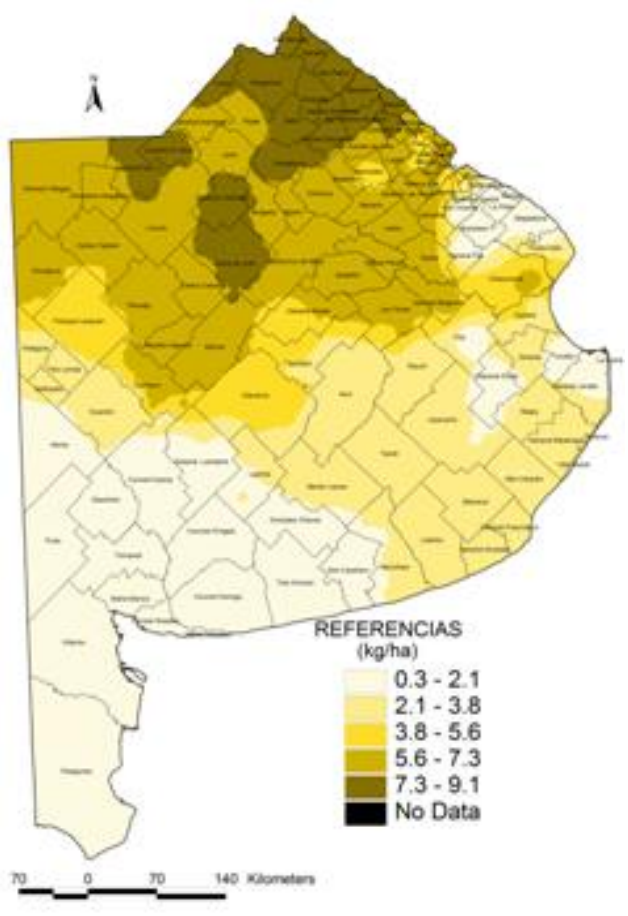

d) 


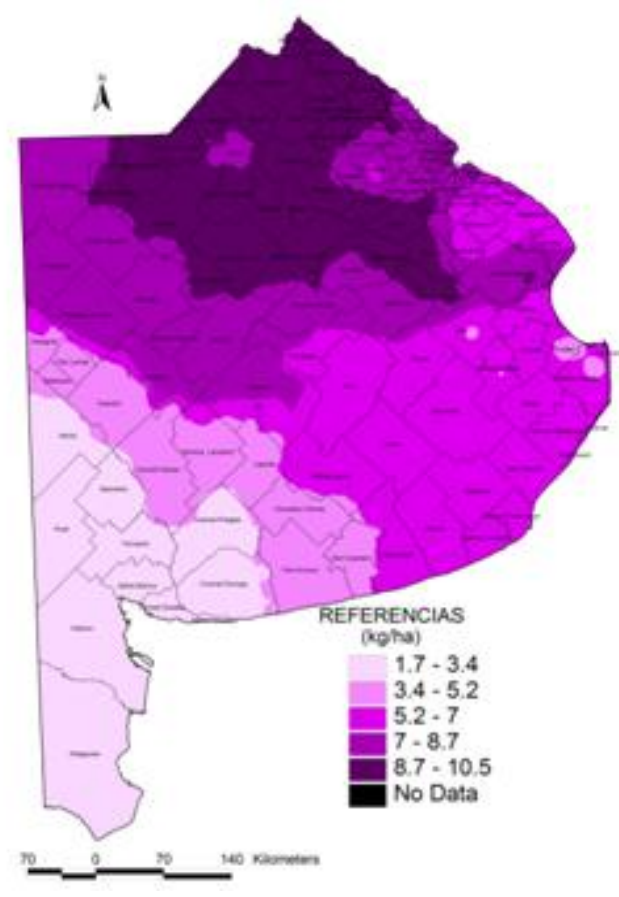

e)

Figura 3.1.3. Extracción anual de nutrientes por unidad de superficie: a) N, b) $P$, c) $K$, d) Ca y e) $S$, debido a cultivos extensivos en la provincia de Buenos Aires (período 2005-2006).

\section{II.1.3.1.2. Extracción total y su distribución espacial}

La extracción total anual de nutrientes debida a cultivos extensivos en la provincia de Buenos Aires fue de 1.399 .631 t, siendo el 64,5\% debido a N. La mayor extracción total anual de nutrientes de los cultivos extensivos se debió a la soja $(65,5 \%)$, seguido del trigo (18\%) y del maíz (9.8\%) (Figura 3.1.4.). La soja fue el cultivo más extractivo por unidad de superficie, y también el de mayor superficie cultivada (42\%). 


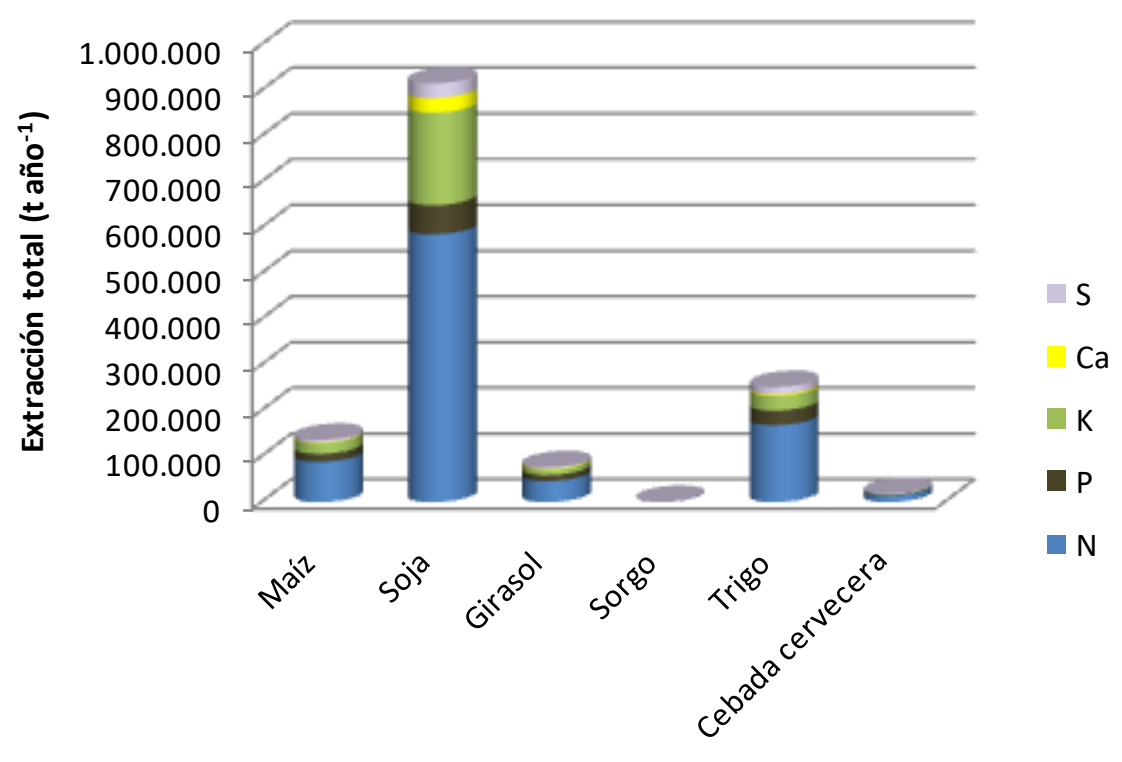

Cultivos

Figura 3.1.4. Extracción total de nutrientes por cultivos extensivos en la provincia de Buenos Aires (período 2005-2006).

En la provincia, la mayor extracción total de nutrientes se registró en el centro norte, noroeste y sudeste (Figura 3.1.5. a, b, c, d, e), correspondiendo con la presencia de partidos de mayor superficie agrícola. La zona de la Pampa Deprimida y el sudoeste presentaron la menor extracción total de nutrientes, dada la menor incidencia en superficie de los cultivos extensivos. De todos los partidos de la provincia se destacó el partido de Pergamino (norte) por presentar la mayor extracción de todos los nutrientes, sumándose el partido de Tres Arroyos (sudeste) en N, P y Ca. 


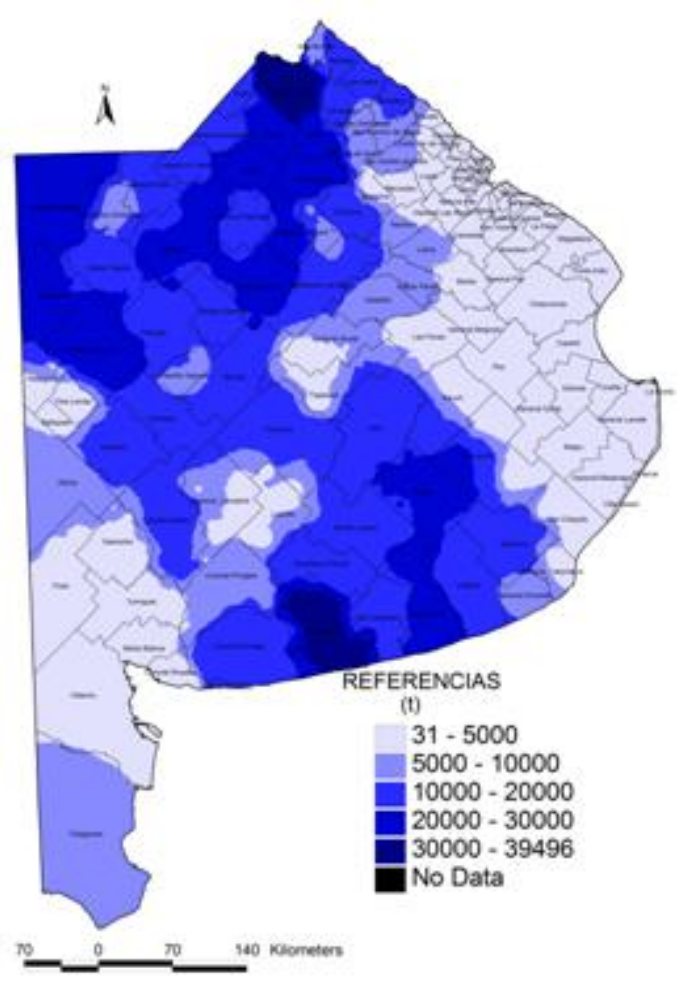

a)

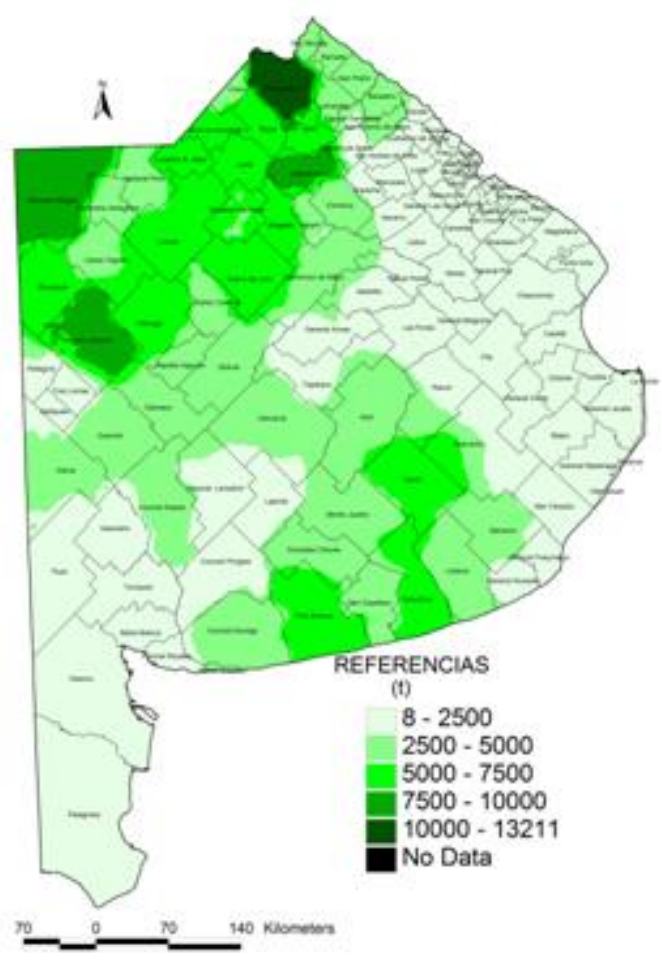

c)

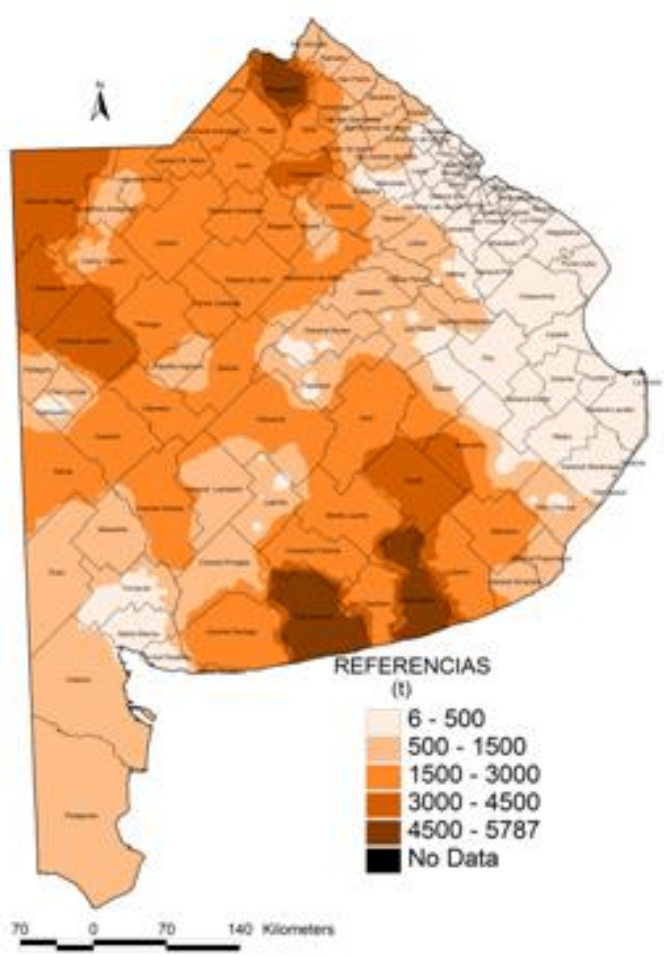

b)

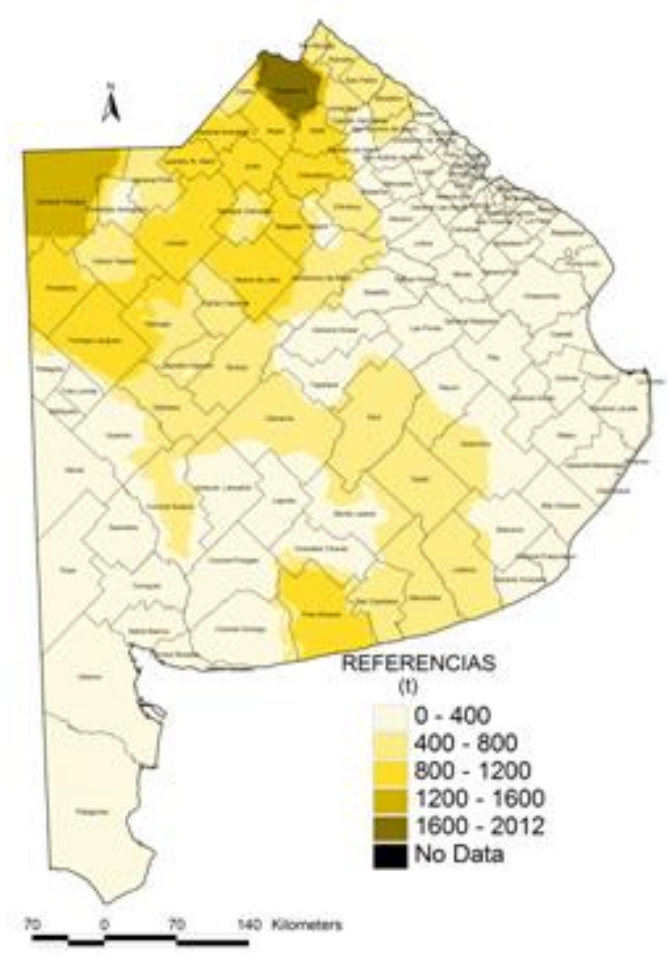

d) 


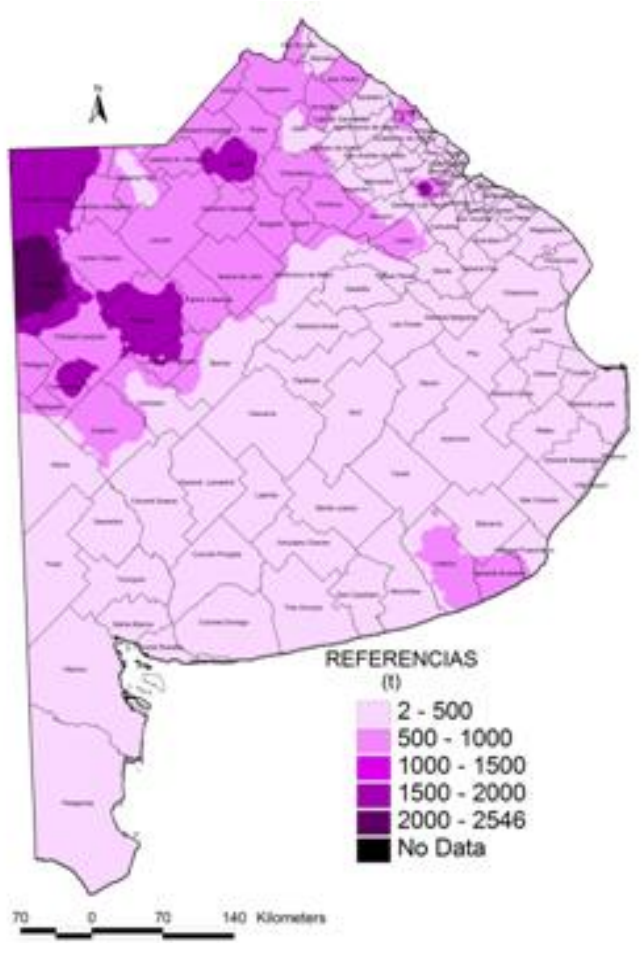

e)

Figura 3.1.5. Extracción total anual de nutrientes: a) $N$, b) $P$, c) $K$, d) Ca y e) $S$, correspondiente a cultivos extensivos en la provincia de Buenos Aires (período 2005-2006).

\section{III.1.3.2. Balance de nutrientes}

\section{III.1.3.2.1. Balance por unidad de superficie y su distribución espacial}

El ingreso de nutrientes promedio (ponderado por la superficie), considerando la fertilización y fijación biológica, fue mayor en $\mathrm{N}$ seguido de $\mathrm{P}$ y, en menor medida, Ca y S (Tabla 3.1.3). El cultivo de soja tuvo la mayor entrada de nutrientes $\left(90,3 \mathrm{~kg} \mathrm{ha}^{-1}\right.$ año-1), seguido del maíz $\left(68,4 \mathrm{~kg} \mathrm{ha}^{-1}\right.$ año-1), y por el trigo y la cebada cervecera (ambos con 60,8 $\mathrm{kg} \mathrm{ha}^{-1} \mathrm{año}^{-1}$ ). El sorgo y el girasol fueron los cultivos que registraron la menor entrada de nutrientes (15,9 y $15,3 \mathrm{~kg} \mathrm{ha}^{-1} \mathrm{año}^{-1}$, respectivamente).

Tabla 3.1.3. Entradas promedio de nutrientes por fertilización y fijación biológica, para diferentes cultivos de la provincia de Buenos Aires (período 2005-2006).

\begin{tabular}{lccccc}
\hline & \multicolumn{6}{c}{ Nutrientes (kg ha-1 $\left.\mathbf{a n ̃ o}^{-1}\right)$} \\
\cline { 2 - 6 } Cultivos & $\mathbf{N}$ & $\mathbf{P}$ & $\mathbf{K}$ & $\mathbf{C a}$ & $\mathbf{S}$ \\
\hline Maíz & 53,70 & 14,10 & 0,00 & 0,00 & 0,69 \\
Soja & 81,40 & 6,00 & 0,00 & 1,72 & 1,29 \\
Sorgo & 9,30 & 6,60 & 0,00 & 0,00 & 0,00 \\
Trigo & 47,30 & 13,30 & 0,00 & 0,02 & 0,24 \\
Girasol & 9,50 & 5,70 & 0,00 & 0,01 & 0,002 \\
Cebada cervecera & 47,30 & 13,30 & 0,00 & 0,02 & 0,24 \\
\hline Promedio & $\mathbf{5 7 , 5 0}$ & $\mathbf{9 , 3 0}$ & $\mathbf{0 , 0 0}$ & $\mathbf{0 , 7 3}$ & $\mathbf{0 , 6 9}$ \\
ponderado & & & &
\end{tabular}


Los balances de nutrientes promedio por unidad de superficie fueron todos negativos, con valores de $-45,2 ;-5,3 ;-30,8 ;-3,6 ;-6,0 \mathrm{~kg} \mathrm{ha}^{-1}$ año-1 para N, P, K, Ca y S, respectivamente. A excepción del balance positivo de $P$ en los cultivos de trigo y cebada cervecera, el resto de los cultivos y nutrientes presentaron balances negativos (Tabla 3.1.4).

Tabla 3.1.4. Balance de nutrientes por unidad de superficie, en cultivos extensivos de la provincia de Buenos Aires (período 2005-2006).

\begin{tabular}{|c|c|c|c|c|c|}
\hline & \multicolumn{5}{|c|}{ Balance de nutrientes $\left(\mathrm{kg} \mathrm{ha}^{-1}\right.$ año-1) } \\
\hline & $\mathbf{N}$ & $\mathbf{P}$ & $\mathrm{K}$ & $\mathrm{Ca}$ & 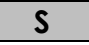 \\
\hline Maíz & $-53,6$ & $-7,4$ & $-28,6$ & $-1,4$ & $-6,5$ \\
\hline Soja & $-76,5$ & $-11,3$ & $-54,5$ & $-6,9$ & $-7,3$ \\
\hline Girasol & $-31,8$ & $-6,3$ & $-10,3$ & $-1,7$ & $-3,4$ \\
\hline Sorgo & $-91,5$ & $-13,6$ & $-20,2$ & $-4,5$ & $-10,1$ \\
\hline Trigo & $-11,0$ & 2,2 & $-11,1$ & $-1,1$ & $-5,3$ \\
\hline Cebada cervecera & $-7,6$ & 7,0 & $-4,2$ & $-0,4$ & $-5,9$ \\
\hline
\end{tabular}

El mayor déficit por unidad de superficie en N, P y S, fue causado por sorgo seguido de soja, mientras que, para $\mathrm{K}$ y $\mathrm{Ca}$, el cultivo de soja fue el responsable de los balances más negativos.

Para N, K, Ca y S se encontraron balances negativos en toda la provincia (Figura 3.1.6. a, c, d, e). En todos los nutrientes se observó que, desde el centro de la provincia hacia el norte, predominaron los balances más negativos. Es decir, se registraron las mayores pérdidas de nutrientes. Esto se debió a que en el norte predominaron los cultivos de verano, principalmente, la soja. Hacia el sur los déficits disminuyeron siendo menores en el suroeste. Sólo los partidos de Lobería, San Cayetano, González Chaves, Tornquist, Puan y Coronel Dorrego registraron balance positivo de $\mathrm{P}$, mientras que para el resto de los partidos, fue negativo. A causa de una fertilización muy baja con K, Ca y S los mapas de extracción y balance por hectárea fueron similares, mientras que, para $\mathrm{N}$ y $\mathrm{P}$, presentaron una mayor variación según el manejo de la fertilización de los cultivos. 


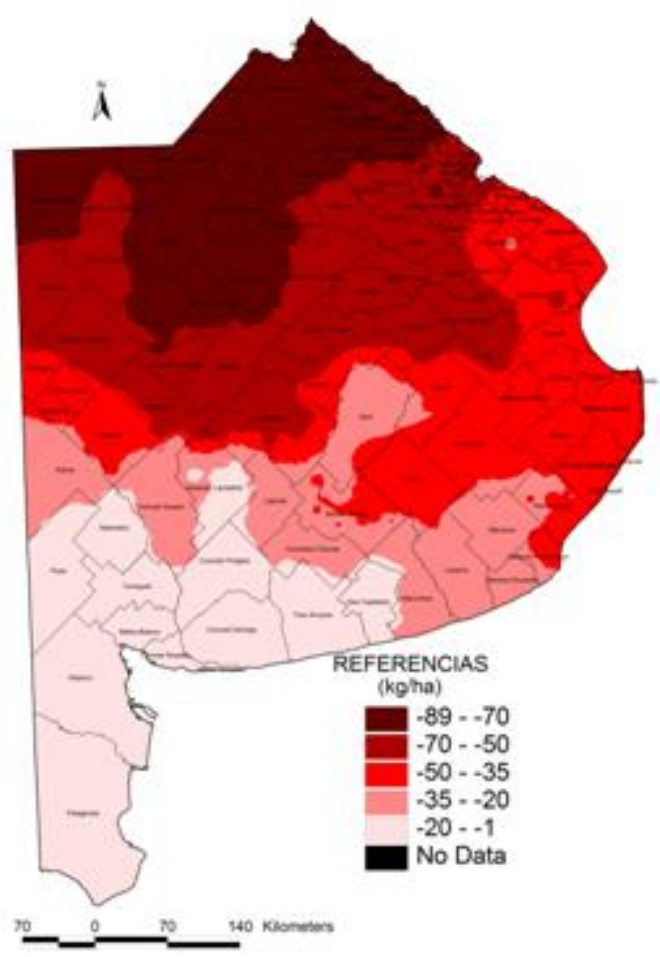

a)

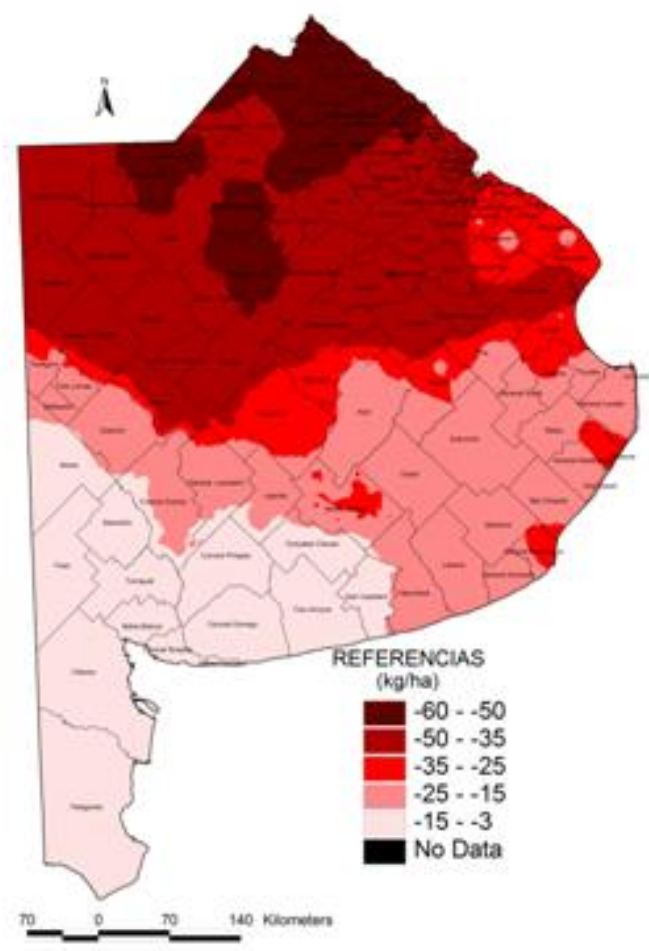

c)

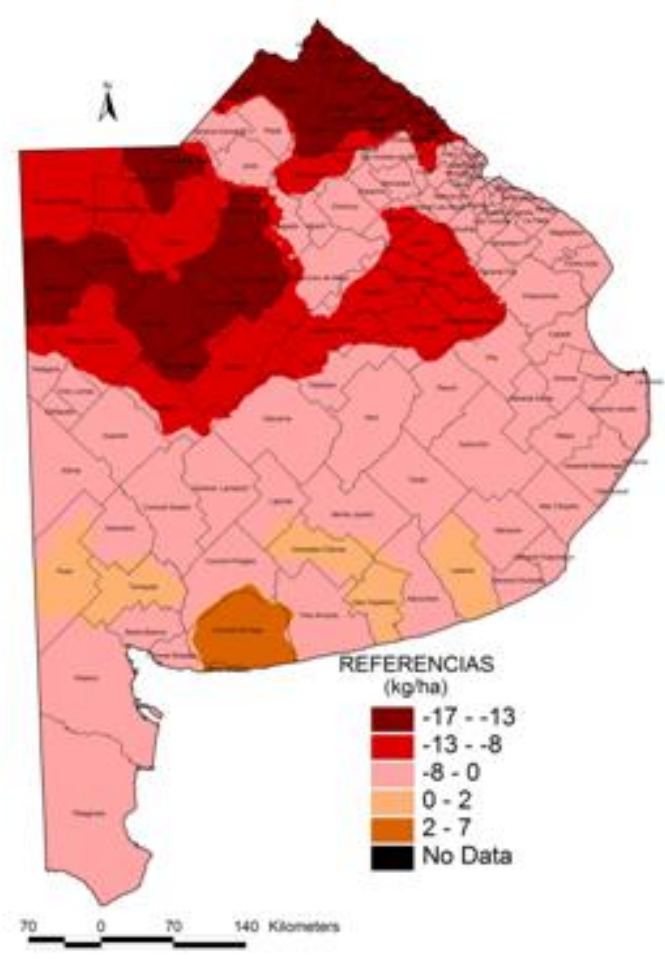

b)

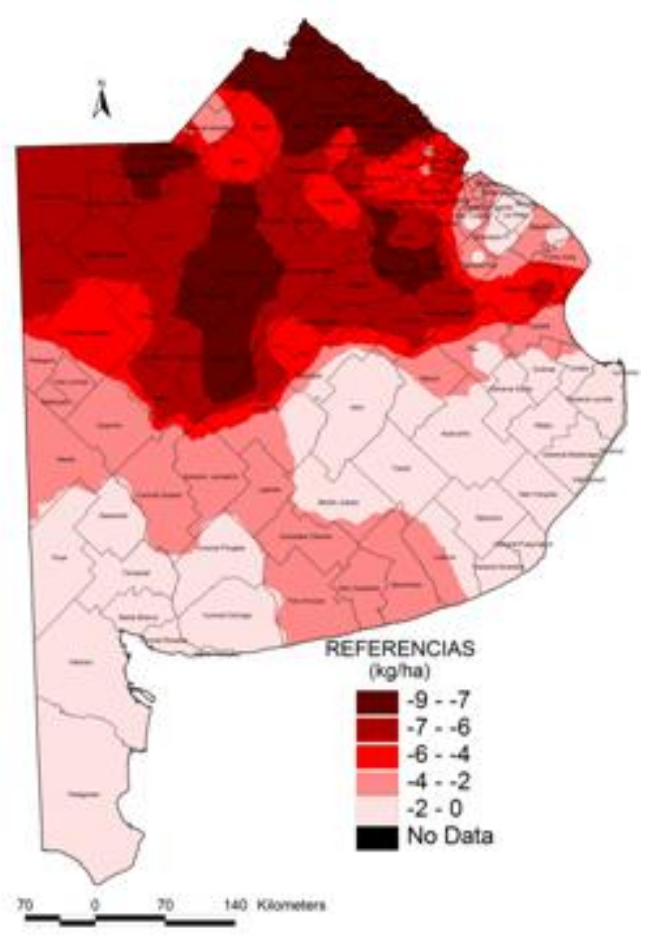

d) 


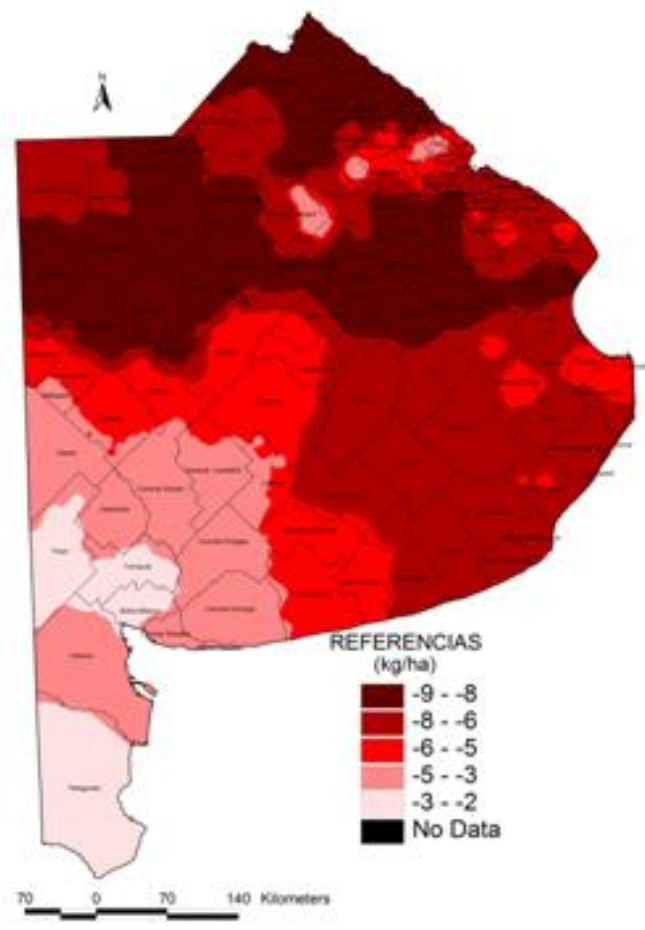

e)

Figura 3.1.6. Balance anual de nutrientes por unidad de superficie: a) N, b) $P$, c) $K$, d) Ca y e) $S$, correspondiente a cultivos extensivos en la provincia de Buenos Aires (período 2005-06).

\section{1.3.2.2. Balance total y su distribución espacial}

La pérdida total de nutrientes por cultivos extensivos en la provincia de Buenos Aires fue de 799.611 t, de las cuales el 49,7 \% fue por $\mathrm{N}$ y el 33,8\%, debido al K. La soja, por tener la mayor área cultivada y con mayores balances negativos por unidad de superficie (Tabla 3.1.4), fue la principal responsable de la pérdida de nutrientes $(72,6 \%)$ (Figura 3.1.7.), seguido de maíz, trigo y girasol (10,0; 9,5; y 7,4\% respectivamente). Sólo se registró una ganancia de $\mathrm{P}$ en trigo y cebada cervecera. 


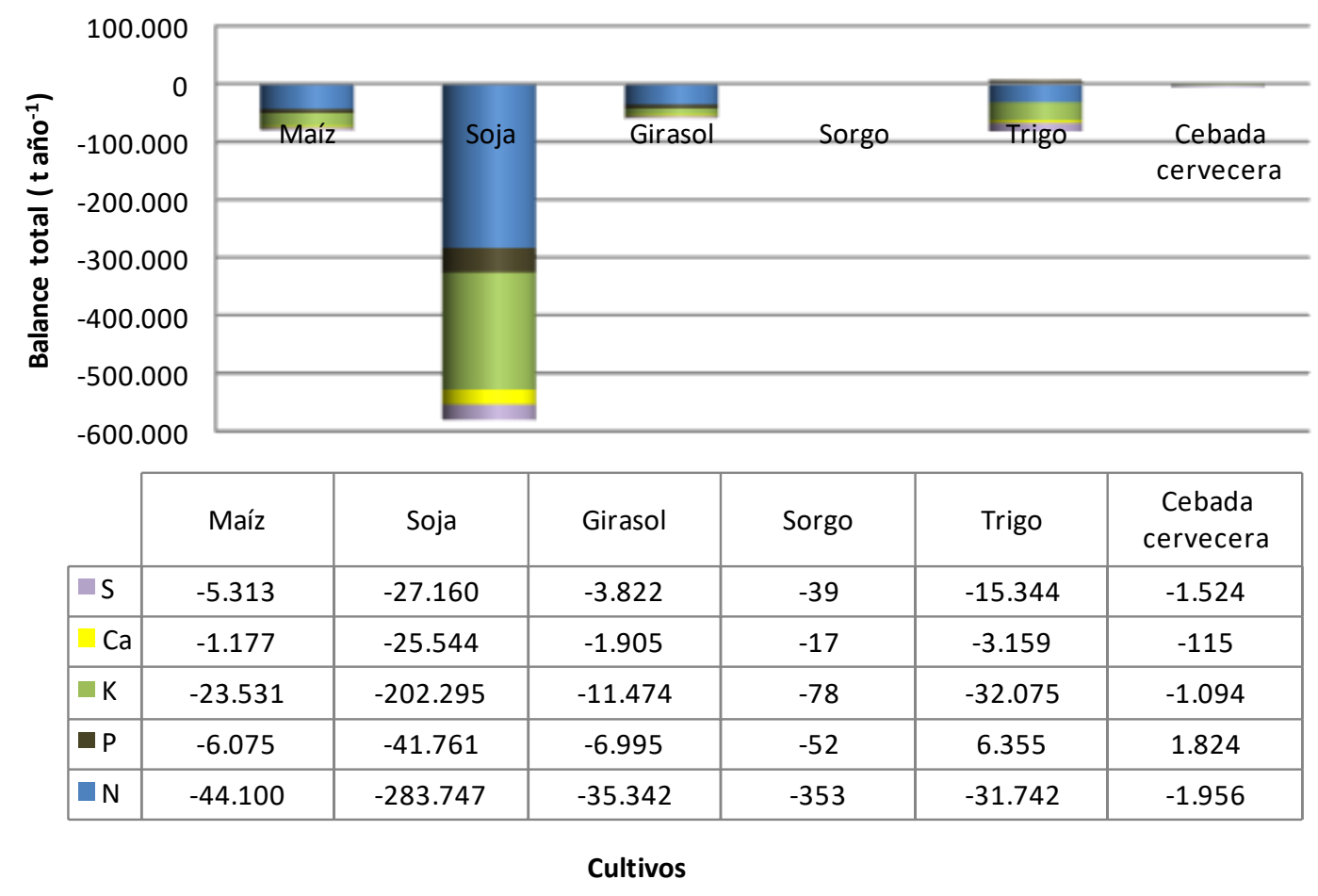

Figura 3.1.7. Balance total de nutrientes de los cultivos extensivos de la provincia de Buenos Aires (período 2005-06).

El noroeste y el sudeste de la provincia son las zonas donde se registraron las mayores pérdidas de nutrientes de la provincia para N, K, Ca y S (Figura 3.1.8. a, c, d, e). Las zonas norte y noroeste presentaron la mayor pérdida de $P$, mientras que en la zona sur, siete partidos presentaron ganancias (principalmente, Coronel Dorrego) y dos pérdidas elevadas (Tres Arroyos y Carmen de Patagones) (Figura 3.1.8. b). 


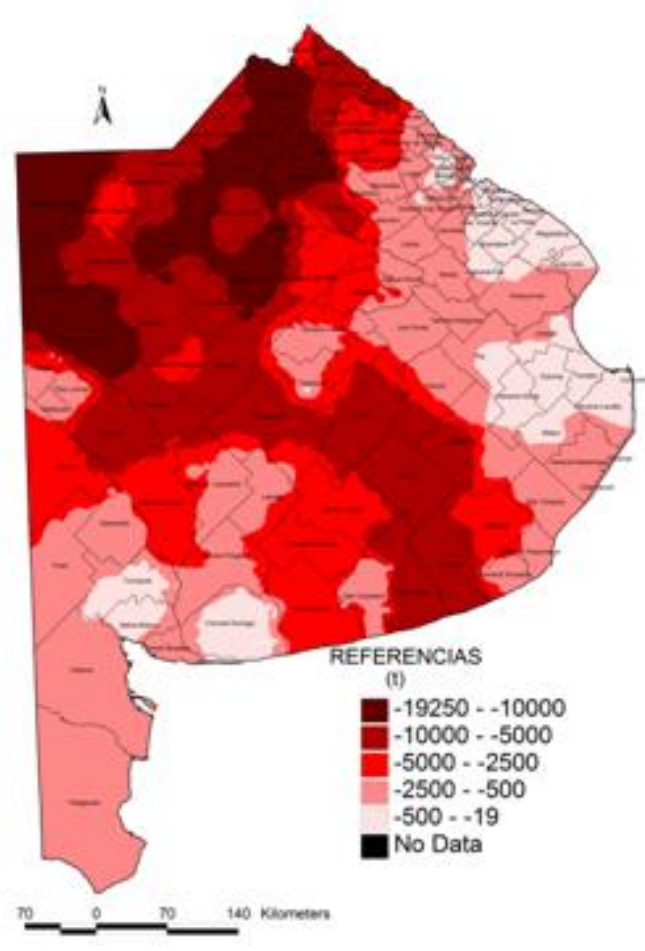

a)

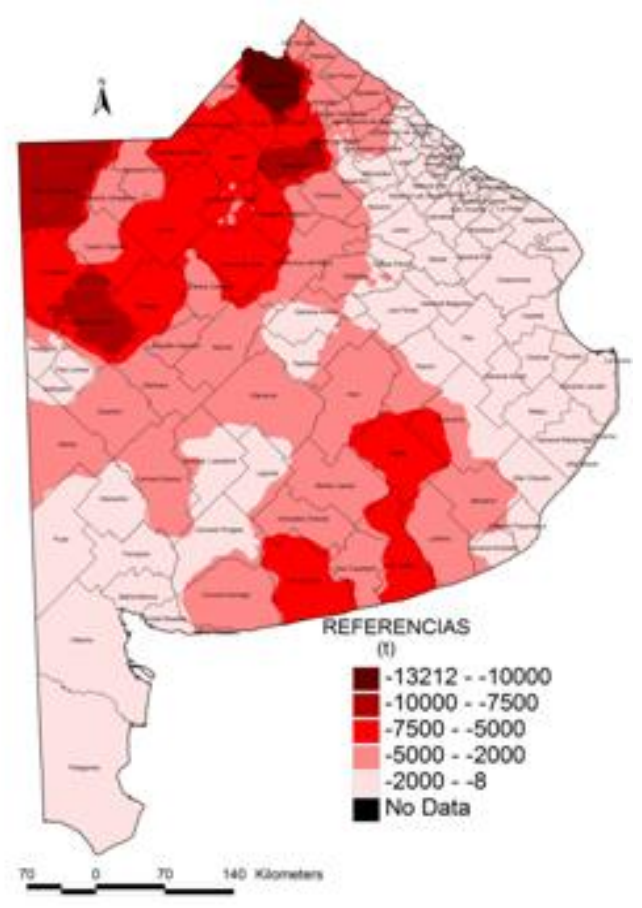

c)

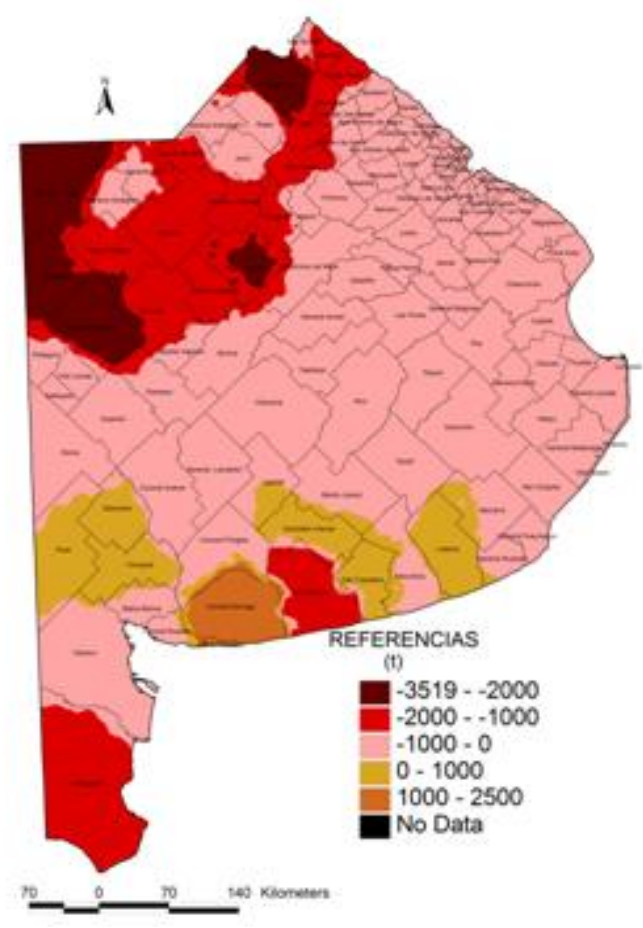

b)

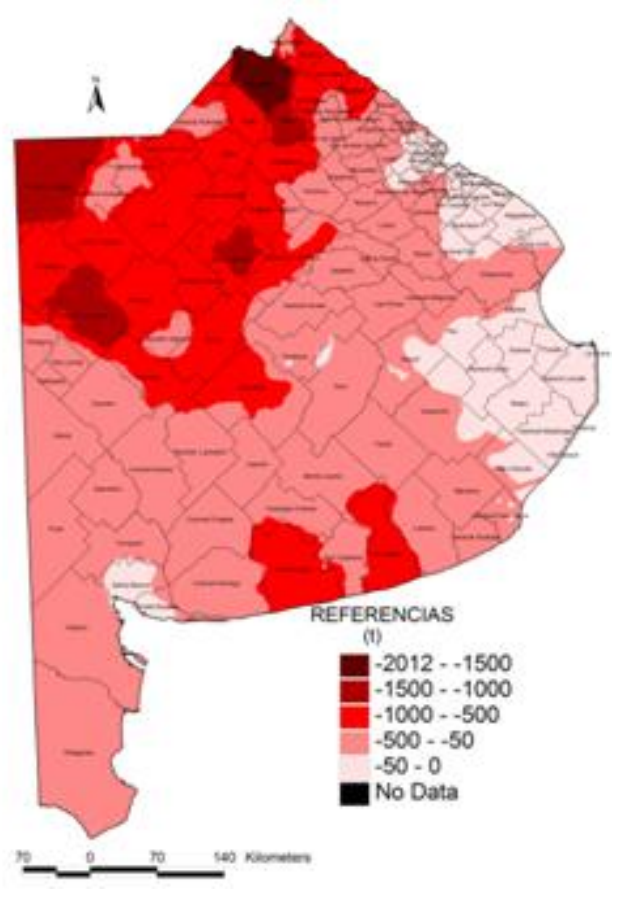

d) 


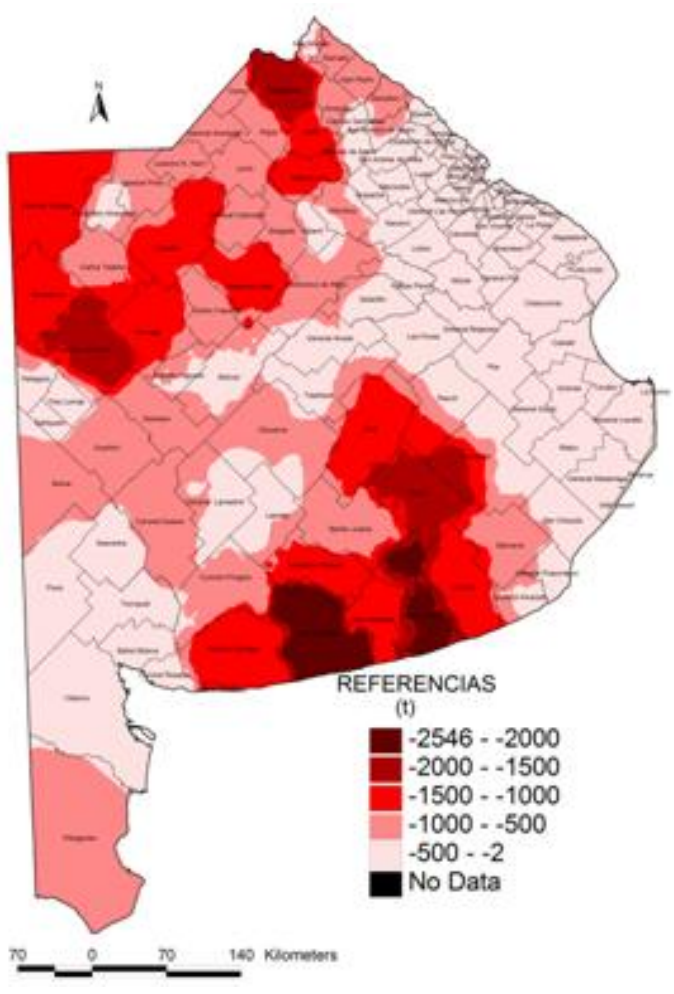

e)

Figura 3.1.8. Balance total anual de nutrientes: a) N, b) P, c) K, d) Ca y e) S, correspondiente a cultivos extensivos en la provincia de Buenos Aires (período 2005-06).

La reposición general de los nutrientes (considerando el aporte de la fijación biológica de la soja) fue del 43\%, siendo del 56; 64; 0; 17; $10 \%$ para N, P, K, Ca y S, respectivamente. En $\mathrm{N}$ y $\mathrm{P}$, a pesar de que registraron la mayor reposición, las elevadas extracciones que realizaron los cultivos, determinaron que sean los de mayores pérdidas en los suelos de la provincia. En N, P y Ca las mayores reposiciones se encontraron en la zona sur de la provincia (Figura 3.1.9. a, b, c), mientras que en $\mathrm{S}$ se dio en las zonas centro y norte (Figura 3.1.9. d) 


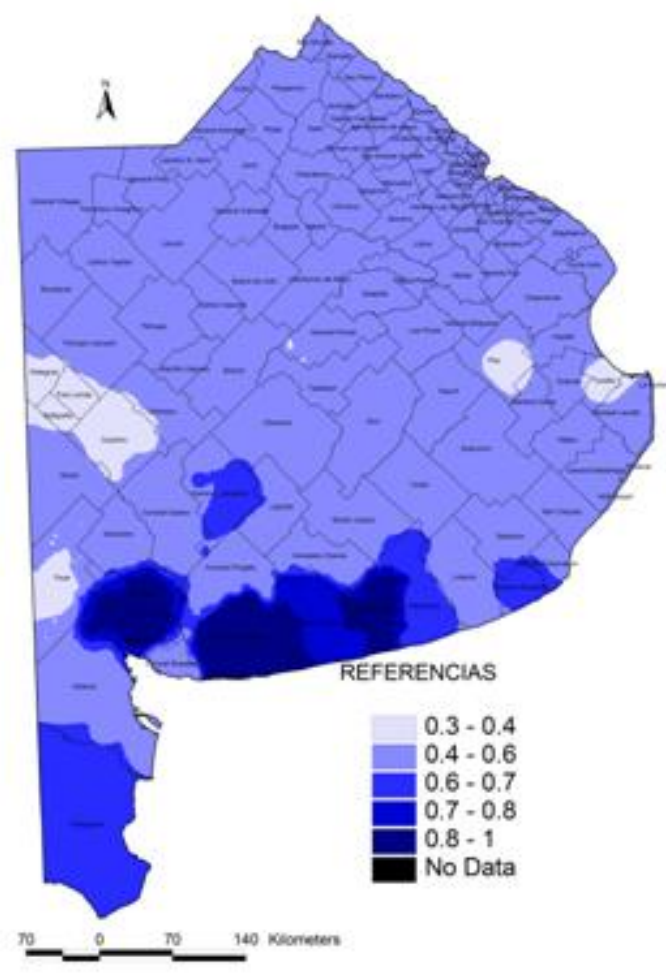

a)

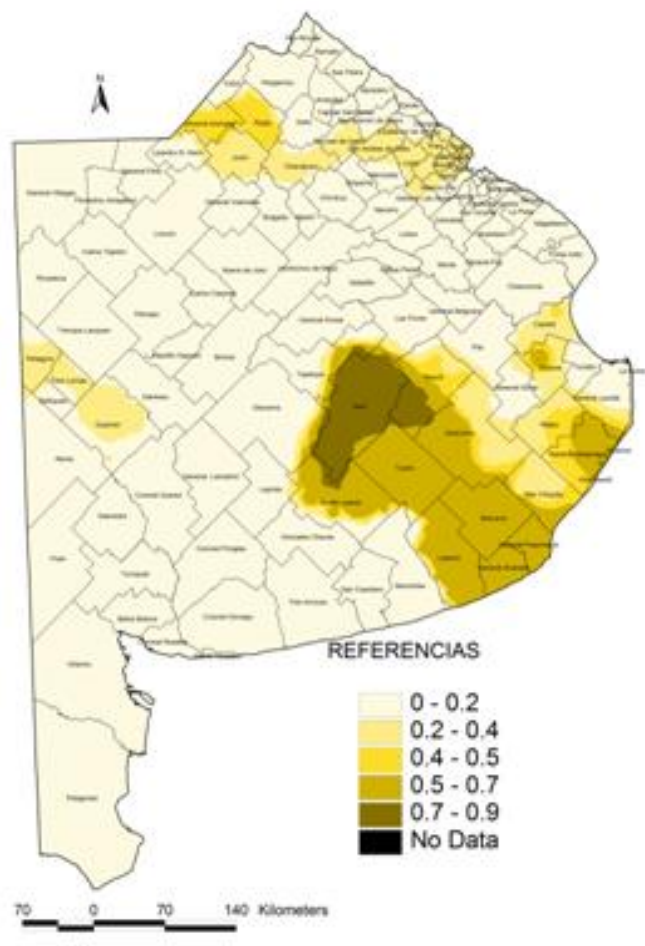

c)

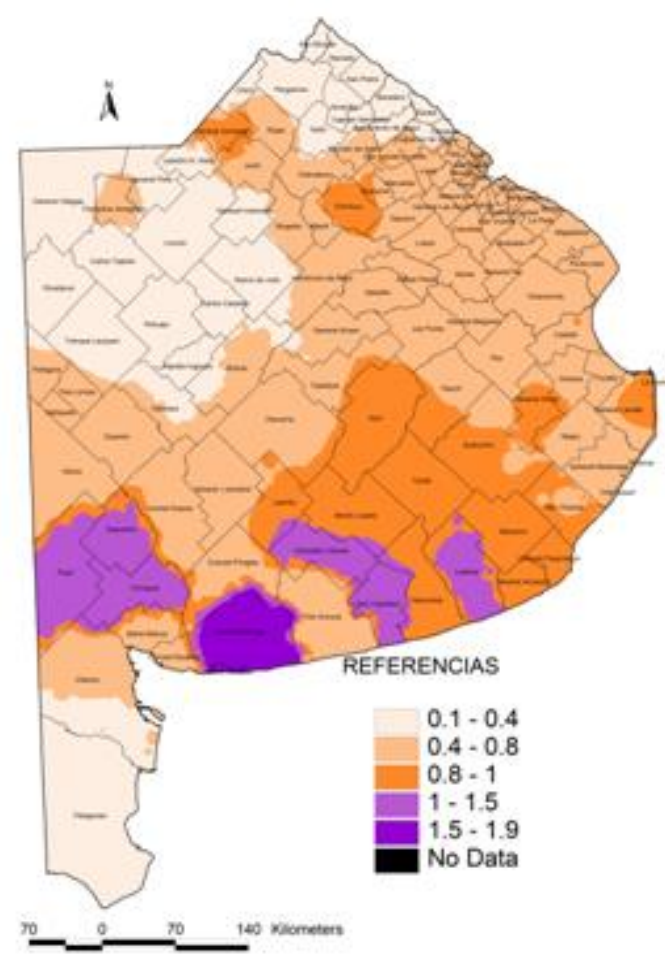

b)

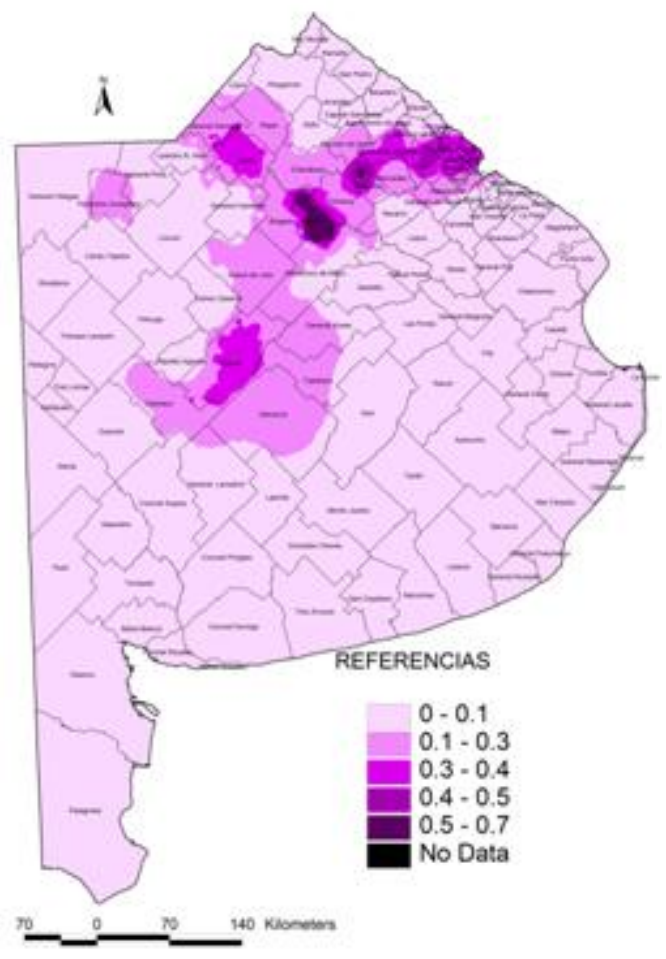

d)

Figura 3.1.9. Reposición anual ( $1=100 \%$ de reposición) de diferentes nutrientes, en cultivos extensivos de la provincia de Buenos Aires: a) N, b) P, c) Ca y d) S (período 2005-06).

La superficie afectada con distintos niveles de reposición fue diferente para cada nutriente (Tabla 3.1.5.). Para K, Ca y S, predominó la superficie con niveles bajos 
de reposición (entre 0 y $25 \%$ ). En N, un $65 \%$ de la superficie presentó una reposición menor al $50 \%$, mientras que para P esta superficie descendió al 34\%, siendo éste el único elemento cuya reposición superó la extracción en un $23 \%$ de la superficie cultivada.

Tabla 3.1.5. Rangos de reposición nutrientes y superficies afectadas por los mismos, en cultivos extensivos de la provincia de Buenos Aires (período 2005-06).

\begin{tabular}{|c|c|c|c|}
\hline Nutriente & $\begin{array}{l}\text { Rango de } \\
\text { reposición (\%) }\end{array}$ & $\begin{array}{l}\text { Superficie } \\
\text { (ha) }\end{array}$ & $\begin{array}{l}\text { Porcentaje de } \\
\text { superficie (\%) }\end{array}$ \\
\hline \multirow[t]{5}{*}{$N$} & $0-25$ & 3.393 .071 & 38,6 \\
\hline & $26-50$ & 2.367 .370 & 26,9 \\
\hline & $51-75$ & 1.758 .723 & 20,0 \\
\hline & $76-99$ & 1.280 .110 & 14,6 \\
\hline & $>100$ & & \\
\hline \multirow[t]{5}{*}{$P$} & $0-25$ & 1.218 .548 & 13,9 \\
\hline & $26-50$ & 1.830 .047 & 20,8 \\
\hline & $51-75$ & 1.299 .904 & 14,8 \\
\hline & $76-99$ & 1.722 .670 & 19,6 \\
\hline & $>100$ & 2.086 .671 & 23,7 \\
\hline \multirow[t]{5}{*}{$\mathrm{K}$} & $0-25$ & 8.797 .422 & 100,0 \\
\hline & $26-50$ & & \\
\hline & $51-75$ & & \\
\hline & $76-99$ & & \\
\hline & $>100$ & & \\
\hline \multirow[t]{5}{*}{$\mathrm{Ca}$} & $0-25$ & 6.802 .214 & 77,3 \\
\hline & $26-50$ & 865.660 & 9,8 \\
\hline & $51-75$ & 975.400 & 11,1 \\
\hline & $76-99$ & 156.000 & 1,8 \\
\hline & $>100$ & & \\
\hline \multirow[t]{5}{*}{$S$} & $0-25$ & 7.639 .264 & 86,8 \\
\hline & $26-50$ & 1.084 .802 & 12,3 \\
\hline & $51-75$ & 75.208 & 0,9 \\
\hline & $76-99$ & & \\
\hline & $>100$ & & \\
\hline
\end{tabular}

\section{III.1.4. DISCUSIÓN}

\section{III.1.4.1. Extracción de nutrientes}

La mayor extracción de N, seguida de las de K, P, Ca y S (Figura 3.1.1), coincide con lo encontrado por Cruzate \& Casas $(2003,2010)$ para el período agrícola 2006-07. A su vez, la soja como cultivo de mayor extracción total (Figura 3.1.4), es coincidente con lo encontrado por Cruzate \& Casas (2003, 2010, 2012), Gelati \& Vázquez (2008) y García \& Vázquez (2012). Entre las oleaginosas se encontró que la extracción de nutrientes de soja fue cuatro veces superior a la de girasol (Figura 3.1.2), lo cual se debe a la composición proteica del grano de soja que extrae gran cantidad de $\mathrm{N}$, a 
la mayor presencia de K en el grano y al mayor rendimiento. Entre los cereales, los de verano (maíz y sorgo) presentaron una mayor extracción respecto de los de invierno (trigo y cebada cervecera) (Figura 3.1.2), debido, sobre todo, al mayor rendimiento de los primeros. Estas características extractivas de los cultivos, y relacionada con el uso de los suelos de la provincia es lo que determinó la mayor extracción por unidad de superficie en el norte y noroeste, disminuyendo hacia el sur y sudoeste (Figura 3.1.3. a, $b, c, d, e)$. En el norte existe un predominio de los cultivos de verano, y hacia el sur se incrementa la presencia de cultivos de invierno, existiendo casi con exclusividad estos últimos en el sudoeste (Figura 2.4).

Esta distribución espacial de la extracción por unidad de superficie disminuyendo de norte a sur (Figura 3.1.3. a, b, c, d, e) fue similar a la hallada por Cruzate \& Casas (2012), aunque en esta tesis se encontró una mayor extracción de $\mathrm{N}$, P, K y $S$ en el centro-este de la provincia. Por otro lado, la extracción total, que incorpora la superficie cultivada, muestra las zonas agrícolas predominantes de la provincia (Figura 3.1.5. a, b, c, d, e), que son el norte junto con el noroeste y el sudeste (Figura 2.9). La extracción total de $\mathrm{P}, \mathrm{Ca}$ y $\mathrm{S}$ en el norte, noroeste y sudeste (Figura 3.1.5. b, d, e), coincide con lo encontrado por Cruzate \& Casas (2003) para la campaña 2001 y 2002 aunque con menores valores de extracción total, producto de la menor superficie agrícola implantada respecto de 2005-2006. Desde 2006, la superficie agrícola total de la provincia se incrementó pasando de casi 9 Mha a casi 12 Mha en la campaña 2014-15 (SIIA, 2016), con un incremento de soja de 3,7 Mha a 6,5 Mha (del $42 \%$ al $55 \%$ del área cultivada) (Figura 2.3). La proporción de cultivos de verano/invierno pasó de 1,77 en 2005-06 a 3,19 en 2014-15. Este fuerte incremento de la superficie agrícola, con un fuerte predominio de cultivos de verano $y$, dentro de éstos, de soja, estaría mostrando que el crecimiento en las extracciones totales de la provincia continúa en aumento. Este proceso es lo que Viglizzo et al. (2010) señalan como "veranización" de la agricultura.

\section{III.1.4.2. Balance de nutrientes}

Los balances de nutrientes calculados por unidad de superficie (Figura 3.1.6 a, b, c, d, e) registraron una variación espacial entre los diferentes partidos de la provincia, siendo mayor la pérdida en la zona norte, disminuyendo hacia el sur. Esta variación sugiere el rechazo de la hipótesis planteada. Los balances totales (Figura 3.1.8 a, b, $c, d, e)$ registraron las mayores pérdidas, principalmente para $N, K$, Ca y $S$, en las zonas con predominio agrícola (Figura 2.9).

Los balances de nutrientes estimados señalan, en coincidencia con lo encontrado por García \& González Sanjuán $(2010)$ y Cruzate \& Casas $(2003,2012)$ que, 
en la provincia de Buenos Aires, se está produciendo un agotamiento de los nutrientes del suelo (Tabla 3.1.4 y Figura 3.1.7). Los balances negativos afectan la calidad de los suelos (fertilidad), el rendimiento de los cultivos, y la sostenibilidad de los sistemas de producción (García \& González Sanjuán, 2010). Estos balances ratifican lo encontrado en partidos (Cabrini et al., 2013) y regiones (Manchado, 2010) de la provincia de Buenos Aires.

A pesar de que el $84 \%$ de los ingresos de nutrientes entre fertilización y fijación biológica correspondió a N (Tabla 3.1.3), este fue el nutriente responsable del $49,7 \%$ de las pérdidas totales, seguido por el $\mathrm{K}$ con un $33,8 \%$. Esto muestra que a pesar de ser el macronutriente por excelencia y que mayor atención recibe para favorecer el crecimiento de los cultivos, sigue siendo subsidiado por los suelos de la provincia. A nivel global, Tan et al. (2005) encontraron que el déficit de K implica el 60\% de las pérdidas de nutrientes, seguido de $\mathrm{N}(28 \%)$ y de $\mathrm{P}(12 \%)$.

Entre los cultivos que generan balances negativos se destaca la soja (Tabla 3.1.4), lo cual coincide con lo encontrado por García \& González Sanjuán (2010), Manchado (2010), Cruzate \& Casas $(2003,2010,2012)$ y González Sanjuán et al. (2013). Este cultivo, por su mayor capacidad extractiva, genera la mayor pérdida por unidad de superficie prácticamente en todos los nutrientes. El $72 \%$ de la pérdida de nutrientes se debe a este cultivo que ocupa el $42 \%$ de la superficie. En esta tesis, basado en trabajos que calculan balances de nutrientes a nivel regional en Argentina (Flores \& Sarandón, 2003; Austin et al., 2006; Cruzate \& Casas, 2010, 2012) se asumió que la fijación biológica en el cultivo de soja aporta el 50\% del $\mathrm{N}$ extraído en la cosecha. Un estudio reciente de Collino et al. (2015) sugiere que en Argentina la fijación biológica aportaría el $60 \%$ del $\mathrm{N}$ absorbido por el cultivo de soja, lo que incluye el $\mathrm{N}$ en la biomasa aérea y en las raíces. Por lo tanto, el aporte por fijación en relación a lo extraído en la cosecha sería superior al $80 \%$. Estos valores variarían dentro la provincia de Buenos Aires en función de la fertilidad de los suelos. Para los cálculos realizados en esta tesis implicaría una disminución sustancial de las deficiencias de $\mathrm{N}$ registradas por la soja $y$, por lo tanto en el total de nutrientes. Será necesario profundizar en esta temática a nivel de cada partido para poder, en un futuro cercano, ajustar los cálculos de balances de nutrientes. Lo referente a la fijación biológica de $\mathrm{N}$ se encuentra muy vinculado a la fertilización nitrogenada. Si bien existe una controversia respecto si la fertilización nitrogenada interfiere con la fijación simbiótica de la soja (García, 2011; Collino et al., 2015), los resultados estimados muestran que el manejo del $\mathrm{N}$ debe ser mejorado. En relación a esto, García (2011) considera que debe buscarse una solución dentro del sistema de rotación de los cultivos y no en el cultivo en sí. Cordone \& Trossero (2012) analizaron el balance de nutrientes de distintas rotaciones y 
encontraron que aquéllas que incluyen mayor proporción de soja generaron los balances más negativos en N, P y S. Sumado a la pérdida de N, el tipo de rastrojo que deja la soja de rápida descomposición y posterior mineralización, contribuye a una mayor disminución de la materia orgánica (Forján et al., 2002, 201 1; Berardo, 2004). Por eso, en los último 25 años no sólo se han perdido nutrientes del suelo sino también materia orgánica (Fontanetto \& Gambaudo, 2010). Forján et al. (2002, 2011) recomiendan mejorar la materia orgánica del suelo, lo cual permitirá mejorar la economía del agua, disminuir la variabilidad de rendimientos y se obtendrían mayores beneficios de la fertilización.

Entre los cultivos que por su manejo generan alguna reposición adecuada de nutrientes se encuentran el trigo y la cebada cervecera. Estos cultivos de invierno responden bien a la fertilización (requieren de mayor disponibilidad de nutrientes en el suelo) por lo que el manejo que reciben genera un balance más equilibrado en $\mathrm{P}$ y no tan negativo en N. A nivel país, García \& González Sanjuán (2010) encontraron exceso de $P$ en trigo, junto con maíz. Manchado (2010) también encontró balance positivo de $\mathrm{N}$ y $\mathrm{P}$ para trigo en el centro sur de la provincia. El excedente de $\mathrm{P}$ en esta región se atribuye, en parte, a que muchos cultivos de trigo se destinan para el cultivo de soja de segunda (García \& González Sanjuán, 2010). No obstante, aunque evaluando los balances generales de ambos cultivos, no se alcanzarían a reponer la extracción total. Por su parte, Sainz Rozas et al. (2012) consideran que la mayor fertilización en P en esta zona se debe, principalmente, al menor contenido de $\mathrm{P}$ nativo de los suelos. La continua pérdida de $\mathrm{P}$ de la agricultura argentina, y de la provincia de Buenos Aires ha conducido a la caída de P disponible, como ocurre en amplio sector de la provincia (García \& González Sanjuán, 2010; Sainz Rozas et al., 2012).

El déficit de N, P y S está siendo subsidiado a partir de la mineralización de la materia orgánica (Darwich, 2003; Melgar, 2011; Sainz Rozas et al., 2012). Por eso, los suelos con menor contenido de materia orgánica y con textura más gruesa estarían registrando mayores caídas de P-Bray a partir de los balances negativos (Sainz Rozas et al., 2012). Estos autores señalan que, en los últimos 25 años, las mayores caídas de $P$ disponible ocurrieron hacia el oeste y norte de la provincia y no tanto hacia el sur. Sin embargo, la creciente expansión de la soja en el sudeste de la provincia desde el año 2010 puede generar una caída aún mayor en el $\mathrm{P}$ disponible. Para la reposición de $\mathrm{P}$ debe tenerse en cuenta la residualidad del mismo, la cual se puede emplear al planificar la fertilización de las rotaciones. Divito et al. (2010), en suelos con alta disponibilidad de $\mathrm{P}$, no encontraron diferencias en el rendimiento por la fertilización con $\mathrm{P}$ particionada anualmente en los cultivos o aplicado todo al inicio de la rotación. 
La fertilización con K, aunque creció hacia el 2010, se situó por debajo del 1\% de la extracción (García \& González Sanjuán, 2010). Esto se debería a la riqueza mineral de este nutriente que presentan los suelos de la provincia (Melgar, 2011; González Sanjuán et al., 2013). Este manejo de los cultivos está generando un agotamiento en el suelo de este nutriente. Sainz Rozas et al. (2014) ya han encontrado una disminución del K extractable, aunque todavía se mantienen por encima de los umbrales de fertilización. La adecuada disponibilidad de K en los suelos de la provincia de Buenos Aires y la baja respuesta a su agregado que tienen los cultivos determina, bajo la lógica de dosis-respuesta, que prácticamente no se realice fertilización potásica en cultivos extensivos. Todavía no se evidencia la disminución de los rendimientos por la escasez de este nutriente, pero de mantenerse este manejo del K, en algunos años será necesaria su incorporación. Con el S ocurrió algo similar que con el K pero, en la actualidad, hay varias zonas de la provincia de Buenos Aires que han incorporado su fertilización para los cultivos de trigo y soja. Esto repetirá el manejo realizado con el $\mathrm{P}$, cuando, en la década del 70 , la alta disponibilidad existente en gran parte de los suelos de la provincia determinaba que no era necesario fertilizar. Luego, 20 años más tarde, el agotamiento del stock de $P$, traducido en una menor disponibilidad del mismo (Sainz Rozas et al., 2012), condujo a una recomendación de fertilización, aunque con el criterio de complementar el P que el suelo brindaba y no con el criterio de reposición.

Melgar (2011) señala que parte de la expansión agrícola en la Argentina se desarrolla sobre suelos de alta disponibilidad de P, lo que lleva a una baja fertilización en este nutriente. Si bien desde el punto de vista económico a corto plazo es la mejor opción, el beneficio económico genera un perjuicio ecológico para las futuras generaciones. Durante mucho tiempo se ha pensado que la Argentina, como posee suelos de buena calidad y escasa historia productiva, puede basar su producción en el subsidio de los nutrientes por el suelo y sólo reponer la diferencia entre lo extraído por los granos y lo aportado por el suelo (Oliverio et al., 2004). Este criterio de desarrollo agrícola, basado también en un análisis económico del corto plazo, ha generado esta degradación del recurso suelo. Es decir, que la actual generación realiza una agricultura que no dejará a las futuras generaciones un suelo con la misma calidad que lo encontró.

Gran parte del deterioro del suelo de la provincia se debe a los criterios agronómicos bajo los cuales se toman las decisiones. Por ejemplo, las recomendaciones de fertilización con $\mathrm{P}$ se basan en el análisis presiembra que determina el nivel de P-Bray a 0-20cm (García \& González Sanjuán, 2010). Este criterio que busca la respuesta económica a partir del incremento del rendimiento del cultivo 
por el agregado del fertilizante, estimula el subsidio de la producción con la pérdida de la fertilidad del suelo, afectando la producción en un futuro. Es decir, se promueve el subsidio de la producción con la pérdida de fertilidad. En la medida que los contenidos de $\mathrm{P}$ vayan disminuyendo se incrementará la dosis de $\mathrm{P}$ hasta que llegará un punto donde se agregará la misma o mayor cantidad que la extracción para poder asegurar el crecimiento de los cultivos, como ocurre en parte de Europa y Estados Unidos (Tan et al., 2005; Vitousek et al., 2009). Esta situación se agrava aún más cuando un cultivo se puede desarrollar con baja disponibilidad de nutrientes en el suelo. Este cultivo, colocado en suelos de alta fertilidad natural, debido a la escasa fertilización que recibiría bajo esta lógica de dosis-respuesta, conduciría a un rápido empobrecimiento de aquéllos.

En general, se asume que la pérdida de fertilidad de los suelos agrícolas ocurre en los países pobres o en vías de desarrollo por el escaso ingreso económico de los agricultores (Tan et al., 2005; Vitousek at al., 2009). Sin embargo, en Argentina, el 60\% de la producción de soja se realiza por arrendamiento (Reboratti, 2010), es decir que son empresas dedicada a la producción agrícola. Por lo tanto, la pérdida de nutrientes estaría más asociada a una especulación de la ganancia que a la escasez de recursos económicos.

Esta pérdida de nutrientes no sólo ocurre en Buenos Aires, sino que forma parte de lo que sucede en toda la Región Pampeana. En Entre Ríos y para el mismo período analizado en esta tesis, Vicente \& Engler (2008) encontraron un balance negativo de $N$ en todos los cultivos agrícolas analizados y sólo balance positivo en maíz y trigo. Ghida Daza (2013) en Córdoba, también encontró balance positivo para N y P en trigo y negativo para el resto de los nutrientes y cultivos. En ambos estudios, la soja fue el cultivo que generó el mayor déficit de N y P. Tan et al. (2005) señalan que la continua disminución de nutrientes del suelo deteriora el bienestar socio-económico, la sostenibilidad del recurso suelo, deteriora la calidad ambiental y reduce los rendimientos por la degradación del suelo. Además, contribuye a un incremento de la erosión por disminución de la materia orgánica y a la disminución de la estabilidad estructural del suelo.

\section{III.1.4.3. Reposición de nutrientes}

El nivel de reposición de nutrientes estimado en esta tesis fue superior en $\mathrm{N}$ y $\mathrm{P}$, e inferior en K, Ca y S, al informado por Cruzate \& Casas (2010) para toda la Argentina, para la campaña 2006-2007 (41 y 61\% de reposición para N y P y 6\%, $48 \%$ y $35 \%$ para K, Ca y S, respectivamente). Respecto a lo calculado por García \& González Sanjuán (2010), también fue mayor en N y P y menor en K y S. La mayor diferencia en cuanto a 
la reposición de $\mathrm{N}$ se debe a si se incluye sólo la reposición mineral o también lo ingresado por fijación biológica (para soja). Si se considera esto último como lo presentado en esta tesis, los valores de reposición de $\mathrm{N}$ resultan mayores. Fontanetto \& Gambaudo (2010) señalaron una reposición del $25-30 \%$ para N, $40-50 \%$ para $\mathrm{P}$ y $7-10 \%$ para $K$ en el período 1996-2001. Para el período 2002-2003, Oliverio et al. (2004) estimaron una reposición del 19,54 y 5\% para N, P y S, y un balance positivo de P en maíz y trigo (103 y 190\% de reposición, respectivamente). Gudelj et al. (2006) informaron una reposición del 37, 27, y 10\% de P, N y S respectivamente, entre 2000 y 2003. Para la campaña 2011-2012 se informó una reposición de nutrientes por fertilizantes del orden de 25-35\% promedio para los principales cultivos (González Sanjuán et al., 2013).

A pesar de que hace casi 20 años que se viene señalando la necesidad de conservar los nutrientes del suelo, se encuentra que los suelos de la provincia realizan el "subsidio silencioso" a la producción agrícola provincial, lo que atenta contra la sostenibilidad de la actividad y pone en riesgo a las futuras generaciones.

\section{III.1.5. BIBLIOGRAFÍA}

Argenfoods. 2010. Tabla de composición de alimentos. $I^{\circ}$ Edición. Universidad Nacional de Luján. Disponible en: http://www.argenfoods.unlu.edu.ar/. Último acceso: junio 2016.

Austin, A.T., G. Piñeiro \& M. González-Polo. 2006. More is less: agricultural impacts on the N cycle in Argentina. Biogeochemistry 79: 45-60.

Berardo, A. 2004. Manejo de la Fertilización en una Agricultura Sustentable. Informaciones Agronómicas 23:23-25.

Bray, R.H. \& L.T. Kurtz. 1945. Determination of total, organic and available forms of phosphorus in soil. Soil Science 59:39-45.

Cabrini, S.M., C.P. Calcaterra \& D. Lema. 2013. Costos ambientales y eficiencia productiva en la producción agraria del partido de Pergamino. Revista Iberoamericana de Economía Ecológica 20:27-43.

Ciampitti, I. \& F.O. García. 2007. Requerimientos nutricionales. Absorción y extracción de macronutrientes y nutrientes secundarios. I Cereales. Oleaginosas e industriales. IPNI. Archivo agronómico 11:13-16.

CNA (Censo Nacional Agropecuario). 2002. Instituto Nacional de Estadísticas y Censos de la República Argentina. Disponible en: http://www.indec.gob.ar/cna index.asp. Último acceso: octubre 2016.

Collino, D.J., F. Salvagiotti, A. Perticari, C. Piccinetti, G. Ovando, S. Urquiaga \& R.W. Racca. 2015. Biological nitrogen fixation in soybean in Argentina: relationships with crop, soil, and meteorological factors. Plant Soil 392:239-252.

Cordone, G. \& M. Trossero. 2012. Costo culto privado y social del sistema productivo. La degradación del suelo pampeano. Informaciones Agronómicas de Hispanoamérica 7:2-5.

Cruzate, G. \& R.R. Casas. 2003. Balance de nutrientes. Revista Fertilizar (Número especial "Sostenibilidad"): 7-13.

Cruzate, G. \& R.R. Casas. 2010. Extracción de nutrientes en la agricultura Argentina. Informaciones Agronómicas 44:21-26.

Cruzate, G. \& R.R. Casas. 2012. Extracción y balance de nutrientes en los suelos agrícolas de la Argentina. Informaciones Agronómicas de Hispanoamérica 6:7-14.

Darwich, N. 2003. El balance físico económico en las rotaciones agrícolas. Proyecto Fertilizar. INTA. $\quad$ Disponible en: http://www.fertilizando.com/articulos/El\%20Balance\%20Fisico\%20Economico\%20en\%20las\%20Rot aciones.asp. Último acceso: abril de 2017. 
Divito, G.A., H. Sainz Rozas \& H.E. Echeverría. 2010. Estrategias de fertilización fosforada en una rotación de cultivos en el sudeste bonaerense. Ciencia del suelo 28(1):47-55.

Ferraris, G.N., M. Toribio, R. Falconi \& F. Moriones. 2015. Efecto de diferentes estrategias de fertilización sobre los rendimientos, el balance de nutrientes y su disponibilidad en los suelos en el largo plazo. Informaciones Agronómicas de Hispanoamérica 19:11-17.

Flores, C.C. \& S.J. Sarandón. 2003. ¿Racionalidad económica versus sustentabilidad ecológica? El ejemplo del costo oculto de la pérdida de fertilidad del suelo, durante el proceso de Agriculturización en la Región Pampeana Argentina. Revista de la Facultad de Agronomía 105 (1):53-67.

Fontanetto, H. \& S. Gambaudo. 2010. El balance de nutrientes para sistemas agrarios sustentables. Sitio de Producción Animal. 4pp. Disponible en: http://www.produccionanimal.com.ar/suelos_ganaderos/77-nutrientes.pdf. Último acceso: mayo 2016.

Forján, H., M. Zamora, R. Bergh, M. Seghezzo \& E. Molfese. 2002. Inclusión de soja en sistemas de cultivos: el balance de nutrientes. INTA. Chacra Experimental integrada Barrow. 8pp.

Forján, H.J., M. Zamora, M.L. Manso, M.L. Seghezzo \& E.R. Molfese. 2011. Inclusión de soja en secuencias agrícolas del sur bonaerense: su efecto sobre el balance de nitrógeno y fosforo. $V$ Congreso de la Soja del Mercosur. Primer Foro de la Soja Asia Mercosur. Sustentabilidad de la producción: 1-5. Disponible en: http://www.acsoja.org.ar/images/cms/contenidos/330 b.pdf. Último acceso: junio 2016.

García, F.O. 2006. La nutrición de los cultivos y la nutrición de los suelos. Informaciones Agronómicas 29:13-16.

García, F.O. 2011. Balances de carbono y de nutrientes: buscando el equilibrio en la agricultura del Cono Sur. II Simposio Nacional de Agricultura. Uruguay. 135-147pp.

García, F.O. \& M.F. González Sanjuán. 2010. Balances de nutrientes en Argentina ¿Cómo estamos? ¿Cómo mejoramos? Informaciones Agronómicas 48:1-5.

García, M.G. \& M.E. Vázquez. 2012. Valoración económico-ecológica de la pérdida de nutrientes básicos de los suelos santafesinos. Revista Iberoamericana de Economía Ecológica 19:29-41.

Gelati, P.R. \& M.E. Vázquez. 2008. Extracciones agrícolas de bases en el norte de la provincia de Buenos Aires, Argentina: costo de su remediación e implicancias económicas. Revista Iberoamericana de Economía Ecológica 7:117-129.

Ghida Daza, C. 2013. Valoración económica del balance de nutrientes en la Provincia de Córdoba. Estación Experimental Agropecuaria Marcos Juárez. INTA. Información para extensión 141.9pp.

González Sanjuán, M.F., A.A. Grasso \& J. Bassi. 2013. Fertilizantes en Argentina. Análisis del Consumo. Revista Fertilizar 25:25-29.

Gudelj, V., C. Galarza, M. Ferrari, C. Senigagliesi, A. Berardo, N. Darwich \& H. Echeverría. 2006. La fertilización en cultivos extensivos de la Región Pampeana Argentina: Aportes del INTA. Informaciones Agronómicas 30: 19-21.

MAA (Ministerio de Asuntos Agrarios). 2007. Nuestra provincia nuestro campo. El sector agropecuario de la provincia de Buenos Aires. 147pp.

Manchado, J.C. 2010. La sustentabilidad en la agricultura pampeana: Valoración económica del balance de nutrientes para las principales actividades agropecuarias extensivas en la Región Centro Sur de la Provincia de Buenos Aires. Revista Argentina de Economía Agraria XII (2):51-68.

Manchado, J.C., S.M. Cabrini, P.K. Natinzon \& C.P. Calcaterra. 2013. Análisis multicriterio: aplicación al estudio de la sustentabilidad en sistemas de producción agropecuarios en la región pampeana. INTA. Estudios socioeconómicos de la sustentabilidad de los sistemas productivos y recursos naturales 18. $31 \mathrm{pp}$.

Melgar, R. 2011. La reposición de nutrientes en EEUU, Brasil y Argentina: tres escenarios contrastantes. Fertilizar 19:5-11.

Melgar, R. \& M. Torres Duggan. 2005. Comercio y abastecimiento moderno de fertilizantes. Editorial Hemisferio Sur S.A. Buenos Aires. 196pp.

Oliverio, G., F. Segovia \& G.M. López. 2004. Fertilizantes para una Argentina de 100 millones de toneladas. Fundación producir conservando. 31pp. Disponible en: http://producirconservando.org.ar//intercambio/docs/fertil 100 tn.pdf. Último acceso: mayo 2016.

Reboratti, C. 2010. Un mar de soja: la nueva agricultura en Argentina y sus consecuencias. Revista de Geografía Norte Grande 45: 63-76.

Sainz Rozas, H., H. Echeverría. \& H. Angelini. 2012. Fósforo disponible en suelos agrícolas de la región pampeana y extra pampeana argentina. INTA. Revista de Investigaciones Agropecuarias 38(1): 33-39. 
Sainz Rozas, H.R., H.E. Echeverría, P.A. Barbieri \& M. Eyherabide. 2014. Relevamiento y mapeo de la fertilidad en suelos agrícolas de la Región Pampeana argentina. Fertilizar N²9:3-8.

SIIA (Sistema Integrado de Informaciones Agropecuarias). 2016. Disponible en: http://www.siia.gov.ar/. Último acceso: septiembre 2016.

Stauffer, M.D. \& G. Sulewski. 2003. Fósforo: Un nutriente esencial para la vida. Actas Simposio "El fósforo en la agricultura Argentina". Rosario, Santa Fe. INPOFOS. 4-7.

Tan, Z.X., R. Lal \& K.D. Wiebe. 2005. Global soil nutrient depletion and yield reduction. Journal of Sustainable Agriculture 26(1):123-146.

Veneciano, J.H. \& K.L. Frigerio. 2003. Exportación de nutrientes en sistemas extensivos de San Luis. Informaciones Agronómicas 17:17-21.

Vicente, G. \& P. Engler. 2008. Valoración económica del balance de nitrógeno y fósforo de los principales rubros agrícolas y pecuarios en la provincia de Entre Ríos. En: Agricultura Sustentable. Actualización técnica. INTA. Estación Agropecuaria Paraná. Serie Extensión 51:80-87.

Viglizzo, E.F., F. Lértora, A.J. Pordomingo, J.N. Bernardos, Z.E. Roberto \& H. del Valle. 2001. Ecological lessons and aplications from one century of low external-input farming in the pampas of Argentina. Agriculture, Ecosystems \& Environment 83:65-81.

Viglizzo, E.F., A.J. Pordomingo, M.G. Castro \& F.A. Lértora. 2002. La sustentabilidad ambiental del agro pampeano. INTA. Programa Nacional de Gestión Ambiental Agropecuaria. Ediciones INTA. 84pp.

Viglizzo, E.F., L.V. Carreño, H. Pereyra, F. Ricard, J. Clatt \& D. Pincén. 2010. Dinámica de la frontera agropecuaria y cambio tecnológico. En: Expansión de la Frontera Agropecuaria en Argentina y su Impacto Ecológico-Ambiental. Viglizzo, E.F. \& E.G. Jobbágy (Editores). Ediciones INTA. Capítulo 1:9-16.

Vitousek, M., R. Naylor, T. Crews, M. B. David, L.E. Drinkwater, E. Holland, P.J. Johnes, J. Katzenberger, L.A. Martinelli, P.A. Matson, G. Nziguheba, D. Ojima, C.A. Palm, G.P. Robertson, P.A. Sanchez, A.R. Townsend \& F.S. Zhang. 2009. Nutrient Imbalances in Agricultural Development. Science 324:1519-1520.

Zazo, F., C. Flores \& S. Sarandón. 2011. El "costo oculto" del deterioro del suelo durante el proceso de "sojización" en el Partido de Arrecifes, Argentina. Revista Brasileira de Agroecología. $6(3): 3-20$ 


\section{CAPÍTULO III}

\section{SUBCAPÍTULO 2}

La horticultura y la conservación de los nutrientes del

suelo

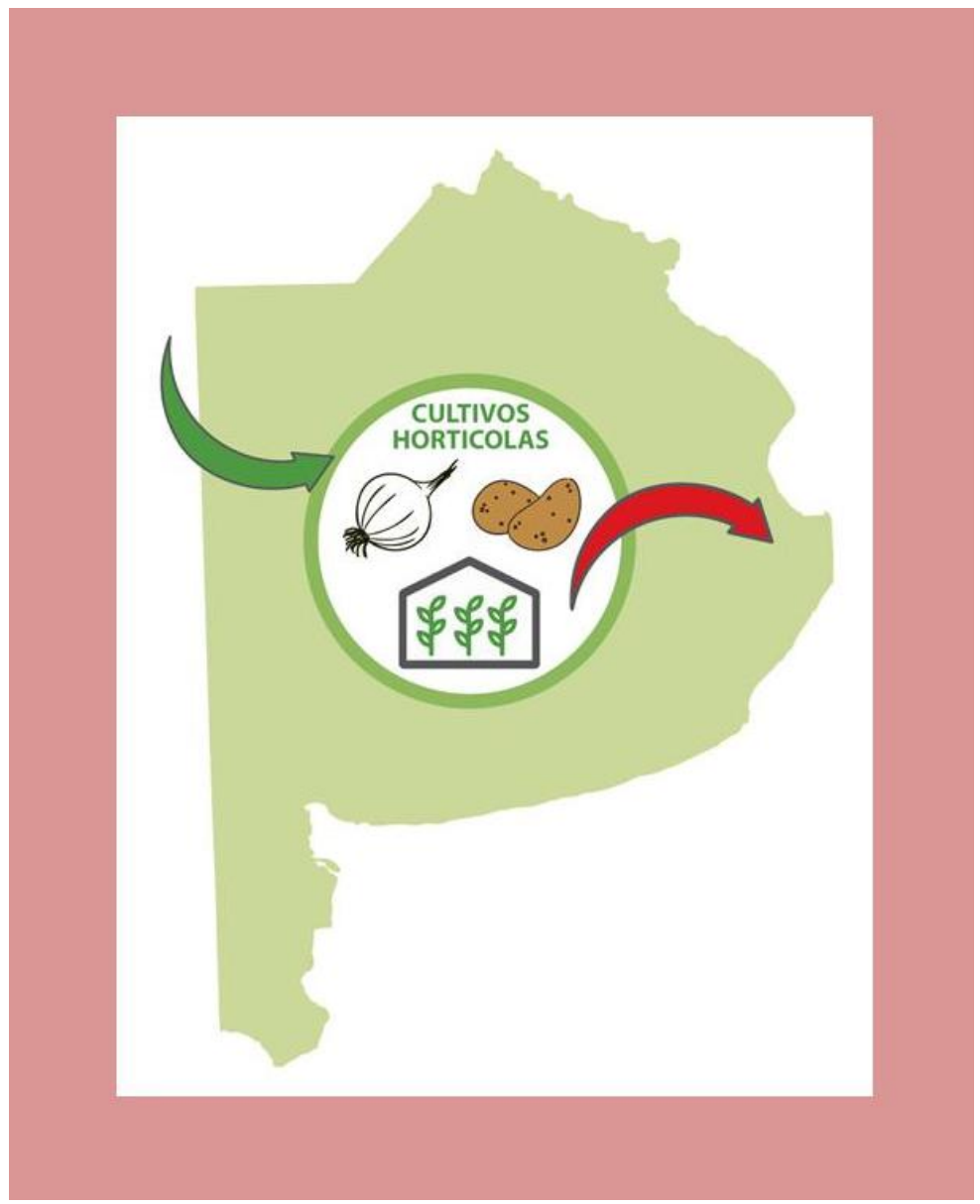




\section{III.2.1. INTRODUCCIÓN}

En la Argentina, la horticultura como actividad más vinculada al mercado, se inicia hacia fines del siglo XIX en los alrededores de los centros poblados más importantes, denominados cinturones hortícolas (ME \& INET, 2010; Fernández Lozano, 2012). Luego, a medida que crecieron la población y los requerimientos de mercado, surgieron las zonas de producción especializadas y las de horticultura extensiva. En la provincia de Buenos Aires, en el 2005, la actividad contaba con 2.934 establecimientos, se desarrollaba en 31.765 ha, siendo 30.540 ha a campo y 1.225 ha bajo cubierta (CHFBA, 2005). No obstante, en 2010, sólo en los alrededores de La Plata, la superficie de producción bajo cubierta había crecido a más de 3.000 ha (Argerich \& Troilo, 2010; Stavisky, 2010; García, 2011). La Provincia de Buenos Aires aporta el 22,2\% del área hortícola total implantada a nivel nacional, y contribuye con el 58,4 y 72,8\% de la producción nacional de papa (Solanum tuberosum L.) y cebolla (Allium cepa L.), respectivamente (MAA, 2007).

La producción hortícola ha sido estudiada en profundidad por su aporte económico o social al desarrollo regional o nacional. Además, en los últimos 10 años, lo ha sido por la creciente preocupación por el impacto ambiental, asociado a la incorporación de cultivo bajo cubierta y al alto uso de agroquímicos (Blandi et al., 2015; Blandi, 2016; DPPBA, 2015; García, 2015). También se desarrollaron estudios acerca del riesgo de contaminación de los acuíferos y la preocupación por la salinización de los suelos a causa de la calidad del agua de riego (Auge et al., 2004; Auge, 2006; Alconada et al., 2011). Sin embargo, el análisis regional sobre el impacto del manejo en la conservación de los nutrientes del suelo ha sido escaso (Abbona et al., 2011). En general, esta preocupación estuvo más vinculada a los cultivos extensivos, por la magnitud de superficie con riesgo al agotamiento de nutrientes. Las producciones hortícolas tienen un elevado uso de insumos, entre ellos los fertilizantes minerales y las enmiendas orgánicas. Se ha informado que este consumo puede ser hasta 20 veces superior que el del resto del sector agropecuario (Fernández Lozano, 2012).

Es necesario cuantificar los nutrientes para conocer si los actuales niveles de fertilización permiten reponer las extracciones en las cosechas o si pueden generar externalidades que afecten otros recursos como el agua o el aire. En relación a los nutrientes en la agricultura, los estudios han estado más vinculados a encontrar la dosis de fertilización necesaria para obtener el máximo rendimiento que para ajustar sus balances. En las producciones de los cinturones hortícolas, además de evaluar los balances, surge la necesidad de monitorear su impacto ambiental, principalmente, por su incidencia en la salud de la población. El objetivo del presente subcapítulo es 
conocer el balance de nutrientes en la actividad hortícola de la provincia de Buenos Aires. Se plantea como hipótesis que el balance de nutrientes por unidad de superficie de la actividad hortícola presenta valores absolutos similares entre los diferentes partidos de la provincia de Buenos Aires.

\section{III.2.2. METODOLOGÍA}

Se consideraron los cultivos cuya producción se realizó en una superficie superior a las 300 ha a nivel provincial (CHFBA, 2005), abarcando las modalidades a campo y bajo invernáculo. Siguiendo los criterios del CHFBA (2005) los cultivos se agruparon en 5 categorías: a) cultivos de hoja (H), b) pesadas y raíz (PyR), c) tallo, flor y fruto (TFyF), d) crucíferas (C) y e) invernáculo (In) (Tabla 3.2.1).

Tabla 3.2.1. Cultivos hortícolas que integran las diferentes categorías empleadas en el análisis de nutrientes en la producción hortícola de la provincia de Buenos Aires. $\mathrm{H}=$ de hojas, PyR= de pesadas y raíz, TFyF= de tallo, flor y fruto, $C=$ de crucíferas, In= de invernáculo.

\begin{tabular}{|c|c|c|}
\hline Grupo & Especie & Nombre científico \\
\hline $\mathrm{H}$ & $\begin{array}{l}\text { Acelga } \\
\text { Cebolla de Verdeo } \\
\text { Espinaca } \\
\text { Lechuga (mantecosa, crespa, } \\
\text { capuchina, criolla) }\end{array}$ & $\begin{array}{l}\text { Beta vulgaris var. cicla (I.) K. Koch } \\
\text { Allium fistulosum L. } \\
\text { Spinacia oleracea L. } \\
\text { Lactuca sativa L. }\end{array}$ \\
\hline PyR & $\begin{array}{l}\text { Anco/Anquito } \\
\text { Batata } \\
\text { Cebolla Valenciana } \\
\text { Papa } \\
\text { Remolacha } \\
\text { Zanahoria } \\
\text { Zapallo }\end{array}$ & $\begin{array}{l}\text { Cucurbita moschata (Duchesne ex } \\
\text { Lam.) Duchesne ex Poir. } \\
\text { Ipomoea batatas (L.) Lam. } \\
\text { Allium cepa L. } \\
\text { Solanum tuberosum L. } \\
\text { Beta vulgaris L. } \\
\text { Daucus carota L. } \\
\text { Cucurbita sp. }\end{array}$ \\
\hline TFyF & $\begin{array}{l}\text { Alcaucil } \\
\text { Choclo } \\
\text { Espárrago } \\
\text { Pimiento } \\
\text { Tomate (perita, redondo) } \\
\text { Zapallo de tronco }\end{array}$ & $\begin{array}{l}\text { Cynara scolymus L. } \\
\text { Zea mays L. } \\
\text { Asparagus officinalis L. } \\
\text { Capsicum annuUm L. } \\
\text { Solanum lycopersicum L. } \\
\text { Cucurbita sp. }\end{array}$ \\
\hline C & $\begin{array}{l}\text { Brócoli } \\
\text { Repollo (blanco, colorado y de } \\
\text { Bruselas) }\end{array}$ & $\begin{array}{l}\text { Brassica oleracea sub. itálica Plenck } \\
\text { Brassica sp. }\end{array}$ \\
\hline $\ln$ & $\begin{array}{l}\text { Espinaca } \\
\text { Lechuga } \\
\text { Pimiento } \\
\text { Tomate }\end{array}$ & \\
\hline
\end{tabular}




\section{III.2.2.1. Balance de nutrientes}

Se realizó un balance de nutrientes (nitrógeno $(N)$, fósforo $(P)$, potasio $(K)$, calcio (Ca)) para cada partido de la provincia de Buenos Aires (134, Lezama se incluye en Chascomús). Debido a la ausencia de datos con el contenido de azufre (S) de la mayoría de los cultivos hortícolas, este nutriente fue excluido del análisis. Se consideró la diferencia entre las entradas y las salidas de nutrientes.

\section{III.2.2.1.1. Entradas de nutrientes.}

Se tuvo en cuenta la fertilización mineral y el estiércol como enmienda orgánica, tanto para la modalidad a campo como bajo invernáculo.

\section{III.2.2.1.1.1. Fertilización mineral de cultivos a campo}

Se consideró la fertilización por grupo de cultivos, respetando las categorías del CHFBA (2005) (Tabla 3.2.1). La fertilización de cada grupo se estimó a partir del dato general de fertilización por cultivo en Argentina según la FAO (2004). En base a consultas a expertos se definió tomar como referencia de fertilización que recibe el grupo TFyF y, al resto de los grupos, se asignó un porcentaje de la misma (Tabla 3.2.2.).

Tabla 3.2.2. Porcentaje de fertilización recibida por cada grupo de cultivos hortícolas respecto a la de TFyF, y superficie total cultivada en la provincia de Buenos Aires. $\mathrm{H}=$ de hojas, PyR= de pesadas y raíz, TFyF= de tallo, flor y fruto, C= de crucíferas, In= de invernáculo.

\begin{tabular}{lcc}
\hline Grupo de cultivos & $\begin{array}{c}\text { Porcentaje de } \\
\text { fertilización asignada } \\
(\%)\end{array}$ & $\begin{array}{c}\text { Superficie } \\
\text { cultivada en la } \\
\text { provincia (ha) }\end{array}$ \\
\hline H & 30 & 8.495 \\
PyR & 40 & $21.197^{* *}$ \\
TFyF & $100^{* * *}$ & 3.942 \\
C & 30 & 1.085 \\
Total & & 34.719 \\
\hline "CHFBA (2005) & \\
" Incluye al cultivo de papa & & \\
$" *$ Valor de referencia & &
\end{tabular}

Primero se calculó la cantidad total de cada nutriente que entra a la superficie hortícola de la provincia por fertilización mineral (1)

$$
n_{T O T}=f \cdot s_{T O T},(1)
$$

donde $n_{T O T}$ es la cantidad total de nutriente aplicado en la provincia de Buenos Aires (kg año-1), f es el valor de aplicación promedio de cada nutriente según la FAO (2004) ( $\mathrm{kg} \mathrm{ha}^{-1} \mathrm{año}^{-1}$ ) (Tabla 3.2.3.) y $S_{T O T}$ es la superficie total cultivada sin considerar la papa (CHFBA, 2005) (23.906 ha), porque la FAO (2004) tiene en cuenta la fertilización de la papa de manera diferenciada. 
Luego, se calculó la cantidad de cada nutriente $(x)$ que recibe el grupo de referencia TFyF (2) consignado los valores en la Tabla 3.2.3.

$$
n_{T O T}=x \cdot s_{T F y F}+0,4 \cdot x \cdot s_{P y R}+0,3 \cdot x \cdot s_{H+C}
$$

donde $x$ (incógnita a despejar), es el valor de referencia de la cantidad de nutriente aplicada al grupo TFyF ( $\left.\mathrm{kg} \mathrm{ha}^{-1} \mathrm{año}^{-1}\right), s_{T F y F}$ : es la superficie correspondiente al grupo TFyF (3.942 ha, Tabla 3.2.2.); $s_{P y R}$ : superficie del grupo PyR (excluye la papa) (10.384 ha, Tabla 3.2.2.); $S_{H+C}$ : superficie de los H y C (9.580 ha, Tabla 3.2.2.).

Tabla 3.2.3. Valor de referencia (f) de nutriente aplicado por fertilización mineral en horticultura según la FAO (2004) y calculado (x) para TFyF.

\begin{tabular}{|c|c|c|}
\hline Nutriente & $\begin{array}{l}\text { Valor de referencia (f) } \\
\quad\left(\mathrm{kg} \mathrm{ha}^{-1} \mathrm{año}^{-1}\right)\end{array}$ & $\begin{array}{l}\text { Valor calculado (x) } \\
\left(\mathrm{kg} \mathrm{ha}^{-1} \text { año-1) }\right.\end{array}$ \\
\hline$N$ & 72 & 157 \\
\hline$P$ & 18,92 & 41,26 \\
\hline K & 19,09 & 41,5 \\
\hline
\end{tabular}

Con el valor calculado $(x)$ de cada nutrientes $y$, teniendo en cuenta los porcentajes de fertilización asignados al resto de los grupos respecto de TFyF (Tabla 3.2.2), se calculó el ingreso por fertilización mineral para los mismos (Tabla 3.2.5).

\section{III.2.2.1.1.2. Fertilización por enmienda orgánica de cultivos a campo}

La cantidad de enmienda (estiércol) aplicada por unidad de superficie se

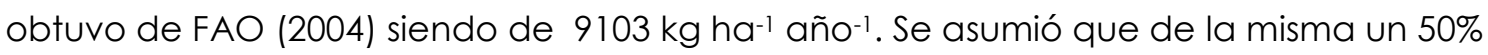
corresponde a ganado vacuno y un $50 \%$ a ganado aviar (gallina). Con el contenido de nutrientes de los mismos se calcularon los nutrientes aportados (Tabla 3.2.4.).

Tabla 3.2.4. Contenido de nutrientes (sobre sustancia seca) y aporte de nutrientes de estiércoles de gallina $(4.551 \mathrm{~kg})$ y ganado vacuno $(4.551 \mathrm{~kg})$.

\begin{tabular}{|c|c|c|c|c|c|}
\hline & \multicolumn{5}{|c|}{ Estiércoles } \\
\hline & \multicolumn{2}{|c|}{ Ganado vacuno } & \multicolumn{2}{|c|}{ Ganado aviar } & \multirow{2}{*}{$\begin{array}{c}\text { Aporte total } \\
\left(\mathrm{kg} \mathrm{ha}^{-1} \text { año-1) }^{-1}\right)\end{array}$} \\
\hline & $\begin{array}{c}\text { Composición } \\
(\%)\end{array}$ & $\begin{array}{c}\text { Aporte } \\
\left(\mathrm{kg} \mathrm{ha}^{-1} \mathrm{año}^{-1}\right)\end{array}$ & $\begin{array}{c}\text { Composición } \\
(\%)\end{array}$ & $\begin{array}{c}\text { Aporte } \\
\left(\mathrm{kg} \mathrm{ha}^{-1} \mathrm{año}^{-1}\right)\end{array}$ & \\
\hline Humedad (\%) & $83^{* 1}$ & & $53^{* 2}$ & & \\
\hline $\mathrm{N}$ & $1,7^{*}$ & 12,7 & $2,4^{* 2}$ & 51,0 & 63,7 \\
\hline$P$ & $0,5^{*}$ & 3,6 & $1,7^{* 2}$ & 36,0 & 39,6 \\
\hline K & $0,5^{1^{*}}$ & 3,5 & $1,1^{* 2}$ & 24,4 & 27,9 \\
\hline $\mathrm{Ca}$ & $1,4^{2^{*}}$ & 11,0 & $2,6^{* 2}$ & 55,0 & 66,0 \\
\hline
\end{tabular}


III.2.2.1.1.3. Fertilización total a campo (mineral y enmienda orgánica)

El aporte de cada nutriente por fertilización mineral y enmienda orgánica para cada grupo de cultivos se presenta en la Tabla 3.2.5.

Tabla 3.2.5. Aporte de nutrientes por fertilización mineral y enmienda orgánica, correspondiente a cada grupo de cultivo de la producción hortícola de la provincia de Buenos Aires. $\mathrm{H}=$ de hojas, PyR= de pesadas y raíz, TFyF= de tallo, flor y fruto, $C=$ de crucíferas, In= de invernáculo.

\begin{tabular}{|c|c|c|c|c|}
\hline Nutriente & $\begin{array}{l}\text { Grupo de } \\
\text { cultivos }\end{array}$ & $\begin{array}{c}\text { Enmienda } \\
\text { orgánica } \\
\left(\mathrm{kg} \mathrm{ha}^{-1} \mathrm{año}^{-1}\right)\end{array}$ & $\begin{array}{c}\text { Fertilización } \\
\text { mineral } \\
\left(\text { kg ha-1 año-1) }^{-1} \text {. }\right.\end{array}$ & $\begin{array}{c}\text { Total } \\
\left(\mathrm{kg} \mathrm{ha-1}^{-1} \mathrm{año}^{-1}\right)\end{array}$ \\
\hline \multirow[t]{4}{*}{$\mathrm{N}$} & $\mathrm{H}$ & 63,7 & 47,1 & 110,8 \\
\hline & PyR & 63,7 & 62,4 & 126,1 \\
\hline & TFyF & 63,7 & 157 & 220,7 \\
\hline & $C^{\prime}$ & 63,7 & 47,1 & 110,8 \\
\hline \multirow[t]{4}{*}{$P$} & $\mathrm{H}$ & 39,6 & 12,3 & 52,0 \\
\hline & PyR & 39,6 & 16,4 & 56,0 \\
\hline & TFyF & 39,6 & 41,0 & 80,6 \\
\hline & C & 39,6 & 12,3 & 52,0 \\
\hline \multirow[t]{4}{*}{ K } & $\mathrm{H}$ & 27,9 & 13,3 & 41,2 \\
\hline & PyR & 27,9 & 16,6 & 44,5 \\
\hline & TFyF & 27,9 & 41,5 & 69,4 \\
\hline & C & 27,9 & 13,3 & 41,2 \\
\hline \multirow[t]{4}{*}{$\mathrm{Ca}$} & $\mathrm{H}$ & 66,0 & - & 66,0 \\
\hline & PyR & 66,0 & - & 66,0 \\
\hline & TFyF & 66,0 & - & 66,0 \\
\hline & C & 66,0 & - & 66,0 \\
\hline
\end{tabular}

Los cultivos de papa y cebolla fueron considerados de manera diferenciada en la fertilización del resto de los cultivos, debido a que su manejo/producción en la provincia es semi-extensivo y diferente al resto. En cambio, para la zanahoria, la batata y la lechuga, si bien pueden encontrarse cultivados de manera semi-extensiva, se tuvieron en cuenta con la fertilización correspondiente a sus respectivos grupos.

La fertilización considerada de los cultivos de cebolla y papa fueron: a) papa:

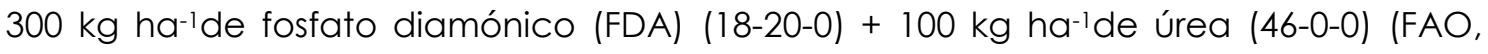
2004). Cebolla: $100 \mathrm{~kg} \mathrm{ha}^{-1} \mathrm{de} F D A+300 \mathrm{~kg} \mathrm{ha}^{-1} \mathrm{de}$ úrea $+100 \mathrm{~kg} \mathrm{ha}^{-1}$ de sulfato de amonio (21-0-0-S 24\%) (Malizia, 2010 Com. Pers.). Los nutrientes aportados por dicha fertilización se encuentran en la Tabla 3.2.6.

Tabla 3.2.6. Aporte de nutrientes por fertilización para los cultivos de papa y cebolla, en la provincia de Buenos Aires.

\begin{tabular}{lccccc}
\hline & \multicolumn{5}{c}{ Nutrientes $\left(\mathbf{k g ~ h a}^{-1} \mathbf{~ a n ̃ o - 1 ~}^{-1}\right)$} \\
\cline { 2 - 6 } Cultivo & $\mathbf{N}$ & $\mathbf{P}$ & $\mathbf{K}$ & $\mathbf{C a}$ & $\mathbf{S}$ \\
\hline Cebolla & 177 & 20 & 0 & 0 & 24 \\
Papa & 100 & 60 & 0 & 0 & 0 \\
\hline
\end{tabular}




\section{III.2.2.1.1.4. Cultivos en invernáculo}

Sólo se consideró fertilización en tomate y pimiento, mientras que la lechuga y la espinaca se tuvieron en cuenta como cultivos secundarios sin fertilizar. Esto último se decidió en base a consulta a expertos. Los datos de fertilización mineral fueron calculados considerando un $70 \%$ de aporte respecto de un planteo de fertilización de alta tecnología para tomate indeterminado, 7-9 coronas con un rendimiento de 100-

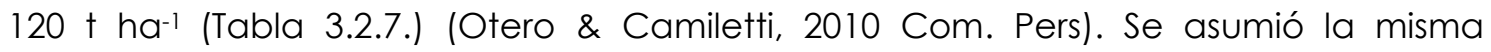
fertilización para pimiento. La aplicación de estiércol se consideró un 50\% superior a la indicada para "cultivos a campo".

Tabla 3.2.7. Aporte de nutrientes por fertilización mineral y orgánica para producción de tomate y pimiento en invernáculo de alta tecnología y asumido como promedio $(70 \%$ respecto al máximo), en la provincia de Buenos Aires.

\begin{tabular}{|c|c|c|c|c|c|}
\hline \multirow{2}{*}{ Fertilización } & \multirow{2}{*}{$\begin{array}{c}\text { Cantidad } \\
\left(\mathrm{kg} \mathrm{ha}^{-1} \text { año-1 }^{-1}\right)\end{array}$} & \multicolumn{4}{|c|}{ Nutriente $\left(\mathrm{kg} \mathrm{ha}^{-1}\right.$ año-1) } \\
\hline & & $\mathbf{N}$ & $\mathbf{P}$ & K & $\mathrm{Ca}$ \\
\hline \multicolumn{6}{|l|}{ Fertilizantes minerales } \\
\hline Nitrato de potasio & 1.000 & 130 & - & 380 & - \\
\hline Cloruro de potasio & 1.050 & - & - & 535 & - \\
\hline Superfosfato triple & 400 & - & 80,0 & - & - \\
\hline Sulfato de Magnesio & 850 & - & - & - & - \\
\hline Nitrato de Calcio & 500 & 77 & - & - & 95 \\
\hline \multicolumn{6}{|l|}{ Enmienda orgánica } \\
\hline $\begin{array}{r}\text { Estiércol } 50 \%+\text { que } \\
\text { campo }\end{array}$ & 13.654 & 96 & 59 & 42 & 99 \\
\hline Total & & 303 & 139 & 957 & 194 \\
\hline $70 \%$ de aplicación & & 212 & 97 & 670 & 136 \\
\hline
\end{tabular}

\section{III.2.2.1.2. Salidas de nutrientes}

Las salidas de nutrientes se calcularon a partir del rendimiento de cada cultivo, en cada partido de la provincia de Buenos Aires (CHFBA, 2005) y del contenido de los mismos tomada de diferentes autores (Tabla 3.2.8.). 
Tabla 3.2.8. Contenido de nutrientes (sobre sustancia fresca) en diferentes cultivos hortícolas.

\begin{tabular}{|c|c|c|c|c|c|}
\hline \multirow{2}{*}{ Cultivo } & \multicolumn{4}{|c|}{ Nutriente $(\mathrm{kg} \mathrm{t}-1)$} & \multirow{2}{*}{ Fuente } \\
\hline & $\mathbf{N}$ & $\mathbf{P}$ & K & $\mathrm{Ca}$ & \\
\hline Acelga & 3,52 & 1,02 & 6,39 & 1,15 & Argenfoods (2010) \\
\hline Alcaucil & 4,64 & 0,94 & 4,30 & 0,40 & $\begin{array}{l}\text { Argenfoods (2010); } \\
\text { Moreiras Tuni et al. (2001) }\end{array}$ \\
\hline Batata & 1,76 & 0,64 & 4,17 & 0,34 & Argenfoods (2010) \\
\hline Brócoli & 8,72 & 0,76 & 0,00 & 1,30 & Maroto (1995) \\
\hline $\begin{array}{l}\text { Cebolla, Cebolla } \\
\text { de verdeo }\end{array}$ & 1,28 & 0,20 & 1,00 & 0,26 & Argenfoods (2010) \\
\hline Choclo & 6,10 & 1,11 & 2,80 & 0,03 & Maroto (1995) \\
\hline Espárrago & 3,52 & 0,39 & 1,36 & 0,25 & Argenfoods (2010) \\
\hline Espinaca & 6,24 & 0,92 & 9,18 & 0,95 & Argenfoods (2010) \\
\hline Lechuga & 1,92 & 0,34 & 2,57 & 0,40 & Maroto (1995) \\
\hline Papa & 4,32 & 0,72 & 4,93 & 0,36 & Argenfoods (2010) \\
\hline Pimiento & 2,08 & 0,26 & 2,13 & 0,11 & Maroto (1995 \\
\hline Remolacha & 3,84 & 0,46 & 3,99 & 0,13 & Moreiras Tuni et al. (2001) \\
\hline Repollo & 3,04 & 0,39 & 2,56 & 0,53 & Maroto (1995) \\
\hline Tomate & 1,60 & 0,43 & 2,67 & 0,09 & Argenfoods (2010) \\
\hline Zanahoria & 1,76 & 0,46 & 3,66 & 0,37 & Argenfoods (2010) \\
\hline $\begin{array}{l}\text { Zapallito, } \\
\text { calabacines }\end{array}$ & 1,28 & 0,33 & 2,03 & 0,24 & Argenfoods (2010) \\
\hline $\begin{array}{l}\text { Zapallo, } \\
\text { calabazas }\end{array}$ & 0,80 & 0,14 & 1,62 & 0,23 & Argenfoods (2010) \\
\hline
\end{tabular}

\section{III.2.3. RESULTADOS}

\section{III.2.3.1. Extracción de nutrientes}

111.2.3.1.1. Extracción por unidad de superficie y su distribución espacial

Los grupos H, PyR, TFyF e In presentaron una mayor extracción anual por unidad de superficie de K, seguido de N, P y Ca (Figura 3.2.1.), mientras que el grupo de C registró una mayor extracción de $\mathrm{N}$ respecto de $\mathrm{K}$, manteniendo el mismo orden en el resto de los nutrientes. La extracción promedio por unidad de superficie en orden decreciente fue de 91,$9 ; 77,3 ; 13,8$ y $8,9 \mathrm{~kg} \mathrm{ha}^{-1}$ año-1 para $K, \mathrm{~N}, \mathrm{P}, \mathrm{y} \mathrm{Ca}$, respectivamente. El grupo PyR, que ocupó el $61 \%$ la superficie cultivada, ejerció una mayor influencia en los valores de extracción promedio, seguido del grupo H con un 
$25 \%$ de la superficie. La mayor extracción de N y Ca se debió al cultivo de papa (160 y $13 \mathrm{~kg} \mathrm{ha}^{-1}$ año-1, respectivamente), mientras que en $\mathrm{P}$ y $\mathrm{K}$ fue por el tomate en invernáculo (40,1 y $248 \mathrm{~kg} \mathrm{ha}^{-1}$ año-1, respectivamente). El grupo PyR presentó la mayor extracción de nutrientes por unidad de superficie, seguido del grupo In (Figura 3.2.1.). En menor medida, y con magnitudes similares entre sí, siguieron en extracción los grupos H, C y TFyF (Figura 3.2.1).

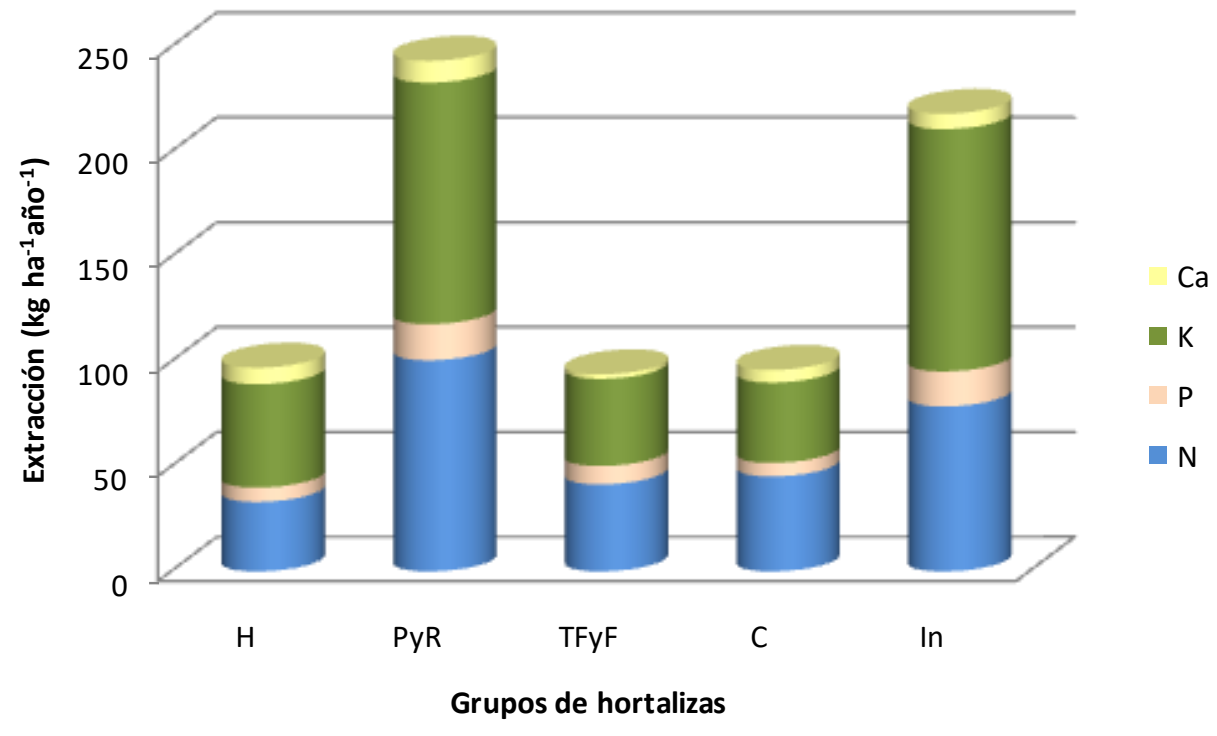

Figura 3.2.1. Extracción de nutrientes por unidad de superficie, debido a diferentes grupos de hortalizas en la provincia de Buenos Aires (año 2005). $\mathrm{H}=$ de hojas, PyR= de pesadas y raíz, TFyF= de tallo, flor y fruto, $C=$ de crucíferas, In= de invernáculo.

Los grupos de PyR e In registraron una mayor producción por unidad de superficie duplicando y casi triplicando, en algunos casos, al resto de los grupos (Tabla 3.2.9.). En el caso de PyR, la elevada producción estuvo acompañada de un menor contenido hídrico del producto extraído respecto del resto de los grupos (Tabla 3.2.9).

Tabla 3.2.9. Producción total, por hectárea (en fresco) y contenido de agua de los diferentes grupos de hortalizas en la provincia de Buenos Aires (año 2005). H = de hojas, PyR= de pesadas y raíz, TFyF= de tallo, flor y fruto, $C=$ de crucíferas, In= de invernáculo.

\begin{tabular}{lrrc}
\hline $\begin{array}{c}\text { Grupo de } \\
\text { hortaliza }\end{array}$ & $\begin{array}{c}\text { Producción } \\
\text { total († año-1) }\end{array}$ & $\begin{array}{c}\text { Producción } \\
\left(\mathbf{k g ~ h a}^{-1} \mathbf{a n ̃ o}\right.\end{array}$ & $\begin{array}{c}\text { Contenido } \mathrm{H}_{2} \mathrm{O} \\
\text { promedio (\%) }\end{array}$ \\
\hline $\mathrm{H}$ & 97.572 & 13.195 & 94 \\
PyR & 671.549 & 32.227 & 84 \\
$\mathrm{TFyF}$ & 38.905 & 15.942 & 87 \\
$\mathrm{C}$ & 11.751 & 14.196 & 90 \\
$\mathrm{In}$ & 77.156 & 41.390 & 94 \\
\hline
\end{tabular}

En el sur y sudeste de la provincia de Buenos Aires (partidos de Balcarce, General Alvarado, Coronel Rosales), se registró la mayor extracción de nutrientes por 
unidad de superficie (Figura 3.2.2. a, b, c, d). En estas zonas predominó el cultivo de papa. El resto de los partidos, donde la magnitud promedio de extracción por unidad de superficie fue menor, presentaron una combinación de cultivos y de producción a campo y bajo invernáculo, que no permitió identificar el origen predominante de la mayor extracción de nutrientes.

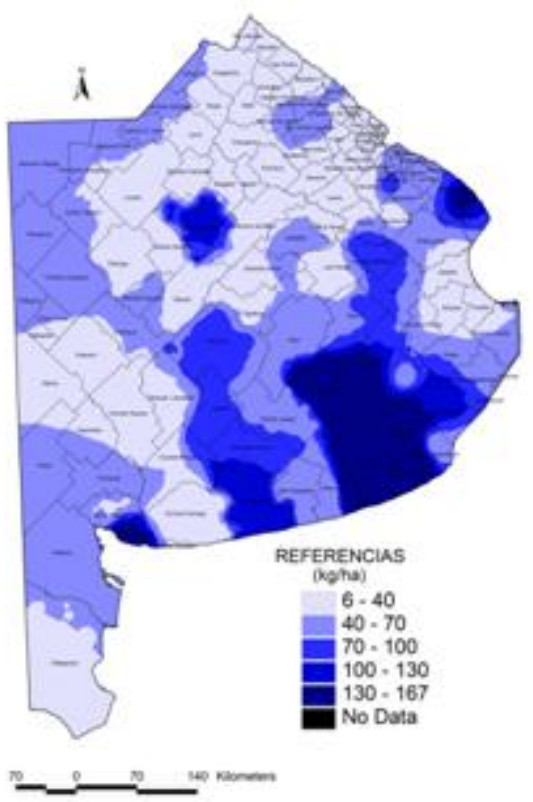

a)

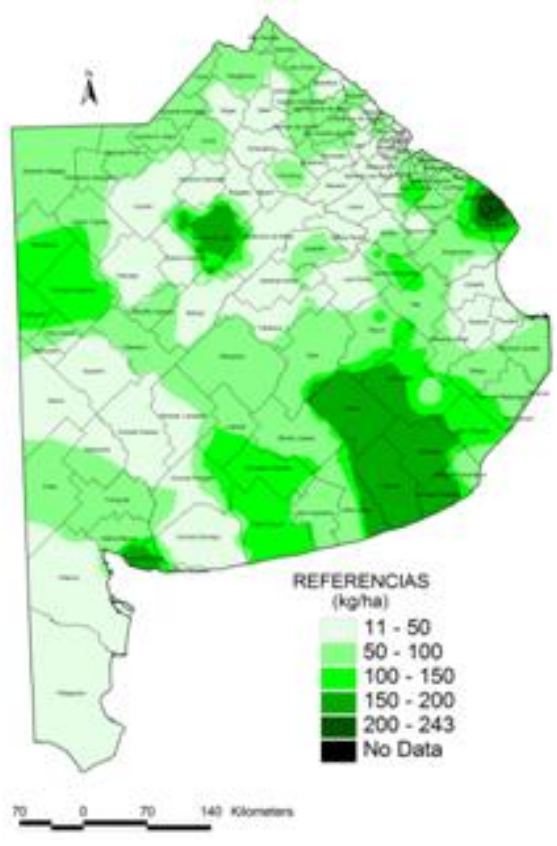

c)

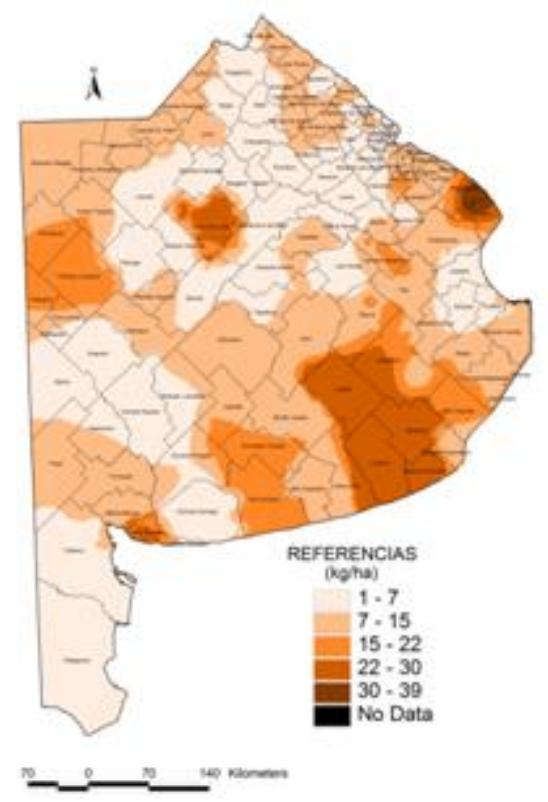

b)

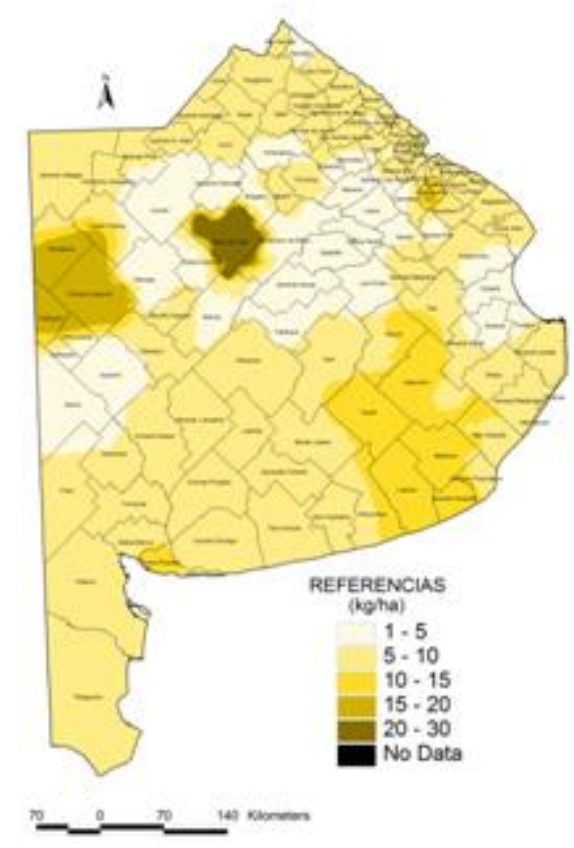

d)

Figura 3.2.2. Extracción anual de nutrientes por unidad de superficie: a) N, b) P, c) K y d) Ca, debido a cultivos hortícolas en la provincia de Buenos Aires (año 2005). 


\section{III.2.3.1.2. Extracción total y su distribución espacial}

La extracción total de los principales macronutrientes debido a cultivos

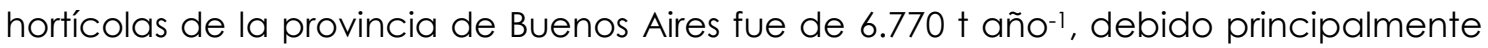
al grupo PyR $(76,2 \%)$, seguido por $H(12,2 \%)$, In $(6,7 \%)$, TFyF $(3,4 \%)$ y $C(1,5 \%)$ (Figura 3.2.3). A pesar de que la superficie cultivada entre los grupos TFyF e In fue similar, la mayor extracción por unidad de superficie del grupo In (Figura 3.2.1) determinó una mayor extracción total de nutrientes.

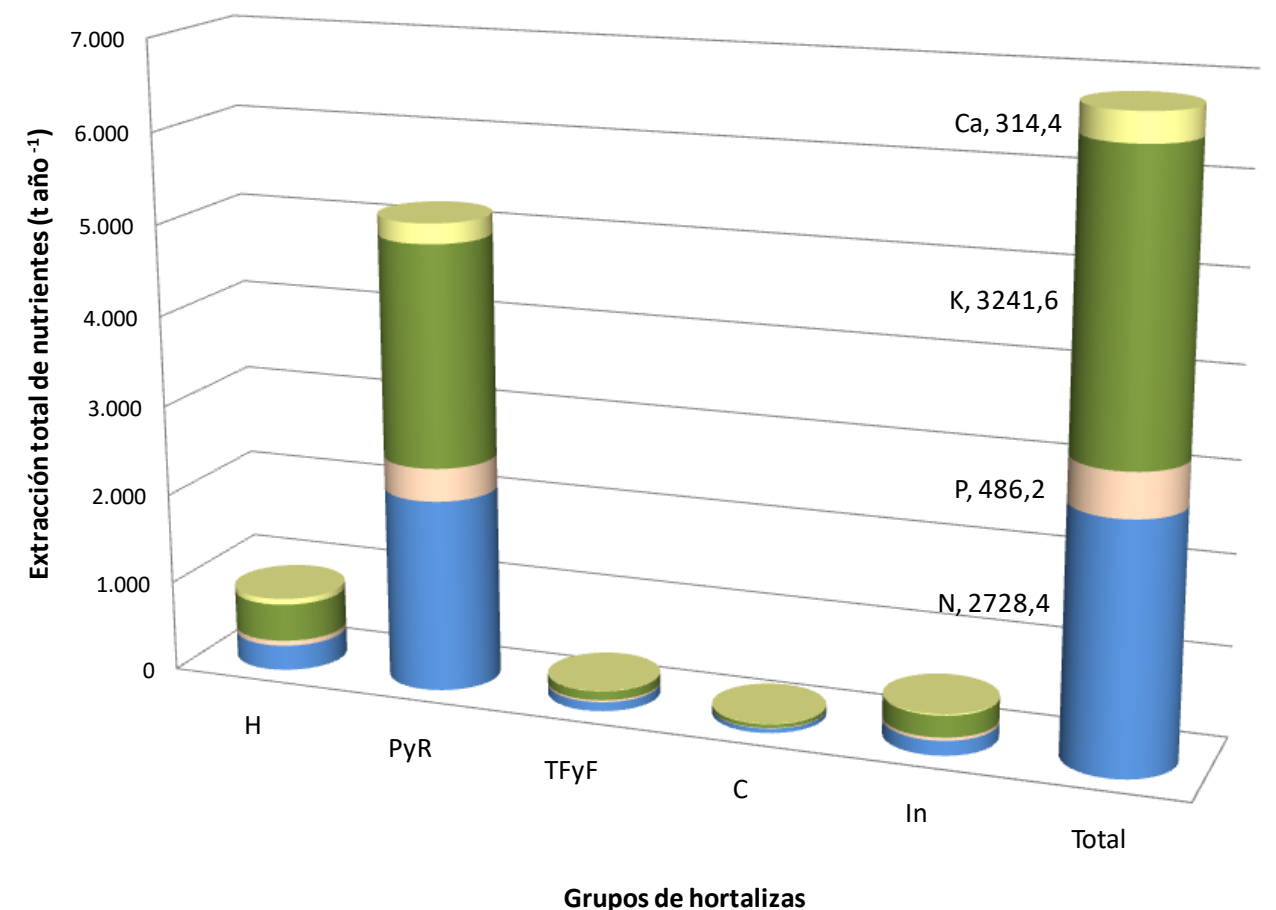

Figura 3.2.3. Extracción total de nutrientes por diferentes grupos de hortalizas en la provincia de Buenos Aires (año 2005). $\mathrm{H}=$ de hojas, PyR= de pesadas y raíz, TFyF= de tallo, flor y fruto, $C=$ de crucíferas, In= de invernáculo.

Los partidos del sudeste y sudoeste presentaron la mayor extracción total de nutrientes (Figura 3.2.4 a, b, c, d), en los primeros predominaron el cultivo de la papa y con manejo semiextensivo y cultivos bajo invernáculo, mientras que en los segundos, predominó la cebolla. Otros partidos que presentaron una elevada extracción total fueron los del cinturón verde de Buenos Aires-La Plata, y el partido de San Pedro. 


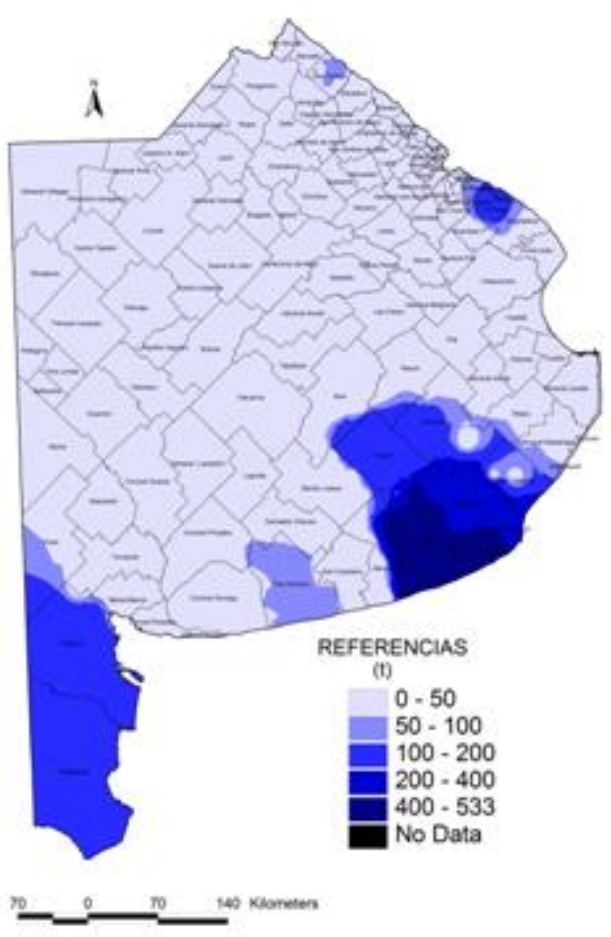

a)

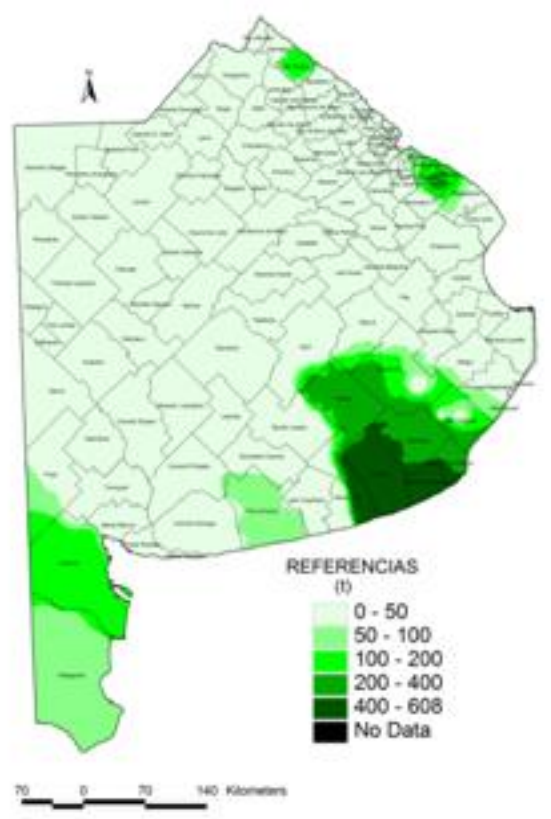

c)

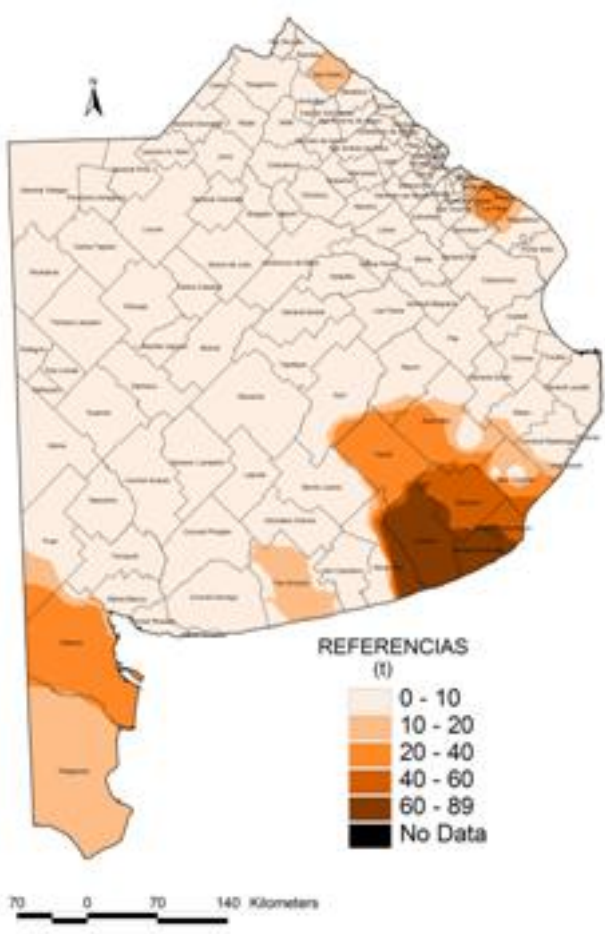

b)

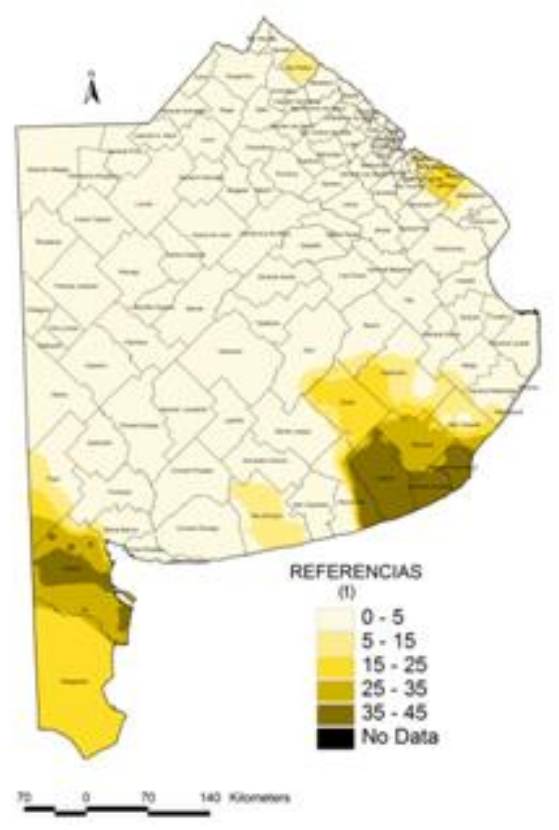

d)

Figura 3.2.4. Extracción total anual de nutrientes: a) $N$, b) $P$, c) $K$ y d) Ca, debido a cultivos hortícolas en la provincia de Buenos Aires (año 2005). 


\section{III.2.3.2. Balance de nutrientes}

\section{III.2.3.2.1. Balance por unidad de superficie y su distribución espacial}

Los balances de nutrientes promedio (ponderados por la superficie) por unidad de superficie fueron positivos para N, P y Ca $(48,9 ; 37,1$ y $24,9 \mathrm{~kg} \mathrm{ha-1}$ año-1, respectivamente), y negativo para $\mathrm{K}\left(-54,9 \mathrm{~kg} \mathrm{ha}^{-1}\right.$ año-1). El grupo TFyF registró los balances más positivos (Figura 3.2.5.). Los grupos que presentaron balances de $\mathrm{K}$ negativos fueron PyR $\left(-106 \mathrm{~kg} \mathrm{ha^{-1 }}\right.$ año-1) y H $\left(-8 \mathrm{~kg} \mathrm{ha}^{-1}\right.$ año-1), contrarrestando el balance positivo del resto de los grupos, principalmente de $\ln \left(147,5 \mathrm{~kg} \mathrm{ha}^{-1}\right.$ año-1).

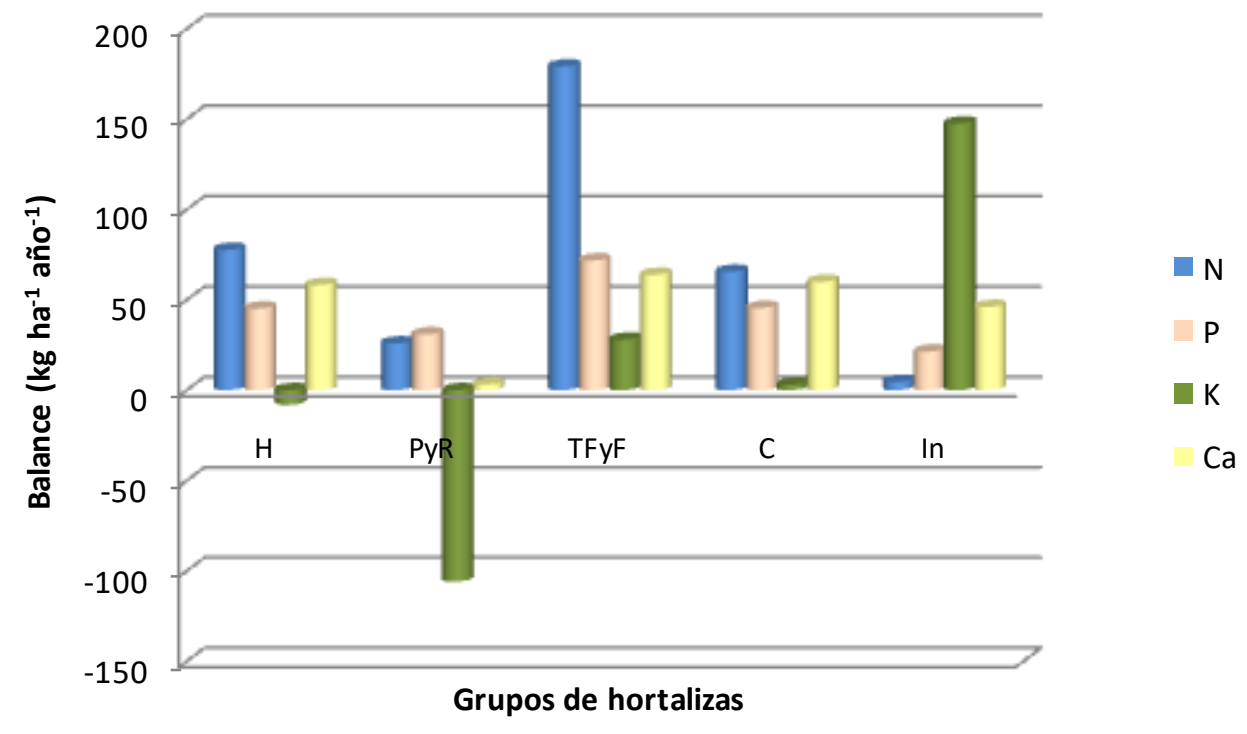

Figura 3.2.5. Balance de nutrientes por unidad de superficie para diferentes grupos de hortalizas en la provincia de Buenos Aires (año 2005). $\mathrm{H}$ = de hojas, PyR= de pesadas y raíz, TFyF= de tallo, flor y fruto, $C=$ de crucíferas, In= de invernáculo.

En $\mathrm{H}$, la acelga y la espinaca presentaron balances negativos de $\mathrm{K}$, mientras que el resto de los cultivos generaron excedentes de todos los nutrientes. En TFyF, sólo el tomate presentó balance de $\mathrm{K}$ negativo $\left(-50,7 \mathrm{~kg} \mathrm{ha}^{-1} \mathrm{año}^{-1}\right)$, mientras que el resto de los cultivos registraron balances positivos de todos los nutrientes. En In, el tomate y el pimiento generaron excedentes de todos los nutrientes principalmente de K (421 y 541 $\mathrm{kg} \mathrm{ha}^{-1} \mathrm{año}^{-1}$, respectivamente), mientras que el resto de los cultivos, debido a la ausencia de fertilización, presentaron déficit de todos los nutrientes. No obstante, los excedentes permitieron contrarrestar los déficits.

En los grupos H, C y PyR (excluyendo la papa y la cebolla), la enmienda orgánica fue la fuente más relevante en el aporte de todos los nutrientes, principalmente en Ca (Figura 3.2.6a, b, c, d). En TFyF e In, la fertilización mineral tuvo mayor relevancia que la enmienda orgánica en el aporte de N, P y K. Para Ca, sólo In 
registró ingreso por fertilización mineral, mientras que el resto de los grupos fue sólo mediante la enmienda orgánica (Figura 3.2.6. d).

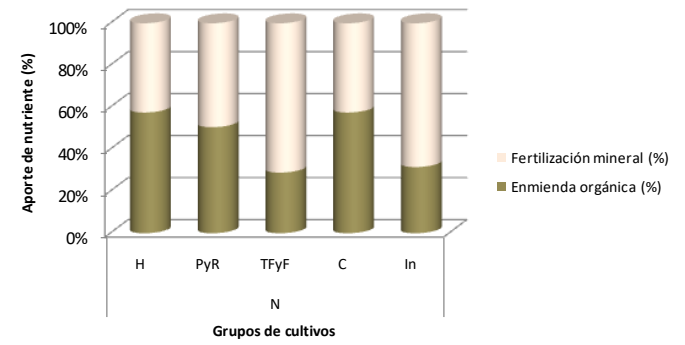

a)

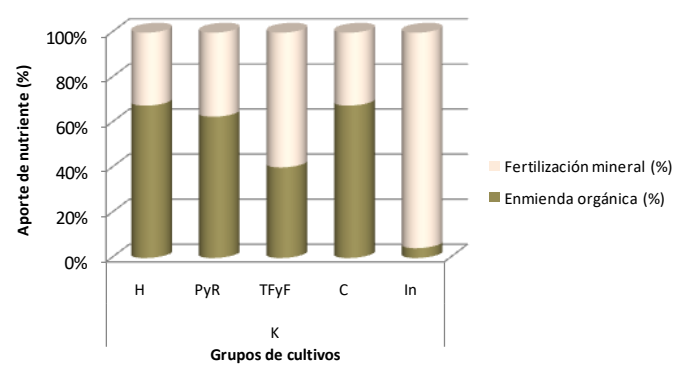

c)

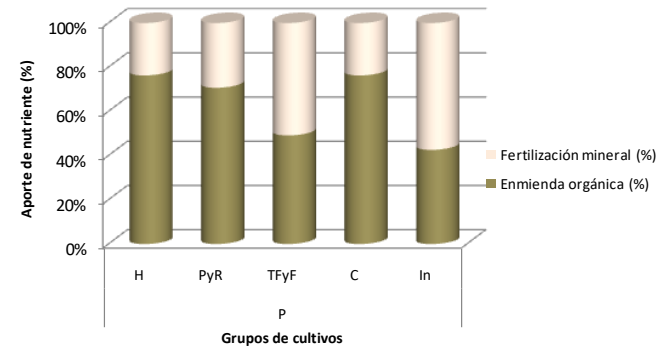

b)

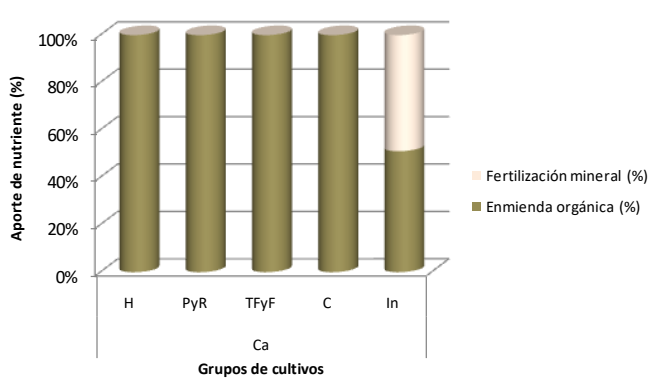

d)

Figura 3.2.6. Aporte proporcional de nutrientes por enmienda orgánica y fertilización de: a) $N$, b) $P, C) K$ y d) Ca), para diferentes grupos de hortalizas en la provincia de Buenos Aires (año 2005). $\mathrm{H}=$ de hojas, PyR= de pesadas y raíz, TFyF= de tallo, flor y fruto, $\mathrm{C}=$ de crucíferas, In= de invernáculo.

Los partidos del sudeste, vinculados a la producción de papa, registraron los balances por hectárea más negativos de N y K (Figura 3.2.7 a, c). También, junto con los partidos del sudoeste ("cebolleros"), presentaron el balance de Ca más negativo (Figuras 3.2.7 d). El balance de $\mathrm{P}$ fue positivo en todos los partidos, siendo los del sudeste y del sudoeste, los de menores excedentes (Figuras 3.2.7 b). 


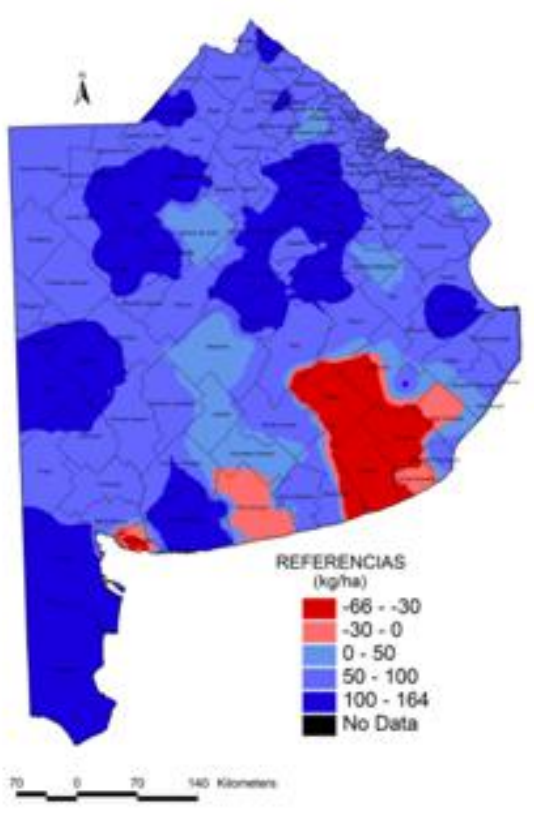

a)

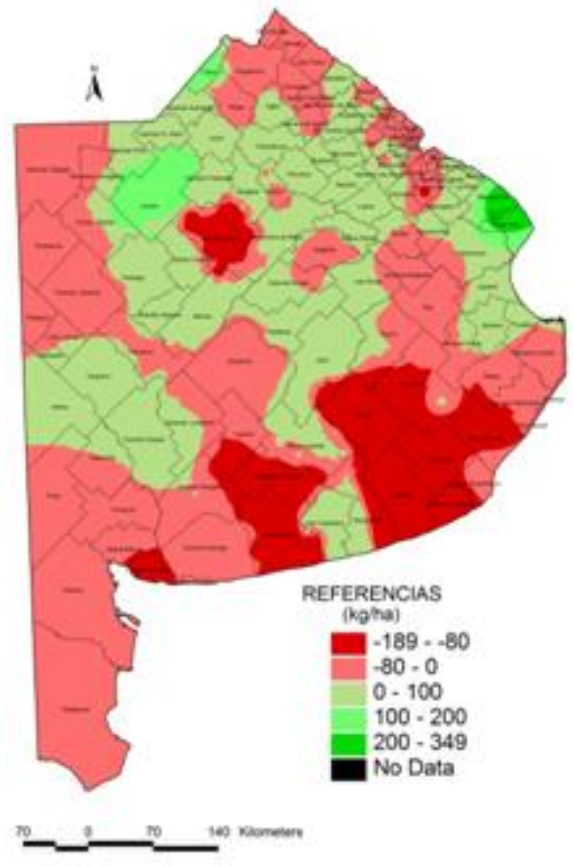

c)

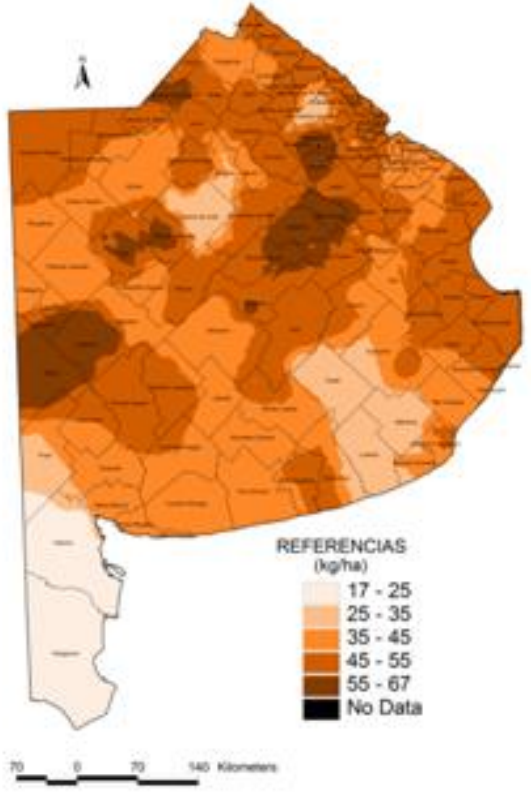

b)

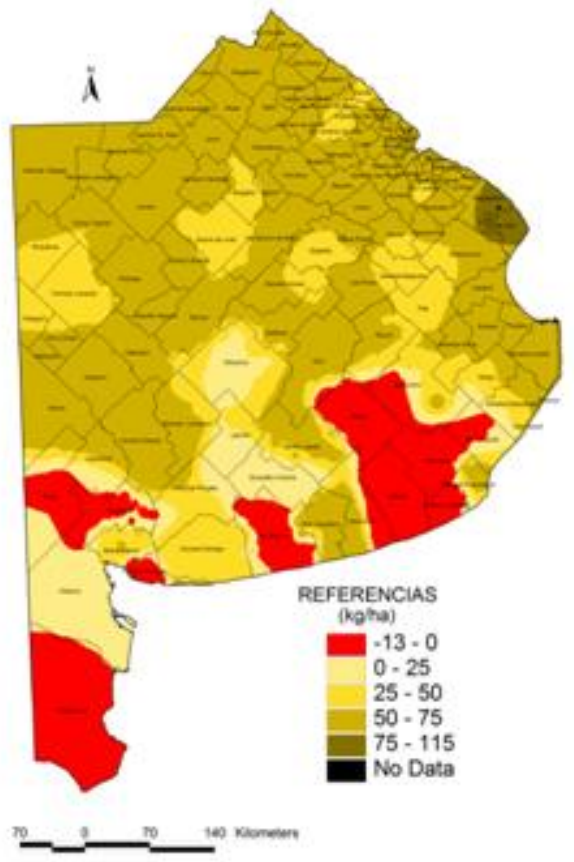

d)

Figura 3.2.7. Balance anual de nutrientes por unidad de superficie: a) $N, b) P$, c) $K$ y d) $C a$, debido a cultivos hortícolas en la provincia de Buenos Aires (año 2005).

\section{III.2.3.2.2. Balance total y su distribución espacial}

Los grupos PyR y $\mathrm{H}$ ejercieron mayor influencia sobre el balance total de nutrientes seguidos, en menor medida, por los grupos de TFyF, In y C (Figura 3.2.8.). El excedente de K que generaron los grupos In y TFyF no compensó el déficit del grupo PyR. Por eso, la horticultura de la provincia, registró un déficit de este nutriente cercano 


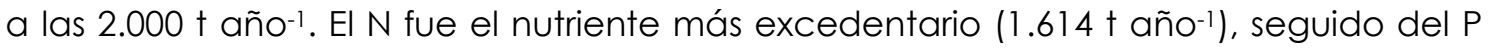
(1.232 † año-1 ) y el Ca $(788$ † año-1 $)$. Los grupos H, PyR y TFyF fueron los que aportaron en mayor medida al exceso de $\mathrm{N}$ y $\mathrm{P}$, mientras que el exceso de Ca fue más relevante en el grupo de $\mathrm{H}$.

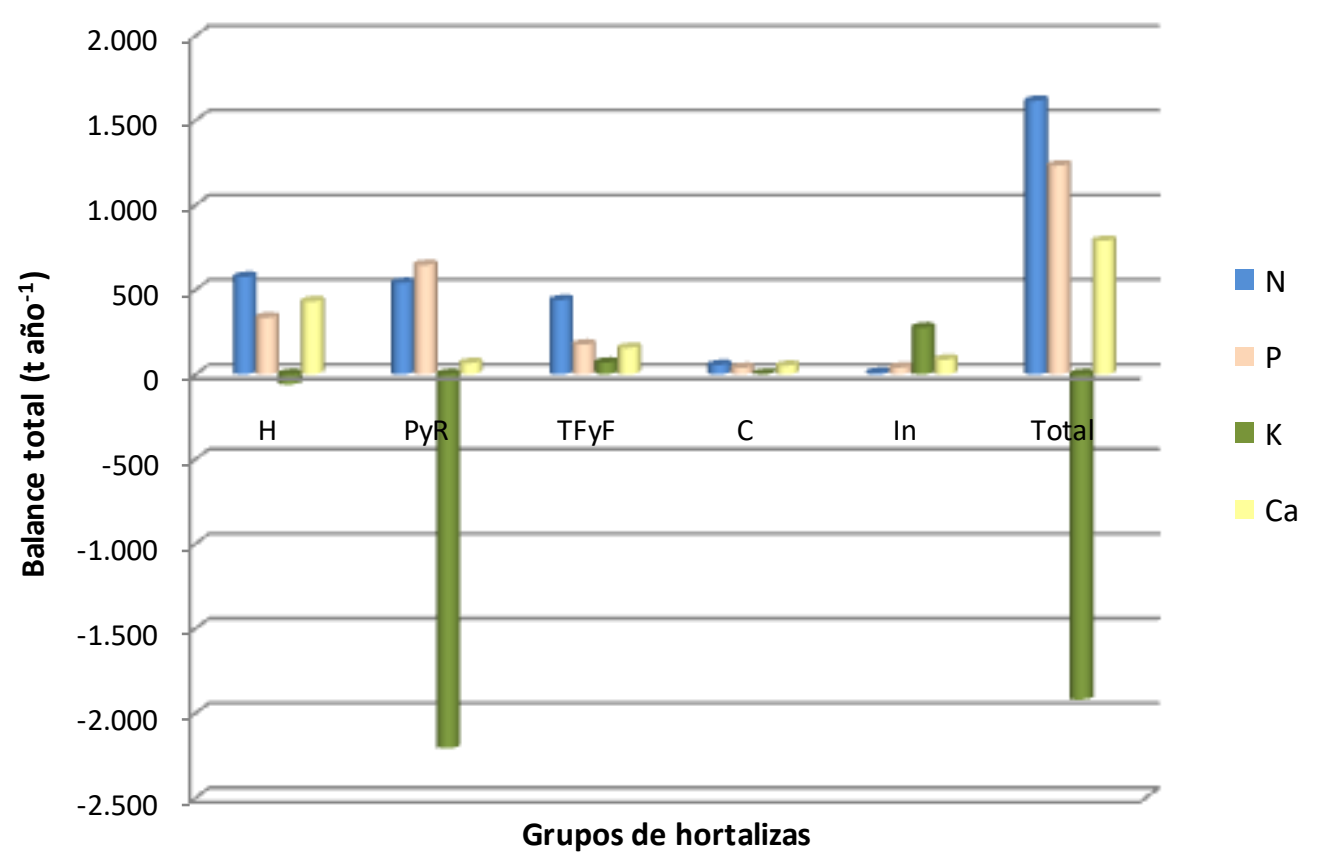

Figura 3.2.8. Balance total de nutrientes para diferentes grupos de hortalizas en la provincia de Buenos Aires (año 2005). $\mathrm{H}=$ de hojas, PyR= de pesadas y raíz, TFyF= de tallo, flor y fruto, $\mathrm{C}=$ de crucíferas, In= de invernáculo.

La mayoría de los partidos de la provincia registraron balance total positivo de $\mathrm{N}$ (Figura 3.2.9.a). Los mayores excedentes se encontraron en los partidos productores de cebolla (sudoeste), los que presentan mayor superficie en cultivos bajo invernáculo (La Plata y alrededores) y/o de hojas (General Pueyrredón y alrededores). Por su parte, los partidos "paperos" (sudeste) mostraron la mayor pérdida de $\mathrm{N}$ de los suelos (Figura 3.2.9.a). En el caso del P, los partidos con producciones más extensivas y/o bajo invernáculo, presentaron los mayores excedentes (Figura 3.2.9.b), a pesar de que no registraron los balances por unidad de superficie más positivos (Figura 3.2.7.a). Los partidos del sudeste registraron la mayor pérdida de K (Figura 3.2.9.c), mientras que, para $\mathrm{Ca}$, los mayores excedentes se verificaron en los partidos con mayor superficie bajo invernáculo (Figura 3.2.9.d). 


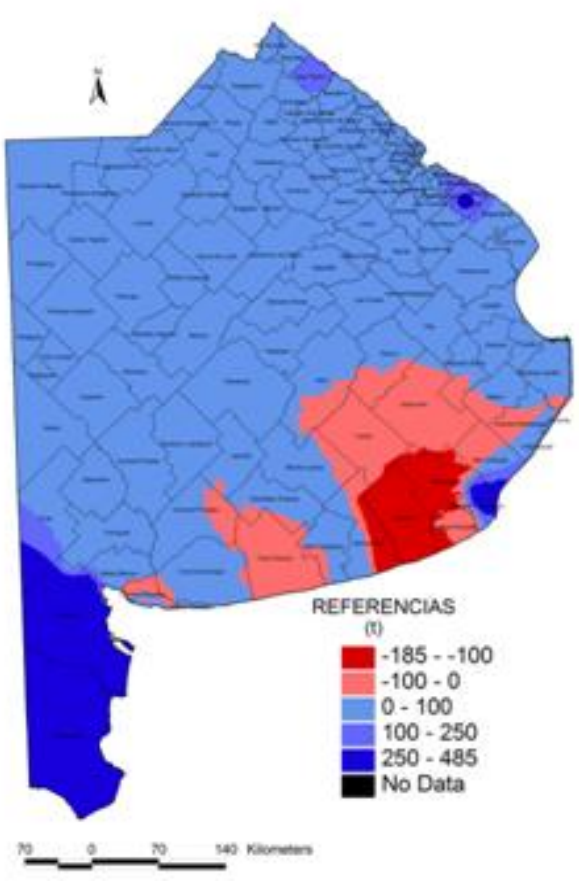

a)

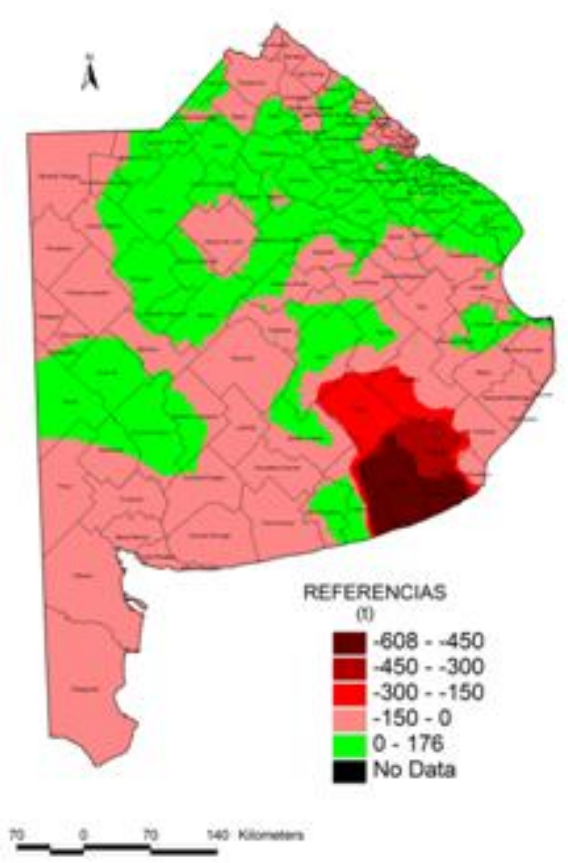

c)

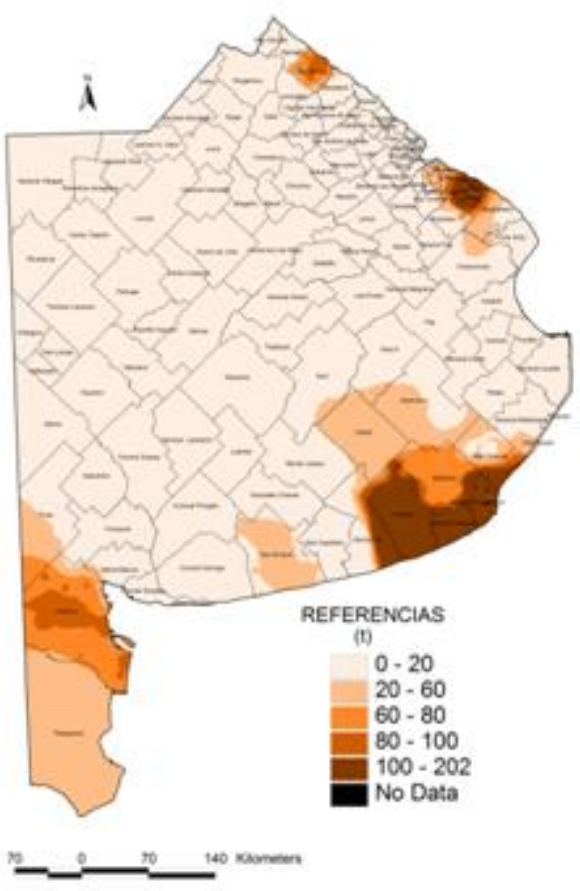

b)
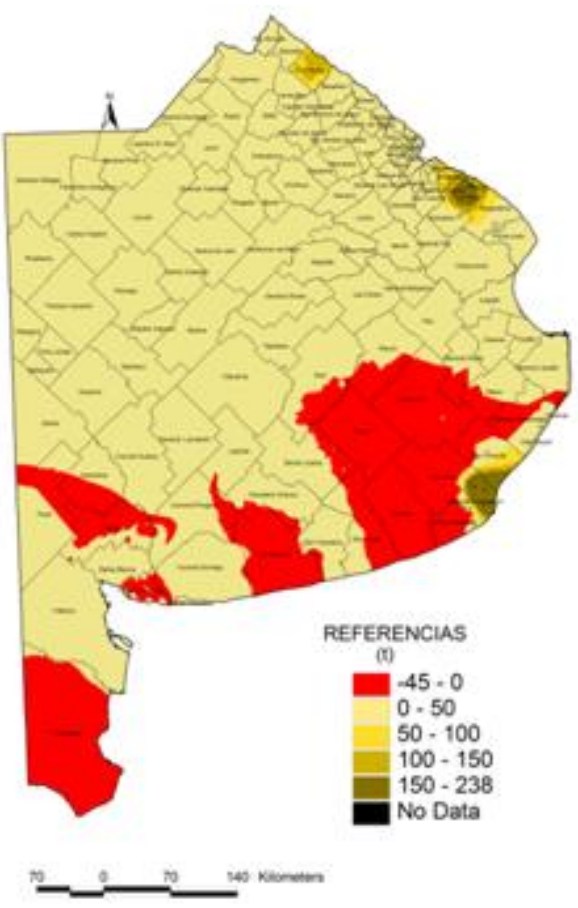

d)

Figura 3.2.9. Balance total anual de nutrientes debido a cultivos hortícolas en la provincia de Buenos Aires: a) N, b) P, c) K y d) Ca (año 2005). 


\section{III.2.4. DISCUSIÓN}

Si bien la horticultura se realiza en toda la provincia de Buenos Aires, las áreas que más influyeron en la extracción total de nutrientes fueron las del sudeste, sudoeste, noreste (San Pedro) y el cinturón verde de Buenos Aires y La Plata (Figura 3.2.4). Estas áreas han sido descritas por Fernández Lozano (2012) y MAA (2007) como las zonas hortícolas más importantes de la provincia. En las tres primeras predominaron los cultivos semi-extensivos a extensivos como la papa y zanahoria en el sudeste, la cebolla en el sudoeste y la batata en el noreste (San Pedro). La zona hortícola del cinturón verde de Buenos Aires - La Plata se destacó en la extracción total de nutrientes, tanto por la superficie destinada a la producción a campo como por la mayor presencia de invernáculos, los cuales tienen una alta productividad por unidad de superficie (Figura 3.2.1). En el resto de la provincia no se observó una elevada concentración de cultivos de los grupos PyR e In, por lo que las extracciones fueron menores.

La mayor extracción de nutrientes por unidad de superficie que registró PyR (Figura 3.2.1), puede estar asociada a que es un grupo que extrae principalmente órganos de reserva (tubérculos, bulbos, raíces engrosadas, etc.), lo que determina la elevada productividad por unidad de superficie.

La mayor extracción por unidad de superficie de K, seguido de N y P (Figura 3.2.1), coincide con lo encontrado por Ribó Herrero (2004) para cultivos hortícolas en España. Esta mayor extracción de K se encontró en 4 de los 5 grupos analizados, lo que muestra la importancia del K en la producción hortícola. A nivel territorial, el 97\% de la superficie cultivada se encuentra con cultivos que extraen $\mathrm{K}$ en mayor medida.

La escasa reposición de $K$ determinó que se genere una pérdida de este nutriente en los suelos hortícolas de la provincia (Figura 3.2.8). Este déficit se debió principalmente al grupo PyR (97\%) y, dentro de éste, al cultivo de papa (88\%). Este cultivo presentó los mayores balances negativos tanto por unidad de superficie como total. Se trata de uno de los cultivos más extractivos de $K\left(182 \mathrm{~kg} \mathrm{ha}^{-1}\right.$ año-1) y en el que, además, la fertilización potásica es nula. Esta baja fertilización se debe a que se aplican criterios semejantes a los cultivos extensivos agrícolas, basados en la respuesta a la fertilización. La buena disponibilidad de K de los suelos (Berardo, 2004; García \& González Sanjuán, 2010;) influye en la decisión de no fertilizar con este elemento, generando una disminución de su reservorio en el suelo.

Se generaron excedentes tanto de $\mathrm{N}$ y $\mathrm{P}$ como de Ca en todos los grupos hortícolas analizados (Figura 3.2.5). Los mayores excedentes se dieron en los grupos $H$, TFyF, C e In predominantes en los cinturones hortícolas y con un manejo más intensivo. Los excedentes en $N$ coinciden con lo encontrado por Ribó Herrero (2004) en 
secuencias hortícolas en España. Si bien los excedentes pueden ser considerados favorables porque no se agotan los suelos, en el caso del $\mathrm{N}$, dichos excedentes pueden generar problemas ambientales como la contaminación de acuíferos (Auge et al., 2004; Auge, 2006; Alconada et al., 2011). Esto adquiere mayor relevancia si se considera que las producciones de los cinturones verdes que circundan las ciudades son las que generan los mayores excedentes de N. Comparando entre las producciones a campo y aquéllas bajo invernáculo, el riesgo de lixiviación es mayor a campo ya que las precipitaciones o el riego por surco pueden contribuir a que el agua percole en profundidad, arrastrando el nitrato en solución excedente hasta los acuíferos. En los invernáculos, este riesgo disminuye debido a la menor percolación a causa de no existir el efecto de la lluvia y, en general, porque se emplea el riego por goteo con láminas que no superan la capacidad de retención hídrica del suelo. El exceso de $\mathrm{N}$ en el grupo PyR afecta una gran extensión de superficie, mientras que en el resto de los cultivos la importancia se circunscribe a la cercanía a los centros urbanos.

En el caso de $\mathrm{P}$ y $\mathrm{Ca}$, por tratarse de nutrientes de baja movilidad, el riesgo de lixiviación se minimiza y, por lo tanto, también el de contaminación de los acuíferos (Auge, 2006). En los invernáculos el excedente de K tampoco generaría problemas ambientales que influyeran en la salud humana. Sin embargo, será necesario monitorear y controlar posibles desbalances en el suelo que pudieran dificultar la absorción de otros nutrientes (Alconada et al., 2011).

En In, la realización de cultivos de hoja sin fertilizar luego de cultivos con alta fertilización favorece la disminución de los excesos de nutrientes, principalmente en $\mathrm{N}$ y $\mathrm{K}$. Si bien los valores de aporte de $\mathrm{N}$ resultaron inferiores a los citados por Alconada et al. (2011) para producción bajo cubierta en el cinturón hortícola de La Plata (1.000 a $1.200 \mathrm{~kg} \mathrm{~N} \mathrm{ha}^{-1} \mathrm{año}^{-1}$ ), los cálculos realizados en el presente estudio arrojaron, de igual manera, balances positivos. Esto indicaría que los excesos en estas producciones podrían ser aún mayores. El excedente de $\mathrm{N}$ aplicado puede acompañar una salinización de los suelos, lo que depende del tipo de fertilizante utilizado. Según Alconada et al. (2011) en los criterios de fertilización en los cultivos bajo cubierta, frecuentemente se considera al suelo como un medio inerte, lo que conduce a la sobrefertilización.

Dado que en la provincia de Buenos Aires los diferentes grupos de cultivos hortícolas a campo y bajo invernáculo, presentaron distintos balances de nutrientes por unidad de superficie (Figura 3.2.5), y que cada partido de la provincia registró diferentes proporciones cultivadas de los mismos, presentando variaciones en los 
balances de nutrientes por unidad de superficie (Figura 3.2.7), se arriba al rechazo de la hipótesis planteada.

En el cálculo del balance de nutrientes de esta tesis se asumió que los restos de cosecha quedan dentro del sector hortícola y no son extraídos. Es necesario profundizar en estudios futuros sobre cuál es el destino predominante de los restos de cosecha, ya que esto puede modificar los balances de nutrientes estimados. Una de las prácticas que se realiza es la quema de los restos de cosecha. En estos casos la salida de $\mathrm{N}$ sería aún mayor que lo estimado, mientras que si las cenizas de los cultivos no son reincorporadas dentro de las parcelas de cultivos se generan transferencias internas de nutrientes.

En el mismo sentido un mayor ajuste de los balances en horticultura requerirá incorporar los aportes de nutrientes a través del agua de riego, considerando las diferencias en su manejo entre la producción a campo y bajo invernáculo (Deluchi et al., 2015), lo cual puede incidir, principalmente, en el aporte de N y K. También deberá tenerse en cuenta la gran expansión que continúa registrándose en la superficie bajo invernáculo, principalmente en el cinturón hortícola de La Plata (Stavisky, 2010; García, $2011)$. Será necesario considerar posibles efectos en el suelo a partir de la fertilización excesiva, así como del impacto de la calidad del agua de riego en la disponibilidad de nutrientes, aspectos que deben ser considerados para evitar problemas futuros.

Si bien en la provincia de Buenos Aires el balance de los nutrientes del suelo en los cultivos bajo producciones intensivas señala que existe acumulación de nutrientes, esto podría generar un riesgo ambiental debido a excedentes lixiviables a los acuíferos. Por otro lado, las producciones semi a extensivas presentan mayores riesgos de agotamiento de los nutrientes del suelo, principalmente de K y Ca.

\section{III.2.5. BIBLIOGRAFÍA}

Abbona, E.A., S.J. Sarandón \& M. Vázquez. 2011. Balance de nutrientes como indicador del manejo sustentable del suelo y el agua en la producción hortícola a campo de la provincia de Buenos Aires, Argentina. VII Congresso Brasileiro de Agroecología. Cadernos de Agroecologia 6(2) 11707: 5pp.

Alconada, M., M. Cuellas, P. Poncetta, S. Barragán, E. Inda \& A. Mitidieri. 2011 . Ferrtirrigación en cultivo de tomate protegido: I- Nutrición nitrogenada. Efectos en el suelo y en la producción. Horticultura Argentina 30(72):5-13.

Argenfoods. 2010. Tabla de composición de alimentos. $I^{\circ}$ Edición. Universidad Nacional de Luján. Disponible en: http://www.argenfoods.unlu.edu.ar/. Último acceso: junio 2016.

Argerich, C. \& L. Troilo. (eds.). 2010. Manual de Buenas Prácticas Agrícolas en la cadena de tomateBuenos Aires: FAO, MAGyP, INTA. 258pp.

Auge, M. 2006. Agua subterránea deterioro de calidad y reserva. 173pp. Disponible en: http://sedici.unlp.edu.ar/bitstream/handle/10915/15908/Documento_completo.pdf?sequence=1 . Último acceso: junio 2016.

Auge, M.P., Hirata, R. \& F. López Vera. 2004. Vulnerabilidad a la contaminación por nitratos del acuífero Puelche en La Plata, Argentina: Informe científico final. Universidad de Buenos Aires. Buenos Aires. 195pp. Disponible en: http://tierra.rediris.es/hidrored/ebooks/miguel/Nitratos.pdf. último acceso: septiembre 2016. 
Berardo, A. 2004. Manejo de la fertilización en una agricultura sustentable. Informaciones Agronómicas 23:23-25.

Blandi, M.L. 2016. Tecnología del invernáculo en el Cinturón Hortícola Platense: análisis de la sustentabilidad y los factores que condicionan su adopción por parte de los productores. 303pp. Tesis doctoral.

Disponible

en: http://sedici.unlp.edu.ar/bitstream/handle/10915/52015/Documento completo .pdf? sequence $=1$. Último acceso: junio 2016.

Blandi, M.L., S.J. Sarandón, C.C. Flores \& I. Veiga. 2015. Evaluación de la sustentabilidad de la incorporación del cultivo bajo cubierta en la horticultura platense. Revista de la Facultad de Agronomía 114(2):251-264.

CHFBA (Censo Hortiflorícola de la Provincia de Buenos Aires). 2005. Gobierno de la Provincia de Buenos Aires, Ministerio de Economía y Ministerio de Asuntos Agrarios. 115pp. Disponible en: http://www.maa.gba.gov.ar/agricultura ganaderia/archivos/resultadofinal.pdf. Último acceso: septiembre 2016.

Deluchi, S.G., C. Flores \& S.J. Sarandón. 2015. Análisis de la sustentabilidad del uso del recurso hídrico bajo tres estilos de producción hortícola en el Cinturón Hortícola Platense. Revista de la Facultad de Agronomía 114(2):287-294.

DPPBA (Defensoría del pueblo de la provincia de Buenos Aires). 2015. Relevamiento de la utilización de agroquímicos en la provincia de Buenos Aires. Mapa de situación e incidencia sobre la salud. Defensor del pueblo de la provincia de Buenos Aires, Universidad Nacional de La Plata. 533pp. Disponible en: http://www.defensorba.org.ar/publicaciones/informeagroquimicos/. Último acceso: octubre 2016.

FAO (Organización de las Naciones Unidas para la Alimentación y la Agricultura). 2004. Uso de fertilizantes por cultivo en Argentina. Roma. 49pp.

Fernández Lozano, J. 2012. La producción de hortalizas en Argentina. Caracterización del sector y zonas de producción. Secretaría de Comercio Interior. Corporación del Mercado Central de Buenos Aires. 29pp.

García, M. 2011. El cinturón hortícola platense: ahogándonos en un mar de plásticos. Un ensayo acerca de la tecnología, el ambiente y la política. Theomai 23:35-53.

García, M. 2015. Horticultura de La Plata (Buenos Aires). Modelo productivo irracionalmente exitoso. Revista de la Facultad de Agronomía (Núm. Esp.1) Agricultura Familiar, Agroecología \& Territorio 114:190-201.

García, F.O. \& M.F. González Sanjuán. 2010. Balances de nutrientes en Argentina ¿̇ómo estamos? ¿̇Cómo mejoramos? Informaciones Agronómicas 48:1-5.

MAA (Ministerio de Asuntos Agrarios). 2007. Nuestra provincia nuestro campo. El sector agropecuario de la provincia de Buenos Aires. 147pp.

Maroto, J.V. 1995. Horticultura herbácea especial. 4ta. edición. Ediciones Mundi-Prensa. Madrid. $611 \mathrm{pp}$.

ME \& INET (Ministerio de Educación de la Nación. Instituto Nacional de Educación Tecnológica). 2010. La horticultura en la Argentina. Informe Final. Disponible en: http://catalogo.inet.edu.ar/files/pdfs/info sectorial/horticultura-informe-sectorial.pdf. Último acceso: junio 2016.

Moreiras Tuni, O., A. Carvajal, L. Cabrera Forneiro \& M. Cuadrado Vives. 2001. Tablas de Composición de Alimentos. Ediciones Pirámide. Madrid. 472pp.

Pascuali, J. 1980. El reciclaje de materia orgánica en la agricultura de América. Boletín de suelos de la FAO 51:161-168.

Ribó Herrero, M. 2004. Balance de macronutrientes y materia orgánica en el suelo de agrosistemas hortícolas con manejo integrado ecológico. Universitat de Valencia. Servei de Publicacions .Tesis doctoral. 185pp.

Sosa, O. 2005. Los estiércoles y su uso como enmiendas orgánicas. Facultad de Ciencias Agrarias de Rosario. Agromensajes de la Facultad 16:30-34.

Stavisky, A. 2010. Situación actual de la plasticultura en Argentina. XXXIII Congreso Argentino de Horticultura. ASAHO. Rosario. 


\section{CAPÍTULO III}

\section{SUBCAPÍTULO 3}

La producción de carne y leche bovinas y la conservación de los nutrientes del suelo

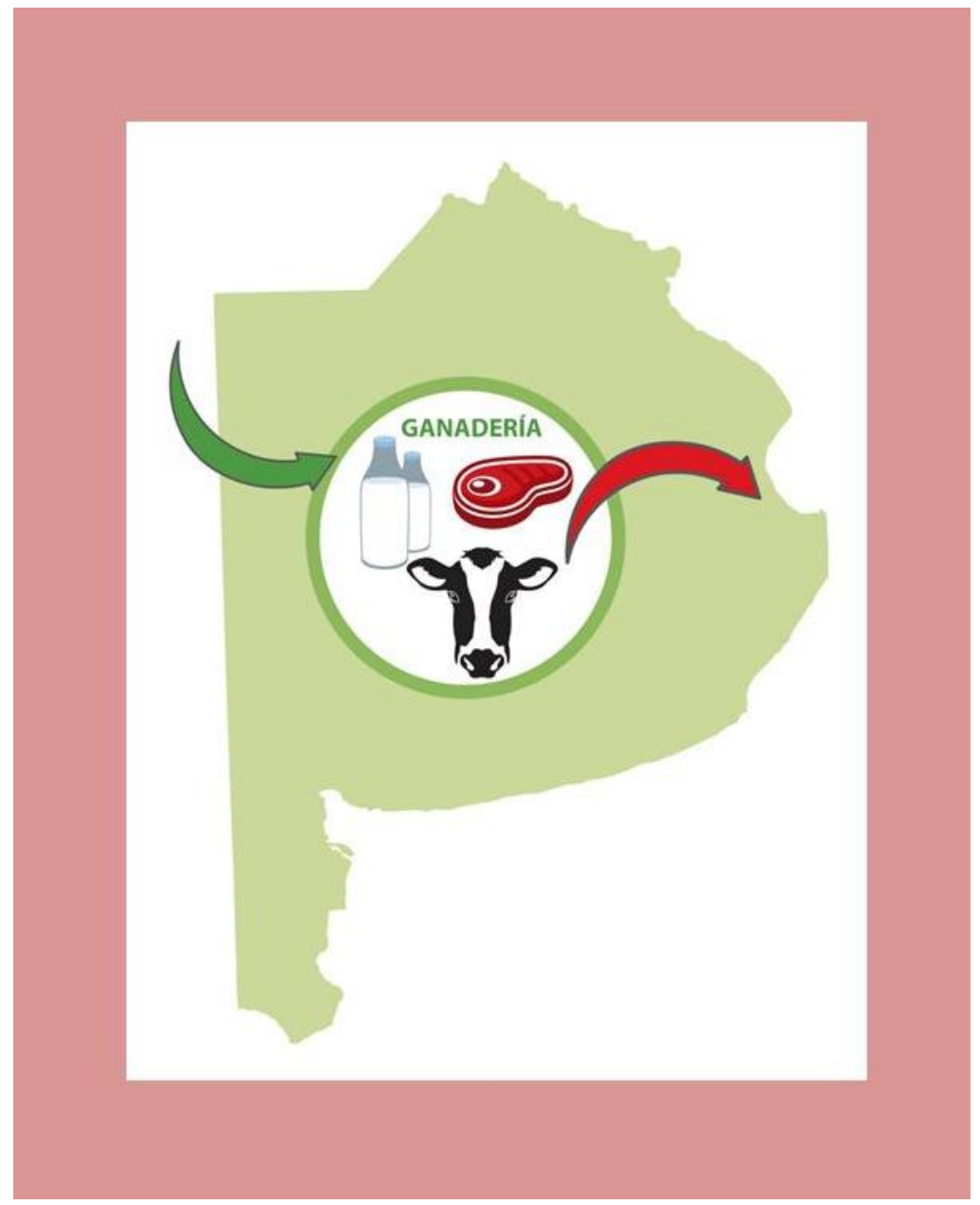




\section{III.3.1. INTRODUCCIÓN}

Una producción agropecuaria sostenible debe ser compatible con la conservación de los recursos naturales, entre ellos el suelo. En los últimos 25 años se ha tomado conciencia de la importancia de conocer cómo el manejo de los nutrientes en las actividades agropecuarias impacta en la calidad del suelo. A partir de esta preocupación, se desarrollaron diversos estudios de balances de nutrientes tanto a nivel internacional (Bekunda \& Manzi, 2003; Oenema et al., 2003; FAO, 2003, 2004a, Gourley et al., 2012) como nacional (Cruzate \& Casas, 2003; Viglizzo et al., 2006). En la Argentina, la mayoría de los estudios sobre balances de nutrientes se centraron sobre los principales cultivos agrícolas (trigo (Triticum aestivum L.), maíz (Zea mays L.), soja (Glycine max (L.) Merr.), sorgo (Sorghum bicolor (L.) Moench), girasol (Helianthus annus L.)) (Flores \& Sarandón, 2003; Cruzate \& Casas, 2012; García \& González Sanjuán, 2010; Zazo et al., 2011). En general, coinciden en la existencia de un déficit en la reposición de nutrientes, lo que señala que se está induciendo a un minado del suelo (Tan et al., 2005). Sin embargo, es menos abundante la investigación sobre balances nutricionales en las producciones de carne (PC) y de leche bovina ( $P L)$, y los resultados no son concluyentes. Herrero et al. (2006) calcularon el balance de N y P en 17 tambos de la provincia de Buenos Aires y señalaron un excedente de estos nutrientes, y Viglizzo et al. (2002), analizando el balance de actividades agrícolas y ganaderas en conjunto en la Región Pampeana, encontraron, a partir de los años 90 , balances positivos en $\mathrm{N}$ y P en planteos de mayor fertilización. Por lo tanto, es necesario mejorar el conocimiento sobre el manejo de los nutrientes en la ganadería de la provincia con el objetivo de contribuir a desarrollar estrategias sostenibles.

La actividad ganadera de la provincia de Buenos Aires se desarrolla en el 54\% de su superficie, aporta el $34 \%$ del stock ganadero bovino (MA, 2015) y el 22,2\% de la producción de leche a nivel nacional (MAA, 2007a). La PC se realiza a partir de los sistemas de cría, recría e invernada que se desarrollan en el 94,2\% de la superficie ganadera, mientras que el resto se destina a la PL, distribuida en seis cuencas (Figura 2.8a), siendo las del oeste y de Abasto sur, las que concentran la mayor cantidad de tambos (Figura 2.8b). Respecto a la PC, existe una zona con predominio de la actividad de cría de ganado vacuno (Pampa Deprimida) y una con predominio de la actividad de "engorde" (invernada) en el oeste de la provincia (Pampa Arenosa) (Figura 2.1). Este extenso y diverso empleo del recurso suelo para la actividad ganadera confirma la necesidad de conocer el impacto sobre la conservación de los nutrientes del mismo.

La escasa preocupación por el balance de nutrientes de la ganadería puede deberse a que esta actividad ha sido considerada siempre como mejoradora de la 
"fertilidad edáfica". De hecho, la inclusión de pasturas perennes incrementa los contenidos de materia orgánica, incorpora nitrógeno $(N)$ por fijación biológica, mejora propiedades físicas tales como la porosidad y la estabilidad de los agregados y, además, incrementa la biomasa microbiana (Díaz Zorita, 2000; García-Prechac et al., 2004; Lemaire et al., 2014). Sin embargo, esta mejora en las propiedades físicas y biológicas, puede enmascarar una disminución de nutrientes del suelo.

Para considerar correctamente los flujos que intervienen en el cálculo del balance de nutrientes, es necesaria una adecuada delimitación del sistema y distinguir flujos internos de ganancias/pérdidas netas. Los sistemas de PC y PL presentan diferencias en la alimentación debido a los requerimientos energéticos y nutricionales. En la PL se necesita una mayor calidad de alimento por lo que la superficie destinada a la misma incluye gran proporción de forrajes implantados, tanto perennes (pasturas) como anuales (verdeos o cultivos para silaje), recurriendo, generalmente, a la suplementación con alimentos externos a los sistemas productivos. En cambio, en la PC, este requerimiento disminuye, siendo menor en la cría que en la invernada. Por eso, la primera basa la alimentación del ganado principalmente sobre pastizal natural, mientras que la segunda, incorpora mayor cantidad de pasturas. Estas diferencias en la alimentación entre los sistemas PC y PL, determinan usos del suelo diferentes que implican distintas tecnologías, como, por ejemplo, la fertilización. En las salidas también existen diferencias ya que en la PC sólo existe una salida (carne) mientras que, en la $\mathrm{PL}$, además de la leche, se extrae carne a través de terneros y vacas de descarte. A pesar de conocer estas diferencias en cuanto a entradas y salidas entre estos sistemas de producción, no se sabe si, contabilizadas en términos de nutrientes, permiten conservar el reservorio de los mismos en el suelo.

El objetivo del presente subcapítulo es conocer el impacto de los sistemas de PC y PL bovina en la conservación de los nutrientes del suelo de la provincia de Buenos Aires. Se plantean como hipótesis que: a) el sistema de PL es más extractivo por unidad de superficie en $N$, fósforo $(P)$, potasio $(K)$, calcio $(C a)$ y azufre $(S)$ que la $P C$, pero, b) debido a la reposición en $\mathrm{PL}$, los nutrientes presentan balances por unidad de superficie más equilibrados que en PC.

\section{III.3.2. METODOLOGÍA}

\section{III.3.2.1. Estimación de la superficie de cría, recría, invernada y tambo}

Se consideró la superficie de pastizales y forrajeras anuales y perennes en los 134 partidos de la provincia (Lezama se incluye en Chascomús) (CNA, 2002). Debido a que no se podía discriminar qué recurso forrajero pertenece a la PC (cría, recría o 
invernada) o PL (tambo), primero se determinó, en cada partido, qué superficie correspondía a la PL. Ésta se calculó a partir de la cantidad de tambos por partido (CNA, 2002) y de la superficie promedio de los tambos en la provincia de Buenos Aires (Chimicz \& Gambuzzi, 2007; MAA, 2007b). Luego, a partir de consultas a expertos, se asumió que la superficie dedicada a tambo en cada partido estaba conformada por $10 \%$ de pastizal natural y el resto (90\%), por una matriz de $3 \times 2$ (3 años con pastura perenne $\times 2$ años con forrajeras anuales). A partir de esta definición y teniendo en cuenta el CNA (2002) se calculó la superficie con pastizal natural, pastura perenne y forrajera anual de cada partido dedicado a la PL, y luego, por diferencia, a la PC.

\section{III.3.2.2. Balance de nutrientes}

Para cada partido de la provincia se realizó un balance de nutrientes (N, P, K, Ca y S) para la PC y PL, tomando como período de referencia el año 2005. El balance se consideró como la diferencia entre las entradas y salidas (extracciones) de nutrientes (Flores \& Sarandón, 2003; García \& González Sanjuán, 2010; García, 2011), tanto por unidad de superficie como total.

\section{III.3.2.2.1. Entradas de nutrientes}

En ambas actividades se consideraron como entradas los ingresos de nutrientes por fertilización de pasturas y forrajeras anuales (verdeos). En la PL, se incluyeron además, los nutrientes que ingresaron a través del alimento balanceado, el cual se consideró que provenía de la actividad agrícola (recurso externo a PL). Se estimó el contenido de nutrientes de una ración diaria de $4,5 \mathrm{~kg}$ de este alimento (base de maíz) por vaca en producción (Mancuso \& Terán, 2008; Chimicz \& Gambuzzi, 2007).

Las dosis de fertilización anual de pasturas y forrajeras anuales se obtuvieron de FAO (2004b) y se ajustaron mediante consulta a expertos. Para las pasturas se asumió que la fertilización se realizó sólo durante la implantación. Considerando una duración promedio de las mismas de 3 años, la superficie anual fertilizada fue del $33 \%$ del total. Para la entrada de $\mathrm{N}$ mediante fijación biológica se consideró $86,8 \mathrm{~kg} \mathrm{ha}^{-1}$ año-1 para pasturas con leguminosas (Racca et al., 2001) y de $5 \mathrm{~kg} \mathrm{ha}^{-1}$ año-1 para pastizal natural (Marino \& Agnusdei, 2007).

\section{III.3.2.2.2. Extracción de nutrientes}

En PC como extracción se consideró la variación anual de peso de las diferentes categorías de animales en el rodeo (Tabla 3.3.1), más un descarte del 20\% de las categorías "vacas" y "toros". En PL se consideró la salida por leche y, además, 
se tuvo en cuenta la salida de carne por terneros (180 kg animal-1) y por vaca de descarte ( $20 \%$ del total de vacas con un peso de $600 \mathrm{~kg}^{\text {animal }}{ }^{-1}$ ).

Para estimar la cantidad de animales en las diferentes categorías en PC y PL se consideraron las existencias totales por categoría de rodeo vacuno y de las categorías del rodeo de tambo según CNA (2002). Para obtener las existencias relacionadas a PC, a las existencias totales por categoría se restaron las existencias para tambo de la misma categoría. Pero en tambo, sólo aparecía la categoría vaquillonas y no se encontraba discriminada en las categorías 1-2 años y +2 años, por lo cual, se asumió que del total de vaquillonas en tambo, el $60 \%$ correspondía a la categoría de 1-2 años y el $40 \%$ a la de más de dos años. En PC, se consideró que un $20 \%$ de las terneras y vaquillonas correspondía a reposición interna, con lo cual no formaron parte de la extracción de carne anual en esas categorías, pero se tuvieron en cuenta en la salida de vacas de descarte (20\% del total de vacas). El contenido de nutrientes de la carne se obtuvo de García (2006) y Fontanetto et al. (2011).

Tabla 3.3.1. Incremento anual de peso para diferentes categorías de ganado en PC.

\begin{tabular}{ll}
\hline Categoría & Incremento anual de peso $(\mathbf{k g}$ año-1) \\
\hline Terneros/as & 170 \\
Vaquillonas 1-2 & 100 (de $170 \mathrm{a} 270 \mathrm{~kg})$ \\
Vaquillonas +2 años & $100($ de $270 \mathrm{a} 370 \mathrm{~kg})$ \\
Novillitos $1-2$ años & 180 \\
Novillos +2 años & 100 \\
Vacas & $400 \mathrm{~kg}$ (peso al momento del descarte) \\
Toros & $600 \mathrm{~kg}$ (peso al momento del descarte) \\
\hline
\end{tabular}

Para el cálculo de la salida de nutrientes por la PL, para el año 2005, se calculó un promedio de producción para cada cuenca lechera (MAA, 2007b), que luego se utilizó para determinar los litros anuales de leche producidos de cada partido en función de las vacas en producción (CNA, 2002). El contenido de nutrientes de la leche se obtuvo de Taverna (2007) y Gourley et al. (2012).

\section{III.3.3. RESULTADOS}

\section{III.3.3.1. Extracción de nutrientes}

\section{III.3.3.1.1. Extracción por unidad de superficie}

La extracción de nutrientes promedio (ponderado por la superficie) de la actividad ganadera (PC y PL) fue de 3,$9 ; 0,9 ; 0,4 ; 1,7$ y $0,2 \mathrm{~kg} \mathrm{ha}^{-1}$ año-1 para $\mathrm{N}, \mathrm{P}, \mathrm{K}, \mathrm{Ca}$ y $S$, respectivamente. Estas extracciones se aproximaron a la de PC (Figura 3.3.1) debido a que esta actividad ocupó la mayor parte de la superficie ganadera $(94,2 \%)$. 
La extracción por unidad de superficie de la PL fue 4,$3 ; 3,6 ; 17,5 ; 2,6$ y 5,5 veces superior a la de PC para N, P, K, Ca y S, respectivamente. Estos resultados confirman la primera hipótesis que la PL es más extractiva por unidad de superficie, en todos los nutrientes, que la PC. En PL la salida de leche contribuyó con $78 ; 73 ; 95 ; 66 ;$ y $84 \%$ de las extracciones de N, P, K, Ca y S, respectivamente, siendo lo restante debido a la carne exportada de ese sistema (terneros y vacas de refugo). Estas proporciones de extracción debidas a la leche en PL son similares a las encontrados por Gourley et al. (2012) para N, P y K (82, 74 y 94\% respectivamente) pero mayor en S (52\%). La extracción de los distintos nutrientes a través de la carne en PL fue en promedio un 10\% menor que en PC, lo que muestra una paridad entre ambas actividades en cuanto a la producción de carne. Las cantidades de $\mathrm{N}$ y $\mathrm{P}$ extraídos por carne y leche en tambos fueron menores que las halladas por Herrero et al. (2006) en la provincia, pero similares a las informadas por Gourley et al. (2012) para 41 tambos de Australia.

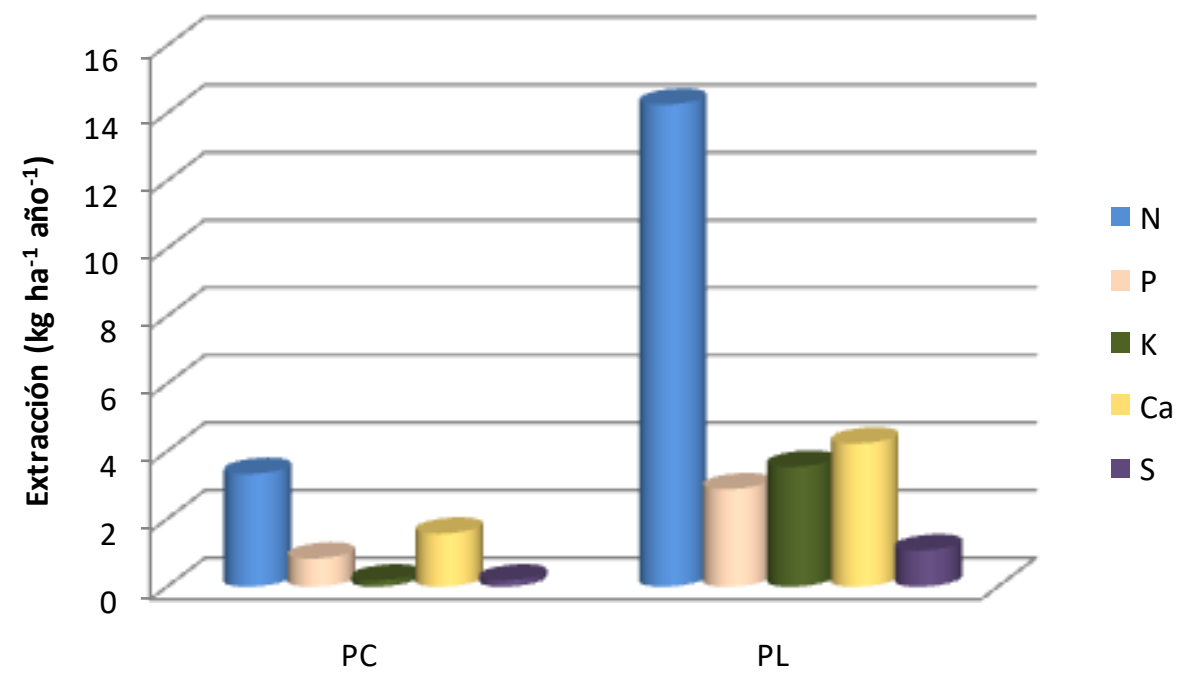

Figura 3.3.1. Extracción de nutrientes por unidad de superficie en producción de carne (PC) y leche (PL), en la provincia de Buenos Aires (año 2005).

En ambas actividades el $\mathrm{N}$ fue el nutriente más extraído seguido del Ca. El tercer nutriente dependió del tipo de producción: fue P en PC y K en PL. El S fue el nutriente menos extraído en ambas actividades (Figura 3.3.1).

\section{III.3.3.1.2. Extracción total}

La mayor extracción total de N, P, Ca y S estuvo determinada por la PC, mientras que la PL fue responsable de la mayor salida de K (Figura 3.3.2). A pesar de la diferencia de superficie entre ambas actividades, PL contribuyó con el 19, 16, 55, 13 y $24 \%$ de las extracciones totales de N, P, K, Ca y S, respectivamente. El N fue el nutriente 
más extraído por la actividad ganadera en su conjunto, siendo 2, 4, 11 y 21 veces superior a Ca, P, K y S.

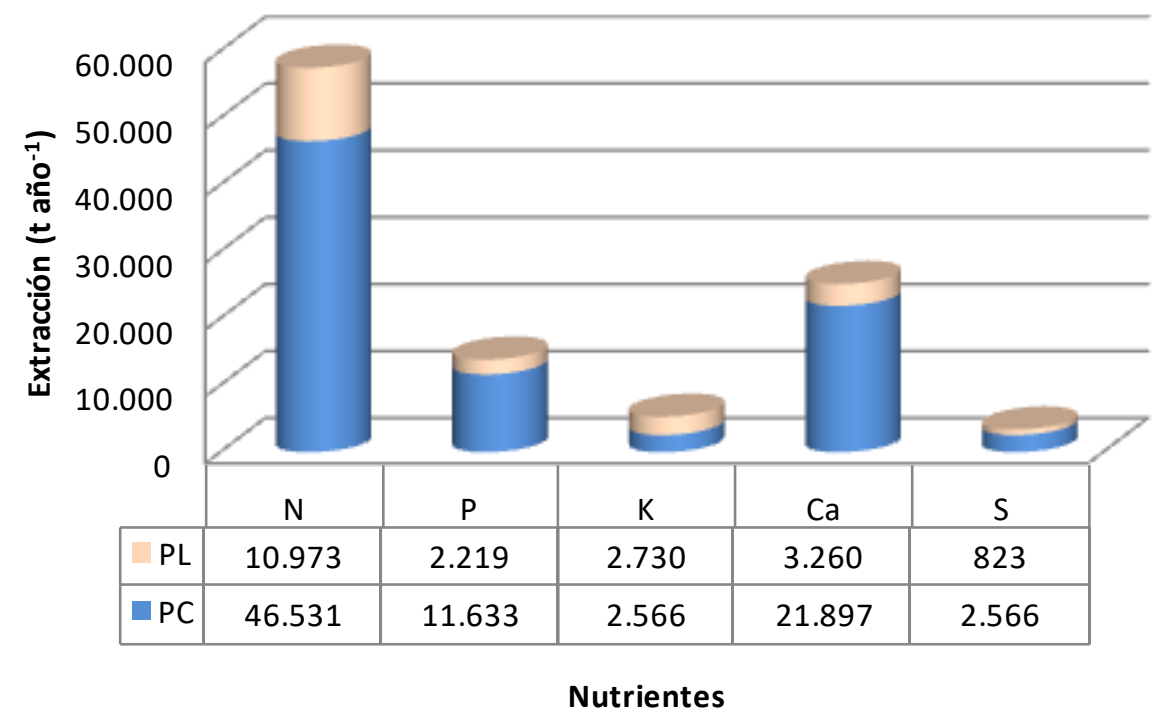

Figura 3.3.2. Extracción total de nutrientes por producción de carne (PC) y leche (PL), en la provincia de Buenos Aires (año 2005).

\section{III.3.3.1.3. Distribución espacial de las extracciones}

La extracción de los diferentes nutrientes por hectárea fue sumamente variable entre los diferentes partidos de la provincia (Figura 3.3.3 a, b, c, d, e). Se observó una mayor extracción por unidad de superficie de todos los nutrientes en las zonas noroeste, norte y sudeste de la provincia, que se corresponde con las cuencas lecheras Oeste, Abasto Norte y Abastos Sur y parte de Mar y Sierras (Figura 2.8). 


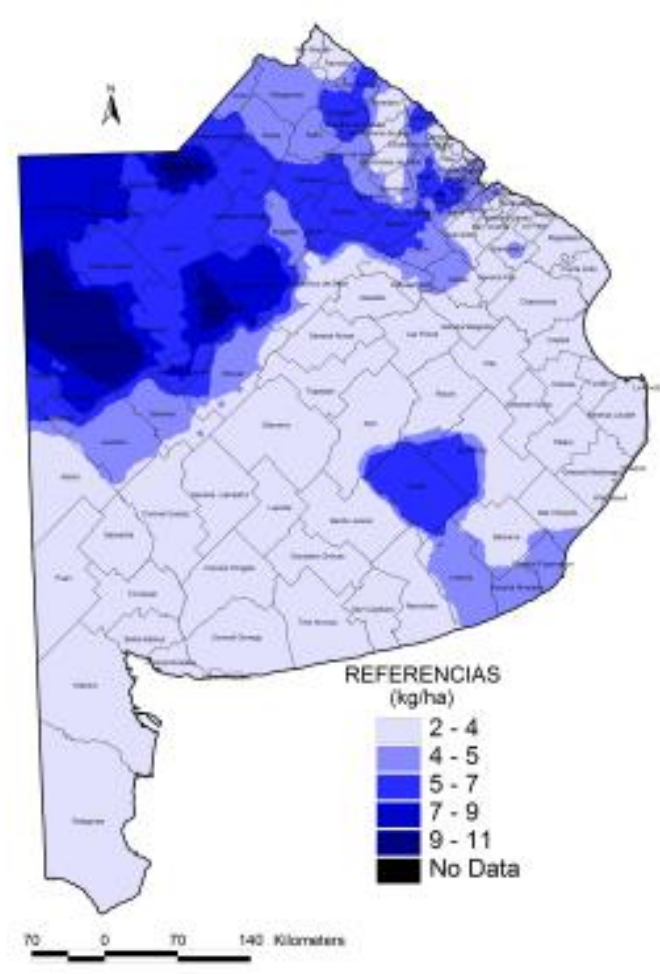

a)

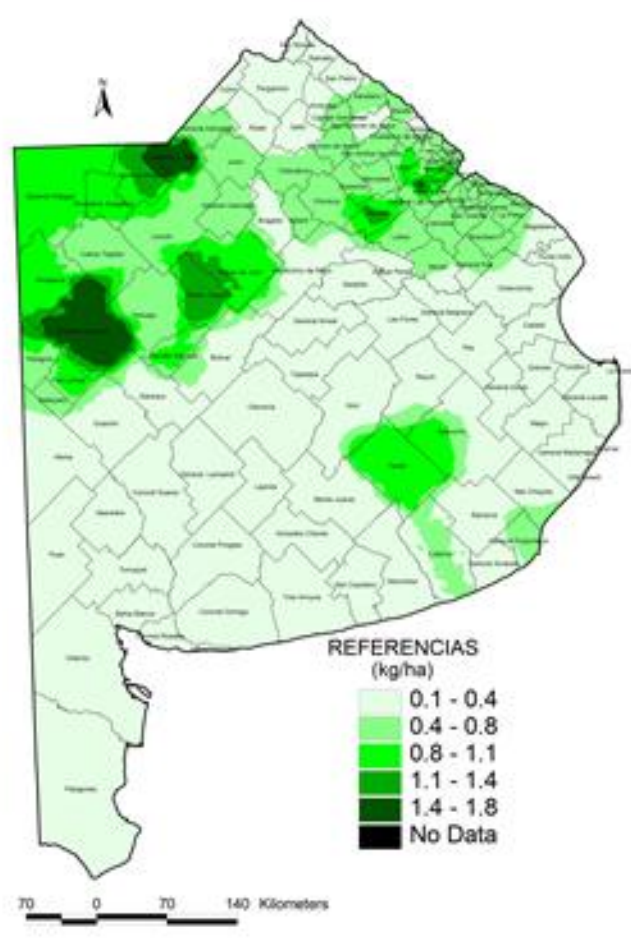

c)

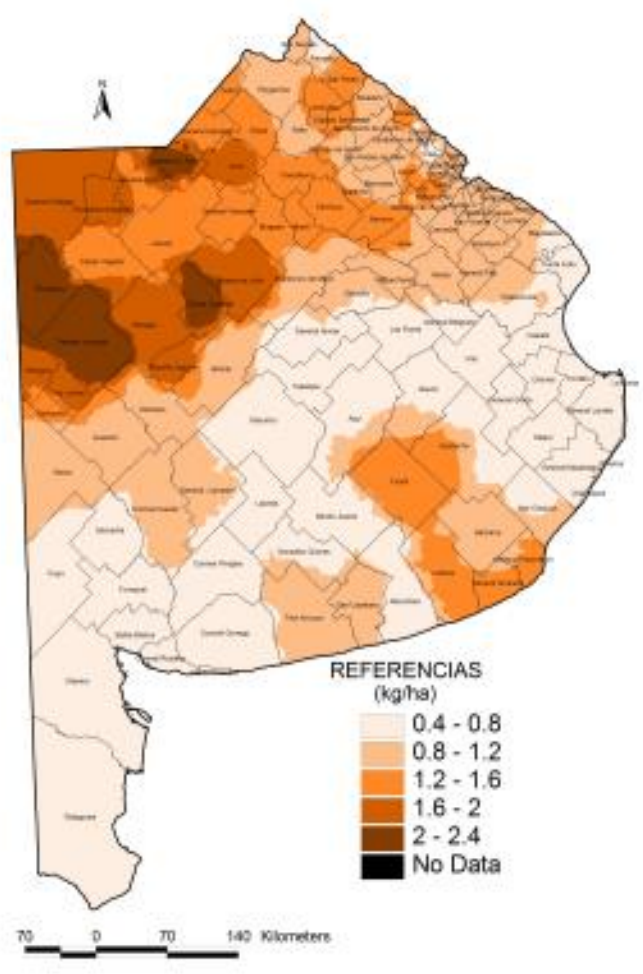

b)

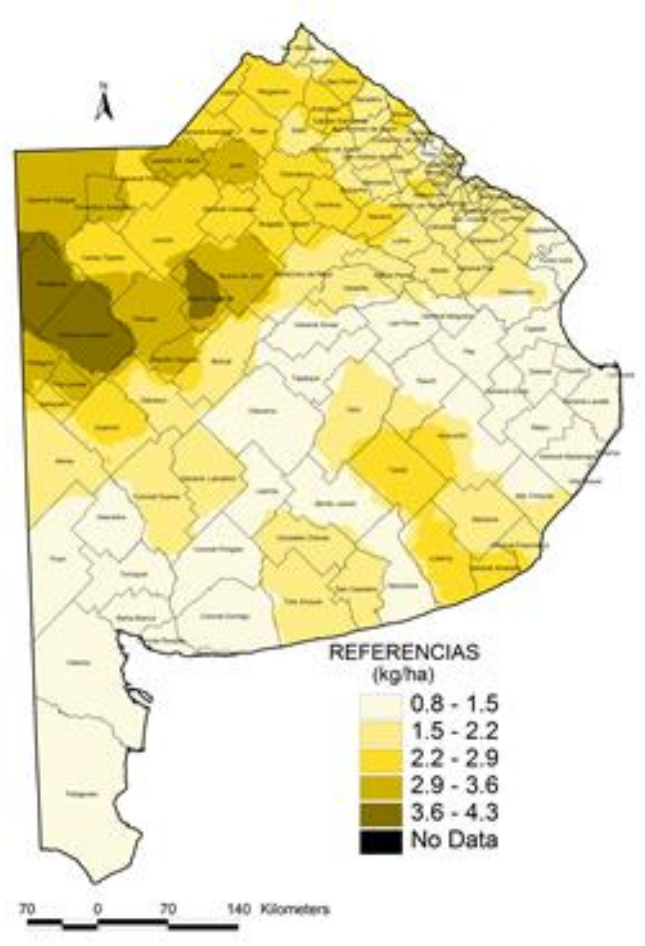

d) 


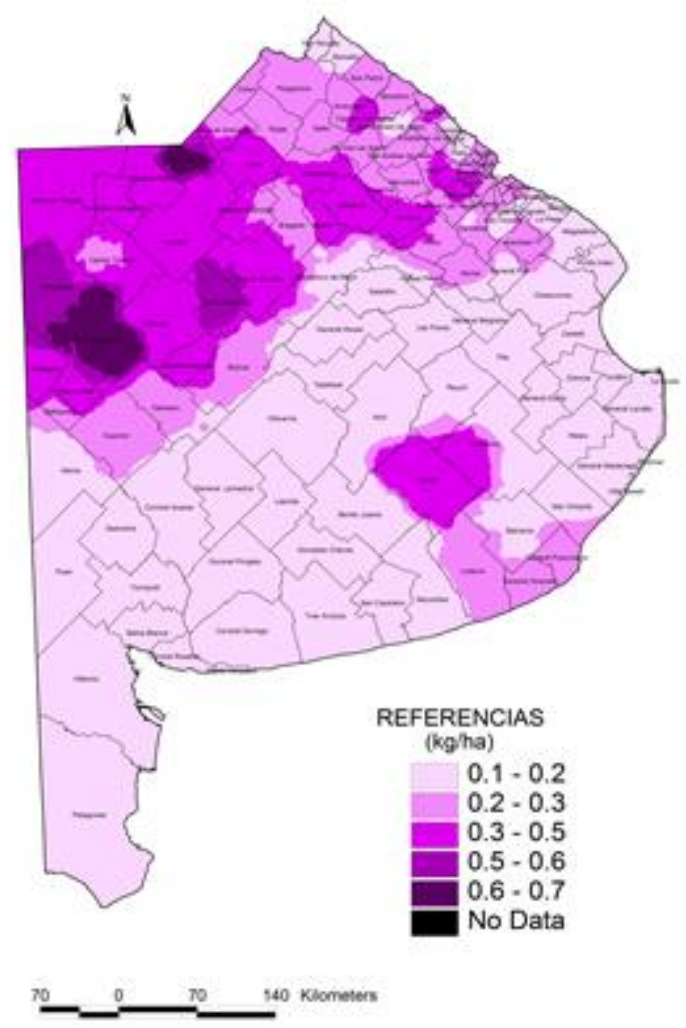

e)

Figura 3.3.3. Extracción anual de nutrientes por unidad de superficie de: a) N, b) P, c) K, d) Ca y e) $S$, generada por la producción de carne y de leche bovinas, en la provincia de Buenos Aires (año 2005).

Las mayores extracciones de nutrientes por unidad de superficie y total se observaron en la zona noroeste (Figuras 3.3.3. y 3.3.4 a, b, c, d, e) que se corresponde con la Pampa Arenosa (Figura 2.1). Ésta es fuertemente ganadera, tanto de tambo (Figura 2.8 a y b) como, dentro de la PC, de invernada.

La extracción total de nutrientes se incrementó de sudeste a noroeste y de este a oeste (Figura 3.3.4 a, b, c, d, e). Esto coincide, por un lado, con una transición dentro de la PC desde un predominio de la cría (este) a la invernada (oeste), la cual genera una mayor producción de carne por hectárea (salida) (MA, 2015). Por el otro, en el noroeste y el sudeste se ubican dos zonas de importante desarrollo de producción lechera (Figura 2.8 a y b). 


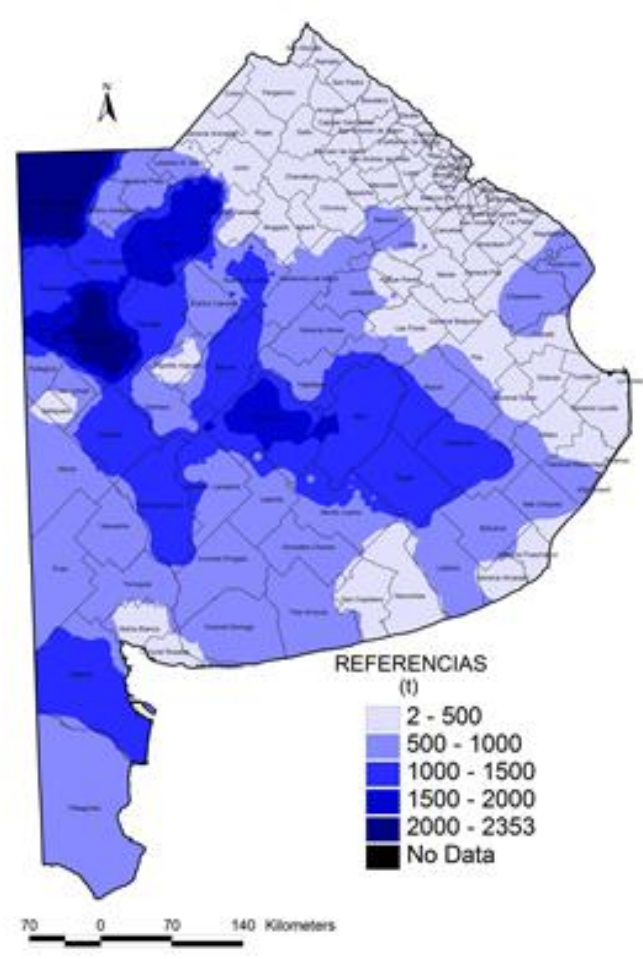

a)

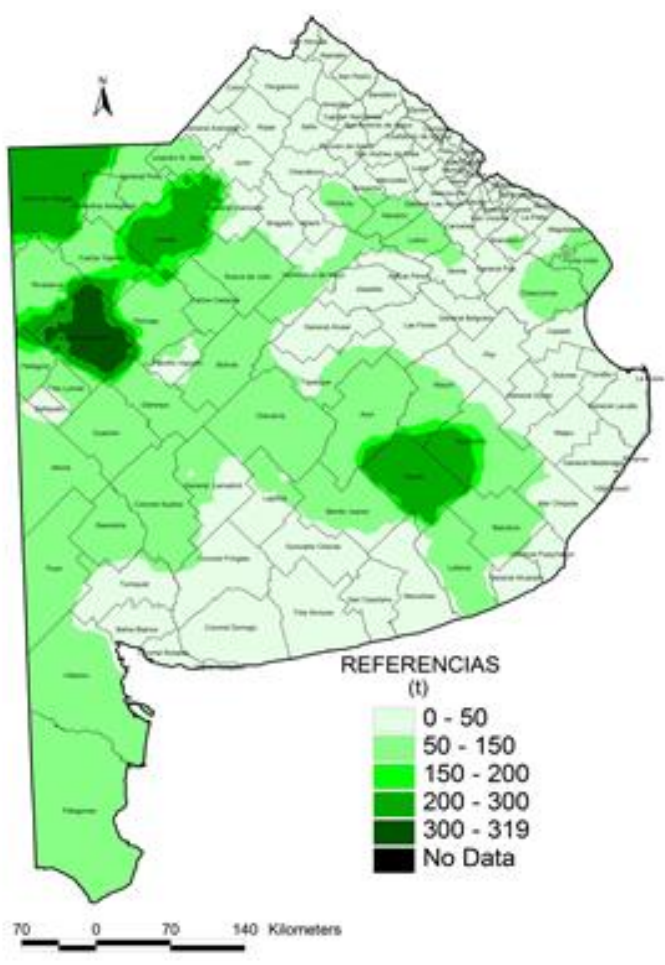

c)

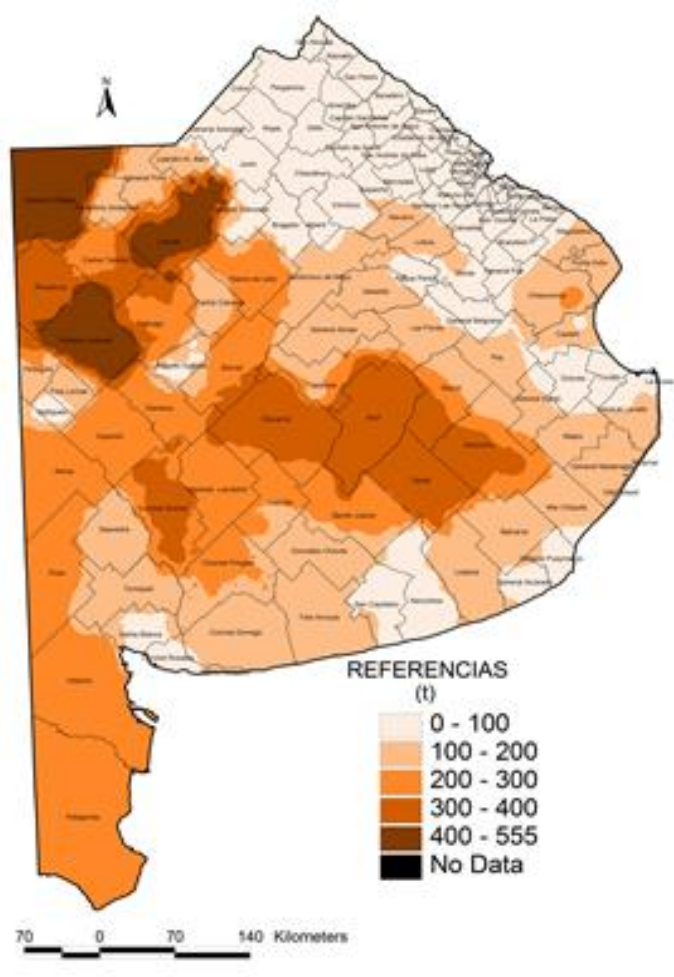

b)

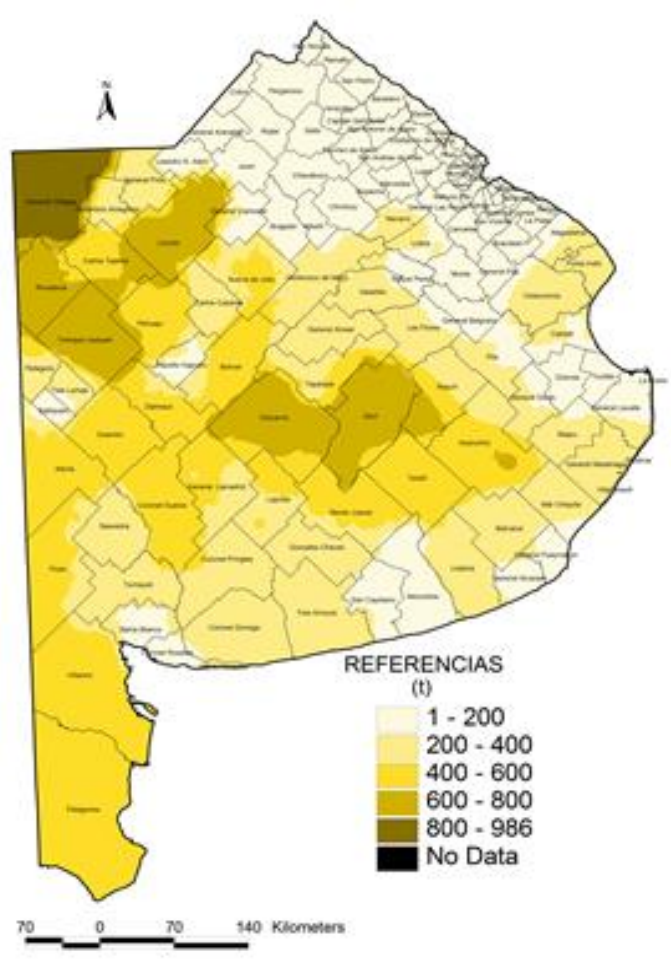

d) 


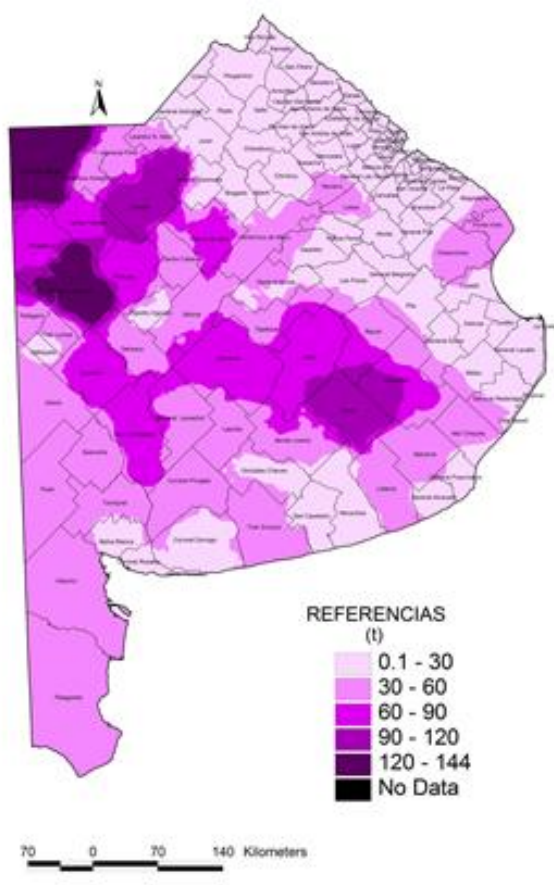

e)

Figura 3.3.4. Extracción total anual de: a) N, b) P, c) K, d) Ca y e) S, debido a la producción de carne y de leche bovinas en la provincia de Buenos Aires (año 2005).

\section{III.3.3.2. Balance de nutrientes}

\section{III.3.3.2.1. Balance por unidad de superficie}

La diferencia entre el ingreso y el egreso de nutrientes en las actividades ganaderas (PC y $\mathrm{PL}$ ) determinó un balance por unidad de superficie positivo para $\mathrm{N}$ y $P$, pero negativo para K, Ca y S (Figura 3.3.5). Herrero et al. (2006) también encontraron un exceso de $\mathrm{N}$ y $\mathrm{P}$ en tambos de la provincia de Buenos Ares. En esta tesis, el balance positivo de $\mathrm{N}$ fue favorecido principalmente por el ingreso vía fijación biológica (70\%) seguido de la fertilización nitrogenada (16\%) y por el consumo de alimento balanceado (14\%). Estos valores difieren de lo encontrado por Herrero et al. (2006) quienes, según el tamaño del establecimiento, informaron que el ingreso de $\mathrm{N}$ por alimento balanceado fue similar a la fijación biológica y menor que por fertilización. También son diferentes a lo indicado por Gourley et al. (2012) quienes señalaron un $43 \%$ del ingreso de $\mathrm{N}$ por los fertilizantes, un $40 \%$ por los alimentos externos y sólo un $16 \%$ por fijación biológica. En la PC, un $90 \%$ del N ingresó por fijación biológica y un 10\% por fertilización. Sólo el aporte de N por fijación permitiría reponer el N extraído en la PC tanto en la cría, que basa su mayor producción en pastizales naturales, como en la invernada, la cual incorpora una mayor proporción de pasturas. Balances positivos 
de $\mathrm{N}$ debido a la presencia de pasturas leguminosas habían sido reportados por Viglizzo et al. (2002).

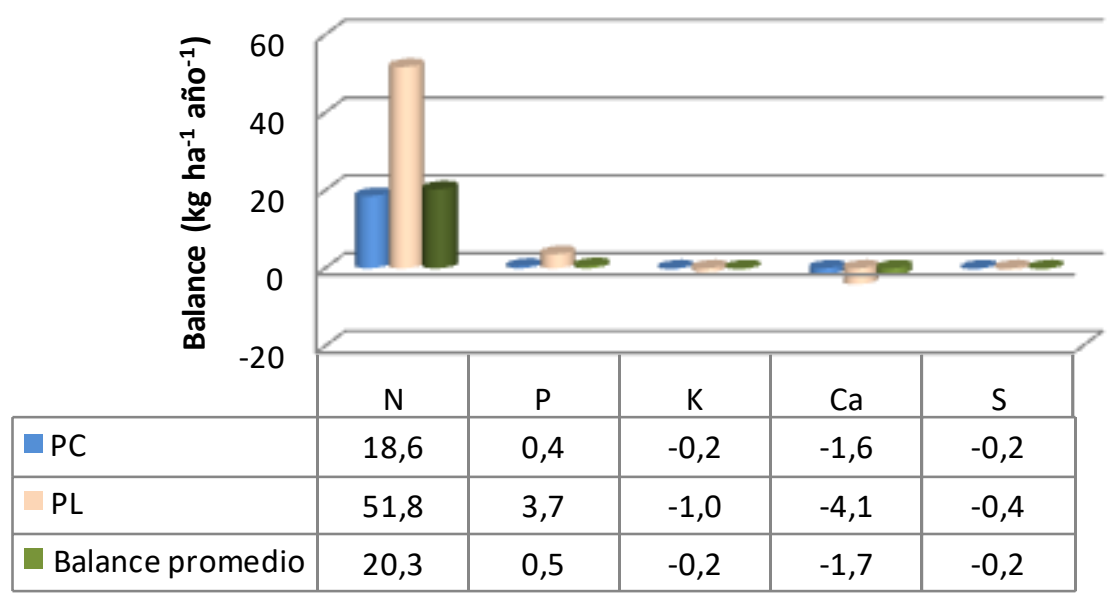

Nutrientes

Figura 3.3.5. Balance de nutrientes en producción de carne (PC), producción de leche (PL) y promedio (ponderado por la superficie), en la provincia de Buenos Aires (año 2005).

Como la base forrajera de la ganadería son el pastizal natural y las pasturas a base de leguminosas, el $\mathrm{N}$ registró balance positivo en casi la totalidad de los partidos de la provincia tanto en la PL, como en la PC y en el promedio entre ambas (ponderado por la superficie de cada actividad) (Figura 3.3.6 a, b, c). En la PL se estimó la mayor cantidad de partidos con exceso del N (Figura 3.3.6 a), debido a la mayor proporción de pasturas a base de leguminosas que producen mayor fijación biológica que los pastizales. A causa de ello, en la PC, que presenta una mayor proporción de pastizales respecto de pasturas, se determinaron menores excedentes de N (Figura 3.3.6 b). Al considerar el balance promedio (ponderado por la superficie), el menor exceso de $\mathrm{N}$ se registró en las zonas de la Pampa Deprimida (Figura 2.1 y Figura 3.3.6 c), coincidiendo con la zona de mayor actividad de cría (MA, 2015). 


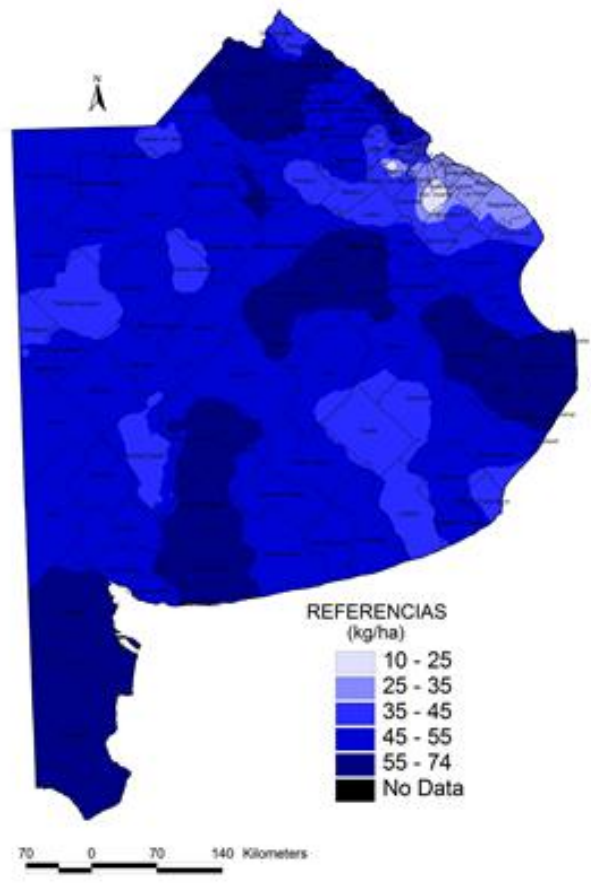

a)

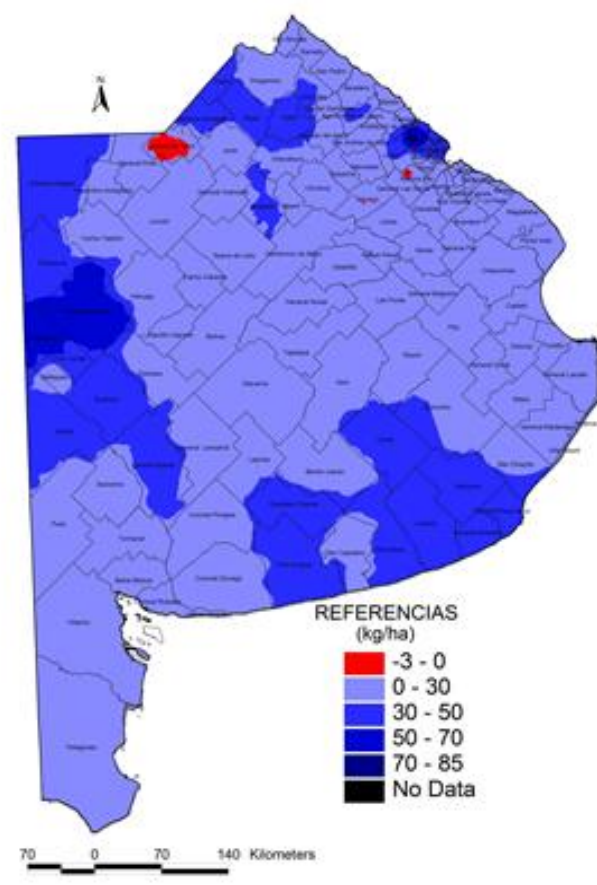

b)

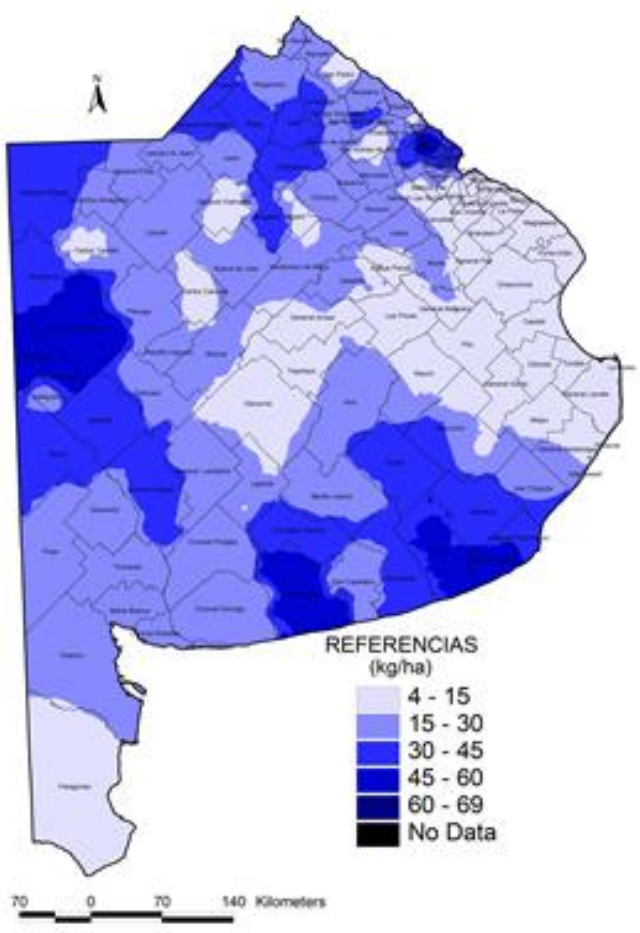

c)

Figura 3.3.6. Balance anual de $\mathrm{N}$ por unidad de superficie en: a) producción de leche (PL), b) producción de carne (PC) y c) promedio ganadero bovino (ponderado por la superficie), en la provincia de Buenos Aires (año 2005).

En la PL, el mayor ingreso de P fue por fertilización (71\%) seguido por el alimento balanceado $(29 \%)$, constituyendo ambos una reposición del $226 \%$. La proporción de $\mathrm{P}$ ingresado por el alimento balanceado fue menor que lo informado por Herrero et al. 
(2006) y Gourley et al. (2012). Como al menos el $60 \%$ de la superficie de PL se fertiliza anualmente (implantación de pasturas + verdeos), todos los partidos presentaron balances positivos de P (Figura 3.3.7 a). En PC el ingreso de P fue sólo por fertilización. A causa de ello, se encontraron balances positivos en el oeste, sudoeste y sudeste, donde hubo una mayor presencia de pasturas perennes y verdeos vinculados a la invernada (Figura 3.3.7 b). Pero se calcularon balances negativos en el resto de la provincia, donde predominó la actividad cría sobre pastizal natural (Figura 3.3.7b). Al considerar ambas actividades y la superficie relativa que ocupa cada una, se encontró un balance negativo en la zona central de la provincia (Pampa Deprimida Figura 2.1)) donde se desarrolla con mayor exclusividad la cría sobre pastizal natural, y levemente positivo en el resto de la provincia (Figura 3.3.7 c).

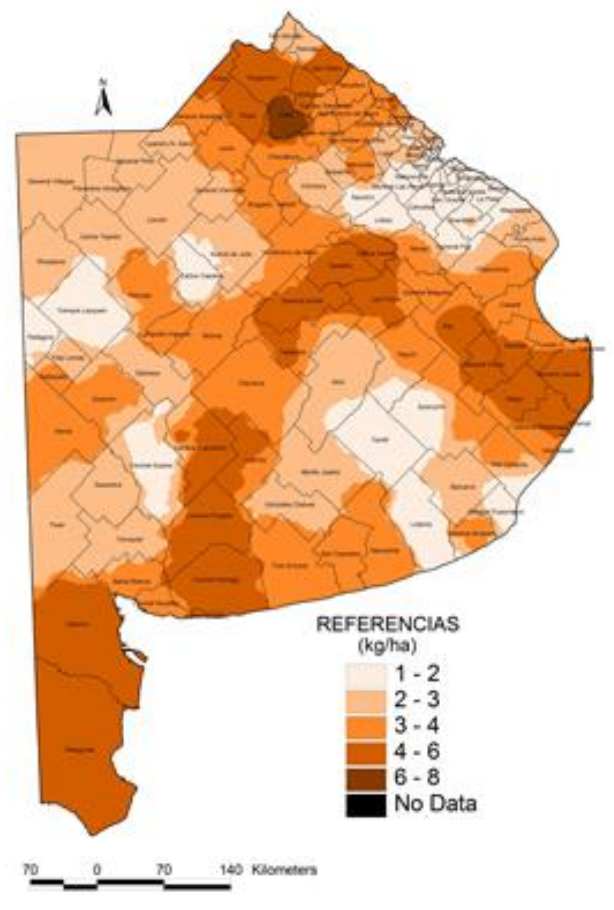

a)

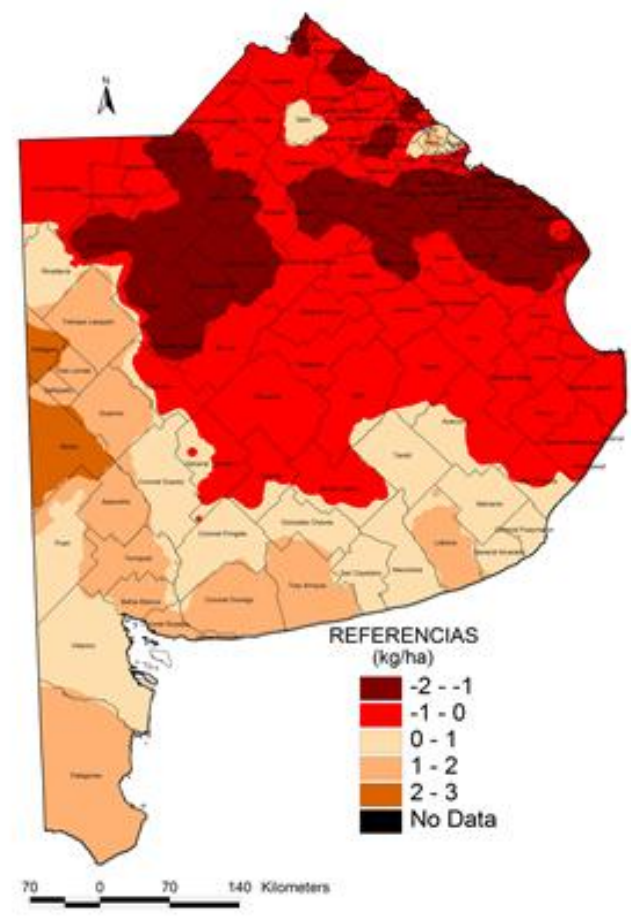

b) 


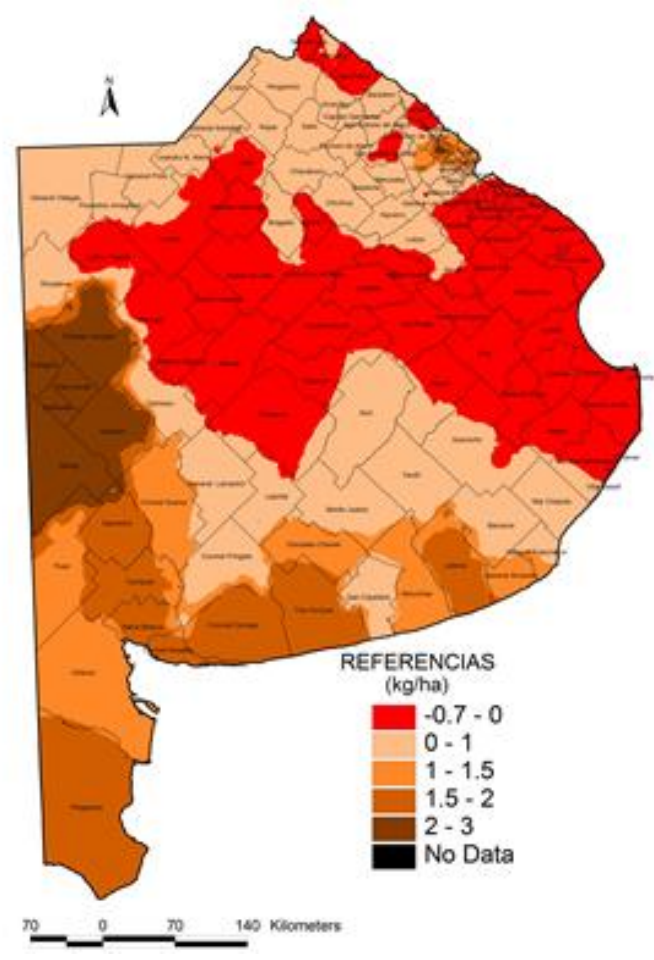

C)

Figura 3.3.7. Balance anual de $P$ por unidad de superficie en: a) producción de leche (PL), b) producción de carne (PC) y c) promedio ganadero (ponderado por la superficie), en la provincia de Buenos Aires (año 2005).

Los balances negativos de K, Ca y S (Figura 3.3.5) señalan que los sistemas ganaderos de la provincia de Buenos Aires afectan negativamente el recurso suelo mediante una pérdida en la dotación de los mismos. Para estos nutrientes sólo se registraron ingresos en PL a través del alimento externo (balanceado), que alcanzaron a reponer el 67,$1 ; 2,2$ y 49,9\% de K, Ca y S, respectivamente. Estos valores difieren de los balances en tambos de Australia donde, por fertilización y alimento balanceado, se generaron balances promedio positivos en $\mathrm{K}$ de $74 \mathrm{~kg} \mathrm{ha}^{-1} \mathrm{año-1}$, llegando en algunos casos a valores de $452 \mathrm{~kg} \mathrm{ha}^{-1}$ año-1 $^{-1}$ Gourley et al., 2012), lo que muestra la diferencia en cuanto al impacto en la conservación de los nutrientes o generación de externalidades de una misma actividad realizada en países con distintas características socioeconómicas. El K, Ca y S registraron un balance negativo en toda la provincia debido a PC y PL (Figura 3.3.8 a, b y c). Los balances más negativos se registraron en las zonas noroeste y oeste, que coinciden con predominio de tambos $y$, dentro de la PC, de invernada. Siendo que la actividad de PC sólo incorporó P y N por fertilización mineral, el $94,2 \%$ de la superficie ganadera está generando una disminución del stock de K, Ca y S, evidenciando un riesgo a la sostenibilidad. 


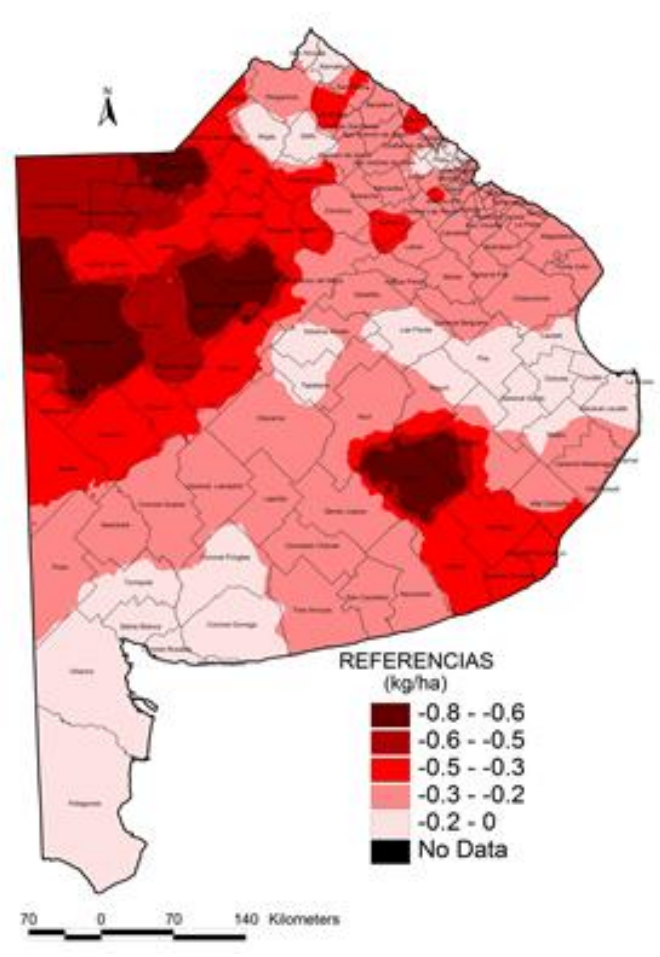

a)

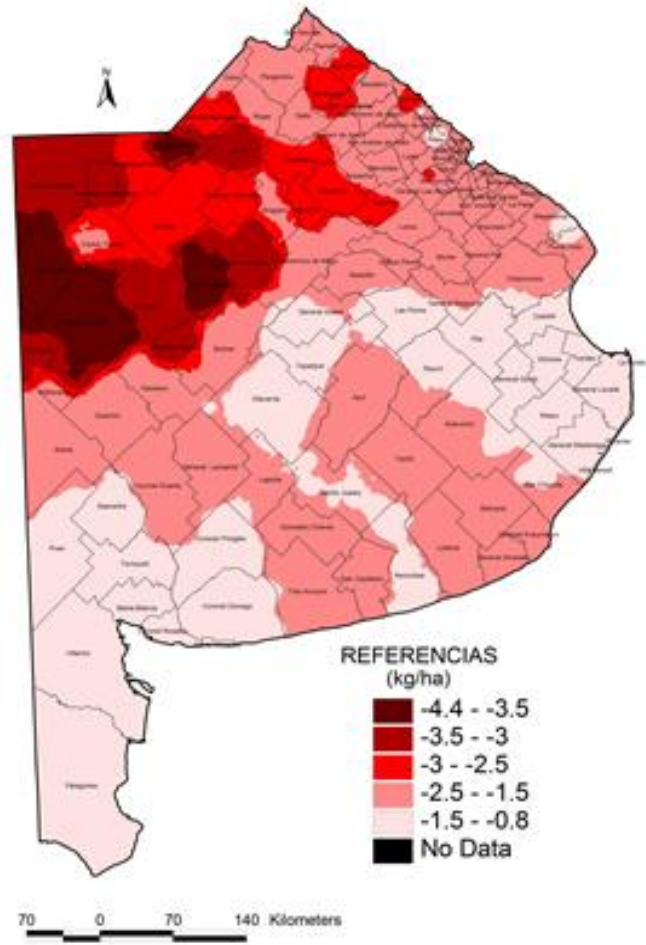

b)
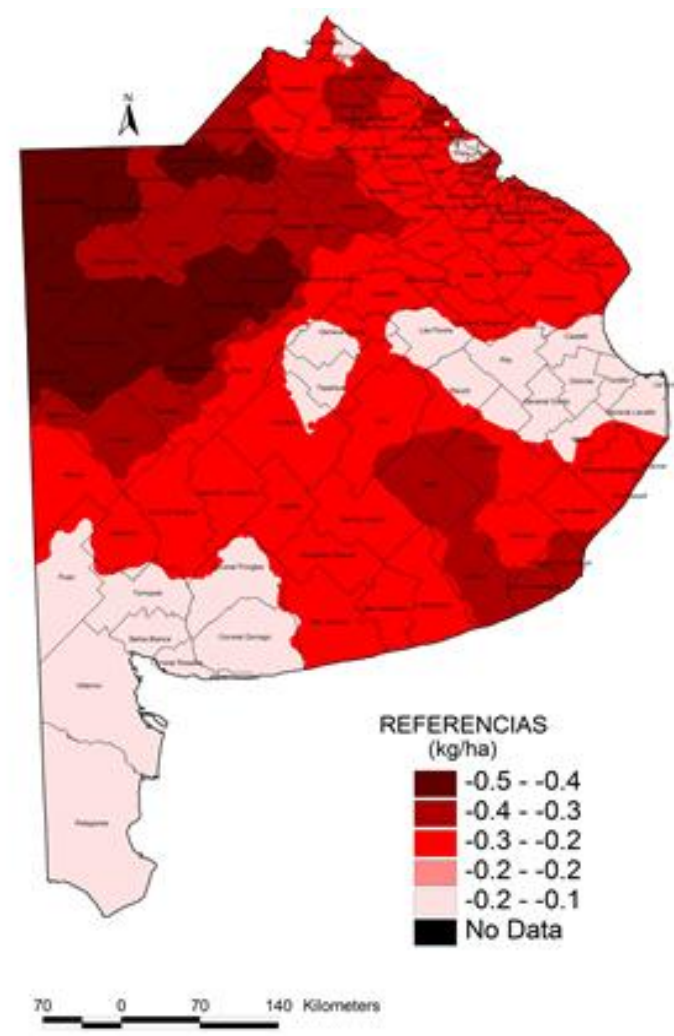

C)

Figura 3.3.8. Balance anual promedio (ponderado por la superficie) de: a) $K$, b) Ca y c) $S$, debido a la producción de carne (PC) y leche (PL) bovinas en la provincia de Buenos Aires (año 2005). 
Los resultados obtenidos descartan lo planteado en la segunda hipótesis ya que la PL genera mayores excedentes por unidad de superficie en $\mathrm{N}$ y $\mathrm{P}$, pero mayores déficits en K, Ca y S que la PC.

\section{III.3.3.2.2. Balance total}

La producción de carne fue la responsable de los mayores excedentes totales de N y P y de los mayores déficits de K, Ca y S (Figura 3.3.9).

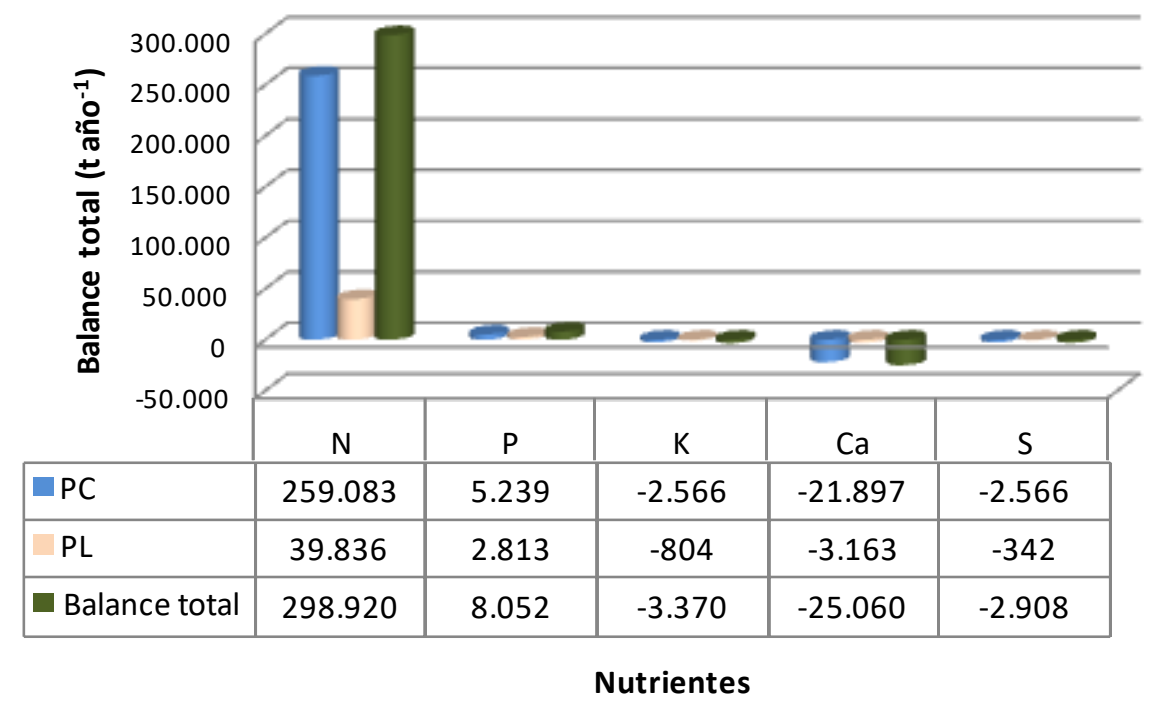

Figura 3.3.9. Balance total de nutrientes debido a la producción de carne (PC), producción de leche (PL) y total ganadero, en la provincia de Buenos Aires (año 2005).

Los mayores excedentes totales de $\mathrm{N}$ se registraron desde la zona centro hacia el oeste y el sudeste de la provincia (Figura 3.3.10 a), coincidiendo con una mayor presencia de pasturas perennes a base de leguminosas. En las zonas noreste, centro y este se registró el menor excedente total de N. El mayor déficit total de $\mathrm{P}$ se presentó en la zona de la Pampa Deprimida (Figura 3.3.10 b). En K, Ca y S se encontró que las zonas que presentaron tanto mayor como menor déficit fueron similares. Las zonas centro y noroeste fueron las que tuvieron los mayores déficits, y éstos disminuyeron en el suroeste y sudeste. Los menores déficits se calcularon para el centro-este y norte (Figura 3.3.10 c, d, e). La alfalfa (Medicago sativa L.) se destaca como especie implantada en pasturas en la zona noroeste y oeste, tanto para la PL como para invernada. El déficit encontrado en Ca en esta zona hace suponer un riesgo para el crecimiento de esta especie así como de otras leguminosas que son muy demandantes de este nutriente (Gelati \& Vázquez, 2008). 


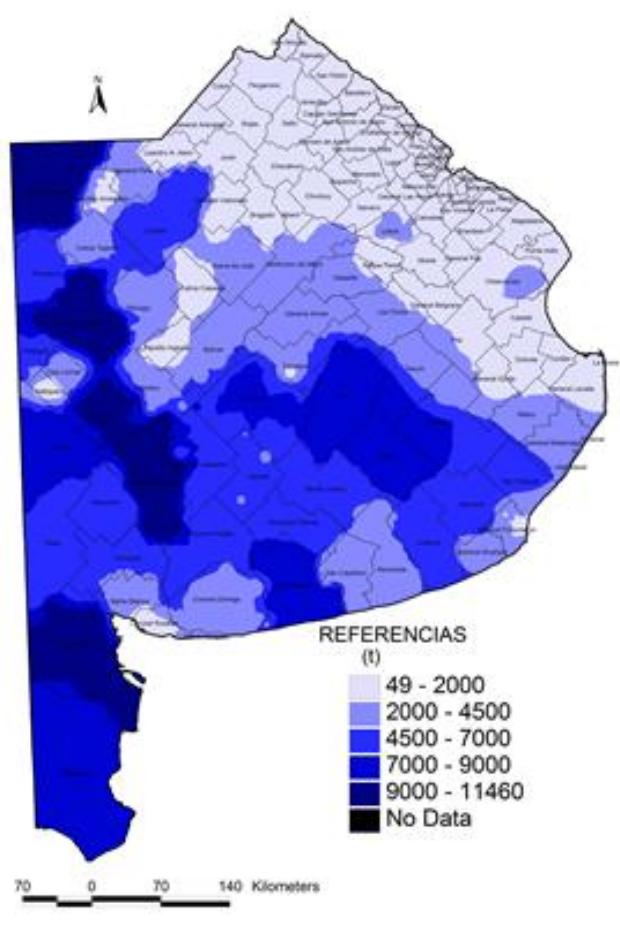

a)

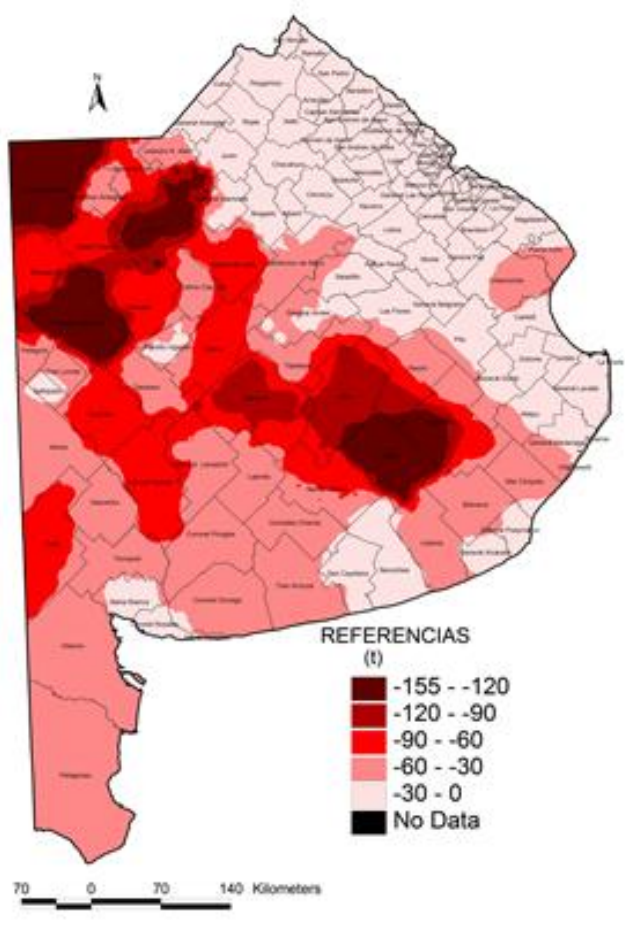

c)

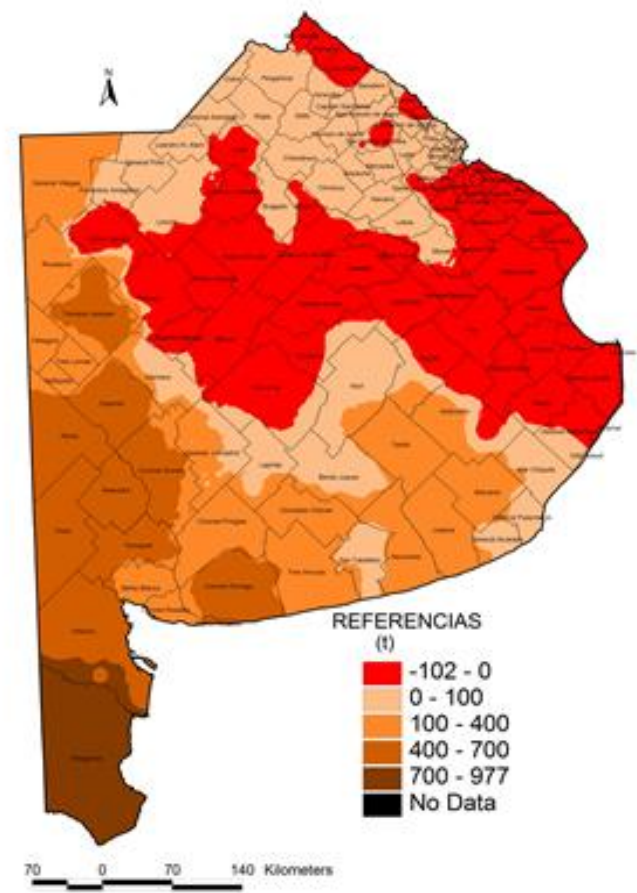

b)

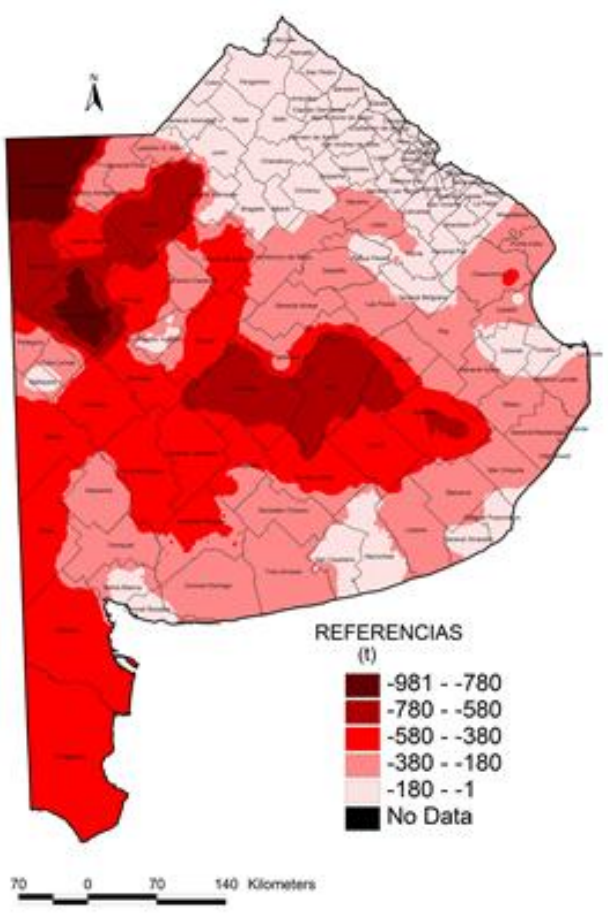

d) 


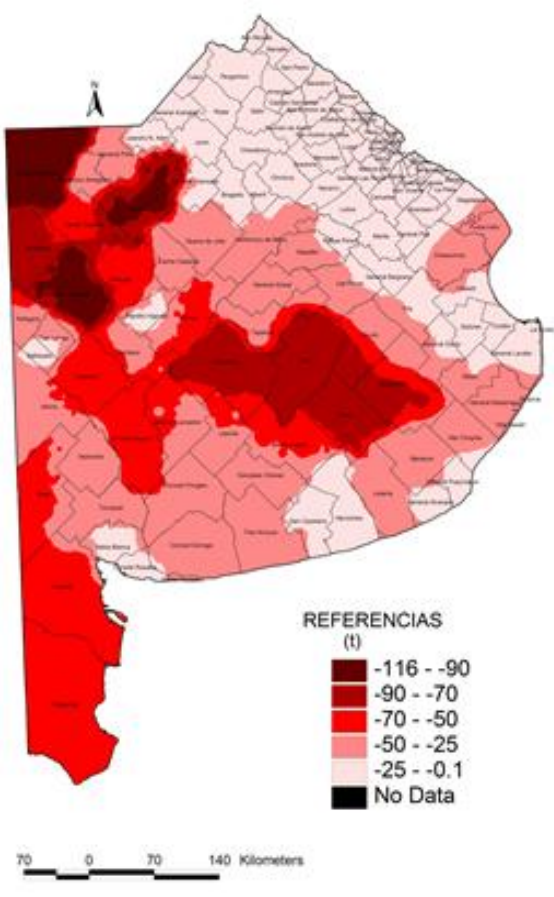

e)

Figura 3.3.10. Balance total anual de nutrientes: a) N, b) P, c) K, d) Ca y e) S, debido a la producción de carne (PC) y leche (PL) bovinas, en la provincia de Buenos Aires (año 2005).

\section{III.3.4. DISCUSIÓN}

El manejo de los nutrientes tanto en los sistemas de PC como en los de PL en la provincia de Buenos Aires presenta riesgos para la sostenibilidad, debido al potencial agotamiento de los suelos en $\mathrm{K}$, Ca y $\mathrm{S}$, así como de $\mathrm{P}$, en la mayor parte de su superficie.

Si bien es conocido que la ganadería, a partir de la incorporación de pasturas, puede restaurar algunos aspectos de la fertilidad del suelo como la materia orgánica y las propiedades físicas y biológicas (Díaz Zorita, 2000; García-Prechac et al., 2004; Lemaire et al., 2014), también puede conducir a la disminución del contenido de varios nutrientes en el suelo como K, Ca y S. Este deterioro es a veces difícil de percibir debido a la mejora en la física y biología del suelo que, en general, se traduce en un mejor crecimiento de los cultivos que suceden a una pastura. Además, como los suelos con pasturas reciben fertilización nitrogenada y fosforada, en general permiten reponer los macronutrientes extraídos en las producciones. Al ser estos nutrientes jerárquicamente definitorios del crecimiento de los cultivos no permiten percibir el agotamiento del resto de los nutrientes que, de continuar en el tiempo, pueden condicionar la producción. La superficie con pasturas y verdeos alcanza hasta un $30 \%$ 
del total ganadero provincial, por lo tanto, el 70\% restante está sufriendo degradación en K, Ca, S y, además, en P.

La PL resultó una actividad más extractiva por unidad de superficie que la PC (Figura 3.3.1) y, a pesar de contar con mayores ingresos de nutrientes por diferentes vías, no alcanzó a reponer todos los nutrientes extraídos (Figura 3.3.5). La cuenca lechera del oeste (Figura 2.8 a) que genera el 59\% de la producción provincial, junto con la de Mar y Sierras (10\%) (MAA, 2007a), registró los mayores déficits en K, Ca y S. La pérdida de $\mathrm{K}$ y $\mathrm{Ca}$, elementos asociados a la basicidad edáfica, provoca problemáticas derivadas de la acidificación (Gelati \& Vázquez, 2008), modificando las condiciones de disponibilidad de algunos nutrientes $y$, con ello, afecta el crecimiento de los cultivos. La alfalfa, un recurso forrajero por excelencia en la zona tambera y de invernada del noroeste, sufre condicionamientos en su instalación y crecimiento por la acidificación de los suelos (Vázquez et al., 2004; 2012).

En los últimos años, se ha observado una tendencia hacia una mayor suplementación del rodeo de tambo a partir del ingreso de alimentos provenientes de otras actividades. El mayor ingreso de alimento y, por lo tanto, de nutrientes, puede mejorar los balances negativos de K, Ca y S, llegando a ser positivos como en Australia (Gourley et al., 2012). Para lograr sistemas de PL sostenibles en este nuevo escenario de mayor suplementación con alimento proveniente de superficie externa a los tambos, será necesario incorporar, en los cálculos de balance de nutrientes, esa superficie agrícola dedicada a la producción de granos destinada a la alimentación del rodeo de tambo. Si esta superficie registra balances negativos, comprometerá la producción de granos y, por lo tanto, también afectará la PL.

La PC y la PL comparten los mayores excedentes de $\mathrm{N}$ por la inclusión de pasturas a base de leguminosas y la fijación atribuida a los pastizales naturales. Los valores de fijación asumidos se encuadran dentro de valores empleados por Cabrini \& Calcaterra (2009) y Manchado (2010) para el cálculo de balances de nutrientes en sistemas ganaderos de la región. Pero es necesaria una estimación más ajustada de los aportes de $\mathrm{N}$ vía fijación en la provincia ya sea en pasturas (puras y consociadas) como en pastizales. El excedente de $\mathrm{N}$, si bien es de origen biológico, puede generar externalidades a través de la lixiviación o desnitrificación (Cassman et al., 2003), aspectos que son necesarios profundizar en futuras investigaciones, a fin de evitar consecuencias ambientales negativas.

El excedente de $\mathrm{P}$ que se genera por fertilización de las pasturas y verdeos presenta menos riesgos ambientales, por un lado, por su baja solubilidad, incluso puede ser aprovechado años después de su incorporación. No obstante, para disminuir el riesgo de externalidad hay que tener en cuenta el momento y forma de 
aplicación del fertilizante, la ocurrencia de lluvias, la pendiente y la cercanía a cursos de agua. La baja superficie con pastura implantada para la cría, determinó balances negativos de $P$, aunque debido a que el pastizal natural es el principal recurso forrajero para esa actividad de la PC y ocupa el $70 \%$ de la superficie ganadera, será necesario generar estrategias de reposición.

En este trabajo se asumió que las deyecciones de los animales permanecen dentro del sistema de PC y PL. Si bien se conoce que una parte del retorno de nutrientes por heces y orina se pierde por lixiviación o volatilización, por dificultad en su cálculo, las mismas fueron omitidas. En ambas producciones estas pérdidas son más importantes para N. Aunque en la PL un inadecuado manejo de los efluentes también puede generar pérdidas internas del resto de los nutrientes $(P, K, C a, S)$ por acumulación y/o lixiviación. Los flujos debido a las deyecciones han sido estudiados a nivel de establecimientos, tanto en tambos (Herrero et al., 2006; Diez, 2010) como en sistemas de producción de carne (Díaz Zorita, 2000). Estos estudios demostraron grandes transferencias de nutrientes entre sectores dentro de los campos, sin una adecuada redistribución posterior. Es necesario complementar el análisis realizado en este subcapítulo incorporando flujos internos para detectar transferencias de nutrientes entre regiones dentro de una mima actividad o incluso hacia otras actividades.

El análisis de balances de nutrientes a escala regional, permite detectar problemas, no visibles a escala predial. En el caso del $P$, aunque se encontró un balance positivo general (Figura 3.3.5) se detectó una gran superficie de la provincia con balances negativos (Figura 3.3.7c). De asumir sólo el valor general se puede afirmar que se está incrementando el $\mathrm{P}$ en el suelo, cuando esto ocurre sólo en una parte de la provincia y en el resto se está agotando.

Es necesario revertir esta tendencia negativa de pérdida de los nutrientes, para lo cual es necesario considerar sus ciclos biogeoquímicos. Sólo el $\mathrm{N}$ tiene posibilidad de reposición a partir de su ciclo gaseoso, ya que en el S la vía atmosférica es de menor relevancia, a excepción de regiones altamente industrializadas. En la ganadería de la provincia la fijación biológica de $\mathrm{N}$ es la principal vía de ingreso y permite la reposición. Para el resto de los nutrientes cuyo ciclo es sedimentario, la posibilidad de reposición está reducida a la incorporación a partir de una fuente, mineral u orgánica, que provenga desde otra actividad no ganadera. Para K, Ca, y S será imprescindible buscar estrategias de reposición. En el caso de P será necesario aumentar la superficie fertilizada. Estas prácticas deberán ser analizadas desde el punto de vista económico considerando el corto y largo plazo, así como la disponibilidad en el tiempo de las fuentes de nutrientes, aspecto abordado en el conjunto de esta tesis. 
A modo de conclusión se puede afirmar que la PL es una actividad más extractiva de nutrientes por unidad de superficie que la PC, aunque esta última es la responsable de la mayor extracción total de nutrientes en la provincia de Buenos Aires. Ambas actividades registraron balances positivos en $N$ y $P$, aunque en la PC se encontró una gran superficie con pérdidas de $\mathrm{P}$ debido a la ausencia de fertilización de los pastizales naturales. Tanto el K, como el Ca y el $S$ son nutrientes que se están agotando de los suelos ganaderos de la provincia, y señalan la necesidad de revertir esta tendencia para avanzar hacia una producción pecuaria sostenible.

Este subcapítulo se redactó a partir del trabajo de "Los sistemas de producción de carne y leche bovina en la Provincia de Buenos Aires żconservan los nutrientes del suelo?", publicado en la Revista Facultad de Agronomía, de la Facultad de Ciencias Agrarias y Forestales, UNLP. (2016) Vol. 115(2):251-263.

\section{III.3.5. BIBLIOGRAFÍA}

Bekunda, M. \& G. Manzi. 2003. Use of partial nutrient budget as an indicator of nutrient depletion in the highlands of southwestern Uganda. Nutrient Cycling in Agroecosystems 67:187-195.

Cabrini, S.M. \& C.P. Calcaterra. 2009. Sistemas de producción en el partido de Pergamino. Valoración económica del impacto sobre la capacidad productiva de los suelos. INTA. Estudios socioeconómicos de la sustentabilidad de los sistemas de producción y recursos naturales 12 . $36 \mathrm{pp}$.

Cassman, K.G., A. Dobermann, D.T. Walters \& H. Yang. 2003. Meeting cereal demand while protecting natural resources and improving environmental quality. Annual Review of Environment \& Resources 28:315-358.

Chimicz, J. \& E.L. Gambuzzi. 2007. Producción primaria y regiones productivas. Revista IDIA XXI (9):8-25.

CNA (Censo Nacional Agropecuario). 2002. Instituto Nacional de Estadísticas y Censos de la República Argentina. Disponible en: http://www.indec.gob.ar/cna index.asp. Último acceso: octubre 2016.

Cruzate, G.A. \& R. Casas. 2003. Balance de nutrientes. Revista Fertilizar (Número especial "Sostenibilidad"):7-13.

Cruzate, G.A. \& R. Casas. 2012. Extracción y balance de nutrientes en los suelos agrícolas de La Argentina. Informaciones Agronómicas de Hispanoamérica 6:7-14.

Díaz-Zorita, M. 2000. Evaluación de la sostenibilidad de sistemas intensivos de producción de carne. INTA. Estación Experimental Agropecuaria General Villegas. Publicación técnica 27. 15pp.

Diez, M. 2010. Manejo de los efluentes originados en tambo: Una experiencia en el este de La Pampa. Informaciones Agronómicas 47: 16-18.

FAO (Organización de las Naciones Unidas para la Alimentación y la Agricultura). 2003. Assessment of soil nutrient balance. Approaches and methodologies. Rome. Fertilizer \& Plant Nutrition Bulletin 14. 88pp.

FAO (Organización de las Naciones Unidas para la Alimentación y la Agricultura). 2004a. Scaling soil nutrient balances. Enabling mesolevel applications for African realities. Rome. Fertilizer \& Plant Nutrition Bulletin 15. 150pp.

FAO (Organización de las Naciones Unidas para la Alimentación y la Agricultura). 2004b. Uso de fertilizantes por cultivo en Argentina. Roma. 49pp.

Flores, C.C. \& S.J. Sarandón. 2003. ¿̇Racionalidad económica versus sustentabilidad ecológica? El ejemplo del costo oculto de la pérdida de fertilidad del suelo, durante el proceso de Agriculturización en la Región Pampeana Argentina. Revista de la Facultad de Agronomía 105 (1) $(2002,2003): 53-67$.

Fontanetto, H., S. Gambaudo \& O. Keller. 2011. Balance de nutrientes en sistemas pastoriles. Sitio Argentino de Producción Animal. Disponible en: http://www.produccion- 
animal.com.ar/produccion_y_manejo_pasturas/pasturas_fertilizacion/52-balance.pdf. último acceso: mayo 2016.

García, F.O. 2006. El rol del fósforo en la producción de pasturas de la región pampeana. Sitio Argentino de Producción Animal. Disponible en: http://www.produccionanimal.com.ar/produccion y manejo pasturas/pasturas fertilizacion/21-fosforo en pasturas.pdf. Último acceso: mayo 2016.

García, F.O. 2011. Balances de carbono y de nutrientes: buscando el equilibrio en la agricultura del Cono Sur. II Simposio Nacional de Agricultura. Uruguay. 135-147.

García, F. \& M.F. González Sanjuán. 2010. Balances de nutrientes en Argentina ¿̇Cómo estamos? ¿Cómo mejoramos? Informaciones Agronómicas 48:1-5.

García-Préchac, F., O. Ernst, G. Siri-Prieto \& J.A. Terra. 2004. Integrating no-till into crop-pasture rotations in Uruguay. Soil \& Tillage Research 77:1-13.

Gelati, P.R. \& M.E. Vázquez. 2008. Extracciones agrícolas de bases en el norte de la provincia de Buenos Aires, Argentina: costo de su remediación e implicancias económicas. Revista Iberoamericana de Economía Ecológica 7:1 17-129.

Gourley, J.P.C., W.J. Dougherty, DM. Weaver, S.R. Aarons, I.M. Awty, D.M. Gibson, M.C. Hannah, A.P. Smith \& K. Peverill. 2012. Farm-scale nitrogen, phosphorus, potassium and sulfur balances and use efficiencies on Australian dairy farms. Animal Production Science 52: 929-944.

Herrero, M.A., S.B. Gil, M.C. Flores, G.M. Sardi \& A.A. Orlando. 2006. Balance de nitrógeno y fósforo a escala predial, en sistemas lecheros pastoriles en Argentina. Investigación Veterinaria 8:9-21.

Lemaire, G., A. Franzluebbers, P.C. de Faccio Carvalho \& B. Dedieu. 2014. Integrated croplivestock systems: Strategies to achieve synergy between agricultural production and environment quality. Agriculture, Ecosystems \& Environment 190:4-8.

MA (Ministerio de Agroindustria). 2015. Caracterización de la producción bovina. Buenos AiresCorrientes- Chaco- Formosa- La Pampa- Misiones. INTA, SENASA. Serie I. 194pp.

MAA (Ministerio de Asuntos Agrarios). 2007a. Nuestra provincia nuestro campo. El sector agropecuario de la provincia de Buenos Aires. 147pp.

MAA (Ministerio de Asuntos Agrarios). 2007b. Dirección de producción láctea. Estadística disponible en http://www.maa.gba.gov.ar/dir_ganaderia/leche/cuencas\%20lecheras.jpg. Último acceso: marzo 2016.

MAA (Ministerio de Asuntos Agrarios). 2007c. Cuencas lecheras de la provincia de Buenos Aires. Disponible en: http://www.maa.gba.gov.ar/dir_ganaderia/lecheria.php. Último acceso: marzo 2016.

Manchado, J.C. 2010. La sustentabilidad en la agricultura pampeana: Valoración económica del balance de nutrientes para las principales actividades agropecuarias extensivas en la Región Centro Sur de la Provincia de Buenos Aires. Revista Argentina de Economía Agraria XII (2):51-68.

Mancuso, W. \& J.C. Terán. 2008. El sector lácteo argentino. XXI Curso Internacional de lechería para profesionales de América Latina. 13-22 pp. Disponible en: http://www.vet.unicen.edu.ar/html/Areas/Prod Animal/Documentos/2012/Aspectos\%20Ambient ales/Lecheria\%20en\%20Argentina.\%20Cuencas,\%20tambos\%20mercados\%202007.pdf. Último acceso: marzo 2016.

Marino, M.A. \& M. Agnusdei. 2007. Abastecimiento de fósforo y nitrógeno en pasturas para una ganadería productiva y sustentable. $12^{\circ}$ Jornada ganadera de Benito Juárez. Sitio Argentino de producción animal. Disponible en: animal.com.ar/produccion y manejo pasturas/pasturas fertilizacion/30-marinofertilizacion.pdf. Último acceso: marzo 2016.

Oenema, O., H. Kros \& W. de Vries. 2003. Approaches and uncertainties in nutrient budgets: implications for nutrient management and environmental policies. European Journal of Agronomy 20:3-16.

Racca, R., D. Collino, J. Dardanelli, D. Basigalup, N. González, E. Brenzoni, N. Hein \& M. Balzarini. 2001. Contribución de la fijación biológica del nitrógeno a la nutrición nitrogenada de la alfalfa en la Región Pampeana. Ediciones INTA. Buenos Aires. 56 pp.

Tan, Z.X., R. Lal \& K.D. Wiebe. 2005. Global soil nutrient depletion and yield reduction. Journal of Sustainable Agriculture 26(1):123-146.

Taverna, M. 2007. Composición química de la leche producida en la Argentina. Revista IDIA XXI 9:112-117.

Vázquez, M.E., A. Piro, G. Millán \& J. Lanfranco. 2004. Corrección de suelos ácidos de la Pampa húmeda para la producción de alfalfa. Informaciones Agronómicas 23:14-20.

Vázquez, M., A. Terminiello, A. Casciani, G. Millán, D. Cánova, P. Gelati, F. Guilino, A. Dorronzoro, Z. Nicora, L. Lamarche \& M. García. 2012. Respuesta de la soja (Glicine max L.Merr) a enmiendas 
básicas en algunos suelos de las provincias de Buenos Aires y Santa Fe. Ciencia del Suelo 30(1):43-56.

Viglizzo, E.F., A.J. Pordomingo, M.G. Castro \& F.A. Lértora. 2002. La sustentabilidad ambiental del agro pampeano. INTA. Programa Nacional de Gestión Ambiental Agropecuaria. Ediciones INTA. 84pp.

Viglizzo, E.F., F. Frank, J. Bernardos, D.E. Buschiazzo \& S. Cabo. 2006. A rapid method for assessing the environmental performance of commercial farms in the pampas of Argentina. Environmental Monitoring \& Assessment 117:109-134.

Zazo, F.E., C.C. Flores \& S.J. Sarandon. 2011. El "costo oculto" del deterioro del suelo durante el proceso de "sojización" en el Partido de Arrecifes, Argentina. Revista Brasileira de Agroecologia $6(3): 3-20$. 


\section{CAPÍTULO III}

\section{SUBCAPÍTULO 4}

Horticultura, cultivos extensivos y producción de carne y leche bovinas en la provincia de Buenos Aires y la conservación de los nutrientes del suelo

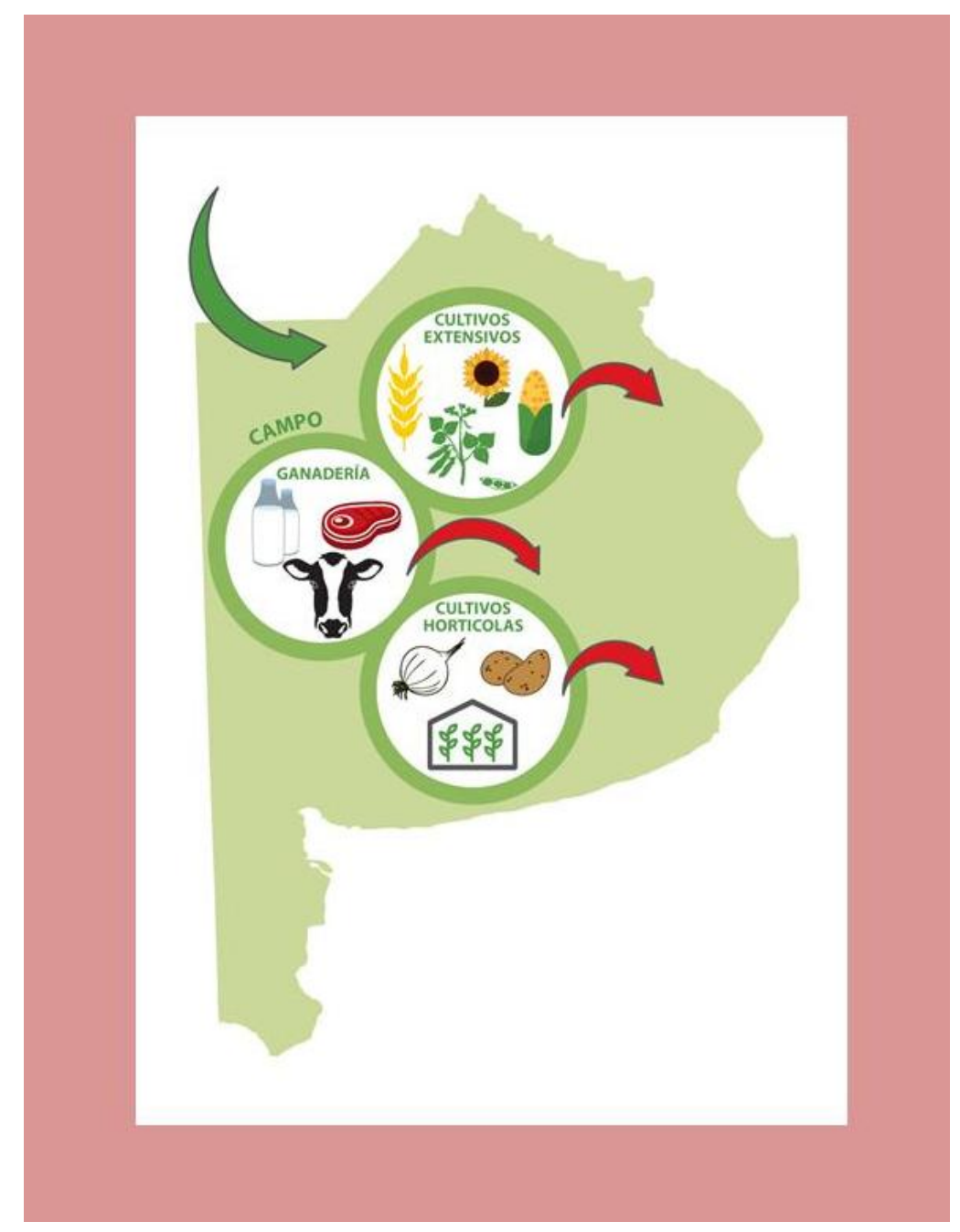




\section{III.4.1. INTRODUCCIÓN}

La producción de alimentos involucra diferentes actividades agropecuarias, como la horticultura, los cultivos extensivos, que incluyen cereales y oleaginosas, y la producción ganadera de carne y leche. Cada una de estas actividades contribuye a generar alimentos que aportan energía y nutrientes al ser humano. La continuidad de la producción de alimentos en el futuro dependerá de que cada una de estas actividades pueda alcanzar un equilibrio entre las dimensiones económica, ecológica y sociocultural, intrínsecas a la sostenibilidad (Sarandón, 2002; Viglizzo et al., 2002; Sarandón \& Flores, 2009, 2014). Estas actividades responden de manera diferente a los cambios en aquellas dimensiones, ya que la intensidad en el uso del suelo, de insumos, mano de obra e infraestructura, la comercialización, y la necesidad de financiamiento, varía en cada una. No obstante, uno de los aspectos que comparten, es que generan productos constituidos por nutrientes, los cuales son tomados de la reserva del suelo. Por lo tanto, cada actividad debería reponer los nutrientes que extrae del suelo para poder sostenerse en el tiempo, ya que, de lo contrario, disminuirá su capacidad productiva.

La cantidad de nutrientes que se extrae en cada actividad varía de acuerdo con las diferentes demandas de los distintos cultivos, el rendimiento y la composición química del producto cosechado. Otro aspecto que determina la cantidad de nutrientes extraídos, es el nivel trófico en que se encuentra el producto obtenido (Odum, 1998). Un producto de un primer nivel trófico como el que generan la horticultura y los cultivos extensivos, extrae una mayor cantidad de nutrientes que un producto de un segundo nivel trófico, como la carne vacuna o la leche. Esto se debe a la transferencia de energía de alta calidad disponible entre un nivel trófico y otro superior, la cual varía entre el 10 y el $20 \%$, es decir, que la energía disponible entre niveles tróficos se reduce entre un 80 y 90\% (Odum, 1998; Gliessman, 2002; Flores \& Sarandón, 2014). En general, este aspecto de las actividades agropecuarias no es considerado al momento de generar políticas que fomenten un determinado uso del suelo. Además, influye en la magnitud de la reposición de nutrientes necesaria para evitar el agotamiento de los suelos.

El riesgo de agotamiento del suelo por las actividades agropecuarias fue visualizado con mayor interés desde la década del 80 del siglo XX. A partir de ese momento, se desarrollaron diferentes cálculos de balance de nutrientes, que se aplicaron en distintos cultivos, actividades agropecuarias y escalas (Smaling \& Fresco, 1993; Koning et al., 1997; Mancassola \& Casanova, 2015). Tanto en la Argentina como en la provincia de Buenos Aires, son escasos los estudios que hayan incluido un análisis 
del balance de nutrientes de las tres actividades agropecuarias y su impacto a escala provincial. Manchado (2010) y Cabrini \& Calcaterra (2009), analizaron el balance de nutrientes en cultivos extensivos y ganadería, en distintas zonas de la provincia de Buenos Aires. Vicente \& Engler (2008) y Ghida Daza (2013), analizaron balances de nutrientes también de actividades extensivas en Entre Ríos y Córdoba, respectivamente. Si bien el cálculo del balance de nutrientes es señalado como una herramienta que contribuiría a lograr una agricultura sostenible (Viglizzo et al., 2002; 2003; Öborn et al., 2003; Dechert et al., 2005; Abbona et al., 2007), pocas veces es utilizado para anticipar tendencias a futuro, sobre todo en cambios en el uso de la tierra. Las actividades agropecuarias no hacen un uso estático del suelo, sino que lo varían con el tiempo, principalmente, en función de los estímulos económicos que no siempre consideran el posible deterioro del recurso. Por lo tanto, conocer el impacto de las diferentes actividades agropecuarias en la conservación de los nutrientes del suelo puede ser una herramienta útil para anticipar tendencias a futuro por el cambio en el uso del mismo.

El objetivo de este subcapítulo es analizar en conjunto la extracción y reposición de nutrientes (nitrógeno $(N)$, fósforo $(P)$, potasio $(K)$, calcio $(C a)$ y azufre $(S)$ ) debida a horticultura, cultivos extensivos y producción de carne y de leche bovinas en la provincia de Buenos Aires, y discutir el impacto del cambio en el uso del suelo en la conservación de los nutrientes.

Se plantea como hipótesis que las actividades ganaderas de producción de carne y de leche bovinas presentan una mejor conservación de los nutrientes del suelo por unidad de superficie que las actividades agrícolas (cultivos extensivos y hortícolas).

\section{III.4.2. METODOLOGÍA}

Se realizó un balance anual de nutrientes (N, P, K, Ca y S) para el conjunto de las actividades de horticultura, cultivos extensivos y ganadería (producción de carne y leche bovinas), para cada partido y total de la provincia de Buenos Aires, para el período 2005-2006. La metodología de cálculo correspondiente a cada actividad se encuentra detallada en los subcapítulos I (cultivos extensivos), II (horticultura) y III (producción de carne y leche bovinas) del presente capítulo. Se estimó el promedio (ponderado por la superficie) de materia seca y húmeda extraída de cada actividad. Para esto se tuvo en cuenta el contenido de agua de cada producto extraído, dato obtenido de las mismas fuentes que aportaron los contenidos de nutrientes de los mismos y las respectivas superficies. 


\section{III.4.3. RESULTADOS}

\section{III.4.3.1. Extracción de nutrientes}

III.4.3.1.1. Extracción por unidad de superficie y su distribución espacial

La extracción de nutrientes promedio (ponderado por la superficie) entre horticultura, cultivos extensivos y ganadería (carne y leche) fue de 40,$9 ; 6,1 ; 11,8 ; 2,7$; $2,7 \mathrm{~kg} \mathrm{ha}^{-1}$ año-1 $^{-1}$ para $\mathrm{N}, \mathrm{P}, \mathrm{K}, \mathrm{Ca}$ y S, respectivamente, por lo que el $\mathrm{N}$ fue el nutriente más extraído seguido del K, P, Ca y S. Los cultivos extensivos generaron la mayor extracción por unidad de superficie de N, P y S, mientras que la horticultura lo hizo en $\mathrm{K}$ y Ca (Figura 3.4.1). La extracción de nutrientes de las actividades ganaderas fue del 3,$8 ; 6,4 ; 1,1 ; 39,0$ y $3,4 \%$, respecto a las extracciones promedio (ponderado por la superficie) entre horticultura y cultivos extensivos para N, P, K, Ca, respectivamente. Para el $S$, debido a la ausencia de datos para horticultura, sólo se comparó entre cultivos extensivos y ganadería.

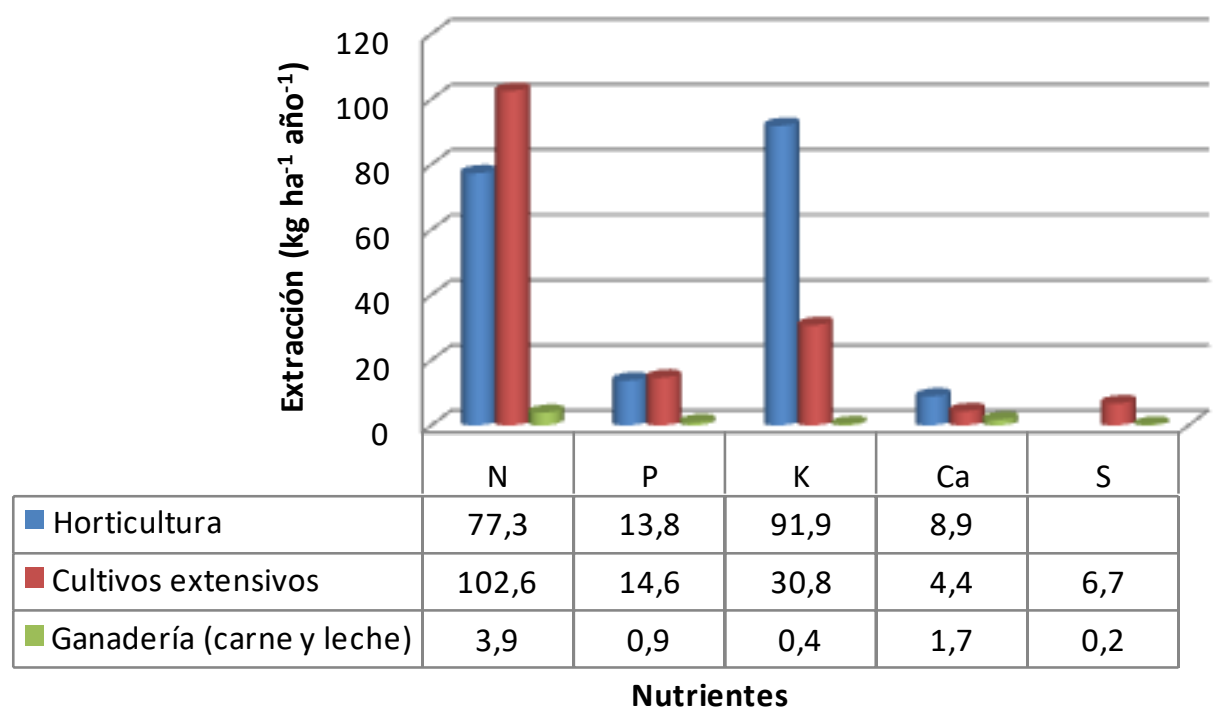

Figura 3.4.1. Extracción de nutrientes por unidad de superficie debida a horticultura, cultivos extensivos y ganadería (carne y leche), en la provincia de Buenos Aires (período 2005-2006).

Dichos valores relativos de extracción de nutrientes por unidad de superficie fueron similares a los calculados para la materia seca exportada de las tres actividades, en que la ganadería registró el menor valor respecto al promedio (ponderado por la superficie) entre cultivos extensivos y horticultura (Tabla 3.4.1). La horticultura extrajo mayor cantidad de materia seca por unidad de superficie que los cultivos extensivos, aunque esta diferencia fue mucho menor respecto a la biomasa o materia húmeda, por el elevado contenido de agua de los productos extraídos en la horticultura (Tabla 3.4.1). 
Tabla 3.4.1. Contenido de agua, materia húmeda y seca exportada y sus relaciones entre horticultura, cultivos extensivos y ganadería (carne y leche), en la provincia de Buenos Aires.

\begin{tabular}{lccc}
\hline & $\begin{array}{c}\text { Contenido } \\
\text { de agua } \\
(\%)\end{array}$ & $\begin{array}{c}\text { Materia } \\
\text { húmeda } \\
\left(\mathbf{k g ~ h a}^{-1} \mathbf{a n ̃ o} \mathbf{0}^{-1}\right)\end{array}$ & $\begin{array}{c}\text { Materia seca } \\
\left(\mathbf{k g ~ h a}^{-1} \mathbf{~ a n ̃ o - 1 ~}\right.\end{array}$ \\
\hline Horticultura (H) & 87,3 & 28.797 & 3.672 \\
Cultivos extensivos (CE) & 13,5 & 3.100 & 2.683 \\
$\begin{array}{l}\text { Ganadería (carne y leche) } \\
\text { Promedio (H y CE) }\end{array}$ & 70,8 & 240 & 70 \\
\hline $\begin{array}{l}\text { (ponderado por la } \\
\text { superficie) }\end{array}$ & 16 & 3.203 & 2.687 \\
$\begin{array}{l}\text { Relación ganadería } \\
\text { /promedio (H y CE) (\%) }\end{array}$ & & & \\
\hline
\end{tabular}

El norte de la provincia de Buenos Aires generó la mayor extracción por unidad de superficie de todos los nutrientes (N, P, K, Ca y S) (Figura 3.4.2 a, b, C, d, e). Lo siguió en intensidad el noroeste y el sudeste $y$, las menores extracciones, se realizaron en las zonas centro, centro-este y suroeste de la provincia.

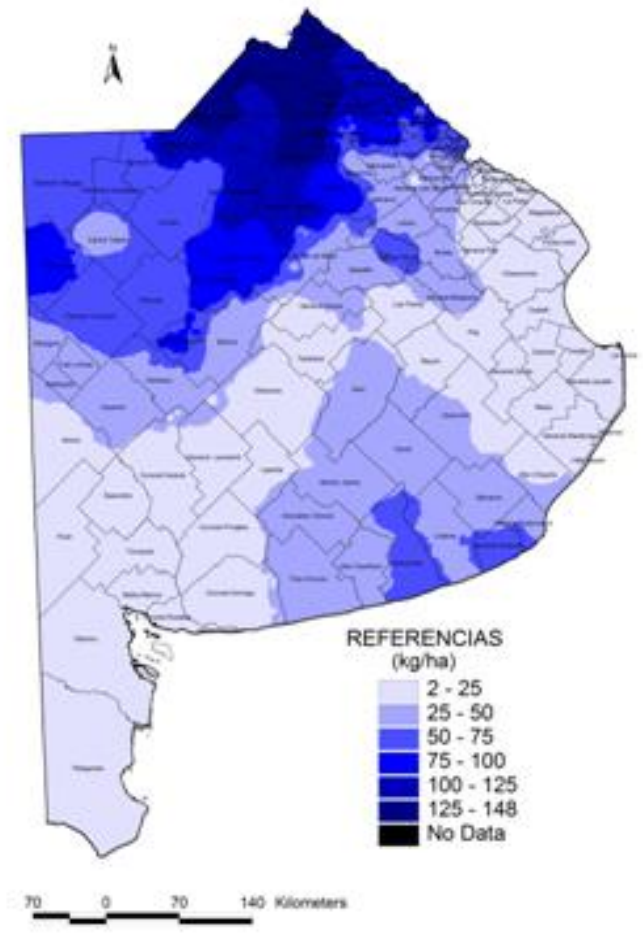

a)

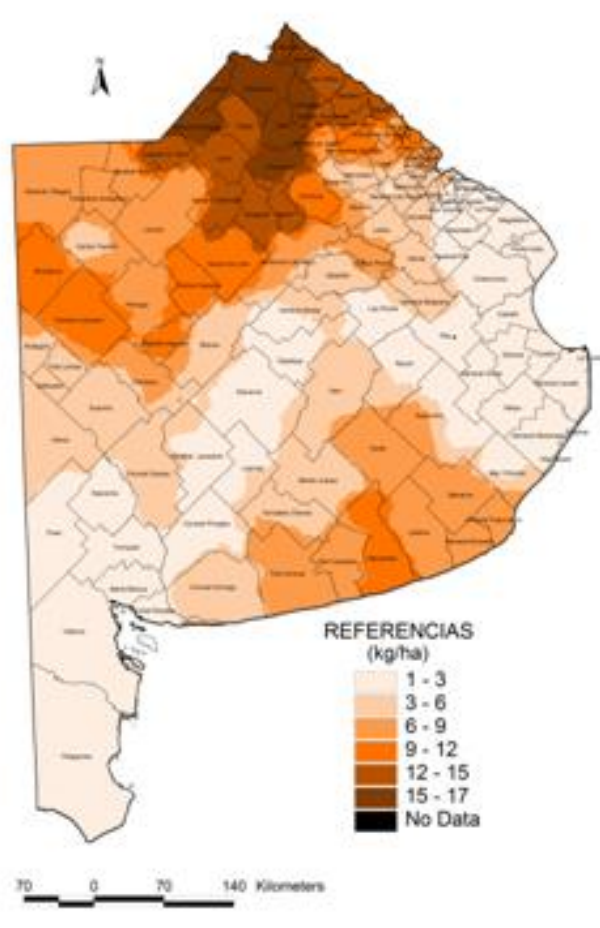

b) 


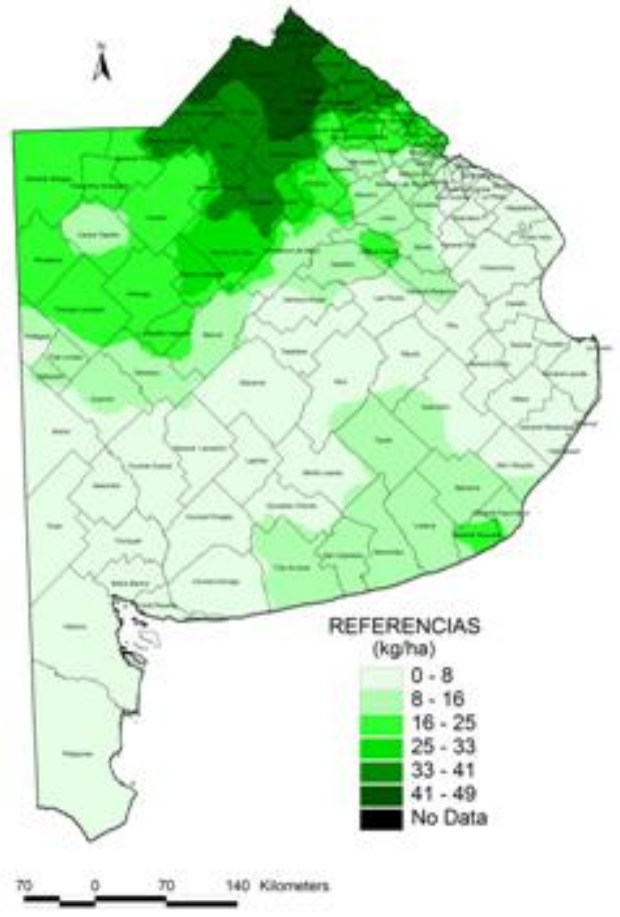

c)

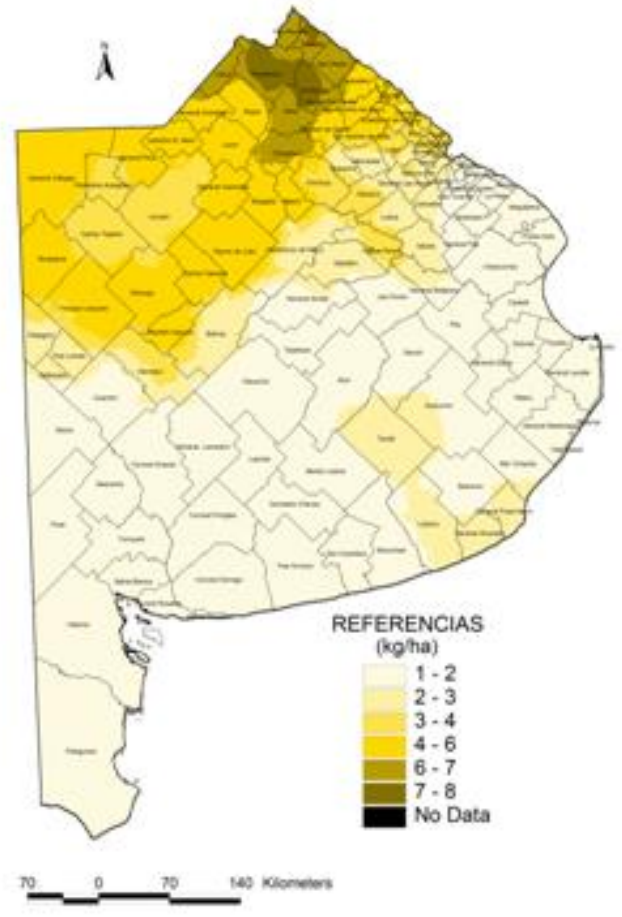

d)

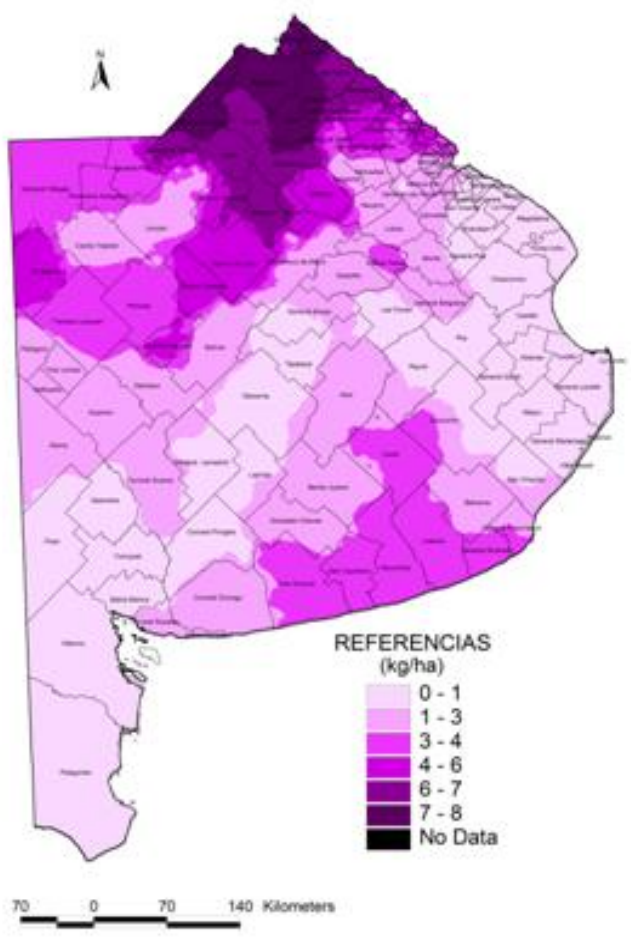

e)

Figura 3.4.2. Extracción anual promedio (ponderado por la superficie) de: a) N, b) P, c) K, d) Ca y e) S, debida a horticultura, cultivos extensivos y ganadería (carne y leche), en la provincia de Buenos Aires (período 2005-2006). 


\section{II.4.3.1.2. Extracción total y su distribución espacial}

La extracción total de nutrientes fue de 1.511 .599 † año-1 correspondiendo el 64; 9; 18; 4 y $4 \%$ a N, P, K, Ca y S, respectivamente. Los cultivos extensivos, por tener elevada extracción por unidad de superficie y ocupar el $37 \%$ de la superficie de la provincia, fueron los responsables de la mayor extracción total de nutrientes, representando el 94; 90; 97; 60 y 94\% del total de la extracción de N, P, K, Ca y S, respectivamente (Figura 3.4.3). La elevada diferencia relativa de superficie entre la actividad ganadera y la horticultura determinó que, a pesar de la mayor extracción por unidad de superficie de la horticultura (Figura 3.4.1), la extracción total en todos los nutrientes fuera mayor en la actividad ganadera (Figura 3.4.3).

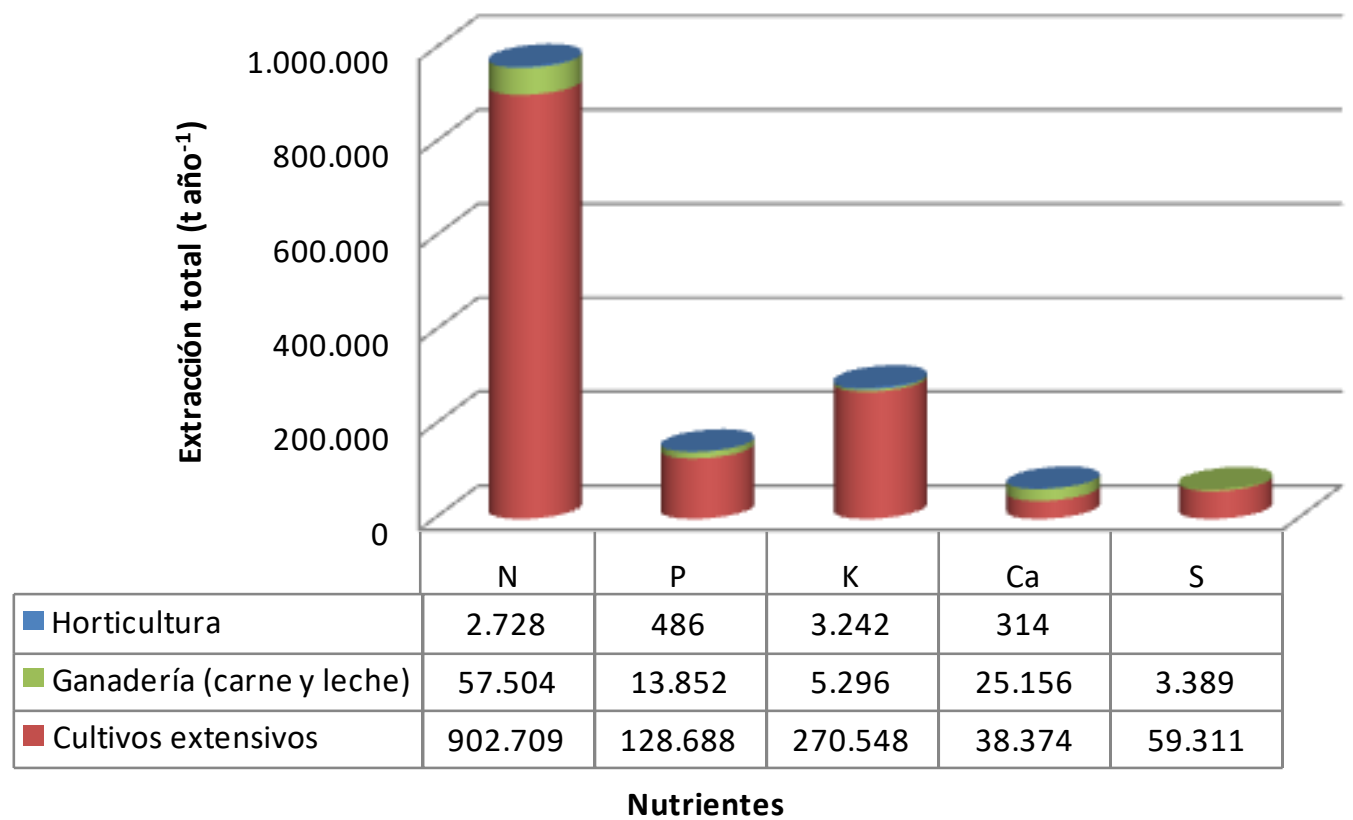

Figura 3.4.3. Extracción total de nutrientes debida a horticultura, ganadería (carne y leche) y cultivos extensivos en la provincia de Buenos Aires (período 2005-2006).

Las mayores extracciones totales de todos los nutrientes (N, P, K, Ca y S) se registraron en el norte, noroeste y sudeste de la provincia, y las menores, en el este y suroeste (Figura 3.4.4 a, b, c, d, e). Pergamino fue el partido de mayor extracción total en el norte, General Villegas y Trenque Lauquen en el noroeste, mientras que Tres Arroyos, seguido de Necochea, Tandil y Lobería, lo fueron en el sudeste. 


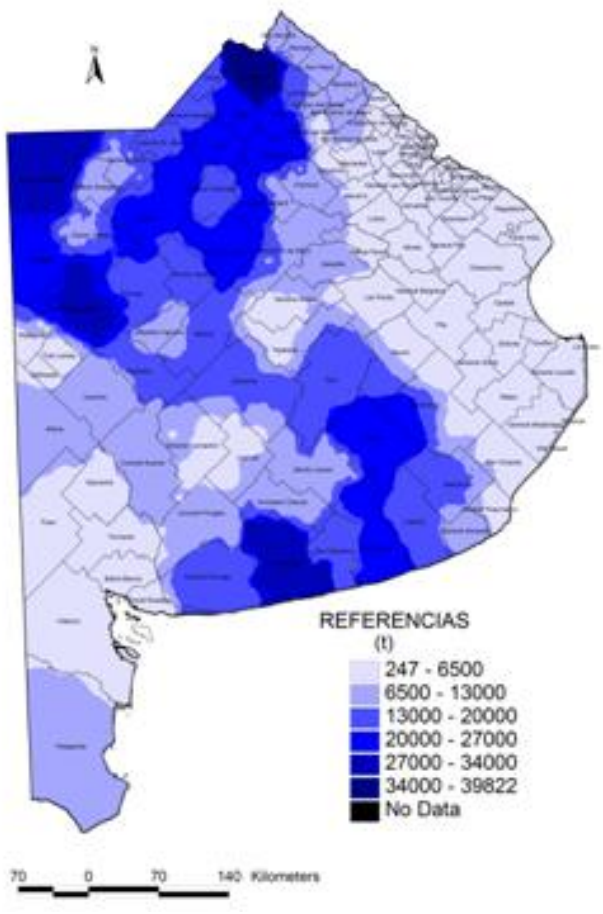

a)

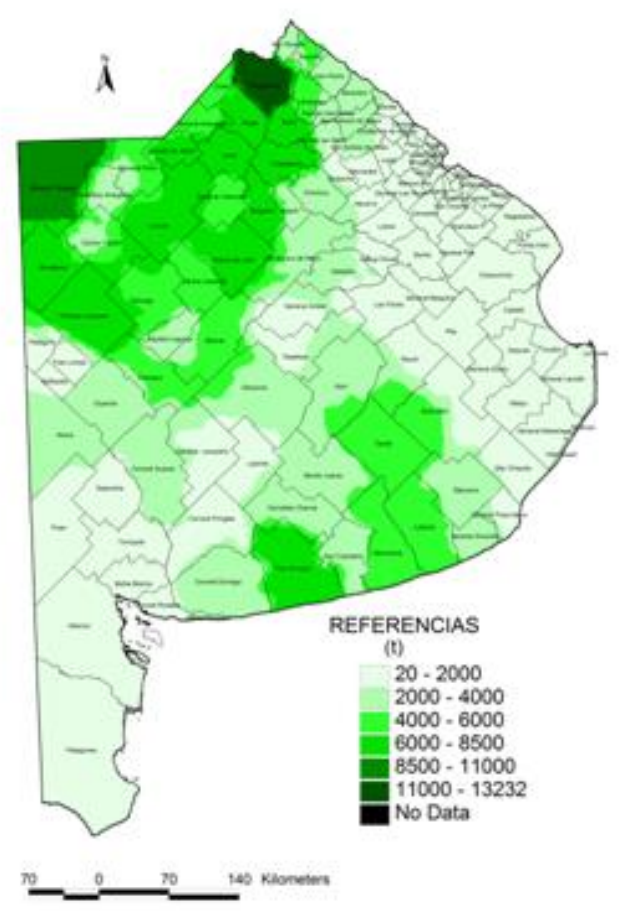

c)

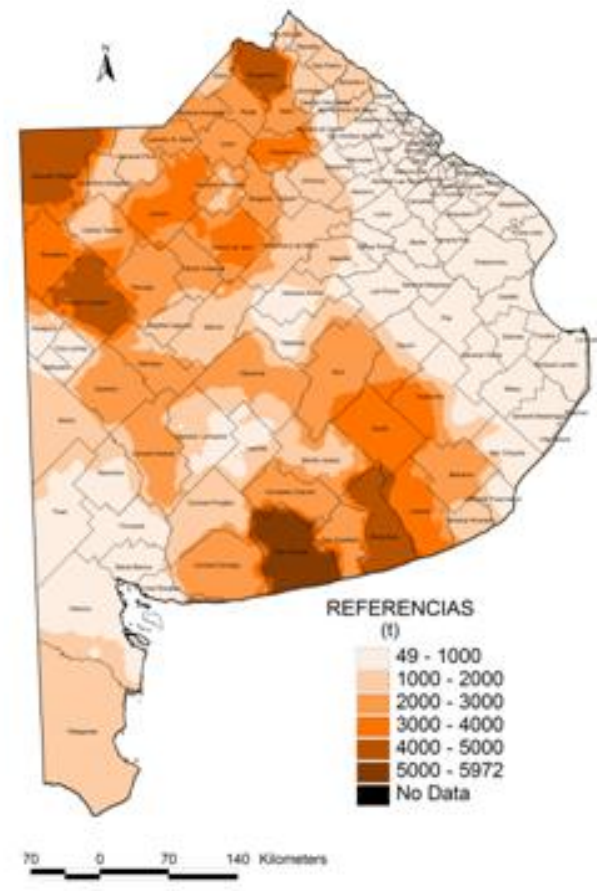

b)

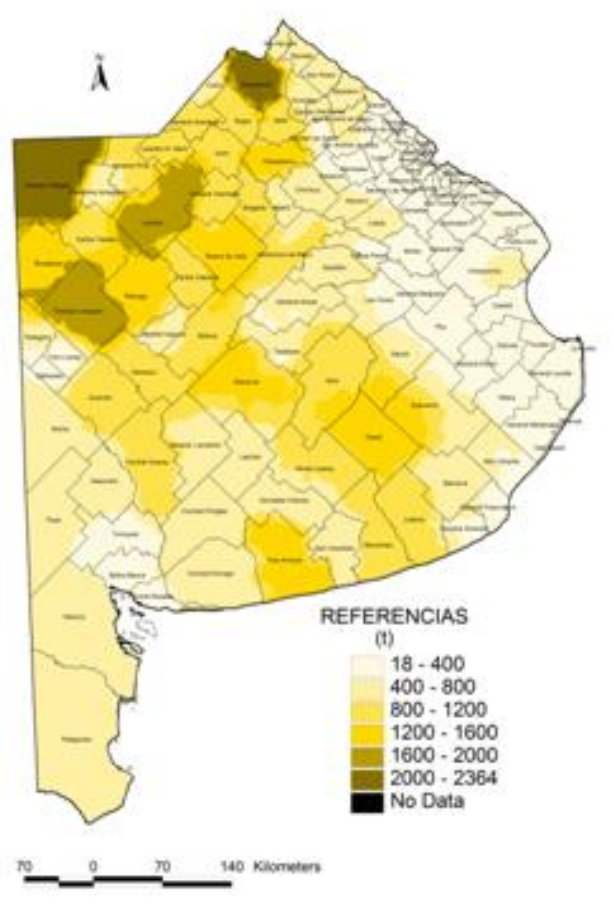

d) 


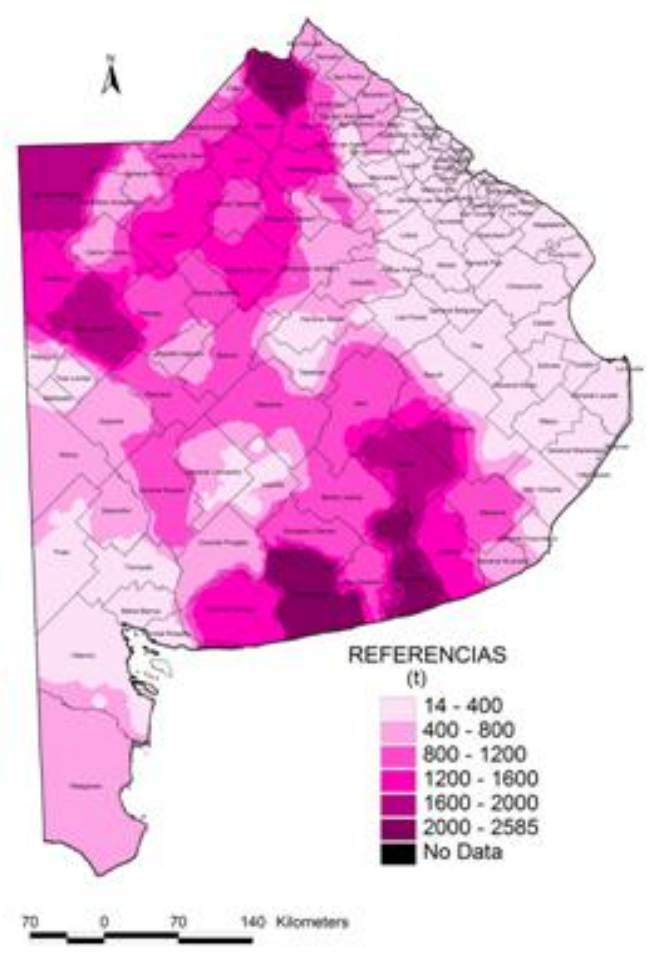

e)

Figura 3.4.4. Extracción total anual de: a) N, b) P, c) K, d) Ca y e) S, debida a horticultura, cultivos extensivos y ganadería (carne y leche), en la provincia de Buenos Aires (período 2005-2006).

\section{III.4.3.2. Balance de nutrientes}

\section{III.4.3.2.1. Balance por unidad de superficie y su distribución espacial}

El manejo de la fertilización en las diferentes actividades agropecuarias generó que los balances por unidad de superficie encontrados difirieran entre ellas, siendo, en promedio (ponderado por la superficie) todos negativos con valores de $-4,1 ;-1,6 ;-11,7$; $-2,4$ y $-2,4 \mathrm{~kg} \mathrm{ha}^{-1}$ año-1 para N, P, K, Ca y S, respectivamente. La horticultura fue la responsable de los mayores excedentes por unidad de superficie de N, P y Ca, y de la mayor pérdida de K. El K fue el único nutriente que tuvo balance negativo en las tres actividades, mientras que Ca y $S$ registraron pérdidas en las actividades de mayor ocupación territorial (cultivos extensivos y ganadería) (Figura 3.4.5). 


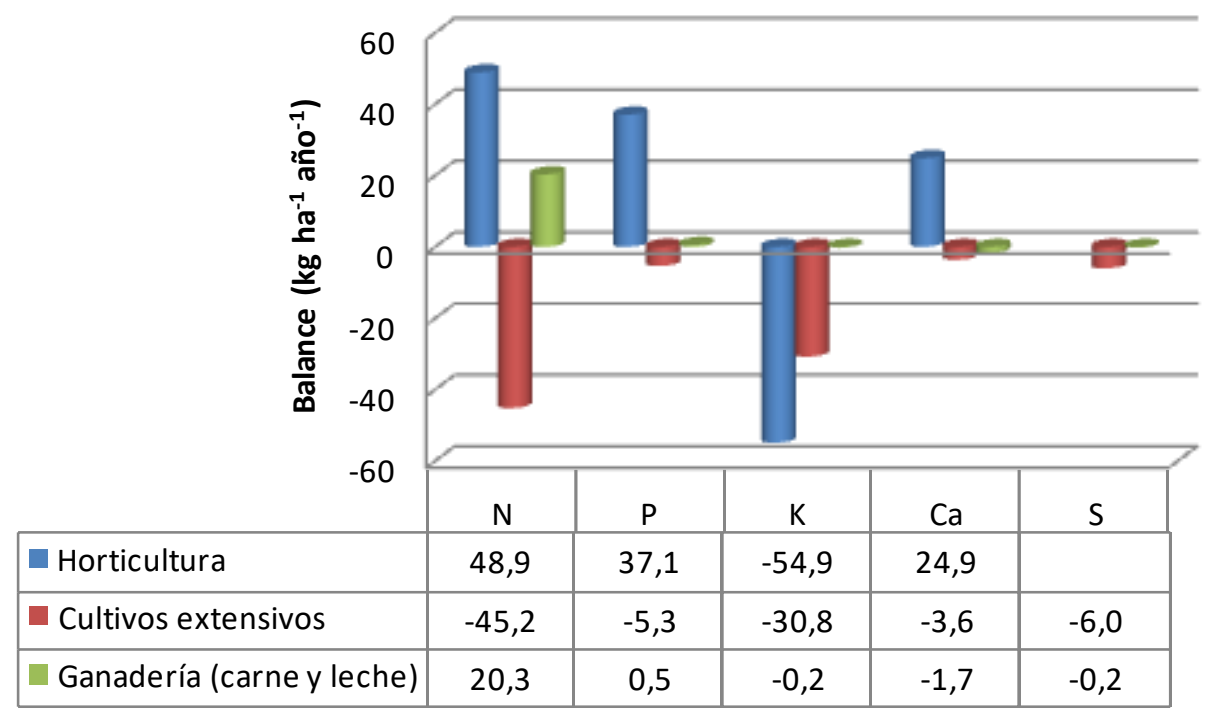

Nutrientes

Figura 3.4.5. Balance de nutrientes por unidad de superficie de las principales actividades agropecuarias de la provincia de Buenos Aires (período 2005-2006).

Se registraron balances negativos de $\mathrm{N}$, en el norte y el noroeste de la provincia y en tres partidos del sudeste (Lobería, Tandil y Necochea) (Figura 3.4.6a). El resto de la provincia presentó balances positivos. En P se encontraron balances positivos en el sudeste, el suroeste y el partido de La Plata y alrededores (Figura 3.4.6b). En el resto de la provincia el balance de $P$ fue negativo, siendo el norte la región, la de mayores pérdidas. En $\mathrm{K}$ y Ca, la zona que presentó balance positivo en ambos nutrientes fue el partido de La Plata (Figura 3.4.6c y d), mientras que en $S$ se registraron balances negativos en toda la provincia, siendo las zonas con mayores pérdidas el norte, el noroeste y el sudeste (Figura 3.4.6 e). 


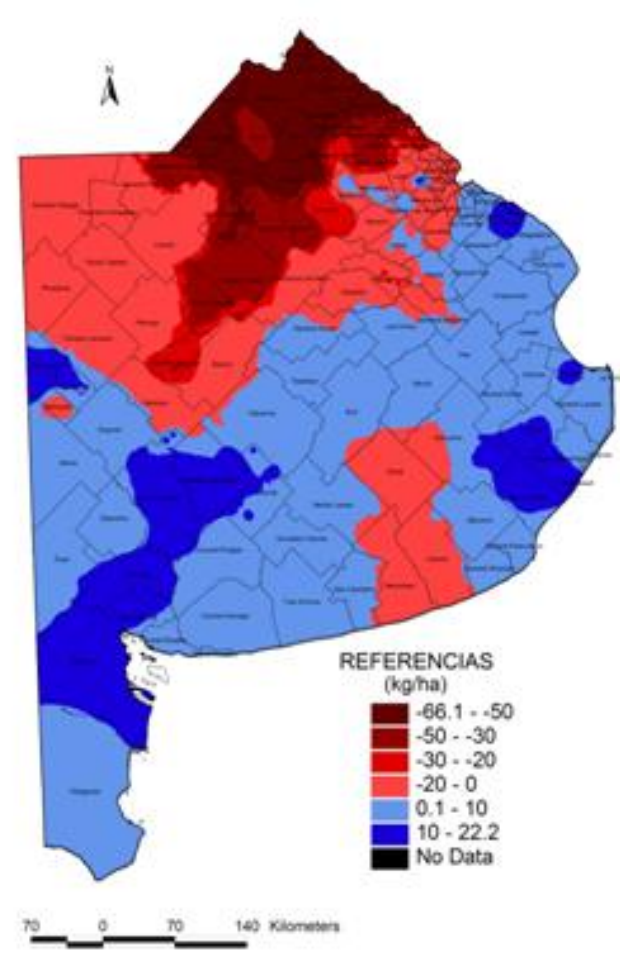

a)

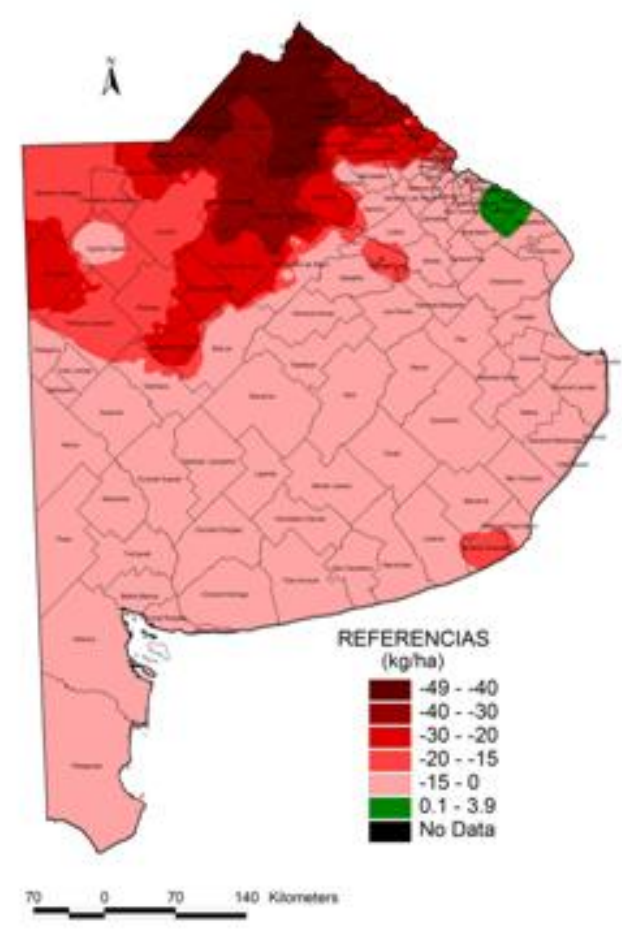

c)

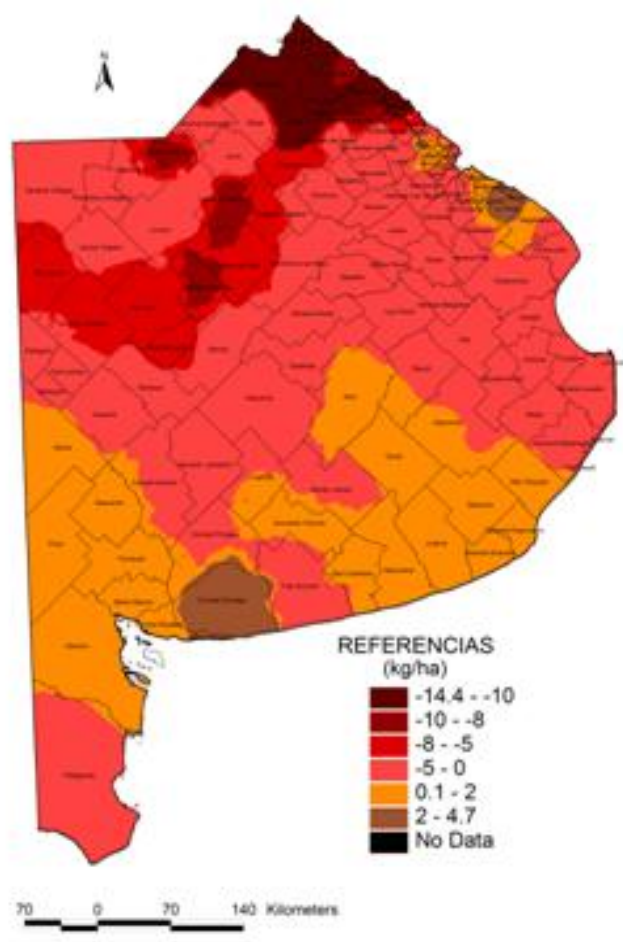

b)

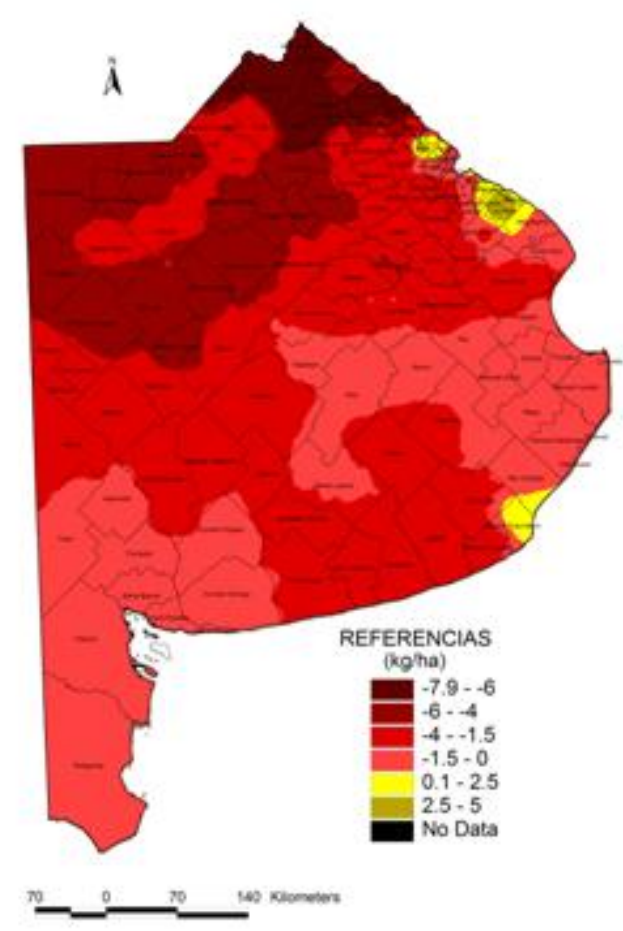

d) 


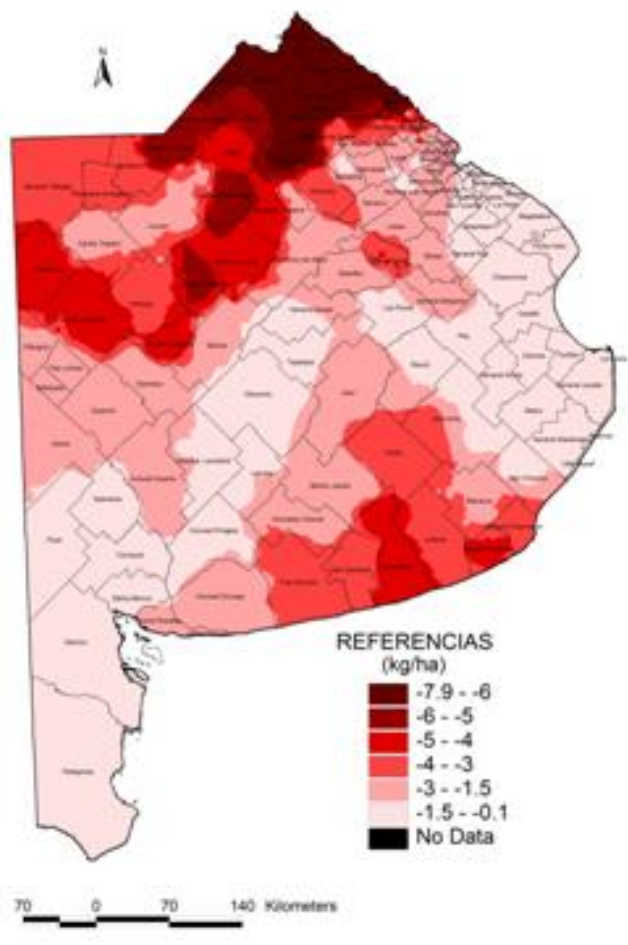

e)

Figura 3.4.6. Balance anual de nutrientes por unidad de superficie de: a) N, b) $P$, c) $K$, d) Ca y e) $S$, debido a horticultura, cultivos extensivos y ganadería (carne y leche), en la provincia de Buenos Aires (período 2005-2006).

\section{III.4.3.2.2. Balance total y su distribución espacial}

A pesar que hay actividades que presentaron balances por unidad de superficie positivos en algunos nutrientes, la superficie relativa ocupada por cada actividad determinó que para el balance total de la provincia fuera negativo para todos los nutrientes (Tabla 3.4.2). La pérdida de nutrientes fue de 522.000 † año-1, de las cuales el 53 \% correspondió a K y el 18; 11,11 y $7 \%$ a N, Ca, S y P, respectivamente. A pesar de que el $P$ fue un nutriente más extraído que Ca y $S$ (Figuras 3.4.1 y 3.4.3), presentó un menor déficit que estos debido a la fertilización.

Tabla 3.4.2. Balance total de nutrientes debido a horticultura, cultivos extensivos y ganadería (carne y leche), en la provincia de Buenos Aires (período 2005-2006).

\begin{tabular}{lccccc}
\hline & \multicolumn{5}{c}{ Nutrientes (t año-1) } \\
\cline { 2 - 6 } & $\mathbf{N}$ & $\mathbf{P}$ & $\mathbf{K}$ & $\mathbf{C a}$ & $\mathbf{S}$ \\
\hline Balance total & -96.706 & -37.420 & -275.840 & -56.189 & -56.110 \\
\hline
\end{tabular}

Los cultivos extensivos contribuyeron en mayor medida al déficit de nutrientes de los suelos de la provincia de Buenos Aires (Figura 3.4.7). En N y en P, el excedente generado por la ganadería y la horticultura, no alcanzó a compensar las pérdidas de 
los cultivos extensivos, provocando una pérdida general de estos nutrientes. Para K, Ca y $S$, las dos actividades más extensivas (cultivos extensivos y ganadería) fueron responsables de la mayor pérdida de nutrientes. Los cultivos extensivos fueron los responsables del $98 ; 57$ y $95 \%$ de las pérdidas de K, Ca y S, respectivamente.

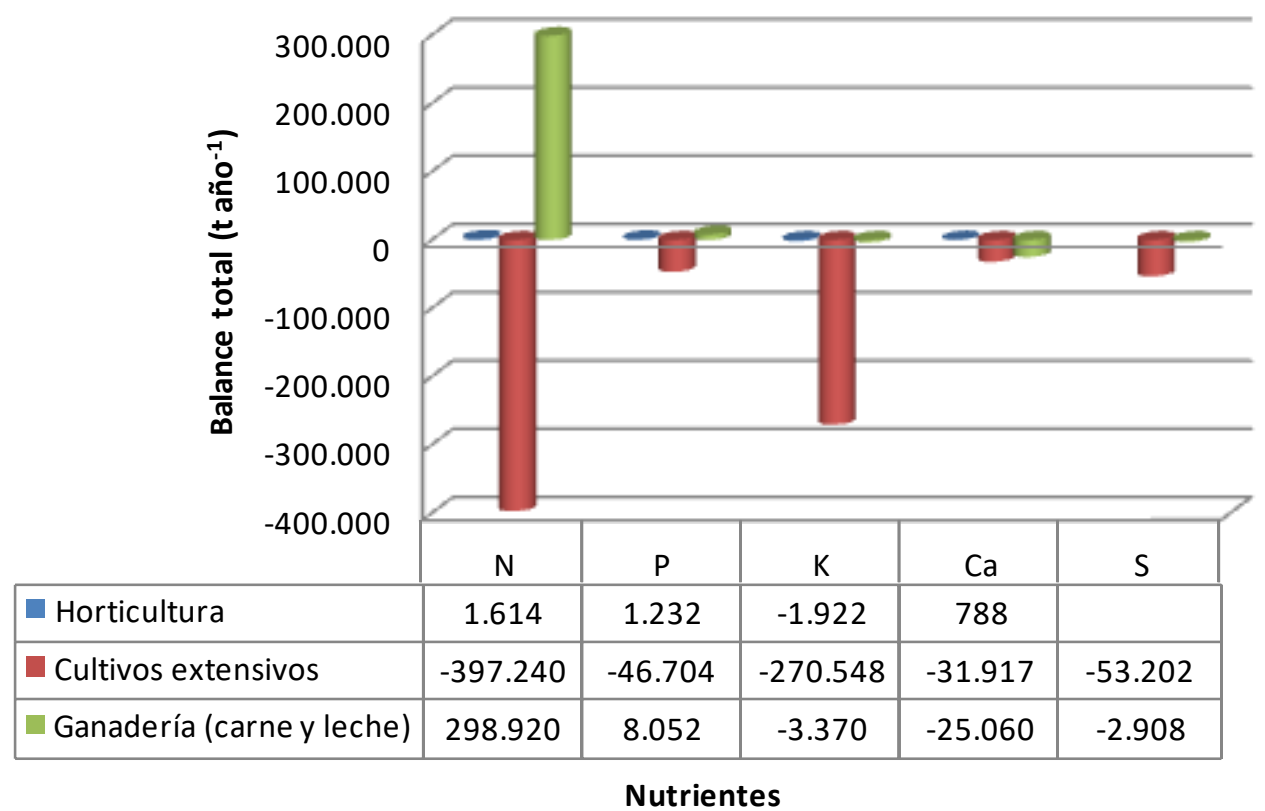

Figura 3.4.7. Balance total de nutrientes debido a horticultura, cultivos extensivos y ganadería (carne y leche), en la provincia de Buenos Aires (período 2005-2006).

Las áreas que presentaron los mayores déficits totales de N, P y S (Figura 3.4.8a, $b$, e) fueron similares a las que presentaron los mayores déficits por unidad de superficie (Figura 3.4.6a, b, e). Para $\mathrm{P}$ y Ca, el sudeste presentó elevadas pérdidas totales (Figura 3.4.8c, d), aunque no registró grandes déficits por unidad de superficie (Figura 3.4.6c, d). 


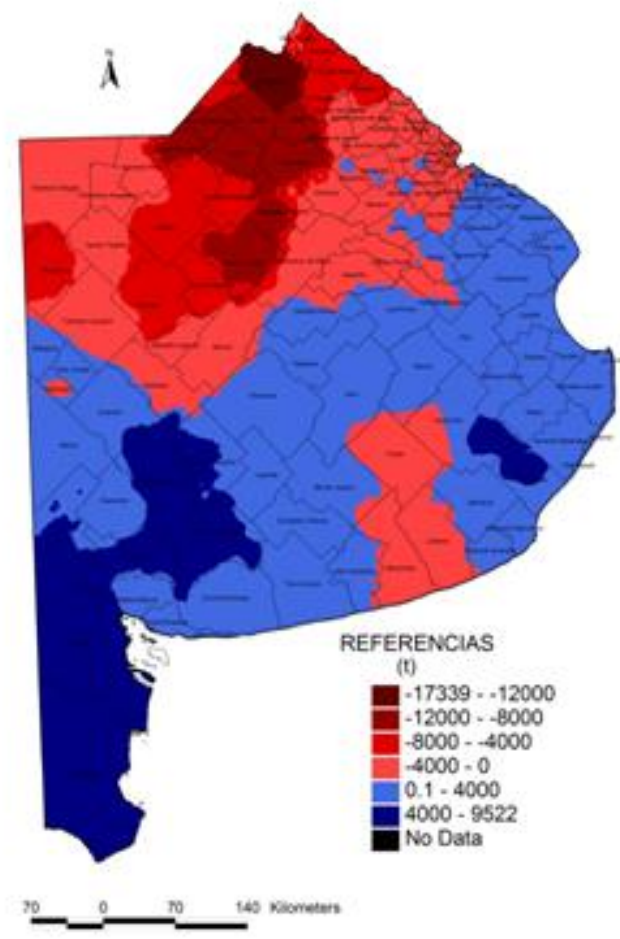

a)

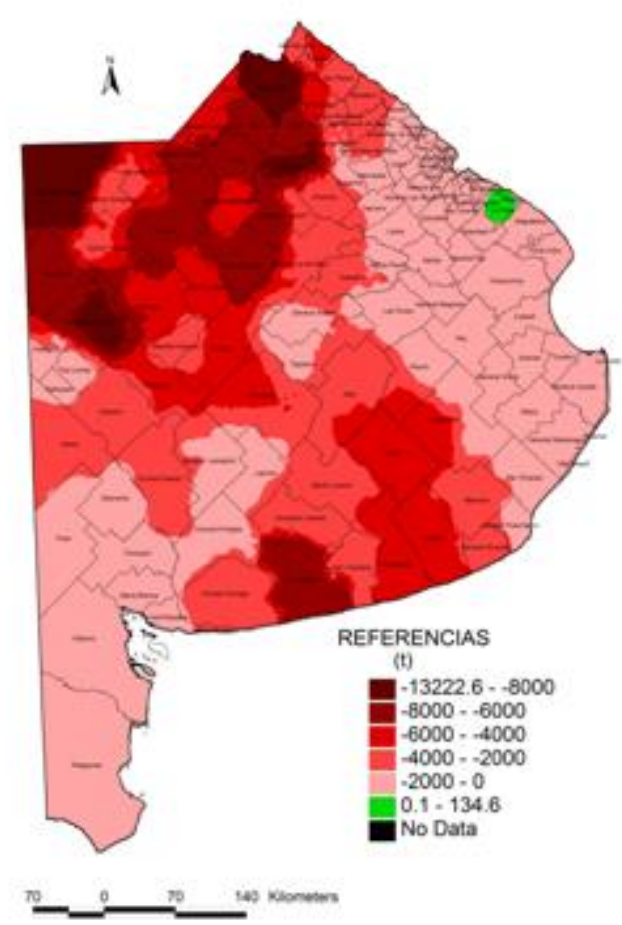

c)

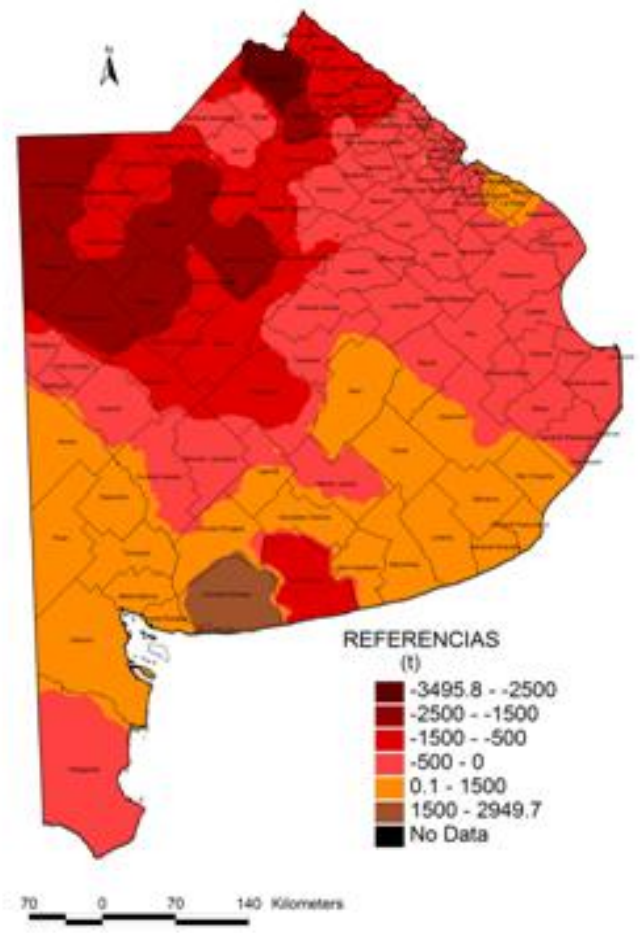

b)

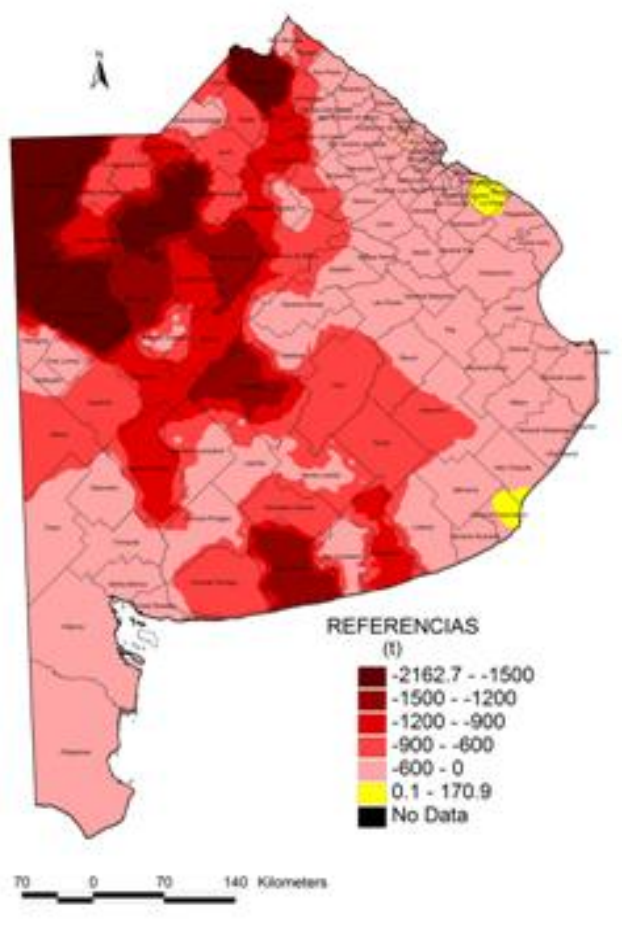

d) 


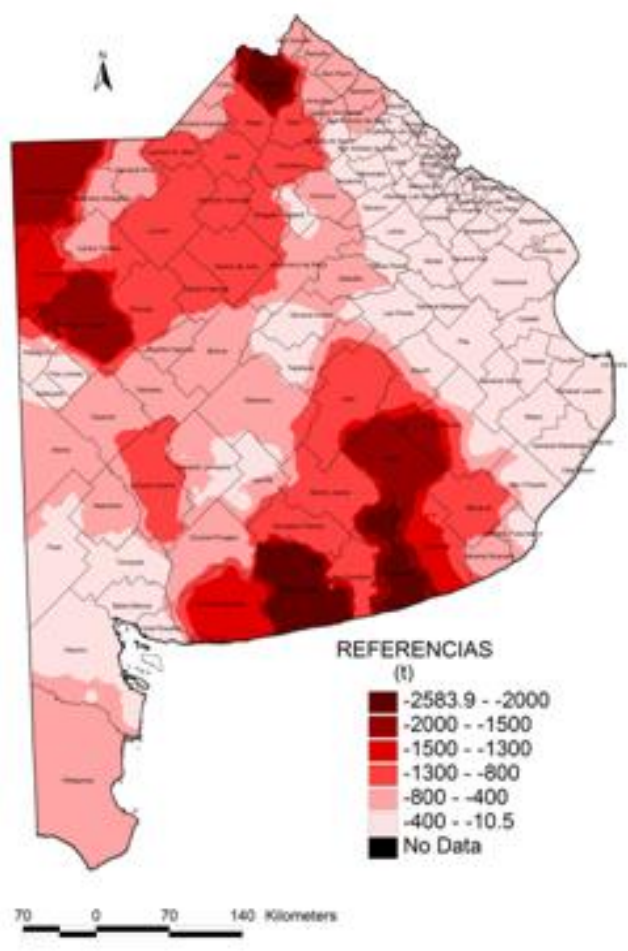

e)

Figura 3.4.8. Balance total anual de: a) N, b) P, c) K, d) Ca y e) S, debido a horticultura, cultivos extensivos y ganadería (carne y leche), en la provincia de Buenos Aires (período 2005-2006).

\section{III.4.4. DISCUSIÓN}

\section{III.4.4.1. Extracción de nutrientes}

La extracción de nutrientes por unidad de superficie de las diferentes actividades, fue claramente diferente entre producciones de un primer nivel trófico (horticultura y cultivos extensivos) y de un segundo nivel (producción de carne y leche bovina) (Figura 3.4.1), aspecto que responde a lo señalado por Odum (1998). En este sentido, también se estimó una mayor extracción de biomasa húmeda y seca en cultivos extensivos y horticultura respecto de la ganadería (carne y leche) (Tabla 3.4.1).

Entre las actividades del mismo nivel trófico se observó que la horticultura extrajo, mayor biomasa húmeda y seca por unidad de superficie, que los cultivos extensivos (Tabla 3.4.1). Esto puede estar influenciado tanto por las especies cultivadas, órgano cosechado, como por ser la horticultura una actividad cuyos cultivos se riegan durante todo o parte de su ciclo, favoreciendo el ritmo de crecimiento de los mismos. Esto último, resulta una gran diferencia respecto a los cultivos extensivos que presentan, proporcionalmente, una escasa superficie con riego suplementario. 
En el Uruguay, Mancassola \& Casanova (2015) evaluaron las extracciones de diferentes producciones y también informaron una mayor extracción de $\mathrm{K}$ y de Ca por unidad de superficie, de cultivos hortícolas respecto a los extensivos.

La extracción total de nutrientes en la provincia de Buenos Aires está influenciada por la capacidad extractiva por unidad de superficie de cada actividad agropecuaria y por la superficie total que ocupan. A causa de ello, los cultivos extensivos fueron los responsables de la mayor extracción total de todos los nutrientes considerados (N, P, K, Ca y S) (Figura 3.4.3). La mayor extracción total de nutrientes de la ganadería respecto a la horticultura se debió a la diferencia en la superficie destinada a cada una de las actividades en el territorio provincial (Figura 2.2).

En el norte, noroeste y sudeste de la provincia, donde predomina la producción agrícola extensiva (Figura 2.9), se observó una mayor extracción de nutrientes por unidad de superficie (Figura 3.4.2 a, b, c, d, e). Ésta fue superior en el norte y noroeste por el predominio de cultivos de verano (más extractivos) en relación al sudeste, que tiene mayor presencia de cultivos de invierno (menos extractivos) (Figura 2.4 y 2.5). Hacia el centro-este y sudoeste de la provincia, áreas con predominio de la actividad ganadera (Figura 2.9), las extracciones por unidad de superficie fueron menores. Como las extracciones promedio por unidad de superficie en la provincia están influenciadas en mayor medida por los cultivos extensivos, los mapas confeccionados se asemejaron a los de extracciones de cultivos extensivos publicados por Cruzate \& Casas (2012). También se visualizó que las áreas agrícolas extensivas (Figura 2.9) mantuvieron la mayor extracción total (Figura 3.4.4a, b, c, d, e). El centro de la provincia, a pesar de registrar una baja extracción por unidad de superficie (Figura 3.4.2a, b, c, d, e), se sumó como zona de alta extracción total (Figura 3.4.4a, b, $c, d, e)$, debido a que combina grandes superficies con ganadería y con cultivos extensivos. El sudeste, que también presenta grandes áreas con cultivos extensivos y ganadería (carne y leche) registró una extracción total similar al norte y noroeste (Figura 3.4.4a, b, c, d, e).

La extracción total de nutrientes de cada actividad agropecuaria, así como su extracción por unidad de superficie, no sólo permiten conocer la situación al momento de la evaluación, sino que también pueden ser de utilidad para predecir tendencias a futuro a partir de un cambio en el uso del suelo. Cuando se fomenta una determinada actividad o cultivo, la mencionada información permitiría estimar si el cambio en el uso del suelo implicará una mayor extracción de nutrientes y, por lo tanto, requerirá de una mayor reposición. Por ejemplo, lo que está sucediendo en la provincia de Buenos Aires con la creciente expansión de la agricultura continua sobre la superficie ganadera (Paruelo et al., 2005; Vázquez \& Zulaica, 2011) (Figura 2.2 a y b), indicaría que se está 
reemplazando producciones de menor extracción por aquéllas más extractivas. Actualmente, este reemplazo de superficies entre actividades no se encuentra debidamente registrado en todos los partidos de la provincia, porque el último censo agropecuario data del 2002. Adicionalmente, dentro de los cultivos extensivos se están reemplazando cultivos de menor extracción por soja (Glycine max (L.) Merr.) (Figura 2.3 y Figura 3.1.2), lo que estaría incrementando aún más las extracciones de nutrientes, hecho que aún no ha sido debidamente considerado en los estamentos de gestión.

\section{III.4.4.2. Balance de nutrientes}

El balance de nutrientes promedio (ponderado por la superficie) de la producción agropecuaria de la provincia de Buenos Aires (horticultura, cultivos extensivos y ganadería de carne y leche), indica que se está generando un vaciamiento de los suelos en todos los nutrientes considerados (Tabla 3.4.2). Cada actividad provocó un impacto diferente en cada uno de los nutrientes evaluados. Esta tendencia al agotamiento de los suelos también ha sido informada en otros países de América Latina (Koning et al., 1997), de África (Smaling \&Fresco, 1993) y a nivel global (Tan et al., 2005).

\section{III.4.4.2.1. Nitrógeno}

Se trata del nutriente para el que se registró el segundo mayor agotamiento en los suelos de la provincia (Tabla 3.4.2). La pérdida de $\mathrm{N}$ del suelo se debe al déficit generado por los cultivos extensivos (Figura 3.4.7), principalmente por el cultivo de soja (Figura 3.1.7). A partir del trabajo realizado por Collino et al. (2015) se podría esperar un menor déficit generado por el cultivo de soja debido a un mayor aporte de la fijación biológica. En esta tesis se asumió un aporte del 50\% del $\mathrm{N}$ lo extraído por el cultivo de soja, mientras que, Collino et al. (2015), estimaron que el mismo puede llegar al $60 \%$ de lo absorbido por el cultivo. Tanto la ganadería como la horticultura causaron un excedente de este nutriente, aunque la magnitud total provocada por la horticultura fue muy baja (Figura 3.4.7). En la provincia de Buenos Aires las zonas norte y noroeste presentaron los balances más negativos por unidad de superficie y totales (Figuras 3.4.6 a y 3.4.8 a), lo que se debe a que predominan los cultivos agrícolas de verano y, principalmente, soja (Figura 2.10). En el sudeste los tres partidos con déficit de $\mathrm{N}$ fueron Tandil, Necochea y Lobería, debido a la mayor presencia del cultivo de soja (Figura 2.10 y Figura 2.11). El resto de la provincia, sea por el predominio ganadero (Figura 2.10) o por compartir esta actividad la superficie con cultivos agrícolas, principalmente de invierno, registraron balances positivos (Figura 3.4.8 a). Igualmente, en el balance de $\mathrm{N}$ total de la provincia, las pérdidas fueron mayores que las ganancias (Tabla 3.4.2). 
Entre la horticultura y la ganadería existieron diferencias en cuanto al origen del $\mathrm{N}$ ingresado. En horticultura casi la mitad del $\mathrm{N}$ que ingresó fue por fertilización mineral y el resto por estiércol (Figura 3.2.6 a), mientras que en la ganadería el $70 \%$ del $\mathrm{N}$ ingresado fue mediante fijación biológica (capítulo III, subcapítulo 3). Del excedente de $\mathrm{N}$ ocurrido en la superficie ganadera, sólo el que se genera en la superficie implantada con forrajes anuales o perennes (30\% de la superficie total ganadera) podría ser potencialmente aprovechada por la agricultura. Esta área es la que podría formar parte de una rotación agrícolo-ganadera. Si bien el excedente puede verse como algo positivo porque no se agotan los suelos, hay que tener en cuenta la magnitud de dicho excedente y la dinámica del nutriente, pues el mismo puede transformarse en un problema de contaminación, a pesar de tener origen orgánico (Cassman et al., 2003).

Resultados similares de excedentes de $\mathrm{N}$ en ganadería y déficits en cultivos extensivos han sido informados por Cabrini \& Calcaterra (2009) en Pergamino, así como por Ghida Daza, (2013) en Córdoba. Estos autores también calcularon que el aporte de $\mathrm{N}$ por fijación biológica en los sistemas ganaderos fue significativo. Vicente \& Engler (2008), en Entre Ríos, también informaron resultados similares, comprobando que el excedente de $\mathrm{N}$ causado por la ganadería permitía contrarrestar las pérdidas de la agricultura extensiva, logrando un superávit en el balance del elemento. En Uruguay, Mancassola \& Casanova (2015) también estimaron déficit de $\mathrm{N}$ generado por cultivos extensivos. Paralelamente, estos autores comprobaron que el excedente originado por la actividad ganadera y forestal, sería el responsable del excedente de $\mathrm{N}$ a nivel de país. En Europa, en general, el conjunto de actividades agropecuarias genera excedentes. A título de ejemplo, en Alemania, Panten et al. (2009) calcularon que los excedentes de $\mathrm{N}$ anual rondaban los $100 \mathrm{~kg} \mathrm{ha}^{-1}$.

\section{III.4.4.2.2. Fósforo}

Debido a una baja reposición, los cultivos extensivos también fueron los responsables de la mayor pérdida de este elemento en los suelos de la provincia. A excepción del trigo (Triticum aestivum L.) y la cebada cervecera (Hordeum vulgare L. var. distichum), el resto de los cultivos extensivos presentaron balances negativos (Figura 3.1.7). En la actividad ganadera, si bien el balance general fue positivo, el $70 \%$ de la superficie (con pastizal natural) no recibió fertilización fosforada, por lo que el excedente provino de la superficie fertilizada en la implantación de pasturas o verdeos. Esto es lo que permite explicar las zonas con balance por unidad de superficie y total, tanto positiva como negativa, encontrados en la provincia (Figuras $3.4 .6 \mathrm{~b}$ y $3.4 .8 \mathrm{~b})$. Las zonas con excedente se corresponden con el sudeste y sudoeste, 
donde predominan los cultivos de invierno (trigo y cebada cervecera) (Figuras 2.4 y 2.5) y la implantación de pasturas y verdeos (Figuras 2.6 y 2.7 ). El sudeste es una zona que tradicionalmente se ha fertilizado con $\mathrm{P}$ por la pobreza de los suelos en este elemento, debido a los materiales originales a partir de los que se desarrollaron sus suelos. La zona centro-este de la provincia que corresponde a la Pampa Deprimida (Figura 2.1), con predominio de actividad ganadera sobre pastizal natural (Figura 2.6), también presentó balance negativo de $\mathrm{P}$ por la ausencia de fertilización (Figura 3.4.8b). En las zonas norte y noroeste, el balance negativo estuvo influenciado por el predominio de cultivos de verano (Figuras 2.4 y 2.5). Al igual que en el caso del N, las áreas ganaderas que pueden contribuir a compensar los déficits causados por la agricultura con su excedente de $P$, son aquéllas donde predomina la implantación de forrajes (pasturas y verdeos), lo que corresponden a un tercio de la superficie total ganadera. Considerando que los cultivos extensivos continúan expandiéndose en toda la provincia (Figuras 2.2 y 2.3), con mayor intensidad hacia el sur, se puede suponer que la pérdida de $\mathrm{P}$ de los suelos continuará y las áreas con disminución de $\mathrm{P}$ disponible crecerán más aún que lo encontrado por Sainz Rozas et al. (2012) en suelos agrícolas, en relación a condiciones prístinas.

Balances positivos de $P$ en ganadería y negativos en cultivos extensivos en diferentes zonas de la región pampeana han sido informados por diversos autores, entre ellos Cabrini \& Calcaterra (2009). En Entre Ríos, Vicente \& Engler (2008) estimaron un balance positivo tanto en cultivos extensivos como en ganadería (carne y leche). Por su parte, Mancassola \& Casanova (2015) comprobaron un excedente de P en los suelos de Uruguay, donde todos los cultivos extensivos, la horticultura y las producciones de carne y leche bovinas registraron balances positivos. Tanto en Entre Ríos como en Uruguay, el bajo contenido de $\mathrm{P}$ de los suelos es lo que condiciona la dosis de fertilización fosfatada.

Se destaca un balance positivo de $\mathrm{P}$ en el partido de La Plata y otros partidos en los alrededores de la Ciudad Autónoma de Buenos Aires (Figura 3.4.8 b), debido a la intensa actividad hortícola que allí se desarrolla. La cercanía a centros urbanos destaca la necesidad de monitorear estos excedentes, a fin de evitar problemas ambientales.

\section{III.4.4.2.3. Potasio}

El K fue el nutriente que presentó el mayor agotamiento en los suelos de la provincia, contribuyendo a este déficit las tres actividades consideradas (Figura 3.4.7). Los mayores déficits de $K$ por unidad de superficie se concentraron en el norte $y$ noroeste de la provincia (Figura 3.4.6 c), donde predomina la agricultura extensiva 
(Figura 2.9) y, principalmente, con cultivos de verano (Figuras 2.4 y 2.5), responsables de los mayores déficits (Tabla 3.1.3). Paralelamente, se observó un elevado déficit total en el sudeste, debido a la gran superficie con agricultura extensiva y el cultivo de papa (Solanum tuberosum L.) (Figura $3.4 .8 \mathrm{c}$ ).

En la horticultura, este déficit se debió principalmente al cultivo de papa, el cual presenta una fertilización con criterio de rentabilidad similar a la de los cultivos extensivos, por lo cual, como los suelos nativos están aún bien provistos de este nutriente (Melgar, 2011; González Sanjuán et al., 2013), no recibe fertilización potásica. En el partido de La Plata y sus alrededores, donde existe una fuerte concentración de superficie bajo invernáculo y, a su vez, una elevada fertilización potásica en tomate (Solanum lycopersicum L.) y pimiento (Capsicum annuum L.), se observó un excedente por unidad de superficie (Figura 3.4.6 c) y total (Figura 3.4.8 c).

Como el K, prácticamente no se emplea en la fertilización de actividades extensivas, se generó un déficit directamente proporcional a la capacidad de extracción de dicha actividad. Debido a ello, los cultivos extensivos contribuyeron más al agotamiento de este nutriente que las actividades ganaderas (Figura 3.4.7). Esto permite explicar que tanto el centro-este como el sudoeste de la provincia, con fuerte presencia de ganadería (Figura 2.9), registraron los menores déficits por unidad de superficie (Figura 3.4.6 c) y totales (Figura 3.4.6 c). A diferencia de lo que podría suceder con $\mathrm{N} \circ \mathrm{P}$, donde, una rotación agrícolo-ganadera podría compensar los déficits de la primera actividad con los excedentes de la segunda, para el caso del $\mathrm{K}$ sólo se cambiaría el ritmo del agotamiento.

Esta pérdida de $\mathrm{K}$ se ha informado también en diversos trabajos en Argentina (Cabrini \& Calcaterra, 2009), Uruguay (Mancassola \& Casanova, 2015) y en el resto del mundo (Sheldrick et al., 2003; FAO, 2004). Los rangos de pérdida de este nutriente calculados en esta tesis variaron entre $54,9 \mathrm{~kg} \mathrm{ha}^{-1}$ año-1 en horticultura a 0,2 kg ha-1 año-1 en ganadería, con un promedio (ponderado por la superficie) de $11,7 \mathrm{~kg} \mathrm{ha}^{-1}$ año-1. En China, Sheldrick et al. (2003) estimaron balances negativos de K en rangos de 28 a $62 \mathrm{~kg} \mathrm{ha}^{-1}$, y señalan que la disponibilidad de este nutriente es el desafío que tiene ese país para sostener e incrementar los rendimientos en el futuro. Krauss (2000) considera que el déficit de $\mathrm{K}$ presenta una situación peor a nivel mundial que el $\mathrm{N}$ y $\mathrm{P}$, porque la pérdida de K afecta la utilización de otros nutrientes por parte de los cultivos. Si bien en gran parte de la provincia aún queda una adecuada dotación de este nutriente, se estima que en los próximos 10-15 años se encontrarán zonas con repuesta a la fertilización potásica, consecuencia de la continua extracción sin reposición (García y González Sanjuán, 2016). 


\section{III.4.4.2.4. Calcio y azufre}

Los cultivos extensivos generaron, en Ca y S, un mayor déficit que la ganadería, mientras que la horticultura registró un excedente de Ca (Figura 3.4.5.) debido a los aportes de estiércoles (Figura 3.2.6). Las zonas hortícolas más importantes de la provincia, el partido de La Plata y sus alrededores, y el partido de General Pueyrredón, registraron excedentes en Ca. En el resto de la provincia, donde predominan las actividades extensivas, se produjeron déficits de Ca (Figuras 3.4.6d y 3.4.8d). Siempre el norte y el noroeste mostraron los mayores déficits, seguidos del sudeste $y$, en menor medida, el centro-este y sudoeste de la provincia.

Este exceso de Ca y S en horticultura y déficit en el resto de las actividades, es similar a lo informado por Casanova \& Mancassola (2015) en Uruguay. Manchado (2010) también estimó déficits de estos elementos en la zona centro sur de la provincia de Buenos Aires debido a los cultivos extensivos y la ganadería.

En función de lo discutido, y para las condiciones asumidas en esta tesis, se acepta parcialmente la hipótesis planteada, debido a que la producción de carne y de leche bovinas contribuyeron a una conservación del $\mathrm{N}$ y $\mathrm{P}$ en los suelos de la provincia, y a una menor pérdida de las dotaciones de $K$, Ca y $S$, que los cultivos extensivos, los cuales generaron una disminución de la dotación de todos los nutrientes. No obstante, la horticultura también contribuyó con una conservación de $\mathrm{N}$, P y, además, de Ca, aunque ejerció una mayor disminución de la dotación de K por unidad de superficie que las producciones de carne y leche bovinas.

\section{III.4.4.3. El uso de la tierra}

Si bien el cálculo del balance de nutrientes es señalado como una herramienta que contribuiría con una agricultura sostenible (Öborn et al., 2003; Dechert et al., 2005; Abbona et al., 2007), pocas veces es utilizado para anticipar tendencias a futuro, sobre todo en cambios en el uso de la tierra. En la provincia de Buenos Aires podría haber sido implementado para predecir el efecto del reemplazo de distintos cultivos extensivos por soja, así como con el avance de los cultivos extensivos sobre superficie dedicada a la ganadería. A fines de la década del 90 del siglo XX, se encontraba documentado cómo el manejo de la fertilización de la soja, en función del criterio de dosis-respuesta, estaba generando un mayor agotamiento de los suelos que otros cultivos (Cruzate \& Casas, 2003; Flores \& Sarandón, 2003). No obstante, por conveniencia económica, tanto de los agricultores como por el beneficio económico que implica para el país, este cultivo creció exponencialmente. La superficie de soja en la provincia de Buenos Aires se incrementó de 1,3 Mha en 1990, a 2,4 Mha en el año 2000 y a 6,5 Mha en el 2015 (SIIA, 2016). Esta expansión implicó, por un lado, el 
reemplazo de cultivos dentro de la superficie dedicada a cultivos extensivos y, por otro, el avance sobre zonas ganaderas con pasturas e incluso pastizales (Paruelo et al., 2005; Viglizzo et al., 2010; Vázquez \& Zulaica, 2011) (Figura 2.2 y 2.3). En función de los datos informados por Cruzate \& Casas $(2003,2012)$, se puede afirmar que el reemplazo de distintos cultivos agrícolas por soja ha llevado a que se incrementaran los déficits de nutrientes señalados anteriormente. Por otro lado, el cambio de la superficie de suelo bajo rotación agrícola-ganadera para convertirse exclusivamente en agrícola con soja, implica que la misma pase de alternar épocas con excedente de $\mathrm{N}$ y $\mathrm{P}$ (uso ganadero) y otras con déficit (uso agrícola), a una nueva situación continua con déficits. De haberse tenido en cuenta los trabajos que, a principios del siglo XXI, estimaron la pérdida de nutrientes originada por el manejo del cultivo de soja, se podría haber condicionado el avance desmedido de este cultivo, principalmente, en áreas ecológicas más frágiles como las dedicadas a pastizales. Si garantizar la producción de alimentos es una preocupación mundial y local, resulta imperante que se comiencen a considerar estos estudios para fomentar o modificar tendencias en el uso de la tierra y en la producción de alimentos.

\section{III.4.5. BIBLIOGRAFÍA}

Abbona, E.A., S.J. Sarandón, M.E. Marasas \& M. Astier. 2007. Ecological sustainability evaluation of traditional management in different vineyard systems in Berisso, Argentina. Agriculture, Ecosystems \& Environment 119:335-345.

Cabrini, S.M. \& C.P. Calcaterra. 2009. Sistemas de producción en el partido de Pergamino. Valoración económica del impacto sobre la capacidad productiva de los suelos. INTA. Estudios socioeconómicos de la sustentabilidad de los sistemas de producción y recursos naturales 12 . $36 \mathrm{pp}$.

Cassman, K.G., A. Dobermann, D.T. Walters \& H. Yang. 2003. Meeting cereal demand while protecting natural resources and improving environmental quality. Annual Review of Environment \& Resources 28:315-358.

Collino, D.J., F. Salvagiotti, A. Perticari, C. Piccinetti, G. Ovando, S. Urquiaga \& R.W. Racca. 2015. Biological nitrogen fixation in soybean in Argentina: relationships with crop, soil, and meteorological factors. Plant Soil 392:239-252.

Cruzate, G. \& R.R. Casas. 2003. Balance de nutrientes. Revista Fertilizar (Número especial "Sostenibilidad"): 7-13pp.

Cruzate, G. \& R.R. Casas. 2012. Extracción y balance de nutrientes en los suelos agrícolas de la Argentina. Informaciones Agronómicas de Hispanoamérica 6:7-14.

Dechert, G., E. Veldkamp \& R. Brumme. 2005. Are partial nutrient balances suitable to evaluate nutrient sustainability of land use systems? Results from a case study in central Sulawesi, Indonesia. Nutrient Cycling in Agroecosystems 72:201-212.

FAO (Organización de las Naciones Unidas para la Alimentación y la Agricultura). 2004. Scaling soil nutrient balances. Enabling mesolevel applications for African realities. Rome. Fertilizer \& Plant Nutrition Bulletin 15. 150pp.

Flores, C.C. \& S.J. Sarandón. 2003. ¿̇Racionalidad económica versus sustentabilidad ecológica? El ejemplo del costo oculto de la pérdida de fertilidad del suelo, durante el proceso de Agriculturización en la Región Pampeana Argentina. Revista de la Facultad de Agronomía 105 (1): 53-67.

Flores, C.C. \& S.J. Sarandón. 2014. La energía en los agroecosistemas. En: Agroecología: bases teóricas para el diseño y manejo de agroecosistemas sustentables. Sarandón, S.J. \& C.C. Flores (Editores). Editorial de la Universidad Nacional de La Plata. Capítulo 7:190-210. Disponible en: http://sedici.unlp.edu.ar/handle/10915/37280. Último acceso: septiembre 2016. 
García, F. \& M.F. González Sanjuán. 2016. Consumo de fertilizantes en el mundo y en Argentina. En: Sustentabilidad de los agroecosistemas y uso de fertilizantes. Lavado R.S. (Coordinador). Editorial Orientación Gráfica. Buenos Aires. Capítulo 3:61-83.

Ghida Daza, C. 2013. Valoración económica del balance de nutrientes en la Provincia de Córdoba. Estación Experimental Agropecuaria Marcos Juárez. INTA. Información para extensión 141.9pp.

Gliessman, S.R. 2002. Agroecología: procesos ecológicos en agricultura sostenible. Turrialba, Costa Rica: CATIE. 359pp.

González Sanjuán, M. F., A.A. Grasso \& J. Bassi. 2013. Fertilizantes en Argentina. Análisis del Consumo. Fertilizar 25:25-29.

Koning, G.H.J., P.J. van de Kop \& L.O. Fresco. 1997. Estimates of sub-national nutrient balances as sustainability indicators for agro-ecosystems in Ecuador. Agriculture, Ecosystems \& Environment 65:127-139.

Krauss, A. 2000. Nutrient cycling and transfers in the global dimension. En: Nutrient management in China. Part 1. Nutrient management and nutrient cycling in agro-ecosystems. Hardter, R., J-C. Xie, J.M. Zhou \& Q-Z. Fan (Editores). International Potash Institute. Capítulo 1:13-24

Mancassola, V. \& O. Casanova. 2015. Balance de nutrientes en los principales productos agropecuarios de Uruguay para los años 1990, 2000 y 2010. Informaciones Agronómicas de Hispanoamérica 17:2-13.

Manchado, J.C. 2010. La sustentabilidad en la agricultura pampeana: Valoración económica del balance de nutrientes para las principales actividades agropecuarias extensivas en la Región Centro Sur de la Provincia de Buenos Aires. Revista Argentina de Economía Agraria XII(2):51-68.

Melgar, R. 2011. La reposición de nutrientes en EEUU, Brasil y Argentina: tres escenarios contrastantes. Fertilizar 19:5-11.

Öborn. I., A.C. Edwards, E. Witter, O. Oenema, K. Ivarsson, P.J.A. Withers, S.I. Nilsson \& A. Richert Stinzing. 2003. Element balances as a tool for sustainable nutrient management: a critical appraisal of their merits and limitations within an agronomic and environmental context. European Journal of Agronomy 20:211-225.

Odum, E.P. 1998. Flujo de energía dentro del ecosistema. En: Ecología; el vínculo entre las ciencias naturales y las sociales. 20 Reimpresión. Compañía Editorial Continental S.A. de C.V.. Capítulo 3:79:113.

Panten, K., J. Rogasik, F. Godlinsky, U. Funder, J-M. Greef \& E. Schung. 2009. Gross soil surface nutrient balances: The OECD Approach implemented under German conditions. Agriculture \& Forestry Research 1 59:19-28.

Paruelo, J.M., J.P. Guerschman \& S.R. Verón. 2005. Expansión agrícola y cambios en el uso del suelo. Ciencia Hoy 15(87):14-23.

Sainz Rozas, H., H. Echeverría. \& H. Angelini. 2012. Fósforo disponible en suelos agrícolas de la región Pampeana y Extra Pampeana argentina. INTA. Revista de Investigaciones Agropecuarias 38(1):33-39.

Sarandón, S.J. 2002. El desarrollo y uso de indicadores para evaluar la sustentabilidad de los agroecosistemas. En: Agroecología. El camino hacia una agricultura sustentable. Sarandón, S.J. (Editor). Ediciones Científicas Americanas. Buenos Aires. Capítulo 20:393-414.

Sarandón, S.J. \& C.C. Flores. 2009. Evaluación de la sustentabilidad en agroecosistemas: una propuesta metodológica. Agroecología 4:19-28.

Sarandón, S.J. \& C.C. Flores. 2014. Análisis y evaluación de agroecosistemas: construcción y aplicación de indicadores. En: Agroecología: bases teóricas para el diseño y manejo de agroecosistemas sustentables. Sarandón, S.J. \& C.C. Flores (Editores). Editorial de la Universidad Nacional de La Plata. Capítulo 14:375-410. Disponible en: http://sedici.unlp.edu.ar/handle/10915/37280. Último acceso: septiembre 2016.

Sheldrick, W.F., J.K. Syers \& J. Lingrad. 2003. Soil nutrient audits for China to estimate nutrient balances and output/input relationships. Agriculture, Ecosystems \& Environment 94:341-354.

SIIA (Sistema Integrado de Informaciones Agropecuarias). 2016. Disponible en: http://www.siia.gov.ar/ Último acceso septiembre 2016.

Smaling, E.M.A. \& L.O. Fresco. 1993. A decision-suppport model for monitoring nutrient balances under agricultural land use (NUTMON). Geoderma 60: 235-256.

Tan, Z.X., R. Lal \& K.D. Wiebe. 2005. Global soil nutrient depletion and yield reduction. Journal of Sustainable Agriculture 26(1):123-146.

Vázquez, P. \& L. Zulaica. 2011. Cambios en el uso de la tierra del partido de Tandil y principales impactos ambientales. Párrafos Geográficos 10(2):242-267. 
Vicente, G. \& P. Engler. 2008. Valoración económica del balance de nitrógeno y fósforo de los principales rubros agrícolas y pecuarios en la provincia de Entre Ríos. En: Agricultura Sustentable. Actualización técnica. INTA. Estación Agropecuaria Paraná. Serie Extensión 51:80-87.

Viglizzo, E.F., A.J. Pordomingo, M.G. Castro \& F.A. Lértora. 2002. La sustentabilidad ambiental del agro pampeano. INTA. Programa Nacional de Gestión Ambiental Agropecuaria. Ediciones INTA. 84pp.

Viglizzo, E.F., A.J. Pordomingo, M.G. Castro \& F.A. Lértora. 2003. Environmental assessment of agriculture at a regional scale in the pampas of Argentina. Environmental Monitoring \& Assessment 87:169-195.

Viglizzo, E.F., L.V. Carreño, H. Pereyra, F. Ricard, J. Clatt \& D. Pincén. 2010. Dinámica de la frontera agropecuaria y cambio tecnológico. En: Expansión de la Frontera Agropecuaria en Argentina y su Impacto Ecológico-Ambiental. Viglizzo, E.F. \& E.G. Jobbágy (Editores). Ediciones INTA. Capítulo 1:9-16. 


\section{CAPITULO IV}

Exportación de granos y harinas para alimentación animal versus carne producida con los mismos: un análisis para la conservación de los nutrientes del suelo

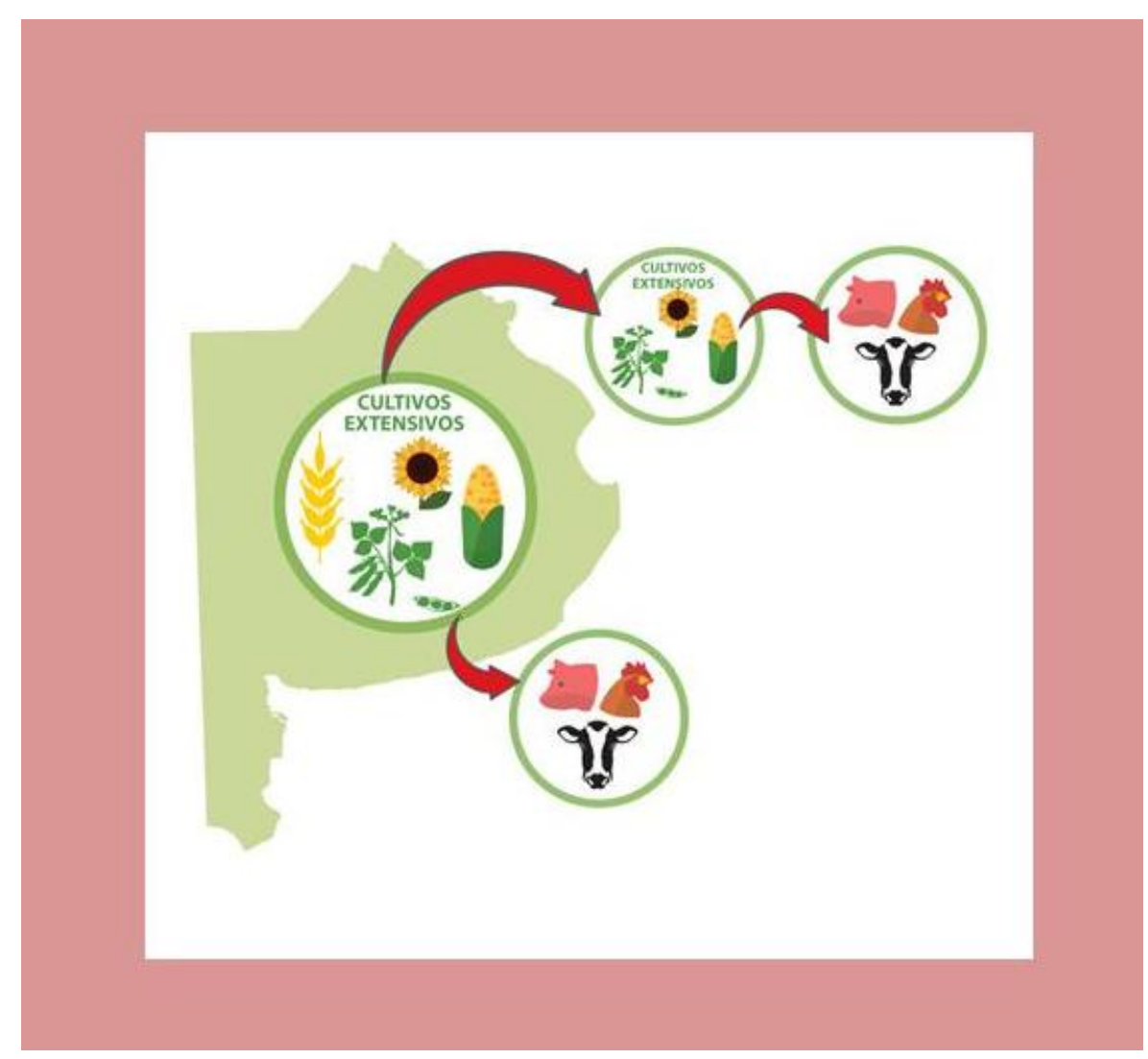




\section{IV.1. INTRODUCCIÓN}

En los últimos años, la preocupación por la producción de alimentos y la sostenibilidad ha contribuido con el incremento en el interés por los flujos de nutrientes a nivel global (Syers et al., 2011; Bouwman et al., 2013). Los científicos han incorporado el estudio de los flujos de nutrientes a través del sistema de producción y consumo (Antikainen et al., 2005; Syers et al., 2011). Smaling et al. (2008) usaron el nitrógeno (N) como traza para analizar la cadena de la soja (Glycine max (L.) Merr.) en Brasil, considerando los flujos internos y los destinos de las exportaciones. Otros estudios que vinculan la alimentación y la agricultura con los nutrientes, son los que abordan la huella dietaria, como la del fósforo (P) (importe medio de P proveniente de la minería necesario para producir los alimentos consumidos por persona por año) (Metson et al., 2012). Estos autores estimaron que, a nivel global, la huella de $P$ se incrementó entre 1961 y 2005 tanto en los países desarrollados como en aquéllos en vías de desarrollo. Este incremento de la huella estuvo impulsado por un cambio en la dieta asociado a un mayor consumo de carnes, lo cual fue acompañado por una mejora en el índice de Desarrollo Humano de los países. Haciendo proyecciones a futuro teniendo en cuenta la variación de la dieta y el aumento poblacional, Sutton et al. (2013) señalan que el consumo de proteína animal entre 2007 y 2030 puede aumentar un 30\%. Pero si el mundo tendiera al consumo de Estados Unidos este aumento sería de un 320\%. Por esta razón, Cordell \& White (2013) aseguran que es necesario un cambio en la trayectoria actual del P para disminuir la demanda en el largo plazo, que se espera suceda debido a una población en crecimiento y una tendencia hacia una dieta con mayor consumo de carne.

Se estima que un tercio de la tierra cultivable y cerca de un tercio de la producción mundial de cereales se usan para la alimentación animal (Bouwman et al., 2013; Schader et al., 2016). Esto genera un debate sobre si la tierra cultivable debe o no tener como destino la alimentación animal, ya que, biológicamente, el ser humano estaría obteniendo energía de un nivel trófico superior, lo que implica la disminución de la energía disponible en entre 5 y $20 \%$. Sin embargo, se destaca la importancia de la producción animal en la alimentación del ser humano por el aporte de proteínas de calidad y de energía (Oltjen \& Beckett, 1996). Asimismo, también se reconoce la competencia por el empleo de alimentos que tendrían un uso directo por el ser humano. Schader et al. (2016) analizan tres estrategias para la producción sostenible de ganado adaptadas de las estrategias para la sostenibilidad del sistema de producción de alimentos de Garnett (2014). Una denominada "estrategia de eficiencia" que intenta mejorar la calidad y el aprovechamiento de los alimentos por el ganado, mejorar la digestibilidad y el contenido de proteína. Otra estrategia es la 
denominada "estrategia de suficiencia", que aborda la reducción en la demanda de alimentos de origen animal a partir de un cambio en la dieta y en los patrones de consumo, la cual también incluye la sustitución de carne de rumiantes por la de monogástricos. Una tercera estrategia es la denominada "estrategias de coherencia" o "transformación del sistema de alimentación", que trata la reducción en el uso de alimentos de competencia entre el ser humano y los animales. Esto podría lograrse a partir del empleo de recursos como pastizales naturales, pasturas, desperdicios de alimentos de la industria, que no pueden ser aprovechados por el ser humano. A su vez, dentro de estas estrategias se incluye el análisis entre la conveniencia en la producción de carne de monogástricos (cerdo, aves) o poligástricos (vacuna, cabra, oveja) (Oltjen \& Beckett, 1996; Tedeschi et al., 2015; Schader et al., 2016). La defensa de la carne de monogástricos se basa en una mejor eficiencia en la conversión energética y proteica de los granos por parte de este tipo de animales, lo que conduce a producir mayor cantidad de carne con el mismo alimento. Además, contribuiría a disminuir la emisión de gases de efecto invernadero (Bouwman et al., 2013). A favor de los rumiantes se menciona la posibilidad de producir alimento de alto valor proteico a partir de forrajes que no compiten con la alimentación del ser humano (Tilman et al., 2002; Schader et al., 2016), por lo que podría liberar más tierra cultivable para la producción de granos con destino a la alimentación humana (Tedeschi et al., 2015). A causa de ello, la producción de carne a partir de rumiantes está siendo cada vez más tenida en cuenta en el planteo de distintas estrategias de producción (Tedeschi et al., 2015). Las estrategias mencionadas forman parte de la discusión tendiente a alcanzar un sistema alimentario sostenible.

La exportación de productos agropecuarios (commodities) ha sido uno de los basamentos de la inserción de Argentina en el mundo y la provincia de Buenos Aires ha tenido un rol relevante en ello (Reca, 2006; MAA, 2007). Las elevadas exportaciones de origen agropecuario que realizó Argentina a fines del siglo XIX y principios del XX, contribuyeron a que recibiera la denominación de "Granero del mundo" (Reca, 2006; Colomé \& Gumierato, 2009). A fines del siglo XIX, Argentina exportaba mayoritariamente productos ligados a la ganadería (cueros, lana) y, desde 1910, la agricultura comienza a tener mayor incidencia que la ganadería en el valor de las exportaciones (Reca, 2006). En lo que va del siglo XXI, la soja se ha transformado en el principal commodity de origen agropecuario exportado por la Argentina (Walter et al., 2013), contribuyendo con el 36 y el $81 \%$ de la harina y aceite de soja del mundo, respectivamente (Pengue, 2015a). La demanda de soja en el mundo ha crecido para la obtención de harinas ricas en proteínas destinadas a la producción animal impulsada principalmente por China (Smaling et al., 2008). Se estima que sólo el 2\% de 
la proteína de soja tiene como destino el consumo humano (Andreani, 2008). Entre los años 2002 y 2007, China pasó de un consumo de carne vacuna de 4,5 a 5,9 kg pers.-1 año-1; de 7,1 a 8,0 kg pers.-1 año-1 en carne aviar y de 33,6 a 41,9 kg pers. ${ }^{-1}$ año-1 en carne de cerdo (Andreani, 2008). Se espera que, debido al creciente consumo de carne a nivel mundial, el mercado de granos se incremente a una tasa mayor que el crecimiento de la población, determinado por el desarrollo económico y la urbanización (Cassman et al., 2003; Schader et al., 2016). Esto sucedería, principalmente, en los países en desarrollo (Cassman et al., 2003).

La mayor demanda de granos para la producción de carne contribuye a un incremento en el comercio internacional (Grote et al., 2005). En este sentido, Pengue (2015b) asegura que la globalización del sistema mundial de alimentos, está conllevando a una sobreexplotación importante de recursos, y a una aceleración de los procesos productivos en términos no sostenibles, que genera pasivos ambientales crecientes. El incremento en la demanda de granos y harina de soja de países como China y los que integran la Unión Europea (Nesme et al., 2016) desde la década del 90, ha impulsado un cambio en el uso de suelo en la Argentina en general y en la provincia de Buenos Aires en particular (Pengue, 2015a), modificando los commodities exportados. Más allá del rédito económico en el corto plazo que puede favorecer esta nueva situación de producción y exportación, es necesario evaluar si la misma genera problemas ambientales que pongan en riesgo la producción de alimentos en el futuro.

Dentro de los aspectos ambientales que deben considerarse, se encuentran los flujos de nutrientes a diferentes escalas y la preservación de las características cuali- y cuantitativas del suelo. Como la exportación de commodities agropecuarios implica exportación de nutrientes (Krauss, 2000; Grote et al., 2005; Pengue, 2007), es importante considerar cuál es el impacto del manejo de los nutrientes en los cultivos exportados, sobre los suelos donde se producen. Conocer esta información contribuiría a dimensionar mejor la pertinencia o no de mantener esta producción. Además, teniendo en cuenta que parte de la exportación que se realiza no es para consumo humano directo sino para la producción animal, es necesario evaluar qué impacto puede tener el reemplazo de las exportaciones (carne en vez de grano para alimentación animal) en la conservación de los nutrientes en el lugar de origen. Los estudios que proponen un cambio en las exportaciones se basan en estudios económicos que proponen dar mayor valor agregado al producto exportado (Bragachini, 2009; Kohan \& Costa, 2011) y no profundizan en aspectos ambientales. Por otro lado, el análisis de flujos de nutrientes a nivel global y regional que busca conocer y mejorar el sistema agroalimentario, se ha realizado principalmente en los países 
desarrollados, que son mayoritariamente importadores de alimentos para animales. Paralelamente, la preocupación de estos países se centra en disminuir la contaminación ambiental generada por los excedentes de nutrientes (Grote et al., 2005). En el debate sobre los sistemas de producción sostenible de alimentos y el uso del suelo, es necesario incluir un análisis desde un área con fuerte vocación agroexportadora como es la provincia de Buenos Aires.

Los objetivos de este capítulo son: a) analizar el balance de los nutrientes (N, P, potasio (K), calcio (Ca) y azufre (S)) en los cultivos que se exportan con destino a la alimentación animal, b) estimar el impacto en la conservación de los nutrientes del suelo si se reemplaza la exportación de granos y harinas destinados a la alimentación animal por la de tres tipos de carnes (vacuna, de cerdo, de pollo) producidas con esos alimentos, c) discutir el uso del suelo para la producción de alimentos para el ser humano y los animales en la provincia de Buenos Aires. Se plantea como hipótesis que la exportación de carne en reemplazo de la de granos destinados a la alimentación de ganado, favorecería una mayor conservación de los nutrientes del suelo en la provincia.

\section{IV.2. METODOLOGÍA}

Para el período 2005-2006 se determinaron tres balances de nutrientes (N, P, K, (a, S): a) en los cultivos extensivos que se exportan con destino a la alimentación animal (granoanimal), b) para la misma superficie, se estimó el balance de nutrientes considerando el reemplazo de la exportación de granos y harinas por la exportación de tres tipos de carnes obtenidas a partir de los mismos granos y harinas y c) también se realizó un balance de nutrientes teniendo en cuenta toda la superficie de cultivos extensivos (granohumano+animal) pero considerando que se exporta carne en reemplazo de grano para alimentación animal.

\section{IV.2.1. Balance de nutrientes}

\section{IV.2.1.1. Balance en la exportación de granos y harinas para alimentación animal (BAL granoanimal)}

El balance se calculó como la diferencia entre las entradas de nutrientes vía fertilización y fijación biológica y las salidas a través de los nutrientes exportados en los granos y harinas (soja, maíz (Zea mays L.), girasol (Helianthus annus L.) y sorgo (Sorghum bicolor (L.) Moench)) con destino a la alimentación animal (incluye pellets y expeller) (granoanimal). 


\section{IV.2.1.1.1. Salidas de nutrientes.}

Para determinar los nutrientes en los granos y harinas exportados con destino a la alimentación animal (NUTgranoanimal) se construyó un flujograma para cada cultivo para el período 2005-2006 (Smaling et al., 2008) (Figura 4.1). Los mismos se construyeron en base a una revisión bibliográfica (Tabla 4.1) y se asumieron como válidos para el período analizado.

Tabla 4.1. Bibliografía empleada para la construcción de los flujogramas de cultivos extensivos de la provincia de Buenos Aires.

\begin{tabular}{ll}
\hline Cultivo & Bibliografía \\
\hline Maíz & CRA (2012) \\
& INTA (2010) \\
& Lezcano (2008) \\
& Goizueta et al. (2013) \\
\hline Soja & Giancola et al. (2009) \\
& MECON (2011) \\
& Andreani (2008) \\
& Franco (2010) \\
& Franco (2013) \\
\hline Girasol & MECON (2011) \\
& Franco (2010) \\
& Franco (2013) \\
\hline Sorgo & INTA (2009) \\
\hline
\end{tabular}

En los flujogramas se estimaron los flujos tanto hacia los mercados externo e interno, así como el destino de los mismos (alimentación animal o consumo humano).

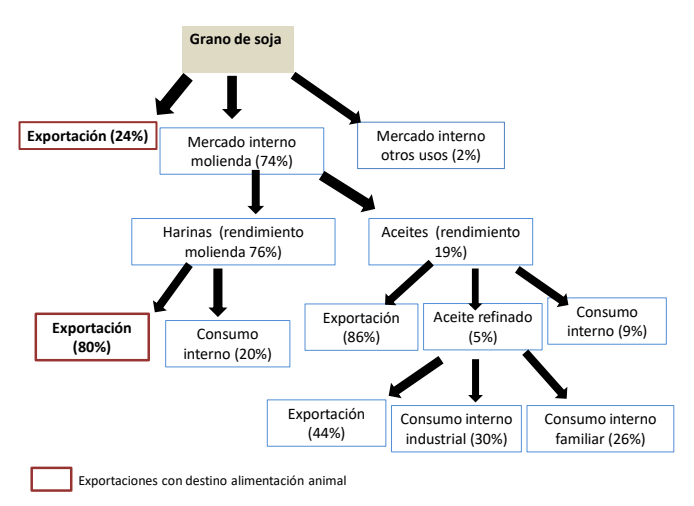

a)

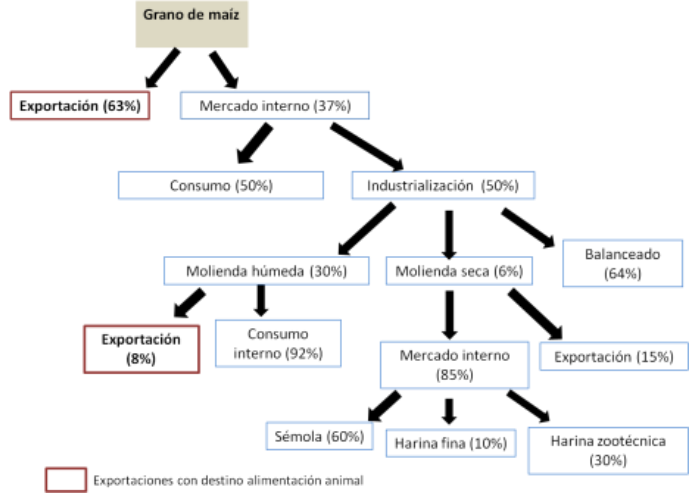

b) 


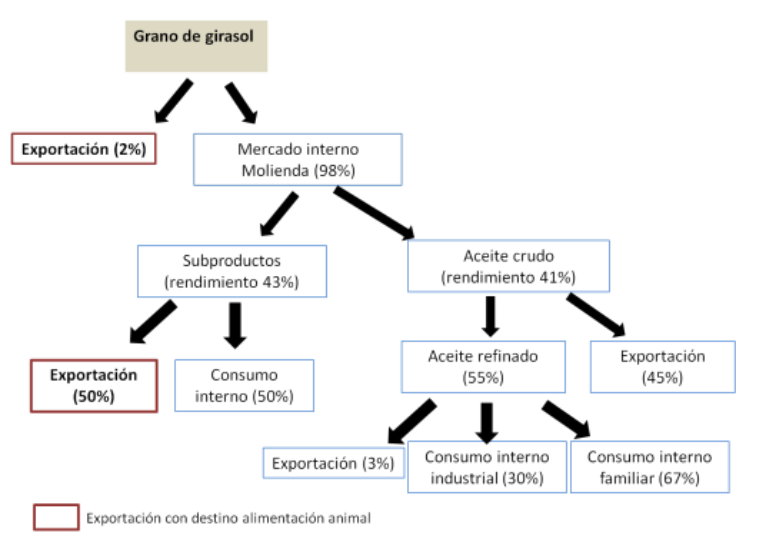

c)

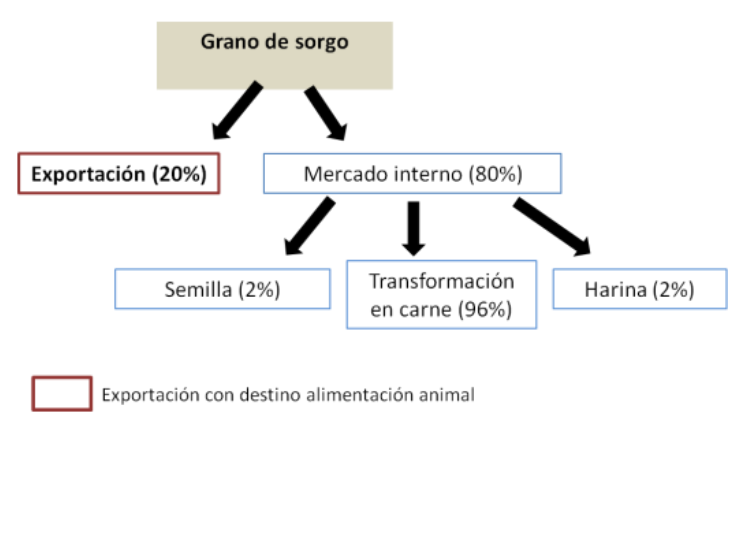

d)

Figura 4.1. Flujogramas de los cultivos de: a) soja, b) maíz, c) girasol y d) sorgo, con destino al mercado interno y externo para el período 2005-2006, asumidos para la provincia de Buenos Aires. Construidos a partir de una revisión bibliográfica (Tabla 4.1).

A partir del contenido de nutrientes de los diferentes productos exportados (Tabla 4.2) se determinaron los nutrientes en dichas exportaciones.

Tabla 4.2. Contenido de nutrientes de granos y harina exportados con destino a la alimentación animal.

\begin{tabular}{|c|c|c|c|c|c|c|}
\hline \multirow[b]{2}{*}{ Cultivo } & \multirow[b]{2}{*}{ Producto } & \multicolumn{5}{|c|}{ Contenido de nutrientes $\left(\mathrm{kg} \mathrm{t}^{-1}\right)$} \\
\hline & & $\mathbf{N}$ & $\mathbf{P}$ & K & $\mathrm{Ca}$ & $S$ \\
\hline \multirow[t]{2}{*}{ Soja } & Grano & 60,0 & 5,0 & 20,0 & 1,7 & 1,7 \\
\hline & Harina & 80,0 & 5,8 & 20,3 & 2,9 & 3,8 \\
\hline \multirow[t]{2}{*}{ Maíz } & Grano & 14,9 & 2,5 & 5,0 & 0,5 & 1,0 \\
\hline & Harina & 14,0 & 4,2 & 3,7 & 1,0 & 1,0 \\
\hline \multirow[t]{2}{*}{ Girasol } & Grano & 25,0 & 4,5 & 6,0 & 2,5 & 2,0 \\
\hline & Harina & 52,0 & 10,0 & 14,0 & 3,2 & 3,1 \\
\hline Sorgo & Grano & 19,0 & 4,0 & 4,0 & 0,1 & 2,0 \\
\hline
\end{tabular}

Fuente: Granos: Tabla 3.1.2 (Capítulo III, Subcapítulo 1). Harinas: Soja: Mateos et al. (2009); Maíz: Fundación Española para el Desarrollo de la Nutrición Animal (2012a); Girasol: Fundación Española para el Desarrollo de la Nutrición Animal (2012b).

\section{IV.2.1.1.2. Entradas de nutrientes.}

Para este cálculo se utilizó la superficie de cada cultivo cuya cosecha se destinó a la exportación para alimentación animal (SUPgranoanimal) considerando la cantidad de grano exportado y el rendimiento medio de los cultivos en la provincia, obtenido del SIIA (2016). Para estimar la cantidad de grano necesario para producir la harina exportada se hizo una conversión de harina a grano en función del rendimiento de la molienda obtenida de las referencias de la Tabla 4.1 (Figura 4.1) (76\% para soja, $43 \%$ para girasol y $60 \%$ para maíz). En la entrada por fertilización y fijación biológica de 
cada cultivo se consideraron los valores medios a nivel provincial estimados (Tabla 3.1.3, Capítulo III, Subcapítulo 1).

\section{IV.2.1.2. Balance en la exportación de diferentes tipos de carne}

Se realizó un balance de nutrientes para cada tipo de carne exportada (vacuna, de cerdo o de pollo).

\section{IV.2.1.2.1. Salidas de nutrientes}

Se asumió que los granos exportados con destino a alimentación animal, se utilizarían para la producción de carne en la misma provincia. Los tres tipos de carnes considerados fueron: vacuna, de cerdo y de pollo. Para estimar la cantidad de carne que se podría producir con los granos y harinas destinados a la producción animal se asumió una conversión de grano a carne para cada tipo de carne (Tabla 4.3).

Tabla 4.3. Conversión de grano a carne asumida para diferentes tipos de carne.

\begin{tabular}{lcl} 
Tipo de carne & $\begin{array}{c}\text { Conversión grano a } \\
\text { carne }\end{array}$ & \multicolumn{1}{c}{ Composición tipo ración } \\
\hline Vacuna & $7: 1$ & $(80 \%$ maíz, 10\% girasol, 10\% soja) \\
Cerdo & $3,5: 1$ & $(75 \%$ maíz, 25\% soja o girasol) \\
Pollo & $2,1: 1$ & $(75 \%$ maíz, 25\% soja) \\
\hline
\end{tabular}

Fuente: Fernández \& Marsó (2003) y consulta a expertos.

Si bien la dieta de los animales que permite cada conversión tiene una composición que combina diferentes granos y harinas (Tabla 4.3), para los fines de la tesis se asumió que todo el grano o harina, indistintamente de la especie vegetal, aporta a la producción de carne según la conversión establecida. Luego, a partir del contenido de nutrientes de los diferentes tipos de carne (Tabla 4.4) se determinaron los nutrientes exportados.

Tabla 4.4. Contenido de nutrientes de carne vacuna, de cerdo y de pollo.

\begin{tabular}{lccccc} 
& \multicolumn{5}{c}{ Contenido de nutrientes $\left.\mathbf{~ k g ~ t}^{-1}\right)$} \\
\cline { 2 - 6 } & $\mathbf{N}$ & $\mathbf{P}$ & $\mathbf{K}$ & $\mathbf{C a}$ & $\mathbf{S}$ \\
\hline Carne de pollo' $^{1}$ & 24,5 & 2,0 & 2,9 & 0,02 & $0,0^{*}$ \\
Carne vacuna $^{2}$ & 27,2 & 6,8 & 1,5 & 12,80 & 1,5 \\
Carne de cerdo' $^{1}$ & 31,8 & 2,3 & 3,8 & 0,02 & $0,0^{*}$ \\
\hline
\end{tabular}

* No se encontraron valores de contenido de $S$. Se asumió que es mínimo (equivalente a $0 \mathrm{~kg} \mathrm{t} \mathrm{t}^{-1}$ ). Fuente: 'Carvajal (2001). ${ }^{2}$ García (2006) y Fontanetto et al. (2011). 


\section{IV.2.1.2.2. Entradas de nutrientes}

Se consideraron los mismos criterios y valores que para exportación de granos y harinas.

Se asumió que la diferencia entre los nutrientes exportados con los granos y harinas para alimentación animal y los nutrientes exportados a partir de la producción de diferentes tipos de carne, retornaron a la superficie donde fueron producidos los granos. Es decir, se asumió una alta eficiencia en el ciclado de nutrientes. De esta manera, se estimó la potencialidad en la recuperación de nutrientes a partir del cambio en el tipo de exportaciones. En la discusión del capítulo se retoma este aspecto.

\section{IV.2.1.3. Balance en la superficie total de cultivos extensivos (BALgranohumano+animal)}

A la superficie total ocupada por cada cultivo en la provincia (SUPgranohumano+animal) se le restó la superficie requerida para la producción de granos y harinas para exportar con destino a la alimentación animal (SUPgranoanimal), determinándose así la superficie de cultivos para consumo humano (SUPgranohumano). Se calculó el balance de nutrientes ( $N, P, K, C a$ y S) para los cultivos con destino al consumo humano (sea para mercados interno o externo) (BALgranohumano). Para cada cultivo se empleó el valor de fertilización media provincial (Tabla 3.1.3, Capítulo III, Subcapítulo I). Luego se realizó un balance global considerando la superficie de cultivos para consumo humano y la de producción de grano con destino a la producción animal (SUPgranohumano+animal), asumiendo tres posibilidades de producción de carne (vacuna, de cerdo o de pollo) en la SUPgranoanimal.

\section{IV.3. RESULTADOS}

\section{IV.3.1. Exportación de nutrientes}

\section{IV.3.1.1. En la exportación de grano y harina con destino a la alimentación animal (granoanimal)}

La exportación total de nutrientes con destino a la alimentación animal (NUT totgranoanimal) fue de 919.181 † año-1, que correspondió al $66 \%$ del total extraído por las cosechas de los cultivos extensivos (NUTtotgranohumano+animal). El $69 \%$ de los nutrientes exportados fue N, mientras que las exportaciones de P, K, Ca y S representaron 6; 19; 2 y $3 \%$, respectivamente. Entre el 42 y el $70 \%$ del total de cada nutriente extraído por 
todos los cultivos extensivos, tuvo como destino la exportación para la alimentación animal, siendo el mayor porcentaje para el N (Tabla 4.5).

Tabla 4.5. Nutrientes extraídos en cultivos extensivos (NUTgranonumano+animal) y exportados por grano y harina con destino a la alimentación animal (NUTgranoanimal) en la provincia de Buenos Aires.

\begin{tabular}{|c|c|c|c|c|c|}
\hline & \multicolumn{5}{|c|}{ Nutrientes ( $($ año-1) } \\
\hline & $\mathrm{N}$ & $P$ & K & $\mathrm{Ca}$ & $S$ \\
\hline $\begin{array}{l}\text { Extracción total por cultivos } \\
\text { extensivos (NUTgranohumano+animal) }\end{array}$ & 902.709 & 128.688 & 270.548 & 38.374 & 59.311 \\
\hline $\begin{array}{l}\text { Exportación total destino } \\
\text { alimentación animal } \\
\text { (NUTgranOanimal) }\end{array}$ & 636.022 & 54.421 & 178.059 & 22.370 & 28.310 \\
\hline Exportación por grano & 206.035 & 20.677 & 68.623 & 6.244 & 7.626 \\
\hline Exportación por harina* & 429.987 & 33.743 & 109.435 & 16.125 & 20.684 \\
\hline $\begin{array}{l}\text { Relación NUTgranoanimal / } \\
\text { NUTgranOhumano+animal (\%) }\end{array}$ & 70 & 42 & 66 & 58 & 48 \\
\hline
\end{tabular}

* Incluye pellets y expeller.

Se exportó una mayor cantidad de nutrientes con destino a la producción animal bajo la forma de harina (64\%) que bajo la de grano (36\%) (Tabla 4.5). El 70\% de la exportación de nutrientes a través de las harinas correspondió a N, el $18 \%$ a K y el resto a P, S y Ca (5,5; 3,5 y 3\%, respectivamente) (Figura 4.2). Los cultivos responsables de tales exportaciones fueron la soja (93\%), seguido por el girasol (7\%). La harina de maíz exportada con fines de alimentación animal presentó muy baja incidencia.

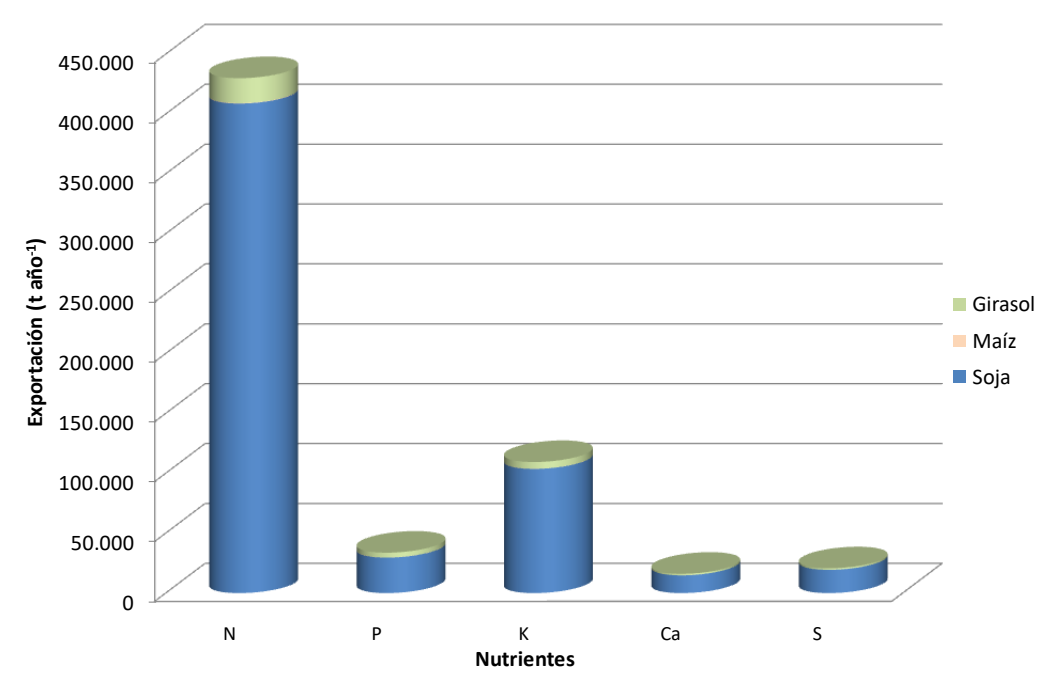

Figura 4.2. Exportación de nutrientes bajo la forma de harina (incluye pellets y expeller) con destino a producción animal, provenientes de diferentes cultivos de la provincia de Buenos Aires. 
El $\mathrm{N}$ y $\mathrm{K}$ fueron los nutrientes más exportados bajo la forma de grano con destino a la alimentación animal (67 y 22\%, respectivamente), (Figura 4.3) seguido de P, S y Ca (7; 2 y $2 \%$, respectivamente). De los nutrientes exportados bajo la forma de grano, la soja aportó el 63\%, seguida de maíz (36\%) y, en menor medida, girasol y sorgo.

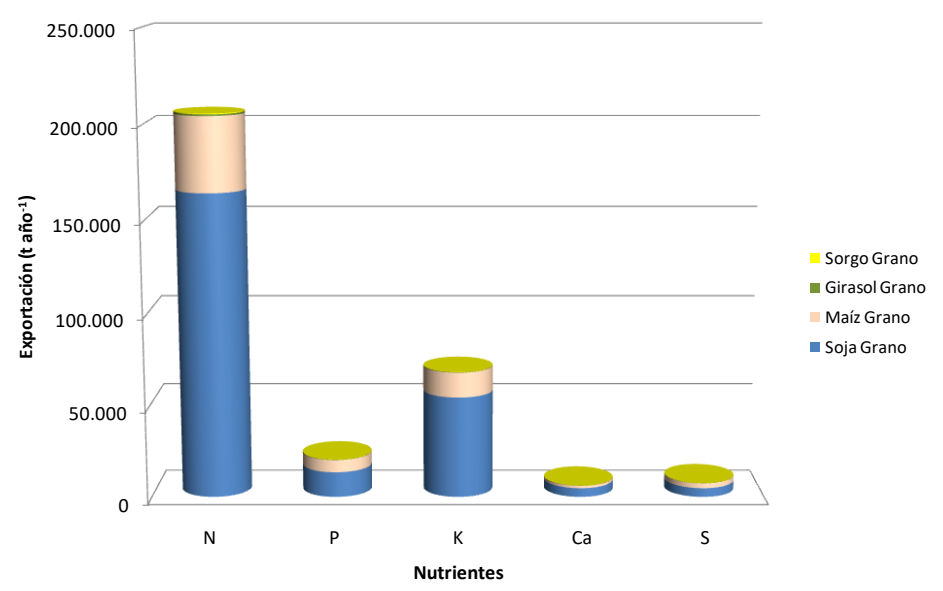

Figura 4.3. Exportación de nutrientes a través de granos con destino a producción animal, provenientes de diferentes cultivos de la provincia de Buenos Aires.

\section{IV.3.1.2. En la exportación de carne obtenida de grano y harina para alimentación animal (grano animal $X$ carne)}

En función de la conversión de grano a carne (Tabla 4.4) se calculó que con los granos y las harinas exportados con destino a la alimentación animal, se produciría una mayor cantidad de carne de pollo, seguida de la de cerdo y la vacuna (Tabla 4.6).

Tabla 4.6. Producción de diferentes tipos de carne, a partir de los productos vegetales exportados con destino a la alimentación animal.

\begin{tabular}{|c|c|c|c|c|c|}
\hline \multirow{2}{*}{ Cultivo } & \multirow{2}{*}{ Producto } & \multirow{2}{*}{$\begin{array}{l}\text { Cantidad } \\
\left({\text { ( } a n ̃ 0^{-1}}^{-1}\right.\end{array}$} & \multicolumn{3}{|c|}{ Producción de carne († año-1) } \\
\hline & & & vacuna & de cerdo & de pollo \\
\hline \multirow[t]{2}{*}{ Soja } & Grano* & 2.737 .020 & 297.000 & 594.000 & 991.000 \\
\hline & Harina & 5.110 .226 & 730.000 & 1.460 .000 & 2.433 .000 \\
\hline \multirow[t]{2}{*}{ Maíz } & Grano & 2.711 .520 & 387.000 & 775.000 & 1.291 .000 \\
\hline & Harina & 22.000 & 3.000 & 6.000 & 10.000 \\
\hline \multirow[t]{2}{*}{ Girasol } & Grano & 38.080 & 5.000 & 11.000 & 18.000 \\
\hline & Harina & 401.172 & 57.000 & 115.000 & 191.000 \\
\hline Sorgo & Grano & 24.200 & 3.000 & 7.000 & 12.000 \\
\hline Total & & & 1.484 .000 & 2.968 .000 & 4.946 .000 \\
\hline
\end{tabular}

* Para soja se asumió que, previo conversión a carne, del grano se obtiene la harina con un $76 \%$ de rendimiento (Figura 4.1 a). 
Con carne vacuna se exportaría sólo el $8 \%$ de los nutrientes (N, P, K, Ca y S) que saldrían con granos y harinas con destino para alimentación animal, mientras que, si se exportara carne de cerdo saldría el $12 \%$ y con carne de pollo, el 16\%. Con carne de pollo se exportaría más $\mathrm{N}$, y K que con carne vacuna y de cerdo y cantidades similares de $\mathrm{P}$ que en carne vacuna (Figura $4.4 \mathrm{a}, \mathrm{b}, \mathrm{c}$ ). Pero, con carne vacuna, se exportaría mayor cantidad de Ca (Figura $4.4 \mathrm{~d}$ ) y de $S\left(2.226 \dagger^{\text {año-1 }}\right.$ ) que con las otras. Debido a la ausencia de contenido de $S$ en carne de cerdo y de pollo, se asumió que la salida de este nutriente debido a estos tipos de carne sería poco significativa.

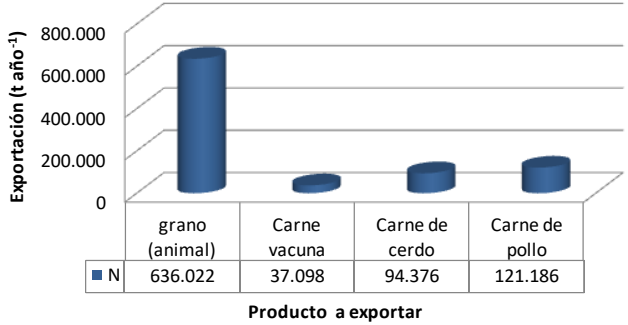

a)

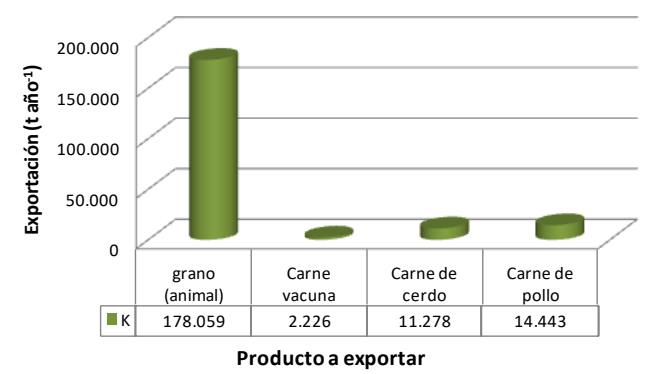

c)

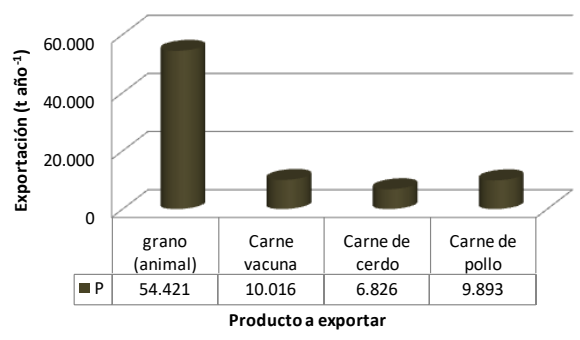

b)

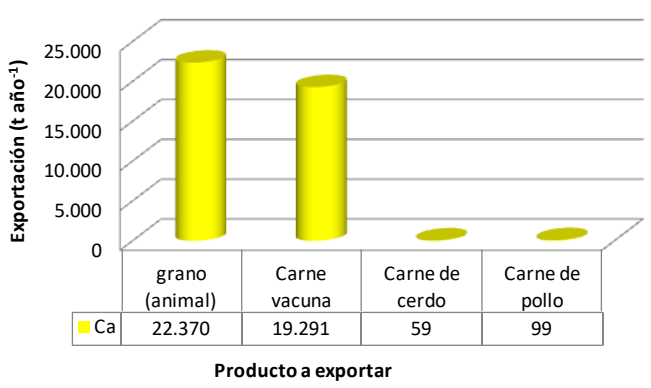

d)

Figura 4.4. Exportación de nutrientes: a) N, b) P, c) K y d) Ca, debido a grano y harina de cultivos extensivos con destino a la alimentación a animal (granoanimal) o a distintos tipos de carne (vacuna, de cerdo o de pollo) que se obtendrían a partir de esos mismos granos, en la provincia de Buenos Aires.

Con la carne vacuna se exportaría el 86,2 \% del Ca que hubiera sido exportado con granos y harinas, pero menos del $1 \%$ si se exportara carne de cerdo o de pollo (Tabla 4.7). El K y S son nutrientes que también reducirían considerablemente sus salidas debido a un cambio en el tipo de producto exportado (Tabla 4.7).

Tabla 4.7. Relaciones (\%) entre los nutrientes que se exportarían en distintos tipos de carne, y el total exportado en granos y harina con destino a la producción animal.

\begin{tabular}{lccccc}
\hline Tipo de & \multicolumn{5}{c}{ Nutrientes } \\
\cline { 2 - 6 } carne & $\mathbf{N}$ & $\mathbf{P}$ & $\mathbf{K}$ & $\mathbf{C a}$ & $\mathbf{S}$ \\
\hline Vacuna & 5,8 & 18,4 & 1,3 & 86,2 & 7,9 \\
Cerdo & 14,8 & 12,5 & 6,3 & 0,3 & $0,0^{*}$ \\
Pollo & 19,1 & 18,2 & 8,1 & 0,4 & $0,0^{*}$ \\
\hline
\end{tabular}

* Asumido a partir de la ausencia de información acerca del contenido de $S$ en las carnes de cerdo y de pollo. 


\section{IV.3.2. Balance de nutrientes}

\section{IV.3.2.1. Balance en la exportación de granos y harinas o carne}

Considerando la producción media de los cultivos en la provincia de Buenos Aires, para producir la cantidad de granos y harinas con destino a alimentación animal de los diferentes cultivos (granoanimal), se requeriría un total de 4.078 .797 ha, lo que representa el $46 \%$ de la superficie considerada con cultivos extensivos (SUPgranohumano+animal), siendo el principal cultivo la soja (Tabla 4.8).

Tabla 4.8. Superficie requerida por diferentes cultivos para producir los granos y harinas exportados con destino a alimentación animal.

\begin{tabular}{lccccc} 
& \multicolumn{4}{c}{ Cultivos } & \multirow{2}{*}{ Total } \\
\cline { 2 - 5 } & Maíz & Soja & Girasol & Sorgo & \\
\hline Superficie (ha) & 384.366 & 3.125 .094 & 564.535 & 4.802 & 4.078 .797 \\
\hline
\end{tabular}

De reemplazar las salidas de nutrientes a través de grano por la de nutrientes en carne producida con los mismos, las salidas se reducirían considerablemente (Tabla 4.9). La extracción por unidad de superficie de la mayoría de los nutrientes bajaría entre 80 y $99 \%$, a excepción del Ca en carne vacuna, que se reduciría en sólo un $13,8 \%$.

Tabla 4.9. Extracción de nutrientes por unidad de superficie debido a granos y harinas con destino a alimentación animal (NUTgranoanimal) o con diferentes tipos de carnes producidas con esos granos y harinas (NUT carne).

\begin{tabular}{|c|c|c|c|c|c|c|c|}
\hline \multirow{2}{*}{ Nutriente } & \multirow{2}{*}{$\begin{array}{c}\text { NUTgranoanimal } \\
\text { Extracción } \\
\left(\mathrm{kg} \mathrm{ha}^{-1} \text { año-1) }\right.\end{array}$} & \multicolumn{2}{|c|}{ NUT carne vacuna } & \multicolumn{2}{|c|}{ NUT carne de cerdo } & \multicolumn{2}{|c|}{ NUT carne de pollo } \\
\hline & & $\begin{array}{c}\text { Extracción } \\
\left(\text { (kg ha-1 año-1) }^{-1}\right)\end{array}$ & $\begin{array}{l}\text { Reducción } \\
(\%)\end{array}$ & $\begin{array}{c}\text { Extracción } \\
\left(\mathrm{kg} \mathrm{ha}^{-1} \text { año-1) }\right.\end{array}$ & $\begin{array}{l}\text { Reducción } \\
(\%)\end{array}$ & $\begin{array}{c}\text { Extracción } \\
\left(\mathrm{kg} \mathrm{ha}^{-1} \mathrm{anno}^{-1}\right)\end{array}$ & $\begin{array}{c}\text { Reducción } \\
(\%)\end{array}$ \\
\hline N & 155,9 & 9,1 & 94,2 & 23,1 & 85,2 & 29,7 & 81,0 \\
\hline P & 13,3 & 2,5 & 81,6 & 1,7 & 87,5 & 2,4 & 81,8 \\
\hline K & 43,7 & 0,5 & 98,7 & 2,8 & 93,7 & 3,5 & 91,9 \\
\hline $\mathrm{Ca}$ & 5,5 & 4,7 & 13,8 & 0,0 & 99,7 & 0,0 & 99,6 \\
\hline$S$ & 6,6 & 0,5 & 91,7 & 0,0 & $100^{*}$ & 0,0 & $100^{*}$ \\
\hline
\end{tabular}

* Asumido a partir de la ausencia en el contenido de $S$ en las carnes de cerdo y de pollo.

La menor extracción de nutrientes que se realizaría con la producción de cualquier tipo de carne y con la fertilización promedio de cada uno de los cultivos podría contribuir, mediante un eficiente ciclado de nutrientes, con el mantenimiento de la fertilidad de los suelos que producen el alimento animal de la provincia de Buenos Aires (BALgranoanimal). Para $\mathrm{N}$, se pasaría de un balance negativo en la producción de granos, a uno positivo con cualquiera de las producciones de carne, 
siendo mayor en la vacuna (Figura 4.5 a). Para P y S también se pasaría de un déficit a un superávit de nutrientes reemplazando las exportaciones de granos y harinas por la de carne (Figura 4.5 b y e). Para Ca, a partir de la alta extracción de la carne vacuna, se mantendría un déficit que sería menor que con los granos. Pero con la producción de carne de cerdo y de pollo se lograría un pequeño superávit (Figura 4.5 d). En el $\mathrm{K}$ el reemplazo de las exportaciones podría reducir el déficit entre el 99, 94 y $92 \%$ si la producción fuese de carne vacuna, de cerdo o de pollo, respectivamente (Figura 4.5 c).

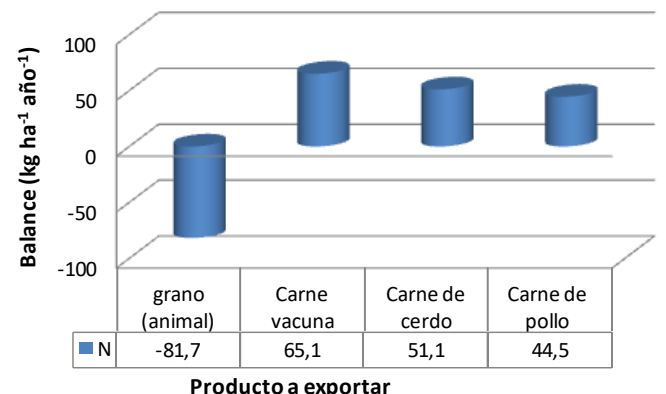

a)

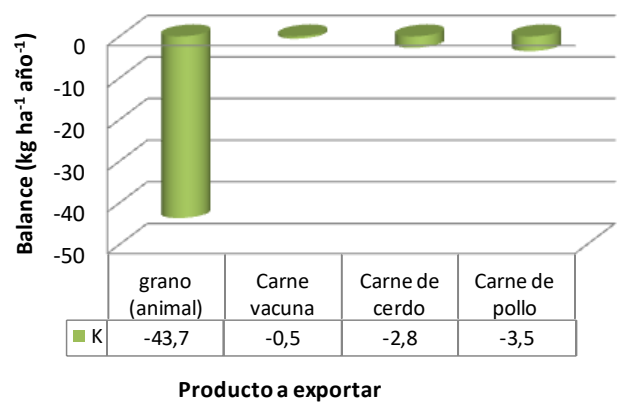

c)

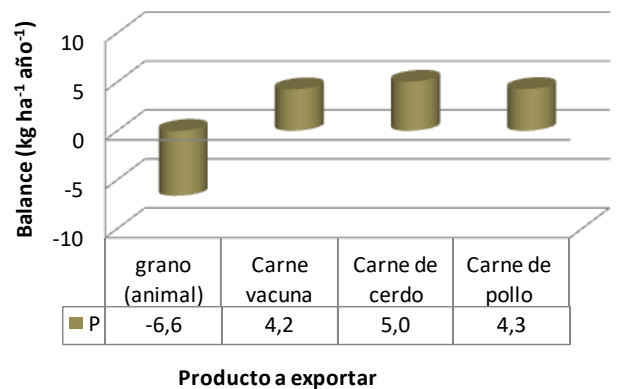

b)

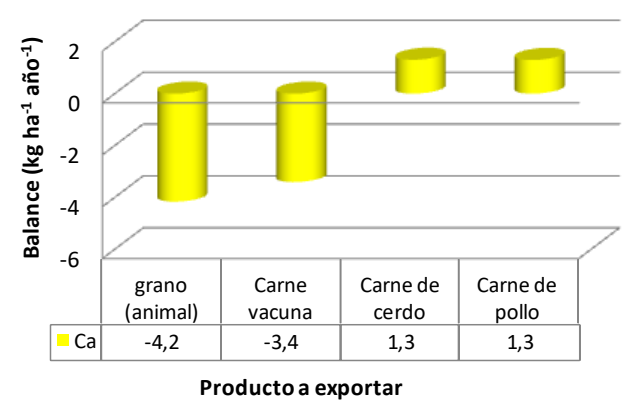

d)

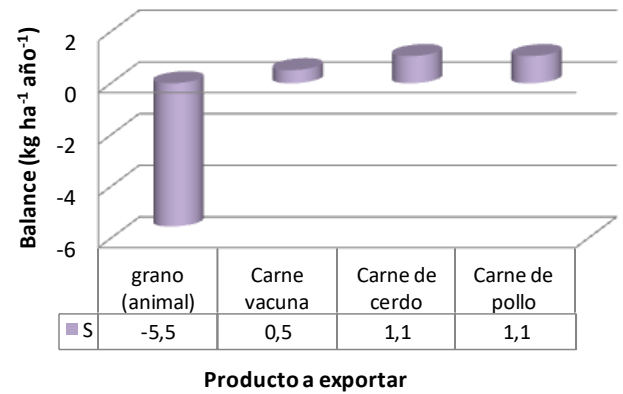

e)

Figura 4.5. Balance de nutrientes por unidad de superficie de: a) $N$, b) $P, c) K$, d) Ca y e) $S$, para el área destinada a la producción de granos y harinas para exportar con destino a la alimentación animal (granoanimal) y el que se generaría con la exportación de diferentes tipos de carne (vacuna, de cerdo o de pollo) obtenidas con los mismos.

El balance total de nutrientes sería muy favorable en $\mathrm{N}$ y, en menor medida, en P, Ca y S (Tabla 4.10). 
Tabla 4.10. Balance total de nutrientes para la producción de granos y harinas para exportación con destino a la alimentación (granoanimal) y para la de producción de diferentes tipos de carne obtenidos con los mismos.

\begin{tabular}{lrrrr}
\hline & \multicolumn{5}{c}{ Balance total $(t$ año-1 $)$} \\
Nutriente & granoanimal & \multicolumn{1}{c}{$\begin{array}{c}\text { Carne } \\
\text { vacuna }\end{array}$} & $\begin{array}{c}\text { Carne de } \\
\text { cerdo }\end{array}$ & $\begin{array}{c}\text { Carne de } \\
\text { pollo }\end{array}$ \\
\cline { 2 - 5 } & -333.292 & 265.632 & 208.374 & 181.607 \\
N & -27.099 & 17.305 & 20.494 & 17.436 \\
P & -178.059 & -2.226 & -11.275 & -14.436 \\
K & -16.977 & -13.898 & 5.333 & 5.294 \\
Ca & -22.601 & 2.070 & 4.296 & 4.296 \\
S & & & & \\
\hline
\end{tabular}

\section{IV.3.2.2. Balances en la superficie total de cultivos extensivos (BALgranohumano+animal)}

Considerando la superficie total con cultivos extensivos (SUPgranohumano+animal), y asumiendo tres hipótesis de uso del suelo combinando la producción de granos con destino al mercado interno y/o exportación para consumo humano (SUPgranohumano), con la de producción de tres tipos de carne (vacuna, de cerdo o de pollo) con los granos que se exportarían (grano y harina) para la alimentación animal (SUPgranoanimal), se obtendría un beneficio en el mantenimiento de la fertilidad del suelo en la provincia de Buenos Aires.

Cualquiera de las combinaciones de uso de suelo que incluya la producción de carne y grano para consumo humano, implicaría pasar de un déficit de $\mathrm{N}$ y $\mathrm{P}$ bajo uso exclusivo de producción agrícola a uno con superávit (Figura 4.6 a y b), siendo más favorable la combinación con producción de carne vacuna para N y la de carne de cerdo, para $P$.

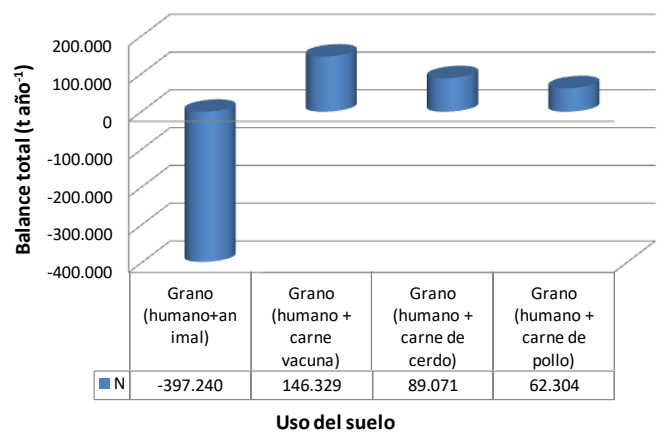

a)

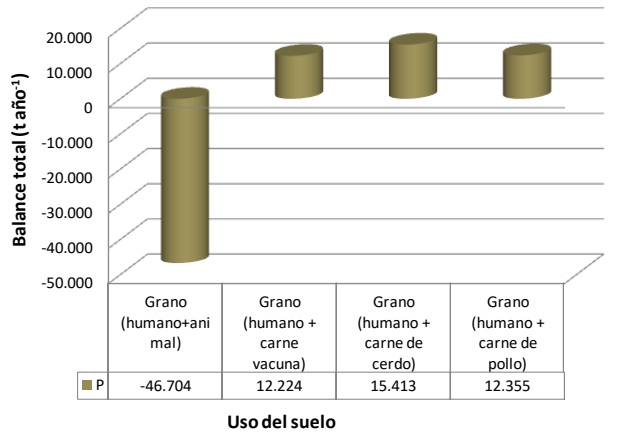

b) 


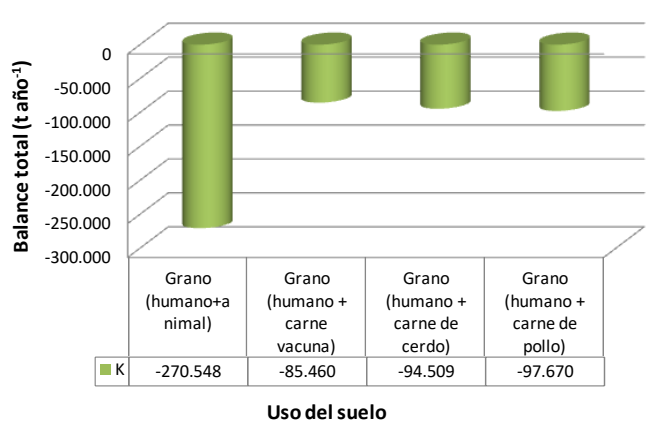

c)

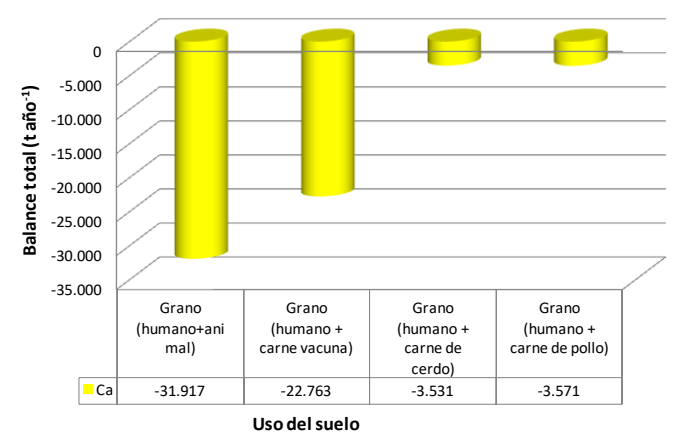

d)

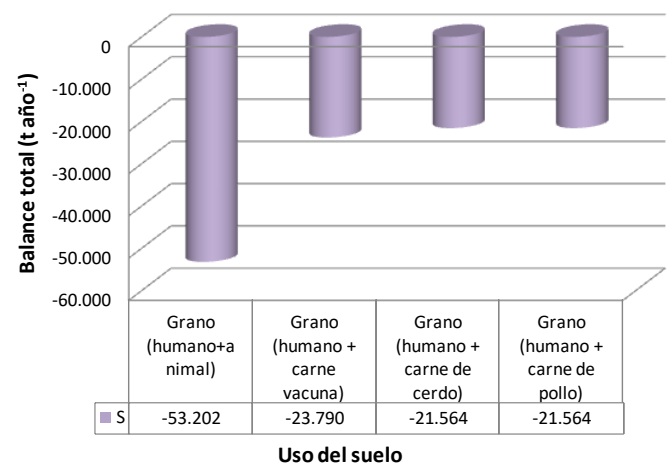

e)

Figura 4.6. Balance total de nutrientes de a) $N$, b) $P$, c) $K$, d) Ca y e) $S$, en cultivos extensivos (granohumano+animal) y en tres hipótesis de uso del suelo, combinando producción de granos con destino alimentación humana (granohumano), con tres variantes de producción de carne (vacuna, de cerdo o de pollo) que se obtendrían de los granos y harinas que se exportan para la alimentación animal, en la provincia de Buenos Aires.

Para K, Ca y S, en cualquier uso del suelo se mantendría el déficit (Figura 4.6, c, d, e), pero cualquiera de las combinaciones con producciones de carne implicaría una disminución del déficit entre el 64 y $68 \%$ para K, del 29 al $89 \%$ para Ca y del 55 al $59 \%$ para $\mathrm{S}$, respecto al uso exclusivo agrícola.

\section{IV.4. DISCUSIÓN}

\section{IV.4.1. El reemplazo de exportaciones y los nutrientes del suelo}

En la provincia de Buenos Aires, la mayor parte de los nutrientes (66\%) que contienen los cultivos extensivos se exportan como granos o harinas para alimentación animal. Al igual que en Brasil (Smaling et al., 2008), la soja es el cultivo que más contribuye a las exportaciones agrícolas con destino a la alimentación animal y también tiene como principales destinos China y la Unión Europea. La gran cantidad de nutrientes que salen de los límites provinciales no son repuestos en igual medida en los suelos que los proveen, lo que genera su agotamiento (Figura 4.5 a, b, c, d, e). A diferencia de lo señalado por Smaling et al. (2008), la soja en la provincia genera una 
pérdida de $\mathrm{N}$ del suelo. Esta diferencia se debe a que para Smaling et al. (2008) la soja fija el $100 \%$ de lo extraído en la cosecha, mientras que en esta tesis se asumió, basado en bibliografía (Flores \& Sarandón, 2003; Cruzate \& Casas, 2012), que la fijación biológica del cultivo de soja corresponde a un 50\% de lo extraído en la cosecha. Con lo informado por Collino et al. (2015), respecto a que la fijación biológica de $\mathrm{N}$ del cultivo de soja en Argentina podría contribuir, en promedio, con el $60 \%$ del $N$ total en el cultivo, los déficits estimados en esta tesis serían menores. No obstante, la pérdida en la provincia de Buenos Aires de todos los nutrientes considerados señala la insostenibilidad del manejo de los cultivos y el riesgo en la producción de alimentos (Capítulo III, Subcapítulo 1).

El reemplazo en la exportación de granos y harinas por la exportación de carne producida a partir de éstos, reduce las salidas de nutrientes entre el 84 y $92 \%$, según cada caso (Tabla 4.9). Esto implica una disminución de lo que Pengue (2015a) denomina "suelo virtual" exportado. Si se produjera carne vacuna, que es la que se produciría en menor cantidad con la oferta de granos establecida, se exportaría mayor cantidad de P, Ca y S que si se produjera carne de cerdo o pollo (Tabla 4.9), lo que muestra la riqueza nutricional de esta carne. Los nutrientes más favorecidos, es decir, con menor pérdida con la exportación de carne de cerdo y pollo serían el Ca y S.

Si a la reducción en las salidas de nutrientes por la producción de carne, se considera la fertilización promedio de los cultivos, la reposición permitiría alcanzar, en la superficie que produce los granos con destino a la alimentación animal, balances positivos de N, P y S para cualquiera de las producciones de carne (Figura 4.5 a, b, e) $y$, en la de pollo y cerdo, también se alcanzarían balances positivos de Ca (Figura 4.5 d). De esta manera, existiría la posibilidad, a partir de un eficiente ciclado de los nutrientes, de mantener la fertilidad en el $46 \%$ de la superficie dedicada a cultivos extensivos en la provincia, es decir más de 4 Mha lo que supondría un gran cambio para la sostenibilidad de la producción agropecuaria de la provincia. Estos resultados confirman la hipótesis de que la exportación de carne en reemplazo de la de granos destinados a la alimentación de ganado, favorecería una mayor conservación de los nutrientes del suelo en la provincia.

Incluso si se analiza en conjunto toda la superficie dedicada a cultivos extensivos, es decir, aquélla con destino al consumo humano y al consumo animal (SUPgranohumano+animal), se encontrarían balances positivos en $\mathrm{N}$ y $\mathrm{P}$ considerando cualquiera de las producciones de carne (Figura 4.6 a y b). Esto muestra la potencialidad que podría tener la decisión sobre el manejo de los productos exportados en el mantenimiento de la fertilidad de los suelos, incluso con los 
principales nutrientes considerados a nivel mundial (Bouwman et al., 2013). Para poder ser valorado positivamente, el $\mathrm{N}$ excedente debería aportar en el incremento del $\mathrm{N}$ orgánico del suelo, lo cual debería traducirse en un incremento de la materia orgánica, ya que el 95\% del $\mathrm{N}$ de suelo se encuentra en forma orgánica (Cassman et al., 2003). De lo contrario, podría representar un nuevo riesgo ambiental hacia los cuerpos de agua o la atmósfera. Pasar de balances deficitarios a balances excedentarios con la misma entrada de P sería una buena oportunidad para terminar con las pérdidas que se han estado registrando en la provincia de Buenos Aires (Cruzate \& Casas, 2003, 2012; Flores \& Sarandón, 2003; García \& González Sanjuán, 2010) y que ha contribuido a una disminución en los valores de $P$ disponible en gran parte de sus suelos (Sainz Rozas et al., 2012). Además, en el caso del P, Syers et al. (2011) consideran que será un nutriente clave en la producción de alimentos a nivel mundial, justamente debido a que para su reposición se depende de yacimientos naturales no ubicuamente distribuidos (Cordell \& White, 2013). Particularmente, la Argentina no dispondría, hasta el presente, de depósitos económicamente aprovechables (Melgar \& Torres Duggan, 2005; Grupo Fosfatos, 2016). La huella de P (Metson et al., 2012) no se vería reducida ya que se utilizaría la misma cantidad de $\mathrm{P}$ para producir igual cantidad de carne, pero sí habría cambios favorables en cuanto a la posibilidad de mantener la fertilidad del suelo, para continuar produciendo alimentos en la provincia de Buenos Aires. Este reemplazo de exportaciones puede aportar a un cambio en la tendencia en el uso de $P$, en el sentido que proponen Cordell \& White (2013), quienes consideran necesario acercar la producción y la demanda de alimentos, para afrontar un mundo en crecimiento y con una mayor demanda de carne.

Respecto a K, Ca y S en toda la superficie extensiva de la provincia (SUPgranohumano+animal), se mantendrían balances negativos, aunque con una considerable reducción de los mismos respecto a si se produjeran sólo granos (Figura $4.6 c, d, e)$. Esto es beneficioso ya que disminuiría la tendencia hacia el agotamiento del suelo e incluso, con un menor incremento en la fertilización, se podrían alcanzar valores de reposición adecuados.

Con estos resultados se muestra que el reemplazo de las exportaciones podría contribuir a cerrar los ciclos de nutrientes a nivel local y disminuir la dependencia de fertilizantes sintéticos, sin afectar la producción de alimentos, aspectos que Tilman et al. (2002) consideran necesarios en una agricultura sostenible. 


\section{IV.4.2. Cambio de exportaciones: nuevos desafíos}

La disminución de la pérdida en la fertilidad química del suelo que podría ser lograda con el cambio en las exportaciones, requeriría paralelamente de una infraestructura adecuada que habilite el ciclado eficiente de los nutrientes para que éstos, efectivamente, retornen al campo donde se produjeron los granos destinados a la alimentación animal. Esto implica el manejo de un volumen mayor de sustancias orgánicas, a partir de la heces y orina de los animales (cualquiera sea el tipo de carne producido), lo que conlleva a un mayor riesgo de contaminación, sea de los acuíferos o de la atmósfera por las pérdidas de N (Bouwman et al., 2013; Syers et al., 2011). La recuperación de $\mathrm{P}$ de las producciones de carne es un tema avanzado en los países desarrollados (Syers et al., 2011), pero de escaso abordaje en los países en vías de desarrollo, dentro de los cuales se encuentra Argentina.

Otro de los aspectos a considerar es que la mayor producción de carne dentro de la provincia implica una mayor huella hídrica del producto exportado, por un mayor uso del "agua azul" (agua dulce subterránea o superficial) por parte de los animales (Pengue, 2006). Esto hace que deba sopesarse ambientalmente, si se quiere tener en cuenta la sostenibilidad del ecosistema alimentario local y global, la conveniencia de la disminución de las pérdidas de nutrientes en relación al mayor uso de agua.

\section{IV.4.3. Producción de carne y demanda de granos: su impacto en la implantación de cultivos}

El reemplazo de la exportación de granos por la de carne producida a partir de los mismos en la provincia de Buenos Aires, podría fomentar un cambio en el uso del suelo. Se podría favorecer la implantación de cultivos que completen la dieta de los animales y que habían perdido superficie por el avance de la soja, tal es el caso de maíz. El maíz es el principal alimento de las dietas en la producción de carne (cualquiera de los tres tipos considerados), por lo que, si en la provincia se decidiera producir una mayor cantidad de carne, es probable que se estimule su implantación. Los beneficios del cultivo del maíz son ampliamente conocidos, por el mayor volumen de rastrojo y su calidad, ya que debido a la cantidad de lignina del mismo se trata de residuos de alta tasa de humificación (Manso \& Forján, 2016). Ambas razones implicarían una mejora en el balance de materia orgánica del suelo, principalmente en planteos de siembra directa que conlleven a menores tasas de mineralización secundaria. Dichos balances favorecerían la estructuración edáfica, su capacidad de retención de agua y de intercambio catiónico, entre otras ventajas. La mayor 
presencia de maíz daría lugar a rotaciones más equilibradas entre gramíneas y soja, contribuyendo a un mejor manejo del suelo (Forján \& Manso, 2016). Incluso podría tener lugar mayor presencia de otras gramíneas como el sorgo, $u$ oleaginosas como el girasol, favoreciendo una mejor diversidad en el uso del suelo.

\section{IV.4.4. Alimentos para el ser humano o para la producción de carnes}

La provincia de Buenos Aires cuenta con 23,5 Mha dedicada a las actividades agropecuarias. De estas, los pastizales ocupan el 44\%, mientras que el $56 \%$ restante corresponde a tierra cultivable. Esto último comprende pasturas, verdeos (forrajes anuales), granos de producción extensiva (granohumano+animal) y horticultura. Si se considera la superficie de pastizales, pasturas, verdeos y la de granos que se exportan con destino a la alimentación animal (granoanimal), se encuentra que la provincia destina el $80 \%$ de su superficie a la producción directa o indirecta de proteína animal. Teniendo en cuenta sólo la superficie total cultivable (excluyendo pastizales), entre pasturas, verdeos y granos para exportación con destino a producción animal se observa que $64 \%$ de estas tierras se destinan a la producción de carne. Esto muestra que la provincia destina el doble del promedio a nivel mundial de tierra cultivable para la producción animal (Bouwman et al., 2013; Schader et al., 2016). Este uso del suelo se asemeja más al de Europa, que destina el $60 \%$ de la producción de cereales para alimento animal (Grote et al., 2005). Además, se encuentra con la controversia de si la tierra cultivable debe tener como destino la alimentación animal (Oltjen \& Beckett, 1996; Tedeschi et al., 2015; Schader et al., 2016).

Con el reemplazo de las exportaciones propuesto, no se cambiaría el uso de la tierra cultivable con destino a la alimentación animal, pero si se podría estar alcanzando una mejor eficiencia en la producción de carne y conservación de nutrientes en el lugar de origen (si se logra una alta eficiencia en la reutilización de los mismos). Esto podría ser encuadrado en la "estrategia de eficiencia" (Schader et al., 2016) dentro de las estrategias que buscan la sostenibilidad de los sistemas ganaderos.

En la discusión acerca de la conveniencia de producir carne de monogástricos o rumiantes con los granos, la mejor eficiencia de conversión de energía y proteína se inclinaría a favor de los monogástricos (Oltjen \& Becket, 1996) (Tabla 4.3), aunque, desde el punto de vista de los nutrientes, esto implicaría una mayor salida (Tabla 4.9). Schader et al. (2016) consideran que la producción de carne debe mejorarse a partir de la conversión de alimentos que no compitan directamente con la alimentación del ser humano. Estos autores hicieron proyecciones para 2050 considerando la producción de carne de rumiantes y encontraron que es posible una adecuada producción de esta carne a nivel mundial utilizando pastizales y que incluso se 
disminuiría la presión sobre tierra cultivable para la producción de granos con destino a la alimentación animal. En este sentido, la provincia podría potenciar aún más la producción de carne vacuna a partir de la superficie con pastizales y pasturas, que son alimentos no disponibles para el ser humano (Oltjen \& Beckett, 1996; Schader et al., 2016).

Con su creciente demanda y producción local de carne, principalmente de cerdo y de pollo, China y la Unión Europea necesitan alimento para sus ganados. Esto genera una presión sobre el uso del suelo en los países proveedores de granos y harinas de cereales y oleaginosas (Pengue, 2015a) que determina un reemplazo de cultivos, así como el corrimiento (avance) de la frontera agrícola. En general, se asume que el avance de la frontera agrícola es una respuesta interna de los países al aumento de su población, y la necesidad de producir alimentos. En Argentina este avance es causado por la demanda externa de granos para alimentación animal y no por el aumento de su población.

En los últimos 15 años, en la provincia de Buenos Aires se observó un reemplazo de cultivos agrícolas y pasturas en favor de la soja y luego un avance sobre tierra con pastizales (Paruelo et al., 2005; Viglizzo et al., 2010; Vázquez \& Zulaica, 2011). Este avance de la frontera agrícola en la provincia incorpora zonas ambientalmente frágiles. Analizado el fenómeno desde el punto de vista de los nutrientes, zonas que antes generaban una baja exportación de los mismos porque estaban dedicadas a la producción de carne pasaron a generar una mayor salida por la producción de granos. Este fenómeno sumado a un inadecuado manejo de la reposición de los nutrientes genera un mayor vaciamiento de los suelos. Estos suelos ecológicamente frágiles, también se ven fuertemente degradados por la disminución de la materia orgánica. Esto muestra la dificultad de mantener estas "nuevas tierras" como tierras cultivables. Si se prevé que esta demanda de carne continúe de manera creciente será necesario replantear la eficiencia ecológica a nivel mundial de los flujos de nutrientes (Cordell \& White, 2013; Pengue, 2015b). Un camino para disminuir esta presión y ser más eficientes, sería producir carne en las cercanías de producción de los alimentos para animales a los fines de cerrar parcialmente los flujos. Esto puede llevar a mantener la producción de carne a partir de pastizales y detener el avance de la frontera agrícola a zonas frágiles ecológicamente.

Por otro lado, si la presión sobre la producción mundial de alimentos lleva a que se produzcan más cultivos agrícolas para la alimentación directa de la población, asumiendo un crecimiento de dieta vegetariana (estrategia de suficiencia) (Schader et al., 2016), redundaría en un beneficio global por una mayor disponibilidad de alimentos, pero, para la provincia, implicaría mantener la actual salida de nutrientes 
que, incluso, podría ser superior si aumentaran los rendimientos. Esto requeriría estrategias de reposición de nutrientes que evitaran continuar con la pérdida. Esto muestra lo complejo de los caminos a seguir para alcanzar la sostenibilidad del ecosistema alimentario a nivel global.

Una estrategia para avanzar hacia un ecosistema alimentario sostenible a nivel global podría ser que cada país optimizara el uso de su suelo para la producción de alimentos de consumo directo de su población (cereales, hortalizas, frutales) y, las necesidades alimenticias extras no cubiertas, como la demanda de proteína animal, fuera abastecida generando el menor movimiento de nutrientes a nivel global. Además, esta puede ser una medida eficaz en un escenario creciente de incertidumbre climática.

Comprender los flujos de los nutrientes a escala global para encaminar el mundo hacia una sostenibilidad se ha convertido en un desafío de los últimos años (Lavelle et al., 2005) pero una vez que se cuente con la información, será necesaria la decisión política y la voluntad a nivel internacional para revertirlo. La eficiencia en la producción de alimentos y la búsqueda de menores distancias recorridas por los nutrientes, con mayores eficiencias en la reutilización de los mismos, puede ser un camino para disminuir la pérdida de fertilidad de los suelos, sobre todo en los países y regiones en los que la mayor producción que generan sus suelos son destinados a la alimentación animal a miles de kilómetros.

\section{IV.5. BIBLIOGRAFÍA}

Andreani, P. 2008. Mercado del complejo soja y análisis de la competitividad de los países exportadores. Programa de Inserción Agrícola. Entidad coordinadora Sociedad Rural Argentina. $169 \mathrm{pp}$.

Antikainen, R., R. Lemola, J.I. Nousiainen, L. Sokka, M. Esala, P. Huhtanen\& S. Rekolainen. 2005. Stocks and flows of nitrogen and phosphorus in the Finish food production and consumption system. Agriculture, Ecosystems \& Environment 107:287-305.

Bouwman, L., K.K. Goldewijk, K.W. Van Der Hoek, A.H.W. Beusen, D.P. Van Vuuren, J. Willems, M.C. Rufino \& E. Stehfest. 2013. Exploring global changes in nitrogen and phosphorus cycles in agriculture induced by livestock production over the 1900-2050 period. Proceedings of the National Academy of Sciences of the United States of America 110(52):20882-20887.

Bragachini, M. 2009. Integración vertical de los sistemas productivos. ¿̇Nuevos paradigmas para los sistemas agropecuarios argentinos? Agregar valor en origen. Disponible en: http://www.cosechaypostcosecha.org/data/articulos/agoindustrializacion/IntegracionVerticalSis temasProductivos.asp. Último acceso: agosto 2016.

Carvajal, G. 2001. Valor nutricional de la carne de res. Corporación de fomento ganadero. San José. Costa Rica. 55pp.

Cassman, K.G., A. Dobermann, D.T. Walters \& H. Yang. 2003. Meeting cereal demand while protecting natural resources and improving environmental quality. Annual Review of Environment \& Resources 28:315-358.

Collino, D.J., F. Salvagiotti, A. Perticari, C. Piccinetti, G. Ovando, S. Urquiaga \& R.W. Racca. 2015. Biological nitrogen fixation in soybean in Argentina: relationships with crop, soil, and meteorological factors. Plant Soil 392:239-252.

Colomé, R.A. \& L.H. Gumierato. 2009. Sobre los orígenes de la comercialización de granos en Argentina (c. 1870 - 1920). Revista de la Bolsa de Comercio de Rosario: 52-61. 
Cordell, D. \& S. White. 2013. Sustainable phosphorus measures: strategies and technologies for achieving phosphorus security. Agronomy 3(1):86-116.

CRA (Conferederaciones Rurales Argentinas). 2012. Ciclo mensual de conferencias de la Tierra a la mesa. Disponible en: http://www.cra.org.ar/0/vnc/seccion.vnc?id=de-la-tierra-a-la-mesa. Último acceso: abril 2017.

Cruzate, G. \& R.R. Casas. 2003. Balance de nutrientes. Revista Fertilizar (Número especial "Sostenibilidad"): 7-13.

Cruzate, G. \& R.R. Casas. 2012. Extracción y balance de nutrientes en los suelos agrícolas de la Argentina. Informaciones Agronómicas de Hispanoamérica 6:7-14.

Fernández, M.V \& M.A. Marsó. 2003. Estudio de la carne de pollo en tres dimensiones: valor nutricional, representación social y formas de preparación. Instituto Universitario de Ciencias de la Salud. Fundación H.A. Barceló. 74pp. Disponible en: http://www.menu.com.py/upload/04Dec10201234pollo.pdf. Último acceso: septiembre 2016.

Flores, C.C. \& S.J. Sarandón. 2003. ¿Racionalidad económica versus sustentabilidad ecológica? El ejemplo del costo oculto de la pérdida de fertilidad del suelo, durante el proceso de Agriculturización en la Región Pampeana Argentina. Revista de la Facultad de Agronomía 105 (1) $(2002,2003): 53-67$.

Fontanetto, H., S. Gambaudo \& O. Keller. 2011. Balance de nutrientes en sistemas pastoriles. Sitio Argentino de Producción Animal. 4pp. Disponible en: http://www.produccionanimal.com.ar/produccion_y_manejo_pasturas/pasturas_fertilizacion/52-balance.pdf. Último acceso: septiembre 2016.

Forján, H. \& L. Manso. 2016. La secuencia de cultivos. En: Rotaciones y secuencias de cultivo en la región mixta cerealera del centro-sur bonaerense. Forján, H. \& L. Manso (Compiladores). Ediciones INTA. Buenos Aires. Capítulo 3: 19-28.

Franco, D. 2010. Anuario estadístico: Oleaginosas. Alimentos argentinos. Una elección natural. Ministerio de Agricultura de la Nación. 8pp.

Franco, D. 2013. Informe sectorial de oleaginosas $N^{\circ} 10$. Alimentos argentinos. Una elección natural. Ministerio de Agricultura de la Nación. 8pp.

Fundación Española para el Desarrollo de la Nutrición Animal. 2012a. Disponible en: http://www.fundacionfedna.org/ingredientes_para_piensos/harina-zoot\%C3\%A9cnica-de-

ma\%C3\%ADz-8-ee-nov-2012 . Último acceso: septiembre 2016.

Fundación Española para el Desarrollo de la Nutrición Animal. 2012b. Disponible en: http://www.fundacionfedna.org/ingredientes_para_piensos/harina-de-extracci\%C3\%B3n-degirasol-30-pb . Último acceso: septiembre 2016.

García, F.O. 2006. El rol del fósforo en la producción de pasturas de la región pampeana. Sitio Argentino de Producción Animal. 6pp. Disponible en: http://www.produccionanimal.com.ar/produccion y manejo pasturas/pasturas fertilizacion/21-fosforo en pasturas.pdf. Último acceso: septiembre 2016.

García, F.O. \& M.F. González Sanjuán. 2010. Balances de nutrientes en Argentina ¿Cómo estamos? ¿ Cómo mejoramos? Informaciones Agronómicas 48:1-5.

Garnett, T. 2014. Three perspectives on sustainable food security: efficiency, demand restraint, food system transformation. What role for life cycle assessment? Journal of Cleaner Production 73: 10-18.

Giancola, S.I., M.L. Salvador, M. Covacevich \& G. Iturrioz. 2009. Análisis de la cadena de la soja en la Argentina. Estudios de los Sistemas Agroalimentarios y Agroindustriales N³. Ediciones INTA. 119 pp.

Goizueta, M.E., A. Castellano \& M. Covacevich. 2013. Alternativas de agregado de valor en la cadena de maíz argentina. Estrategias y actores diferenciales por agroindustria derivada. INTA. XLIV Reunión Anual de la Asociación Argentina de Economía Agraria. San Juan. 24pp.

Grote, U., E. Craswell \& P. Vlek. 2005. Nutrient flows in international trade: Ecology and policy issues. Environmental Science \& Policy 8:439-451.

Grupo Fosfatos. 2016. Yacimientos. Manifestaciones en Argentina. Disponible en: http://fosfatos.gl.fcen.uba.ar/index.php/yacimientos/manifestaciones-en-argentina/. Último acceso: septiembre 2016.

INTA (Instituto Nacional de Tecnología Agropecuaria). 2009. Programa Nacional cereales Documento base. PMP 2009-2011. 67pp.

INTA (Instituto Nacional de Tecnología Agropecuaria). 2010. Maíz Cadena de Valor Agregado. Alternativas de transformación e industrialización. Actualización técnica 54.36pp.

Kohan, L. \& R. Costa. 2011. Panorama general de las nuevas formas de organización del agro: las principales cadenas agroalimentarias. Comisión Económica para América Latina y el Caribe (CEPAL). Colección Documentos de proyectos. Chile. 88pp. 
Krauss, A. 2000. Nutrient Cycling and transfers in the global dimension. En: Nutrient management in China. Part 1. Nutrient management and nutrient cycling in agro-ecosystems. Hardter R., J-C. Xie, J.M. Zhou \& Q-Z. Fan (Editores). International Potash Institute. Capítulo 1:13-24.

Lavelle, P., R. Dugdale, R. Scholes, A.A. Berhe, E. Carpenter, L. Codispoti, A-M. Izac, J. Lemoalle, F. Luizao, M. Scholes, P. Tre'guer \& B. Ward. 2005. Nutrient Cycling. En: Ecosystems and Human Wellbeing: Current State and Trends, Volume 1. R. Hassan, R. Scholes \& N. Ash (Editores). Editorial Island Press. Estados Unidos. Capítulo 12:331-353.

Lezcano, E. 2008. Maíz, productos y derivados. Alimentos argentinos 42:20-23.

Lezcano, E.P. 2011. Cadena de la harina de trigo segunda parte. Evolución de los principales indicadores sectoriales en el periodo 2002-2011. Alimentos Argentinos. 27pp.

MAA (Ministerio de Asuntos Agrarios). 2007. Nuestra provincia nuestro campo. El sector agropecuario de la provincia de Buenos Aires. 147pp.

Manso, L. \& H. Forján. 2016. La materia orgánica del suelo. En: Rotaciones y secuencias de cultivo en la región mixta cerealera del centro-sur bonaerense. Forján, H. \& L. Manso (Compiladores). Ediciones INTA. Buenos Aires. Capítulo 5: 34-40.

Mateos, G.G., M. Hermida, M. Pérez-Serrano \& R.P. Lázaro. 2009. Evaluación de la calidad de las harinas de soja disponibles en el mercado europeo para la producción de piensos. XXV Curso de especialización FEDNA. Madrid. 24pp.

MECON (Ministerio de Economía y Finanzas Públicas). 2011. Complejo Oleaginoso Serie: "Producción regional por complejos productivos". Direcciones de Información y Análisis Regional y Sectorial. Subsecretaría de programación económica. 28pp.

Melgar, R. \& M. Torres Duggan. 2005. Comercio y abastecimiento moderno de fertilizantes. Editorial Hemisferio Sur S.A. Buenos Aires. 196pp.

Metson, G.S., E.M. Bennett \& J.J. Elser. 2012. The role of diet in phosphorus demand. Environmental Research Lette rs 7 (4) 044043.

Nesme, T., S. Roques, G.S. Metson \& E.M. Bennett. 2016. The surprisingly small but increasing role of international agricultural trade on the European Union's dependence on mineral phosphorus fertiliser. Environmental Research Letters 11 (2) 025003.

Oltjen, J.W. \& J.L. Beckett. 1996. Rol of ruminant livestock in sustainable agricultural systems. Journal of Animal Science 74:1406-1409.

Paruelo, J.M., J.P. Guerschman \& S.R. Verón. 2005. Expansión agrícola y cambios en el uso del suelo. Ciencia Hoy 15(87):14-23.

Pengue, W. 2006. "Agua virtual", agronegocio sojero y cuestiones económico ambientales futuras. Fronteras 5:14-25.

Pengue, W. 2007. Modelo agroexportador, monoproducción y deuda ecológica. ¿̇acia el agotamiento del granero del mundo? Revista Aportes para el Debate 59:81.

Pengue, W. 2015a. Suelos, huellas de nutrientes y estabilidad ecosistémica. Fronteras 13:1-18.

Pengue, W. 2015b. Recursos naturales, servicios ambientales y desarrollo en América Latina. Revista Redbioética/UNESCO 1 (11):64:69.

Reca, L.G. 2006. Aspectos del Desarrollo Agropecuario argentino 1875-2005. Academia Nacional de Agronomía y Veterinaria. Buenos Aires, 78pp. Disponible en: http://www.anav.org.ar/trabajos_publicados/4/reca.pdf. Último acceso: agosto 2016.

Sainz Rozas, H., H. Echeverría. \& H. Angelini. 2012. Fósforo disponible en suelos agrícolas de la región Pampeana y Extra Pampeana argentina. Revista de Investigaciones Agropecuarias 38(1):33-39.

Schader, C., A. Muller, N.E-H. Scialabba, J. Hecht, A. Isensee, K-H. Erb, P. Smith, H.P.S. Makkar, P. Klocke, F. Leiber, P. Schwegler, M. Stolze \& U. Niggli. 2016. Impacts of feeding less foodcompeting feedstuffs to livestock on global food system sustainability. Journal of the Royal Society Interface 12: 20150891.

SIIA (Sistema Integrado de Informaciones Agropecuarias). 2016. Disponible en: http://www.siia.gov.ar/. Último acceso: septiembre 2016.

Smaling, E.M.A., R. Roscoe, J.P. Lesschen, A.F. Bouwman \& E. Comunello. 2008. From forest to waste: Assessment of the Brazilian soybean chain, using nitrogen as a marker. Agriculture, Ecosystems \& Environment 128: 185-197.

Sutton, M.A., A. Bleeker, C.M. Howard, M. Bekunda, B. Grizzetti, W. de Vries, H.J.M. van Grinsven, Y.P. Abrol, T.K. Adhya, G. Billen, E.A. Davidson, A. Datta, R. Diaz, J.W. Erisman, X.J. Liu, O. Oenema, C. Palm, N. Raghuram, S. Reis, R.W. Scholz, T. Sims, H. Westhoek \& F.S. Zhang. 2013. Our Nutrient World: The challenge to produce more food and energy with less pollution. Global Overview of Nutrient Management. Centre for Ecology and Hydrology, Edinburgh on behalf of the Global Partnership on Nutrient Management and the International Nitrogen Initiative. 128pp.

Syers, K., M. Bekunda, D. Cordell, J. Corman, J. Johnston, A. Rosemarin, I. Salcedo \& T. Lougheed. 2011. Phosphorus and food production. En: UNEP, Year Book. UNEP, Nairobi. 34-45. 
Tedeschi, L.O., J.P. Muir, D.G. Riley \& D.G. Fox. 2015. The role of ruminant animals in sustainable livestock intensification programs. International Journal of Sustainable Development \& World Ecology 22(5):452-465.

Tilman, D., K.G. Cassman, P.A. Matson, R. Naylor \& S. Polasky. 2002. Agricultural sustainability and intensive production practices. Nature 418:671-677.

Vázquez, P. \& L. Zulaica. 2011. Cambios en el uso de la tierra del partido de Tandil y principales impactos ambientales. Párrafos Geográficos 10(2):242-267.

Viglizzo, E.F., L.V. Carreño, H. Pereyra, F. Ricard, J. Clatt \& D. Pincén. 2010. Dinámica de la frontera agropecuaria y cambio tecnológico. En: Expansión de la Frontera Agropecuaria en Argentina y su Impacto Ecológico-Ambiental. Viglizzo, E.F. \& E.G. Jobbágy (Editores). Ediciones INTA. Capítulo 1:9-16.

Walter, M., J. Brun, P. Pérez-Manrique, A.C. González-Martínez \& J. Martínez Alier. 2013. Análisis del flujo de materiales de la economía Argentina (1970-2009) Tendencias y conflictos extractivo. Ecología política 45:94-98. 


\section{CAPÍTULO $v$}

Ciudad - Campo: construyendo un ecosistema alimentario en la provincia de Buenos Aires

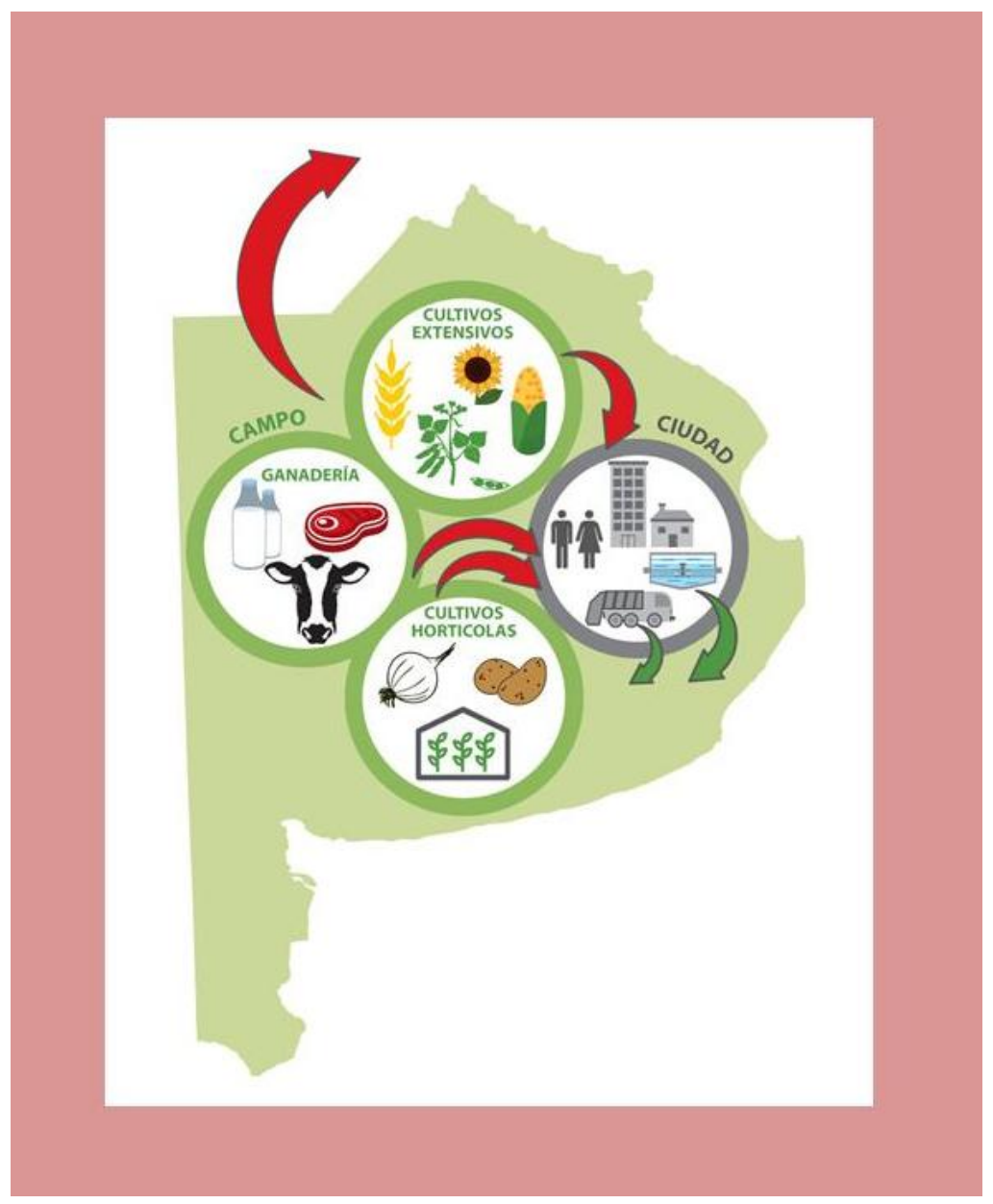




\section{V.1. INTRODUCCIÓN}

La alimentación del ser humano es una necesidad básica que involucra la producción de los alimentos y su procesamiento, transporte, venta y consumo. Actualmente se reconoce que el hambre en el mundo no es un problema de producción, sino de distribución y acceso a los alimentos (FAO, 2001; Ingram et al., 2012). Para mejorar la alimentación a nivel mundial se han propuestos distintos enfoques que intentan abordar el tema integralmente para visualizar, analizar y conocer las distintas etapas que comprenden desde la producción hasta el consumo de alimentos (Ingram et al., 2012; Garnett, 2014; Soussana, 2014). También se han desarrollado enfoques que buscan mejorar distintas etapas del sistema alimentario. Por ejemplo, en la etapa de producción de alimentos se propone la intensificación sostenible (Godfray \& Garnett, 2014), la intensificación ecológica (Tittonell, 2014). Por otro lado, en la discusión acerca de la alimentación de la población actual y futura, se somete a discusión el rol de las diferentes dietas en la demanda de alimentos (Cordell et al., 2009; Godfray et al., 2010; Soussana, 2014; Godfray \& Garnett, 2014; Westhoek et al., 2014), así como las pérdidas y desperdicios de alimentos (Godfray et al., 2010; Gustavsson et al., 2012; Garrone et al., 2014; Papargyropoulou et al., 2014). En las discusiones sobre la producción de alimentos y la alimentación, la cuestión de los nutrientes, se encuentra presente de manera directa $\mathrm{o}$ indirecta (Fernández-Mena et al., 2016).

En la etapa de producción de alimentos (agricultura) los nutrientes han sido tenidos en cuenta, principalmente, para mejorar el crecimiento y la productividad de los cultivos. Paralelamente, se han buscado las posibilidades de su reposición a los fines de no agotar los suelos, procurando minimizar las pérdidas que generan problemas de contaminación (Gaj \& Bellaloui, 2012). A excepción del nitrógeno (N), que se obtiene de la atmósfera por el proceso de Haber-Bosch, el fósforo (P), el potasio (K) y otros nutrientes, son restituidos al suelo con productos provenientes de la minería (Cordell \& White, 2013; Syers et al., 2011). La fertilización mineral ha permitido mantener y aumentar la producción agropecuaria por muchos años (Bouwman et al., 2009; Vitousek et al., 2009). No obstante, se ha comenzado a tener conciencia de que estas reservas minerales de nutrientes son finitas (Sutton et al., 2013) y que, en algunos casos como en el $\mathrm{P}$, cada vez se dificulta más la obtención del mineral apto para su empleo como fertilizante (Gilbert, 2009; Cordell \& White, 2013). Otra preocupación que generan los nutrientes en esta primera etapa de la alimentación, es la contaminación de agua y aire a través de la lixiviación, erosión o pérdida gaseosa, por ejemplo, de $\mathrm{N}$ (Oenema et al., 2003; Vitousek et al., 2009). 
En las etapas de procesamiento, distribución, consumo y pos-consumo de alimentos, los nutrientes son considerados por sus consecuencias ambientales, tanto hacia el agua como hacia el aire (Zhao et al., 2011; Papargyropoulou et al., 2014). En el sistema alimentario, los nutrientes también son tenidos en cuenta en la nutrición de las personas en su vinculación con la salud humana.

Las pérdidas y desperdicios de alimentos tuvieron su mayor repercusión a nivel internacional a partir del trabajo de Gustavsson et al. (2012), en el cual se menciona que un tercio de la producción mundial de alimentos se pierde o desperdicia. Esto alertó sobre la necesidad de reducir estas pérdidas y desperdicios para que una mayor cantidad de los alimentos producidos llegaran a la población. Particularmente, si se considera que, para su producción, se requiere el uso de recursos naturales (agua y suelo) y de tierra cultivable, que en algunos casos lleva implícito una deforestación previa (Graham Rowe et al., 2014).

Las externalidades que genera el sistema alimentario han contribuido a que los aspectos ambientales sean transversales a los nuevos enfoques sobre dicho sistema. Si bien los enfoques no están de acuerdo sobre los caminos a seguir (Godfray \& Garnett, 2014; Tittonell, 2014), coinciden en la preocupación sobre el deterioro ambiental que generan, tanto la producción de alimentos, como su procesamiento, distribución y consumo. A pesar de este nuevo vínculo entre los temas ambientales y la alimentación, se requiere ampliar la mirada ecológica de esta última, visualizándola como un proceso ecológico en el cual el ser humano adquiere del ambiente la energía y los nutrientes necesarios para vivir y debe devolver estos últimos a donde fueron tomados, para que el ciclo pueda recomenzar. Esta idea permitiría insertar al ser humano nuevamente dentro de un "ecosistema alimentario", en el cual debería gestionar la energía y los nutrientes, como ocurre en los ecosistemas naturales. En éstos, la energía que proviene de una fuente inagotable (sol) fluye de manera unidireccional en el ambiente mientras que, los nutrientes, ayudados por la energía, participan en los ciclos de la materia (Odum, 1998). Los ecosistemas naturales tienen distintas estrategias de utilización de los nutrientes, pero son eficientes en su uso y están adaptados a la disponibilidad espacio temporal de los mismos (Odum, 1998). En cambio, el actual "ecosistema alimentario del ser humano" se basa principalmente en la transferencia unidireccional de nutrientes, que se vehiculiza a través de distintos componentes separados espacial y temporalmente (Figura 1.1). Desde los campos, los nutrientes van a las industrias y de estos a los consumidores para finalizar en los cuerpos de agua o enterrados en vertederos (Nebel \& Wright, 1999). Se debe asumir entonces el desafío de cerrar los flujos de nutrientes del ecosistema alimentario, a los fines de 
disminuir la dependencia de fuentes externas. A su vez, esto permitiría extender la vida útil de estas reservas finitas (Odum, 1998).

Una manera de cerrar los flujos de nutrientes es a partir de los alimentos que llegan a la población (Metson \& Bennett, 2015). Una parte de los alimentos se desperdicia (Gustavsson et al., 2012) y pasa a integrar los residuos sólidos urbanos, mientras que otra parte que es consumida, termina en las aguas servidas (Morée et al., 2013; Bodirsky et al., 2014). Dependiendo de la presencia de instalaciones de redes cloacales, el destino final de estos flujos de nutrientes serán cuerpos de agua superficiales (arroyos, ríos, mares) o los acuíferos (por la existencia de pozos ciegos).

El empleo de las heces y orina como fertilizantes en la agricultura se remonta a las primeras civilizaciones (Syers et al., 2011; Lavado, 2012). Durante el siglo XIX, el reciclado de los desechos urbanos fue común en varios países industrializados como fuente de nutrientes en la agricultura (Morée et al., 2013). La orina es rica en macronutrientes $(\mathrm{N}, \mathrm{P}, \mathrm{K})$ mientras que las heces contienen mayormente materia orgánica (Richert et al., 2011). En los últimos dos siglos, la creciente urbanización de la población mundial, el aumento en tamaño de las ciudades y los problemas ambientales que generaba la acumulación de desechos orgánicos dentro de las mismas, condujo a que se desarrollaran los sistemas de alcantarillado (redes cloacales) y de recolección de residuos sólidos (Barles, 2007). Las redes cloacales permitieron la recolección de gran cantidad de heces y orina y su transporte hacia afuera de las urbes para su posterior vertido en aguas superficiales. A partir de la contaminación de los cuerpos de agua originada por este vertido, se desarrollaron sistemas de saneamiento previos (Nebel \& Wright, 1999). Como la finalidad de estos tratamientos ha sido disminuir la contaminación, lo que buscan es disminuir la presencia de materia orgánica en el agua vertida. Sin embargo, el contenido de nutrientes muchas veces es elevado (Syers et al., 2011) y el residuo sólido del sistema de saneamiento (lodos) pocas veces es tratado para su posterior uso agrícola. Los mayores impedimentos para ello, han sido las cuestiones de sanidad de la población (Toze, 2006). Por otra parte, la recolección de residuos sólidos urbanos también permitió retirar de las ciudades tanto los desperdicios alimenticios como otros elementos, los cuales tuvieron como destino final el relleno sanitario.

A pesar de que desde hace muchos años se señala la necesidad de generar ciclos cerrados de nutrientes (Odum, 1998), poco se ha avanzado al respecto. Para conocer cuántos nutrientes son potencialmente reutilizables con el ciclado entre la ciudad y el campo, se requiere generar modelos que permitan cuantificar estos nutrientes. El análisis y la cuantificación de los nutrientes contenidos en la etapa de pre-posconsumo, ha tenido como prioridad la disminución del impacto ambiental y no 
la necesidad de cerrar los ciclos de nutrientes en el ecosistema alimentario (Toze, 2006; Forkes, 2007; Westhoek et al., 2014). Algunos enfoques que han trabajado y analizado la demanda y el destino de nutrientes de las ciudades, son el metabolismo urbano (Barles, 2007; Forkes, 2007) y el balance de nutrientes urbanos (Farge et al., 2001). Estos estudios se refieren a los nutrientes requeridos por la población urbana a partir de la alimentación y el destino de los mismos, pero no analizan la potencial reutilización para la producción agroalimentaria. Un mayor conocimiento de los flujos de nutrientes urbanos puede ayudar a estimar el potencial reciclamiento de nutrientes hacia la agricultura (Faerge et al., 2001). Este ciclado puede contribuir a revertir la producción "minera" de los suelos agrícolas y a disminuir el problema ambiental (Faerge et al., 2001), aspecto que Jönsson et al. (2004) y Syers et al. (2011) denominan "saneamiento ecológico". Estos autores señalan que el saneamiento ecológico permitiría crear ciclos de nutrientes sostenibles en las sociedades, de la misma forma que en el resto de la naturaleza.

Antikainen et al. (2005) han realizado en Finlandia uno de los trabajos más completos que involucra los flujos de nutrientes del sistema alimentario a nivel de país, donde se puede visualizar los diferentes flujos de nutrientes tanto en la producción agropecuaria como en las ciudades a través de los alimentos, y su posterior destino en las aguas servidas y rellenos sanitarios. La provincia de Buenos Aires carece de análisis similares. Los estudios que involucran nutrientes de manera directa $\mathrm{O}$ indirecta en el sistema alimentario de la provincia, han sido parciales y fueron analizados desde diferentes disciplinas. En la etapa de producción, los nutrientes han sido considerados por la agronomía en los balances de nutrientes (Viglizzo et al., 2002; Flores \& Sarandón, 2003; Cruzate \& Casas, 2003, 2012; García, 2006; García \& González Sanjuán, 2010). En lo que respecta a la alimentación, se han considerado las cantidades y tipos de alimentos consumidos (Piola et al., 2011; Parra \& Justo, 2003; Ferrato \& Rodríguez Fazzone, 2010), relacionados a la nutrición y la salud (Bernadou, 2005; Mangialavori et al., 2012), o al gasto en los hogares (Britos et al., 2010). Otros estudios que vinculan la Ingeniería y la Ecología, han analizado la composición física de los residuos sólidos urbanos (Rossi et al., 2002; González, 2010; FIUBA-CEAMSE, 2011; Schejtman \& Cellucci, 2014). No obstante, sigue pendiente un estudio desde los nutrientes, que vincule la ciudad y el campo, asumiendo la necesidad de cerrar los ciclos para un "ecosistema alimentario provincial". Esto requiere comprender los mayores flujos de nutrientes en las ciudades y la potencialidad en el ciclado hacia el campo, en función de las extracciones que realizan las diferentes actividades agropecuarias de la provincia. Siendo que la provincia aporta el 34\% del stock ganadero bovino (MA, 2015), el 22,2\% de la producción de leche y el 35\% de los cereales, a nivel nacional (MAA, 2007), esto 
permite suponer una elevada extracción de nutrientes por el conjunto de las actividades agropecuarias. Paralelamente, la provincia concentra el $38 \%$ de la población nacional (MAA, 2007) lo que indicaría una alta demanda de alimentos, por lo tanto de nutrientes. No obstante, se desconoce la potencialidad para la reposición de nutrientes de un ciclado de nutrientes entre el campo y la ciudad. Aunque, debido a las elevadas extracciones de las actividades agropecuarias se esperaría que este ciclado de nutrientes no fuera suficiente para la reposición de la totalidad de nutrientes extraídos.

El objetivo de este capítulo es conocer el uso de nutrientes en la población de la provincia de Buenos Aires a partir de la alimentación, y su potencial, en la reposición de los nutrientes para las actividades agropecuarias de la provincia.

Se plantea como hipótesis que el potencial reaprovechamiento de los residuos domiciliarios y aguas servidas a nivel provincial, resultaría insuficiente para reponer los nutrientes extraídos en la actividad agropecuaria.

\section{V.2. METODOLOGÍA}

Para cada uno de los partidos de la provincia de Buenos Aires (134) y para la provincia en su conjunto, se calculó, para el año 2006, la demanda de nutrientes de la población en el consumo de alimentos (N, P, K, calcio (Ca) y azufre (S)). También se estimó el destino actual y potencial de los nutrientes a partir de los residuos sólidos urbanos y de las aguas servidas (Faerge et al., 2001, Barles, 2007; Forkes, 2007). Luego, se compararon los nutrientes contenidos en los residuos sólidos urbanos y aguas servidas de cada partido y a nivel provincial, con los nutrientes extraídos por el conjunto de las principales actividades agropecuarias de cada partido y de la provincia en su conjunto. Para el análisis también se incluyó el consumo y destino de los alimentos de la población de la Ciudad Autónoma de Buenos Aires, para el mismo año. Geográficamente ésta se encuentra rodeada de la provincia de Buenos Aires y los flujos de nutrientes que ingresan y salen a la misma relacionados a la alimentación, se encuentran íntimamente ligados a la provincia.

Para determinar los flujos de nutrientes, se siguieron los siguientes pasos: I) se calculó la demanda de alimentos y nutrientes para la población, II) se calculó el estado actual y potencial de reutilización de los nutrientes en desperdicios alimenticios en residuos sólidos urbanos, y III) se calculó el estado actual y potencial de reutilización de los nutrientes en aguas servidas provenientes de la alimentación. 


\section{V.2.1. Demanda de alimentos y nutrientes para la población}

Se consideró la hoja de balance de alimentos (Cotier \& Morón, 1997) para la Argentina para el año 2006 (FAO, 2006). De la misma se consideraron los grupos cereales, raíces y tubérculos, hortalizas, frutas, carnes y huevo, pescados y leche. Con el contenido de nutrientes de los alimentos (Tabla 5.1) se determinó la cantidad de nutrientes demandada por persona para los diferentes grupos y para el total.

Tabla 5.1. Consumo y contenido de nutrientes de diferentes grupos de alimentos considerados para la provincia de Buenos Aires y la Ciudad Autónoma de Buenos Aires (año 2006).

\begin{tabular}{|c|c|c|c|c|c|c|c|}
\hline \multirow{2}{*}{ Grupo } & \multirow{2}{*}{ Alimento } & \multirow{2}{*}{$\begin{array}{c}\text { Consumo } \\
\text { (kg pers.-1 año-1) }\end{array}$} & \multicolumn{5}{|c|}{ Contenido de nutrientes $\left(\mathrm{kg} \mathrm{t}^{-1}\right)$} \\
\hline & & & $\mathbf{N}$ & $\mathbf{P}$ & K & $\mathrm{Ca}$ & S \\
\hline \multicolumn{8}{|l|}{ Cereales } \\
\hline & Trigo & 111,0 & 21,0 & 3,5 & 5,0 & 0,7 & 1,2 \\
\hline & Arroz & 6,2 & 15,0 & 3,0 & 3,0 & 0,1 & 0,6 \\
\hline & Maíz & 10,2 & 14,9 & 2,5 & 5,0 & 0,5 & 1,0 \\
\hline \multicolumn{8}{|c|}{ Raíces y tubérculos } \\
\hline & Papa & 35,4 & 4,3 & 0,7 & 4,9 & 0,4 & \\
\hline & Raíces varias & 8,7 & 2,5 & 0,5 & 3,9 & 0,3 & \\
\hline \multicolumn{8}{|l|}{ Hortalizas } \\
\hline & Tomate & 15,9 & 1,6 & 0,4 & 2,7 & 0,1 & \\
\hline & Cebolla & 11,1 & 1,3 & 0,2 & 1,0 & 0,3 & \\
\hline & Hoja Tallo peciolo & 10,0 & 3,4 & 0,7 & 5,2 & 0,7 & \\
\hline & Inflorescencia & 1,0 & 6,3 & 0,7 & 3,1 & 0,8 & \\
\hline & Zapallo Zapallito & 8,0 & 1,3 & 0,3 & 2,4 & 0,3 & \\
\hline \multicolumn{8}{|l|}{ Frutas } \\
\hline & Naranjas/mandarinas & 24,6 & 1,8 & 0,3 & 2,3 & 0,9 & 0,3 \\
\hline & Limones & 12,0 & 1,6 & 0,2 & 1,7 & 0,7 & 0,1 \\
\hline & Bananas & 11,4 & 2,0 & 0,4 & 6,0 & 1,0 & \\
\hline & Manzanas & 12,6 & 2,5 & 0,4 & 1,4 & 0,6 & \\
\hline & Otras & 11,6 & 3,0 & 0,5 & 3,5 & 1,1 & \\
\hline \multicolumn{8}{|l|}{ Carne } \\
\hline & Vacuna & 55,5 & 25,0 & 6,7 & 1,5 & 13,0 & 1,5 \\
\hline & Pollo & 27,8 & 24,5 & 2,0 & 2,92 & 0,02 & \\
\hline & Cerdo & 6,6 & 31,8 & 2,3 & 3,8 & 0,02 & \\
\hline & Huevos & 9,4 & 19,2 & 2,13 & 1,4 & 0,6 & \\
\hline & Pecados varios & 9,1 & 29,6 & 1,9 & 2,8 & 0,8 & \\
\hline Leche (I) & & 184,6 & 5,0 & 0,9 & 1,5 & 1,2 & \\
\hline Total & & 582,6 & & & & & \\
\hline
\end{tabular}

Se asumió un consumo de alimentos de las poblaciones de la provincia de Buenos Aires y de la Ciudad Autónoma de Buenos Aires igual al promedio nacional. La población de cada partido y el total provincial, al igual que la de la Ciudad 
Autónoma de Buenos Aires para el año 2006, se estimó a partir de los datos de los Censos Nacionales de Población y Vivienda 2001 y 2010 (INDEC, 2016). Se asumió que todos los nutrientes de la alimentación fluyen hacia los residuos sólidos urbanos o hacia las aguas servidas. Jönsson et al. (2004) señalan que entre los 2 y 17 años de edad el cuerpo retiene parte de los nutrientes ingeridos (entre el $2 \%, 6 \%$ y $0,6 \%$ para N,P y K, respectivamente), pero una vez que se alcanza la talla completa no se retienen ni acumulan más nutrientes en el cuerpo. Forkes (2007) señala que el 10\% del N ingerido queda retenido en los cuerpos dentro de los límites de las ciudades. Para los fines de esta tesis se asumió que la cantidad de nutrientes excretados (entre orina y heces) es igual a la de los ingeridos.

\section{V.2.2. Situación actual y potencial de reutilización de los desperdicios alimenticios en residuos sólidos urbanos}

Se asumió una tasa de desperdicio de alimentos en los hogares a partir de los datos presentados por Gustavsson et al. (2012), quienes establecieron las pérdidas y los desperdicios en diferentes etapas de la cadena de producción, comercialización y consumo de alimentos, para diferentes regiones del mundo. A partir de dicha publicación se asumió un porcentaje de desperdicio para cada grupo de alimentos que se consideró que tenía como destino los residuos sólidos urbanos (cereales (10\%), raíces y tubérculos $(4 \%)$, hortalizas (10\%), frutas (10\%), carne y huevos (6\%), pescado (4\%) y leche (4\%)).

\section{V.2.3. Situación actual y potencial de reutilización de los nutrientes de la alimentación en aguas servidas}

Los nutrientes que no tenían como destino los residuos sólidos urbanos se consideraron nutrientes ingeridos. Se asumió que los mismos finalizaban en las aguas servidas, pudiendo tener como destino las cloacas o pozos ciegos. La población con disponibilidad de servicio de cloacas o que disponían de pozo ciego de cada partido de la provincia de Buenos Aires, se obtuvo en base al Censo Nacional de Hogares y Viviendas 2010 (INDEC, 2016). Para el potencial de nutrientes reutilizables se asumió un procesamiento y retorno del $100 \%$ de los nutrientes ingeridos.

\section{V.2.4. Extracción de nutrientes de las actividades agropecuarias}

Para cada partido de la provincia de Buenos Aires y para el conjunto, se consideraron las extracciones generadas por cultivos extensivos, horticultura y 
producción de carne y leche bovina, obtenidas en el subcapítulo 4 del capítulo III (Figuras 3.4.3 y 3.4.4).

\section{V.2.5. Generación de mapas temáticos}

Los mapas temáticos fueron generados asignando un único valor por partido, en un entorno SIG.

\section{V.3. RESULTADOS}

Se estimó un consumo de alimentos de $583 \mathrm{~kg}$ pers.-1 año-1 (Tabla 5.1), siendo $31,7 \%$ aportado por leche y derivados; $21,9 \%$ por cereales; $17 \%$ por carne y huevos y el 12,$4 ; 7,6 ; 7,9$ y $1,6 \%$ por los grupos frutas, hortalizas, raíces/tubérculos y peces, respectivamente. Los grupos de cereales y carne y huevo aportaron la mayor cantidad de N, P y S (Figura 5.1). El aporte principal de Ca fue por los grupos de carne y huevo/leche, mientras que el $\mathrm{K}$ fue el nutriente con aportes más equitativos de todos los grupos, siendo mayor para los cereales (Figura 5.1).

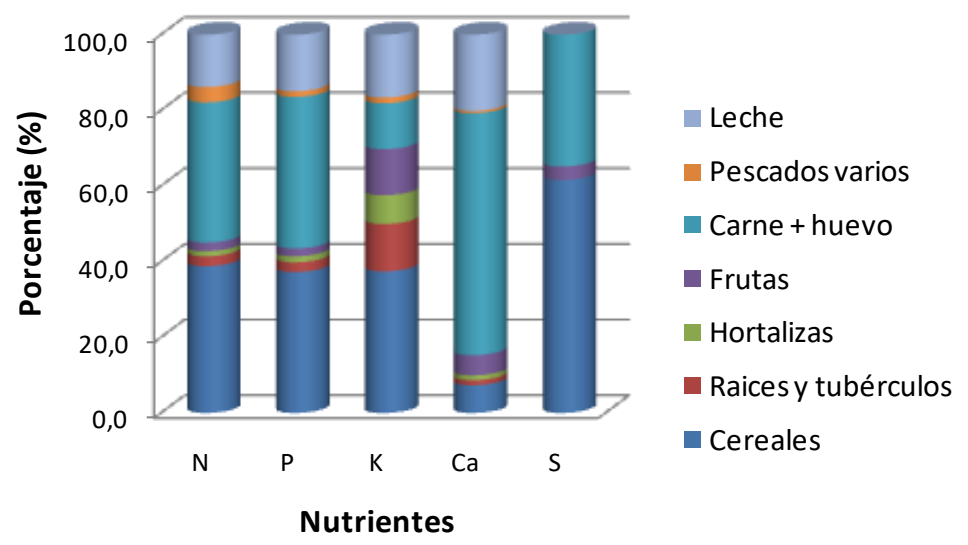

Figura 5.1. Aporte de nutrientes de los diferentes grupos de alimentos para la provincia de Buenos Aires (año 2006).

El $\mathrm{N}$ fue el nutriente de mayor cantidad en los alimentos, seguido de K, P, Ca y, en menor medida, S (Tabla 5.2). De los nutrientes en los alimentos, un 93\% fue ingerido, mientras que el $7 \%$ restante fue derivado a residuos sólidos urbanos.

Tabla 5.2. Nutrientes en la alimentación de la población y su destino en ingesta o residuos sólidos urbanos, en la provincia de Buenos Aires (año 2006).

\begin{tabular}{lccccc}
\hline & \multicolumn{5}{c}{ Nutrientes (kg pers. ${ }^{-1}$ año-1) $^{-1}$} \\
\cline { 2 - 6 } & $\mathbf{N}$ & $\mathbf{P}$ & $\mathbf{K}$ & $\mathbf{C a}$ & $\mathbf{S}$ \\
\hline Nutrientes en la alimentación de & 6,64 & 1,16 & 1,67 & 1,14 & 0,24 \\
la población & 6,20 & 1,09 & 1,54 & 1,08 & 0,22 \\
$\begin{array}{l}\text { Nutrientes ingeridos } \\
\text { Nutrientes en residuos sólidos }\end{array}$ & 0,48 & 0,08 & 0,13 & 0,07 & 0,02 \\
urbanos & &
\end{tabular}


Siendo que la población de la provincia de Buenos Aires estimada para 2006 fue de 14.854.210 habitantes, el contenido total de los principales nutrientes en la alimentación (N, P, K, Ca, S) fue de $161.168+$ año-1. Estos nutrientes representaron el $11 \%$ del total de nutrientes extraídos por las principales actividades agropecuarias de la provincia, siendo Ca y $S$ los nutrientes con mayor y menor relación, respectivamente (Tabla 5.3).

Tabla 5.3. Nutrientes extraídos en las principales actividades agropecuarias (cultivos extensivos, horticultura, producción de carne y leche bovinas) y los contenidos en los alimentos de la población de la provincia de Buenos Aires (año 2006).

\begin{tabular}{lrrr}
\hline Nutrientes & \multicolumn{1}{c}{$\begin{array}{c}\text { Extracción total } \\
\text { actividades } \\
\text { agropecuarias }(\mathbf{t} \text { año-1) }\end{array}$} & $\begin{array}{c}\text { Nutrientes en la } \\
\text { alimentación de la } \\
\text { población (t año-1) }\end{array}$ & $\begin{array}{c}\text { Relación nutrientes } \\
\text { en alimentación / } \\
\text { extracción }\end{array}$ \\
\hline $\mathrm{N}$ & 962.942 & 98.632 & 0,10 \\
$\mathrm{P}$ & 143.026 & 17.231 & 0,12 \\
$\mathrm{~K}$ & 279.085 & 24.807 & 0,09 \\
$\mathrm{Ca}$ & 63.845 & 16.934 & 0,27 \\
$\mathrm{~S}$ & 62.008 & 3.565 & 0,06 \\
\hline
\end{tabular}

Para todos los nutrientes considerados, la relación a nivel provincial entre los nutrientes en la alimentación y los nutrientes extraídos por actividades agropecuarias, fue menor que 1. Sin embargo, dependiendo de los nutrientes, se estimaron entre $34 \mathrm{y}$ 37 partidos con índice superior a 1 (Figura 5.2a, b, c, d, e). Estos partidos correspondieron al Conurbano Bonaerense, Gran La Plata y los partidos de La Costa, Pinamar, Villa Gesell y Bahía Blanca. 


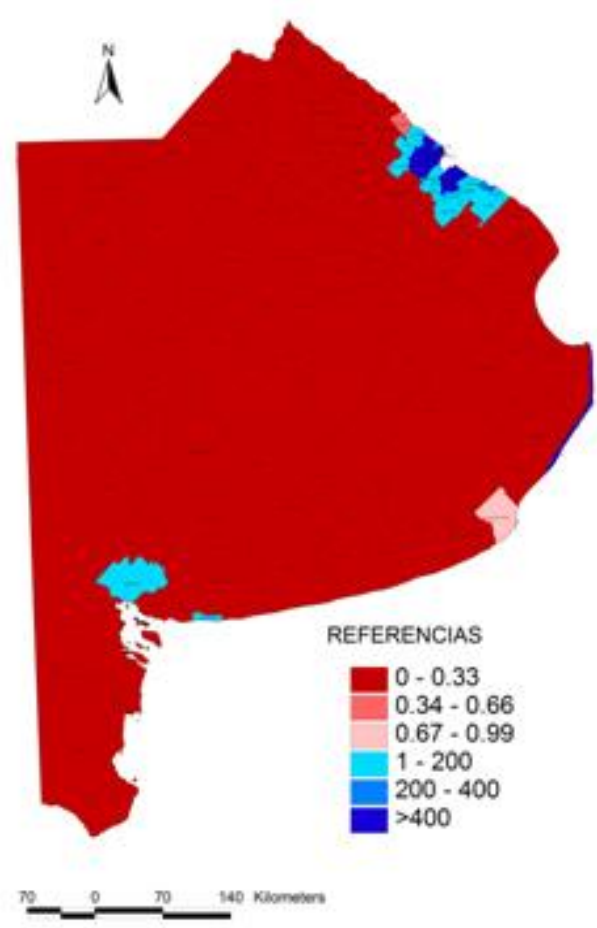

a)

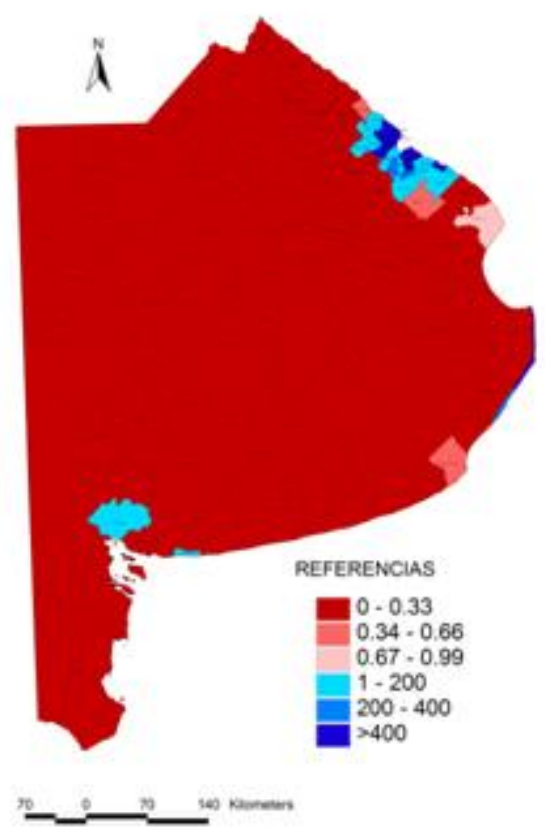

c)

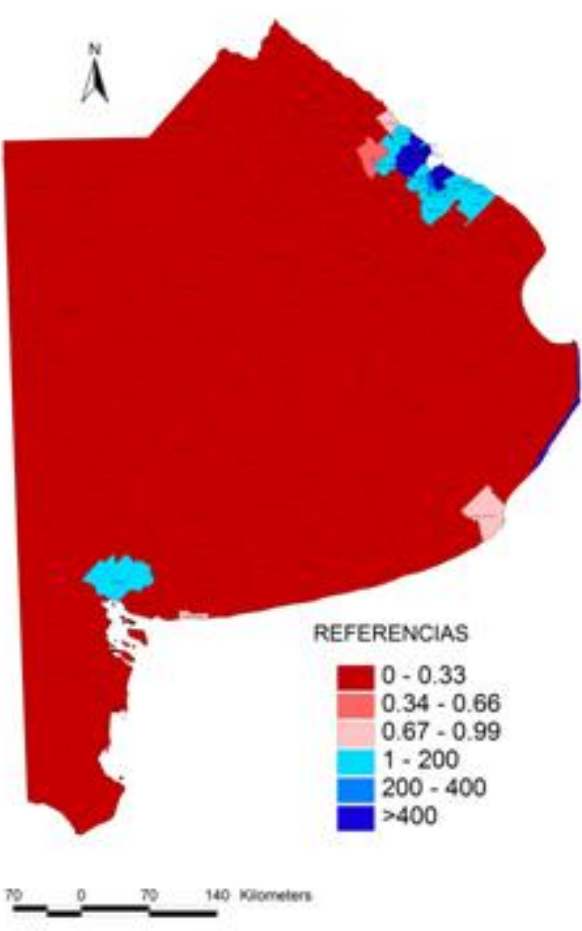

b)

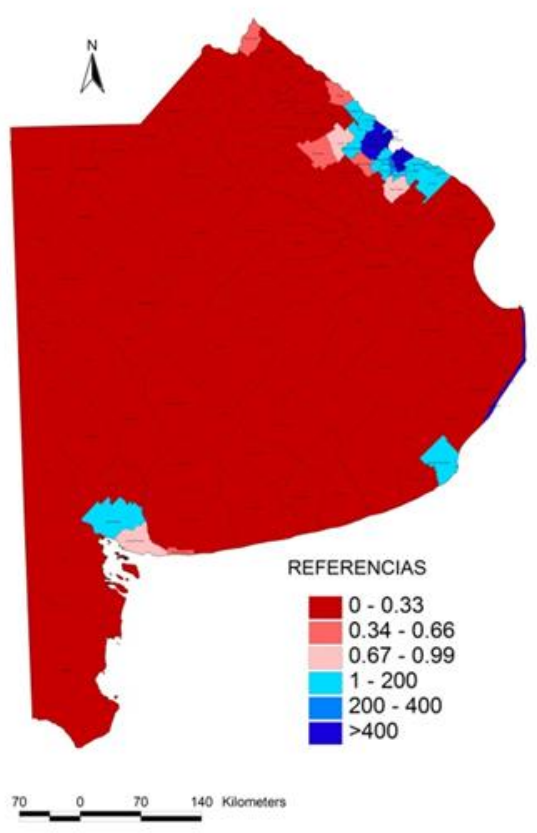

d) 


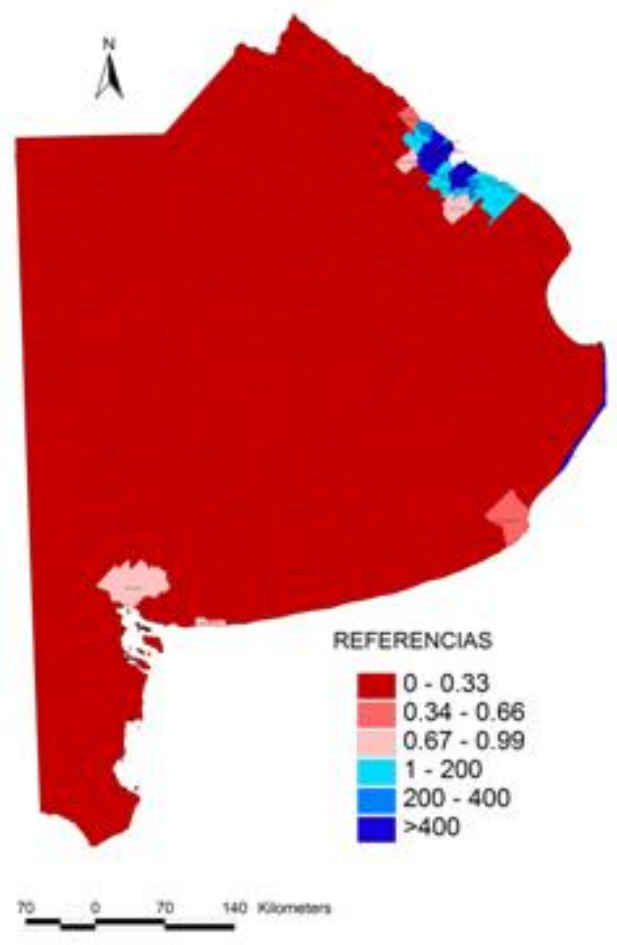

e)

Figura 5.2. Relación entre los nutrientes en la alimentación de la población y los nutrientes extraídos por cultivos extensivos, horticultura, producción de carne y leche bovina, en la provincia de Buenos Aires: a) N, b) P, c) K, d) Ca y e) S (año 2006).

La mayor proporción de nutrientes ingeridos respecto a los contenidos en residuos sólidos urbanos, determinaron un mayor potencial de reposición de nutrientes a partir de las aguas servidas (Tabla 5.4). El Ca fue el nutriente que mayor reposición podría alcanzar a partir del ciclado de los nutrientes de la ciudad, seguido de P, N, K y $S$.

Tabla 5.4. Relación entre los nutrientes ingeridos y los contenidos en residuos sólidos urbanos (RSU) respecto a los nutrientes extraídos por las principales actividades agropecuarias de la provincia de Buenos Aires (año 2006).

\begin{tabular}{lcccc}
\hline & $\begin{array}{c}\text { Nutrientes } \\
\text { ingeridos por } \\
\text { alimentación* } \\
(\dagger \text { año-1) }\end{array}$ & $\begin{array}{c}\text { Relación } \\
\text { ingesta / } \\
\text { extracción }\end{array}$ & $\begin{array}{c}\text { Nutrientes } \\
\text { en RSU } \\
(\dagger \text { año-1) }\end{array}$ & $\begin{array}{c}\text { Relación } \\
\text { nutrientes } \\
\text { en RSU / } \\
\text { extracción }\end{array}$ \\
\hline $\mathrm{N}$ & 92.136 & 0,10 & 7.185 & 0,01 \\
$\mathrm{P}$ & 16.139 & 0,11 & 1.252 & 0,01 \\
$\mathrm{~K}$ & 22.940 & 0,08 & 1.902 & 0,01 \\
$\mathrm{Ca}$ & 16.080 & 0,25 & 1.034 & 0,02 \\
$\mathrm{~S}$ & 3.269 & 0,05 & 305 & 0,00 \\
\hline
\end{tabular}

* La totalidad de los nutrientes ingeridos se consideran en las aguas servidas. 
Se observó que los partidos que presentaron una relación alimentaciónextracción superior a uno, también mantuvieron la potencialidad de reponer los nutrientes extraídos en las actividades agropecuarias a partir de la reutilización de las aguas servidas (Figuras 5.3a, 5.4a, 5.5a, 5.6a, 5.7a). Sólo en los partidos del conurbano, La Costa, Villa Gesell y Pinamar, la utilización de los residuos sólidos urbanos serían suficientes para reponer los nutrientes extraídos por sus respectivas actividades agropecuarias (Figuras 5.3b, 5.4b, 5.5b, 5.6b, 5.7b).

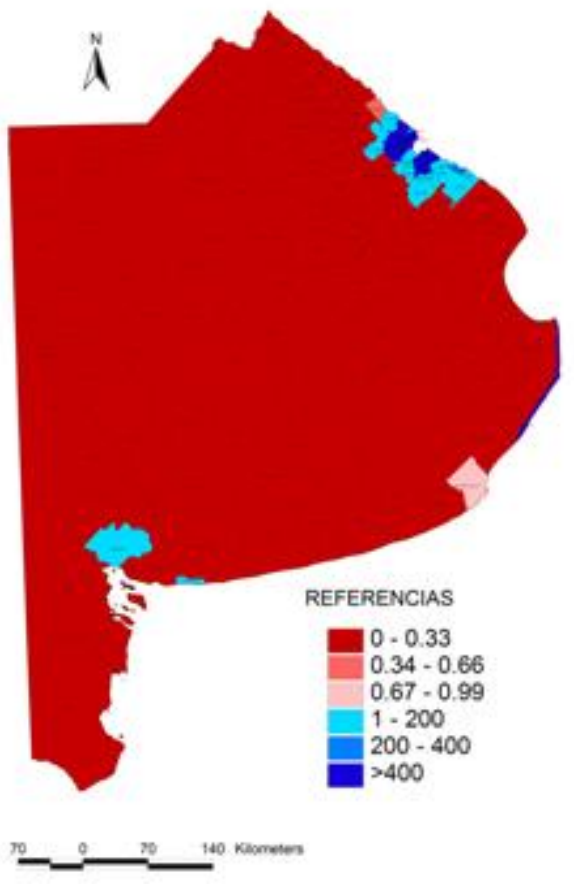

a) N aguas servidas / $\mathrm{N}$ extracción

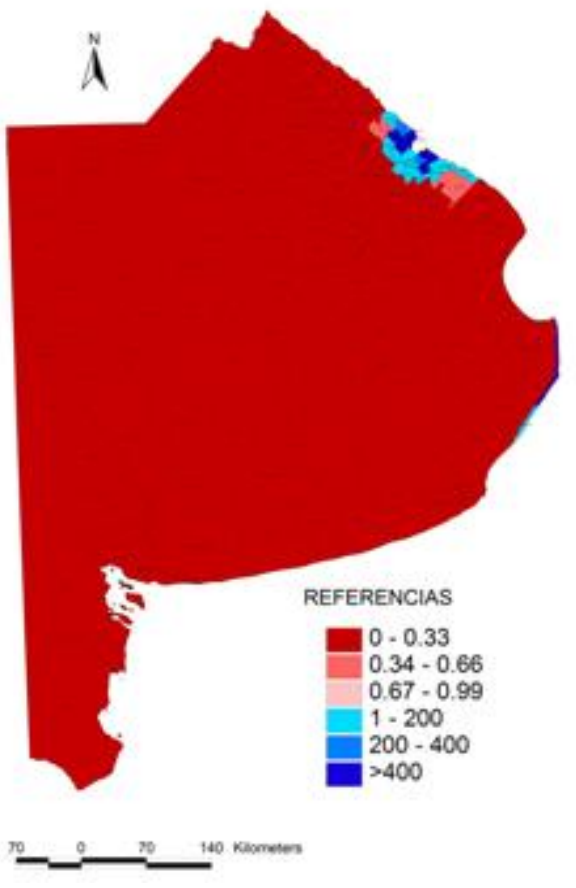

b) N RSU / N extracción

Figura 5.3. a) $\mathrm{N}$ en aguas servidas y b) $\mathrm{N}$ en residuos sólidos urbanos (RSU), ambos en relación al $\mathrm{N}$ extraído por cultivos extensivos, horticultura, producción de carne y leche bovinas, en la provincia de Buenos Aires (año 2006). 


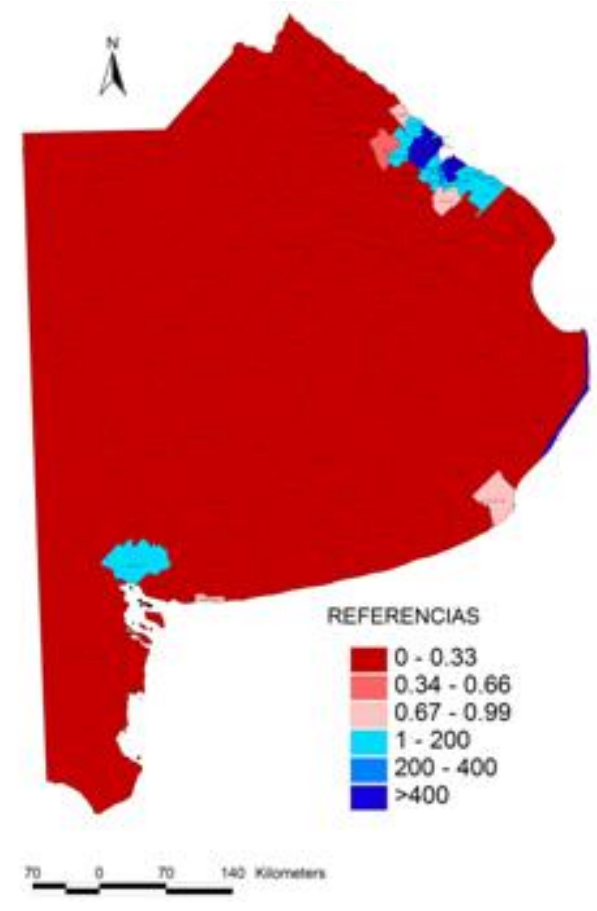

a) P aguas servidas / P extracción

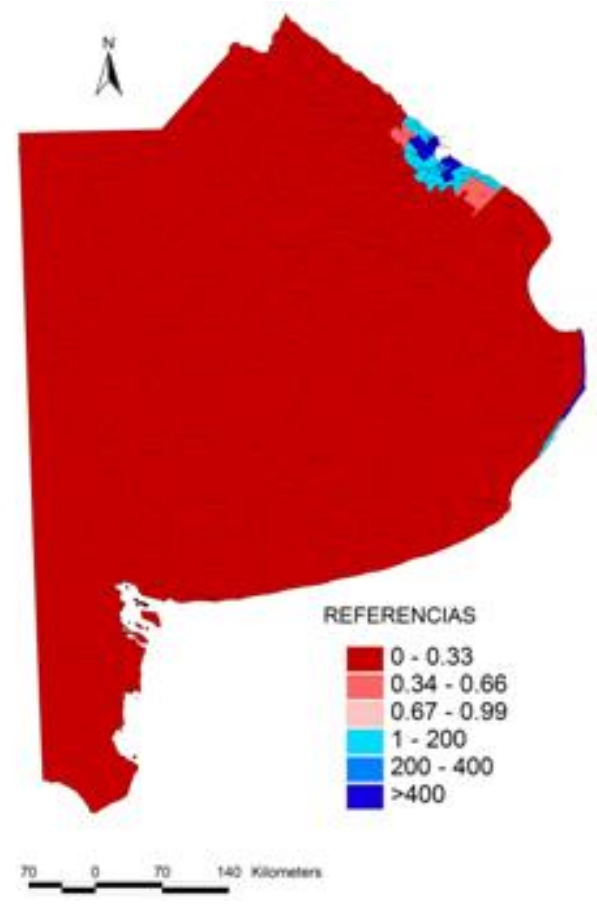

b) P RSU / P extracción

Figura 5.4. a) $P$ en aguas servidas y b) $P$ en residuos sólidos urbanos (RSU), ambos en relación al P extraído por cultivos extensivos, horticultura, producción de carne y leche bovinas, en la provincia de Buenos Aires (año 2006).

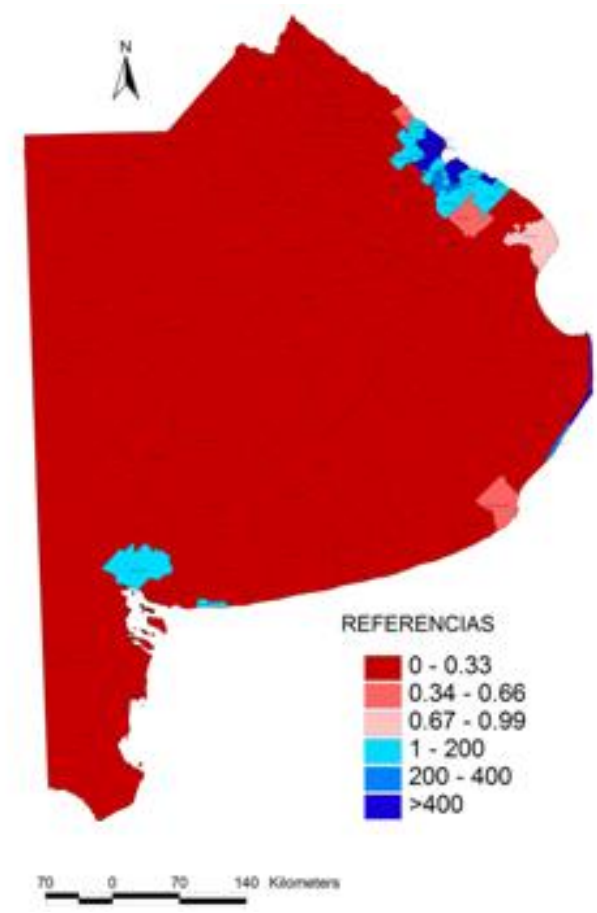

a) K aguas servidas / $K$ extracción

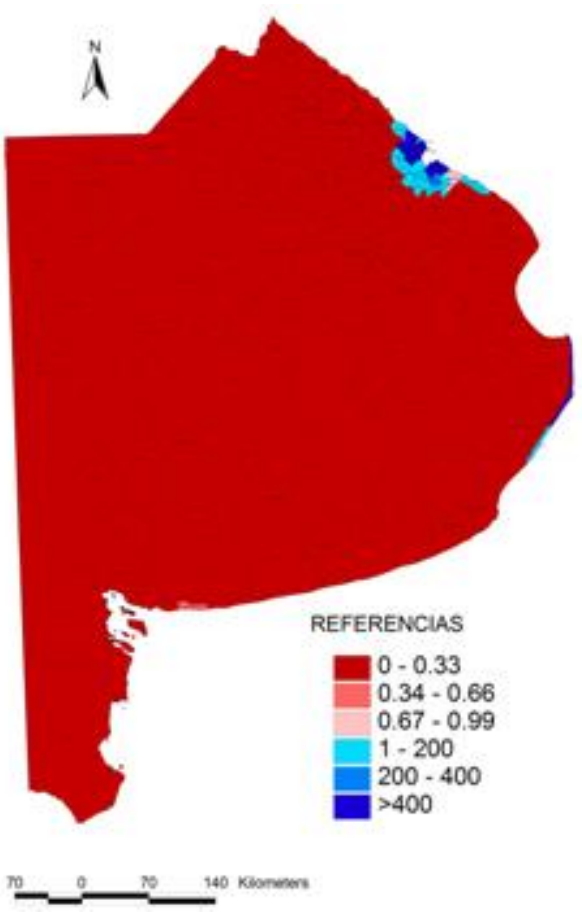

b) K RSU / K extracción

Figura 5.5. a) K en aguas servidas y b) K en residuos sólidos urbanos (RSU), ambos en relación al K extraído por cultivos extensivos, horticultura, producción de carne y leche bovinas, en la provincia de Buenos Aires (año 2006). 


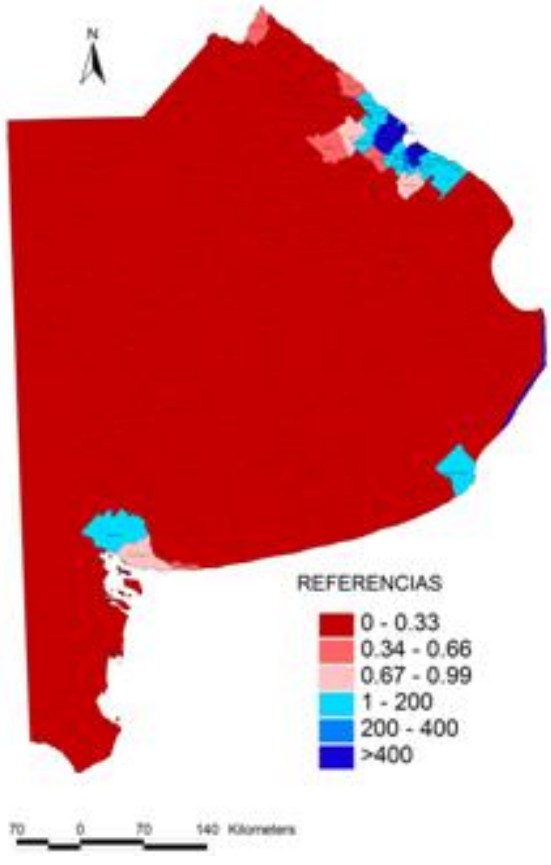

a) Ca aguas servidas / Ca extracción

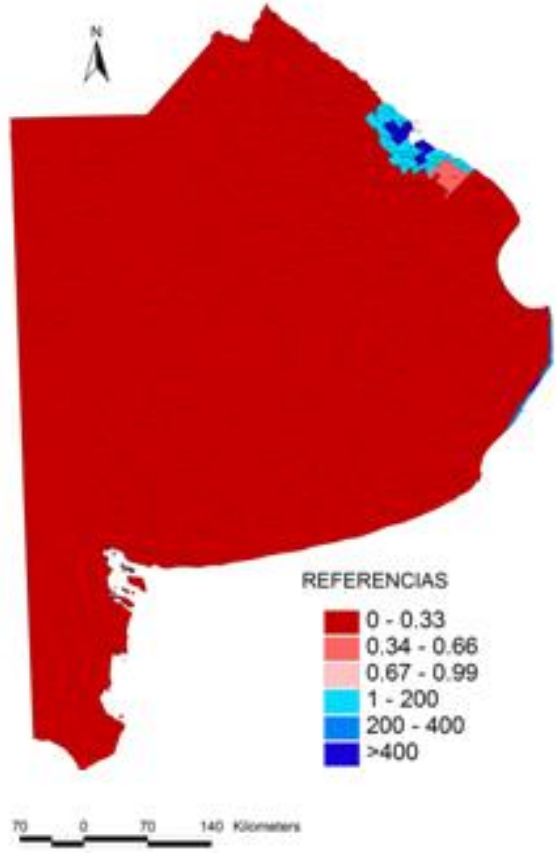

b) Ca RSU / Ca extracción

Figura 5.6. a) Ca en aguas servidas y b) Ca en residuos sólidos urbanos (RSU), ambos en relación al Ca extraído por cultivos extensivos, horticultura, producción de carne y leche bovinas, en la provincia de Buenos Aires (año 2006).

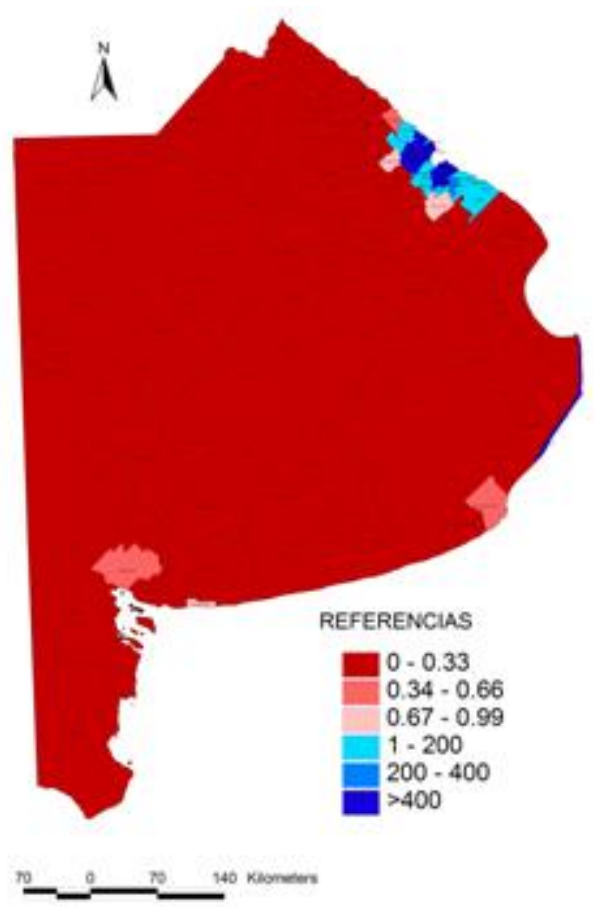

a) S aguas servidas / S extracción

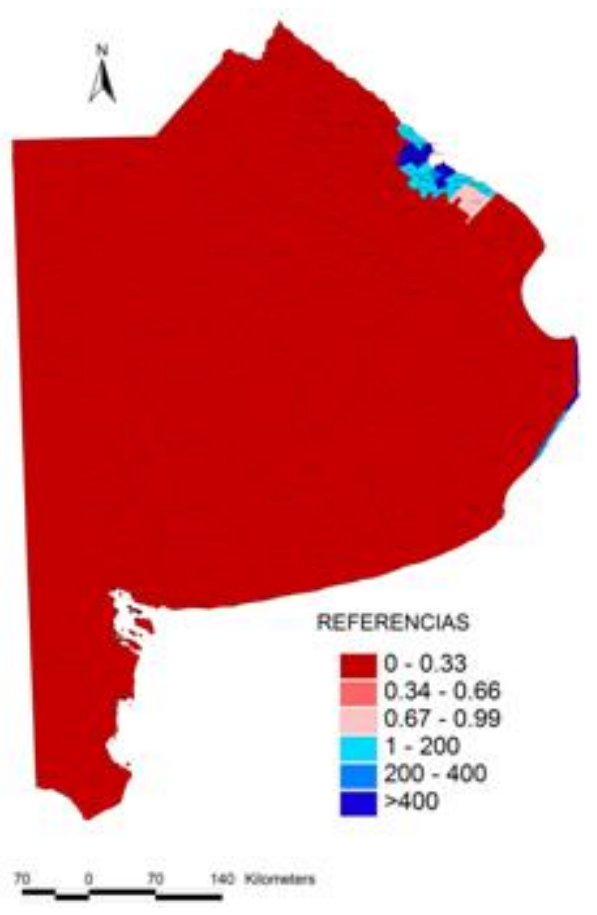

b) S RSU / S extracción

Figura 5.7. a) S en aguas servidas y b) $S$ en residuos sólidos urbanos (RSU), ambos en relación al $S$ extraído por cultivos extensivos, horticultura, producción de carne y leche bovinas, en la provincia de Buenos Aires (año 2006). 
Considerando que la población estimada con red cloacal para el año 2006 fue del $46 \%$, la mayor cantidad de los nutrientes ingeridos se perderían por el sistema de pozos y terminarían en las napas o acuíferos, mientras que el resto sería potencialmente sujeto a recuperación mediante el tratado de aguas servidas (Tabla $5.5)$.

Tabla 5.5. Nutrientes en la red cloacal o en pozo derivados de la alimentación en la provincia de Buenos Aires (año 2006).

\begin{tabular}{lccccc}
\hline & \multicolumn{5}{c}{ Nutrientes $(\mathbf{t}$ año-1) } \\
\cline { 2 - 6 } & $\mathbf{N}$ & $\mathbf{P}$ & $\mathbf{K}$ & $\mathbf{C a}$ & $\mathbf{S}$ \\
\hline $\begin{array}{l}\text { Nutrientes en red } \\
\text { Cloacal }\end{array}$ & 42.174 & 7.387 & 10.500 & 7.360 & 1.496 \\
$\begin{array}{l}\text { Nutrientes en } \\
\text { pozo }\end{array}$ & 49.962 & 8.751 & 12.439 & 8.720 & 1.772 \\
\hline
\end{tabular}

Al sumar a la población de la provincia de Buenos Aires, la correspondiente a la Ciudad Autónoma de Buenos Aires, estimada para 2006 en 2.844 .619 personas, se estimó un leve incremento de la relación entre nutrientes en los alimentos y las extracciones totales de las principales actividades agropecuarias (Tablas 5.4 y 5.6 ). También se calculó un leve incremento de las relaciones de los nutrientes ingeridos o en residuos sólidos urbanos respecto de los extraídos en las actividades agropecuarias (Tablas 5.5 y 5.6 ).

Tabla 5.6. Nutrientes extraídos en las principales actividades agropecuarias de la provincia de Buenos Aires y contenidos en los alimentos de la población de la provincia y la Ciudad Autónoma de Buenos Aires (año 2006) y sus relaciones con los nutrientes ingeridos y en residuos sólidos urbanos (RSU) de ambas poblaciones.

\begin{tabular}{|c|c|c|c|c|c|}
\hline Nutriente & $\begin{array}{l}\text { Extracción total } \\
\text { actividades } \\
\text { agropecuarias } \\
(† \text { año-1) }\end{array}$ & $\begin{array}{l}\text { Nutrientes en } \\
\text { alimentación de } \\
\text { la población } \\
(\dagger \text { año-1) }\end{array}$ & $\begin{array}{c}\text { Relación } \\
\text { nutrientes en } \\
\text { alimentación } \\
\text { / extracción }\end{array}$ & $\begin{array}{l}\text { Relación } \\
\text { ingesta*/ } \\
\text { extracción }\end{array}$ & $\begin{array}{c}\text { Relación } \\
\text { nutrientes } \\
\text { en RSU / } \\
\text { extracción }\end{array}$ \\
\hline$N$ & 962.942 & 117.520 & 0,12 & 0,11 & 0,01 \\
\hline$P$ & 143.026 & 20.531 & 0,14 & 0,13 & 0,01 \\
\hline K & 279.085 & 29.557 & 0,11 & 0,10 & 0,01 \\
\hline $\mathrm{Ca}$ & 63.845 & 20.177 & 0,32 & 0,30 & 0,02 \\
\hline S & 62.008 & 4.248 & 0,07 & 0,06 & 0,01 \\
\hline
\end{tabular}

* La totalidad de los nutrientes ingeridos se consideran en las aguas servidas.

\section{V.4. DISCUSIÓN}

\section{V.4.1. Alimentación}


La cantidad de alimentos estimados para la población de la provincia de Buenos Aires fue de $583 \mathrm{~kg}$ pers.-1 año-1, lo cual resultó levemente inferior a lo que Gustavsson et al. (2012) estiman para los países del hemisferio norte. Los consumos de hortalizas, y de raíces y tubérculos estimados fueron de $90 \mathrm{~kg}$ pers.-1 año-1, similar al mencionado por Aulicino \& Moré (2000) en los alrededores de la Ciudad Autónoma de Buenos Aires. Con la adición del consumo de frutas, se alcanzó un valor de $162 \mathrm{~kg}$ pers. ${ }^{-1}$ año-1 , la cual casi duplica valores informados por Piola et al. (2011) para el área metropolitana de Buenos Aires y por Ferrato \& Rodríguez Fazzone (2010) para Argentina, este último, a partir de una revisión bibliográfica. Esta gran diferencia puede estar asociada a que la hoja de consumo de la FAO se realiza desde la disponibilidad de alimento a nivel de país, mientras que el estudio de Piola et al. (2011) lo hace desde la demanda de la población. La ingesta de productos derivados de la producción animal fue superior a la mencionada por Westhoek et al. (2014) para los países de Europa Oriental (283 vs. $256 \mathrm{~kg}$ pers.- ${ }^{-1}$ año-1, respectivamente), siendo principalmente por el mayor consumo de carnes (vacuna, de cerdo, de pollo) y huevos (93 vs. $54 \mathrm{~kg}$ pers..$^{-1}$ año-1), porque el consumo de productos lácteos estimados fue menor (184 vs. $202 \mathrm{~kg}$ pers. ${ }^{-1}$ año-1, respectivamente). Estos valores de consumo de carne son muy superiores a los que registra China, principal impulsor de la demanda de granos para la producción de carne. Si bien la producción de alimentos no es una limitante para la alimentación de la población de la provincia de Buenos Aires, las características y proporciones de los diferentes alimentos que se consumen, al igual que en varios países desarrollados, deben ser revisados para promocionar consumos más saludables (Sutton et al., 2013), que involucren menos proteínas de origen animal y menos grasas saturadas (Westhoek et al., 2014). Uno de los problemas que se puede enfrentar en el corto y mediano plazo es que se profundice la pérdida de diversidad de cultivos y que, aunque se mantenga la seguridad alimentaria, se corra el riesgo de la pérdida de soberanía alimentaria y se termine en una dieta que promueva la malnutrición (Godfray \& Garnett, 2014).

La cantidad de $\mathrm{N}$ y $\mathrm{P}$ calculada en la alimentación de la población de la provincia de Buenos Aires (Tabla 5.2) fue similar a la informada por Antikainen et al. (2005) para Finlandia. Los aportes calculados de los diferentes grupos de alimentos al total de $\mathrm{N}$ en la alimentación fueron mayores en carnes (37\% vs $28 \%$ ), pero menores por pescado ( $4 \%$ vs. $11 \%$ ) y leche (14\% vs. $27 \%$ ), respecto de lo estimado por Antikainen et al. (2005). En P, los aportes encontrados por carne fueron similares en ambos (40\%), pero menores en leche ( $14 \%$ vs. $27 \%$ ) y pescados (1,5\% vs. $8 \%$ ) a los registrados por Antikainen et al. (2005). 
Aunque la provincia de Buenos Aires, para el año 2006, concentraba el 38\% de la población de la Argentina, la demanda de nutrientes para su alimentación alcanzó el $11 \%$ de los nutrientes extraídos por el conjunto de las principales actividades agropecuarias de la provincia (relación nutriente en alimentación/extracción). Incluso, al adicionar la demanda de nutrientes de la población de la Ciudad Autónoma de Buenos Aires (con lo que se alcanzó el $46 \%$ de población nacional), ésta sólo se incrementó hasta el $13 \%$ de lo extraído. Esto muestra la gran capacidad de producir alimentos que posee la provincia, y que podría proveer a toda la población del país. No obstante, debido a la desigual distribución de la población en el territorio provincial, se registraron áreas en las cuales los nutrientes en la alimentación superaron ampliamente a los nutrientes extraídos por las actividades agropecuarias, como el Conurbano Bonaerense (MAA, 2007), el gran La Plata, Bahía Blanca y General Pueyrredón (incluye Mar del Plata) (Figura 5.2). El conjunto del Conurbano Bonaerense y el Gran La Plata concentró el $66 \%$ de la población provincial en una superficie menor al 3\% (MEBA, 2014). Por otra parte, en Pinamar, Villa Gesell y la Costa también se estimaron relaciones superiores al $100 \%$ (Figura 5.2) pero, en estos casos fue debido a la baja actividad agropecuaria de los mismos. En las áreas donde la demanda superó la extracción existiría la posibilidad de cerrar los ciclos de nutrientes entre el campo y la ciudad a nivel local, incluso podrían realizar trasferencias entre partidos cercanos. Sin embargo, a nivel provincial, el reciclado del 100\% de los nutrientes que llegan a la alimentación de la población no sería suficiente para reponer los nutrientes extraídos por las actividades agropecuarias.

\section{V.4.2. Desperdicios}

Gustavsson et al. (2012), señalan que, en los países más ricos, se genera más desperdicio por el consumo de la población, mientras que en los países más pobres se acentúan las pérdidas entre producción y distribución. Basado en aquel trabajo de Gustavsson et al. (2012), los cálculos de los desperdicios en la alimentación en la provincia de Buenos Aires fueron bajos (cercanos al 7,5\%). Trabajos preliminares realizados recientemente en el país aplicando la metodología de la FAO, indicarían que en la Argentina, la pérdida y desperdicio total rondaría el $12,5 \%$, siendo el $90 \%$ debido a pérdidas y el 10\% a desperdicio (Rivas et al., 2015; Basso et al., 2016). Esto último indicaría que el desperdicio asumido en esta tesis no difiere sustancialmente de los trabajos realizados localmente.

La cantidad de alimento desperdiciado en la provincia fue de $40 \mathrm{~kg}$ pers. ${ }^{-1}$ año1, lo cual coincide con lo señalado por Basso et al. (2016). Este valor se encuadraría entre el menor rango encontrado por Katajajuuri et al. (2014) en Finlandia, para los 
sectores hogares, servicios de comida y mercado minorista (entre 48 y 60 kg pers. ${ }^{-1}$ año-1). Sin embargo, los informes que analizan los residuos sólidos urbanos en la provincia de Buenos Aires y la Ciudad Autónoma de Buenos Aires (González, 2010; FIUBA-CEAMSE, 2011), indican que los desperdicios alcanzan el $40 \%$ de los residuos totales y estarían en el orden de los $120 \mathrm{~kg}$ pers. ${ }^{-1}$ año-1. Este valor se acercaría más a la magnitud de los desperdicios registrados en Europa y Estados Unidos (Garrone et al., 2014; Gustavsson et al., 2012). La disparidad entre los valores estimados en esta tesis y los informados por distintos autores para Argentina muestra que aún es necesario profundizar el estudio acerca de los desperdicios de alimentos, tanto en la provincia de Buenos Aires como en el país. También se deberá tener mayor precisión acerca del contenido de nutrientes de los desperdicios alimenticios. Según Faerge et al. (2001), los desperdicios tendrían una menor calidad nutricional $\mathrm{y}$, los contenidos de $\mathrm{N}$ y $\mathrm{P}$, deberían ser un $25 \%$ menor respecto al alimento consumido.

Si bien los residuos sólidos urbanos contendrían en promedio un $7 \%$ de los nutrientes de los alimentos de la población, en el Conurbano Bonaerense, Gran La Plata, Pinamar, La Costa y Villa Gesell serían más que suficientes para reponer los nutrientes (N, P, K, Ca, S) extraídos en las actividades agropecuarias (Figuras 5.3b, 5.4b, $5.5 \mathrm{~b}, 5.6 \mathrm{~b}, 5.7 \mathrm{~b})$. No obstante, en el resto de la provincia serían insuficientes. Esto se debe a que dichos partidos presentan escasa actividad agropecuaria o gran demanda de alimentos por elevada población, con baja actividad agropecuaria.

Para su posterior uso agrícola, la fracción orgánica de los residuos sólidos urbanos debe ser compostada. Por eso, el mayor desafío del manejo de los residuos sólidos urbanos para ser utilizados en la agricultura radica en la necesidad de estudiar técnicas que permitan optimizar el proceso de compostaje y mejorar la calidad del producto (Tognetti et al., 2011), sin descuidar las externalidades que pueda generar este proceso (Zhao et al., 2011). Esto debe ser acompañado por un adecuado marco legal, el cual todavía está pendiente de desarrollo en la Argentina (Laos et al., 2012). Si bien son crecientes las experiencias de compostaje de residuos sólidos urbanos en la Argentina (Satti et al., 2012; Sanchez de Pinto et al., 2012) y se menciona que alcanza el $15 \%$ de los municipios más pequeños (entre 2.000 y 10.000 habitantes) (González, 2010), es importante fomentar aún más su implementación.

\section{V.4.3. Aguas servidas}

La cantidad de N, P y K ingeridos en la alimentación (Tabla 5.2) son superiores a los mencionados por Richert et al. (2011) para diferentes países de Europa, Asia y África. En parte, esto se debe a la dieta rica en carnes o derivados de productos lácteos (Figura 5.1). Para alcanzar un ecosistema alimentario, la recuperación de 
nutrientes a partir del tratamiento de aguas servidas será el mayor desafío en el futuro, por ser el flujo que concentra la mayor cantidad de nutrientes relacionados a la alimentación de la población (Tabla 5.2). En este sentido, será necesario superar la actual fase de tratamiento de las aguas servidas sólo como medida para disminuir el vertido de materia orgánica a los cuerpos de agua (Nebel \& Wright, 1999) y se requerirá profundizar el esfuerzo para generar tecnologías que permitan la recuperación de nutrientes que puedan ser empleados nuevamente en la agricultura (Syers et al., 2011 ; Sutton et al., 2013; Torri et al., 2017).

El tratamiento de las aguas servidas frecuentemente genera como subproducto el lodo (o barro cloacal) (Nebel \& Wright, 1999). En general, estos lodos son colocados en vertederos y pocas veces son tratados nuevamente para convertirlos en un compost. En Argentina, existen pocas experiencias que realicen el compostaje de lodos (Mazzarino et al., 2012; Peralta et al., 2012), pero es auspicioso que se encuentren sistematizadas y señalen la viabilidad de los mismos. El uso de agua servida tratada en la agricultura, es un tema en que se ha avanzado en varios países (Toze, 2006). Aunque la finalidad de ello sea la disminución de la presión de la agricultura sobre los cuerpos de agua, indirectamente también permite la recuperación de nutrientes en el campo. A partir del trabajo de Antikainen et al. (2005) se puede inferir que aproximadamente el $70 \%$ del $\mathrm{N}$ en las aguas servidas continúa en la misma luego del tratamiento de saneamiento, mientras que, en el caso del $\mathrm{P}$, el $85 \%$ formaría parte de los lodos y el 15\% restante continuaría en el agua. Esto muestra que la posibilidad de recuperación y las tecnologías a aplicar deberán ser específicas de cada nutriente.

En la provincia de Buenos Aires, las zonas del Conurbano Bonaerense, Gran La Plata, Bahía Blanca, General Pueyrredón, La Costa, Pinamar y Villa Gesell podrían autoabastecerse de nutrientes, e incluso generar un excedente a partir de reciclar los nutrientes entre la ciudad y el campo (Figuras 5.3a, 5.4a, 5.5a, 5.6a, 5.7a). No obstante, a nivel provincial se podrían restituir sólo el $11 \%$ de los nutrientes extraído por las actividades agropecuarias. Aunque, en el caso del Ca se podría recuperar el $25 \%$ de lo extraído (Tabla 5.4). El Conurbano Bonaerense y el Gran La Plata se convierten en las zonas con mayor relación nutrientes en ingesta versus nutrientes extraídos en actividades agropecuarias, por lo que los mayores esfuerzos deberán estar focalizados en esta área.

El 97,3\% de la población de la provincia se encuentra urbanizada (en ciudades de más de 2000 habitantes) (MEBA, 2014). Por ello, el tratamiento de las aguas servidas debe ser un camino a seguir en toda la provincia. La ampliación del sistema cloacal será uno de los pasos necesarios para poder cerrar los ciclos, ya que en 2006 sólo el 
$46 \%$ de la población tenía acceso a la red cloacal. Esto señala que los acuíferos son los mayores receptores de descarga de nutrientes provenientes de la alimentación en la provincia de Buenos Aires (Tabla 5.5). Cerrar los ciclos de nutrientes implicará recuperar los nutrientes de las aguas servidas, sin descuidar el gran desafío desde el punto de vista de la salud de la población que implica el uso de este tipo de aguas (Toze, 2006).

\section{V.4.4. Ecosistema alimentario}

El ecosistema alimentario requerirá, en un futuro cercano, cerrar los ciclos de nutrientes que se generan entre el campo y la ciudad, con el fin de disminuir la dependencia de fuentes externas de nutrientes para sostener la producción de alimentos y para disminuir la contaminación que generan las ciudades por el vertido de aguas sin tratar a los cuerpos de agua (Sutton et al., 2013). La provincia de Buenos Aires, aún si lograse una eficiencia del 100\% en la recuperación de todos los nutrientes que consume la población, lo que sería prácticamente imposible desde el punto de vista tecnológico, podría recuperar sólo el $11 \%$ de los nutrientes que las principales actividades agropecuarias extraen de los suelos. Al sumarse la población de la Ciudad Autónoma de Buenos Aires, es decir que en conjunto serían 16,4 millones de personas, que corresponden al $46 \%$ de la población estimada para Argentina en 2006, se podría eventualmente reponer $13 \%$ de los nutrientes extraídos en los suelos de la provincia de Buenos Aires.

La desigual distribución de la población en el territorio provincial, determina que el Conurbano Bonaerense y el Gran La Plata, sean los grandes demandantes de alimentos en el territorio provincial $y$, debido a su baja incidencia de actividades agropecuarias, genere excedentes de nutrientes. La ubicación de este conglomerado cerca del río de La Plata condiciona la posibilidad de utilizar el agua servida con fines agrícolas. Por lo tanto, el desafío deberá estar centrado en extraer los mayores contenidos de nutrientes de las aguas en los tratamientos de saneamiento, para poder hacer posible el retorno de los mismos a los campos agrícolas. Diferente es la situación de las ciudades y pueblos del interior de la provincia, que sí podrían hacer un uso más adecuado de los nutrientes a partir de los residuos domiciliarios y de las aguas servidas. A pesar de la baja incidencia que puede tener la reutilización de los nutrientes provenientes de las ciudades del interior de la provincia, en la reposición de nutrientes a los suelos agrícolas, esta práctica debería ser implementada, empleada y sostenida buscando cerrar los ciclos a nivel local.

Un ecosistema alimentario eficiente deberá contemplar el cierre de los ciclos de nutrientes a diferentes escalas. Para la provincia de Buenos Aires, esto sólo 
contribuiría a una mantener una parte de la fertilidad de los suelos, la otra gran parte dependerá del retorno de los nutrientes que se exportan en diferentes productos agropecuarios. En un futuro cercano esto no podrá realizarse sólo a partir de fuentes minerales. Una posibilidad de contribuir con el cierre de los ciclos sería a través de cambios en los escenarios del tipo de producto agropecuario exportado. Como se observó en el Capítulo IV, el cambio en las exportaciones podría disminuir considerablemente las salidas de nutrientes y, con ello, la necesidad de reposición, lo que facilitaría el cierre de los ciclos de nutrientes. Sin descuidar que con ello es necesaria una eficiente redistribución de los nutrientes en el territorio provincial.

\section{V.5. BIBLIOGRAFÍA}

Antikainen, R., R. Lemola, J.I. Nousiainen, L. Sokka, M. Esala, P. Huhtanen \& S. Rekolainen. 2005. Stocks and flows of nitrogen and phosphorus in the Finish food production and consumption system. Agriculture, Ecosystems \& Environment 107:287-305.

Aulicino, J.M. \& M.R. Moré. 2000. El consumo de verduras de los habitantes de los alrededores de Buenos Aires: un estudio exploratorio. Centro de Estudios del Sistema Agroalimentario. Facultad de Ciencias Agrarias. Universidad Nacional de Lomas de Zamora. Cuadernos del Ceagro 2:7598.

Barles, S. 2007. Feeding the city: Food comsumption and flow of nitrogen, Paris, 1801-1914. Science of the Total Environment 375:48-58.

Basso, N., M. Brkic, C. Moreno, P. Pouiller \& A. Romero. 2016. Valoremos los alimentos, evitemos pérdidas y desperdicios. DIAETA 34(155):25-32.

Bernadou, F. 2005. ¿¿Qué comen los argentinos? Disponible en: www.produccion-animal.com.ar. Último acceso: agosto 2016

Bodirsky, B.L., A. Popp, H. Lotze-Campen, J.P. Dietrich, S. Rolinski, I. Weindl, C. Schmitz, C. Müller, M. Bonsch, F. Humpenöder, A. Biewald \& M. Stevanovic. 2014. Reactive nitrogen requirements to feed the world in 2050 and potential to mitigate nitrogen pollution. Nature Communications 5:3858.

Bouwman, A.F., A.H.W. Beusen \& G. Billen. 2009. Human alteration of the global nitrogen and phosphorus soil balances for the period 1970-2050. Global Biogeochemical Cycles 23 GBOA04: 116.

Britos, S., A. Saraví \& F. Vilella. 2010. Buenas prácticas para una alimentación saludable de los argentinos. la ed. - Buenos Aires: Universidad de Buenos Aires. 64pp.

Cordell, D. \& S. White. 2013. Sustainable phosphorus measures: strategies and technologies for achieving phosphorus security. Agronomy 3(1):86-116.

Cordell, D., J-O. Drangert \& S. White. 2009. The story of phosphorus: Global food security and food for thought. Global Environmental Change 19:292-305.

Cotier, J.P. \& C. Morón. 1997. Hojas de balance de alimentos. En: Producción y manejo de datos de composición química de alimentos en nutrición. FAO, Universidad de Chile. Capítulo 5: 43-55.

Cruzate, G. \& R.R. Casas. 2003. Balance de nutrientes. Revista Fertilizar (Número especial "Sostenibilidad"): 7-13.

Cruzate, G. \& R.R. Casas. 2012. Extracción y balance de nutrientes en los suelos agrícolas de la Argentina. Informaciones Agronómicas de Hispanoamérica 6:7-14.

FAO (Organización de las Naciones Unidas para la Alimentación y la Agricultura). 2001. Cuestiones éticas en los sectores de la alimentación y la agricultura. Estudio FAO: Cuestiones de ética. Disponible en: ftp://ftp.fao.org/docrep/fao/003/×9601s/×9601s00.pdf. 39pp. Último acceso: septiembre 2016.

FAO (Organización de las Naciones Unidas para la Alimentación y la Agricultura). 2006. Hoja de Balances de alimentos de Argentina. Disponible en: http://faostat3.fao.org/download/FB/FBS/S. Último acceso: septiembre 2016.

Farge, J., J. Magid \& F.W.T. Penning de Vries. 2001. Urban nutrient balance for Bangkok. Ecological Modelling 139:63-74. 
Fernández-Mena, H., T. Nesme \& S. Pellerin. 2016. Towards an agro-industrial ecology: A review of nutrient flow modelling and assessment tools in agro-food systems at the local scale. Science of the Total Environment 543:467-479.

Ferrato, J.A. \& M. Rodríguez Fazzone. 2010. La cadena agroalimentaria. El mercado consumidor. En: Buenas Prácticas Agrícolas para la agricultura familiar. Cadena de las principales hortalizas de hojas en Argentina. FAO, MAGyP, INTA. Capítulo 4, Subcapítulo 1:97:1 13.

FIUBA-CEAMSE (Facultad de Ingeniería de la Universidad de Buenos Aires. Coordinación Ecológica Metropolitana). 2011. Estudio de la calidad de los residuos sólidos urbanos del área metropolitana de Buenos Aires. Tercer Informe de avance. 106pp.

Flores, C.C. \& S.J. Sarandón. 2003. ¿ Racionalidad económica versus sustentabilidad ecológica? El ejemplo del costo oculto de la pérdida de fertilidad del suelo, durante el proceso de Agriculturización en la Región Pampeana Argentina. Revista de la Facultad de Agronomía 105 (1) $(2002,2003): 53-67$.

Forkes, J. 2007. Nitrogen balance for the urban food metabolism of Toronto, Canada. Resources, Conservation \& Recycling 52:74-94.

Gaj, R. \& N. Bellaloui. 2012. Evaluation of phosphorus and nitrogen balances as an indicator for the impact of agriculture on environment: A comparison of a case study from Poland and Mississippi US. Agricultural Sciences 3(2):317-329.

García, F.O. 2006. La nutrición de los cultivos y la nutrición de los suelos. Informaciones Agronómicas 29:13-16.

García, F.O. \& M.F. González Sanjuán. 2010. Balances de nutrientes en Argentina ¿Cómo estamos? ¿Cómo mejoramos? Informaciones Agronómicas 48:1-5.

Garnett, T. 2014. Three perspectives on sustainable food security: efficiency, demand restraint, food system transformation. What role for life cycle assessment? Journal of Cleaner Production 73:10-18.

Garrone, P., M. Melacini \& A. Perego. 2014. Opening the black box of food waste reduction. Food Policy 46:129-139.

Gilbert, N. 2009. The disappearing nutrient. Nature 461:716-718.

Godfray, H. \& T. Garnett. 2014. Food security and sustainable intensification. Philosophical Transactions of the Royal Society B: Biological Sciences 369:20120273.

Godfray, H.C.J., J.R. Beddington, I.R. Crute, L. Haddad, D. Lawrence, J.F. Muir, J. Pretty, S. Robinson, S.M. Thomas \& C. Toulmin. 2010. Food Security: The Challenge of Feeding 9 Billion People. Review. Science 327:812-818.

González, G.L. 2010. Residuos sólidos urbanos en Argentina. Tratamiento y disposición final. Situación actual y alternativas futuras. Área de Pensamiento Estratégico. Cámara Argentina de la Construcción. 63pp.

Graham Rowe, E., D. C. Jessop \& P. Sparks. 2014. Identifying motivations and barriers to minimizing household food waste. Resources, Conservation \& Recycling 84:15-23.

Gustavsson, J., C. Cederberg, U. Sonesson, R. van Otterdijk \& A. Meybeck. 2012. Pérdidas y desperdicio de alimentos en el mundo. Alcance, causas y prevención. FAO. Roma. 33pp.

INDEC (Instituto Nacional de Estadística y Censos). 2016. Censo Nacional de Población, Hogares y Viviendas 2001; Censo Nacional de Población, Hogares y Viviendas 2010. Disponibles en: http://www.indec.gov.ar/micro sitios/webcenso/. Último acceso: octubre 2016.

Ingram, J., P. Aggarwal, P. Ericksen, P. Gregory, L. Horn-Phathanothai, A. Misselhorn \& K. Wiebe. 2012. Food security for a planet under pressure. Rio+20 Policy Brief 2. 8pp. Disponible en: http://www.icsu.org/rio20/policy-briefs/BiodiversityLowRes.pdf. Último acceso: abril 2017.

Jönsson, H., A.R. Stintzing, B. Vinnerås \& E. Salomon. 2004. Lineamientos para el uso de la orina y heces en la producción de cultivos. Serie de publicaciones EcoSanRes. Reporte 2004-2. 46pp.

Katajajuuri, J-M., K. Silvennoinen, H. Hartikainen, L. Heikkilä \& A. Reinikainen. 2014. Food waste in the Finnish food chain. Journal of Cleaner Production 73:322-329.

Laos, F., M.J. Mazzarino \& P. Satti. 2012. Aspectos legales del uso de residuos orgánicos. En: Compostaje en la Argentina: experiencias de producción, calidad y uso. Mazzarino, M.J. \& P. Satti (Editoras). Editorial Orientación Gráfica. Buenos Aires. Capítulo 4:55-66.

Lavado, R.S. 2012. Compostaje: producción calidad y uso. En: Compostaje en la Argentina: experiencias de producción, calidad y uso. Mazzarino, M.J. \& P. Satti (Editoras). Editorial Orientación Gráfica. Buenos Aires. Capítulo 1:3-12.

MA (Ministerio de Agroindustria). 2015. Caracterización de la producción bovina. Buenos AiresCorrientes- Chaco- Formosa- La Pampa- Misiones. INTA, SENASA. Serie I. 194pp.

MAA (Ministerio de Asuntos Agrarios). 2007. Nuestra provincia nuestro campo. El sector agropecuario de la provincia de Buenos Aires. 147pp.

Mazzarino, M.J., P. Satti, F. Laos, L. Roselli, M.P. Crego, E. Kowalsky, H. Fernández \& L. Poulsen. 2012. Compostaje de biosólidos: 12 años de la planta de Bariloche. En: Compostaje en la 
Argentina: experiencias de producción, calidad y uso. Mazzarino, M.J. \& P. Satti (Editoras). Editorial Orientación Gráfica. Buenos Aires. Capítulo 6:77-98.

MEBA (Ministerio de Economía de la provincia de Buenos Aires). 2014. Distribución de la población de la provincia de Buenos Aires. Período 1947 - 2010. Serie Estudios Demográficos 19. $29 \mathrm{pp}$.

Metson, G.S. \& E.M. Bennett. 2015. Phosphorus cycling in Montreal's food and urban agriculture systems. PLOS ONE 10(3): e0120726.

Morée, A.L., A.H.W. Beusen, A.F. Bouwman \& W.J. Willems. 2013. Exploring global nitrogen and phosphorus flows in urban wastes during the twentieth century. Global Biogeochemical Cycles 27:836-846.

Mangialavori, G., A. Biglieri Guidet, E. Abeyá Gilardon, P. Durán \& L. Kogan. 2012. Alimentos consumidos en Argentina. Resultados de la Encuesta Nacional de Nutrición y Salud -ENNyS 2004/5. Buenos Aires. 54pp.

Nebel, B.J. \& R.T. Wright. 1999. Ciencias Ambientales. Ecología y desarrollo sostenible. Sexta edición. Editorial Prentice Hall. México. 720pp

Odum, E.P. 1998. Ecología: El vínculo entre las ciencias naturales y las ciencias sociales. Editorial Continental S.A. XX Reimpresión. Mexico. 295pp.

Oenema, O., H. Kros \& W. de Vries. 2003. Approaches and uncertainties in nutrient budgets: implications for nutrient management and environmental policies. European Journal of Agronomy 20:3-16.

Papargyropoulou, E., R. Lozano, J.K. Steinberger, N. Wright \& Z. bin Ujang. 2014. The food waste hierarchy as a framework for the management of food surplus and food waste. Journal of Cleaner Production, 76:106-115.

Parra, P.A. \& A.M. Justo. 2003. Balance entre ingesta recomendada y consumo estimado de hortalizas. Documento de Trabajo $N^{\circ}$ 28. Disponible en: www.inta.gov.ar/ies. Último acceso: agosto 2016.

Peralta, E., R. González, G. von Haeften, A.P. Comino, G. Gyoso, S. Vergara, G. Genga \& M. Scagliola. 2012. El compostaje aplicado a los barros cloacales primarios de la ciudad de Mar del Plata. En: Compostaje en la Argentina: experiencias de producción, calidad y uso. Mazzarino, M.J. \& P. Satti (Editoras). Editorial Orientación Gráfica. Buenos Aires. Capítulo 8:107-123.

Piola, M., E.Y. El Jaber \& M. Mitidieri. 2011. Estudio sobre incentivos y obstáculos en el consumo de frutas y hortalizas en mujeres del área metropolitana de Buenos Aires, Argentina. Publicación INTA. Disponible en: www.inta.gov.ar/sanpedro. Último acceso: abril 2017.

Richert, A., R. Gensch, H. Jönsson, T-A. Stenström \& L. Dagerskog. 2011. Guía Práctica de uso de la orina en la producción agrícola. Stockholm Environment Institute. EcoSanRes Series 2. 73pp.

Rivas, A., C. Blengino, B. Alvarez de Toledo \& D. Franco. 2015. Pérdidas y desperdicio Alimentario (PDA ) en Argentina. Un ejercicio de estimación. Alimentos Argentinos 65:4-11.

Rossi, A., R. Sarafián, A. Cittadino \& D. Castiglione. 2002. Diagnóstico de la Situación de los Residuos Sólidos en Argentina. AIDIS Argentina. 232pp.

Sánchez de Pinto, M.I, R. Umbides, P. Domínguez, A. Albanesi \& A. Polo. 2012. Compostaje y lombricompostaje de residuos biodegradables de diferentes orígenes. En: Compostaje en la Argentina: experiencias de producción, calidad y uso. Mazzarino, M.J. \& P. Satti (Editoras). Editorial Orientación Gráfica. Buenos Aires. Capítulo 9:125-140.

Satti, P., M.J. Mazzarino, F. Laos, L. Roselli \& M.P. Crego. 2012. Compostaje de materiales de diferente origen: experiencias del grupo de Suelos del CRUB.En: Compostaje en la Argentina: experiencias de producción, calidad y uso. Mazzarino, M.J. \& P. Satti (Editoras). Editorial Orientación Gráfica. Buenos Aires. Capítulo 6:77-98.

Schejtman, L. \& M. Cellucci. 2014. Gestión integral de residuos sólidos urbanos. Políticas municipales que promueven la sustentabilidad. Serie buenas prácticas municipales 3. 33pp.

Soussana, J-F. 2014. Research priorities for sustainable agri-food systems and life cycle assessment. Journal of Cleaner Production 73:19-23.

Sutton, M.A., A. Bleeker, C.M. Howard, M. Bekunda, B. Grizzetti, W. de Vries, H.J.M. van Grinsven, Y.P. Abrol, T.K. Adhya, G. Billen, E.A. Davidson, A. Datta, R. Diaz, J.W. Erisman, X.J. Liu, O. Oenema, C. Palm, N. Raghuram, S. Reis, R.W. Scholz, T. Sims, H. Westhoek \& F.S. Zhang. 2013. Our nutrient world: The challenge to produce more food and energy with less pollution. Global Overview of Nutrient Management. Centre for Ecology and Hydrology, Edinburgh on behalf of the Global Partnership on Nutrient Management and the International Nitrogen Initiative. 128pp.

Syers, K., M. Bekunda, D. Cordell, J. Corman, J. Johnston, A. Rosemarin, I. Salcedo \& T. Lougheed. 2011. Phosphorus and food production. En: UNEP, Year Book. UNEP, Nairobi. 34-45.

Tittonell, P. 2014. Ecological intensification of agriculture — sustainable by nature. Current Opinion in Environmental Sustainability 8:53-61. 
Tognetti, C., M.J. Mazzarino \& F. Laos. 2011. Comprehensive quality assessment of municipal organic waste compost produced by different preparation methods. Waste Management 31:1146-1152.

Torri, S.I., R.S. Corrêa \& G. Renella. 2017. Biosolid application to agricultural land- a contribution to global phosphorus recycle: A review. Pedosphere 27(1): 1-16.

Toze, S. 2006. Reuse of effluent water-benefits and risks. Agriculture \& Water Management 80:147159.

Viglizzo, E.F., A.J. Pordomingo, M.G. Castro \& F.A. Lértora. 2002. La sustentabilidad ambiental del agro pampeano. INTA. Programa Nacional de Gestión Ambiental Agropecuaria. Ediciones INTA. 84pp.

Vitousek, M., R. Naylor, T. Crews, M.B. David, L.E. Drinkwater, E. Holland, P.J. Johnes, J. Katzenberger, L.A. Martinelli, P.A. Matson, G. Nziguheba, D. Ojima, C.A. Palm, G.P. Robertson, P.A. Sanchez, A.R. Townsend \& F.S. Zhang. 2009. Nutrient imbalances in agricultural development. Science 324:1519-1520.

Westhoek, H., J.P. Lesschen, T. Rood, S. Wagner, A. De Marco, D. Murphy-Bokern, A. Leip, H. van Grinsven, M.A. Sutton \& O. Oenema. 2014. Food choices, health and environment: Effects of cutting Europe's meat and dairy intake. Global Environmental Change 26:196-205.

Zhao, W., G. Huppes \& E. van der Voet. 2011. Eco- efficiency for greenhouse gas emissions mitigation of municipal solid waste management: A case study of Tianjin, China. Waste Management 31:1407-1415. 


\section{DISCUSIÓN GENERAL}

Las sociedades dependen y dependerán de la producción, la distribución y el acceso a los alimentos (Ingram et al., 2012; Garnett, 2014; Soussana, 2014), pero también del retorno de los nutrientes a los suelos que los generaron, para que el ciclo pueda reiniciarse (Odum, 1998; Nebel \& Wright, 1999). Pasar de una concepción lineal de sistema alimentario a una cíclica de ecosistema alimentario, puede ser uno de los cambios necesarios para avanzar hacia un desarrollo sostenible.

El ecosistema alimentario es un nuevo concepto, más amplio, en el que no se excluye el análisis de los flujos de nutrientes en distintas etapas o procesos del mismo, sino que brinda a estos estudios una mejor comprensión de su inserción en el contexto global. En la provincia de Buenos Aires, el estudio de nutrientes a partir de flujos y balances en el ecosistema alimentario permite tener un mejor conocimiento acerca de los desafíos que requiere alcanzar la sostenibilidad.

\section{LA AGRICULTURA Y LOS NUTRIENTES}

Por las diferentes actividades agropecuarias, en la provincia de Buenos Aires se extrae una mayor cantidad de nutrientes de la que son repuestos por fertilización y fijación biológica, lo que señala la disminución del reservorio de nutrientes del suelo con el consiguiente riesgo a la sostenibilidad. El conocimiento acerca de la manera en que cada actividad (horticultura, cultivos extensivos y ganadería (carne y leche bovinas)) incide en la conservación de los nutrientes del suelo, es una contribución a los estudios de balances que se habían realizado en la provincia sobre algunas actividades, principalmente cultivos extensivos (Flores \& Sarandón, 2003; Berardo, 2004; García, 2006; Fontanetto \& Gambaudo, 2010; García \& González Sanjuán, 2010; Manchado, 2010; Fontanetto et al., 2011; Zazo et al., 2011; Cordone \& Trossero, 2012; Cruzate \& Casas, 2012; Cabrini et al., 2013; Manchado et al., 2013).

La horticultura es la actividad que mejor conserva los nutrientes del suelo, a excepción del potasio (K) (Figura 3.4.5). Sin embargo, esta actividad ocupa sólo el $0,15 \%$ de la superficie agropecuaria de la provincia (Figura 2.2). La diferencia de manejo entre los cultivos hortícolas intensivos y los semiextensivos determina un cambio en la reposición de nutrientes y, con ello, en la conservación de los mismos en el suelo. Por un lado, las producciones más intensivas, que se realizan cerca de los centros urbanos son las que generan mayores excedentes de nutrientes. Si bien desde el punto 
de vista de la conservación del suelo es positivo, por otro lado no lo es, debido al riesgo de contaminación de los acuíferos por el lixiviado, principalmente de nitratos (Auge et al., 2004; Auge, 2006; Alconada et al., 2011). Estos acuíferos cumplen la función de proveer de agua a la población, por lo que su contaminación implica un riesgo para la sanidad y mayor costo de saneamiento. En este sentido, los cinturones verdes de Buenos Aires, La Plata y Mar del Plata, serían los que generarían mayor riesgo de contaminación por exceso de nitratos (Figura 3.2.9a), problema que ya ha sido evidenciado (Auge, 2006). Monitorear estas áreas para disminuir y, en lo posible, revertir la contaminación de los acuíferos es uno de los desafíos del ecosistema alimentario de la provincia de Buenos Aires. En cambio, las producciones semiextensivas (principalmente de papa (Solanum tuberosum L.)) generan las mayores pérdidas de K, calcio (Ca), e incluso de nitrógeno (N) (Figura 3.2.9 a, c, d), que señalan un riesgo por agotamiento de nutrientes del suelo. Estas diferencias en el manejo de los nutrientes en las producciones hortícolas intensivas y semiextensivas señalan la necesidad de generar estrategias diferenciadas para abordar el tema de los nutrientes, su conservación en el suelo y la disminución del impacto ambiental.

Uno de los aportes de esta tesis es la visualización de la ganadería (producción de carne y leche bovinas) como una actividad que genera, en toda su extensión, un vaciamiento de los suelos en $K$, Ca y azufre $(S)$ y, además, de fósforo $(P)$ en las zonas de pastizal natural (Figura 3.3.10 b, c, d, e). Esto no siempre ha sido claramente percibido porque se considera a la ganadería una actividad restauradora de fertilidad, principalmente por el beneficio que se observa en el crecimiento de los cultivos agrícolas que rotan con pasturas perennes. La mejora en las propiedades físicas y biológicas del suelo que realizan las pasturas implantadas (Díaz Zorita, 2000; García-Prechac et al., 2004; Lemaire et al., 2014), ayudadas por la fertilización fosforada, se traduce en una mejora de la disponibilidad y absorción de nutrientes por los cultivos que rotan con ganadería. Este beneficio que se genera con las pasturas dificulta visualizar un posible agotamiento en el resto de los nutrientes. En este sentido, la ganadería sobre pastizal natural también se asocia a esta idea de que restaura la fertilidad, a pesar de no recibir fertilización. Esto genera, no sólo una pérdida de K, Ca y $S$, sino también un agotamiento de $P$. Siendo que la actividad ganadera sobre pastizal natural es y será uno de los pilares de la actividad agropecuaria de la provincia porque ocupa el $70 \%$ de la superficie ganadera y casi un tercio de todo el territorio provincial, será necesario atender a aquel proceso degradativo del suelo.

La fijación biológica es una vía natural de ingreso de $\mathrm{N}$ que, para los valores asumidos en esta tesis, permite reponer adecuadamente este nutriente en la totalidad de los suelos ganaderos de la provincia. Así como Bouwman et al. (2013) plantean la 
importancia que la fijación biológica ha tenido en la reposición de $\mathrm{N}$ a nivel global a principios del siglo XX, actualmente, la misma, lo sigue siendo para la ganadería de la provincia de Buenos Aires. Sin embargo, el cambio en el uso del suelo a partir del avance de la producción agrícola continua sobre pasturas implantadas (Paruelo et al., 2005; Viglizzo et al., 2010; Vázquez \& Zulaica, 2011) señalaría que, en esta superficie, se corre riesgo de perder este beneficio restaurador de $\mathrm{N}$.

La producción de leche, aún siendo más extractiva que la de carne, genera mayores excedentes en $\mathrm{N}$ y $\mathrm{P}$ por la fertilización y la fijación biológica de $\mathrm{N}$, pero mayores pérdidas por unidad de superficie en el resto de los nutrientes ( $K$, Ca y S). En parte, esto se debe a que la mayor proporción de la superficie para producción de leche, aquélla con pasturas y forrajes anuales, se fertiliza con $N$ y P. Respecto al escenario del 2006 planteado en esta tesis, es probable que, debido a una mayor suplementación con granos externos a la actividad lechera, actualmente estos balances se aproximen a la reposición equilibrada o incluso generen excedentes como en Australia (Gourley et al., 2012). Para K, Ca y S esto podría implicar terminar con los déficits encontrados en esta tesis. No obstante, se puede incrementar el riesgo de contaminación por los excedentes generados, principalmente de N y P. A partir de esta nueva forma de producción, será necesario redefinir los límites de la producción de leche asumidos en esta tesis e incorporar la producción de granos para los alimentos balanceados dentro de los límites de la producción de leche. Esto permitirá estimar si el conjunto de los suelos destinados a la producción de leche conserva los nutrientes $o$ si existe una transferencia intrarregional de nutrientes con déficit en algunas zonas y excesos en otras. Si se compara la ganadería en su conjunto con la agricultura, tanto las extracciones como las pérdidas son mucho menores. No obstante, hay que tener en cuenta que la actividad ganadera se realiza desde mediados del siglo XIX (Reca, 2006), básicamente sin reposición de nutrientes. Es decir, que en la provincia, la ganadería genera menores pérdidas de nutrientes que la agricultura, pero lleva más años generando dichas pérdidas.

Los cultivos extensivos han sido más tenidos en cuenta en los balances de nutrientes que el resto de las actividades. Lo estimado en esta tesis no presenta diferencia con lo ya señalado por otros autores (Cabrini \& Calcaterra, 2009; García \& González Sanjuán, 2010; Manchado, 2010; Zazo et al., 2011; Cruzate \& Casas, 2012), en cuanto a que es una actividad que genera vaciamiento de los suelos. A excepción de $P$ en trigo (Triticum aestivum L.) y cebada cervecera (Hordeum vulgare L. var. distichum), en el resto de los cultivos, se registraron pérdidas en todos los nutrientes (Figura 3.1.7). El déficit de N, P y S estaría siendo subsidiado a partir de la mineralización de la materia orgánica (Darwich, 2003; Melgar, 2011; Sainz Rozas et al., 2012). Por eso, 
en los suelos con menor contenido de materia orgánica y con texturas más gruesas se estarían registrando mayores caídas de $\mathrm{P}$ disponible a partir de los balances negativos (Sainz Rozas et al., 2012). La disminución del contenido de K y Ca, elementos asociados a la basicidad edáfica, provoca problemáticas derivadas de la acidificación (Vázquez et al., 2004; Gelati \& Vázquez, 2008; Vázquez et al., 2012), modificando las condiciones de disponibilidad de algunos otros nutrientes y afectando el crecimiento de los cultivos. Esta pérdida de nutrientes ha estado promovida por las decisiones de manejo de los cultivos, principalmente de verano y, entre ellos, la soja (Glycine max (L.) Merr.). Este cultivo que genera la mayor extracción de nutrientes (Figura 3.1.4) y recibe una baja reposición, en el año 2006 ocupaba el 42\% de la superficie agrícola de 9 Mha y actualmente ocupa el 55\% de la superficie agrícola extensiva, de 12 Mha (SIIA, 2016). A pesar de que el déficit de nutrientes que genera este cultivo ya había sido señalado a principios del siglo XXI (Cruzate \& Casas, 2003; Darwich, 2003; Flores \& Sarandón, 2003; García, 2006), no sólo han sido escasas las acciones para revertir esta tendencia, sino que, por el contrario, se la estimuló.

El uso de la superficie agrícola extensiva en los últimos 15 años ha estado regido por un aumento en la proporción de cultivos de verano por sobre los de invierno (Viglizzo et al., 2010) y, debido al criterio de fertilización basado, principalmente, en dosis-respuesta, se estima que se ha acrecentado la pérdida de los nutrientes del suelo en un área agrícola mayor que la de 2006 (García \& González Sanjuán, 2010; Cruzate \& Casas, 2012). Además, si se tiene en cuenta que este aumento de la superficie agrícola se ha basado en el reemplazo de pastizales y pasturas por cultivos agrícolas, se puede asumir que ha ocurrido un incremento en la degradación de los suelos de la provincia. Según Flores \& Sarandón (2003) y Pengue (2015a), la inadecuada reposición de nutrientes se debe a una errónea valoración económica de las producciones agropecuarias, al no tener en cuenta la degradación ambiental. De hecho, la mayor parte del cultivo de soja se realiza en arrendamiento (Reboratti, 2010) bajo una modalidad empresarial, es decir con posibilidad de acceso a las tecnologías y a los insumos disponibles. Sin embargo, la fertilización no es la adecuada, ya que se basan su decisión exclusivamente en el análisis costo-beneficio (Flores \& Sarandón, 2003). A raíz de esto, la fertilidad natural de los suelos continúa subsidiando la producción de los cultivos en la provincia, lo que indica que el manejo actual de las producciones agropecuarias dejará los recursos naturales en peores condiciones a las generaciones futuras, señalando su insostenibilidad. A pesar de mostrar una gran capacidad de producción de alimentos, los conceptos analizados permiten prever que dicha capacidad irá mermando progresivamente. 


\section{LAS EXPORTACIONES Y LA CONSERVACIÓN DE LOS NUTRIENTES DEL SUELO}

Las actividades agropecuarias extensivas siguen siendo parte importante del desarrollo del país, principalmente por su incidencia en las exportaciones (Reca, 2006; MAA, 2007; Colomé \& Gumierato, 2009; Walter et al., 2013). Sólo los nutrientes contenidos en la exportación de granos y harinas con destino a la alimentación animal constituyen el $66 \%$ de los nutrientes del conjunto de cultivos extensivos. Para un desarrollo sostenible hay que considerar los recursos internos y externos de los cuales depende, y los impactos que se ejercen sobre los mismos (Capítulo I). La exportación de productos agropecuarios implica la exportación de nutrientes (Krauss, 2000; Grote et al., 2005; Pengue, 2007; Nesme et al., 2016), por lo tanto, un país que basa su desarrollo sobre un modelo agroexportador, atenta contra los recursos naturales propios. Por eso, este modelo de desarrollo, basado en el capital natural interno, debe ser analizado para no hipotecar la posibilidad de desarrollo de las futuras generaciones. Si bien parece que, al emplear recursos naturales internos este modelo sólo depende de sí, esto no es cierto, porque al exportar nutrientes, comienza a depender de recursos externos (nutrientes). Estos nutrientes deben ser incorporados para sostener el crecimiento de los cultivos y los flujos de nutrientes exportados. De lo contrario sería un desarrollo autodegradativo.

Debido a una insuficiente reposición de nutrientes, los productos que son exportados se llevan parte de los suelos de la provincia (Pengue, 2007, 2015b) (Capítulos III y IV). Una alternativa para que la exportación de los productos agrícolas con destino a la alimentación animal disminuya el grado de deterioro que ocasiona en el suelo, sería modificando el tipo de producto agropecuario exportado. La sustitución de las exportaciones de granos con destino a la alimentación animal por la de carne obtenida con los mismos (vacuna, de cerdo o de pollo), implicaría una disminución de la cantidad de nutrientes que saldrían de los límites del país (generados por la provincia) (Tabla 4.9). Esta disminución, sería entre un 84 y $92 \%$ dependiendo el tipo de carne, lo que podría contribuir, junto con una adecuada y eficiente redistribución de los nutrientes, a mantener una mayor cantidad de los mismos en los suelos de la provincia (Figura 4.5 y 4.6 ).

Este cambio en las exportaciones no implicaría un cambio en la cantidad de alimento que genera la provincia, ya que la cantidad de proteína animal obtenida no disminuiría, pero sí modificaría el lugar de generación de esa proteína, que en vez de ser China o Europa (Grote et al., 2005; Andreani, 2008; Smaling et al., 2008) sería la provincia de Buenos Aires. Esta mayor conservación de nutrientes en el lugar de origen podría encuadrarse en la "estrategia de eficiencia" (Schader et al., 2016), dentro de las estrategias que buscan la sostenibilidad de los sistemas ganaderos. Al acercar la 
producción de alimento animal y la producción de carne, disminuirían las distancias recorridas de los flujos de nutrientes. En este sentido, se favorecería lo que Cordell \& White (2013) señalan acerca de la necesidad de acercar la producción y el consumo de alimento para hacer más eficiente el uso del $\mathrm{P}$, aunque no se modificaría la huella de $P$ (Metson et al., 2012). Este cambio en los flujos permitiría mejorar un aspecto ecológico de la sostenibilidad, que sería contribuir con la conservación de los nutrientes del suelo (Abbona et al., 2007). No obstante, la propuesta debería ser atendida procurando que las dimensiones sociales y económicas también se vean beneficiadas, habilitando un mejor desarrollo social de la provincia. La exportación de carne permitiría exportar un producto con mayor valor agregado (Bragachini, 2009; Kohan \& Costa, 2011). Esto brindaría, paralelamente, la oportunidad de fomentar una diversificación de los cultivos extensivos empleados, a los fines de atender mejor la demanda de alimentos para la dieta de los animales y disminuir la pérdida de diversidad cultivada que se registra en los últimos años. A título de ejemplo, la implantación de maíz podría incrementar la rotación de los cultivos y, con ello, varios aspectos del suelo relacionados con la materia orgánica y las propiedades físicas, en consecuencia (Forján \& Manso, 2016; Manso \& Forján, 2016).

Lo que no se evita con este uso del suelo, es la discusión acerca de si la tierra arable debe destinarse a producir alimentos directos para el ser humano o para el consumo animal (Oltjen \& Beckett, 1996; Tedeschi et al., 2015; Schader et al., 2016). Si con los granos se alimenta el ganado y, con la carne obtenida el ser humano, la disponibilidad de alimento final es menor que si el ser humano se alimentara directamente de grano (Odum, 1998). En el año 2006, la provincia de Buenos Aires destinó el $64 \%$ de la tierra arable a la producción de proteína animal, valor que duplica el promedio a nivel mundial (Bouwman et al., 2013; Schader et al., 2016) y se asemeja al de Europa (Grote et al., 2005).

Si las proteínas de origen animal son necesarias en la alimentación a nivel global, primero debería optimizarse la producción de carne de rumiantes a partir del empleo de alimentos que no compitan con los del ser humano (pastizales y pasturas) (Schader et al., 2016). En esto, la provincia tiene potencialidad para mejorar la producción de carne vacuna. Aunque las pasturas se implantan sobre suelos que podrían producir cultivos de la base alimentaria del ser humano, la alternancia entre pasturas y cultivos agrícolas trae beneficios para el suelo (Díaz Zorita, 2000; GarcíaPrechac et al., 2004; Lemaire et al., 2014). Esta alternancia debería incluir el manejo de los nutrientes que permitan la conservación de la dotación de los nutrientes del suelo.

De ser necesaria, además de la carne vacuna, la producción de carne de pollo y de cerdo a partir de granos de cereales y oleaginosas, se tendrían que tener en 
cuenta las distancias que recorren los nutrientes e intentar cerrar los ciclos. En esto, sería conveniente que la provincia de Buenos Aires dejara de transportar granos a miles de kilómetros para producir carne (Smaling et al., 2008), y trasforme la proteína vegetal en animal en sus propios territorios. De realizar esto, con una adecuada redistribución de los nutrientes en el territorio, implicaría disminuir el recorrido de nutrientes a nivel global y contribuiría con una mejor conservación de los nutrientes en los suelos de la provincia, a partir de generar ciclos más cerrados. A su vez, se estaría fomentando un modelo de desarrollo que dependiera menos de recursos naturales externos (nutrientes).

Si se opta por aumentar la producción de carne a nivel local, se debería tener en cuenta la disponibilidad hídrica, ya que una mayor producción implicaría un mayor consumo de agua para el abastecimiento de los animales, sobre todo de agua azul, que es la que también utiliza el ser humano. Es decir, se produciría un incremento en la huella hídrica del producto exportado (Pengue, 2006), por lo tanto, un mayor uso de otro recurso natural interno. Tampoco se debería descuidar el impacto ambiental que se podría generar por el mayor flujo de materia orgánica a partir del manejo de los excrementos que se originarían con la producción local de carne (Bouwman et al., 2013; Syers et al., 2011) y que, si no es utilizada correctamente como enmienda orgánica, también puede transformarse en una amenaza para el desarrollo.

\section{EL ECOSISTEMA ALIMENTARIO DE LA PROVINCIA DE BUENOS AIRES}

La provincia de Buenos Aires, si bien cuenta con el 38\% de la población del país, genera alimentos que supera la posibilidad de alimentar al país completo (Capítulo V). Sin embargo, la tendencia encontrada en los flujos de nutrientes entre el campo y la ciudad (Capítulos III y V) permiten prever, de continuar la situación, el riesgo de producir alimentos para las generaciones futuras. La construcción de un ecosistema alimentario requiere vincular los flujos de nutrientes que llegan a la alimentación de la población en las ciudades, con su retorno al campo.

Hasta fines del siglo XIX y principios del XX, muchas sociedades tenían estrecha vinculación entre las ciudades y el campo, con elevado reciclaje de los nutrientes provenientes de las mismas (Barles, 2007; Cordell et al., 2009; Bouwman et al., 2013; Morée et al., 2013). La gran urbanización que se ha producido, durante el siglo XX, a nivel mundial y en América Latina (Vignoli, 2002; Lattes, 2004), incluyendo la provincia de Buenos Aires (MEBA, 2014), ha determinado una gran demanda y concentración de alimentos en áreas reducidas. Por lo tanto, se ha generado una gran concentración de desechos orgánicos y nutrientes que son retirados de las mismas tratando de disminuir problemas ambientales y de salud (Nebel \& Wright, 1999; Rossi et 
al., 2002). Para los desperdicios alimenticios se generó la recolección de residuos sólidos urbanos con posterior deposición en rellenos sanitarios controlados o a cielo abierto (Rossi et al., 2002; González, 2010). Hacia fines del siglo XX, en la provincia de Buenos Aires se comenzó a analizar la posibilidad de separación de los residuos sólidos urbanos para disminuir la cantidad de residuos vertidos y su posterior reutilización, siendo pionero el partido de Trenque Lavquen (Rossi et al., 2002). En general, la separación y reciclaje ha estado más apuntado a los residuos secos (vidrios, cartón, papel) que a los desechos orgánicos.

Aunque se calcula que en la Argentina se desperdicia menos del $10 \%$ de los alimentos (Rivas et al., 2015; Basso et al., 2016), los residuos orgánicos constituyen el $40 \%$ de lo recolectado en residuos sólidos urbanos (González, 2010; FIUBA-CEAMSE, 2011; Schejtman \& Cellucci, 2014). Este porcentaje disminuyó desde el año 2000 cuando se calculaba que era del 58\% (Rossi et al., 2002). Si bien, de los nutrientes contenidos en los alimentos sólo una pequeña parte forma parte de los desperdicios en los residuos sólidos urbanos $(7 \%)$, estos no dejan de ser una adecuada fuente de nutrientes para la agricultura, posterior a su compostaje. Si cerrar los ciclos de nutrientes entre el campo y la ciudad es un camino indispensable para un ecosistema alimentario, será necesario profundizar las investigaciones que tiendan a disminuir el impacto ambiental del compostado y que disminuya el riesgo de trasmisión de enfermedades (Zhao et al., 2011; Satti et al., 2012; Sánchez de Pinto et al., 2012).

Esto mismo será necesario realizar en el tratamiento de aguas servidas, que concentra la mayor cantidad de nutrientes relacionados a la alimentación (93\%). La recuperación de los nutrientes de las aguas servidas será uno de los mayores desafíos, por la infraestructura y volúmenes de agua tratar. Según Van Drecht et al. (2009), se distinguen tres tratamientos de aguas servidas con diferente recuperación de nutrientes: a) primaria, con remoción del $10 \%$ de $N$ y $P, b)$ secundaria, con remoción del $35 \%$ de $N$ y $45 \%$ de $P, c)$ terciaria, con $80 \%$ de $N$ y $90 \%$ de P. En esta tesis se asumió una eficiencia del $100 \%$ en la recuperación de nutrientes, y se estimó que esto implicaría una posibilidad de reposición de sólo del 10\% de los nutrientes que se extraen en las actividades agropecuarias (un $12 \%$ si se incluyen los nutrientes provenientes de las aguas servidas de la Ciudad Autónoma de Buenos Aires), es decir que el $90 \%$ restante deberá reponerse recurriendo a otras fuentes. A partir de esto, surgen los interrogantes ¿̇serán nutrientes provenientes del tratamiento de residuos sólidos urbanos o aguas servidas de otras provincias o países?, ¿provendrán de fuentes minerales finitas? Será necesario profundizar en las respuestas a los mismos para la sostenibilidad del ecosistema alimentario en la provincia de Buenos Aires. 
La distribución de la población en el territorio también debe ser tenida en cuenta para poder lograr un ecosistema alimentario más eficiente. El Conurbano Bonaerense y el Gran La Plata concentran el $66 \%$ de la población provincial en una superficie menor que el 3\% (MEBA, 2014), toda ubicado en el noreste de la provincia. Esto señala que los recorridos de los alimentos del campo a la ciudad y el retorno de estos al campo, a partir de los residuos sólidos urbanos o aguas servidas, será a través de grandes distancias. Planificar los asentamientos poblacionales, pensando en lograr ecosistemas alimentarios locales también será parte del desafío de los próximos años en la provincia de Buenos Aires.

\section{REFLEXIÓN FINAL}

Desde principios del siglo XIX, la responsabilidad de los nutrientes en la alimentación estuvo acotada a los agricultores con el fin de mantener y mejorar la producción. Posteriormente, se incorporaron los científicos y agrónomos en el manejo de los nutrientes, primero vinculados a la productividad para luego considerar el impacto ambiental que estos generaban en las distintas etapas del sistema alimentario. Sin embargo, para construir el ecosistema alimentario será necesario que se involucre la sociedad en su conjunto. Un ecosistema alimentario será posible si la sociedad se asume inserta en el mismo. La obtención de los alimentos no debería ser la única preocupación, sino también el destino de los residuos y de los nutrientes que genera, comprendiendo que los mismos deben ser repuestos a los suelos agropecuarios de donde fueron extraídos. Esto implica un cambio profundo en la relación entre la sociedad y la naturaleza, sobre la cual será necesario avanzar para construir un ecosistema alimentario sostenible.

\section{BIBLIOGRAFÍA}

Abbona, E.A., S.J. Sarandón, M.E. Marasas \& M. Astier. 2007. Ecological sustainability evaluation of traditional management in different vineyard systems in Berisso, Argentina. Agriculture, Ecosystems \& Environment 119:335-345.

Alconada, M., M. Cuellas, P. Poncetta, S. Barragán, E. Inda \& A. Mitidieri. 2011 . Ferrtirrigación en cultivo de tomate protegido: I- Nutrición nitrogenada. Efectos en el suelo y en la producción. Horticultura Argentina 30(72):5-13.

Andreani, P. 2008. Mercado del complejo soja y análisis de la competitividad de los países exportadores. Programa de Inserción Agrícola. Entidad coordinadora Sociedad Rural Argentina. 169pp.

Auge, M. 2006. Agua subterránea deterioro de calidad y reserva. 173pp. Disponible en: http://sedici.unlp.edu.ar/bitstream/handle/10915/15908/Documento completo.pdf? sequence=1 . Último acceso: junio 2016.

Auge, M.P., Hirata, R. \& F. López Vera. 2004. Vulnerabilidad a la contaminación por nitratos del acuífero Puelche en La Plata, Argentina: Informe científico final. Universidad de Buenos Aires. Buenos Aires. 195pp. Disponible en: http://tierra.rediris.es/hidrored/ebooks/miguel/Nitratos.pdf. último acceso: septiembre 2016. 
Barles, S. 2007. Feeding the city: Food comsumption and flow of nitrogen, Paris, 1801-1914. Science of the Total Environment 375:48-58.

Basso, N., M. Brkic, C. Moreno, P. Pouiller \& A. Romero. 2016. Valoremos los alimentos, evitemos pérdidas y desperdicios. DIAETA 34(155):25-32.

Berardo, A. 2004. Manejo de la Fertilización en una Agricultura Sustentable. Informaciones Agronómicas 23:23-25.

Bouwman, L., K.K. Goldewijk, K.W. Van Der Hoek, A.H.W. Beusen, D.P. Van Vuuren, J. Willems, M.C. Rufino \& E. Stehfest. 2013. Exploring global changes in nitrogen and phosphorus cycles in agriculture induced by livestock production over the 1900-2050 period. Proceedings of the National Academy of Sciences of the United States of America 110(52):20882-20887.

Bragachini, M. 2009. Integración vertical de los sistemas productivos. ¿̇Nuevos paradigmas para los sistemas agropecuarios argentinos? Agregar valor en origen. Disponible en: http://www.cosechaypostcosecha.org/data/articulos/agoindustrializacion/IntegracionVerticalSis temasProductivos.asp. Último acceso: agosto de 2016.

Cabrini, S.M. \& C.P. Calcaterra. 2009. Sistemas de producción en el partido de Pergamino. Valoración económica del impacto sobre la capacidad productiva de los suelos. INTA. Estudios socioeconómicos de la sustentabilidad de los sistemas de producción y recursos naturales 12. $36 \mathrm{pp}$.

Cabrini, S.M., C.P. Calcaterra \& D. Lema. 2013. Costos Ambientales y Eficiencia Productiva en la Producción Agraria del Partido de Pergamino. Revista Iberoamericana de Economía Ecológica 20:27-43.

Colomé, R.A. \& L.H. Gumierato. 2009. Sobre los orígenes de la comercialización de granos en Argentina (c. 1870 - 1920). Revista de la Bolsa de Comercio de Rosario: 52-61.

Cordell, D. \& S. White. 2013. Sustainable phosphorus measures: strategies and technologies for achieving phosphorus security. Agronomy 2013 3:86-116.

Cordell, D., J-O. Drangert \& S. White. 2009. The story of phosphorus: Global food security and food for thought. Global Environmental Change 19:292-305.

Cordone, G. \& M. Trossero. 2012. Costo culto privado y social del sistema productivo. La degradación del suelo pampeano. Informaciones Agronómicas de Hispanoamérica 7:2-5.

Cruzate, G. \& R.R. Casas. 2003. Balance de nutrientes. Revista Fertilizar (Número especial "Sostenibilidad"): 7-13.

Cruzate, G. \& R.R. Casas. 2012. Extracción y balance de nutrientes en los suelos agrícolas de la Argentina. Informaciones Agronómicas de Hispanoamérica 6:7-14.

Darwich, N. 2003. El balance físico económico en las rotaciones agrícolas. Proyecto Fertilizar. INTA. $\quad$ Disponible en: http://www.fertilizando.com/articulos/El\%20Balance\%20Fisico\%20Economico\%20en\%20las\%20Rot aciones.asp. Último acceso: abril 2017.

Díaz-Zorita, M. 2000. Evaluación de la sostenibilidad de sistemas intensivos de producción de carne. INTA. Estación Experimental Agropecuaria General Villegas. Publicación técnica 27. 15pp. FIUBA-CEAMSE (Facultad de Ingeniería de la Universidad de Buenos Aires. Coordinación Ecológica Metropolitana). 2011. Estudio de la calidad de los residuos sólidos urbanos del área metropolitana de Buenos Aires. Tercer Informe de avance. 106pp.

Flores, C.C. \& S.J. Sarandón. 2003. ¿Racionalidad económica versus sustentabilidad ecológica? El ejemplo del costo oculto de la pérdida de fertilidad del suelo, durante el proceso de Agriculturización en la Región Pampeana Argentina. Revista de la Facultad de Agronomía 105 (1) $(2002,2003): 53-67$.

Fontanetto, H. \& S. Gambaudo. 2010. El balance de nutrientes para sistemas agrarios sustentables. Sitio de producción Animal. 4pp. Disponible en: http://www.produccionanimal.com.ar/suelos ganaderos/77-nutrientes.pdf. Último acceso: septiembre 2016.

Fontanetto, H., S. Gambaudo \& O. Keller. 2011. Balance de nutrientes en sistemas pastoriles. Sitio Argentino de Producción Animal. Disponible en: http://www.produccionanimal.com.ar/produccion_y_manejo_pasturas/pasturas_fertilizacion/52-balance.pdf. Último acceso: septiembre 2016.

Forján, H. \& L. Manso. 2016. La secuencia de cultivos. En: Rotaciones y secuencias de cultivo en la región mixta cerealera del centro-sur bonaerense. Forján, H. \& L. Manso (Compiladores). Ediciones INTA. Buenos Aires. Capítulo 3: 19-28.

García, F.O. 2006. La nutrición de los cultivos y la nutrición de los suelos. Informaciones Agronómicas 29:13-16.

García, F.O. \& M.F. González Sanjuán. 2010. Balances de nutrientes en Argentina ¿Cómo estamos? ¿ Cómo mejoramos? Informaciones Agronómicas 48:1-5.

García-Préchac, F., O. Ernst, G. Siri-Prieto \& J.A. Terra. 2004. Integrating no-till into crop-pasture rotations in Uruguay. Soil \& Tillage Research 77:1-13. 
Garnett, T. 2014. Three perspectives on sustainable food security: efficiency, demand restraint, food system transformation. What role for life cycle assessment? Journal of Cleaner Production 73:10-18.

Gelati, P.R. \& M.E. Vázquez. 2008. Extracciones agrícolas de bases en el norte de la provincia de Buenos Aires, Argentina: costo de su remediación e implicancias económicas. Revista Iberoamericana de Economía Ecológica 7:117-129.

González, G.L. 2010. Residuos sólidos urbanos en Argentina. Tratamiento y disposición final. Situación actual y alternativas futuras. Área de Pensamiento Estratégico. Cámara Argentina de la Construcción. 63pp.

Gourley, J.P.C., W.J. Dougherty, DM. Weaver, S.R. Aarons, I.M. Awty, D.M. Gibson, M.C. Hannah, A.P. Smith \& K. Peverill. 2012. Farm-scale nitrogen, phosphorus, potassium and sulfur balances and use efficiencies on Australian dairy farms. Animal Production Science 52: 929-944.

Grote, U., E. Craswell \& P. Vlek. 2005. Nutrient flows in international trade: Ecology and policy issues. Environmental Science \& Policy 8:439-451.

Ingram, J., P. Aggarwal, P. Ericksen, P. Gregory, L. Horn-Phathanothai, A. Misselhorn \& K. Wiebe. 2012. Food security for a planet under pressure. Rio+20 Policy Brief 2. 8pp. Disponible en: http://www.icsu.org/rio20/policy-briefs/BiodiversityLowRes.pdf Último acceso: abril 2017.

Kohan, L. \& R. Costa. 2011. Panorama general de las nuevas formas de organización del agro: las principales cadenas agroalimentarias. Comisión Económica para América Latina y el Caribe (CEPAL). Colección Documentos de proyectos. Chile. 88pp.

Krauss, A. 2000.Nutrient cycling and transfers in the global dimension. En: Nutrient management in China. Part 1. Nutrient management and nutrient cycling in agro-ecosystems. Hardter, R., J-C . Xie, J.M. Zhou \& Q-Z. Fan (Editores). International Potash Institute. Cap 1:13-24.

Lattes, A.E. 2004. La urbanización y otros modos de asentamiento de la población: desafíos para la reflexión conceptual y la producción de datos demográficos. Población y Sociedad N¹0/11 2003/2004:71-108.

Lemaire, G., A. Franzluebbers, P.C. de Faccio Carvalho \& B. Dedieu. 2014. Integrated croplivestock systems: Strategies to achieve synergy between agricultural production and environment quality. Agriculture, Ecosystems \& Environment 190:4-8.

MAA (Ministerio de Asuntos Agrarios). 2007. Nuestra provincia nuestro campo. El sector agropecuario de la provincia de Buenos Aires. 147pp.

Manchado, J.C. 2010. La sustentabilidad en la agricultura pampeana: Valoración económica del balance de nutrientes para las principales actividades agropecuarias extensivas en la Región Centro Sur de la Provincia de Buenos Aires. Revista Argentina de Economía Agraria XII (2):51-68.

Manchado, J.C., S.M. Cabrini, P.K. Natinzon \& C.P. Calcaterra. 2013. Análisis multicriterio: aplicación al estudio de la sustentabilidad en sistemas de producción agropecuarios en la región pampeana. INTA. Estudios socioeconómicos de la sustentabilidad de los sistemas productivos y recursos naturales 18. $31 \mathrm{pp}$.

Manso, L. \& H. Forján. 2016. La materia orgánica del suelo. En: Rotaciones y secuencias de cultivo en la región mixta cerealera del centro-sur bonaerense. Forján, H. \& L. Manso (Compiladores). Ediciones INTA. Buenos Aires. Capítulo 5: 34-40.

MEBA (Ministerio de Economía de la provincia de Buenos Aires). 2014. Distribución de la población de la provincia de Buenos Aires. Período 1947 - 2010. Serie Estudios Demográficos 19. $29 \mathrm{pp}$.

Melgar, R. 2011. La reposición de nutrientes en EEUU, Brasil y Argentina: tres escenarios contrastantes. Fertilizar 19:5-11.

Metson, G.S., E.M. Bennett \& J.J. Elser. 2012. The role of diet in phosphoorus demamd. Environmental Research Letters 7 (4) 044043.

Morée, A.L., A.H.W. Beusen, A.F. Bouwman \& W.J. Willems. 2013. Exploring global nitrogen and phosphorus flows in urban wastes during the twentieth century. Global Biogeochemical Cycles 27:836-846.

Nebel, B.J. \& R.T. Wright. 1999. Ciencias Ambientales. Ecología y desarrollo sostenible. Sexta edición. Editorial Prentice Hall. México. 720pp.

Nesme, T., S. Roques, G.S. Metson \& E.M. Bennett. 2016. The surprisingly small but increasing role of international agricultural trade on the European Union's dependence on mineral phosphorus fertiliser. Environmental Research Letters 11 (2) 025003.

Odum, E.P. 1998. Ecología: El vínculo entre las ciencias naturales y las ciencias sociales. Editorial Continental S.A. XX Reimpresión. Mexico. 295pp.

Oltjen, J.W. \& J.L. Beckett. 1996. Rol of ruminant livestock in sustainable agricultural systems. Journal of Animal Science 74:1406-1409. 
Paruelo, J.M., J.P. Guerschman \& S.R. Verón. 2005. Expansión agrícola y cambios en el uso del suelo. Ciencia Hoy 15(87):14-23.

Pengue, W. 2006. "Agua virtual", agronegocio sojero y cuestiones económico ambientales futuras. Fronteras 5:14-25.

Pengue, W. 2007. Modelo agroexportador, monoproducción y deuda ecológica. ¿̇Hacia el agotamiento del granero del mundo? Revista Aportes para el Debate 59-81.

Pengue, W. 2015a. Recursos naturales, servicios ambientales y desarrollo en América Latina. Revista Redbioética/UNESCO. Año 61 (11):64:69.

Pengue, W. 2015b. Suelos, huellas de nutrientes y estabilidad ecosistémica. Fronteras 13:1-18.

Reboratti, C. 2010. Un mar de soja: la nueva agricultura en Argentina y sus consecuencias. Revista de Geografía Norte Grande 45:63-76.

Reca, L.G. 2006. Aspectos del desarrollo agropecuario argentino 1875-2005. Academia Nacional de Agronomía y Veterinaria. Buenos Aires, 78pp. Disponible en: http://www.anav.org.ar/trabajos_publicados/4/reca.pdf. Último acceso: agosto 2016.

Rivas, A., C. Blengino, B. Alvarez de Toledo \& D. Franco. 2015. Pérdidas y desperdicio Alimentario (PDA ) en Argentina. Un ejercicio de estimación. Alimentos Argentinos 65:4-11.

Rossi, A., R. Sarafián, A. Cittadino \& D. Castiglione. 2002. Diagnóstico de la situación de los residuos sólidos en Argentina. AIDIS Argentina. 232pp.

Sainz Rozas, H., H. Echeverría. \& H. Angelini. 2012. Fósforo disponible en suelos agrícolas de la región Pampeana y Extra Pampeana argentina. INTA. RIA. Revista de Investigaciones Agropecuarias 38(1):33-39.

Sánchez de Pinto, M.I, R. Umbides, P. Domínguez, A. Albanesi \& A. Polo. 2012. Compostaje y lombricompostaje de residuos biodegradables de diferentes orígenes. En: Compostaje en la Argentina: experiencias de producción, calidad y uso. Mazzarino, M.J. \& P. Satti (Editoras). Editorial Orientación Gráfica. Buenos Aires. Capítulo 9:125-140.

Satti, P., M.J. Mazzarino, F. Laos, L. Roselli \& M.P. Crego. 2012. Compostaje de materials de diferente origen: experiencias del grupo de Suelos del CRUB.En: Compostaje en la Argentina: experiencias de producción, calidad y uso. Mazzarino, M.J. \& P. Satti (Editoras). Editorial Orientación Gráfica. Buenos Aires. Capítulo 6:77-98.

Schader, C., A. Muller, N.E-H. Scialabba, J. Hecht, A. Isensee, K-H. Erb, P. Smith, H.P.S. Makkar, P. Klocke, F. Leiber, P. Schwegler, M. Stolze \& U. Niggli. 2016. Impacts of feeding less foodcompeting feedstuffs to livestock on global food system sustainability. Journal of the Royal Society Interface 12: 20150891.

Schejtman, L. \& M. Cellucci. 2014. Gestión integral de residuos sólidos urbanos. Políticas municipales que promueven la sustentabilidad. Serie buenas prácticas municipales 3. 33pp.

SIIA (Sistema Integrado de Informaciones Agropecuarias). 2016. Disponible en: http://www.siia.gov.ar/. Último acceso: septiembre 2016.

Smaling, E.M.A., R. Roscoe, J.P. Lesschen, A.F. Bouwman \& E. Comunello. 2008. From forest to waste: Assessment of the Brazilian soybean chain, using nitrogen as a marker. Agriculture, Ecosystems \& Environment 128: 185-197.

Soussana, J-F. 2014. Research priorities for sustainable agri-food systems and life cycle assessment. Journal of Cleaner Production 73:19-23.

Syers, K., M. Bekunda, D. Cordell, J. Corman, J. Johnston, A. Rosemarin, I. Salcedo \& T. Lougheed. 2011. Phosphorus and food production. En: UNEP, Year Book. UNEP, Nairobi. 34-45.

Tedeschi, L.O., J.P. Muir, D.G. Riley \& D.G. Fox. 2015. The role of ruminant animals in sustainable livestock intensification programs. International Journal of Sustainable Development \& World Ecology 22(5):452-465.

Van Drecht, G., A.F. Bouwman, J. Harrison \& J. M. Knoo. 2009. Global nitrogen and phosphate in urban wastewater for the period 1970 to 2050. Global Biogeochemical Cycles 23:GB0A03. 19pp.

Vázquez, M.E., A. Piro, G. Millán \& J. Lanfranco. 2004. Corrección de suelos ácidos de la Pampa húmeda para la producción de alfalfa. Informaciones Agronómicas 23:14-20.

Vázquez, M., A. Terminiello, A. Casciani, G. Millán, D. Cánova, P. Gelati, F. Guilino; A. Dorronzoro, Z. Nicora, L. Lamarche \& M. García. 2012. Respuesta de la soja (Glicine max L. Merr) a enmiendas básicas en algunos suelos de las provincias de Buenos Aires y Santa Fe. Ciencia del Suelo 30(1):43-56.

Vázquez, P. \& L. Zulaica. 2011. Cambios en el uso de la tierra del partido de Tandil y principales impactos ambientales. Párrafos Geográficos 10(2):242-267.

Viglizzo, E.F., L.V. Carreño, H. Pereyra, F. Ricard, J. Clatt \& D. Pincén. 2010. Dinámica de la frontera agropecuaria y cambio tecnológico. En: Expansión de la Frontera Agropecuaria en Argentina y su Impacto Ecológico-Ambiental. Viglizzo, E.F. \& E.G. Jobbágy (Editores). Ediciones INTA. Capítulo 1:9-16. 
Vignoli, J.R. 2002. Distribución territorial de la población de América Latina y el Caribe: tendencias, interpretaciones y desafíos para las políticas públicas. CEPAL ECLAC Serie Población y Desarrollo. $\quad 32-\quad 82 . \quad$ Disponle en: http://repositorio.cepal.org/bitstream/handle/11362/7170/S02121008_es.pdf;sequence=1. Último acceso: abril 2017.

Walter, M., J. Brun, P. Pérez-Manrique, A.C. González-Martínez \& J. Martínez Alier. 2013. Análisis del flujo de materiales de la economía Argentina (1970-2009) Tendencias y conflictos extractivo. Ecología política 45: 94-98.

Zazo, F., C. Flores \& S. Sarandón. 2011. El "costo oculto" del deterioro del suelo durante el proceso de "sojización" en el Partido de Arrecifes, Argentina. Revista Brasileira de Agroecología. $6(3): 3-20$.

Zhao, W.G. Huppes \& E. van der Voet. 2011. Eco-efficiency for greenhouse gas emissions mitigation of municipal solid waste management: A case study of Tianjin, China. Waste Management 31:1407-1415. 